\title{
Katalog \\ der mittelalterlichen Handschriften des Stifts Beromünster
}

Dörthe Führer

Mikkel Mangold

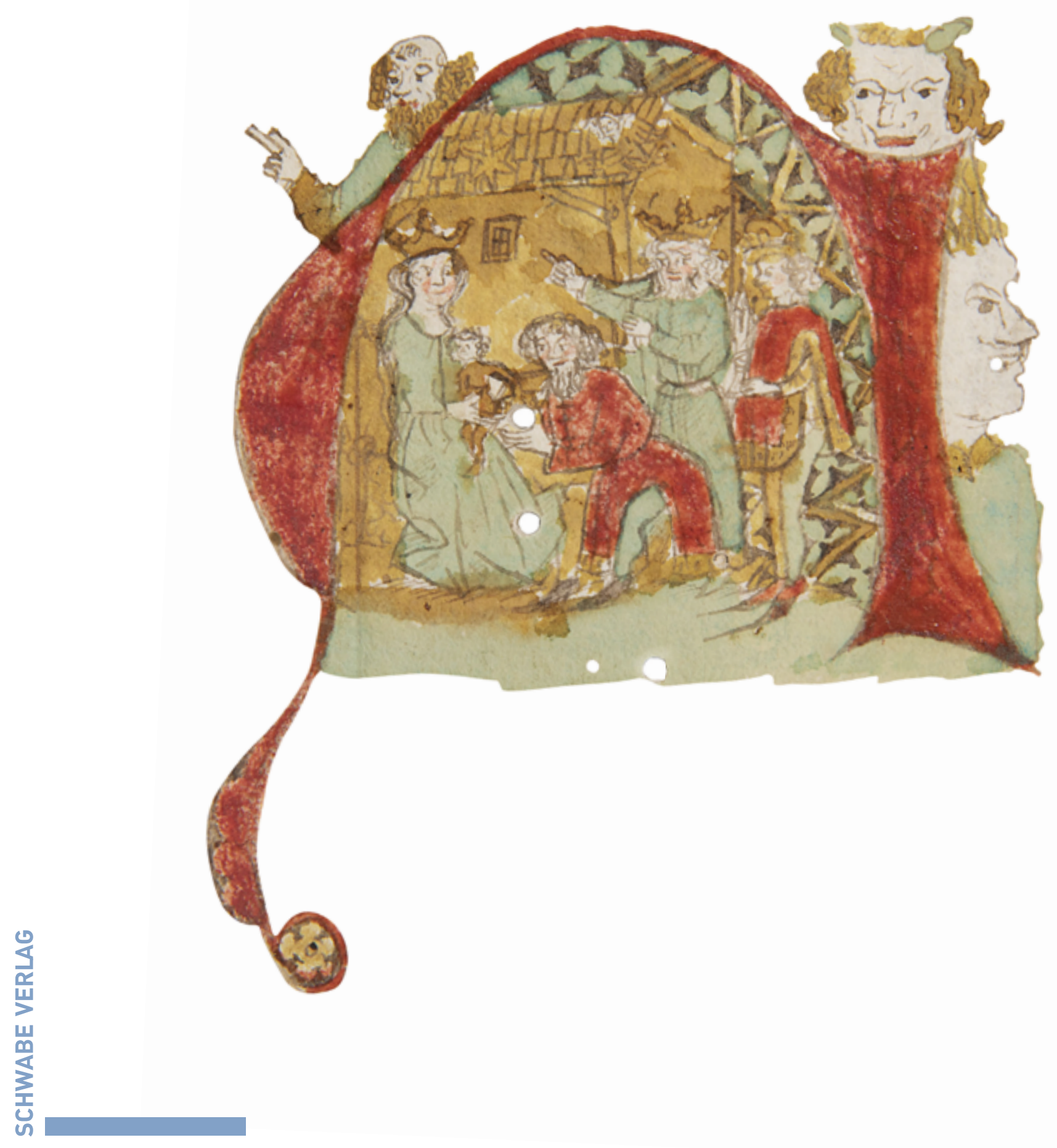




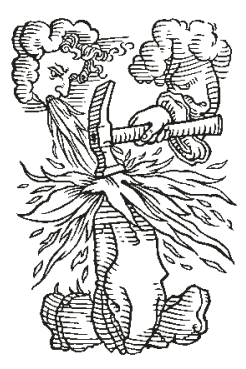



Dörthe Führer

Mikkel Mangold

Katalog der mittelalterlichen Handschriften des Chorherrenstiftes St. Michael Beromünster

Schwabe Verlag 


\section{Die Erstellung des Katalogs wurde durch folgende Institutionen und Privatpersonen ermöglicht}

- Schweizerischer Nationalfonds, Bern

- Kaplanei Mariazell, Sursee

- Römisch-katholische Landeskirche des Kantons Luzern

- Römisch-katholische Kirche Zürich

- Kulturförderung Kanton Luzern

- UBS Kulturstiftung, Zürich

- Ernst Göhner Stiftung Zug

- Dr. Annemarie S. Reynolds, Emmetten

- Goethe Stiftung für Kunst und Wissenschaft, Zürich

- Josef Müller Stiftung Muri AG

- Maria-Himmelfahrtsbruderschaft am Chorherrenstift Beromünster

- Raiffeisenbank Beromünster

- Kurt und Silvia Huser-Oesch Stiftung, Horw

Die Druckvorstufe dieser Publikation wurde vom Schweizerischen Nationalfonds zur Förderung der wissenschaftlichen Forschung unterstützt.

Erschienen (C) 2020 im Schwabe Verlag Basel

Bibliografische Information der Deutschen Nationalbibliothek

Die Deutsche Nationalbibliothek verzeichnet diese Publikation in der Deutschen Nationalbibliografie; detaillierte bibliografische Daten sind im Internet über http://dnb.dnb.de abrufbar.

\section{(c) (1) (9)}

Dieses Werk ist lizenziert unter einer Creative Commons Attribution-NonCommercial-NoDerivatives 4.0 International (CC BY-NC-ND 4.0)

Abbildung Umschlag: Anbetung der Könige, C 45, $1^{\mathrm{r}}$

Fotografien: Johann Frick, Universitätsbibliothek Basel; e-codices.ch; e-rara.ch

Umschlaggestaltung: icona basel gmbh, Basel

Layout: Urs Graf Verlag GmbH, Dietikon-Zürich

Satz: Schwabe Verlag, Berlin

Druck: Hubert \& Co., Göttingen

Printed in Germany

ISBN Printausgabe 978-3-7965-4252-7

ISBN eBook (PDF) 978-3-7965-4253-4

DOI 10.24894/978-3-7965-4243-4

Das eBook ist seitenidentisch mit der gedruckten Ausgabe und erlaubt Volltextsuche.

Zudem sind Inhaltsverzeichnis und Überschriften verlinkt.

rights@schwabe.ch

www.schwabe.ch 


\section{Inhaltsverzeichnis}

Vorwort

Einleitung

1. Zur Geschichte von Stift und Bibliothek

2. Die liturgischen Handschriften

$\begin{array}{lr}\text { 3. Die Verwaltungshandschriften } & 18\end{array}$

4. Die Stiftsbibliothek $r$

\begin{tabular}{ll}
4.1 & Friedrich von Lütishofen \\
\hline
\end{tabular}

$\begin{array}{ll}4.2 \text { Ludwig Zeller } & 24\end{array}$

$\begin{array}{lll}4.3 & \text { Der sonstige Bestand der Stiftsbibliothek } & 27\end{array}$

$\begin{array}{lr}\text { Anmerkungen } & 29\end{array}$

$\begin{array}{lr}\text { Abgekürzt zitierte Literatur } & 33\end{array}$

Signaturenkonkordanz 36

Katalog

Die liturgischen Handschriften in der Schatzkammer

II C 1 - II C 3, C 5 fol.

Die mittelalterlichen Handschriften in der Stiftsbibliothek

A 66 fol., C 8 - C 14, C 40 - C 46, C 49 - C 55, C 57, C 61 - C 65, C 67, C 69

Die mittelalterlichen Buchhandschriften im Stiftsarchiv

StiAB 01.01.463, 599, 600, 602, 603, 615-617, 634a, 635, 663, 709, 714, 715, 718, 719, 736

Anhang

Register der Verfasser, Namen, Orte und Sachen 



\section{Vorwort}

Seit dem 10. Jahrhundert gibt es in Beromünster ein Gotteshaus, an dem eine Gemeinschaft von Chorherren lebt. Es wurde als Grabkirche der Grafen von Lenzburg errichtet. Die heute noch bestehende Kirche erlebte ihre Weihe 1036. Es ist eine dreischiffige romanische Basilika, die in zwei Phasen am Ende des 17. Jahrhunderts und in den Jahren 1773 bis 1775 - eine Barock-, resp. Rokoko-Ausstattung erhielt.

In der ersten Zeit kamen die Chorherren vorwiegend aus dem Ministererialadel der weiteren Umgebung, dann aus den Patrizierfamilien der Stadt Luzern. Einige mischten im Kulturleben mächtig mit. Der Chorherr Rudolf von Liebegg aus dem 14. Jahrhundert ist bekannt als lateinischer Dichter. Helias Helye fertigte 1470 den ersten datierten Druck der heutigen Schweiz an, den Mammotrectus super Bibliam. Er war ein Handbuch für Geistliche und erklärte schwierige Ausdrücke der Bibel. Geschrieben hatte das Manuskript 1360 der italienische Franziskaner Giovanni Marchesino. Johann II. Dörflinger ist der Schreiber des Hochdorfer Missales von 1474/76, das bei www.e-codices einzusehen ist und sich unter den katalogisierten Handschriften findet. Andere Chorherren machten auswärts Karriere. So war Heinrich Vogt 1490/1491 Rektor der Universität Basel. Die gleiche Aufgabe hatte Erhard Battmann 1492 inne. Jost von Silenen wurde Bischof von Grenoble und Sitten.

Eine ernste Bedrohung in seiner Existenz erfuhr das Stift 1798 durch den Einfall der Franzosen. Es konnte aber überleben. Dieses und weiteres Ungemach hatte wohl Propst Mathias Riedweg vor Augen, als er 1881 in seiner «Geschichte des Kollegiatstiftes Beromünster» schrieb: «Unser Stift erhob sich ... wiederholt aus der Asche und drohende Gefahren wurden durch Gottes Güte abgelenkt, der hl. Michael, unser Schutzpatron, zog sein Flammenschwert und schreckte die Feinde $\gg$. Seit 1806 verbringen Weltgeistliche, die in Pfarreien gewirkt haben, in unserem Stift ihren Ruhestand. Zu ihren
Aufgaben gehören neben Eucharistiefeier und Chorgebet die Vermittlung der kulturellen Schätze für die Besucher des Stiftes und Aushilfen in den Pfarreien.

Die Stiftsbibliothek umfasst rund 10'000 Bände aus Theologie, Philosophie, Geschichte und Geographie. Sie sind an drei Orten zu finden: Im Kulturgüterschutzraum unter dem nördlichen Vorplatz der Stiftskirche, im Lesesaal und in der CompactusAnlage im Propsteigebäude (www.stiftberomuenster.ch/ stiftsbibliothek). Vorgestellt wird unsere Bibliothek u. a. im «Handbuch der historischen Buchbestände in der Schweiz», Hildesheim-Zürich-New York 2011.

Die Musikbibliothek verfügt in 276 Schachteln über Manuskripte und Drucke aus dem 17., 18. und 19. Jahrhundert. Damit wird die Aufführungstätigkeit des Stiftes von geistlichen und profanen Werken dokumentiert. Der Inhalt ist über www.rism.ch einsehbar.

Die wissenschaftliche Darstellung unserer Handschriften wäre nicht möglich gewesen ohne die grosszügigen Beiträge von Sponsoren. Ihre Namen werden an eigener Stelle (S. 4) erwähnt. Die Reaktionen der Gönner waren für uns ein Zeichen für die dauernde Wertschätzung unseres Stiftes. Besten Dank!

Herzlich danke ich den Bearbeitern: In zweijähriger Arbeit waren Dr. Mikkel Mangold, Basel, und Dr. Dörthe Führer, Zürich, daran, unsere Handschriften zu erfassen. Sie haben es sehr sorgfältig getan. Sie wurden begleitet durch das «Kuratorium für die Katalogisierung der mittelalterlichen und frühneuzeitlichen Handschriften der Schweiz» der Schweizerischen Akademie der Geistes- und Sozialwissenschaften (SAGW). Dr. Ueli Dill, Leiter der Handschriftenabteilung der Universitätsbibliothek Basel, hat uns bei seinen Besuchen in Beromünster wertvolle Hinweise gegeben. Ihm sage ich: «Danke schön!»

Jakob Bernet, Stiftsbibliothekar 



\section{Einleitung}

\section{Zur Geschichte von Stift und Bibliothek}

Über die Gründung des Stiftes St. Michael in Beromünster sind keine zeitgenössischen schriftlichen Zeugnisse erhalten ein Stiftungsbrief fehlt ebenso wie historiographische Berichte. Erst für das Jahr 1036 scheinen in einer abschriftlich überlieferten Urkunde ausführliche Angaben zur Stiftsverfassung vorzuliegen. Graf Ulrich I. von Lenzburg traf in diesem Dokument angeblich genaue Regelungen über die Rechte und Besitzungen von Vogt und Kapitel des Kanonikerstifts, das in Beromünster «zuerst von meinen Vorvätern und dann von mir der Ehre des heiligen Michael gewidmet wurde $\gg .{ }^{1}$ Bereits hier ist von Büchern die Rede: Der Vogt wird verpflichtet, dem Stift die kanonischen (also wohl die für den Gottesdienst notwendigen) Bücher zur Verfügung zu stellen. ${ }^{2}$ Es ist jedoch auffällig, dass nicht nur die Angaben in der Urkunde selbst widersprüchlich sind, ${ }^{3}$ sondern die darin enthaltenen Bestimmungen auch in keinem späteren Zeugnis genannt werden. Im Gegenteil: Obwohl es in dem auf 1036 datierten Dokument ausdrücklich heisst, Ulrich wolle sein Eigenstift nicht in ein Reichsstift umwandeln, ${ }^{4}$ wird genau dieser Vorgang im Jahr 1045 von König Heinrich III. beurkundet. Seine Urkunde ist im Gegensatz zu der Ulrich zugeschriebenen bis heute im Stiftsarchiv erhalten. 5 Der König bestätigt darin eine Reihe von Besitzrechten und garantiert dem Kapitel die freie Wahl des Propstes. Die von Ulrich angeblich nur neun Jahre früher bis ins Detail festgelegten Pflichten des Vogtes werden jedoch ebenso wenig erwähnt wie die sorgfältig ausgearbeiteten Verfahrensschritte, mit denen das Kapitel sich gegen mögliche Übergriffe von dessen Seite verteidigen sollte. Sie haben auch in keine der späteren, durchweg im Original erhaltenen Königs- oder Papsturkunden Eingang gefunden.

Bei dem auf 1036 datierten Dokument könnte es sich also um eine Fälschung handeln, die im Zuge einer späteren Auseinandersetzung zwischen dem Stift und seinem Vogt entstand. Möglicherweise hängt sie mit einem Streit zwischen den Chorherren von Beromünster und den Grafen Werner und Hartmann von Kyburg zusammen, der sich in mehreren Urkunden von 1223 niederschlug. Für eine Entstehung in diesem Zusammenhang spricht auch, dass in der Urkunde stark betont wird, es solle jeweils nur ein einziger Nachfahre Ulrichs die Vogtei erben. ${ }^{6}$ Das Stift suchte damals Unterstützung bei Kaiser Friedrich II., Papst Honorius III. und Bischof Konrad von Konstanz. ${ }^{7}$ Schon sechs Jahre zuvor hatten die Kyburger, wie der Stiftspropst Dietrich klagte, alle Chorher-

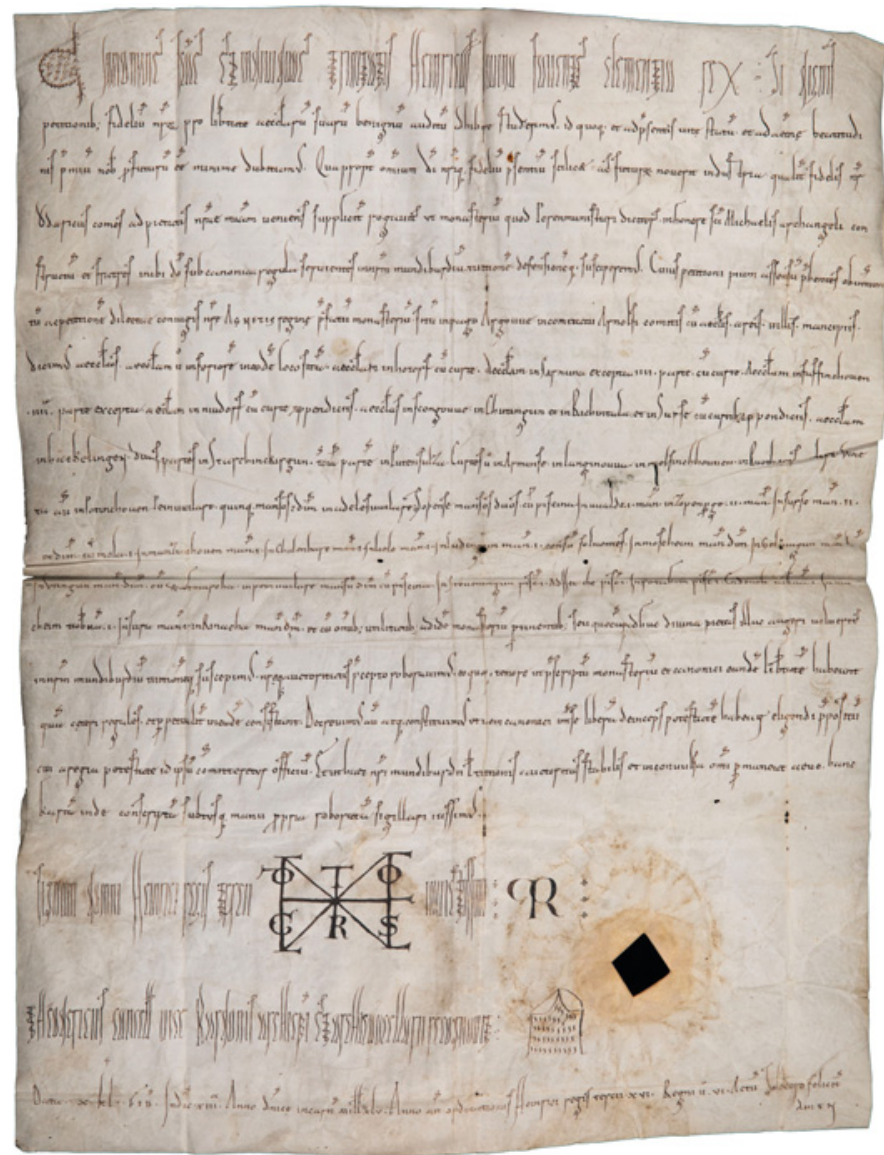

Schirmurkunde König Heinrichs III. für das Stift Beromünster von 1045, Original im Stiftsarchiv erhalten.

ren aus Beromünster vertrieben, so dass keine Messe mehr gehalten werden konnte. Eine Urkunde des ersten sicher bekannten Stifters, in der Vorkehrungen gegen derartige Übergriffe durch den Vogt getroffen wurden, musste in dieser Lage äusserst begehrenswert sein.

Alle Versuche, in der Stiftsgeschichte weiter zurück zu gehen, stützen sich auf den Namen Bero. Schon im Obituar des sogenannten Directorium chori, einer heute verlorenen, mutmasslich ebenfalls im frühen 13. Jahrhundert entstandenen liturgischen Handschrift aus Beromünster, ${ }^{8}$ ist für den 20. August «Graf Bero von Lenzburg, der Gründer dieser Kirche» verzeichnet. ${ }^{9}$ Ein Lenzburger Graf dieses Namens ist jedoch nicht bekannt - zumindest der Titel dürfte also anachronistisch sein. Im 19. Jahrhundert meinte man, Bero in einem Thurgauer Grafen Paringerus (urkundlich belegt 941-951), einem comes palatii Childeberts III. (urkundlich belegt 710) 
oder einem oberelsässischen Grafen Bernhard (urkundlich belegt 896) wiedererkennen zu können. ${ }^{10}$ Josef Siegwart lehnte diese Identifizierungsversuche in einem 1964 erschienen Aufsatz ab und datierte die Gründung des Stifts anhand von genealogischen Überlegungen auf die Zeit um 920.11 Er ging davon aus, dass die heutige Pfarrkirche St. Stephan den ursprünglichen Kern des Stifts bildete, das Michaelspatrozinium habe es erst etwa ein Jahrhundert später im Zusammenhang mit einer Verlegung an seinen heutigen Ort erhalten. Diese Darstellung findet sich als vorläufig wahrscheinlichste Annahme auch in den Nachschlagewerken. ${ }^{12}$ Archäologische Untersuchungen im Zuge von Renovierungsarbeiten in den Jahren 1975 bis 1984 ergaben allerdings einen karolingischen Vorgängerbau unter der heutigen Stiftskirche, die ihrerseits in ottonischer Zeit entstanden sein dürfte. ${ }^{13}$

Erst Ulrich I. von Lenzburg lässt sich also anhand der bereits erwähnten Urkunde König Heinrichs III. sicher als Eigenkirchenherr des Chorherrenstifts in Beromünster feststellen. Von den Lenzburgern ging die Vogtei im 12. Jahrhundert an die Kyburger über und von diesen wiederum im 13. Jahrhundert an die Habsburger. ${ }^{14}$ Nach der Eroberung des Aargaus durch die Eidgenossen 1415 gehörte das Stift dann zum Besitz von Luzern. Die Kämpfe zwischen den Habsburgern und den Eidgenossen gingen jedoch nicht spurlos daran vorbei: Im Jahr 1352 wurden Kirche und Flecken von Luzerner, Schwyzer und Zürcher Truppen niedergebrannt. Auch sonst kam es gelegentlich zu Plünderungen und Bränden. ${ }^{15}$

Diese Ereignisse dürften auch den Handschriftenbestand des Stifts betroffen haben. Allerdings sind kaum gesicherte Aussagen darüber möglich, seit wann in Beromünster eine Bibliothek bestand und welchen Umfang sie hatte. Erst für das Jahr 1392 findet sich ein Hinweis in der Jahrzeit des Johannes von Ems: Der Verstorbene hatte dem Stift drei kanonistische Texte geschenkt, «die für immer in der Bibliothek der Kirche von Beromünster bleiben sollen».16 (Sie sind nicht geblieben). Zu dem sechzehn Jahre später eingetragenen Johannes Witzig heisst es, er habe dem Stift ein Buch für den Gebrauch im Stundengebet (vielleicht ein Brevier) gegeben, unter der Bedingung, dass es mit einer eisernen Kette öffentlich im Chor angeschlossen würde, zusammen mit den anderen Büchern, die dort zum Nutzen der Gemeinschaft befestigt seien. ${ }^{17}$ Unter den erhaltenen mittelalterlichen Handschriften lassen sich aber nur an einem einzigen Band Spuren von einer Kettenklammer erkennen. ${ }^{18}$

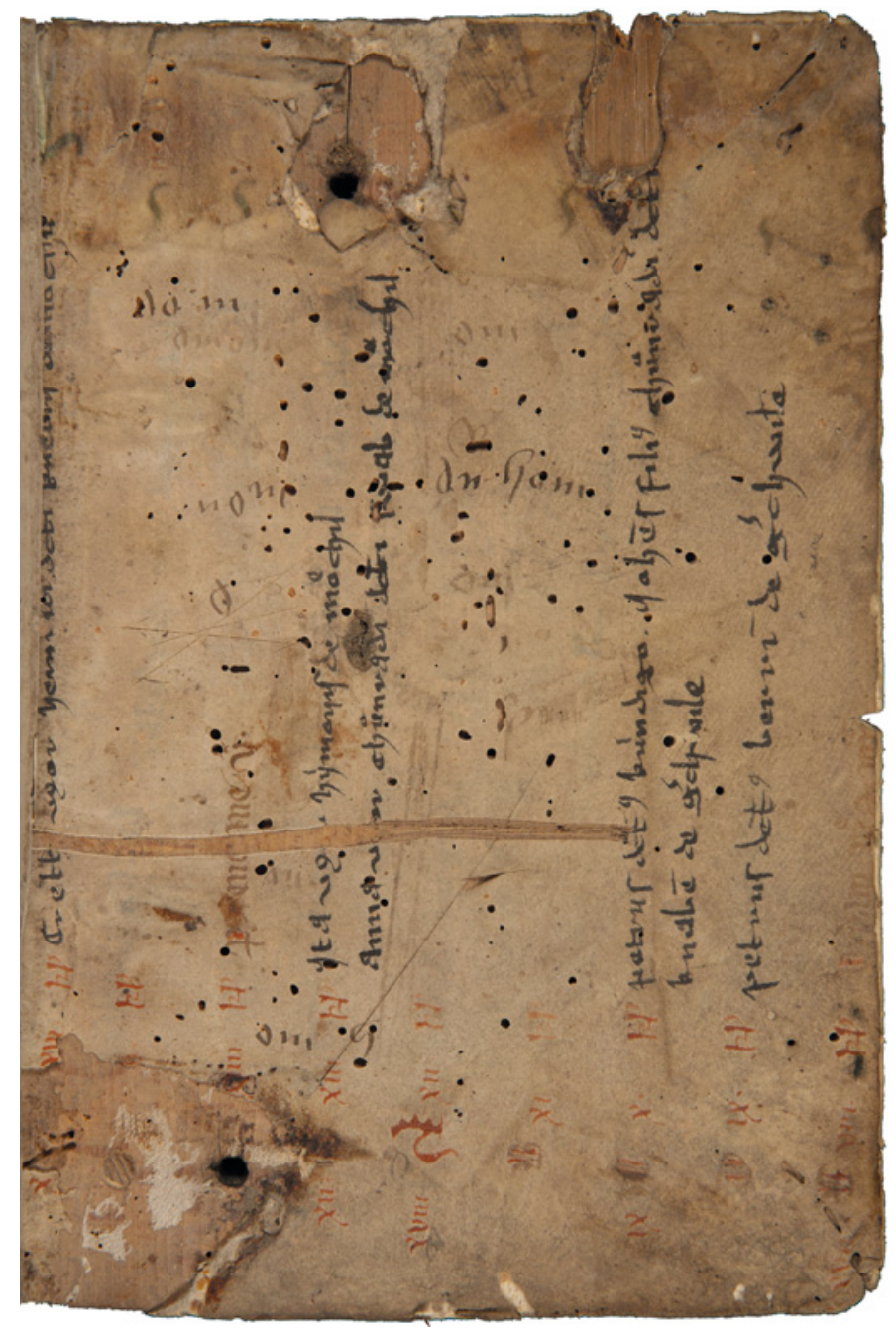

Spuren einer nicht erhaltenen Kettenklammer am hinteren Einbanddeckel der Sammelhandschrift C 14.

Eine weitere Büchersammlung dürfte sich in der Stiftsschule befunden haben. Das Amt des scholasticus (Lehrer oder Schulaufseher) ist ab dem frühen 13. Jahrhundert belegt, und seit dieser Zeit sind auch einzelne Amtsinhaber namentlich bekannt. Man nimmt jedoch an, dass die Schule schon früher bestand. ${ }^{19}$ In den Handschriften selbst findet sich allerdings kein Hinweis auf eine Benutzung im Unterricht vor Ort, und typische Schultexte fehlen. ${ }^{20}$ Auch das Pastorale novellum, ein Lehrgedicht für angehende Priester, ist in der Stiftsbibliothek nicht vertreten, obwohl sein Verfasser Rudolf von Liebegg selbst als scholasticus in Beromünster tätig war. ${ }^{21}$

Der grösste Teil der Handschriften, die heute der Stiftsbibliothek gehören, stammt anscheinend aus dem privaten Besitz der Chor- 
herren. Es handelte sich dabei um einen recht wohlhabenden Personenkreis - nur etwa 5\% stammten aus Familien niederer Dienstleute, die meisten aus Ministerialengeschlechtern oder (besonders seit das Stift luzernisch geworden war) aus der städtischen Oberschicht. ${ }^{22}$ Viele von ihnen gingen zum Studium an die Universität, anfangs meist nach Bologna, später nach Wien, Heidelberg, Freiburg und Basel. Von 1269 bis 1516 ist für 92 Chorherren und Kapläne ein Universitätsstudium nachgewiesen (bei 21 gleichzeitig besetzten Chorherrenpfründen). ${ }^{23}$ Sicherlich kauften sie an ihren verschiedenen Studienorten Bücher oder schrieben selbst Texte $\mathrm{ab}$, doch gelangten die meisten dieser Handschriften offenbar nicht in die Stiftsbibliothek. Nur den Sammlungen des Chorherren Friedrich von Lütishofen und des Kaplans Ludwig Zeller lassen sich jeweils mehrere Bände sicher zuweisen.
Selten gibt es Hinweise darauf, was sonst mit den Privatsammlungen der Stiftsangehörigen geschah. Der Chorherr Werner von Wollishofen verkaufte seine Bücher; eine Liste mit Angaben zu den Preisen ist in einer Handschrift des Klosters Einsiedeln (Ms 193, 217v) erhalten. ${ }^{24}$ Die Büchersammlung des Johannes von Gundoldingen erbte nach dessen Tod seine Mutter und gab sie 1476 an seinen Neffen Werner von Selden weiter, der am Stift Beromünster eine Kaplanei innehatte. Obwohl sie verfügte, dass die Bücher nach Werners Tod «an das Stifft Münster vallen und in die liberie daselbs gethan werden $\gg$ sollten, ${ }^{25}$ ist nur für eine einzige Handschrift nachweisbar, dass sie aus diesem Bestand stammt. ${ }^{26}$ Zumindest zeigt die Verfügung aber, dass es zu dem betreffenden Zeitpunkt am Stift Beromünster eine Bibliothek gab. Die Bücher

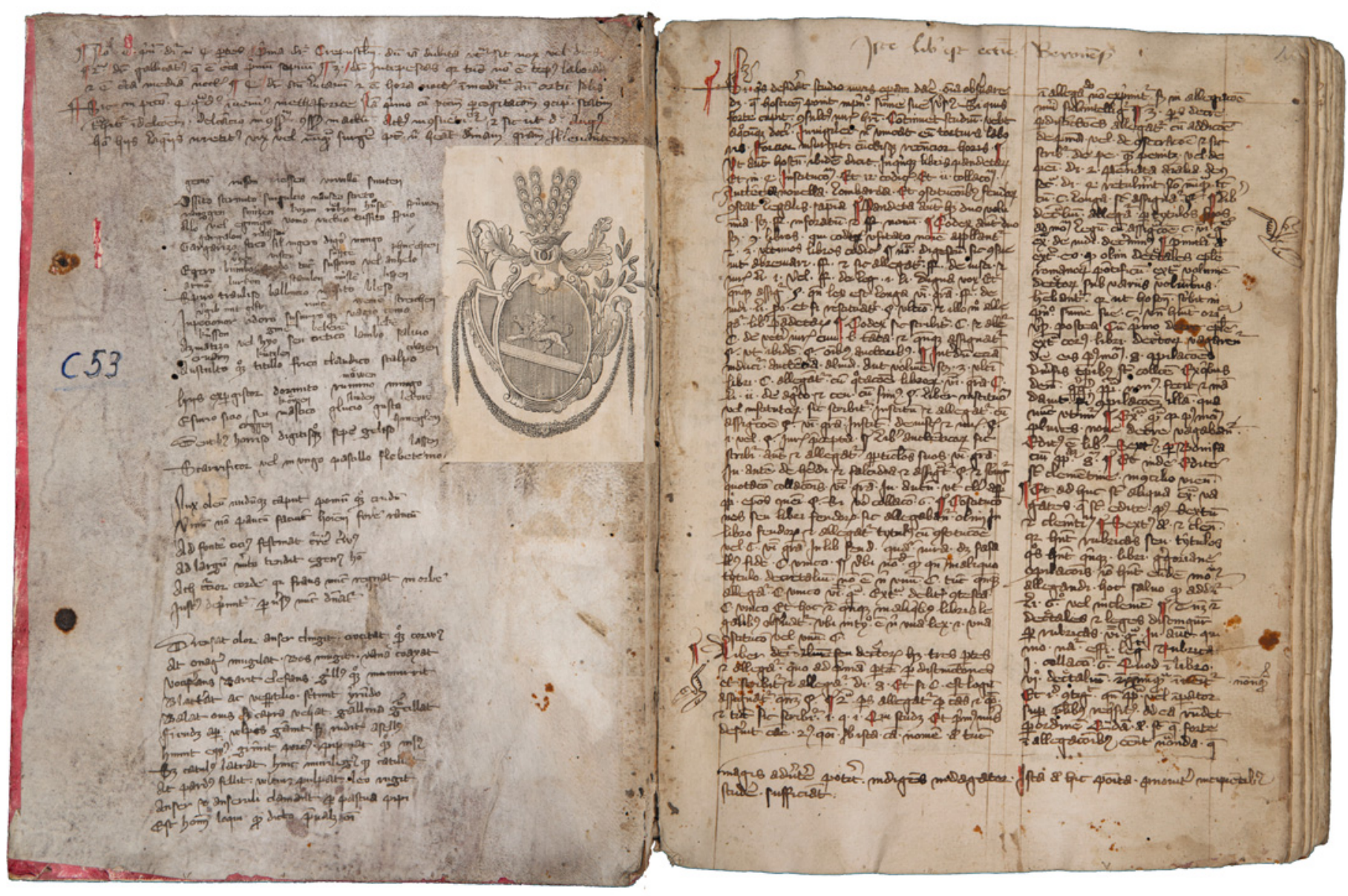

Band C 53: Exlibris der Stiftsbibliothek, wohl bei der Signierung durch Ignaz Vital Herzog in die Bände geklebt, auf dem ersten Blatt mittelalterlicher Besitzeintrag: Iste liber est ecclesie Beronensis. 
12 wurden jedoch nicht systematisch gekennzeichnet: Nur in einem einzigen Handschriftenband der Stiftsbibliothek findet sich ein zeitgenössischer Besitzeintrag. ${ }^{27}$ Einen ähnlichen Eintrag enthält eine Handschrift aus dem späten 10. oder frühen 11. Jahrhundert, die sich heute in der Universitätsbibliothek von Freiburg im Breisgau befindet. ${ }^{28}$ Sie verliess Beromünster im 18. Jahrhundert mit dem Freiherrn Joseph von Lassberg.

Am Stift selbst entstanden wohl nur wenige Handschriften, und zwar in erster Linie Verwaltungstexte. Unter Propst Jakob von Rinach (Amtszeit 1313-1362) wurden die Besitz- und Rechtsverhältnisse des Stifts systematisch untersucht und aufgezeichnet. ${ }^{29}$ Eine weitere Gruppe von Verwaltungshandschriften stammt aus dem letzten Viertel des 15. Jahrhunderts. Aber auch ein Missale für den Gebrauch in der Patronatskirche Hochdorf (C 5 fol.) wurde zu dieser Zeit im Umfeld des Stifts geschrieben. Ungewöhnlicher als solche Arbeiten für den eigenen Gebrauch war die Errichtung einer der frühesten europäischen Druckpressen in Beromünster. ${ }^{30}$ Der Chorherr Elias Elye verlegte dort, schon fast 70jährig, als erstes ein umfangreiches Hilfsmittel für die Bibellektüre. Der auf den Vortag von St. Martin 1470 datierte (tatsächlich spätestens am 27. November dieses Jahres vollendete) «Mammotractus super Bibliam » umfasst zusammen mit den beigefügten kleineren Traktaten nicht weniger als 300 Blätter. ${ }^{31}$ Bis zu seinem Todesjahr 1475 druckte Elye noch vier weitere, weniger lange Werke, das letzte davon sogar in zwei Auflagen. ${ }^{32}$ Darunter ist auch ein Traktat des Zürcher Arztes Eberhard Schleusinger über eine Kometenerscheinung im Jahr 1472, den Elye spätestens 1474, möglicherweise aber noch im selben Jahr fertigstellte. 33 Neben diesen in Beromünster selbst erschienen Büchern besitzt die Stiftsbibliothek eine Reihe von weiteren Inkunabeln. ${ }^{34}$ Wie die Handschriften dürften sie meist aus dem Privatbesitz der Chorherren stammen. Die Druckerei wurde nach Elyes Tod nicht weiterbetrieben.

Auch nachdem die Buchproduktion bereits im Wesentlichen von den Druckern übernommen worden war, entstanden in Beromünster noch zwei bedeutende handgeschriebene Liturgica. Das ältere davon ist ein monumentales zweibändiges Graduale von der Hand des reisenden Buchmalers Claudio Rofferio aus Aosta. ${ }^{35}$ Das Stift beauftragte ihn im Oktober 1561 mit der Herstellung der beiden grossformatigen, reich ausgestatteten Bände, wobei seine Anstellungsbedingungen vertraglich genau geregelt wurden. ${ }^{36}$ Rofferios Arbeit zog sich mit Unterbrechungen über mehrere Jahre hin, im Januar 1567 erfolgte dann die Schlussabrechnung. Eine letzte Prestigehandschrift erhielt das Stift schliesslich mit einem ebenfalls zweibändigen, üppig ausgemalten Antiphonar von der Hand des Künstlers Johann Caspar Winterlin, einem Mönch aus Muri. Den Winterteil hatte der Kaplan Rudolf Engels bereits 1601 begonnen, aber nicht fertiggestellt. Winterlin führte die Arbeit 1611 unentgeltlich zu Ende und schuf in den folgenden drei Jahren auch den dazugehörigen Sommerteil. ${ }^{37}$ Die beiden Werke wurden in den vorliegenden Katalog aus chronologischen Gründen nicht mit einbezogen - sie verdienen eigene kunsthistorische Untersuchungen.

Erst im Jahr 1603 wurden Statuten erlassen, in denen auch ein Bibliothekar erwähnt wird und dessen Verpflichtungen festgelegt werden. ${ }^{38}$ Nach diesem Regelwerk ist der Bibliothekar gehalten, alle alten, bereits vorhandenen Bücher zu ordnen

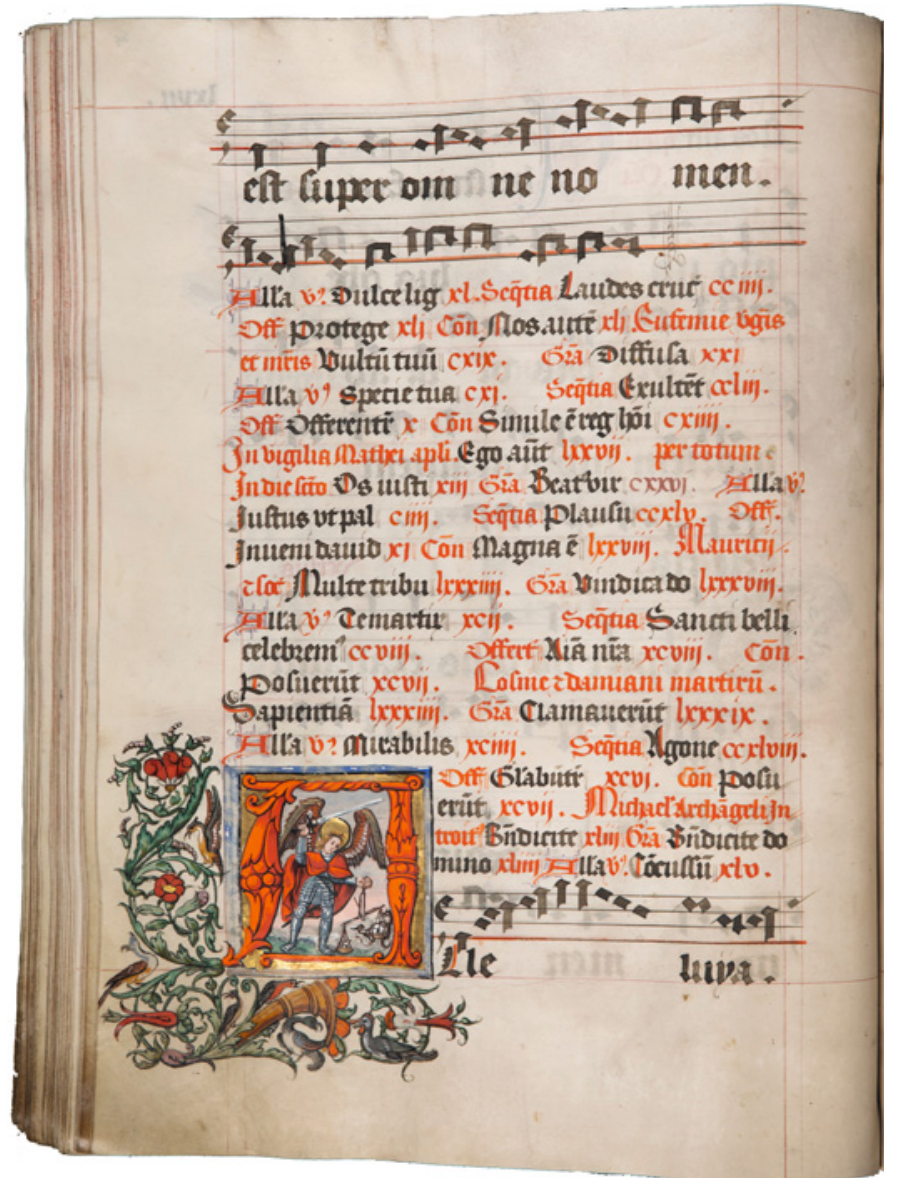

Der Stiftspatron St. Michael als Seelenwäger mit Schwert und Drachen, Illumination von der Hand Claudio Rofferios (Ms C 136, 69v). 
und zu inventarisieren. Zu Beginn jedes Jahres soll er dem Kapitel die Autoren nennen, die neu angeschafft werden müssen - besonders wenn ein jüngeres Werk gedruckt wurde. Er darf niemandem ein Buch verleihen, ohne es quittieren zu lassen, und muss alle ausgeliehenen Bücher Anfang September zurückfordern. Dabei hat er auf Verluste und Beschädigungen zu achten, für deren Behebung der Schuldige selbst aufkommen muss. Neben diesen Pflichten obliegt dem Bibliothekar auch die Aufsicht über den Lehrer und dessen Unterricht, nicht zuletzt im Hinblick darauf, dass keine moralisch oder dogmatisch anstössigen Werke behandelt werden.

Die Verbindung zwischen Bibliotheks- und Schulaufsicht lässt vermuten, dass die Unterrichtswerke zu diesem Zeitpunkt zum Bestand der Stiftsbibliothek gehörten. Daneben werden in den Statuten ein separates Archiv und eine Sammlung von liturgischen Handschriften in der Sakristei erwähnt, die beide dem Kustos unterstanden. Auch der 1527 gegründeten Prädikatur, die dem wachsenden Einfluss der Reformation entgegenwirken sollte, ${ }^{39}$ stand vielleicht eine eigene Büchersammlung zur Verfügung. Sie wird allerdings nirgendwo explizit erwähnt und auch ihr Bestand konnte nicht identifiziert werden. Es dürfte sich in erster Linie um gedruckte Werke gehandelt haben.

Im weiteren Verlauf der frühen Neuzeit, als gemäss den Statuten von 1603 eine systematisch gepflegte Bibliothek in Beromünster anzunehmen wäre, vermachten dennoch viele der dortigen Chorherren ihre persönlichen Büchersammlungen nicht ihrer eigenen Stiftsbibliothek, sondern anderen Institutionen. So führt Alois Kopp in seiner Bibliotheksgeschichte des Stifts Beromünster eine Reihe von Nachlässen an verschiedene Schweizer Klöster auf. ${ }^{40}$ Andererseits verzeichnet er aber auch einige grössere Bücherschenkungen, wie etwa 250 Bände des Leutpriesters Jeremias Meier $(\dagger 1671)$ sowie die Sammlungen des Propstes Wilhelm Meier (†1674) und des Chorherren Johann Heinrich Fleischlin (†1681). ${ }^{41}$ Ihre Verfügungen werfen erneut Licht auf den Zustand der Stiftsbibliothek. So hinterliessen die beiden Erstgenannten ihre Bücher ausdrücklich der Leutpriesterei. Die Bestimmung von Propst Wilhelm Meier, dass bei einem Wechsel des Leutpriesters jeweils überprüft werden solle, ob alle Bücher vollständig vorhanden seien, weist auf ihre Aufbewahrung im Pfarrhaus hin. Fleischlin wiederum erklärte als Zweck seiner Stiftung ausdrücklich, «daß mit der zeit ein rechte Bibliotheca, wie es einer so lobl. Stift schon lengsten wohl angestanden währe, möchte uffgerichtet werden». Es scheint also in der zweiten Hälfte des 17. Jahrhunderts am Michaelsstift keine Büchersammlung gegeben zu haben, die den zeitgenössischen Anforderungen hätte genügen können. Um Fleischlins Bücher und Gemälde angemessen unterzubringen, wurde folglich beschlossen, eine Bibliothek über der neuen Sakristei im Kapitelhaus einzurichten. ${ }^{42}$

Für das Jahr 1785 liegt abermals eine Klage über die Vernachlässigung der Stiftsbibliothek vor, doch in der Folgezeit wurden offenbar ernsthafte Anstrengungen unternommen, die Situation zu verbessern. ${ }^{43}$ Man forderte von den Chorherren nun regelmässige Beiträge zum Bibliotheksbudget ein, und zahlreiche wurmstichige Bücher - glücklicherweise aber nicht die Handschriften - wurden neu eingebunden. Eine Verlegung aus dem klimatisch ungünstigen Dachgeschoss in einen hellen, trockenen Raum im Chorhof des damaligen Bibliothekars Franz Bernhard Göldlin wurde zwar ins Auge gefasst, aber letztlich nicht durchgeführt. ${ }^{44}$ Erst 1813 kamen die Bücher tatsächlich an einen neuen Standort, den noch heute verwendeten Bibliothekssaal im zweiten Stock der Propstei. Im Jahr 1980 wurden das Archiv und die mittelalterlichen Handschriften dann nach fünfjähriger Planungs- und Bauphase in einen klimatisierten Schutzraum mit modernem Regalsystem in der ehemaligen Sakristei unter der Kirche verlegt, wo sie optimale Erhaltungsbedingungen fanden..$^{45}$ Das alte Signaturensystem, das zwischen Quart- und Folioformat unterschieden hatte, wurde nun zugunsten einer fortlaufenden Nummerierung aufgehoben. Um den Anschein von Doppelungen bei den Signaturen zu vermeiden, reihte man die Foliobände hinter den Quartbänden ein. Nur das Hochdorfer Missale, das sich zu diesem Zeitpunkt bereits in der Schatzkammer befand, wurde dabei nicht berücksichtigt und trägt noch immer seine alte Signatur C 5 folio. Da die Handschriften auch in der Literatur meist noch nach diesem System zitiert werden, ist dem Katalog eine Signaturenkonkordanz vorangestellt und die alten Signaturen der Foliobände werden in jeder Beschreibung unter der Rubrik «Besitzer, Signatur » angegeben.

Bereits 1763 waren die Bücher in einem Katalog verzeichnet worden, der allerdings zunächst nur die Druckschriften berücksichtigte. ${ }^{46}$ In zwei Zusätzen $\left(41^{\mathrm{r}-\mathrm{v}}\right.$ und $\left.44^{\mathrm{v}}-53^{\mathrm{v}}\right)$ wurden nachträglich auch die Handschriften darin aufgenommen. $\mathrm{Zu}$ diesem Zeitpunkt bildeten sie in der Systematik gemeinsam mit einigen Inkunabeln eine eigene Abteilung, die Classis nona, die im ersten Zusatz unter den fortlaufenden Nummern 1 bis 34 aufgelistet wird. Von 26 Einträgen, die 


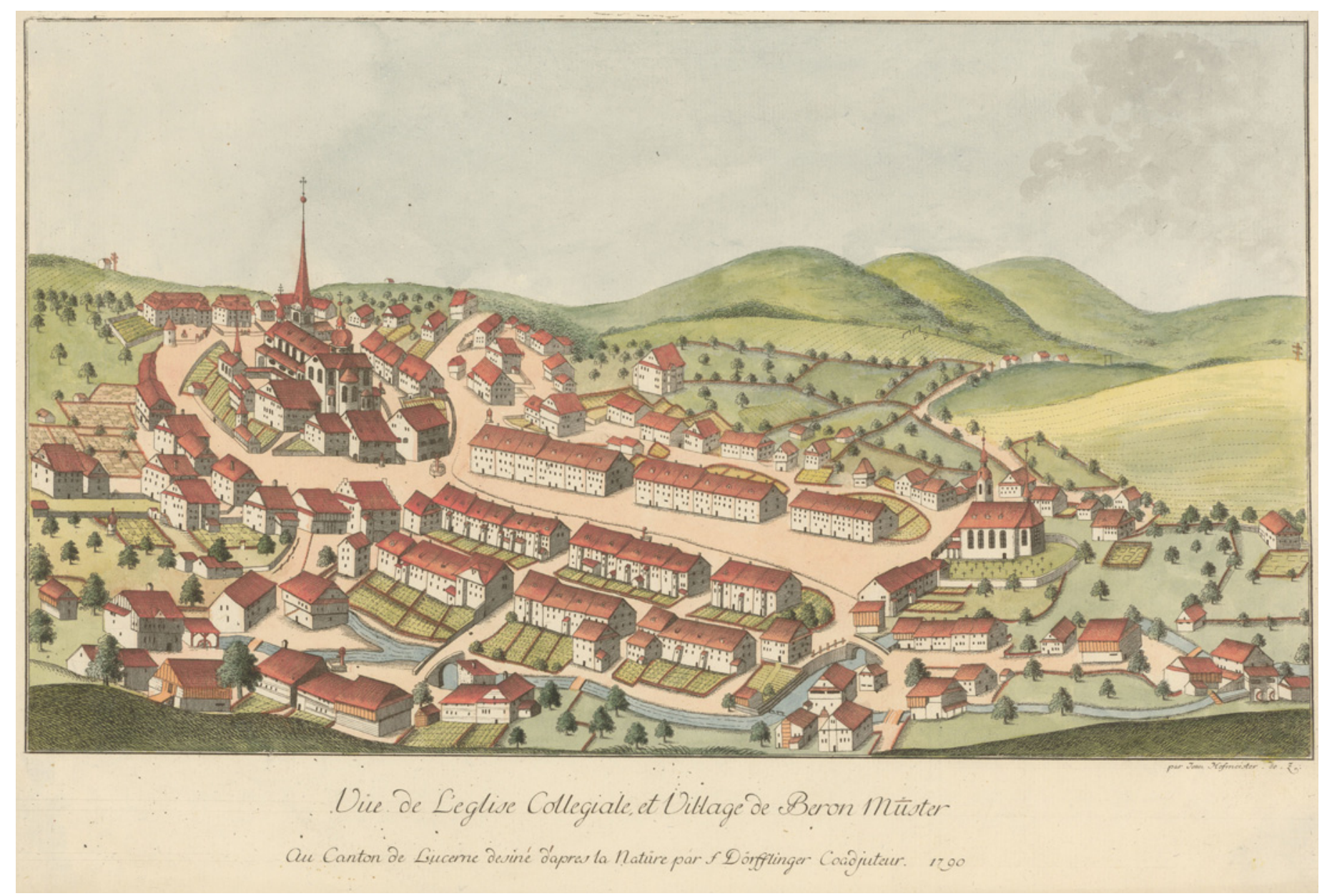

Blick auf Stift und Flecken von Beromünster, Johannes Hofmeister, [Zürich] 1790

(Zentralbibliothek Zürich, LU, Beromünster I, 3 Pp A2, https://doi.org/10.3931/e-rara-38002).

sich ausdrücklich auf Handschriften beziehen, konnten 19 sicher mit einem der erhaltenen Codices zusammengebracht werden. Im zweiten Zusatz wurden für einige ausgewählte Stücke von anderer Hand genaue Inhaltsangaben ergänzt. Im Jahr 1826 legte dann der historisch interessierte Stiftsbibliothekar Ignaz Vital Herzog einen weiteren Bibliothekskatalog (StiAB 01.01.1245) an, der nun mit einem Verzeichnis der Handschriften beginnt. Diese sind wiederum durchnummeriert, wobei kein Zusammenhang mit der älteren Zählung erkennbar ist. Die Handschriften wurden aber nicht nur im Katalog verzeichnet, sondern auch mit Rückenschildern versehen, auf denen ein Kurztitel und die jeweilige Katalognummer stehen. Wahrscheinlich wurden auch die Exlibris bei dieser Gelegenheit in die Buchdeckel geklebt. ${ }^{47}$ Für viele Bücher ist die Erwähnung in einem dieser beiden Kataloge streng ge- nommen der erste (oder im Fall eines Bandes, der sich heute in der Zentral- und Hochschulbibliothek Luzern befindet, der letzte $)^{48}$ explizite Besitznachweis. Allerdings findet sich in beiden Katalogen ein etwas unterschiedlicher Bestand, und keiner von ihnen enthält alle heute bekannten Handschriften des Stifts Beromünster. Wie diese Unterschiede zu erklären sind, ist unklar - vielleicht weisen sie auf Ausleihen hin? Spätestens seit den 1760er Jahren, als Josef Anton Felix von Balthasar mit seinen Antiquitates Beronenses (ZHB Luzern, BB Ms 74) eine umfangreiche Materialsammlung zur Stiftsgeschichte zusammenstellte, wurde das Stiftsarchiv immer wieder für historische Studien ausgewertet. Doch obwohl von Balthasar auch eine Reihe von Handschriften aus der Bibliothek verzeichnete, fanden diese zunächst vergleichsweise wenig Beachtung. In den Jahren 1903 und 1904 veröffentlichte 


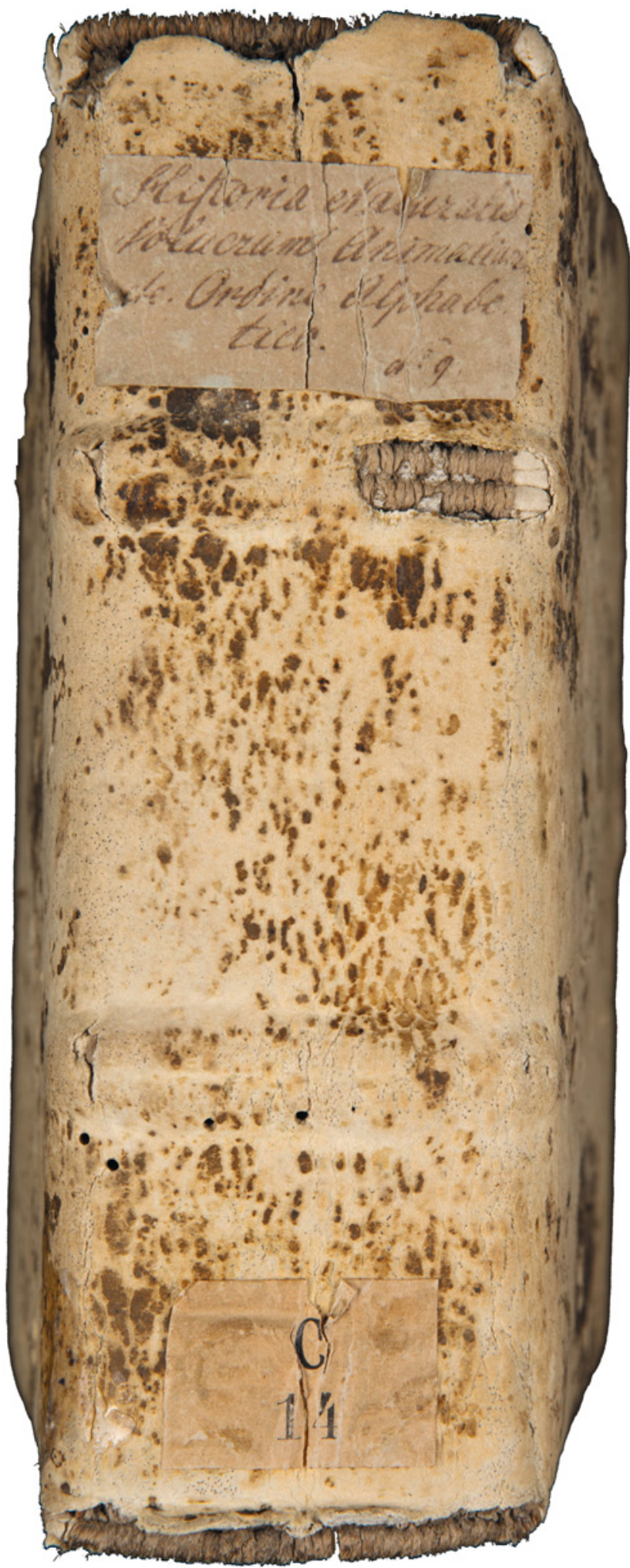

Rückenschild aus der Zeit der Katalogisierung durch Ignaz Vital Herzog (C 14) dann der Stiftsbibliothekar Karl Alois Kopp eine Studie zur Bibliotheksgeschichte, deren zweiten Teil ein Katalog der Handschriften und Inkunabeln bildete. 60 Jahre später verband Albert Bruckner in einem Kapitel seines 14bändigen Werkes «Scriptoria Medii Aevi Helvetica» die Bibliotheksgeschichte des Stifts Beromünster mit Kurzbeschreibungen der Handschriften. Im vorliegenden Katalog werden erstmals alle mittelalterlichen Buchhandschriften systematisch nach modernen Standards erfasst.

\section{Die liturgischen Handschriften}

Nicht nur die jüngsten, sondern auch die ältesten Prachthandschriften des Stifts St. Michael wurden für den Gebrauch im Gottesdienst geschaffen. Eine von ihnen, ein im ersten Viertel des 11. Jahrhunderts wohl auf der Reichenau geschrie-

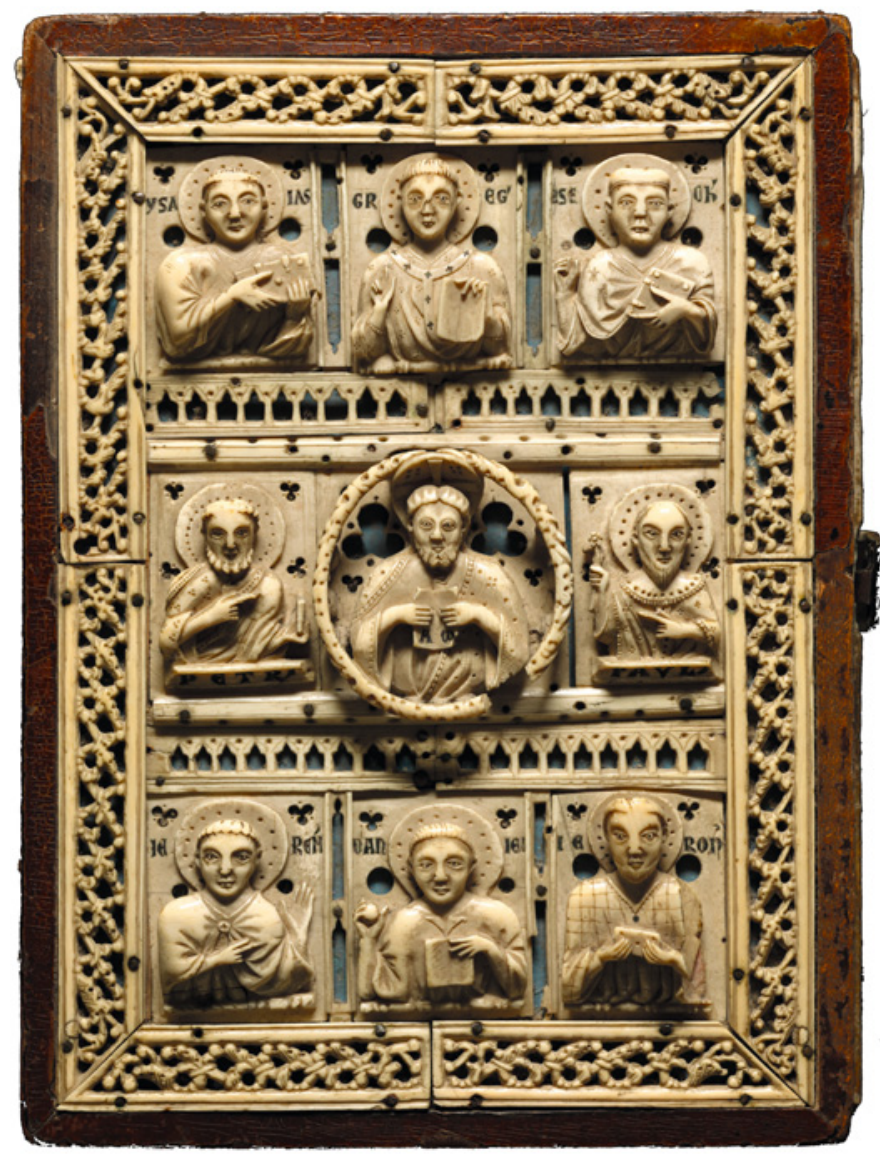

Vorderdeckel des Epistolars II C 3 (e-codices.ch/de/sbb/epist//bindingA). 
benes Epistolar (II C 3), könnte als Stiftung Graf Ulrichs I. von Lenzburg nach Beromünster gekommen sein. $\mathrm{Zu}$ seinem Memorialeintrag im verlorenen Directorium chori hiess es nämlich weiter: «Graf Ulrich stellte diese Kirche wieder her und beschenkte sie [...] mit einem goldenen Kelch und einem mit Gold unterlegten Elfenbeinepistolar, das bis heute erhalten ist, während ein Evangeliar verloren ging».49 Das Epistolar ist demnach das einzige erhaltene Buch aus der Frühzeit des Stiftes. Die Elfenbeinschnitzereien, die es heute schmücken, dürften jedoch erst im späten 13. Jahrhundert entstanden sein. Damit sind sie deutlich jünger als die Handschrift selbst oder auch das Directorium chori. ${ }^{50}$ Man bezog die Er-

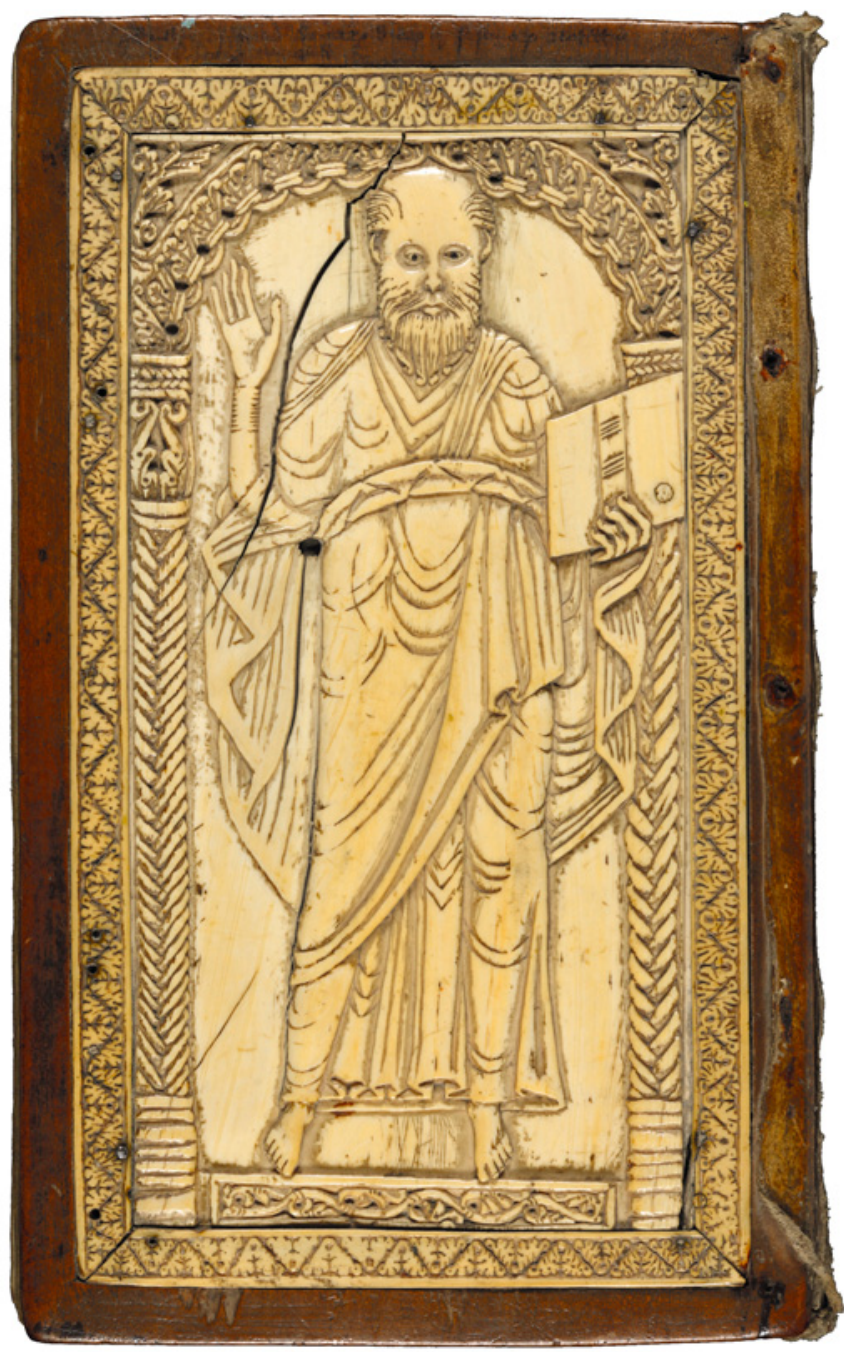

Rückdeckel des Cantatoriums II C 2 (e-codices.ch/de/sbb/cant//bindingC). wähnung von Elfenbein in Ulrichs Memorialeintrag deshalb auf die beiden frühmittelalterlichen Darstellungen der Apostel Petrus und Paulus, die heute auf dem Einband des Cantatoriums (II C 2) angebracht sind. ${ }^{51}$ Allerdings ist diese Annahme nicht zwingend notwendig, denn die Notiz im Directorium chori wurde wohl erst nachträglich hinzugesetzt. ${ }^{52}$ Ihre Datierung ist ungewiss - vielleicht stammt sie aus derselben Zeit wie die Verse, die auf dem Vorsatzblatt des Epistolars selbst stehen:

Hunc librum Pauli doctoris denique summi

Scripturis totum simul auro eboreque paratum

Marchio Uddalricus tibi, Criste, sanxit in usum

Qui post hanc vitam mereatur habere quietem.

(«Dieses Buch schliesslich, das für die Schriften des erhabensten Lehrers Paulus ganz in Gold und Elfenbein hergerichtet wurde,

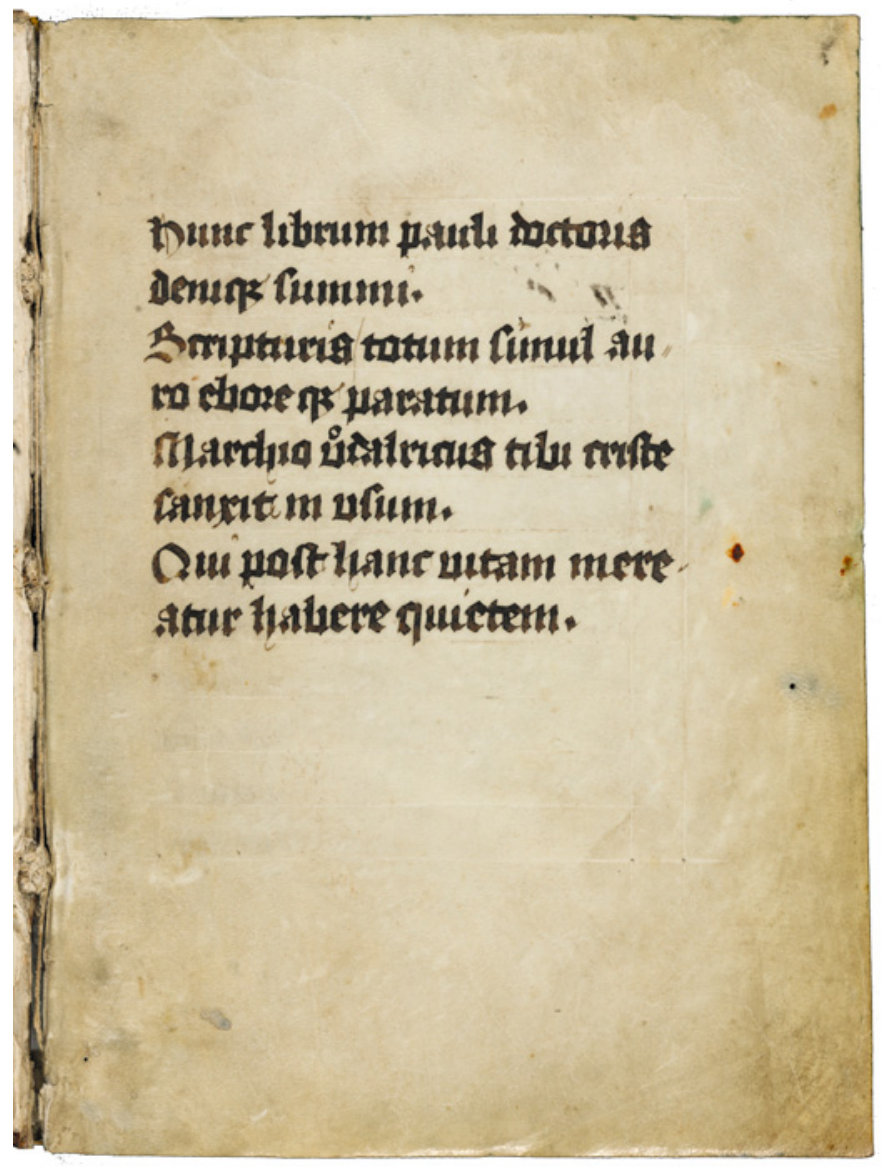

Nachtrag von der Hand des Johannes Dörflinger mit Nennung Ulrichs I. von Lenzburg als Stifter des Epistolars II C 3, 1r. 
hat Markgraf Ulrich Dir, Christus, zum Gebrauch geweiht. Möge er nach diesem Leben Ruhe verdienen.») Es handelt sich dabei um einen Nachtrag von der Hand des Kaplans Johannes Dörflinger, der im letzten Drittel des 15. Jahrhunderts in Beromünster tätig war. 53

Gegen die Theorie, dass die Einbanddeckel des Cantatoriums ursprünglich zum Epistolar gehörten, sprechen die Grössenverhältnisse der beiden Handschriften. Denn während das Epistolar ein vergleichsweise breites Format hat (rund 4:3), sind die beiden Platten mit den Aposteldarstellungen ebenso wie der Buchblock des Cantatoriums, auf dessen Einband sie heute angebracht sind, eher schmal (rund 2:1). Dieses «Diptychonformat $\gg^{54}$ und die Verwendung von viel älteren Elfenbeinarbeiten ist typisch für Handschriften, in denen der musikalische Teil von Messe und Officium aufgeschrieben wurde. 55

Wie das Epistolar ursprünglich eingebunden war, lässt sich nicht mehr sicher feststellen. Ein Hinweis findet sich aber in Zusammenhang mit den oben zitierten Versen. Johannes Dörflinger kopierte sie nämlich noch in eine weitere liturgische Prachthandschrift, das goldgeschmückte Evangelistar (II C 1). Dabei gab er auch an, woher die Verse stammten: Es handele sich um eine Aufschrift, die aussen in die silbernen Ränder des Epistolars graviert sei, das Graf Ulrich von Lenzburg Christus und dem Heiligen Michael geweiht habe. ${ }^{56}$ Möglicherweise hatte Dörflinger sie selbst von dort abgeschrieben und in die beiden Handschriften übertragen, als der betreffende Einband - aus welchem Grund auch immer durch die heute erhaltene Elfenbeinarbeit ersetzt wurde.

Das Cantatorium, auf dem die beiden frühmittelalterlichen Elfenbeinplatten mit den Reliefs der Apostel Petrus und Paulus angebracht sind, wurde im 13. Jahrhundert geschrieben und ist damit die zweitälteste erhaltene Handschrift des Stifts Beromünster. Den prächtigsten Einband hat aber die jüngste der drei Schatzhandschriften, das in der ersten Hälfte des 14. Jahrhunderts entstandene Evangelistar. Es ist mit fein gearbeiteten Goldelementen, transluzider Emaille und Edelsteinen aufwendig verziert, im Zentrum trägt es eine vollplastische Darstellung von Christus als Weltenretter. Anscheinend wurde es von einem Konstanzer Künstler speziell für das Stift St. Michael geschaffen, denn auf den Medaillons am Rand ist auch der Erzengel im Kampf mit dem Drachen dargestellt. ${ }^{57}$ Im Gegensatz zu den beiden anderen Schatzhandschriften, die zwar sehr schön, aber nicht besonders prächtig geschrieben sind, ist in diesem Band auch der Text selbst aufwendig

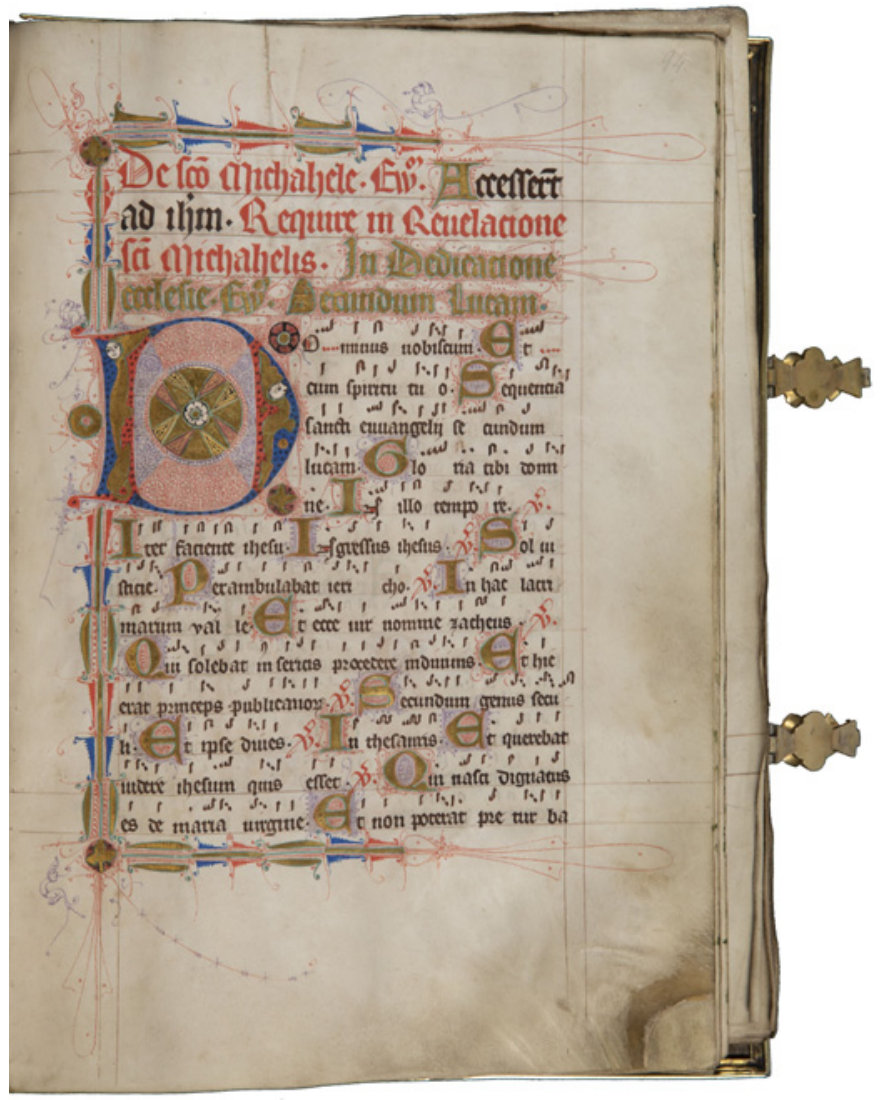

Beginn der Michaelsmesse im Evangelistar, aufwendig mit Gold plattiert (II C 1, 94r).

verziert: Initialen und Ränder sind mit Ornamenten, Pflanzen und Drachen in Deckfarbenmalerei mit Goldauflagen geschmückt. Auch dabei ist die Messe zu Ehren des Heiligen Michael besonders hervorgehoben.

An liturgischen Handschriften aus dem Mittelalter sind am Stift Beromünster ausser diesen drei Bänden heute nur noch zwei Missalia erhalten. Eines davon (C 55) gehörte ursprünglich in die Schlosskapelle der Zürcher Familie Göldlin. Es wurde dem Stift von Renwald Göldlin von Tiefenau geschenkt, der seit 1551 Chorherr in Beromünster war. Das andere Missale (C 5 fol.) schrieb der bereits erwähnte Johannes Dörflinger. Es gehörte offenbar zur Ausstattung eines neu gestifteten Altars zu Ehren der Apostel Petrus und Paulus, den der Dekan und Leutpriester Johannes Teller gemeinsam mit seinem gleichnamigen Bruder in Hochdorf, einer Patronatskirche des Stifts Beromünster, einrichtete. Die Stiftungsurkunde vom 26. September 1469, in der das liturgische Gerät (darunter auch 
das Missale) und die Ausstattung der Pfründe genau aufgeführt sind, kopierte Dörflinger in das Proprium de tempore zwischen Gründonnerstag und Ostern $\left(81^{\mathrm{rb}}-82^{\mathrm{vb}}\right)$.

Schon 1459 hatte Johannes Teller ein heute verlorenes Missale im Wert von 28 Gulden an die Kaplanei St. Thomas gestiftet, ${ }^{58}$ deren Inhaber zu dieser Zeit Dörflinger war. Aber auch sonst sind öfters Schenkungen von liturgischen Büchern belegt, die nicht erhalten blieben. So stiftete Gerung von Säckingen im Jahr 1312 dem Altar der 11'000 Jungfrauen in der Galluskapelle unter anderem ein Missale. ${ }^{59}$ Vierzehn Jahre später widerrief er einen anderen Teil der Schenkung, gab aber zugleich ein zweiteiliges Missale und ein Brevier an den Hauptaltar in der Stiftskirche. ${ }^{60}$ Von dem Brevier des Johannes Witzig war oben bereits die Rede, und ein Rektor von Römerswil namens Eberhard vermachte dem Kapitel ein Diurnale. Der betreffende Eintrag im Jahrzeitbuch von Schwarzenbach ist allerdings mehrdeutig: Es heisst darin, um den Preis des Buches sei Eberhards Gedenktag gekauft worden. ${ }^{61}$ Bestand die Bezahlung in dem Diurnale selbst oder wurde es verkauft, um mit dem Ertrag die Messe zu finanzieren? Vielleicht sind auch andere Schenkungen von Büchern nicht unbedingt als Beitrag an die Bibliothek zu verstehen, sondern geschahen mit Hinblick auf deren materiellen Wert. Viele Bände, die heute nicht mehr vorhanden sind, haben aber wohl schlicht den Lauf der Jahrhunderte nicht überstanden - das betrifft besonders diejenigen, die regelmässig im Gottesdienst benutzt wurden.

Reste von zerstörten liturgischen Handschriften finden sich zahlreich im Stiftsarchiv: Viele der jüngeren Verwaltungshandschriften sind in Fragmente eingebunden. Allerdings muss es sich dabei nicht unbedingt um Blätter aus Handschriften des Stifts selbst handeln, denn nach der Reformation wurden liturgische Bücher aus dem Bestand der aufgelösten Klöster auch systematisch auseinandergeschnitten und als Einbandmaterial verkauft. 62

\section{Die Verwaltungshandschriften}

Überreste von makulierten Handschriften fanden in Beromünster nicht nur als Aktenumschläge Verwendung, sondern kommen auch in fast allen Bänden der Stiftsbibliothek vor. Eine Sammlung von abgelösten Fragmenten wird heute im Stiftsarchiv verwahrt. ${ }^{63}$ Auch darin finden sich viele Blätter aus liturgischen Handschriften, häufig mit Musiknotation. Ausserdem enthält sie theologische Texte wie Psalmenkommentare, ${ }^{64}$ ein thematisch geordnetes Cassian-Florileg, eine Kompilation über verschiedene Häresien aus Isidors Etymologiae und die Legenda aurea. Mit einem Blatt aus dem Decretum Gratiani und einem Doppelblatt aus dem Ordo iudiciarius des Aegidius de Fuscarariis sind auch juristische Schriften vertreten. Für den Bereich der Medizin steht ein Doppelblatt aus dem Carmen de urinis des Aegidius von Corbeil, ein weiteres Doppelblatt über die Lepra und ihre Therapie aus einer Foliohandschrift des 14. Jahrhunderts und eines mit Eintragungen zu Aderlassterminen aus einem Kalendar (14./15. Jh.). Falls diese Fragmente Hinweise auf den früheren Bestand der Stiftsbibliothek geben, lassen sie auf eine am praktischen Nutzen orientierte Handschriftenauswahl schliessen. Anders verhält es sich mit einem Fragment, das heute nicht mehr in Beromünster, son-

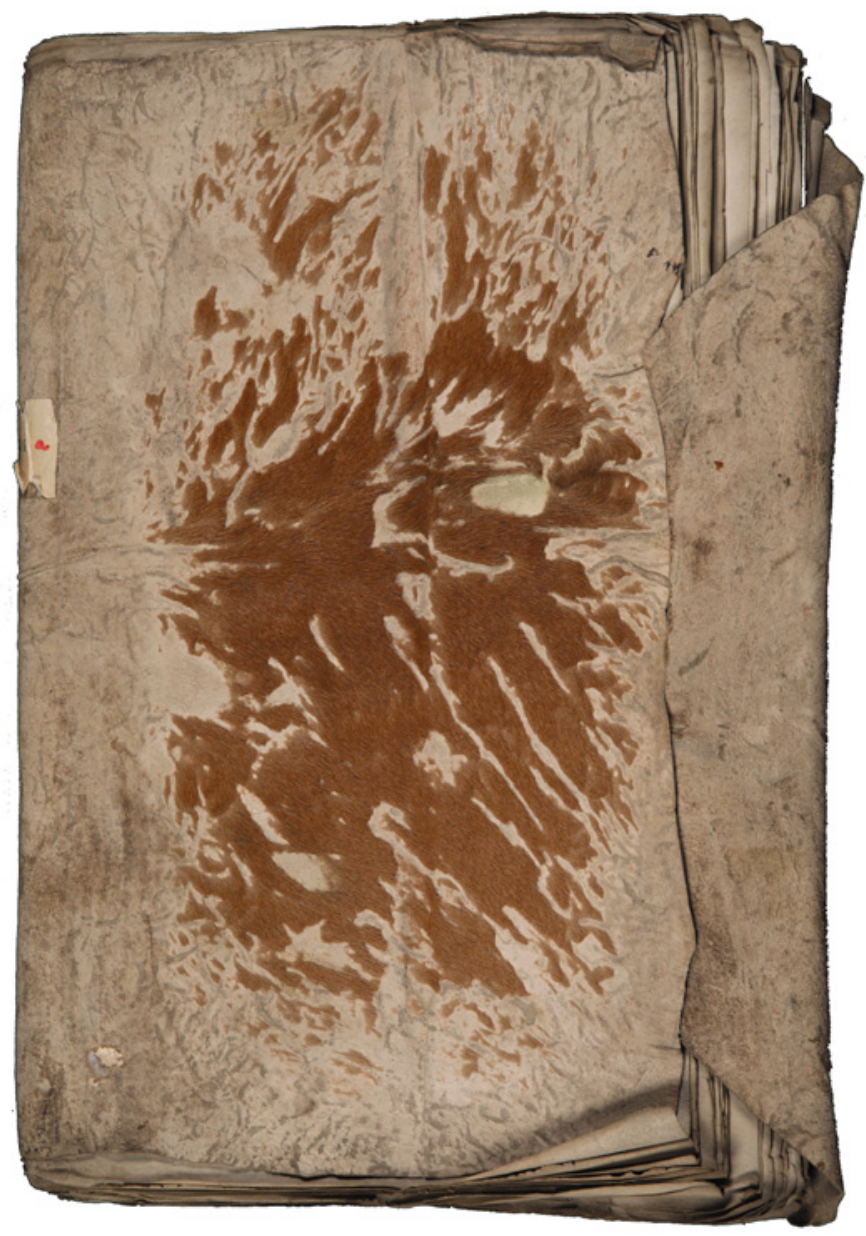

Koperteinband des Liber crinitus mit Resten der stark abgeriebenen Behaarung (StiA Bm 634a). 
dern in der Badischen Landesbibliothek in Karlsruhe liegt: In einem Aktenumschlag im Stiftsarchiv entdeckte Joseph von Laßberg noch vor 1825 die sogenannte «Nibelungenhandschrift G» (Donaueschingen 64).65 Sie ist eine der wenigen Spuren von literarischem Interesse im engeren Sinne.

Abgesehen von diesem berühmten Fragment ist wohl der Liber crinitus (StiA Bm 634a) die bekannteste Handschrift des Stiftsarchivs. Das «behaarte Buch» erhielt seinen Namen nach dem rotbraunen Fell seines Koperteinbands. Inhaltlich handelt es sich um eine Sammlung von Dokumenten und Verwaltungstexten, die aus mehreren ursprünglich voneinander unabhängigen Teilen besteht. Auf dem hintersten Blatt einer Lage mit Urkundenabschriften $\left(46^{v}\right)$ ist noch der Abdruck eines eisernen Beschlages erkennbar - offenbar bildete dieses Heft ursprünglich die letzte Lage in einem fest gebundenen Codex. Den Beginn der Sammlung, wie sie heute vorliegt, bildet die mutmasslich gefälschte Urkunde Ulrichs I. von Lenzburg. Sie erscheint hier zum ersten Mal, und das gleich dreifach. ${ }^{66}$ Wie viele andere Texte in dem Band wurde sie sehr sorgfältig geschrieben, für die Königsurkunden wurden sogar die Monogramme genau nachgezeichnet. Die besondere Bedeutung des Liber crinitus für das Stift Beromünster lässt sich auch daran ablesen, dass er wohl zu verschiedenen Gelegenheiten mit Nähten und aufgeklebten Pergamentflicken repariert wurde. Unter diesen Flicken sind auch Fragmente einer prächtigen Handschrift aus dem 15. oder 16. Jahrhundert mit Deckfarbenmalerei und Silberplattierung. Im frühen 17. Jahrhundert wurde der ganze Band aufwendig faksimiliert. ${ }^{67}$

Während der Liber crinitus erst nachträglich und unsystematisch aus verschiedenen bereits vorhandenen Teilen zusammengefügt wurde, beauftragten der Propst und das Kapitel im Jahr 1504 den Notar Andreas Erni mit einer vollständigen Abschrift aller wichtigen Dokumente des Stifts (StiAB 01.01.635). Auch dieser Band beginnt mit der Urkunde im Namen Ulrichs I. von Lenzburg. Wie der Liber crinitus erhielt er einen Koperteinband, der diesmal aus zwei Doppelblättern eines Missales aus dem 14. Jahrhundert besteht. Nach seinem Schreiber trägt er den Namen «Ernis Buch».

Die ältesten Handschriften im Stiftsarchiv neben dem Liber crinitus sind Verzeichnisse über Besitzverhältnisse und Einkünfte des Stifts, die unter Propst Jakob von Rinach angelegt wurden. Im Roten Jahrzeitbuch von 1323/24 und im Weissen Jahrzeitbuch von 1345/47 wurden nicht nur die Messfeiern eingetragen, die das Stift im Jahreslauf zu leisten hatte, son- dern auch die Erträge aus den dazugehörigen Stiftungen. ${ }^{68}$ Anschliessend wurden in einem eigenen Teil alle Zahlungen, die dem Kammeramt, dem Kelleramt, dem Fabrikamt, der Kustodie und den Zelebranten zustanden, noch einmal separat aufgelistet. Im sogenannten Feudenbuch, das etwa zur gleichen Zeit entstand wie das Weisse Jahrzeitbuch, finden sich Verzeichnisse über die Erträge der einzelnen Präbenden. Alle diese Aufzeichnungen dienten dem doppelten Zweck, einerseits die Rechts- und Besitzverhältnisse des Stifts zu dokumentieren und andererseits Verteilungsstreitigkeiten zu vermeiden, denn jede Chorherrenpfründe in einem Säkularkanonikerstift wie St. Michael bildete eine mehr oder weniger eigenständige wirtschaftliche Einheit. Die Bände dienten ausserdem als Beweismittel für die Ansprüche des Stifts bei der Abgabenerhebung. ${ }^{69}$

Im 15. und 16. Jahrhundert wurden weitere Jahrzeitbücher für Patronatskirchen und einzelne Amtsträger (Scholasticus, Kämmerer) angelegt..$^{70}$ Die Jahrzeitbücher der Kirchen von Schongau, Neudorf und Schwarzenbach stammen wohl alle von der Hand des bereits mehrfach erwähnten Johannes Dörflinger. ${ }^{71}$ Während er sich im Neudorfer Jahrzeitbuch ausdrücklich als Schreiber nannte, ${ }^{72}$ taucht sein Name im Schwarzenbacher Jahrzeitbuch nur in seinen Jahrzeiteinträgen und in Randnotizen auf. ${ }^{73}$ Für Verwirrung sorgte der Umstand, dass im Schwarzenbacher Jahrzeitbuch unter dem 12. Dezember auch Dörflingers eigener Tod verzeichnet ist. Damit scheint er als Schreiber aus logischen Gründen auszuscheiden, obwohl seine Hand paläographisch gut erkennbar ist. Tatsächlich trug Dörflinger sich selbst in beiden Büchern unmittelbar neben dem Memorialeintrag für seinen Onkel Heinrich ein, der zugleich sein Amtsvorgänger als Rektor von Schwarzenbach war. Während er in das Neudorfer Jahrzeitbuch an dieser Stelle nur eine Schreibernotiz setzte, heisst es im Schwarzenbacher Jahrzeitbuch: «Im Jahr 1500 starb Johannes Dörflinger, der Rektor dieser Kirche und Neffe des eben genannten Herrn Heinrich ». ${ }^{74}$ Allerdings ist die Jahreszahl in einer Lücke nachgetragen und die lateinische Schreibweise Anno domini $M^{o} d^{o}$ ermöglichte es, das genaue Jahr zu ergänzen, für das auch genügend Platz freigelassen wurde. Es dürfte sich an dieser Stelle also lediglich um das Datum der geplanten Seelenmesse handeln, das nicht notwendigerweise mit dem eigentlichen Todestag übereinstimmen muss. Ein Nachtrag von der Hand seines Neffen und Nachfolgers Georg verzeichnet Dörflingers Tod für den 26. Juni 1504.75 Mit dem Eintrag zum 12. Dezember wollte Dörflinger wohl schon bei 
der Anlage des Jahrzeitbuches sein Gedenken in der eigenen Pfarrkirche vorbereiten. Doch es kam anders: Im Jahr 1511 fügte der Stiftsnotar Andreas Erni im Schwarzenbacher Jahrzeitbuch eine förmliche Notiz über die Kassation der Jahrzeit infolge eines Kapitelsbeschlusses ein. ${ }^{76}$

Fast alle der hier genannten Jahrzeitbücher wurden über mehrere Jahrhunderte weitergeführt. In den Patronatskirchen scheinen sie allerdings etwas länger in Gebrauch geblieben zu sein als am Stift selbst: Während die jüngsten Nachträge im roten Jahrzeitbuch aus dem 15. Jahrhundert stammen, wurden das Weisse Jahrzeitbuch und die Jahrzeitbücher des Kammeramts, des Johannes Hitzmann und des Scholasticus bis ins 17. Jahrhundert hinein um neue Stiftungen und andere Notizen ergänzt. Die Nachträge im Schongauer, Schwarzenbacher und Hägglinger Jahrzeitbuch reichen dagegen bis ins 18. Jahrhundert.

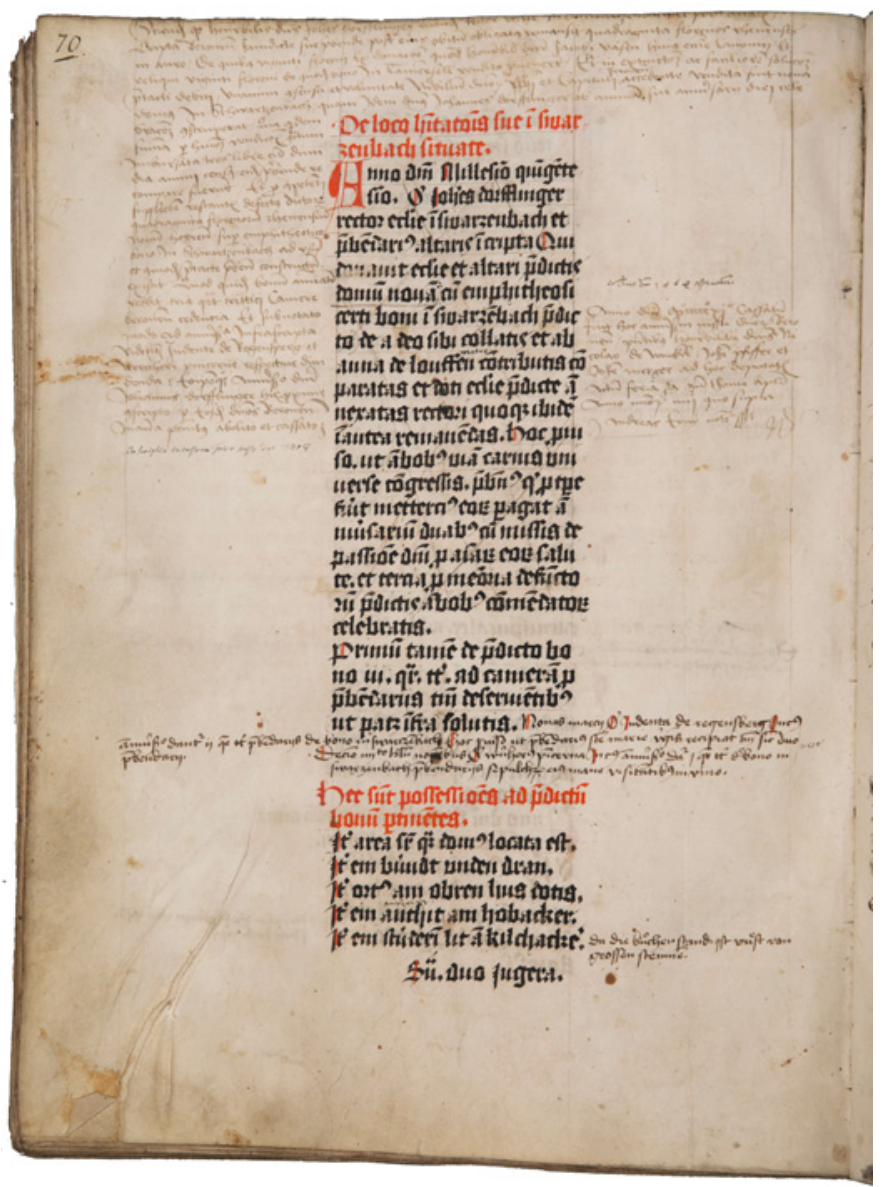

Eigenhändiger Gedenkeintrag des Johannes Dörflinger im Schwarzenbacher Jahrzeitbuch, mit Kassationsnotiz durch den Stiftsnotar Andreas Erni (StiAB 01.01.615, S. 70).
Neben diesen systematisch als Herrschaftsinstrumente angelegten Handschriften enthält das Stiftsarchiv auch einige aus aktuellem Anlass entstandene Arbeitsinstrumente, deren Erhaltung eher zufällig zu sein scheint. Darunter ist die zweibändige Aktensammlung zu einem Streit zwischen dem Stift Beromünster und der Deutschritterkommende Hohenrain, der sich mindestens von 1459 bis 1465 hinzog. Beromünster wurde dabei von demselben Elias Elye vertreten, ${ }^{77}$ der wenige Jahre später als Drucker in Erscheinung treten sollte. Verhandlungsleiter war der Basler Konsistorialrichter Laurentius Kron, ${ }^{78}$ und unter den vielen Händen, die an der Entstehung der Akten beteiligt waren, finden sich verschiedene Basler Notare. Bei genauerem Hinsehen zeigt sich allerdings, dass nicht immer die Person selbst schrieb, deren Name in der Subskription steht - nicht einmal, wenn dies ausdrücklich behauptet wird.

An weiteren Handschriften aus dem Stiftsarchiv, die wenig planmässig nach den Erfordernissen des Tagesgeschehens entstanden, ist das sogenannte Propstei-Rotbuch (StiAB 01.01.463) zu nennen. Es handelt sich dabei um eine Sammlung von Ordnungen, Eidformeln, Stiftungen, Verträgen, Gerichtsbeschlüssen, Zeugenaussagen und anderem mehr aus der Zeit um 1500. Die Texte sind ohne erkennbare Ordnung eingetragen, und am Ende folgen noch das Luzerner Stadtrecht und die Landgerichtsordnung. Eine ähnliche, jüngere Sammlung liegt in dem dunkel eingebundenen Schwarzbuch vor (StiAB 01.01.715). Dass man diesen Band trotz seines unübersichtlichen Aufbaus intensiv benutzte, lässt sich auch daran ablesen, dass er zweimal mit detaillierten Inhaltsverzeichnissen erschlossen wurde. Das erste davon entstand rund 60 Jahre nach Anlage der Handschrift und befindet sich heute in der Zentral- und Hochschulbibliothek Luzern, ${ }^{79}$ das zweite wurde geschrieben, als die Sammlung nicht mehr weitergeführt wurde. Dieses Verzeichnis wird im Staatsarchiv Luzern aufbewahrt. ${ }^{80}$ Dazu kommt noch eine Handschrift, in die der Chorherr Heinrich Gartner (†1519) seine Rechnungen notierte (StiAB 01.01.714). ${ }^{81}$ Sie ist wirtschafts- und sozialgeschichtlich besonders interessant, weil sie über mehrere Jahrzehnte hinweg ganz unterschiedliche Bereiche abdeckt. So finden sich darin nicht nur Abrechnungen über die Verteilung von Einkünften des Stifts auf die verschiedenen Chorherren, die Gartner in offizieller Funktion erstellte, sondern auch Details über die Bezahlung seines Dieners und dessen Ausgaben auf Reisen in Gartners Auftrag. Sie enthält Hinweise darauf, wie sich die Angehörigen der Familie 
gegenseitig finanziell unterstützten und dass Gartner die Einkünfte aus seiner Pfründe und der Pfarrei in Rickenbach zeitweise wohl aufbesserte, indem er mit Gewürzen handelte. Die ersten Einträge in seinem Rechnungsbuch stammen von 1479, als letztes wurde im Jahr nach Gartners Tod noch eine Abrechnung mit seinen Erben nachgetragen.

\section{Die Stiftsbibliothek}

Von den heute 30 mittelalterlichen Handschriften in der Bibliothek des Stifts Beromünster dürften jeweils mindestens neun von dem Chorherrn Friedrich von Lütishofen und von dem Kaplan Ludwig Zeller stammen. Während Zeller seine Bücher mit Besitzeinträgen kennzeichnete, lassen sich die Bücher Friedrichs von Lütishofen allerdings nur daran erkennen, dass er zahlreiche Anmerkungen darin eintrug. ${ }^{82}$ Es wäre also möglich, dass hier der eine oder andere Band seiner Sammlung zugewiesen wird, mit dem er zwar arbeitete, den er aber nicht selbst besass. Umgekehrt könnte die Stiftsbibliothek weitere Handschriften aus seinem Besitz enthalten, die er nicht annotierte. Die Angaben zu seiner Sammlung sind daher etwas weniger sicher als die für diejenige von Ludwig Zeller. Trotzdem lassen sich für beide charakteristische Tendenzen erkennen, die einerseits mit ihren persönlichen Interessen und andererseits mit ihrem finanziellen Hintergrund zusammenhängen dürften.

\subsection{Friedrich von Lütishofen}

Die Familie von Lütishofen besass nicht nur das Bürgerrecht in Luzern, wo sie zweimal das Amt des Schultheissen besetzen konnte, ${ }^{83}$ sondern stand zugleich auch in einem Lehensverhältnis mit den Habsburgern. ${ }^{84}$ Im Jahr 1420 präsentierte die Herzogin von Österreich Burkhard I. als Anwärter für eine Pfründe in Beromünster, ab 1426 ist er als Chorherr nachgewiesen. In der nächsten Generation gehörten gleich drei Mitglieder der Familie dem Stift an: Burkhards zwei illegitime Söhne, Burkhard II. und Friedrich von Lütishofen, ausserdem ihr Cousin Rudolf. Friedrich von Lütishofen und Burkhard II. immatrikulierten sich beide an der Universität Heidelberg, 85 Friedrich im Jahr 1449, Burkhard 1450. Doch während für Burkhard kein Abschluss nachweisbar ist, legte Friedrich schon zwei Jahre nach seiner Immatrikulation das Baccalaureat ab, und drei Jahre darauf erwarb er den Grad eines Magister artium.

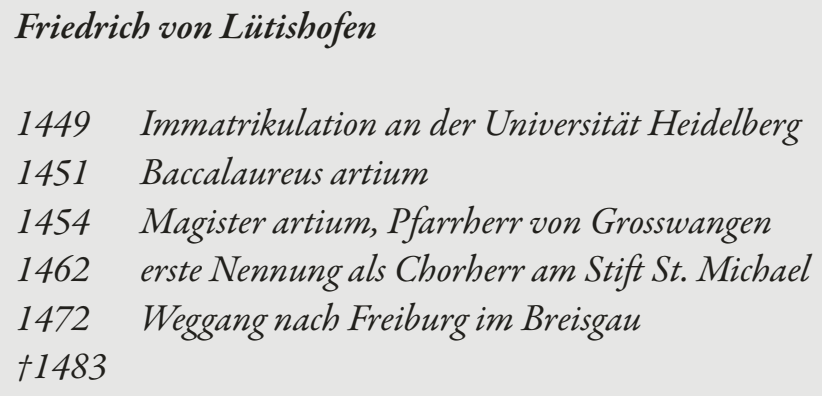

Handschriften:

C 40 und 41, C 43, C 44, C 51, C 61-64

In dieser Zeit schrieb er wohl selbst das Aggregatorium Rhetorice (C 44) seines Lehrers Erhard Knab von Zwiefalten ab. ${ }^{86}$ Der Text besteht aus zwei Teilen, von denen der erste sich mit der Frage befasst, wie ein Brief aufgebaut sein soll $\left(8^{\mathrm{r}}-51^{\mathrm{r}}\right)$, während der zweite anhand von zahlreichen Beispielbriefen den Redeschmuck erklärt $\left(64^{\mathrm{r}}-107^{\mathrm{r}}\right)$. Ein Vergleich mit Erhard Knabs Autograph zeigt, dass Friedrich von Lütishofen in diesen Beispielen die Namen von Schreibern und Empfängern durch Namen von Personen aus seinem eigenen Umfeld ersetzte. ${ }^{87}$ Mehrfach findet sich darunter Johannes von Gundoldingen, der gleichzeitig mit Friedrich in Heidelberg studierte und anschliessend Schulmeister am Stift Beromünster wurde. ${ }^{88}$ In den Brief eines Schülers an seinen Lehrer fügte Friedrich sich selbst als Empfänger und Johannes von Buseck als Absender ein. ${ }^{89}$ Mit Heinrich und Konrad von Buseck erscheinen noch zwei weitere Mitglieder von dessen Familie in den geänderten Beispielbriefen. Die wichtige Rolle, die sie während Friedrichs Heidelberger Zeit in dessen Leben spielte, lässt sich noch an einer weiteren Handschrift aus seiner Sammlung ablesen: In einem Band mit Quaestionen zu Werken des Aristoteles, dessen zweiter Teil auf 1451 bis 1452 datiert ist (C 41), schrieb Friedrich mehrmals den Namen «von Buseck» auf die Seitenränder, einmal auch in Verbindung mit dem Vornamen Ottilie. «An Frau Otti[lie]» adressierte er auch einen Brief in der Beispielsammlung des Aggregatorium Rhetorice, den dessen Autor Erhard Knab an eine Katharina gerichtet hatte. Und Ottilie hiess schliesslich Friedrichs uneheliche Tochter. ${ }^{90}$ Als das Aggregatorium Rhetorice in den späten 1470er oder frühen 1480er Jahren seinen heutigen Einband erhielt, ${ }^{91}$ verstärkte der Buchbinder die Fälze mit Streifen von einer Urkunde, die der erwirdig wolgelert Meister 


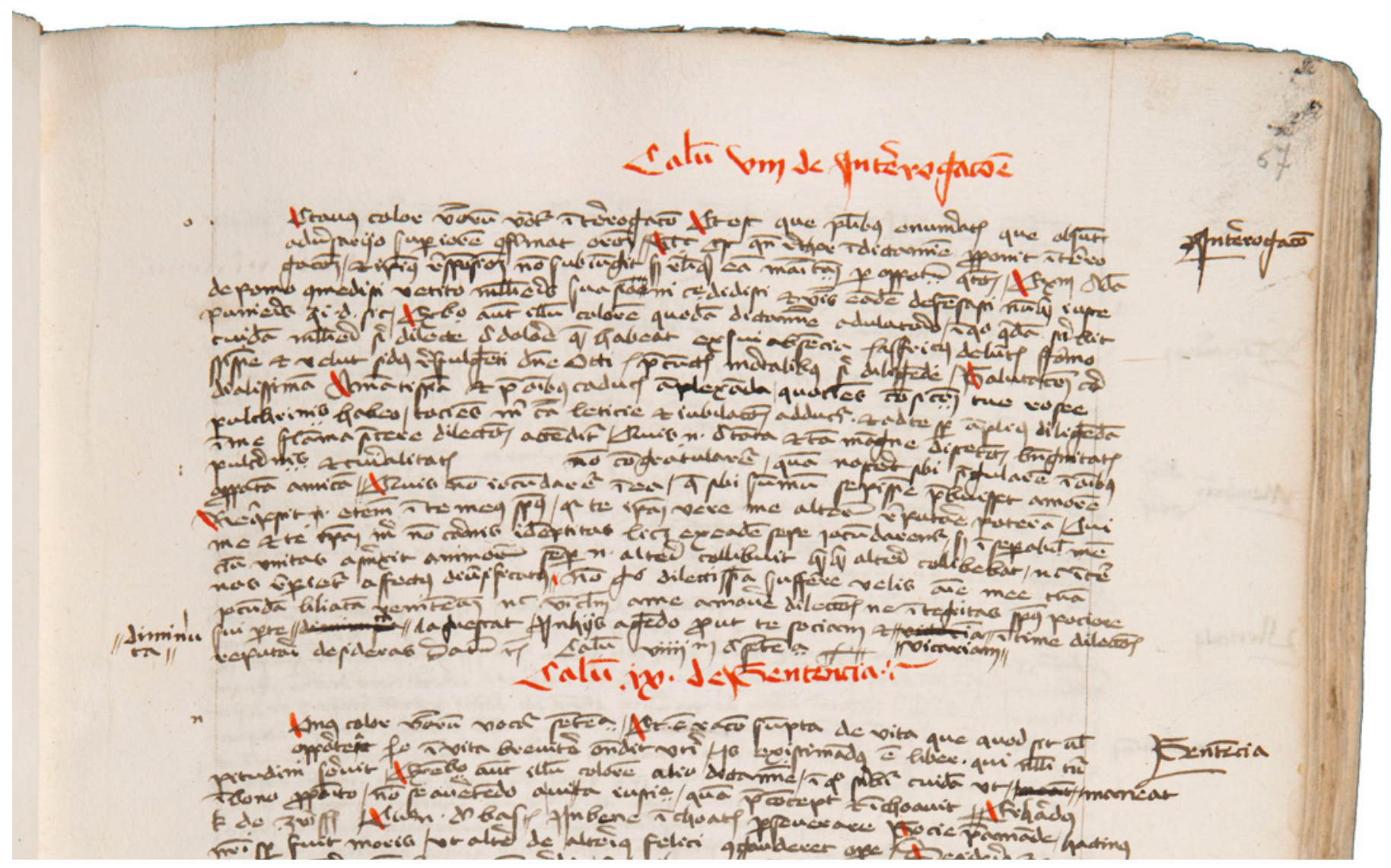

Musterbrief im Rhetorikhandbuch des Erhard Knab von Zwiefalten, in Zeile 6f. setzte Friedrich von Lütishofen seinen eigenen Namen und den der Ottilie von Busseck ein (C 44, 67r).

Fridrich von Lütishoffen, kilchher zü wangen zugunsten der vorgemelden Otilien von Busegg ausgestellt hatte. ${ }^{92}$ So finden sich über Friedrichs Studienhandschriften verstreut wohl die Spuren einer verflossenen Liebe.

Ausser dem Aggregatorium Rhetorice enthält der Band C 44 noch drei weitere, in unterschiedlichen Zusammenhängen entstandene Teile. Einen davon, die fälschlich Boethius zugeschriebene Disciplina scholarium, schrieb ebenfalls Friedrich von Lütishofen in seiner Heidelberger Zeit. Einen anderen legte rund 15 Jahre früher Thomas Ebinger an und verkaufte ihn Friedrichs Onkel Ludwig von Lütishofen für zwei Gulden. ${ }^{93}$ Dieser Teil enthält ein Vokabular, das Friedrich um einige zusätzliche Lemmata ergänzte. Das jüngste Stück des Bandes sind Gasparino Barzizzas Epistolae, eine Sammlung von humanistischen Modellbriefen, die spätestens im Jahr 1472 in Basel gedruckt wurde. Der ganze Band dient also der
Schulung im Lateinischen und zeichnet den Fortschritt seines Besitzers vom einfachen Schüler bis zum humanistisch beeinflussten Stilisten nach.

Während Friedrichs Heidelberger Studienzeit entstanden ausserdem mehrere Bände, die er offenbar selbst in Auftrag gab. Zwei von ihnen (C 40 und C 41) enthalten Quaestionen zu Werken des Aristoteles, der eine ausserdem den von Johannes de Sacrobosco verfassten Tractatus de sphaera (C 40). Die Texte der beiden Bände gehören nicht nur inhaltlich zusammen, sondern wurden teilweise auch auf dem gleichen Papier geschrieben, haben die gleiche Anlage und erhielten ihre Einbände in derselben Werkstatt. ${ }^{94}$ Papier und Einband stimmen ausserdem mit einer dritten Handschrift überein, in der die Evangelien, Merkverse zur Kanontafel sowie ein Traktat über die Messfeier enthalten sind (C 64). 95 Sie wurde von Johannes Remishůb aus Feldkirch in Vorarlberg geschrieben. Mögli- 
cherweise gehörte sie aber nicht Friedrich, sondern seinem Bruder Burkard, der zu dieser Zeit ebenfalls noch in Heidelberg studierte. Jedenfalls schenkte Burkard, als er 1467 in Beromünster das Amt des Kustos antrat, eben diese Evangelienhandschrift dem Stift. ${ }^{6}$ Den Tractatus de sphaera in C 40 hatte Friedrich von Lütishofen selbst begonnen, doch übertrug er die Arbeit bald an seinen Studienkollegen Johann Schumacher aus Lenzburg, ${ }^{97}$ dessen Hand sich auch in einem Teil von C 41 findet. ${ }^{98}$ Den anderen Hauptteil von C 40 und C 41 schrieb ein weiterer Heidelberger Student, der Luzerner Konrad Menger.99 Nur Johannes Remishůbs Name erscheint nicht in der Matrikel der Universität Heidelberg, er stand den Brüdern von Lütishofen aber wie die beiden anderen wohl aufgrund seiner Herkunft nahe.

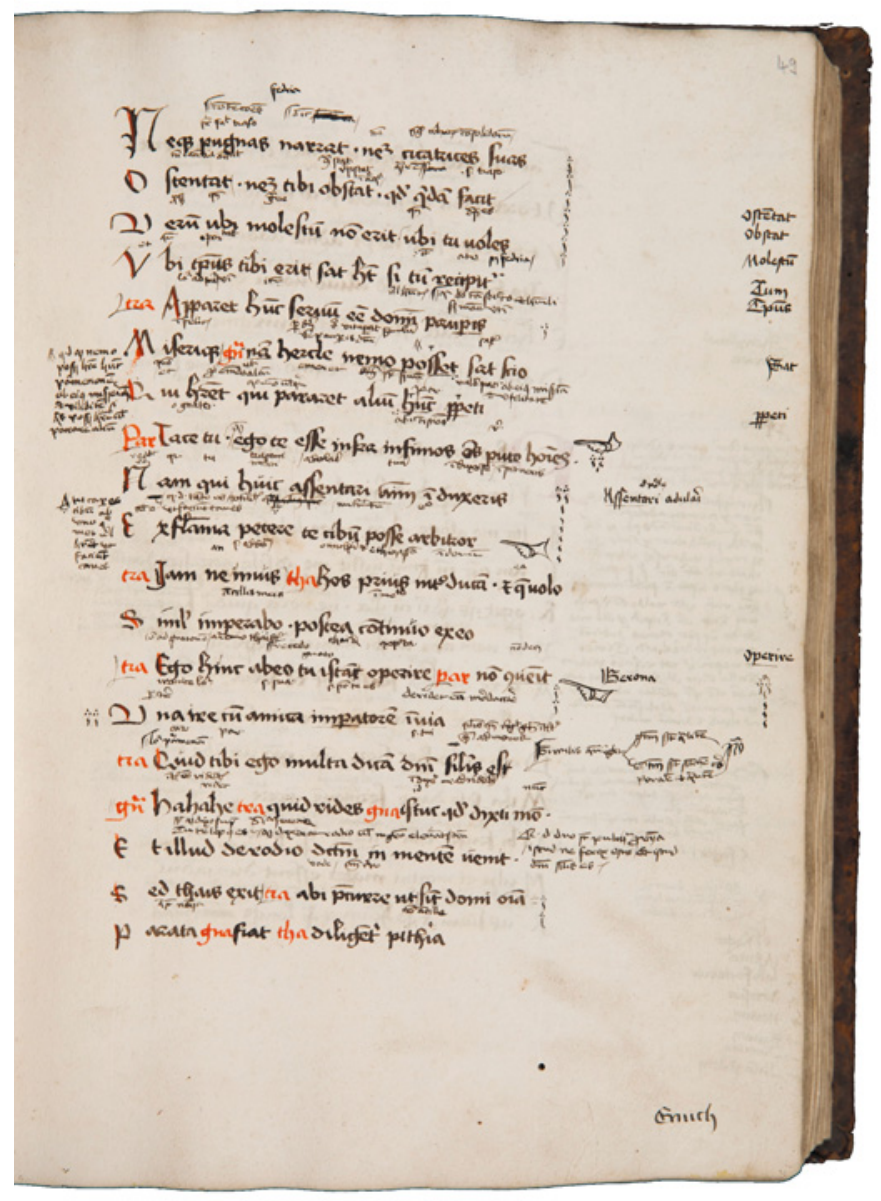

Annotierte Klassikerhandschrift Friedrichs von Lütishofen, auffällig der Handweiser mit der Anmerkung Berona zu Eunuchus, Vers 494 (C 61, 49r).
Alle Handschriften aus Friedrichs Heidelberger Studium enthalten Anmerkungen von seiner Hand, die belegen, wie gründlich er mit den darin enthaltenen Texten arbeitete. Doch auch nachdem ihm der Magistertitel bereits verliehen worden war, erwarb Friedrich weitere Bücher. Dabei lässt sich eine Verschiebung seiner Interessen feststellen: $\mathrm{Zu}$ Texten aus dem Bereich der Artes kommen nun vermehrt theologische hinzu. Von einigen älteren Handschriften ist allerdings unklar, wann sie in Friedrichs Besitz gelangten. So wurde ein Band, der das Compendium theologicae veritatis und Predigten enthält (C 63), bereits 1432 geschrieben. Im Gegensatz zu den bisher betrachteten Büchern finden sich darin nur ganz vereinzelt Anmerkungen von Friedrichs Hand. Auch C 51 enthält Teile, die schon vor seiner Zeit, nämlich gegen Ende des 14. Jahrhunderts bzw. 1408 geschrieben wurden: Kommentare zum Psalter, zum athanasischen, apostolischen und nicaenischen Glaubensbekenntnis sowie zum Kapitel über die Beichtpflicht aus den Beschlüssen des 4. Laterankonzils. Den letzten Teil bildet ein auf 1460 datiertes Speculum clericorum, das Friedrich wie seine Studienhandschriften mit zahlreichen Anmerkungen versah. Die Texte wurden von dem Heidelberger Buchbinder Albert Schwab zu einem Band zusammengefügt, Friedrich scheint sich zu dieser Zeit also immer noch im Umfeld der Universität aufgehalten zu haben. Aus derselben Werkstatt stammt auch der Einband einer etwa fünf Jahre älteren Handschrift, die Kommentare zum Hohenlied und zu den Zehn Geboten enthält (C 62). Beide Texte versah Friedrich von Lütishofen nicht nur mit seinen üblichen Anmerkungen, sondern auch mit ihren teilweise rot geschriebenen Kopftiteln.

Zwei weitere Handschriften dürften in den 1460er Jahren entstanden sein: Die Evangelien-Konkordanz des Zacharias Chrysopolitanus (C 43), in der Friedrich von Lütishofen wie in C 40 einen kurzen Abschnitt selbst schrieb, und ein Speculum Marie (C 65), das mit mehreren Drucken aus den Jahren von 1473 bis 1475 zusammengebunden ist. Darunter befinden sich nicht nur ein Beichthandbuch, zwei Moraltraktate und ein Kommentar zum Vaterunser, sondern auch zwei humanistische literarische Texte: Enea Silvio Piccolominis De duobus amantibus und De remedio amoris. Beide Handschriften erhielten ihre Einbände in einer Werkstatt, aus der auch sieben Inkunabelbände der Stiftsbibliothek stammen. ${ }^{100}$ Es ist denkbar, dass auch sie ehemals Friedrich von Lütishofen gehörten, zumal die erste Initiale in einer dieser Inkunabeln mit dem Familienwappen geschmückt ist. ${ }^{101}$ Sicher klären lässt 
24 sich die Frage bei Friedrichs Verzicht auf Besitzeinträge aber nicht. So kann man auch für ein Exemplar des Mammotrectus nur vermuten, dass es zu seiner Büchersammlung gehört haben mag. ${ }^{102}$

Als letzte Handschrift, die sicher Friedrich von Lütishofen zugewiesen werden kann, ist eine Sammlung von Klassikertexten zu nennen (C 61), die im mittelalterlichen Bestand der Stiftsbibliothek von Beromünster einzigartig ist. Sie enthält die Komödien des Terenz, Vergils Georgica und Bucolica sowie Ciceros Epistulae ad familiares, dazu kommen jeweils zwei Rhetorik-Handbücher der Humanisten Agostino Dati (†1478) und Peter Luder (†1472). Luder war erst 1456 von einem langen Aufenthalt in Italien nach Heidelberg zurückgekehrt, ${ }^{103}$ möglicherweise lernte Friedrich ihn dort persönlich kennen. Die Handschrift selbst ist aber jünger, sie dürfte um dieselbe Zeit entstanden sein, in der Barzizzas Briefsammlung in Basel gedruckt wurde. Für den Text von Luders Schriften steht sie einer Freiburger Handschrift nahe, ${ }^{104}$ und in Freiburg hielt sich seit 1472 auch Friedrich von Lütishofen auf. ${ }^{105}$ Anscheinend beschäftigte er sich dort mit den nördlich der Alpen noch jungen studia bumanitatis.

Insgesamt zeichnet sich die Büchersammlung Friedrichs von Lütishofen, soweit man sie nach den in der Stiftsbibliothek erhaltenen Handschriften beurteilen kann, durch einige charakteristische Besonderheiten aus. So handelt es sich durchgehend um sorgfältig geschriebene Bände im Folioformat mit grosszügiger Textanlage, die Friedrich alle mit einem festen Einband ausstatten liess. ${ }^{106}$ Sie enthalten stets vollständige Texte, und die meisten davon dürften in Friedrichs Auftrag geschrieben worden sein. Dabei ist die Textauswahl ganz auf der Höhe seiner Zeit: Viele Werke waren erst wenige Jahre alt, als Friedrich Abschriften davon erwarb. So steht seine Sammlung für das glückliche Zusammentreffen von intellektuellem Interesse und den finanziellen Mitteln, um dieses Interesse ohne grosse Einschränkungen pflegen zu können.

Von Friedrichs behaglicher Lage profitierte nicht zuletzt das Stift Beromünster, dem er seine Büchersammlung vererbte. ${ }^{107}$ Doch schon zu seinen Lebzeiten hatte er zum Wohlstand des Stifts beigetragen. So erbaute er vor seinem Wegzug nach Freiburg einen neuen Chorhof im Stiftsbezirk, und noch nachdem er Beromünster bereits verlassen hatte, beteiligte er sich an einer der grössten Schenkungen, die dem Stift Beromünster im Laufe des Mittelalters gemacht wurden: Im Jahr 1479 übertrugen er und sein Bruder Burkard diesem gemeinsam mit drei weiteren männlichen Verwandten fünf Kirchensätze und vier Kapellen. Darunter war auch das Patronatsrecht der Kirche von Grosswangen, das Friedrich 1454 von seinem Vater erhalten hatte. ${ }^{108}$ In seinem Testament vermachte er St. Michael ausserdem Silbergeschirr, aus dem eine Christophorus-Statuette hergestellt werden sollte. ${ }^{109}$ Diese Figur ist bis heute im Stiftsschatz erhalten.

\subsection{Ludwig Zeller}

Neben Friedrich von Lütishofen hat der etwa eine Generation jüngere Ludwig Zeller mit seiner Büchersammlung wesentlich zum Bestand der Stiftsbibliothek beigetragen. Mindestens neun Handschriftenbände, ein Sammelband mit handschriftlichen und gedruckten Teilen sowie acht Inkunabelbände sind durch seine Hände gegangen. ${ }^{110}$ Er besass aber zu seinen Lebzeiten sicherlich noch mehr Bücher, wie ein Frühdruck der Kantonsbibliothek Aarau (Inc. 12a fol.) zeigt. Dieser enthält gleich zwei Kaufvermerke und einen Besitzeintrag, aus denen hervorgeht, wie sehr Zeller offenbar an seinen Büchern hing:111 Nachdem er den Band 1481 für dreieinhalb Gulden an den Leutpriester von Staufen Johannes Fry verkauft hatte, muss er ihn binnen kurzer Zeit schon wieder zurückgekauft haben. So konnte er ihn ein Jahr später (jetzt um einen halben Gulden teurer) erneut verkaufen, diesmal an Henmann Reber von Laufenburg. Mit ihm war Zeller schon lange bekannt: Rund zwanzig Jahre zuvor hatte eben dieser Henmann Reber den Liber floretus mitsamt dem dazugehörigen Kommentar des Pariser Kanzlers Jean Gerson abgeschrieben (C 45), und

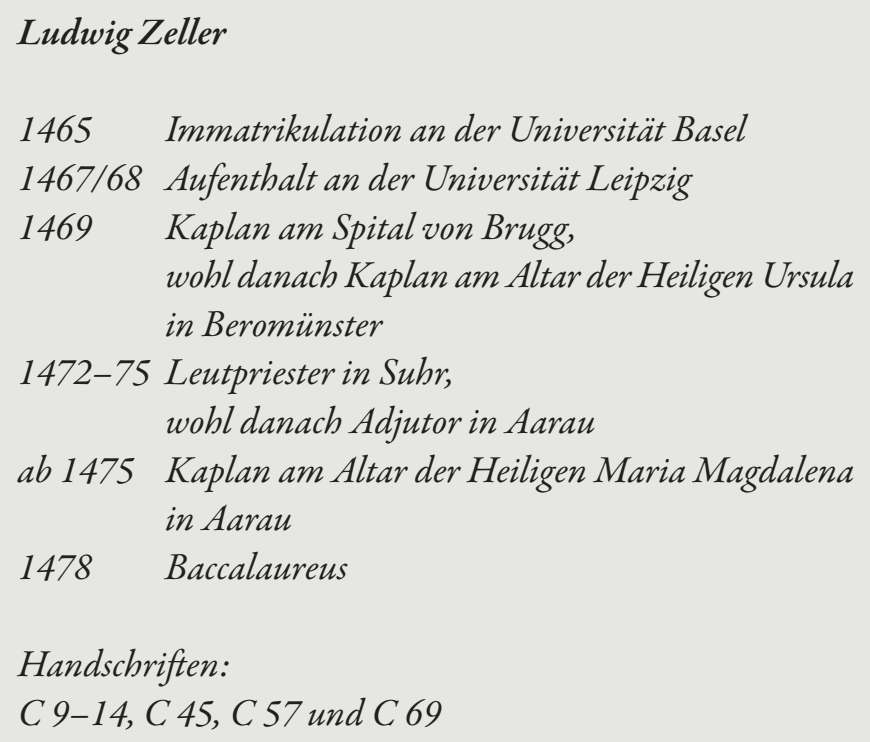


zwar wahrscheinlich in Zellers Auftrag. ${ }^{12}$ Doch auch Reber behielt den Druck nicht dauerhaft: Für das Jahr 1489 findet sich wieder ein Besitzeintrag Ludwig Zellers darin.

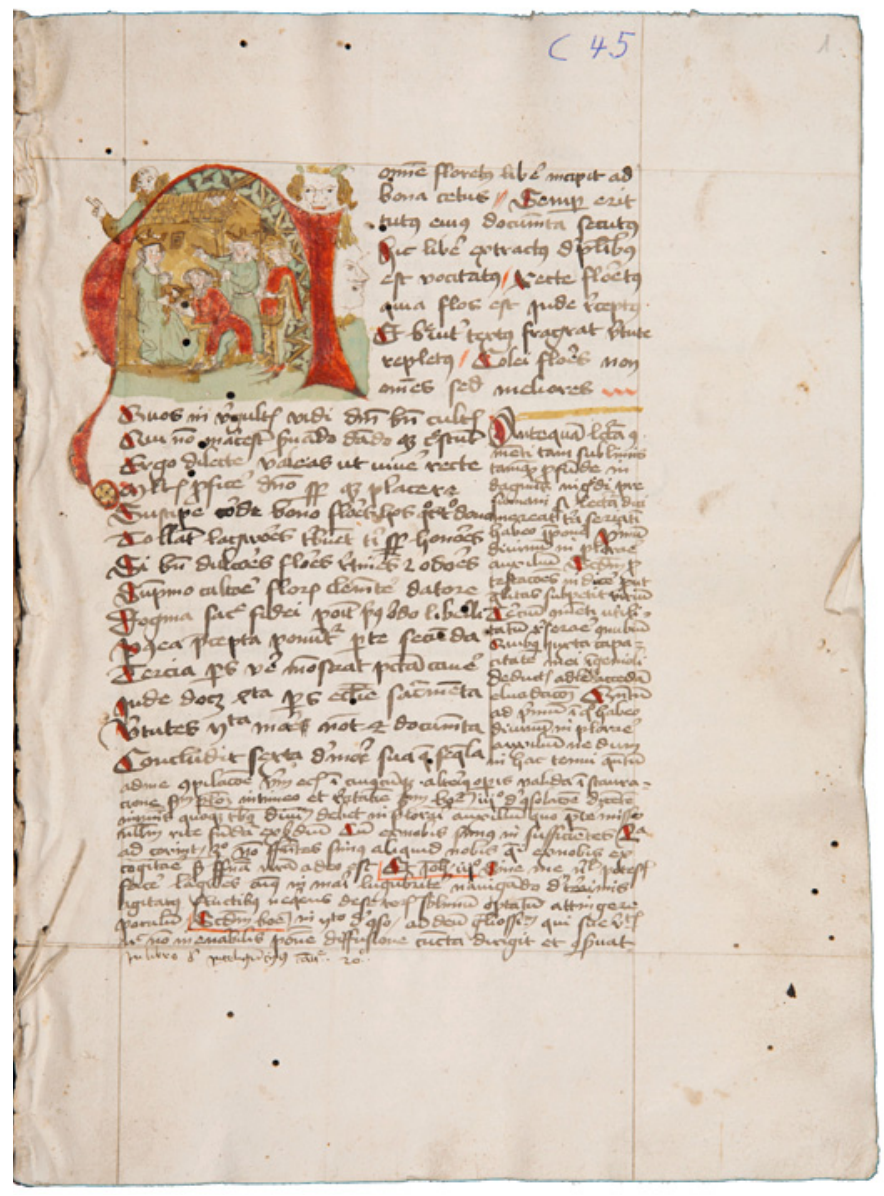

Beginn des von Henmann Reber geschriebenen Liber Floretus (C 45, 1r) mit Rahmenkommentar. Diese Handschrift enthält die einzige historisierte Initiale des gesamten Bestandes.

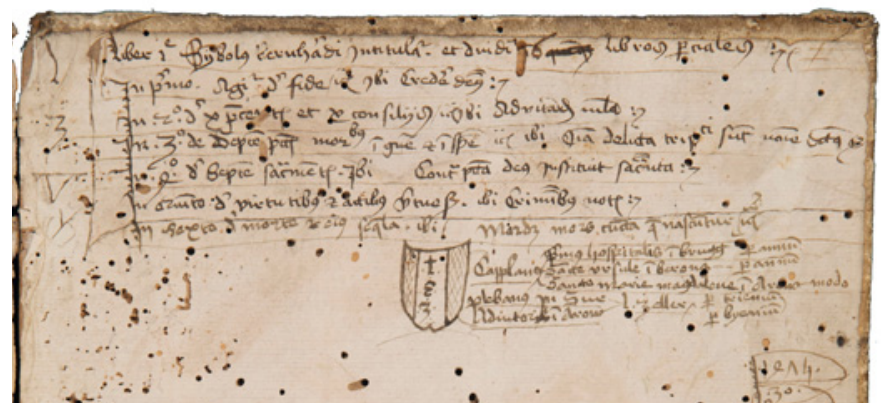

Ämterverzeichnis Ludwig Zellers, von seiner eigenen Hand im hinteren Spiegel von C 45 eingetragen (unter Inhaltsverzeichnis).
Auch sonst spiegelt Zellers Büchersammlung das Beziehungsnetz und den Lebenslauf ihres Besitzers wider. ${ }^{113}$ Die meisten heute bekannten biographischen Informationen über ihn finden sich in einem Eintrag von seiner eigenen Hand auf dem hinteren Spiegel der eben genannten Floretus-Handschrift. Dort listete Zeller im Jahr 1475 die verschiedenen Stationen seiner bisherigen Laufbahn auf: ${ }^{114}$ Ein Jahr lang amtierte er als erster Kaplan des Spitals in Brugg, ein weiteres Jahr an der St. Ursula-Kaplanei in Beromünster, und schliesslich an der Maria Magdalena-Kaplanei in Aarau. Ausserdem war Zeller drei Jahre lang Priester in Suhr und zwei Jahre Adjutor in Aarau. Die Stellung als Kaplan von Maria Magdalena kann über den Zusatz modo auf das Jahr des Eintrags datiert werden. In diesem Amt ist er angeblich noch im Jahr 1491 urkundlich belegt. ${ }^{115}$ Sicher hatte er es im Jahr 1489 inne, denn Zeller selbst bezeichnete sich in seinem jüngsten Besitzeintrag in dem oben besprochenen Aarauer Inkunabelband als Kaplan von Maria Magdalena in Aarau.

Wie Friedrich von Lütishofen hatte auch Ludwig Zeller ein Universitätsstudium absolviert. Er immatrikulierte sich 1465 an der wenige Jahre zuvor gegründeten Universität Basel und erwarb dort, nun schon als geweihter Priester, 1478 den Titel eines Baccalaureus artium. ${ }^{116} \mathrm{Im}$ Jahr 1468 studierte er jedoch an der Universität Leipzig, und von dort brachte er auch das Material für eine Sammelhandschrift (C 57) zurück. Sie enthält nicht weniger als zwölf Schreiber- und Besitzeinträge von der Hand Ludwig Zellers, viele davon verbunden mit einem Hinweis auf die Entstehung der betreffenden Teile in Leipzig. Eine Lage wurde, ebenfalls in Leipzig, von einem Landsmann Zellers geschrieben, der am Ende des Teils neben Angaben über den Text auch seinen Namen sowie Ort und Jahr der Abschrift festhielt: Rùdolfus Grünli. Augustinus de cognicione vere vite explicit feliciter, finitus in alma universitate Lipzensi 1468 $\left(74^{\mathrm{ra}}\right)$. Ob Grünli und Zeller ihre Reise nach Leipzig gemeinsam antraten oder ob sie einander erst dort begegneten, ist unklar, und auch die Identität der drei anderen beteiligten Schreiber konnte nicht ermittelt werden. Einer von ihnen dürfte aber nicht in Sachsen, sondern in der Schweiz tätig gewesen sein: Die erste Lage der Handschrift ist ein Jahr später entstanden als die anderen, enthält keinen Hinweis auf Leipzig und das Papier trägt Wasserzeichen, die typisch für die Region um Basel sind. Dieser Umstand zeigt ebenso wie die zahlreichen Besitzeinträge, dass Zeller seine Unterlagen in Form von einzelnen Faszikeln zurück nachhause brachte, die 
26 er erst später binden liess. Inhaltlich handelt es sich um eine bunte Mischung von Texten, darunter eine Reihe von asketischen Schriften, die dem Kirchenvater Augustinus zugeschrieben wurden (nur zwei davon nach heutigen Erkenntnissen authentisch), Exzerpte aus autoritativen Lehrwerken wie dem Sentenzenkommentar des Johannes de Fonte und dem Breviloquium des heiligen Bonaventura und als weiterer Schwerpunkt Texte, die eine solide Basis für die Ausübung des Priesteramts legen konnten: Pönitentiare und Beichtspiegel, Schriften zum arbor consanguinitatis, über die Gebetszeiten und über das Vaterunser. Besonders auffällig ist darunter ein Traktat über die sieben Todsünden, den Zeller mutmasslich selbst verfasste. Nach einer ausführlichen Einleitung zur Sünde im Allgemeinen und einer vollständigen Aufzählung der Todsünden im Besonderen werden nämlich nur drei von ihnen (superbia, avaricia und luxuria) tatsächlich behandelt, und je weiter der Text fortschreitet, desto mehr nimmt er den Charakter einer Materialsammlung an.

Eine andere von Zellers Handschriften (C 10) besteht aus zwei Teilen: Den ersten, der inhaltlich um Gottesdienst und Beichte kreist, ${ }^{117}$ kaufte Zeller 1475 von Jakob Hilflin, der ihn selbst geschrieben hatte. Hilfflin war wie Zeller Adiutor in Aarau. Den zweiten Teil, mit den Dialogen Gregors des Grossen und einem Traktat über die Passion Christi, schrieb Zeller selbst. Beide Teile liess er in derselben Werkstatt zusammenbinden, in der auch die Schriften aus seiner Leipziger Zeit ihre heutige Form erhielten.

Wie diese und andere Handschriften zeigen, schrieb Ludwig Zeller viele Partien seiner Bücher selbst ab. Für längere Texte begnügte er sich öfters mit Exzerpten, und wenn er Abschriften kaufte, handelte es sich häufig nur um einzelne Lagen, nicht um ganze Codices. So enthält ein weiterer Band aus seinem Besitz (A 66) neben mehreren Drucken auch zwei von unterschiedlichen Schreibern angefertigte Manuskriptfaszikel. Einer davon, mit einem Traktat zur Eucharistie, wurde schon 1430 geschrieben. Im anderen, der die Briefe des Apostels Paulus enthält, haben wohl zwei frühere Besitzer zwischen den Zeilen und am Rand Anmerkungen zum Text hinzugefügt. Zeller hatte die beiden handschriftlichen Teile also nicht selbst in Auftrag gegeben, sondern erhielt sie von früheren Besitzern. Schliesslich liess er sie, wohl um 1475, in der Werkstatt des Buchbinders Uoldaricus mit mehreren Drucken zusammenbinden, fügte auf dem ersten Blatt ein Inhaltsverzeichnis für den gesamten Band ein und auf schrieb auf das letzte Blatt seinen Besitzeintrag.

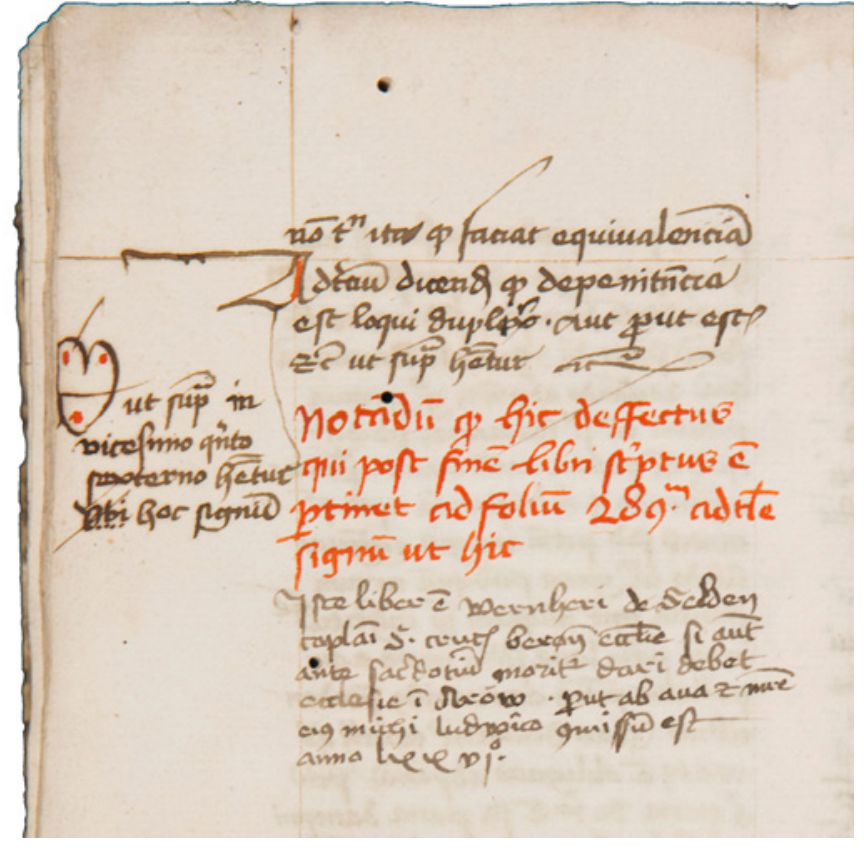

Leihvermerk von der Hand Ludwig Zellers in einer Abschrift der Abbreviatio Bonaventurae aus dem Besitz Werners von Selden (C 69, 383va).

Für sein Studium konnte Zeller aber nicht nur auf Bücher zurückgreifen, die er selbst abschrieb, gebraucht kaufte oder schreiben liess, sondern auch auf Exemplare, die ihm geliehen wurden. So trägt der Band C 11 auf dem Vorsatzblatt von Zellers Hand den Eintrag: «Buch Ludwigs Zellers. Es gehört in die Bibliothek der Chorherren». Ein weiterer Band (C 69) stammt aus der Sammlung des oben bereits erwähnten Johannes von Gundoldingen, der zusammen mit Friedrich von Lütishofen in Heidelberg studiert hatte und später die Schule in Beromünster leitete. Nach dem Tod des gelehrten Chorherren im Jahr 1474 hatte dessen Mutter seine Bücher ihrem Enkelsohn, Werner von Selden, übermacht. ${ }^{118}$ Werner war zu diesem Zeitpunkt aber offenbar in seiner Ausbildung noch nicht so weit fortgeschritten, dass er das Legat hätte nutzen können - für seine Kaplanei an der Heilig Kreuz-Pfründe in Beromünster wurde zunächst ein Stellvertreter eingesetzt, und erst zwei Jahre später nahm Werner ein Studium in Basel auf. ${ }^{119}$ Seine Grossmutter gab deshalb mindestens eines der Bücher an Ludwig Zeller weiter, der die Bedingungen für die Leihgabe auf der letzten Textseite notierte: «Dieses Buch gehört Werner von Selden, Kaplan des Heilig Kreuz-Altars in 
der Kirche von Beromünster. Falls er aber vor der Priesterweihe stirbt, soll es der Kirche von Aarau gegeben werden, wie seine Grossmutter und Mutter mir, Ludwig Zeller, im Jahr [14]76 aufgetragen haben». ${ }^{120}$ Werner von Selden sollte das Buch, das die umfangreiche Abbreviatio Bonaventurae Heinrichs von Zürich enthält, also offenbar erst mit Antritt seines Amtes als Kaplan bekommen. Im Vergleich zu den oben besprochenen Codices, die Zeller selbst binden liess, zeigen sich bei diesem Band deutliche Unterschiede: Das Bezugsleder ist unverziert und weniger glatt, und anstelle von nach vorn greifenden Kantenschliessen besitzt er nach hinten greifende Langriemenschliessen. Auf dem Vorderdeckel trägt er ein Titelschild des 15. Jahrhunderts aus Pergament.

Alle diese äusserlichen Eigenheiten verbinden ihn mit einer Quarthandschrift von Johannes Herolts Predigtsammlung De eruditione christifidelium (C 13), die einen Besitzeintrag Ludwig Zellers enthält. Es ist also denkbar, dass auch sie aus der Sammlung des Johannes von Gundoldingen stammte. Allerdings sollte man die rein äusserlichen Übereinstimmungen nicht zu hoch bewerten. So gleicht eine weitere Quarthandschrift aus Zellers Bestand (C 9) der eben genannten Predigtsammlung mit dem einzigen Unterschied, dass sie anstelle eines Titelschilds eine Aufschrift direkt auf dem Bezugsleder trägt. Wie die beiden anderen (C 69 und C 13) ist sie noch in der ersten Hälfte des 15. Jahrhunderts entstanden. Sie kann jedoch nicht zum Nachlass des Johannes von Gundoldingen $(† 1474)$ gehört haben: Ein datierter Nachtrag Ludwig Zellers auf $94^{\mathrm{v}}$ zeigt, dass er bereits 1461 damit arbeitete. ${ }^{121}$ Inhaltlich ist sie mit einem lateinisch-deutschen Glossar und einer Sammlung von Hymnen in Prosawortordnung mit deutschen Übersetzungen eher für Studienanfänger geeignet (neben diesen Hilfsmitteln enthält sie Predigten und Predigtmaterialien).

Auch bei den anderen Handschriften mit Ludwig Zellers Besitzeintrag handelt es sich um Quartformate. Es sind eine $\mathrm{Zu}$ sammenstellung von Predigten (C 11) und eine Abschrift der Legenda aurea (C 12), die aus der ersten Hälfte des 15. Jahrhunderts stammen und den himbeerroten Einband haben, der für die älteren Handschriften charakteristisch ist. Die zweite davon enthält einen Besitzeintrag eines Franziskaners namens Oswald. Insgesamt lässt sich festhalten, dass Zellers Handschriften auf seine Arbeit als Priester ausgerichtet waren. Das Profil seiner Sammlung lässt sich gerade im Vergleich mit derjenigen Friedrichs von Lütishofen gut erkennen. Wäh- rend der Ältere aktuelle Werke zur aristotelischen Philosophie und zur Rhetorik sowie Klassikertexte in repräsentativen, grossen Codices abschreiben liess, erwarb Ludwig Zeller eher ältere Handschriften oder auch einzelne Faszikel und schrieb viele Texte selbst ab, häufig auch nur in Form von Exzerpten. Dabei ging es ihm offenbar um Geschwindigkeit und Platzersparnis, die Schrift und die Seitenanlage sind häufig mehr flüchtig als schön. Inhaltlich handelt es sich fast durchweg um Werke, die er für seine Tätigkeit als Priester brauchte.

\subsection{Der sonstige Bestand der Stiftsbibliothek}

Auch über die Provenienz von Handschriften, die nicht den Sammlungen Friedrichs von Lütishofen und Ludwig Zellers zugewiesen werden können, lassen sich in einigen Fällen nähere Aussagen machen. Zwei davon, eine Zusammenstellung von Beichthandbüchern und Moraltraktaten (C 8) sowie eine Predigtsammlung (C 53) wurden von Johannes Eggli, dem Leutpriester von Buochs, geschrieben. Da beide sich zu wesentlichen Teilen aus verschiedenen kleineren Stücken und Exzerpten zusammensetzen, ist wohl davon auszugehen, dass er sie für seinen eigenen Gebrauch herstellte. Über welche Zwischenstationen sie in die Stiftsbibliothek gelangten, ist allerdings unklar. Die Schreiber von weiteren Handschriften der Stiftsbibliothek Beromünster waren Ulrich Wachter aus Laufenburg, Leutpriester in Birndorf (C 54), und Henmann Murer (C 50). Der Chorherr Jacob Väsen erscheint als Besitzer einer Predigtsammlung, die er auch selbst abgeschrieben haben dürfte. ${ }^{122}$ Väsen stand in engem Kontakt mit dem oft genannten Johannes Dörflinger, der sein letzter Beichtvater war. ${ }^{123}$ Zur Herkunft von anderen Handschriften liegen nur Indizien vor. So wurde ein zweites Exemplar der Evangelien-Konkordanz des Zacharias Chrysopolitanus mit einer Predigtsammlung zusammengebunden, die deutliche Bezüge nach Beromünster aufweist: Sie enthält Predigten für die Patronatsfeste von St. Laurentius in Eich und St. Bartholomäus in Römerswil (C 52). Zum Entstehungsort von einem Exemplar des Dekretalen-Kommentars des bretonischen Juristen Heinricus Bohicus (C 67) finden sich Hinweise in den Falzverstärkungen: Der Buchbinder verwendete dafür unter anderem Streifen von einer Urkunde, die 1394 wohl für das Martinsmünster in Colmar ausgestellt wurde. Zumindest der Einband, der nicht wesentlich jünger als die Handschrift selbst ist, dürfte also im Oberelsass entstanden sein. Eine Sammelhandschrift aus den Jahren 1455 bis 1469 (C 46) enthält neben unter- 
schiedlichen theologischen Texten auch mehrere kleinere Werke des Enea Silvio Piccolomini, die zum Zeitpunkt der Abschrift erst wenige Jahre alt waren. Sie würde gut in das Profil der Sammlung Friedrichs von Lütishofen passen.

Zusammenfassend lässt sich festhalten, dass in den Handschriften der Stiftsbibliothek Texte mit einem praktischen Nutzen für die seelsorgerische Tätigkeit wie Beichthandbücher und Predigten deutlich überwiegen. Dazu kommen
Werke, die eine Rolle in der Ausbildung zum Kleriker spielten. Nur vereinzelt erscheinen Texte wie die Papstgeschichte des Amalricus Augerius oder die Klassiker aus der Sammlung Friedrichs von Lütishofen, die spezifische Interessen ihrer Besitzer widerspiegeln. In ihrer frühen Phase war die Bibliothek offenbar mehr ein Aufbewahrungsort für die Bücher, die dem Stift von einzelnen seiner Angehörigen geschenkt oder hinterlassen wurden, als eine planvoll aufgebaute Sammlung. 


\section{Anmerkungen}

1 Liebenau, Urkundenbuch, Nr. 1: canonica mea que est in loco que (sic) dicitur Peronis monasterium a parentibus meis primitus, postmodum a me sancti Michaelis honori attributum.

2 In canonicis libris et muris et tectis paraturis et claustrum atque officinas omnes indubitanter per se restauret.

3 So heisst es darin zunächst, die Söhne des Grafen seien bereits vor dem Zeitpunkt der Ausstellung verstorben (cum omnepatrimonium meum non in filios, quoniam illis orbatus sum, sed in nepotes meos sit transiturum), kurz darauf wird jedoch festgelegt, der Besitz des Stiftes Beromünster solle nach Ulrichs Tod zunächst auf seinen Sohn Heinrich übergehen (ego habeam eundem locum in dies vite mee, et flius meus Henricus habeat prefatum locum quam diu in hoc seculo uiuat).

4 «Ich wollte es nicht in ein Königsstift umwandeln, wenn ich nicht dazu gezwungen werde, weil es häufig vorkommt, dass ein kleiner Besitz, der in die Hände von Grossen gerät, entweder gänzlich vernachlässigt oder nachlässig verteidigt wird» (Regalem nolui facere, nisi coactus, quoniam sepe accidit, si parva res in manus magnorum evenerit, ut vel omnino negligatur aut parvum defendatur).

5 Liebenau, Urkundenbuch, Nr. 3.

6 «Und nach seinem Tode soll einer von seinen rechtmässigen Erben, nämlich der ältere, [die Vogtei] innehaben und besitzen, ohne dass die anderen irgendwelche Bedingungen stellen, denn diese Übergabe betrifft niemanden von ihnen ausser einem einzigen. Beachtet, was ich sage, Ihr Gegenwärtigen und Zukünftigen: Einer, nicht alle, dass einer der Erben des vorbenannten Arnolf, der aus meinem Geschlecht hervorgeht, sie innehaben und besitzen soll» (Et post obitum illius unus de legitimis heredibus eius, qui sit maior etate, sine condictione aliorum, cum hec tradicio nulli facta sit illorum nisi uni, teneat atque possideat. Notate tam presentes quam futuri, quod dico: unus, non omnes, ut unus semper heredum predicti Arnolf, qui scilicet de stirpe mea generetur, teneat atque possideat).

7 Liebenau, Urkundenbuch, Nr. 18, 21 und 22.

8 Siehe Melchior Estermann, Das älteste Directorium Chori von Beromünster, in: Anzeiger für schweizerische Altertumskunde, N. F. 8 (1906), S. 143145.

9 Siehe Liebenau, Urkundenbuch, S. 32.

10 Ebd. S. 33f.

11 Josef Siegwart, Die Gründungsgeschichte von Beromünster, in: Der Geschichtsfreund 117 (1964), S. 133-171.

12 Vgl. Anton Gössı, Artikel Beromünster (Stift), in: Historisches Lexikon der Schweiz, Bd. 2, Basel 2003, S. 322 und Helene Büchler-Mattmann, Heinz Lienhard, St. Michael in Beromünster, in: Helvetia Sacra, Bd. II.2, Bern 1977, S. 162.

13 Siehe Peter Eggenberger, Das Stift Beromünster. Ergebnisse der Bauforschung 1975-1983, Luzern/Stuttgart 1986, S. 32-34 und 55-59.

14 Alle historischen Angaben entsprechen, soweit nicht anders angegeben, dem eben zitierten Artikel der Helvetia sacra.

15 Vgl. BüCHLER, Beromünster, S. 183-185.

16 Hic etiam dedit huic ecclesie Decretales, Sectum et Clementinas perpetue in liberia ecclesie Beronensis permanenda. Ignaz Vital Herzog, Jahrzeitbücher des Mittelalters, Teil 4: Des Chorherrenstifts in Beromünster, in: Der Geschichtsfreund 5 (1848), S. 87.

17 Dedit prefatus dominus Johannes Witzig senior eidem ecclesie quemdam librum, continentem hyemalem et estivalem partes horarum canonicalium; in bunc modum, quod idem liber alligari debet publice kathena ferrea ad eiusdem ecclesie chorum cum aliis libris ibidem alligatis communitati serviendis. Ignaz Vital Herzog, Jahrzeitbücher des Mittelalters, Teil 4: Des Chorherrenstifts in Beromünster, in: Der Geschichtsfreund 5 (1848), S. 138.
18 Es handelt sich um die Quarthandschrift C 14.

19 Siehe BÜCHLER, Beromünster, S. 107-109 mit weiterer Literatur.

20 Zum üblichen Spektrum der Unterrrichtstexte vgl. Günter GLAUCHE, Schullektüre im Mittelalter, München 1970.

21 Erich Kleinschmidt, Artikel Rudolf von Liebegg, in: Verfasserlexikon², Bd. 8, Berlin/New York 1992, Sp. 360-364. Allerdings wurde das Pastorale novellum wohl erst 1323 vollendet, während Rudolfs Tätigkeit in Beromünster urkundlich von 1304 bis 1316 belegt ist. Spätestens 1318 verliess er das Stift mit päpstlichem Dispens.

22 Siehe Luzius Meyer, Das Chorherrenstift Beromünster 1313-1500, Liz. Zürich 1987, S. 26-28.

23 BÜCHLER, Beromünster, S. 109-116.

24 Digitalisat online unter: http://e-codices.ch/de/sbe/0193/217v. Abdruck der Bücherliste bei BRUCKNER, Scriptoria 9, S. 22-24, frühere Literatur dazu in der Beschreibung durch Odo LANG 2015, http://e-codices.ch/de/description/ sbe/0193/Lang.

25 Ignaz Vital Herzog, Die St. Peter- und Pauls-, die hl. Kreuz-Caplanei, und die Predigerpfründe zu Beromünster, in: Der Geschichtsfreund 10 (1854), S. 46.

26 Es handelt sich um den Band C 69. Er gibt zugleich einen Hinweis darauf, dass die oben zitierte Vergabung an die Bibliothek von Beromünster anscheinend keinen Bestand hatte: In einem Eintrag auf $383^{\text {va }}$ heisst es, die Handschrift solle im Fall von Werners frühem Tod der Kirche von Aarau übergeben werden, vgl. unten, S. 148.

27 Iste liber est ecclesie Beronensis (C 53, ${ }^{\mathrm{r}}$ ).

28 Ms 380, dort mit dem Zusatz site in pago qui dicitur Argovvia (1v), siehe Winfried Hagenmaier: Die lateinischen Handschriften der Universitätsbibliothek (ab Hs. 231), Wiesbaden 1980 (Kataloge der Universitätsbibliothek Freiburg im Breisgau, Bd. 1.3), S. 116f. Die Handschrift enthält Cassians Collationes XVIII-XXIV sowie einige kleine Texte.

29 BüChler, Beromünster, S. 16f. Aus seiner Amtszeit stammen das Rote und das Weisse Jahrzeitbuch (StiAB 01.01.599 und 600), der Liber crinitus (StiAB 01.01.634a), die Aufzeichnung der Stiftsstatuten in der Matricula Beronensis (Liebenau, Urkundenbuch, Nr. 388), der erste Teil des Feudenbuchs (StiAB 01.01.736), in dem die Einkünfte aus den einzelnen Präbenden des Stifts verzeichnet sind, und das Kelleramtsurbar (StiAB 01.01.709). Die Handschriften werden unten näher besprochen.

30 Die Buchdruckerei in Beromünster und ihre Erzeugnisse wurden in einer Festschrift ausführlich behandelt: Erster datierter Schweizer Druck. Gedenkschrift zur 500-Jahr-Feier in Beromünster 1470-1970, Beromünster 1970.

31 GW M20793. Siehe Erster datierter Schweizer Druck, S. $91 \mathrm{f}$.

32 GW M38460 und M38461: Rodericus Zamorensis, Speculum vitae humanae.

33 GW 07252. Faksimile-Ausgabe mit kritischer Edition und Übersetzung: Eberhard Schleusinger, De cometis - Traktat über den Kometen von 1472, hrsg. v. Peter Stotz und Philipp Roelli, Zollikon-Zürich 2012.

34 Ein Verzeichnis von Helene BüChleR-MatTmann findet sich in dem Sammelband Erster datierter Schweizer Druck, S. 108-137.

35 Ehemals $\mathrm{C} 3$ und 4, heute $\mathrm{C} 135$ und 136. Zu Rofferios Leben und Werk siehe Elisabeth Hemfort, Monastische Buchmalerei zwischen Mittelalter und Renaissance, Bergisch Gladbach 2001, S. 129-142.

$36 \mathrm{Zu}$ Rofferios Arbeit in Beromünster siehe Alfred A. SCHмID, Die Buchmalerei des XVI. Jahrhunderts in der Schweiz, Olten 1954, S. 3-76 und 131-132.

37 Ebd., S. 96-98 und 129-131; Martin AllemanN, «Ad honorem Dei», in: Unsere Heimat 72 (2004), S. 5-96, hier S. 52-55.

38 StiAB 01.01.752, lateinischer Wortlaut der im Folgenden zusammengefassten Stelle bei BRUCKNER, Scriptoria 9, S. 35. 
39 Vgl. Ignaz Vital Herzog, Die St. Peter- und Pauls-, die hl. Kreuz-Caplanei und die Predigerpfründe zu Beromünster, in: Der Geschichtsfreund 10 (1854), S. 53-57 (Nr. 14 und 15).

40 Kopp, Stiftsbibliothek, Teil I, S. 5-7.

41 Ebd., S. 12-14.

42 Ebd., S. 17.

43 Ebd., S. 14-16.

44 Kopr, Stiftsbibliothek, Teil I, S. 18.

45 Freundliche Mitteilung des Stiftsarchivars Dr. Josef Blum. Die Akten über den Vorgang sind im Stiftsarchiv unter der Signatur StiAB 02.02.26.34 abgelegt.

46 StiAB 01.01.1243.

47 Sie werden von Agnes Wegmann (Exlibris, Bd. 1, S. 52) auf etwa 1830 datiert.

48 Pp 146 fol. mit dem antijüdischen Scrutinium scripturarum des Paulus von Burgos ( $† 1435)$, dem Sentenzenkommentar Heinrichs von Gorkum (†1435) und Quaestionen über das Evangelium zu Mariä Verkündigung eines Pseudo-Albertus Magnus. Die Handschrift wurde in den Jahren 1466 und 1467 von Johannes Schumacher aus Lenzburg geschrieben, der auch an den Bänden C 40 und C 41 aus der Privatsammlung des Friedrich von Lütishofen beteiligt war. Laut dem Titelschild aus dem 15. Jahrhundert schenkte sie der Schulmeister Johannes von Gundoldingen an das Stift St. Michel. Der Verlust der Handschrift für Beromünster ereignete sich offenbar erst im 19. Jahrhundert.

49 Der Wortlaut des Eintrags unterscheidet sich in verschiedenen Abschriften leicht. In den Antiquitates Beronenses des Joseph Anton Felix von Balthasar aus dem Jahr 1765 sind zwei Abschriften davon enthalten (Zentral- und Hochschulbibliothek Luzern, BB Ms 74, S. 683 und 686): Ulricus comes de Lenzburg restauravit hanc ecclesiam anno 1036 ditans eam iis praediis [...] recentius adscriptum cum zypho aureo et libro epistolari eburneo auro suffosato adhuc manente, evangelari vero dilapso. Eine jüngere Abschrift durch Franz Bernard Göldlin von Tiefenau ist etwas kürzer (Kantonsbibliothek Aargau, Ms Mur F 67, 15v, 1805): Ulricus comes obiit, qui hanc ecclesiam ditavit hiis praediis [...] cum zypho aureo et libro epistolari eburneo auro suffossato adhuc manente, evangeliario vero dilapso.

50 Adolf Reinle, Die Kunstdenkmäler des Kantons Luzern, Bd. 4: Das Amt Sursee, Basel 1956, S. 80. Der ganze Einband wurde in seiner heute erhaltenen Form im späten 16. Jahrhundert angefertigt.

51 Kopp, Stiftsbibliothek, II, S. 5f.; Fritz W. Volbach, Frühmittelalterliche Elfenbeinarbeiten in der Schweiz, in: Frühmittelalterliche Kunst in den Alpenländern. Akten zum III. Int. Kongress für Frühmittelalterforschung, Olten/ Lausanne 1954, S. 106; BRUCKNER, Scriptoria 9, S. $12 f$.

52 Siehe Liebenau, Urkundenbuch, Bd. 1, S. 31.

53 Immatrikulation in Heidelberg am 21. August 1457, Kaplan am MauritiusAltar in der Krypta der Stiftskirche und Dekan von Schwarzenbach ab 1467, gestorben wohl 1504.

54 Walter Berschin, Diptychonformat, in: Philobiblon 44 (2000), S. 231-236.

55 So schreibt Michel Huglo (The Cantatorium: From Charlemagne to the Fourteenth Century, in: The Study of Medieval Chant. Paths and Bridges, East and West, hrsg. v. Peter Jeffery, Cambridge 2001, S. 89-103): «The Cantatorium disappeared gradually after the eleventh century, becoming combined with other notated books such as the Troper-Proser. Nevertheless, these two books retained the same external characteristics, namely the oblong format and, quite often, a luxurious binding of very old ivory plaques mounted on sturdy wooden boards.» (S. 98-100) und «The ivories in square or rectangular format come from Sacramentaries or Gospel books, while those in oblong format are from a cantatorium or a Troper-Proser.» (S. 101).

56 Epitaphium argenteis insculptum afforis marginibus epistolaris libri quem Udalricus marchio de Lentzburg Christo sanxit et Michabeli.

57 Adolf Reinle (wie Anm. 51), S. 87-91 mit Abb. 76-83. Dort finden sich auch eine detaillierte Beschreibung und eine kurze kunsthistorische Einordnung.

58 Liebenau, Urkundenbuch, Bd. 1, S. 20.

59 Liebenau, Urkundenbuch, Bd. 1, S. 362 (Nr. 304).

60 Liebenau, Urkundenbuch, Bd. 2, S. 153 (Nr. 385).

61 StiAB 01.01.615, S. 29 als Eintrag zum 25. Juni: Obiit dominus Eberhardus rector eclesie in Rómerswile legavit capitulo librum diurnalem cuius precio emptus est anniversarius suus dies eo pacto ut omnes regentes curam perpetuo sui anniversarii procurent intitulari memoriale.

62 Vgl. den Basler Ratsbeschluss über Makulierung und Verkauf liturgischer Handschriften im Staatsarchiv Basel-Stadt, Univ.-Archiv B 1 (1) Acta et Decreta, 96' , gedruckt in: Albert BRUCKNER, Scriptoria medii aevi Helvetica, Bd. 12: Das alte Bistum Basel, Genf 1971, S. 10, Anm. 2.

63 In einer Archivschachtel mit der Signatur 38. Sie enthält neben Einbandfragmenten auch einige Briefe, Urkunden und Abschriften des 14. bis späten 18. Jahrhunderts.

64 Die Enarrationes in Psalmos des Augustinus sind vertreten mit einem Einzelblatt, geschrieben im 10./11. Jh., der Psalmenkommentar des Petrus Lombardus mit einem Doppelblatt, geschrieben im späten 13. oder im 14. Jahrhundert.

65 Beschreibung, Provenienzangaben und weitere Literatur siehe Handschriftencensus: http://www.handschriftencensus.de/1083 und Christoph MACKERT, Nicole EICHenberger, Überarbeitung und Online-Publikation der Erschliessungsergebnisse aus dem DFG-Projekt zur Neukatalogisierung der ehemals Donaueschinger Handschriften in der Badischen Landesbibliothek Karlsruhe: http://www.manuscripta-mediaevalia.de/dokumente/html/obj31576092.

66 StiAB 01.01.634a, $1^{\mathrm{r}}, 42^{\mathrm{r}}$ und $57^{\mathrm{v}}$.

67 StiAB 01.01.634b von 1619.

68 StiAB 01.01.599 und StiAB 01.01.600. Zum Aufbau der Jahrzeitbücher und ihrer Bedeutung für das Stift siehe HugENER, Buchführung, S. 148-167.

69 Siehe Hugener, Buchführung, S. $165 f$.

70 Schongauer Jahrzeitbuch (4. Viertel des 15. Jhs.), StiAB 01.01.616; Jahrzeitbuch von Schwarzenbach (um 1479-1492), StiAB 01.01.615; Jahrzeitbuch des Kammeramts (Ende 15.Jh.), StiAB 01.01.663; Jahrzeitbuch des Johannes Hitzmann (1500-1517), StiAB 01.01.603; Jahrzeitbuch von Hägglingen (1. Viertel des 16. Jhs.), StiAB 01.01.617; Jahrzeitbuch des Scholasticus (1534-1537), StiAB 01.01.602.

71 Das Jahrzeitbuch von Neudorf im dortigen Pfarrarchiv (Mikrofilm im Staatsarchiv Luzern, FA 29/167).

72 Johannes Dor ${ }^{e} f f$ inger prebendarius altaris Sancti Mauricii in cripta scripsit bunc librum anniversariorum causa Dei et Sancte Agathe virginis gloriose huius eclesie patrone, $1486(27 \mathrm{r})$. Vgl. SuTER, in: Erster datierter Schweizer Druck, S. 78.

73 Auf S. 86, im hinteren Teil der Handschrift, die auch Notizen zur Verwendung von Mitteln und Beilegung von Streitsachen zwischen Dörflinger und seiner Gemeinde enthält, steht am unteren Rand: Sciendum quod ego Iohannes Dörflinger fui prebendarius altaris sancti Thome ad octo annos ... et post prebendarius altaris in cripta ... und auf S. 92 eine weitere, auf 1473 datierte Selbstbezeichnung: ego Iohannes Dörffinger altaris in cripta prebendarius.

74 Anno domini $M^{\circ} d^{o}$ obiit Iohannes Dörffinger rector huius eclesie fratruelis predicti domini Heinrici.

75 Er stammt wohl von Dörflingers Neffen Georg und lautet: Anno domini 1504 obiit dominus Iohannes Dörflinger rector huius eclesie in Schwarzenbach et capplanus ecclesie Beronensis altaris S. Mauricii qui bunc conscripsit librum. 
Cuius anima requiescat in pace. Am Rand steht von der gleichen Hand: Annotatio obitus m. Georgii d. (S.29).

76 Um die von Dörflinger hinterlassenen Schulden zu tilgen, hatte das Kapitel sein Haus in Schwarzenbach verkauft, aus dessen Einkünften die Jahrzeit hätte finanziert werden sollen (StiAB 01.01.615, S. 70).

77 Er wird unter anderem in StiAB 01.01.718, xiiiiv als Syndicus und Prokurator von Propst und Kapitel des Stifts Beromünster bezeichnet (dominus Helias, conventus ecclesie collegiate Beronensis Constanciensis dyocesis sindicus et procurator venerabilium et honorabilium virorum dominorum prepositi et capituli supradicte ecclesie Beronensis constitutus).

78 Helvetia sacra I/1, S. 250f.

79 Bürgerbibliothek, Ms 304.a.4º um 1570.

80 AKT 19D/405, um 1650.

$81 \mathrm{Zu}$ Gartner siehe BüCHLER, Beromünster, S. 297.

82 Nur auf dem Deckel von C 41 findet sich ein Besitzvermerk Friedrichs von Lütishofen: Iste liber est magistri Fride[rici] de Lütishoffen.

83 Petermann von Lütishofen war Schultheiss in den Jahren 1441 und 1444, siehe Peter QuAdri, Artikel Lütishofen, Petermann von, in: Historisches Lexikon der Schweiz, Bd. 8, Basel 2009, S. 121.

84 Zur Familie von Lütishofen siehe BÜCHLER, Beromünster, S. 61-63.

85 Zu Friedrich von Lütishofen siehe BüCHLER, Beromünster, S. 337f., zu Burkhard II. ebd., S. $336 f$.

861439 in Heidelberg immatrikuliert, 1440 baccalarius, 1443 licentiatus artium, Rektor zuerst 1461, 1464 schliesslich Professor der Medizin ebendort, gest. 1480, siehe Colette Jeudi, Ludwig SchubA, Erhard Knab und die Heidelberger Universität im Spiegel von Handschriften und Akteneinträgen, in: Quellen und Forschungen aus italienischen Bibliotheken und Archiven 61 (1981), S. 60-108.

87 Biblioteca Apostolica Vaticana, Pal. lat. 1589, 69r-139v und 140-194v

88 Siehe BüCHLER, Beromünster, S. $305 f$.

89 Die Familie von Buseck stammte aus der Gegend von Giessen, Friedrich und Burkhard dürften den genannten Personen in Heidelberg begegnet sein. Zur Familie siehe J. Friedrich Battenberg, Archiv der Familie von Buseck und der Ganerbschaft Buseckertal (Bestände B 14 und F 28). Mit Stammtafeln von Elke Noppes, Darmstadt 2000.

90 Siehe BÜCHLER, Beromünster, S. 337f.

91 Das Wasserzeichen der Vorsatzblätter ist um 1478 belegt.

92 Als Pfarrer in Grosswangen ist Friedrich dann im Jahr seines Abschlusses (16. Okt. 1454) nachgewiesen.

93 Zur Verwandtschaft zwischen Ludwig und Friedrich von Lütishofen siehe BüCHLER, Beromünster, Stammtafel 2.

94 Möglicherweise bei dem Heidelberger Buchbinder Albert Schwab. Die Stempel auf den Einbänden gehören zwar mit Ausnahme einer kleinen Rosette (s006281) auf C 64 nicht zu dem Material, das in der Einbanddatenbank seiner Werkstatt (500047s, Alberthus) zugewiesen wird, sie kommen aber auf anderen Einbänden mit dessen typischen Stempeln kombiniert vor. Es handelt sich um zwei Blüten (s025996 auf C64 und C 40 sowie s025999 auf C 64), die auf dem Einband von Augsburg, Universitätsbibliothek, Cod. II $1,2^{\circ} 126$ zusammen mit dem Schriftzug deo laus (s025997) erscheinen.

95 In allen drei Handschriften kommt Papier mit den Wasserzeichen Piccard, Wasserzeichenkartei Nr. 75508 und 75846 vor, in C 40 und C 41 ausserdem Nr. 75123 , in C 41 und C 64 ausserdem Nr. 75238.

96 Er vermerkte die Schenkung mit dem genauen Datum in einem Nachtrag: Ego Burcardus de Lütishoffen, canonicus necnon custos huius ecclesie, legavi bunc librum predicte ecclesie pro remedio omnium fidelium defunctorum atque omnium meorum superstitum sub anno incarnacionis domini $M^{\circ} c c c c^{\circ} l x 7^{\circ}$ Michaelis May [8. Mai] (272 $\left.{ }^{\mathrm{vb}}\right)$. Vgl. auch BüCHLER, Beromünster, S. 173.
$97 \mathrm{Zu} \mathrm{ihm} \mathrm{siehe} \mathrm{BüCHLER,} \mathrm{Beromünster,} \mathrm{S.} 158$ mit Anm. 95.

98 Johannes Schumacher schrieb auch eine Handschrift, die Friedrichs Studienkollege Johannes von Gundoldingen dem Stift Beromünster schenkte und die im 19. Jahrhundert an die Zentral- und Hochschulbibliothek Luzern gelangte (Pp 146 fol.), vgl. Anm. 49.

99 Zu Menger siehe Mathias Stauffacher, Artikel Menger, Konrad, in: Verfasserlexikon², Bd. 6, Berlin/New York 1987, Sp. $387 f$.

100 «er Buchbinder mit den Muschelstempeln» nach Helene Mattmann, Inkunabelverzeichnis der Stiftsbibliothek Beromünster, in: Erster datierter Schweizer Druck, hier S. 147f. mit Taf. $17 f$.

101 Es handelt sich um den Band mit der Signatur A 6, vgl. Mattmann, Inkunabelverzeichnis (wie Anm. 101), S. 119, Nr. 54. Zwar enthält die Inkunabel A 19 einen Besitzeintrag Ludwig Zellers, doch könnte Zeller sie von Friedrich erhalten haben.

102 Der Einband stammt wie der von C 61 aus der Werkstatt des Buchbinders Reussenhock, vgl. Mattmann, Inkunabelverzeichnis (wie Anm. 101), S. 106f. mit Taf. 13f. Bei den abgebildeten Stempeln handelt es sich nach der Einbanddatenbank um s014706, s014708, s014709, s014713, s014714, s014717 und s014720. Für C 61 verwendete der Buchbinder die Stempel s014705, s014709, s014713, s014716, s014717 sowie ein Vierblatt in Quadrat. Über den Ort der Werkstatt herrscht noch keine völlige Klarheit. Während er zunächst in Strassburg vermutete wurde, zog man später auch das württembergische Schwaben oder Freiburg i. Br. in Betracht (Strassburg[?]: Ernst Kyriss, Deutsche Buchbinder der Spätgotik und Renaissance, in: Archiv für Geschichte des Buchwesens 3 (1960), Sp. 192, Nr. 88. Württembergisches Schwaben: Ilse SchunKe, Konrad von Rabenau, Die Schwenke-Sammlung gotischer Stempel- und Einbanddurchreibungen, Bd. II, Berlin 1996, S. 248f. Freiburg: Vera SACK, Die Inkunabeln der Universitätsbibliothek und anderer öffentlicher Sammlungen in Freiburg im Breisgau und Umgebung. Teil 2, Wiesbaden 1985, S. 811f., Nr. 2418). Die Verbindungen der Handschrift C 61 und ihres Besitzers Friedrich von Lütishofen nach Freiburg machen es wahrscheinlich, dass der Einband dort entstanden ist.

103 Siehe Frank BAron, Artikel Luder, Peter, in: Verfasserlexikon², Bd. 5, Berlin/ New York 1985, Sp. 954-959.

104 Freiburg i. Br., Universitätsbibliothek, Hs. 89.

105 Siehe BüCHLER, Beromünster, S. 337. Einen Eintrag in C 62, Br datierte Friedrich von Lütishofen 1473 in universitate Fryburgensi.

106 Nur das Compendium theologicae veritatis von 1432 hatte wohl bereits seinen heute erhaltenen Einband, als es mutmasslich in Friedrichs Besitz kam.

107 Die Handschriften sollten Friedrichs Testament zufolge nach dem Tod seiner Tochter Ottilie an die Stiftsbibliothek fallen, sie wurden aber im Zusammenhang mit einem Erbschaftsstreit dem Kapitel schon vorzeitig als Prozesskostenentschädigung zugesprochen, siehe BüCHLER, Beromünster, S. 173 mit Anm. 147 und S. 337 mit Anm. 15.

108 Siehe BüCHLER, Beromünster, S. 62f. und 37.

109 Siehe BüCHLER, Beromünster, S. 181.

110 Es handelt sich neben den oben genannten Handschriften um die Inkunabeln $\mathrm{A}$ 9, A 12, A 16 und A 17, A 19, A 68, A 73 sowie A 88 und den Sammelband A 66.

111 Der erste Besitzeintrag in Aarau, Kantonsbibliothek, Inc. 12a fol. lautet: Emptus a Ludovico Zeller per me Johannem Fry de Baden plebanum in Stauffen 1481 pro iiij fl. Anschliessend folgt: Emptus a Ludowico Zeller per me Hemann Reber de Loffenberg ante festum S. Katerine [?] anno 1482 pro iiii fl. Und schliesslich: Ludwici Zellery caplani in Arow S. Marie Magdalene 1489 iiii fl., siehe Inge DAHM, Aargauer Inkunabelkatalog, Aarau u. a. 1985, S. 104, Nr. 300.

112 Auf 260r schliessen sich an den Text ein Explicit (Et sic finis est buius floreti) und ein Besitzeintrag (Ludowici Zeller de Brugg) an. Darauf folgt eine Jahres- 
und Ortsangabe (1463 Friburgi in O̊chtland in domo domini etc.) die wohl später hinzugefügt wurde, sowie eine Ergänzung zu dem Explicit: Bernhardi doctoris eximii, per Hemannum Reber de Lüffenberg. Ein weiterer Teil der Ergänzung wurde teilweise beim Binden abgeschnitten und sein Bezug ist nicht ganz klar. Zu erkennen ist nur noch der Beginn des Wortes Requies [cat] oder Requis[icione] und eine Ergänzung zu Ludwig Zeller: Capplani primi hospitalis ibidem in Brugg. Falls requisicione die richtige Lesung ist, wäre Zeller der Auftraggeber. Falls requiescat gemeint ist, wäre der Eintrag wohl auf Henmann Reber zu beziehen und müsste nach 1482 entstanden sein.

113 Siehe dazu auch Kopp, Stiftsbibliothek, I, S. 11, Clara MüLLER, Geschichte des aargauischen Schulwesens vor der Glaubenstrennung, Aarau 1917, S. 95, Nr. 171; S. 97, Nr. 231; Erster datierter Schweizer Druck, S. 15f.; SidLleR, Bildungsverhältnisse, S. 175f. Nr. 160.

114 C 45, Spiegel hinten: Capplanus primus hospitalis in Bruggper annum, Sancte Ursule in Berona per annum, Sancte Marie Magdalene in Arow modo, plebanus in Sur L. Zeller per triennium, Adiutor in Arow per biennium. 1475.

115 Joseph Ludwig AeBI, Die Buchdruckerei zu Beromünster im fünfzehnten Jahrhundert. Einsiedeln 1870, S. 28 (ohne Beleg).

116 Hans Georg Wackernagel, Die Matrikel der Universität Basel, Bd 1: 1460-1529, Basel 1951, S. 54.

117 Er enthält das Lavacrum conscientiae des Jacobus von Gruitrode (?), ein pseudoaugustinisches Speculum peccatoris, einen Traktat zur Messe, den Dialogus de septem sacramentis des Guillelmus Parisiensis (?), ein Exzerpt aus der Summa de casibus conscientiae des Bartholomaeus Pisanus, sowie einen Traktat über die Krankenseelsorge.

118 Siehe Herzog (wie Anm. 39), S. 46. Nach Werners Tod sollten die Bücher an die Liberie des Stifts St. Michael übergehen.

119 Siehe SidLER, Bildungsverhältnisse, S. 183 und BüCHLER, Beromünster, S. $378 f$.

120 Iste liber est Wernheri de Selden caplani S. Crucis Beronensis ecclesie. Si autem ante sacerdotium moritur, dari debet ecclesie in Arow, prout ab ava et matre eius michi Ludwico commissum est anno lxxvio.

121 Er lautet: Hec sunt octo species luxurie per me Ludvicum Zeller de Brugg. $1461^{\circ}$.

122 Gemäss Schriftvergleich mit der von Väsen als Schreiber subskribierten Handschrift Basel, Universitätsbibliothek, F V 5. Väsen war ein Sohn des Untervogtes in Reinach und hatte in Erfurt studiert (Immatrikulation 1452). Für das Stift Beromünster erscheint er 1472 als Wartner, 1478 als Chorherr; als Leutpriester war er in Kirchberg (1475), Rickenbach (1483) und Suhr tätig (siehe Sidler, Bildungsverhältnisse, S. 165, Nr. 124; BüCHLER, Beromünster, S. 393f., Nr. 363). Er starb am 10. (Jahrzeitbuch von Schwarzenbach) oder 11. Mai (Weisses Jahrzeitbuch) 1488.

123 Ein Randzusatz in Dörflingers Verzeichnis von Wohltätern seiner Pfründe vermerkt zu einer Schenkung von zwanzig Goldgulden: Faciente hoc Iohanne Dórflinger ultimo confessore prediciti Jacobi Vesen (Jahrzeitbuch von Schwarzenbach, StiAB.01.01.615, S. 69). 


\section{Abgekürzt zitierte Literatur}

$\mathrm{AH}$

Antiquitates Beronenses

BERTALOT, Initia humanistica Latina

BHL

BLOOMFIELD, Incipits

BONAVENTURA, opera omnia

BRIQUET

BRUCKNER, Scriptoria 9

BRUYLANTS

BÜCHLER, Beromünster

Cantus ID

Catalogus 1763

Catalogus 1826

CC

$\mathrm{CC} \mathrm{CM}$

$\mathrm{CMD}-\mathrm{CH}$

Colophons

CPL

Distelbrink, Bonaventurae scripta

EBDB

EgLOFF, Herr in Münster

EGLOFF, Urbar

ESTERMANN, Sehenswürdigkeiten

Estermann, Stiftsschule

Erster datierter Schweizer Druck
Guido Maria Dreves, Clemens Blume, Henry A. Bannister (Ed.), Analecta hymnica medii aevi, 55 Bde., Leipzig 1886-1922.

Josef Anton Felix von Balthasar, Antiquitates Beronenses, sive Breve Chronicon Insignis et antiquae Ecclesiae Beronensis, in Argovia et Pago Lucernatum sita, a prima sua fundatione ad Seculum usque XVI. productum, ac varias de rebus helveticis medii aevi memorias exhibens. Pars I, [Beromünster] 1765 (Zentral- und Hochschulbibliothek Luzern, BB Ms 74).

Ludwig Bertalot, Initia humanistica Latina. Initienverzeichnis lateinischer Prosa und Poesie aus der Zeit des 14. bis 16. Jahrhunderts, 2 Bde. (in 3 Teilen), Tübingen 1985-2004.

Société des Bollandistes (Ed.), Bibliotheca hagiographica latina antiquae et mediae latinitatis, 2 Bde., Brüssel 1898-1901.

Morton W. Bloomfield, Incipits of Latin Works on the Virtues and Vices, 1100-1500 A.D., Cambridge Mass. 1979.

Doctoris seraphici S. Bonaventurae S.R.E. Episcopi Cardinalis opera omnia, 11 Bde., Quaracchi 1882-1902.

Charles Moïse BRIQUET, Les filigranes. Dictionnaire historique des marques du papier dès leur apparition vers 1282 jusqu,en 1600, 4 Bde., 2. Aufl., Leipzig 1923.

Albert BRUCKNER, Scriptoria medii aevi Helvetica, Bd. 9: Schreibschulen der Diözese Konstanz. Stadt und Landschaft Luzern, Genf 1964.

Placide BRUYLANTS, Les oraisons du missel romain, 2 Bde., Louvain 1952.

Helene BüChler-Mattmann, Das Stift Beromünster im Spätmittelalter, 1313-1500. Beiträge zur Sozial- und Kulturgeschichte, Beromünster 1976.

Cantus Index: Online catalogue for Mass and Office chants (www.cantusindex.org).

Catalogus Librorum Bibliothecae Insignis et Perantiquae Ecclesiae Collegiatae ad D. Michael. Arch. Beronae vulgo Můnster Aergoviae Helvetorum, [Beromünster] 1763 (StiA Bm 1, 1, 1243).

Ignaz Vital Herzog, Catalogus Librorum Insigni ecclesiae collegii Beronensis, [Beromünster] 1826 (Stiftsbibliothek Beromünster, ohne Signatur).

Corpus christianorum. Series Latina, Turnhout 1954ff.

Corpus christianorum. Continuatio mediaevalis, Turnhout $1971 \mathrm{ff}$.

Katalog der datierten Handschriften in der Schweiz in lateinischer Schrift vom Anfang des Mittelalters bis 1550, bearb. v. Beat M. von Scarpatetti u. a., 3 Bde., Dietikon-Zürich 1977-1991.

BÉNÉDICTINS DU BouvERET (Red.), Colophons des manuscrits occidentaux des origines au XVIe siècle, Bd. 1ff., Fribourg 1965ff.

Eligius Dekkers, Aemilius GaAr, Clavis patrum Latinorum, 3. Aufl., Steenbrugge 1995.

Balduinus Distelbrink, Bonaventurae scripta: authentica dubia vel spuria critice recensita, Rom 1975 (Subsidia scientifica Franciscalia, 5).

Staatsbibliothek zu Berlin. Einbanddatenbank (www.hist-einband.de).

Gregor Egloff, Herr in Münster. Die Herrschaft des Kollegiatstifts St. Michael in Beromünster in der luzernischen Landvogtei Michelsamt am Ende des Mittelalters und in der frühen Neuzeit (1420-1700), Basel 2003.

Gregor EgLOFF, Das Urbar als Werkzeug historischer Erinnerung und Legitimation. Güterverzeichnisse des Kollegiatstifts St. Michael in Beromünster vom 14. bis ins 17. Jahrhundert, in: Thomas Meier, Roger Sablonier (Hg.), Wirtschaft und Herrschaft. Beiträge zur ländlichen Gesellschaft in der östlichen Schweiz (1200-1800), Zürich 1999, S. 371-396.

Melchior Estermann, Die Sehenswürdigkeiten von Bero-Münster mit geschichtlichen Erläuterungen, Luzern 1878.

Melchior Estermann, Die Stiftsschule von Bero-Münster, ihr und der Stift Einfluss auf die geistige Bildung der Umgebung. Ein Kulturbild seit der Gründung der Stift bis auf unsere Tage urkundlich dargestellt, Luzern 1876.

Erster datierter Schweizer Druck. Gedenkschrift zur 500-Jahr-Feier in Beromümster 1470-1970, Beromünster 1970. 


\author{
FRANZ, Benediktionen \\ GW \\ HAIN
}

Helvetia sacra

HLS

Hugener, Buchführung

JANNER/JUROT/WEBER, Handschriftliche Überlieferung

KAEPPELI, Scriptores

Kopp, Stiftsbibliothek

KRISTELLER, Iter Italicum 5

LEHMANN, MABK 1

LIEBENAU, Urkundenbuch

LINDT

LOHR, Aristotelica Helvetica

MAdre, Dinkelsbühl

NöRR, Kanonistische Literatur

PicCARD, Wasserzeichenkartei

PL

QW

$\mathrm{RB}$

REINLE, KDM Luzern 4

RIEDWEG, Beromünster

SCHNEYER

SCHNEYER, 1350-1500

Schulte, Geschichte

SIDLER, Bildungsverhältnisse

THORNDIKe/KIBRE, Incipits

TsCHUDIN

Verfasserlexikon ${ }^{2}$

WALTHER, Carmina
Adolph Franz, Die kirchlichen Benediktionen im Mittelalter, 2 Bde., Freiburg 1909.

Gesamtkatalog der Wiegendrucke, Bd. 1-7, Leipzig 1925-1940; Bde. 8ff. Stuttgart/Berlin/New York 1972ff.; GW (online): www.gesamtkatalogderwiegendrucke.de.

Ludwig HaIn, Repertorium bibliographicum, in quo libri omnes ab arte typographica inventa usque ad annum MD, typis expressi ordine alphabetico vel simpliciter enumerantur vel adcuratius recensentur, Stuttgart/Paris 1826-1838.

Helvetia sacra, hrsg. v. Albert Bruckner u. a., 34 Bde., Bern/Basel 1972-2007.

Historisches Lexikon der Schweiz, 13 Bde., Basel 2001-2014; e-HLS (online): www.hls.ch.

Rainer Hugener, Buchführung für die Ewigkeit. Totengedenken, Verschriftlichung und Traditionsbildung im Spätmittelalter, Zürich 2014.

Sara Janner, Romain Jurot, Dorothea Weber, Handschriftliche Überlieferung der Werke des heiligen Augustinus, Bd. IX/1-2: Schweiz, 2 Bde., Wien 2001 (Österreichische Akademie der Wissenschaften. Philosophisch-historische Klasse, Sitzungsberichte, Bd. 688).

Thomas Kaeppeli, Scriptores ordinis Praedicatorum medii aevi, 4 Bde., Rom 1970-1993.

Karl Alois Kopp, Die Stiftsbibliothek von Beromünster. Historisch-bibliographische Skizze. I.

Geschichtliches, Luzern 1903; II. Die Manuskripte und ältesten Druckwerke, Luzern 1904.

Paul Oskar Kristeller, Iter Italicum, Bd. 5, Leiden 1990.

Paul Lehmann, Mittelalterliche Bibliothekskataloge Deutschlands und der Schweiz, Bd. 1, München 1918.

Theodor von Liebenau, Urkundenbuch des Stiftes Bero-Münster, 2 Bde., Stans 1903-1913.

Johann LINDT, The paper-mills of Berne and their watermarks 1465-1859, Hilversum 1964.

Charles LoHr, Aristotelica Helvetica, Freiburg 1994.

Alois MADRE, Nikolaus von Dinkelsbühl, Leben und Schriften, Münster/Westfalen 1965.

Knut Wolfgang NörR, Die kanonistische Literatur, in: Helmut Coing, Handbuch der Quellen und Literatur der neueren europäischen Privatrechtsgeschichte, Bd. 1, München 1973.

Hauptstaatsarchiv Stuttgart: Bestand J 340, Wasserzeichenkartei Piccard (www.lad-bw.de).

Patrologiae cursus completus, Series latina, ed. Jacques-Paul Migne, 221 Bde., Paris 1844-1864.

Quellenwerk zur Entstehung der Schweizerischen Eidgenossenschaft. Urkunden, Chroniken,

Hofrechte, Rödel und Jahrzeitbücher bis zum Beginn des 15. Jahrhunderts, Bd. 1ff., Aarau $1933 \mathrm{ff}$.

Friedrich STEGMÜLleR, Repertorium biblicum medii aevi, 11 Bde., Madrid 1950-1981.

Adolf Reinle, Die Kunstdenkmäler des Kantons Luzern, Bd. 4: Das Amt Sursee, Basel 1956.

Mathias RIEDWEG, Geschichte des Kollegiatstiftes Beromünster, Luzern 1881.

Johannes Baptist SCHNEYER, Repertorium der lateinischen Sermones des Mittelalters für die Zeit von 1150-1350, 9 Bde., Münster Westfalen 1969-1980.

Repertorium der lateinischen Sermones des Mittelalters für die Zeit von 1350-1500. Nach den Vorarbeiten von Johann Baptist SCHNEYER hrsg. v. Ludwig Hödl und W. Knoch, CD-ROM, Münster Westfalen 2001.

Johann Friedrich von Schulte, Die Geschichte der Quellen und Literatur des canonischen Rechts, Bd. 2, Stuttgart 1877.

Josef SidLER, Die Bildungsverhältnisse im Kanton Luzern mit besonderer Berücksichtigung des Klerus, von ca. 1250 bis um 1530, Stans 1970 (Beiheft Nr. 13 zum Geschichtsfreund).

Lynn Thorndike, Pearl Kibre, A Catalogue of Incipits of mediaeval scientific Writings in Latin, London 1963.

Fritz Tschudin, The ancient paper-mills of Basle and their marks, Hilversum 1958.

Die deutsche Literatur des Mittelalters. Verfasserlexikon des deutschen Mittelalters, hrsg. v. Kurt Ruh, 2. völlig neu bearb. Aufl., 14 Bde., Berlin/New York 1978-2008.

Initia carminum ac versuum medii aevi posterioris Latinorum. Alphabetisches Verzeichnis der Versanfänge mittellateinischer Dichtungen, bearb. v. Hans WALTHER, Göttingen 1959. 
WALther, Proverbia

Wegmann, Exlibris

ZUMKELLER, Manuskripte
Proverbia sententiaeque Latinitatis medii ac recentioris aevi. Lateinische Sprichwörter und Sentenzen des Mittelalters in alphabetischer Anordung gesammelt, Bd. 1-6 hrsg. v. Hans WALTHER, Bd. 7-9 aus dem Nachlass von Hans Walther hrsg. v. Paul Gerhard Schmidt, Göttingen 1963-1986.

Agnes Wegmann, Schweizer Exlibris bis zum Jahre 1900, 2 Bde., Zürich 1933-1937.

Adolar Zumkeller, Manuskripte von Werken der Autoren des Augustiner-Eremitenordens in mitteleuropäischen Bibliotheken, Würzburg 1966. 


\section{Signaturenkonkordanz}

Die Signaturen der Handschriften in der Schatzkammer und im Archiv sind im Wesentlichen unverändert, für die Quarthandschriften wurde lediglich die Formatangaben aufgehoben. Im folgenden Verzeichnis werden daher allein die alten Signaturen der Foliohandschriften aufgeführt.

\begin{tabular}{|c|c|c|}
\hline Signatur alt & Signatur neu & Titel \\
\hline \multirow[t]{3}{*}{ C 6 fol. } & \multirow[t]{3}{*}{ C 57} & Augustinus; Ps.-Augustinus; Albertus de Ferrariis; Gerardus Monachus; Jacobus de \\
\hline & & Paradiso; Johannes Andreae; Johannes de Deo; Johannes de Fonte; Johannes Hispalensis; \\
\hline & & Walter Map; Excerpta \\
\hline C 10 fol. & C 61 & P. Terentius Afer; P. Vergilius Maro; Augustinus Datus; Petrus Luder; M. Tullius Cicero \\
\hline C 11 fol. & C 62 & Honorius Augustodunensis; Johannes Nider \\
\hline C 12 fol. & C 63 & Hugo Argentinensis; Aegidius Romanus \\
\hline C 13 fol. & C 64 & Evangelia; Versus; Nicolaus de Dinkelspuhel \\
\hline C 14 fol. & C 65 & Fünf Inkunabeln, Conradus de Saxonia \\
\hline C 17 fol. & C 67 & Henricus Bohicus \\
\hline C 19 fol. & C 69 & Henricus de Turego \\
\hline C 20 fol. & C 40 & $\begin{array}{l}\text { Quaestiones super Aristotelis libros Physicorum; Quaestiones super Aristotelis De caelo } \\
\text { et mundo; Johannes de Sacrobosco }\end{array}$ \\
\hline C 21 fol. & C 41 & Marsilius de Inghen; Quaestiones super Aristotelis De anima \\
\hline C 22 fol. & C 42 & Jacobus de Paradiso; Sermones \\
\hline C 23 fol. & C 43 & Zacharias Chrysopolitanus \\
\hline \multirow[t]{2}{*}{ C 24 fol. } & \multirow[t]{2}{*}{ C 44} & Eberhardus Knab de Zwifalten; Partes dictaminis; Ars epistolandi et praedicandi; \\
\hline & & Ps.-Boethius; Gasparinus Barzizius; Vocabularium \\
\hline C 25 fol. & $\mathrm{C} 45$ & Liber floretus; Johannes Gerson \\
\hline \multirow[t]{4}{*}{ C 26 fol. } & \multirow[t]{4}{*}{ C 46} & Honorius Augustodunensis; Jacobus de voragine; Pius II papa; Laurus Quirinus; Paulus \\
\hline & & apostolus; Tractatulus de quinque floribus mundi contemnendis; Andreas de Escobar; \\
\hline & & Expositio hymnorum; Ps.-Dionysius Areopagita; Thomas Palmeranus; Jacobus de Paradiso; \\
\hline & & Marquard von Lindau; Lactantius; Eberhard Mardach \\
\hline C 29 fol. & C 49 & Isidorus Hispalensis \\
\hline C 30 fol. & C 50 & Discipulus \\
\hline C 31 fol. & C 51 & $\begin{array}{l}\text { Psalterium glossatum; Expositio trium symbolorum; Henricus de Odendorp; Speculum } \\
\text { clericorum }\end{array}$ \\
\hline C 32 fol. & C 52 & Sermones; Zacharias Chrysopolitanus \\
\hline C 33 fol. & C 53 & Expositio hymnorum; Henricus de Frimaria; Sermones \\
\hline C 34 fol. & C 54 & Amalricus Augerius \\
\hline C 35 fol. & C 55 & Missale Turicense \\
\hline
\end{tabular}


Die liturgischen Handschriften in der Schatzkammer 
Pergament, 115 Blätter, 34,5 × 24,5-25 cm

Oberrhein (?), erste Hälfte des 14. Jahrhunderts und Beromünster (?), zweite Hälfte des 15. Jahrhunderts

Lagen, Foliierung: Lagen: $6 \mathrm{VI}^{70}+(\mathrm{V}+1)^{81}+\mathrm{V}^{91}+2 \mathrm{VI}^{114}$, das erste Blatt der ersten und das letzte Blatt der letzten Lage als Spiegelblätter in die Deckel geklebt, letzteres heute abgelöst; die ganze letzte Lage bis auf den obersten Bund lose; Bl. 71 Einzelblatt, hinten an Bl. 81 genäht. Lagenzählung ius $\left(10^{v}\right)-v i^{u s}\left(70^{v}\right)$. Reklamanten, $10^{\mathrm{v}}$ und $34^{\mathrm{v}}$ ornamental in Rot gerahmt. Neuere Foliierung: [A]. 1-114.

Einrichtung und Ausstattung: Tintenliniierung, Schriftraum mit Doppellinien begrenzt, $21 \times 14,5$, 17 Zeilen. Textualis, $1^{\mathrm{r}-107^{\mathrm{v}}}$ von einer Hand, die neumierten Teile sowie $90^{\mathrm{v}}-91^{\mathrm{v}}$ in kleinerer Schrift; am Rand Vorgaben für die Rubrizierung (bzw. Vergoldung); $\mathrm{A}^{\mathrm{r}}$ sowie 107va $-114^{\mathrm{vb}}$ von der Hand des Johannes Dörflinger. Rubriziert, rote Überschriften; $1^{\mathrm{r}}$, $2^{\mathrm{v}}, 5^{\mathrm{v}}, 21^{\mathrm{v}}, 34^{\mathrm{r}}, 36^{\mathrm{r}}, 43^{\mathrm{r}}, 63^{\mathrm{r}}, 72^{\mathrm{r}}, 78^{\mathrm{r}}, 88^{\mathrm{r}}, 90^{\mathrm{v}}$ und $94^{\mathrm{r}}$ goldene, grün konturierte Überschriften mit rotem und lilafarbenem Fleuronné; einzeilige goldene Lombarden in gleicher Gestaltung. $8^{\mathrm{r}}$ und $19^{\mathrm{r}}$ zweizeilige ornamental gespaltene Initialen in Gold, Rot und Blau, im Binnenfeld rotes und lilafarbenes Fleuronné (und $8^{\mathrm{r}}$ eine goldene Blüte, vgl. 85v); 66v $69^{\mathrm{v}}$, 90v und $94^{\mathrm{r}}$ fünfzeilig, im Buchstabenkörper goldene Fabelwesen mit weissen Gesichtern (meist im Profil), in der Mitte eine (66v weiss-grüne, $69^{\mathrm{v}}$ und $90^{\mathrm{v}}$ weisse) Erdbeerblüte auf goldenem Blätterkranz oder Stern, 90v zusätzlich mit kleinen grünen und roten Blüten im Fleuronné des Binnenfelds. Rot-blau, rot-grün oder grün-rosa $\left(100^{\mathrm{r}}\right.$ rosa-gelb) ornamental gespaltene, schwarz und/oder weiss ornamentierte (meist gepunktete) Initialen in Deckfarbenmalerei mit Fleuronné: In illo tempore ... 26 $6^{\mathrm{r}}$ 6zeilig, 51 $1^{\mathrm{r}}, 62^{\mathrm{r}}, 76^{\mathrm{r}}, 82^{\mathrm{r}}, 89^{\mathrm{r}}$ und $93^{\mathrm{r}} 7 \mathrm{zeilig}$, 30 , 35 , $37^{\mathrm{r}}, 39^{\mathrm{r}}, 47^{\mathrm{r}}, 59^{\mathrm{r}}, 63^{\mathrm{r}}, 68^{\mathrm{r}}, 75^{\mathrm{r}}, 81^{\mathrm{r}}, 85^{\mathrm{r}}, 96^{\mathrm{r}}, 99^{\mathrm{r}}, 101^{\mathrm{r}}$ und $105^{\mathrm{r}} 8$ zeilig eingerückt, in der Schaftaussparung drachenartige Fabelwesen mit Menschengesichtern in Gold, teils auch vegetabile (florale) oder geometrische Motive; Flügel und Gesichter schwarz auf Weiss, Gelb oder Grün; $59^{\mathrm{r}}$ mit weissen Knospen und Blüten, 63 mit grünen und lilafarbenenen Blättern, Eicheln (mit Gold, gleich auch 76 $6^{\mathrm{r}}, 78^{\mathrm{r}}$ und $103^{\mathrm{v}}$ ) und einem Hund (in Lila). 68 $\mathrm{v}$ eine goldene Initiale mit roten und blauen Rauten, die beiden blauen mit weissen Fabeltieren, das Gold schwarz ornamentiert; $70^{\mathrm{v}}$ eine rot-weiss gespaltene mit goldener und grüner Blattranke, $93^{\mathrm{r}}$ gerautet mit goldenen Lilien; $47^{\mathrm{r}}$ nicht gespalten, sondern auf schraffiertem Grund, $103^{\mathrm{r}}$ rechtwinklig umgebrochen und unter dem Schriftraum entlanggeführt. $1^{\mathrm{r}}$ der Schriftraum auf allen vier Seiten von Fleuronnéstäben umgeben, bei allen anderen Initialen dreiseitig, mit Gold dort, wo auch goldene Überschriften sind (und zudem 65v); in den Ecken und teilweise auch an den Initialen selbst Medaillons mit Fabeltieren oder Rosetten; zu den Rändern hin Fadenranken und Fabeltiere in Federzeichnung. Der Buchschmuck weist Ähnlichkeiten mit dem sog. Oberrheinischen Initialstil auf (vgl. Ellen J. BEER, Beiträge zur Oberrheinischen Buchmalerei in der ersten Hälfte des 14. Jahrhunderts unter besonderer Berücksichtigung der Initialornamentik, Basel; Stuttgart 1959). $8^{\mathrm{r}-\mathrm{v}}, 66^{\mathrm{v}}-67^{\mathrm{v}}$ und $94^{\mathrm{r}}-95^{\mathrm{r}}$ neumiert, zudem vier Zeilen auf $18^{\mathrm{r}}$ : Hely, Hely, lamasabacthani. Hoc est: Deus meus, deus meus, ut quid dereliquisti me? Im Reliquienverzeichnis $\left(107^{\mathrm{v}}-114^{\mathrm{v}}\right)$ zweizeilige rote Lombarden mit Punktverdickungen.

Korrekturen und Nachträge: $77^{\mathrm{v}}$ eine Streichung in Rot, ansonsten keine Korrekturen im Evangelistar; $109^{\mathrm{r}}$ eine Korrektur von der Hand J. Dörflingers; $110^{\mathrm{r}}$ vier leicht radierte und gestrichene Zeilen in der Schrift des Hauptteils (Evangelistar: //onem cum eis. Et accedens ... - ... quinque talenta mich tra// Mt 25,19/20). $\mathrm{A}^{\mathrm{r}}$ Nachtrag von der Hand des Johannes Dörflinger, siehe Inhalt (vgl. II C 3, $1^{\mathrm{r}}$ ). Im Reliquienverzeichnis 
mehrere Nachträge, etwa $109^{\mathrm{r}}$ datiert $1506,113^{\mathrm{r}}$ eine Notiz über die notfallmässige Translation von Reliquien aus dem Basler Münster während der Reformation (im Bildersturm): Notandum quod anno 1529 allate sunt reliquie per adolescentem Casparem Schufelbül huius ecclesie canonicum, e Basilea, ubi illic omnia templa per Zvinglianam sectam civibus sunt devastata ... Melchior Estermann, Die Stiftskirche von Beromünster, ihre Umbauten, ihre Kult- und Kunstschätze einst und jetzt, in: Katholische Schweizer-Blätter, N. F. 14 (1898), S. 280; LÜtolf, S. 177. Im hinteren Spiegel eingeklebt ein Zettel aus Papier: Wir Iohannes Abbte von gottes verhenngnuss des wurdigen gotzhuss zu Tysentis ... Actum in crastino post festum sanctorum Placidi et Sygeberti anno etc. vito. Urkunde über die Translation der Reliquien der Heiligen Placidus und Siegebert von Disentis nach Hochdorf am 12. Juni 1506 (eine Abschrift in den Antiquitates Beronenses, S. 744).

Einband: Holzdeckel, mit vergoldeten Silberarbeiten verkleidet, wohl von einer Konstanzer Werkstatt für das Stift Beromünster, 1. Hälfte 14. Jh., vgl. Heuser, S. 72-74 sowie Fritz, S. 179 und 331. Rückdeckel (Schauseite): vollplastische Darstellung von Christus als Salvator mundi im Zentrum eines durch plastische Wimperge und Pfeiler kreuzförmig gegliederten Feldes, die Flächen dazwischen mit gravierten architektonischen Mustern und einem Überzug aus blauem, rotem und grünem transluzidem Email gefüllt, in den vertieften Räumen unter den Eckbögen Darstellungen der vier Evangelisten an ihren Schreibpulten; alles umgeben von einem Rahmen, auf dem mit Edelsteinen und plastischem Eichenlaub geschmückte Felder sich mit farbigen Darstellungen der Apostel, der Gottesmutter und des Erzengels Michael abwechseln. Das Email ist an verschiedenen Stellen abgeplatzt. Vorderdeckel: Flächenfüllung aus kleinen Lilien in einem rhombischen Gitter, parallel darüber wiederum gitterförmig plastische Leisten, auf den Kreuzungspunkten Rosetten. Zwei nach vorn greifende, mit jeweils drei Edelsteinen besetzte Kantenschliessen, am Kopf und am Schwanz Reste von je einer weiteren Schliesse. Rücken aus weissem Leder. Spiegelblätter Pergament (siehe Lagen); im vorderen Deckel auf dem Spiegelblatt Exlibris des Chorherrenstifts Beromünster (WEGMANN, Exlibris, Nr. 619).

Herkunft: Die Gestaltung der Dedicatio ecclesiae spricht nicht gegen eine Bestimmung für das Stift Beromünster selbst. Das durch eine goldene Überschrift hervorgehobene Fest zu Fronleichnam (1264 eingeführt, aber erst nach dem Konzil von Vienne ab 1312 allgemein umgesetzt) spricht gegen eine Datierung noch in das 13. oder ganz frühe 14. Jahrhundert, ebenso der Buchschmuck. Vgl. insbesondere auch die Argumente mit Bezug auf den Einband, v. a. Guth-Dreyfus, S. 40 und Heuser, S. 168. Das Reliquienverzeichnis und stammt von Johannes Dörflinger und ist entsprechend in die zweite Hälfte des 15. Jhs. zu datieren.

Besitzer: In den Antiquitates Beronenses, S. 684, als Nr. 4 und S. 741-744 als Nr. I verzeichnet. Auf dem Exlibris handschriftlich 1891. II. C. 1. Der Eintrag auf $\mathrm{A}^{\mathrm{r}}$ und das Reliquienverzeichnis und der Zettel im hinteren Spiegel belegen die Beziehung der Handschrift nach Beromünster und Hochdorf.

Literatur: [Beat Fidel Zurlauben], Tables généalogiques des augustes maisons d'Autriche et de Lorraine, Paris 1770, S. 42f.; Estermann, Stiftsschule, S. 24-27; Estermann, Sehenswürdigkeiten, S. 34 (Nr. 2) und 59f.; Johann Rudolf RaHn, Zur Statistik schweizerischer Kunstdenkmäler. IX. Canton Luzern, in: Anzeiger für schweizerische Alterthumskunde 18 (1885) = Bd. 5, Zürich 1887, S. 130; Kopp, Stiftsbibliothek, II, S. 6f.; Konrad LüTOLF, Dörflingers Reliquienverzeichnis von Beromünster, in: Zeitschrift für Schweizerische Kirchengeschichte 12 (1918), S. 157-197; Joseph TrOXLER, Liturgisches aus Beromünster, in: Zeitschrift für schweizerische Kirchengeschichte 14 (1920), S. 112 und 118f.; Katia Guth-Dreyfus, Transluzides Email in der ersten Hälfte des 14. Jahrhunderts am Ober-, Mittel- und Niederrhein, Basel 1954 (Basler Studien zur 
Kunstgeschichte IX), S. 36-40 und 116 (Nr. 4) sowie Taf. 19; ReInle, KDM Luzern 4, S. 87-91 mit Abb. 78-83; Bruckner, Scriptoria 9, S. 20f. sowie Taf. 33, 34, 45 und 46; Hans-Jörgen Heuser, Oberrheinische Goldschmiedekunst im Hochmittelalter, Berlin 1974, S. 72-74, 167-169 (Nr. 66) mit Abb. 452-460; Johann Michael Fritz, Goldschmiedekunst der Gotik in Europa, München 1982, S. 179 mit Taf. III; Adolf ReInle, Die Kunst der Innerschweiz von 1200 bis 1450. Ein Überblick, in: Innerschweiz und frühe Eidgenossenschaft. Bd. 1: Verfassung, Kirche, Kunst, Olten 1990, S. 349-351 mit Abb. 197-199; Helene Büchler-Mattmann, Das Beromünsterer Evangelistar: Ein Glanzstück mittelalterlicher Goldschmiedekunst, in: Die Bibel in der Schweiz: Ursprung und Geschichte, Basel 1997, S. 87f. mit Abb. S. $87\left(62^{\mathrm{v}}-63^{\mathrm{r}}\right)$ und. 89 (Rückdeckel).

$\mathrm{A}^{\mathrm{r}}$ Nachtrag. Epitaphium argenteis insculptum afforis marginibus epistolaris libri quem Üdalricus marchio de Lentzburg Christo sanxit et Michaeli. Anschliessend vier Hexameter: Hunc librum Pauli doctoris denique summi, Scripturis totum simul auro eboreque paratum, Marchio Uddalricus tibi Criste sanxit in usum, Qui post hanc vitam mereatur habere quietem.

Av leer.

$1^{\mathrm{r}}-63^{\mathrm{r}}$ Proprium de tempore. Evangelienperikopen, Weihnachten - 23. Sonntag nach Trinitas. In Rot: $>$ Incipiunt evangelia festivalia per circulum anni<. In Gold: >In vigilia nativitatis domini, secundum Matheum<. In illo tempore cum esset desponsata mater Ihesu Maria ... 2 $2^{\mathrm{v}}>$ Ad publicam missam, secundum Iohannem <. In principio erat verbum ... $5^{\mathrm{v}}>$ In octava domini, secundum Lucam<. In illo tempore ... $21^{\mathrm{v}}>$ In die sancto Pasche, secundum Marcum<. In illo tempore ... - ... 59 $>$ r Dominica xxia, secundum Matheum<. In illo tempore ... 62 $2^{\mathrm{v}}$ In illo tempore, loquente Ihesu ad turbas ... 34 $4^{\mathrm{r}}$ Auffahrt, 36r Pfingsten, $43^{\mathrm{r}}$ Corpus Christi.

$63^{\mathrm{r}}-99^{\mathrm{r}}$ Proprium de sanctis. Evangelienperikopen, Andreas - Elisabeth von Thüringen (Konrad). $>D e$ sancto Andrea, secundum Matheum<. In illo tempore, ambulans Ihesus iuxta mare Galylee ... - ... > Cunradi episcopi, ewangelium <. Sint lumbi vestri precincti. $>$ Require $U^{o}$ dalrici<. 66 Johannes Ev., $72^{\mathrm{r}}$ Annuntiatio BMV, 78 Revelatio Michaelis, 88r Assumptio BMV, 90v Nativitas BMV, 94 Dedicatio ecclesiae (Michael).

$99^{\mathrm{r}}-107^{\mathrm{v}}$ Commune sanctorum. Evangelienperikopen. > Incipit commune sanctorum, primo de apostolis, ewangelium secundum Iohannem <. In illo tempore, dixit Ihesus discipulis suis: Hoc est preceptum meum ut diligatis invicem ... - ... > De virginibus, ewangelium <. Simile est regnum celorum decem virginibus. $>$ Require supra Lucie virginis<. Simile est regnum celorum thesauro. $>$ Require Margarethe virginis $<$. Apostel, 100 Märtyrer, 106 ${ }^{\mathrm{r}}$ Bekenner, 107v Jungfrauen.

$107^{\mathrm{va}}-114^{\mathrm{vb}}$ Conspectus reliquiarum. $>$ Ee sunt reliquie contente in patrono nostro sancto Michabele $<$. De corpore sancti Iacobi fratris domini. Reliquie sanctorum martirum Mauricii et sociorum eius ... $108^{\mathrm{rb}}>$ Hee sunt reliquie in maiori cruce contente $<$. In dorso de ligno sancte crucis ... 110 va Notiz zu der Translation von Reliquien der Thebäer aus Solothurn, $111^{\text {va }}$ über die Aufbewahrung der Asche von Reliquien, die bei dem Angriff von Rudolf von Habsburg 1352 verbrannt waren; $112^{\text {va }}$ nochmals beide Ereignisse und weitere Translationsnotizen, $113^{\mathrm{va}} \mathrm{zu}$ 1353: Reliquie sancti Othmari abbatis et sancti Galli confessoris sumpte anno $M^{\circ} c c c^{\circ}$ liii $^{\circ}$... Zuletzt in kleinerer Kursive: Udalricus dei et apostolice sedis gracia abbas monasterii sancti Galli ... Anno domini Millesimo quadringentesimo octuagesimo sexto die vero translationis sepedicti sancti Galli que fuit tercio Nonas Marcii. Edition: LütolF, S. 180-184. Vgl. auch Antiquitates Beronenses, S. 742-744. 
Pergament, 70 Blätter, 25,5-26×15,5 cm

13. Jahrhundert

Lagen, Foliierung: Lagen: 9 IV70, das erste Blatt der ersten und letzte Blatt der letzten Lage als Spiegelblätter in die Deckel geklebt. Längere Nähte von der Pergamentherstellung in Bl. 12 und im hinteren Spiegelblatt (dort rotes Garn), Bl. 70 unregelmässig geformt. Bl. 1-6 unten lose. Neuere Foliierung: 1-70, Bleistift, mit Tinte nachgezeichnet.

Einrichtung und Ausstattung: Tintenliniierung, Schriftraum 17,5 ×9, 18 Zeilen. Textualis von einer Hand. Rubriziert, rote Überschriften, längere Melismen rot unterstrichen. Einzeilige schwarze, $9^{\mathrm{r}}-10^{\mathrm{v}}, 12^{\mathrm{v}}-16^{\mathrm{v}}$, $33^{\mathrm{v}}-37^{\mathrm{r}}, 53^{\mathrm{v}}-58^{\mathrm{r}}$ sowie $59^{\mathrm{r}}-69^{\mathrm{r}}$ abwechselnd rote und blaue Initialen; zu Beginn der einzelnen Tage zweizeilige, abwechselnd rote und blaue Initialen mit Fleuronné, teils in der Gegenfarbe, teils zweifarbig, $7 \mathrm{v}$ mit Gesichtsdarstellung im Binnenfeld; $1^{\mathrm{r}}, 2^{\mathrm{v}}, 17^{\mathrm{r}}, 21^{\mathrm{r}-\mathrm{v}}, 23^{\mathrm{v}}$ und $44^{\mathrm{v}} 2-4 z e i l i g e$ rot-blaue Spaltleisteninitialen mit zweifarbigem Fleuronné. 15 Raum für eine drei- und eine einzeilige Initiale sowie zwei längere Rubriken ausgespart. Durchgehend neumiert mit kleineren Lücken auf $6{ }^{\mathrm{v}}-7^{\mathrm{r}}, 53^{\mathrm{v}}, 54^{\mathrm{v}}, 55^{\mathrm{v}}, 61^{\mathrm{v}}-62^{\mathrm{r}}$ und $65^{\mathrm{r}-\mathrm{v}}$.

Korrekturen und Nachträge: Korrekturen von der Hand des Schreibers, teilweise auf Rasur, z. B. $2^{\mathrm{r}}, 24^{\mathrm{v}}, 49^{\mathrm{v}}$, $67^{r}$. Die beiden letzten sowie die viertletzte Zeile auf $65^{r}$ teilweise radiert, im Spiegel hinten die fünf letzten. Nachträge von verschiedenen Händen des 13. bis 15. Jhs.: Am unteren Rand von $33^{\mathrm{r}}$ eine kurze Melodie in Quadratnotation, abgewaschen; zwei Sequenzen: 42v-43r Alleluia. Gaude celestis curia, Afra ovis perdita ad veri pastoris redit ovilia und $51^{\mathrm{v}}-52^{\mathrm{r}}$ Alleluia. Turme virginee venerantibus annua festa Assint celicole solantes pectora mesta, von einer Hand des 13./14. Jhs., auf 52r eine weitere Zeile abgewaschen; 47v und 49r zwei Tropen zum missa est, von einer Hand des 14. Jhs.: Ite plebs fidelis ... Ite deo laus hodie ... TroxLER, Liturgisches, S. 121; 57v >De sancta Afra<. Alleluia. Gaudete Syon filie Pastor reduxit hodie Ovem centesimam In deserto perditam, 14. Jh.; 58 $-59^{\mathrm{r}}$ Kyrie fons bonitatis ... AH 47 Nr. 5 (1a, 2a [1-2: Christe genite Summi patris unice], 3c [4-5: te laudare possimus omnes]), zweistimmig, 14. Jh.; 59v-60v Cunctipotens genitor ... AH 47 Nr. 4 (1a, 2a, 3a), zweistimmig, diastematische Neumen im Fünfliniensystem, 14. Jh., GeERIng, Organa, S. 85 Nr. 2. Auf dem Spiegel hinten ein nicht mehr lesbarer Nachtrag, der in den Antiquitates Beronenses, S. 747, mit «... dns. Parochus. acta sunt $\mathrm{a}^{\circ}$ MM.CC.LVIIII.» wiedergegeben wird, Jahreszahl nachgezeichnet. Längere Nachträge auf 58 $8^{\mathrm{r}-\mathrm{v}}, 70^{\mathrm{v}}$ und den Spiegelblättern aus der Zeit bald nach Entstehung der Handschrift sowie auf 32v, 14. Jh., siehe Inhalt.

Einband: Holzdeckel, Rücken aus hellem Leder, oben und unten mit Darmsaiten (?) an die Bünde genäht, deren Enden in die Deckel eingepflockt wurden, 14./15. Jh. Buchblock in der Breite leicht überstehend. Vorne und hinten jeweils eine hochrechteckige Elfenbeinplatte, umrahmt von vier Elfenbeinleisten mit Blättermuster, die obere und untere Leiste der Vorderseite beschädigt, $24 \times 13,5$ (vorne) bzw. $13 \mathrm{~cm}$ (hinten). Vorne Petrus, hinten Paulus, beide barfuss in langer Tunica und Mantel unter einem niedrigen Rundbogen stehend, in der Linken ein Buch, die Rechte erhoben. Vordere Platte links entlang der Kontur des Heiligen gerissen, sechs paarweise angeordnete Löcher an den Kanten der beiden Teile sind Spuren einer ehemaligen Reparatur. Im selben Bereich der hinteren Platte von oben ausgehend ebenfalls ein Riss. Befestigung mit Eisenstiften und Garn, mehrere Löcher und Elfenbeinstifte von einer früheren Befestigung. Die Darstellung wird von Volbach (Frühmittelalterliche Elfenbeinarbeiten, S. 105f.) in das 8./9. Jh. datiert. Am oberen Rand des 
hinteren Deckels zweizeilige Aufschrift, 14./15. Jh., nicht vollständig lesbar: [...] off[icia h] orarum dierumque festivorum not [...]. Spiegelblätter Pergament (siehe Lagen); im vorderen Deckel unter dem Spiegelblatt Exlibris des Chorherrenstifts Beromünster (Wegmann, Exlibris, Nr. 619).

Herkunft: Möglicherweise für das Stift Beromünster selbst geschrieben, da die Dedicatio ecclesiae im Proprium de sanctis unmittelbar auf Michaelis folgt. Zu der These, die Elfenbeinplatten des Einbands hätten ehemals zu dem Epistolar II C 3 gehört, siehe Einleitung, S. $16 f$.

Besitzer: In den Antiquitates Beronenses, S. 747, als Nr. III verzeichnet. Im vorderen Spiegel Exlibris des Chorherrenstifts Beromünster, darauf handschriftlich 1891. II. C. 2.

Literatur: Estermann, Stiftsschule, S. 19f.; Estermann, Sehenswürdigkeiten, S. 30f. (Nr. 3) und 58f.; Johann Rudolf RAHN, Geschichte der bildenden Künste in der Schweiz von den ältesten Zeiten bis zum Schlusse des Mittelalters, Zürich 1876, S. 114f. (mit Fig. 15 auf S. 115, einem Holzschnitt nach einer Originalzeichnung, ZB Zürich, Graphische Sammlung, Rahn I, 84: http://doi.org/10.7891/e-manuscripta-24811); Kopp, Stiftsbibliothek, II, S. 5-7; Joseph TroxLER, Liturgisches aus Beromünster, in: Zeitschrift für schweizerische Kirchengeschichte 14 (1920), S. 112-123; Arnold GeERING, Die Organa und mehrstimmigen Conductus in den Handschriften des deutschen Sprachgebietes vom 13. bis 16. Jahrhundert, Bern 1952, S. 7 Nr. 11, S. 85 und 88f.; Fritz W. Volbach, Frühmittelalterliche Elfenbeinarbeiten in der Schweiz, in: Frühmittelalterliche Kunst in den Alpenländern. Akten zum III. Int. Kongress für Frühmittelalterforschung, Olten/Lausanne 1954, S. 105f., Abb. 51f.; ReINLE, KDM Luzern 4, S. 77f. mit Abb. 66; Manuscripts of polyphonic music. 11th - early 14th century, hrsg. v. Gilbert Reaney, München 1966, S. 50f.; BRUCKNer, Scriptoria 9, S. 20 f. sowie Taf. 34 und 44; Adolf Reinle, Die Kunst der Innerschweiz von 1200 bis 1450. Ein Überblick, in: Innerschweiz und frühe Eidgenossenschaft. Bd. 1: Verfassung. Kirche, Kunst, Olten 1990, S. 351. Die Hs. ist seit dem 21.12.2009 online, mit Beschreibung von Marina BERNASCONi Reusser: http://www.e-codices.ch/ $\mathrm{de} /$ description/sbb/cant.

Spiegelblatt: Nachtrag. Et dixit ad Ihesum, Celi et terre conditorem ... Fortsetzung des tropierten Evangeliums von $70^{v}$, TroxLER, Liturgisches, S. $117 \mathrm{f}$.

$1^{\mathrm{r}}-31^{\mathrm{v}}$ Proprium de tempore. 1 . Advent -24 . Sonntag nach Trinitas. Ad te levavi animam meam ... - ... $>$ Communio<. Amen dico vobis quicquid. $2^{\mathrm{r}}$ Weihnachten. $5^{\mathrm{v}}$ Quadragesima, Cantus ID g00678, $7^{\mathrm{r}}$ Cantus ID g02166, 7v Cantus ID g00747, $8^{\mathrm{v}}$ Cantus ID g00803. 9r Palmsonntag mit Prozession, Cantus ID 001852a und 001976, 9v Cantus ID 001983, 10 ${ }^{\mathrm{r}}$ Cantus ID 001437, $10^{\mathrm{r}} \mathrm{AH} 50 \mathrm{Nr} .117,1-12,11^{\mathrm{r}}$ Cantus ID g00847, $11^{\mathrm{v}}$ Cantus ID g00848. 12 $2^{\mathrm{r}}$ Karfreitag mit Prozession, 12 ${ }^{\mathrm{v}}$ Cantus ID 008451-008453. 13 ${ }^{\mathrm{v}}$ Ostern mit Prozession, AH 50 Nr. 30 (1-5 [4,1: lichnis, 4,2: lignis acfacibus condita poscimus] und 9 [9,3: quam tribuat, 9,4: luce]), 14 AH 50 Nr. 183 (1f., 4 [4,2: consonentque], 3 [3,1: O Iohannes, 3,2: precamine], 5f. [5,4: iuvamine], 8, 7, 9f.), 15v Cantus ID a01500, 16r AH 50, Nr. 69 (39f., 31f., 1f., 37f., 33-36 und 47f.). $21^{\mathrm{v}}$ Pfingsten. $23^{\mathrm{r}}$ Trinitas. $29^{\mathrm{r}}$ wurde der 17. Sonntag nach Trinitatis falsch als $x v i[$ bis] gezählt, danach alle Zahlen um eins verschoben.

$31^{\mathrm{v}}-32^{\mathrm{r}}$ Versus alleluiatici. $>$ Dominicalia $<$. Aevia. Confitemini domino ... - ... > Versus $<$. Qui posuit fines tuos pacem et adipe frumenti satiat te.

$32^{v}$ Nachtrag. Sanctus und Benedictus, Quadratnotation im Vierliniensystem. GeERING, Organa, S. 88f. Nr. 5. $33^{\mathrm{r}}-53^{\mathrm{r}}$ Proprium de sanctis. Andreas - Katharina. $>$ Andree apostoli<. Michi autem nimis honor ... - ... $>$ Communio< Diffusa est gratia. 36v Purificatio BMV mit Prozession, Cantus ID g00068 und g00069. 40v Inventio crucis (Rubrik: exaltatio crucis). 42v Afra. 44v Nativitas BMV mit AH 47 Nr. 1005 und neumiertem 
Evangelium. 46v Exaltatio crucis. 47v Michael. 48v Dedicatio ecclesie mit AH 55 Nr. 337 (1-4), AH 47 Nr. 4 , AH 49 Nr. 398, (1-13, 15 [15,3: Neque luctus neque clamor], 14 [14,2: gloriantes, 14,3: canunt deo, 14,6: neque dolor erit ultra gaudia permanent sempiterna, que prima abierunt], 16-18 [18,5: renovatur ecclesia]), AH 49 Nr. 454 (2a: regat, 2b: dele, 4: seculis iustorum) und Sequenz Patris ac nati bonitas (vgl. St. Gallen, Stiftsbibliothek, Cod. Sang. 359, S. 13f.).

$53^{v}-60^{r}$ Commune sanctorum. $>$ De Evangelistis<. Aevia. Dorsa eorum plena sunt oculis ... - ... Aevia. Omnis gloria eius flie regis ab intus in fimbris aureis. Versus alleluiatici: $53^{\mathrm{v}}$ Evangelisten, Apostel, $54^{\mathrm{r}}$ Märtyrer, 55 Bekenner, $57^{\mathrm{r}}$ Jungfrauen. 59r $>$ Tractus iste canitur in quadragesima de apostolis $<$. Qui seminat in lacrimis ... Tractus für Apostel, Märtyrer und Jungfrauen, deren Gedenktag in die Fastenzeit fällt. 58 ${ }^{\mathrm{r}-\mathrm{v}}$ zwischen die beiden Teilen eingeschobener Nachtrag: Venite exultemus ... Cantus ID 909030.

60r-70v Tropar. Firmator sancte firmamenti ... AH 47 Nr. 92 (3a: iustorum), 60v >Ve [r] sus super Kyrie<. Cunctipotens genitor ... AH 47 Nr. 4. 61 ${ }^{\mathrm{r}}>$ Cantus angelicus<. Gloria ... Tropen zu Gloria und Kyrie: 61 ${ }^{\mathrm{v}}$ AH 47 Nr. 94, 63 ${ }^{\text {r AH }} 47$ Nr. 98 (1a-c, 2a, c: Virgo mater esse meruisti, 3a: te collaudantes, b, c: tibifaventes). $64^{\mathrm{r}}>$ In summisfestis $<$. Kyrie ... $64^{\mathrm{v}}$ AH $47 \mathrm{Nr}$. 29 (2a,2: canentes, 2a,3: in evum, 3c,3: addito, 3c, 6: sonora), 65 AH 20 Nr. 51 (2,6: natura perterit, 3,6: invicibilem). 66 $6^{\mathrm{r}}>$ Conductus $<$. Conditor alme syderum ... AH 20 Nr. 2 (1,6: vita salus, 2,9: procedenti de, 3,1: redemptos, 3,3: ne serviamus, 3,6: ut ne), 66v AH 20 Nr. 55 (1, 3 [3,5: unitur, 3,6: nascitur], 2 [2,2: est dei miseratio]), 66v AH 20 Nr. 52 (1), 67v AH 47 Nr. 290 (2,1: per quem, 2,2: mira gratia, 3,1: in quo, 3,2: sapientia, 3,3: excedit). $67^{\mathrm{r}}>$ Super sanctus $<$. Sanctus ... $68^{\mathrm{r}}>$ Item versus $<$. Agnus dei ... AH 47 Nr. 401, 68v Troxler, Liturgisches, S. 120, 69r AH 47 Nr. 459 (1,2:produxit, 2,3: sumitur, 3,3: sumite), 69 $\mathrm{r}$ AH $47 \mathrm{Nr} .464$ (3,2: nobis hic). 69v > Isti versus cantantur super Libera me domine de defunctis in processione<. Libera me ... AH 49 Nr. 784, S. 387: Qui ambulabat iacet (mit vielen Variationen), $70^{r}$ AH 49 Nr. 779 (mit Variationen in Strophe 5, 7b: fac te Christe, 8,3 fehlt).

70v Nachtrag. Tropiertes Evangelium zu Kirchweih. In illo tempore ingressus Ihesus Dominus deus Sabaoth ... fortgesetzt auf dem Spiegel hinten, dort am Rand: Cetera invenis in io folio, Ende der Lesung auf dem Spiegel vorne. TROXLER, Liturgisches, S. $117 \mathrm{f}$.

Pergament, 129 Blätter, $23,5 \times 16,5-17 \mathrm{~cm}$

Reichenau (?), erstes Viertel des 11. Jahrhunderts

Lagen, Foliierung: Lagen: 15 IV $^{120}+(\mathrm{IV}+1)^{129}$, Bl. 129 Einzelblatt, mit einem angeklebten Pergamentsteg um die Lage gebunden. Neuere Foliierung: 1-129.

Einrichtung und Ausstattung: Blindliniierung, Schriftraum 13,5-14 × 10, zusätzlich auf beiden Seiten eine schmale Spalte für die Initialen, 13 Zeilen. Karolingische Minuskel von einer Hand. Überschriften in roter Capitalis rustica (Text am Rand mit dem Griffel vorgeschrieben), erste Textzeile in Unziale; 1-3zeilige rote Lombarden. 2 ${ }^{\mathrm{r}}$ (Anfangsseite), 36 ${ }^{\mathrm{v}}$ (Karsamstag), 37r (Ostersonntag), 52 ${ }^{\mathrm{v}}$ (Auffahrt), 56r (Pfingsten) 3-5zeilige goldene Spaltleisteninitialen mit Ranken, Spaltfüllungen rot, Flächenfüllung blau und grün; dort zusätzlich zweite Textzeile in Capitalis rustica; $2^{\mathrm{r}}$ zuerst zwei Zeilen Capitalis, die erste und der erste Buchstabe der zweiten in Gold, die zweite in Schwarz mit goldener Flächenfüllung. 
Korrekturen und Nachträge: Korrekturen von der Hand des Schreibers auf Rasur, z. B. 7v, 49v, 90 r, 129v. $1^{\mathrm{r}}$ Nachtrag von der Hand des Johannes Dörflinger, siehe Inhalt (vgl. II C 1, A r).

Einband: Holzdeckel, Leder des Bezugs vorne kupferglänzend lackiert, darin eingelegt eine 23,5 $\times 17 \mathrm{~cm}$ grosse, aus 27 Einzelelementen zusammengesetzte Elfenbeinplatte, mit kleinen Eisenstiften auf der blau gefärbten Unterlage fixiert: Rahmen aus einer durchbrochenen Blätterranke, darin drei von Masswerk getrennte Zeilen mit jeweils drei Halbfiguren in Relief; im Zentrum Jesus, umgeben von einem vollplastisch gearbeiteten Kranz, daneben auf ihn weisend Petrus (von rechts) und Paulus (von links); oben Jesaja, Gregor der Grosse und Ezechiel, unten Jeremia, Daniel und Hieronymus (linker Arm z. T. abgebrochen), alle sechs mit Namensinschrift. Die Elfenbeinarbeit wird von ReINLE in das späte 13. Jh. datiert (KDM Luzern 4, S. 80). Zu der These, dass zu dem Epistolar ursprünglich die heute auf dem Einband des Cantatoriums angebrachten Elfenbeinplatten gehörten, siehe Einleitung, S. 15-17. Hinten mit hellem Leder bezogener Holzdeckel, 16. Jh., mit Rollen- und Einzelstempeln, Kanten an der Längsseite zu beiden Seiten der Schliesse, an den Schmalseiten im mittleren Bereich abgeschrägt, eine nach vorn greifende Kantenschliesse aus Messing mit den Buchstaben BMB, Raste auf der Innenseite des Vorderdeckels angebracht. Lederbezug des hinteren Deckels ehemals über den Rücken gespannt und unter dem Vorderdeckel fixiert, heute vorne lose. Darunter ehemals vier Pergamentstreifen (Fragmente). Kapitale mit rotem und gelbem Seidengarn umstochen, nur oben erhalten, Schnitt blau gefärbt. Spiegelblätter Papier, Wasserzeichen hinten Bär, ähnlich PICCARD, Wasserzeichenkartei Nr. 84601 (1568), darunter Abklatsch eines früheren Spiegelblattes aus Pergament (Ez 24,1), 13. Jh. Im vorderen Spiegel Exlibris des Chorherrenstifts Beromünster (Wegmann, Exlibris, Nr. 619). Auf dem hinteren Deckel Papiermarke mit Beschriftung No. 25579.3 in blauem Mäanderrahmen.

Herkunft: Hoffmann (Buchkunst, S. 312-314) identifizierte den Schreiber mit demjenigen von Basel, Universitätsbibliothek, B II 5, Teil IIIA (Bl. 126-141) und von London, British Library, Arundel 390. Er datierte die Hs. auf das erste Viertel des 11. Jahrhunderts und wies sie dem Scriptorium des Klosters Reichenau zu. Zur Identifizierung mit einem angeblich von Graf Ulrich von Lenzburg gestifteten Epistolar siehe Einleitung.

Besitzer: In den Antiquitates Beronenses, S. 683, als Nr. 1 und S. 745-747 als Nr. II verzeichnet. Im vorderen Spiegel Exlibris des Chorherrenstifts Beromünster, darauf handschriftlich 1891. II. C. 3.

Literatur: [Beat Fidel ZurLauben], Tables généalogiques des augustes maisons d'Autriche et de Lorraine, Paris 1770, S. 40-42; Estermann, Stiftsschule, S. 20-22; Johann Rudolf Rahn, Geschichte der bildenden Künste in der Schweiz von den ältesten Zeiten bis zum Schlusse des Mittelalters, Zürich 1876, S. 276 (fälschlich als Evangeliarium bezeichnet); Estermann, Sehenswürdigkeiten, S. 31f. (Nr. 4) und 59; Kopp, Stiftsbibliothek, II, S. 3f.; ReInLE, KDM Luzern 4, S. 79f. mit Abb. 67; BRUCKNER, Scriptoria 9, S. 11-13 mit Taf. I und XLIV; Hartmut Hoffmann, Buchkunst und Königtum im ottonischen und frühsalischen Reich, Stuttgart 1986, S. 312-314; Corpus Inscriptionum Medii aevi Helvetiae. Bd. 4, bearb. von Wilfried KeTTLER, Philipp Kalbermatter, Freiburg 1997, S. 138f., Nr. 48, Taf. 27 Fig. 122. Die Hs. ist seit dem 21.12. 2009 online, mit Beschreibung von Marina Bernasconi Reusser: http://www.e-codices.ch/de/description/sbb/epist.

$1^{\mathrm{r}}$ Nachtrag, vier Hexameter: Hunc librum Pauli doctoris denique summi Scripturis totum simul auro eboreque paratum Marchio Uddalricus tibi, Criste, sanxit in usum, Qui post hanc vitam mereatur habere quietem. $1^{\mathrm{v}}$ leer.

$2^{\mathrm{r}}-113^{\mathrm{v}}$ Proprium de tempore et de sanctis. Weihnachtsvigil - Thomas. $>$ Fratres, Paulus servus Christi Ihesu vocatus apostolus $<$ segregatus in evangelium dei $(\mathrm{Rm} 1,1) \ldots 2^{\mathrm{v}}>$ Lectio Esaiae prophetae $<$. $>$ Haec dicit dominus $<$. 
Propter Syon non tacebo (Is 62,1) ... - .... >In nat [ali] s. Thomae apostoli<. Benedictio domini super caput iusti (Prv 10,6), require in vigilia $S$. Adree apostoli. $5^{\mathrm{v}}$ Weihnachten, $29^{\mathrm{r}}$ Quadragesima, 37r Ostersonntag, 52v Auffahrt, 55v Pfingsten, 108 $\mathrm{v}$ erster Advent, $113^{\mathrm{r}}$ fünfter Advent: >Dominica ante nat [ali] domini ad Philippenses<. Ausser den Marienfesten, den Kreuzfesten und den Festen der Apostel $8^{\mathrm{r}}$ Stephanus, 10 ${ }^{\mathrm{r}}$ Innocentes, $51^{\mathrm{r}}$ Litania maior, 69r Johannes der Täufer, $74^{\mathrm{r}}$ Paulus, $78^{\mathrm{r}}>$ In depositione sancti Benedicti<, $81^{\mathrm{v}}$ Vincula Petri, $>$ Eodem die nat [alitia] vii fratrum Maccabaeorum $<, 85^{\mathrm{r}}$ Laurentius, $97^{\mathrm{r}}$ Michael.

$113^{\mathrm{v}}-125^{\mathrm{v}}$ Commune sanctorum. $>$ In nat [alitiis] omnium apostolorum. Lectio aepistulae beati Pauli apostoli ad Effesios <. Fratres, iam non estis hospites (Eph 2,19) ... - .. 124 12 Lectio libri sapientiae<. 125 $5^{\mathrm{r}}$ Domine deus meus exaltasti (Sir 51,13) ... laudem dicam nomini tuo, domine deus noster. $115^{\mathrm{r}}$ Heilige, 116 $6^{\mathrm{v}}$ Märtyrer, $118^{\mathrm{v}}$ Priester, $121^{\mathrm{r}}$ Märtyrer oder Bekenner, $123^{\mathrm{r}}$ Jungfrauen.

125 $-129^{v}$ In dedicatione ecclesiae. >In dedicatione aecclesiae lectio libri Apocalypsis Iohannis apostoli<. In diebus illis vidi civitatem (Apc 21,2) ... 127 $7^{\mathrm{r}}>$ Item alia in dedicatione aeclesię lectio libri Apocalypsis Iohannis apostoli<. In diebus illis venit angelus (Apc 21,9) ... - ... nisi qui scripti sunt in libro vitae et agni.

\section{5 fol. HOCHDORFER MISSALE}

Pergament, 236 Blätter, 34,5 × 24,5 cm

Beromünster oder Schwarzenbach, 1474-1476

Lagen, Foliierung: Lagen: $(\mathrm{II}-1)^{3}+2 \mathrm{~V}^{23}+(\mathrm{V}-2)^{31}+(\mathrm{V}-1)^{40}+\mathrm{V}^{50}+(\mathrm{V}-\mathrm{III})^{54}+4 \mathrm{~V}^{94}+\mathrm{IV}^{102}+(\mathrm{V}-1)^{111}$ $+5 \mathrm{~V}^{161}+(\mathrm{V}-1)^{170}+5 \mathrm{~V}^{220}+\mathrm{IV}^{228}+(\mathrm{III}-2)^{232}$, vor Bl. 1, 25, 26 und 35 sowie nach Bl. 111 und vor Bl. 163 je ein Blatt, nach B1. 232 zwei Blätter herausgeschnitten, zudem auch die äussere Spalte von Bl. 69; nach B1. 52 fehlen sechs Blätter. Textverlust. Der Buchblock beschnitten, der äussere Rand von Bl. 5, 8, 10, 12, 35-38, 115, 116, 119, 143, 153, 164, 169 und 189 ganz weggeschnitten, ebenso der untere Rand von Bl. 114. Das Pergament vereinzelt mit (vor dem Aufspannen und Trocknen genähten) Schadstellen, der Schriftraum auch bei wenigen grösseren Löchern im Pergament (B1. 45, 54 und 126) angepasst. Reklamanten: 23v , 31v, 40v $50^{v}$, $54^{\mathrm{v}}-94^{\mathrm{v}}, 121^{\mathrm{v}}-180^{\mathrm{v}}, 200^{\mathrm{v}}$, z. T. stark beschnitten, zusätzlich meist auch ein Zeichen (Fadenkreuz) in der Mitte des unteren Randes. Alte Foliierung (Zählung der Doppelseiten) mit Bezug auf die (besonders ab $216^{\mathrm{vb}}$ ) zahlreichen internen Verweise, zuerst $18^{\mathrm{ra}}$ Mirabilis natura, xi (vgl. 15 ${ }^{\mathrm{ra}}$ ) und Ego sum pastor bonus, Cviii (vgl. 93 $\left.3^{\mathrm{ra}}\right)$, in Rot: $i\left(4^{\mathrm{v}}\right)-x x i\left(24^{\mathrm{v}}\right) \cdot x x i i i\left(25^{\mathrm{v}}\right) \cdot x x v(26 \mathrm{v})-x x x i i i\left(34^{\mathrm{v}}\right) \cdot x x x v\left(35^{\mathrm{v}}\right)-\operatorname{lii}\left(52^{\mathrm{v}}\right) \cdot \operatorname{lix}\left(53^{\mathrm{v}}\right)-$ lxxvi (70v). lxxvi (71'v). lxxviii $\left(72^{\mathrm{v}}\right)-C x\left(94^{\mathrm{v}}\right) . C x x i\left(95^{\mathrm{v}}\right)-C x x v i i i\left(128^{\mathrm{v}}\right) . C x x x i\left(112^{\mathrm{v}}\right)-C x x x v i i\left(118^{\mathrm{v}}\right)$. Cxxxvii (119v). Cxxxix $\left(120^{\mathrm{v}}\right)-C l x x x i\left(162^{\mathrm{v}}\right) \cdot C l x x x i i i\left(163^{\mathrm{v}}\right)-C C x v i i(197 \mathrm{v}) \cdot a\left(198^{\mathrm{v}}\right)-r\left(214^{\mathrm{v}}\right) \cdot C C x x x v$ $\left(215^{\mathrm{v}}\right)-\operatorname{CCxl}\left(220^{\mathrm{v}}\right)$. Neuere Foliierung: A, B. 1-232. C, D.

Einrichtung und Ausstattung: Tintenliniierung, Schriftraum $25 \times 16$, zweispaltig (7-7,5), 32 Zeilen, Bl. 107-109 21, Bl. 110 und 11120 Zeilen. Textualis von der Hand des Johannes Dörflinger, 107r $-111^{\mathrm{r}}$ (Canon missae) möglicherweise von einer anderen Hand (andere Formen etwa bei e und a). In der ersten Zeile knapp der Hälfte aller Seiten $\left(6^{\mathrm{v}}-102^{\mathrm{v}}, 112^{\mathrm{r}}-199^{\mathrm{r}}\right)$ grosse schwarze und rote Zierinitialen, z. T. mit Cadellen. Vor allem in den Rubriken wiederholt charakteristische, konzentrisch ornamentale S-Majuskeln, z. B. 13 ${ }^{\text {va, }}$ $15^{\mathrm{vb}}$ (schwarz), 16 ${ }^{\mathrm{rb}-\mathrm{va}}, 17^{\mathrm{rb}}, 18^{\mathrm{r}-\mathrm{b}}, 19^{\mathrm{va}}$ (schwarz) oder $199^{\mathrm{ra}}, 217^{\mathrm{vb}}$ und zuletzt $22^{\mathrm{ra}}$. Rubriziert, rote Überschriften. 1-2zeilige rote, seltener auch blaue Lombarden mit Punktverdickungen und (vereinzelt) 
Konturbegleitstrichen, $103^{\mathrm{ra}}-105^{\mathrm{rb}}$ (Praefationes) auch 3-4zeilig; im Canon missae $\left(107^{\mathrm{r}}-111^{\mathrm{r}}\right)$ einzeilig, zudem rote Kreuze. $4^{\mathrm{ra}}, 14^{\mathrm{ra}}$ und $112^{\mathrm{ra}}$ 8zeillige blaue Initialen mit Punktverdickungen und rotem Fleuronné in rotem Rahmen, mit Blatt- und Fadenranken; 112 $2^{\text {ra }}$ im Binnenfeld ein Stelz- und ein Raubvogel (im Kampf); 83 ra 10zeilig, im Binnenfeld ein Gesicht; 131 va in Rot, im Binnenfeld ein Stelzvogel (ähnlich einem Pelikan, bevor er sich die Brust aufreisst); $221^{\text {va }} 5$ zeilig, in Rot mit rotem Fleuronné, im Binnenfeld ein Gesicht. $107^{\mathrm{r}}$ (Te igitur) 4zeilige blaue Initiale auf rotem Grund von Halbpalmetten und Knospen, in rotblauem Rahmen. 106 Kanonbild, Deckfarbenmalerei in Blau, Rot, Grün, Gelb, Braun, Schwarz und Weiss, in rotem Rahmen mit waag- und senkrecht rhythmisch ausstrahlender Schraffur, wie bei den Initialen.

Korrekturen und Nachträge: Wenige Korrekturen von der Hand des Schreibers, z. B. 30 ${ }^{\text {va }}$ (rot), $32^{\text {ra }}$ (teilw. auf Rasur), 101 va $149^{\mathrm{va}}$, 229 ${ }^{\mathrm{rb}}$, Streichungen: $7^{\mathrm{va}}, 178^{\mathrm{rb}}$; zeitgenössisch: 196 $6^{\mathrm{va}}$; 227 $7^{\mathrm{ra}}$ Rasur, Lücke mit rotem Zeilenfüller. $A^{\mathrm{v}}-\mathrm{B}^{\mathrm{r}}$ Nachträge, 15.-18. Jh.; 78va_82 vb am Rand der Urkunden Marginalien und Nachträge, 15.-17. Jh., $78^{\mathrm{va}}$ mit Datum 1482 (beschnitten), 82 ${ }^{\mathrm{rb}}$ ein Handweiser; 232 ${ }^{\mathrm{rb}}$ Nachtrag, wohl 17. Jh. (vgl. $A^{\mathrm{v}}$ ). $110^{\mathrm{v}}$ ein kleines aufgenähtes Stück Pergament mit Zeichen: roter Ring mit Resten von Vergoldung, darüber vier Punkte (Reichsapfel?).

Einband: Mit hellem Leder bezogene Holzdeckel, 15. Jh. Streicheisenlinien, Einzel- und Rollenstempel (Paris und Helena). Auf dem Vorder- und Rückdeckel je fünf Hutbuckel, an den Ecken und den oberen Kanten zum Schnitt hin Messingbeschläge. Zwei nach vorn greifende Messingschliessen. Gelenke teilweise aufgeplatzt. Am Schwanz braun-weisse Kapitale. Spiegel- und Vorsatzblätter (A, B, C, D) Papier, um die erste bzw. letzte Lage gezogen. Bl. 4, 83, 106 und 218 weisse Ledersignakel, Bl. 14, 29, 101, 105, 107, 108, 109, 112, 199, 215 , 222, 225 und 230 braune Ledersignakel; Spuren auch auf 103, 201, 223 und 224. Im vorderen Spiegel Exlibris des Chorherrenstifts Beromünster (Wegmann, Exlibris, Nr. 619).

Herkunft: Geschrieben von Johannes Dörflinger, vgl. CMD-CH 2, Textband, S. 226, wohl im Auftrag von Johannes Teller, Dekan und Leutpriester der neuerrichteten Kaplanei St. Peter und Paul in Hochdorf (Urkundenabschriften $78^{\mathrm{ra}}-82^{\mathrm{vb}}$ ), der das fertige Buch nicht mehr zu sehen bekam, vgl. im Kalendar $1^{\mathrm{vb}}$ (und entsprechend StiAB 01.01.615, S. 19); zu ihnen siehe BüCHLER, Beromünster, S. 287 (Nr. 71 ) und $387 f$. (Nr. 345). Die Schreibervermerke $131^{\mathrm{rb}}$ und 232 $2^{\text {ra }}$ führen zwei historische Daten an, den 13 . November 1474 und den 21. Juni 1476, die als Termini post quos zu verstehen sind.

Besitzer: Im vorderen Spiegel Exlibris des Chorherrenstifts Beromünster.

Literatur: Melchior Estermann, Drei kleine Notizen zu den Burgunderkriegen aus dem Stiftsarchiv BeroMünster, in: Anzeiger für Schweizerische Geschichte, N. F. 7 (1876), S. 209f.; Estermann, Stiftsschule, S. 138; Estermann, Sehenswürdigkeiten, S. 66-70; Kopp, Stiftsbibliothek, II, S. 8f.; Wolfgang Irtenkauf, Das Missale speciale Constantiense - wieder einmal nach seiner liturgischen Seite untersucht, in: Archiv für Geschichte des Buchwesens 15 (1959), S. 1333-1343, besonders S. 1342 (Nr. 9, Sigle Be 2); BRUCKNER, Scriptoria 9, S. 32f. sowie Taf. 33, 39, 41, 42 und 46; Robert Ludwig Suter, Johannes Dörflinger, der Illuminator des Helias Helye, in: Erster datierter Schweizer Druck, S. 77 (Tabelle 1), 80, 82 und 86; Bü CHLER, Beromünster, S. 141, 174, 235f. (Anm. 15-23) und 287 (über J. Dörflinger); CMD-CH 2, Nr. 85; HugENER, Buchführung, S. 89. Die Hs. ist seit dem 23.9.2014 online: https://e-codices.ch/de/list/one/sbb/C0005-2.

$\mathrm{A}^{\mathrm{r}}$ leer.

$\mathrm{A}^{\mathrm{v}}-\mathrm{B}^{\mathrm{r}}$ Liste der Inhaber der Peter-und-Pauls-Pfründe zu Hochdorf. Fundatores huius beneficii sanctorum apostolorum Petri et Pauli: per me Scolarum Capituli Hochdorfensis una cum Presbyteris hic adscripsimus. 
Reverendus b. Ioannes Teller ... Ego B. Jacobus Felix Luc. Scolaris Capituli Hochd. Anschliessend von verschiedenen Händen fortgesetzt bis 1734.

$\mathrm{B}$ leer.

$1^{\mathrm{ra}}-3^{\mathrm{vb}}$ Kalendar. Sonntagsbuchstaben, Kalenden, Festgrade. Rot hervorgehoben u. a. Revelacio Ursi et sociorum (4. 3.), Pancracii martiris (12. 5.), Uddalrici episcopi (4. 7.), Pelagii (28. 8.), Verene virginis (1. 9.), Ursi et sociorum eius (30. 9.), Undecim milia virginum (21. 10.), Passio ymaginis domini Ihesu in Iericho (9. 11.), Cunradi episcopi (26. 11.). Nachträge, zum 22. Januar (1 1 ra): Obiit Johannes Teller laicus qui eciam fuit fundator huius prebendie (sic) Petri et Pauli sub anno domini $M^{\circ} c c c c^{\circ} l x 9^{\circ}$, zum 20. April ( $\left.1^{\mathrm{vb}}\right)$ : Hac die obiit dominus Johannes Teller canonicus ecclesie Beronensis, dechanus huius capituli fundator huius prebende. Anno 1474.

$4^{\mathrm{ra}}-77^{\mathrm{vb}}$ Proprium de tempore. 1. Sonntag im Advent - Gründonnerstag. >Dominica prima in adventu domini<. Ad te levavi animam meam ... >Versus<. Vias tuas ... > Oracio<. Excita domine quesumus ... $11^{\mathrm{vb}}$ Weihnachten mit AH 53 Nr. 15 und 16 (3, 1: inter nebulosa), 15 va Stephanus mit Nr. 215 (11, 2: elegit), 16 ${ }^{\text {rb }}$ Nativitas Johannis Ev. mit Nr. 168, $17^{\text {ra }}$ Innocentes mit Nr. 157, 19va Epiphanie mit Nr. 29; es folgen die Sonntage bis zur Fastenzeit, sowie Epistel und Evangelium jeweils für Mittwoch und Freitag: $21^{\text {ra }}>$ Dominica $i^{a}$ post epiphania $<. .24^{\mathrm{ra}}>$ Dominica iiia post epiphania $<\ldots 24^{\mathrm{rb}}$ Mulier potestatem sui corporis non habet //. Bricht in der Epistellesung für den Freitag ab, Fortsetzung im Evangelium für Mittwoch in der 4. Woche nach der Epiphanie: 25 $5^{\mathrm{ra}} / /$ immundis spiritibus ... 25 $5^{\mathrm{rb}}>$ Dominica $v^{\mathrm{a}}$ post epiphania $<. .25^{\mathrm{vb}}$ ut quieti sitis //. Bricht in der Epistellesung (I Th 4,9-11) für den Freitag ab, Fortsetzung im Evangelium (Mt 20,15-16) für den Sonntag Exsurge (Septuagesima): 26ra // ego bonus sum ... > Feria iiiia. Ad Hebreos $<\ldots$ 26 $6^{\mathrm{vb}}$ Sexagesima, $28^{\mathrm{vb}}$ Quinquagesima, 29va Aschermittwoch, es folgen ausführlicher die Tage der Fastenzeit: 32va Invocavit (Quadragesima), 34 $4^{\mathrm{va}}>$ Feria iii $^{\circ}<$. Domine refugium ... 34 $4^{\mathrm{vb}}$ Et accesserunt ad eum ceci //. Bricht im Evangelium (Mt 21,10-14) für den Dienstag nach Invocavit ab, Fortsetzung im Evangelium (Mt 12,41-50) für Mittwoch: $35^{\mathrm{ra}} / /$ nabunt eam, quia penitenciam egerunt ... 35 $5^{\mathrm{rb}}>$ Feria Quinta<. Confessio et pulchritudo ... 39 $9^{\mathrm{ra}}$ Reminiscere, $46^{\mathrm{rb}}$ Oculi, $52^{\mathrm{va}}>$ Sabbato<. Verba mea ... 52 $2^{\mathrm{vb}}$ Et videbant eam senes cottidie ingredientem et ambulantem //. Bricht in der alttestamentlichen Lesung (Dn 13,1-8) für den Samstag nach Oculi ab, es fehlt der grössere Teil der vierten Fastenwoche, Fortsetzung im Evangelium (Io 9,25-38) für Mittwoch nach Letare: $53^{\mathrm{ra}} / /$ ergo ille: Si peccator est ... 53 $3^{\mathrm{rb}}>$ Feria $v<$. Letetur cor ... 57 $7^{\mathrm{ra}}$ Passionssonntag, $63^{\mathrm{rb}}$ Palmsonntag ... 69ra testimonium ergo per//. Es fehlen zwei Spalten im Evangelium für den Montag der Karwoche (Io 12,17-35), Fortsetzung $69^{\mathrm{vb}} / /$ ut non tenebre ... $73^{\mathrm{vb}}$ Gründonnerstag, $77^{\mathrm{ra}}>$ Oracio $<$. Concede quesumus o domine ut qui festa paschalia aguntur ... > Deinde fit benedictio fontis. Qua finita legitur trina letania. Qua finita cantor imponit ad missam <. Kyrieleyson ... - ... > Missa terminatur cum< Benedicamus domino. Alleluia. Die Blätter xxii, xxiiii, xxxiiii und liii-lviii (alte Foliierung) fehlen, zudem die Hälfte von $l x x v$, vgl. oben (auch Lagen, Foliierung).

$78^{\mathrm{ra}}-82^{\mathrm{vb}}$ Diplomata ecclesiae in Hochdorf. Urkundenabschriften betreffend die Errichtung der Kaplanei St. Peter und Paul in Hochdorf. Nicolaus de Gundelfingen decretorum doctor ... honorabili viro domino Iohanni Teller dechano in Hochdorff... Sane cum tu ... Beromünster, 21. Mai 1457. 78va Ich Hans Üli von Arburg weibel ze der stiffte münster in ergow ... 2. Juni 1457. 80vb Vicarius reverendi in Christo patris et domini domini Hermanni ... Konstanz, 24. Mai 1469. 81 rb In nomine domini Amen. Anno a nativitate eiusdem Millesimo quadringentesimo sexagesimo nono ... - ... rogatus et requisitus. 26. Sept. 1469, darin festgehalten auch die Stiftung eines (dieses?) Missale. Estermann, Sehenswürdigkeiten, S. 68 (Regesten der vier Urkunden); Ders., Geschichte der alten Pfarrei Hochdorf, Luzern 1891, S. 101-110 (Geschichte der Peter und Paulspfründe). 
$83^{\mathrm{ra}}-102^{\mathrm{vb}}$ Proprium de tempore. Ostern - Corpus Christi. Resurrexi et adbuc tecum sum ... mit AH 53 Nr. 36, AH 50 Nr. 240 (2a, 1: Crucis virtutum, 2b, 1: Cum, 2b, 4: pandis, 3b, 1: hominis, 3b, 4: Hic dies), AH 53 Nr. 56 (4,1: Quo devicit), AH 54 Nr. 230 (2, 2: seram, 4, 2: Magdalenam consumebat, dann 5-8 und 11-14 entspr. S. 366 sowie Nr. 7, 6-7), Nr. 7 und 148 (1-3, S. 226: Ignis volat ... 4, 3: Spirat aura levius, 5, 1 und 2 umgestellt, 6, 4: Imperium in nobis, 7 [Versfolge: 5-6, Ut deus preceperat, 7, 1-4]), 90 ${ }^{\mathrm{rb}}>$ Dominica $i^{\mathrm{a}}$ post pasca<. Quasi modo ... 91 $1^{\mathrm{va}}$ Freitag, $91^{\mathrm{vb}}>$ Hac feria via posset celebrari festum clavorum et lancee domini<. Foderunt manus meas ... AH $54 \mathrm{Nr}$. 140, $92^{\mathrm{vb}}>$ Dominica $i i^{a}<$. Miseria domini plena est terra ... $94^{\mathrm{rb}}>$ Dominica $i_{i i}{ }^{<}<$. Iubilate deo ... 94 $4^{\mathrm{vb}}>$ Completorium <. Modicum et //. Anschliessend fehlen zehn Blätter, 4. bis 6. Woche nach Ostern und Pfingsten. 95 $5^{\text {ra } / / ~ s e n s i b u s . ~ T u ~ p u r i f i c a t o r ~ . . . ~ 95 ~}{ }^{\text {va }}$ Pfingstmontag mit AH 54 Nr. 153 (7, 3 und 8, 3 umgestellt), 101 ${ }^{\mathrm{rb}}$ Trinitas mit AH $53 \mathrm{Nr}$. 81 (1, 4: unitas, 8, 2: deus honor, 15: $O$ adoranda trinitas, 16: $O$ veneranda unitas), 101 ${ }^{\mathrm{vb}}$ Corpus Christi mit $\mathrm{AH} 50 \mathrm{Nr} .385$ (1b, 1: tantum gaude, 3b, 3: pasca vetus terminat, 5b, 1: sapis, 6a, 2: signis tamen) und AH 54 Nr. 169 (8, 1: Ut carnales) ... > Completorium <. Fac nos ... prefigurat, qui cum //. Bricht ab. Die Blätter $C x i-C x x$ sowie $C x x i x$ und $C x x x$ (alte Foliierung) fehlen.

$103^{\text {ra }}-105^{\text {va }}$ Praefationes, ordinarium missae. $>$ In Nativitate domini prefacio $<$. O eterne deus ... Praefationes zu Weihnachten, Epiphanie, 103 ${ }^{\text {rb }}$ Quadragesima, Ostern, 103 va Auffahrt, 103 ${ }^{\text {vb }}$ Pfingsten, 104 ${ }^{\text {ra }}$ Trinitas, $>$ In Cena domini, sive De sancta cruce prefacio $<$, jeweils mit einem zweiten Abschnitt $>$ Infra actionem $<$; $104^{\mathrm{rb}}$ BMV, 104 $4^{\mathrm{va}}$ Apostel, >Cottidiana prefacio<. Per omnia secula seculorum, Amen. Dominus vobiscum ... 104 ${ }^{\mathrm{vb}}$ Sanctus ... Benedictus ... > De beata virgine $<$. Benedictus ... $>$ Cottidianum $<$. Gloria ... $105^{\text {ra }}>$ De beata virgine $<$. Gloria ... 105 ${ }^{\mathrm{rb}}$ Credo ...

$105^{\mathrm{vb}}$ leer.

$106^{\mathrm{r}}$ leer.

$106^{\mathrm{v}}$ Kanonbild.

$107^{\mathrm{r}}-111^{\mathrm{r}}$ Canon missae. Te igitur ...

$111^{\mathrm{v}}$ leer.

$112^{\mathrm{r}}-131^{\mathrm{rb}}$ Proprium de tempore. Sonntage nach Trinitas. Domine in tua misericorda speravi $\ldots 112^{\mathrm{ra}}>A \mathrm{~b}$ hinc usque ad adventum domini, singulis dominicis diebus dicitur prefacio de Trinitate quando agitur de tempore. Completorium <. Narrabo omnia mirabilia tua ... > Dominica secunda<. Factus est dominus protector ... $124 \mathrm{ra}$ $>$ Dominica xviiia $<$. Iustus es ... 124va $>$ Feria iiiia iiiior temporum $<$. Exultate deo ... - ... 131 $1^{\mathrm{ra}}>$ Dominica xxv<. Dicit dominus: Ego cogito ... sacramenti quid sumpsimus medicacione curetur, per. Anschliessend Schreibervermerk, in Rot: Scriptum per manus Iohannis Dorfflinger prebendarii Beronensis Anno domini $M^{\circ}$ $\operatorname{ccc}^{\circ}$ lxxiiiio die quo confederatores commiserunt ante Elegurt ter stragem contra Italicos bellicosam.

$131^{\mathrm{va}}-198^{\mathrm{vb}}$ Proprium de sanctis. Andreas - Konrad. $>$ In vigilia sancti Andree apostoli<. Dominus secus mare Galylee ... > Versus <. Celi enarrant ... > Oracio<. Quesumus omnipotens deus, ut beatus Andreas appostolus tuum pro nobis imploret auxilium ... mit AH 55 Nr. 57, 133 ra Barbara, $133^{\text {rb }}$ Nicolaus mit AH 54 Nr. 66 (1-22; 4, 1: Ad mamillas, 20, 3: ubi pax et gaudia, 21, 1: Ipsam), 133 vb Octava Andreae mit AH 53 Nr. 122 (6, 1: Istum), 134 $\mathrm{rb}^{\mathrm{rb}}$ Conceptio BMV mit AH $54 \mathrm{Nr} 188$ (1, 1: Concepcio, 4, 2: surgens egreditur), 134 ${ }^{\mathrm{vb}}$ Lucia, 135 $5^{\mathrm{ra}}$ Ottilia, Jodocus, 135 $5^{\mathrm{rb}}$ Thomas, $135^{\mathrm{vb}}>$ Erhardi episcopi<. Sacerdotes tui ... 136 $6^{\mathrm{ra}}>$ Pauli primi heremite sicut oracio Egidii (cf. 179va). Hylarii episcopi<. Sacerdotes dei ... 136 $6^{\mathrm{rb}}$ Felix in pincis, 136 va Marcellus, 137 ${ }^{\mathrm{ra}}$ Antonius, 137 rb Prisca, 138 ra Agnes mit AH 55 Nr. 51 (7, 3: Splendore lucis cooperta, 11, 3-4: Eius floris et pudoris, non ferens pudenciam, 12, 4: clemenciam), 138 va Vincentius, 138vb Timotheus, 139 ${ }^{\mathrm{ra}}$ Conversio Pauli mit AH 50 Nr. 269 (7a, 1-2: Hic lingua sacerdotum, more canum perlinxit, 7b, 1: Collegit universas, 8a und 8b umgestellt), 
$140^{\mathrm{va}}$ Johannes Chrysostomus, $141^{\mathrm{ra}}$ Octava Agnetis, $141^{\mathrm{rb}}>$ Kalendas Februarii. Natalis S. Ignacii episcopi et martiris. Ad missam. Officium S. Pollicarpii ultra per totum. Eodem die Brigide virginis. Oracio<. Deus qui ad declarandam virginitatis integritatem ... 141 va Purificatio BMV mit AH 53 Nr. 99 (1, 4: colit laudibus, nach Str. 2: Sanctissima corpore ... S. 173), 142 va Blasius, $143^{\text {ra }}$ Agathe, $143^{\text {vb }}$ Dorothea, $143^{\text {va }}$ Apollonia, 143 vb Scholastica, 144 Valentin, 144 $4^{\mathrm{va}}>$ Iste Valentinus presbiter fuit, Rome sub Claudio cesare fustibus cesus et decollatus. Alius est Valentinus Interamnane urbis eppiscopus qui eodem die virgis cesus post diuturnam cedem custodie mancipatus, tandem decollatur. Ad cuius missam poteris cantare officium Pollicarpi. Et sic facit chorus noster Beronensis. Item Iuliane virginis et martiris <. Me expectaverunt peccatores ... $144^{\mathrm{vb}}$ Kathedra Petri, $145^{\mathrm{rb}}$ Matthias, 146 ${ }^{\text {ra }}$ Revelatio Ursi (vgl. Estermann, Sehenswürdigkeiten, S. 69), $146^{\text {rb }}$ Fridolin, $146^{\text {va }}$ Gregor, 146 $6^{\mathrm{vb}}$ Benedikt, 147 $7^{\mathrm{rb}}$ Annuntiatio BMV, 147va Ambrosius, 147vb Tiburtius und Valerianus, $148^{\mathrm{ra}}$ Georg, Marcus, 148 ${ }^{\mathrm{rb}}$ Vital, $148^{\mathrm{va}}$ Philipp und Jacob, $149^{\mathrm{ra}}$ Walpurga, $149^{\mathrm{rb}}$ Inventio crucis mit AH 54 Nr. 126 (7, 1 : O lux vere luminum), 150 ${ }^{\text {ra }}$ Corona domini mit AH 54 Nr. 135 (1, 3: laudent salvatorem, 3, 1: Cuius), 151 ra Johannes ante portam Latinam, 151 ${ }^{\text {rb }}$ Revelatio Michaelis, 152 ${ }^{\text {ra }}$ Gordian und Epimach, 152 $2^{\text {rb }}$ Pancratius, $152^{\text {va }}$ Gangolf, $152^{\text {vb }}$ Potentiana, Urban, $153^{\text {ra }}$ Petronilla, $153^{\text {rb }}$ Nicomedes, $153^{\text {va }}$ Marcellinus und Petrus,

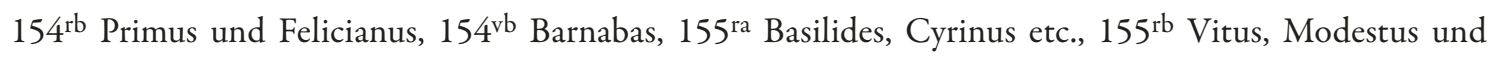
Crescentia, 155 ${ }^{\text {va }}$ Onofrius, 156ra Marcus und Marcellianus, 156rb Gervasius und Protasius, 156 ${ }^{\text {va }}$ Albanus, 156rb Decem milia martyres, 157rb Johannes Bapt. mit AH 55 Nr. 168 (2, 1: Cuius, 3, 2-3 und 4, 2-3 umgestellt, 5,1-6,1: Trinitatis mysterium primus hic sensit hominum salvatoris hic angelus, Heremi hic angelus cultor nobilis), 159 Johannes und Paul, 159 $9^{\text {rb }}$ Peter und Paul mit AH 53 Nr. 210 (8, 1: Doctilogos philosophos), 161 ${ }^{\text {ra }}$ Commemoratio Pauli mit AH 55 Nr. 281 (2, 1: ligno crucis, 10,2: Eius sancta prece), 161 ${ }^{\text {vb }}$ Octava Johannis Bapt. mit AH 53 Nr. 163, 162 $2^{\text {ra }}$ Visitatio BMV mit AH 54 Nr. 193, 162 vb $>$ Eodem die Processi et Martiniani. Oracio<. Deus qui ... > Completorium<. Corporis sacri et preciosi sanguinis repleti libamine quesumus domine noster, ut quod //. Bricht ab, nach Bl. 162 fehlt ein Blatt (Udalricus, Octava apostolorum?). 163ra // [Clamaverunt iusti, et dominus ex] audivit eos et ex omnibus tribulacionibus eorum liberavit eos ... Septem fratres, 163 ${ }^{\mathrm{va}}$ Kaiser Heinrich, 163 vb Divisio apostolorum mit AH 50 Nr. 267 (3b, 2: «ex muliere» fehlt, 4b, 2-4: ... in multis argumentis ... annuncians, 11a, 2: suscitat terra nostra, 11a, 5: faciat, 12b, 6: unum et in te unum), 164 $\mathrm{va}$ Alexius, 164 $4^{\mathrm{vb}}$ Margarethe, 165 $5^{\mathrm{ra}}$ Arbogast, 165 $5^{\mathrm{va}}$ Praxedis, Maria Magdalena mit AH 50 Nr. 268 (8a, 4: saturatus, 11a, 3: si non venie), 166rb Appollinaris, 167ra Christina, 167rb Jacobus ap., 167va Christophorus, 168 $8^{\mathrm{ra}}$ Anna, 168 $\mathrm{rb}$ Martha mit AH 55 Nr. 246 (6, 1: egreditur, 11, 3: in celis locata), 169 ${ }^{\mathrm{ra}}$ Pantaleon, 169 rb Felix papa, 169va Abdo und Sennes, 170 ${ }^{\text {ra }}$ Vincula Petri, 170 rb Inventio Stephani, 170va Oswald, $171^{\mathrm{ra}}$ Sixtus, $171^{\mathrm{rb}}>$ Hec dicenda est benedictio uvarum infra actionem post hunc locum $<$. Intra quorum nos consorcium ... > Benedictio uve<. Benedic domine et hos fructus novos ... vgl. Franz, Benediktionen, Bd. 1, S. 372f.; 171 va Afra mit AH 53 Nr. 119 (7, 2: Christi, 10, 3: degustando, 17, 2: sacramentorum suorum, 26: Zacheus dans dimidium bonorum, fraudem redemit in quadruplum, 27, 5: Christi martir), 172rb Cyriacus, $172^{\text {va }}$ Laurentius, $>$ Et masculinum pro feminino legitur, ut sic $<$ : Et in medio ignis non sum estuatus. $>$ Et subsequenter<: Memoratus sum ... mit AH 53 Nr. 173, 173 va Tiburtius, $173^{\text {vb }}$ Hippolytus, $174^{\text {ra }}$ Assumptio BMV mit AH 53 Nr. 104, 175 va Theodul, Ocava Laurentii, 175 vb Agapitus, Bernhard, 176 ${ }^{\text {ra }}$ Octava assumptionis, 176 $6^{\mathrm{va}}$ Bartholomaeus, 176 $6^{\mathrm{vb}}$ Pelagius, 177 ${ }^{\mathrm{ra}}>$ Eodem die Augustini episcopi<. In medio ecclesie ... $177^{\mathrm{rb}}>$ Sequencia<. Augens fidem christianam Augustinus sane sanam dat doctrinam et prophanam damnat ydolatriam ... 177vb Decollatio Johannis mit AH 50 Nr. 270 (7a, 2: lucerna lucens, 8a, 2: puella saltat, 10a, 1-3: percepimus, talis ac tantus est, quia vicinus, 12: Herodis quo spreta mensa altaris tui mensa, ipsum dum te 
sumimus semper tibi psallimus), 178 ${ }^{\mathrm{vb}}$ Sabina, 179 ${ }^{\mathrm{ra}}$ Felix und Adauctus, 179 ${ }^{\mathrm{rb}}$ Verena, 179va Aegidius, 179vb Nativitas BMV mit AH 53 Nr. 95, $181^{\text {rb }}$ Gorgonius, Protus und Hyacinthus, Felix und Regula, $181^{\text {va }}$ Exaltatio crucis mit AH 54 Nr. 120 (1-9, 12-13, 10-11, 14-21; 7, 1: Forma crucis), Cornelius et Cyprianus, 182 va Eufemia, 182 vb Matthaeus, 183 va Mauritius mit AH 53 Nr. 186 (5: Contra scelestos herculeus auget prelia), $184^{\mathrm{ra}}$ Cosmas und Damian, 184 $4^{\mathrm{rb}}$ Michael mit AH 53 Nr. 190 (9, 3: nobis ter tripartita, 10, 4: alminoma, 16, 5: demus hinc per liricas cytharas), 185 ${ }^{\mathrm{rb}}$ Hieronymus, $185^{\mathrm{va}}$ Ursus und Victor, $185^{\mathrm{vb}}$ Remigius, $186^{\mathrm{rb}}$ Leodegar, 186 $6^{\text {va }}$ Franciscus, 186 vib Fides, 187 ${ }^{\text {ra }}$ Marcus papa, 187 ${ }^{\text {rb }}$ Dionysius, $187^{\text {va }}$ Gereon, $188^{\text {ra }}$ Fortunata, $188^{\text {rb }}$ Calixtus, $188^{\mathrm{va}}$ Gallus mit AH 53 Nr. 149, 189 ${ }^{\text {ra }}$ Lucas, 189 rb Januarius, 189va Ursula mit AH 55 Nr. 333 (1, 2-3: Ihesu Christo qui connexus donum sentit gracie, 10, 2-3: sponte transeut virgines, 15, 3: clarum flumen, 16, 2: ad portum, 17, 3: barbarorum acies, 18, 3: cruentarunt facies), 190va Cordula, Severin, 190vb Crispinus und Crispinianus, 191 $1^{\text {ra }}$ Simon und Judas, 191 vb Wolfgang, 192 ${ }^{\text {ra }}$ Allerheiligen mit AH 53 Nr. 112, $193^{\mathrm{va}}$ Leonhard, 194 $4^{\mathrm{ra}}$ Theodorus, 194 ${ }^{\mathrm{rb}}$ Martin mit AH 53 Nr. 181, 194 ${ }^{\mathrm{vb}}$ Brictius, 195 ${ }^{\mathrm{rb}}$ Othmar mit AH 53 Nr. 203, 195 va Elisabeth mit AH 55 Nr. 120 (1, 3: fulgur speculi, 8, 2: demonstratur, 11, 1: fulges signis), $196^{\mathrm{rb}}$ Praesentatio BMV mit AH 54 Nr. 189 (17, 1: Hunc), 197 ${ }^{\mathrm{ra}}$ Caecilia, 197 ${ }^{\mathrm{rb}}$ Clemens, $197^{\mathrm{va}}$ Chrysogonus, 197vb Katharina mit AH 55 Nr. 206 (3, 2-3 und 4, 2-3 umgestellt, ebenso 5, 2-3 und 6, 2-3; 9, 1: Cuius), $198^{\mathrm{va}}$ Konrad. Das Blatt Clxxxii (alte Foliierung) fehlt.

199ra $-215^{\text {rb }}$ Commune sanctorum. > Sequitur nunc Commune sanctorum. Et primo Sequencie<. Clare sanctorum senatus apostolorum princeps ... AH 53 Nr. 228, AH 54 Nr. 87 (3, 4: per mundi climata, zw. 9 u. 10 eine Strophe eingeschoben, vgl. S. 126, Hs. R, jedoch extollit ecclesia, 10, 2: electi domini), AH 55 Nr. 6 (12, 2: is mactatur, 14, 1: Voce datur suscitatus), AH 53 Nr. 229, AH 55 Nr. 14 (6, 1: Ut invicti, 9, 1: Cum sic), Nr. 10 (2, 3 offen: $N$. memoria, 5, 1 mit Alternative: Ave martir preciose, vel: O confessor preciose), Nr. 37 (21-26, interlinear mit Alternativen im Singular), Nr. 29 und AH 50 Nr. 271 (3a, 4: sunt edita, 3b, 3: cuius hec festa, 5a, 4: observare, 6a, 3: vincere virginem, 8a, 1: Nunc inter, 8a, 3: mater est, 8b, 6: ierit). 200va Tractus (mit Versen): > De apostolis, vel de martiribus vel de una virgine que fuit martir $<$. Qui seminant in lacrimis ... $>D e$ uno martire vel sacerdote qui non fuit eppiscopus vel simplici confessore $<$. Desiderium anime ... 200 ${ }^{\mathrm{vb}}>$ De eppiscopo <. Beatus vir qui timet dominum ... > De virgine que non fuit martir<. Audi filia ... Anschliessend Lektionar: >De apostolis. Ad Ephesios<. Iam non estis ... 201 ${ }^{\mathrm{vb}}$ Evangelisten, 203 ${ }^{\mathrm{vb}}$ Märtyrer; Bekenner und Jungfrauen $\left(214^{\mathrm{ra}}\right)$ ohne Überschrift.

$215^{\mathrm{rb}}-216^{\mathrm{vb}}$ Dedicatio ecclesiae et altaris. $>$ In dedicacione eclesie $<$. Terribilis est locus iste ... mit AH 53 Nr. 247 (10, 1: Fugiant, 11, 1: Pereant, 13, 2: redundet, 14, 3: resultet). 216 ${ }^{\mathrm{rb}}>$ In dedicacione altaris<. Dicit dominus: Sermones meos quos dedi...

$216^{\mathrm{vb}}-221^{\mathrm{rb}}$ Missae votivae. $>$ Feria $i i^{a}$, de sapiencia $<$. Lex domini. $>$ xliii. Oracio $<$. Deus qui per coeternam tibi

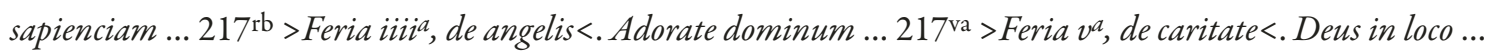
$218^{\mathrm{ra}}>$ Feria via de sancta cruce $<$. Nos autem ... 118 ${ }^{\mathrm{rb}}>$ Infra adventum domini. In Sabbato, de beata virgine $<$. Rorate celi ... $118^{\mathrm{va}}>$ A nativitate domini usque ad purificacionem in Sabbato de beata virgine. Introitus $<$. Vultum tuum ... mit AH 54 Nr. 2 (6, 2: neque virgo filio, 12, 1 und 2 umgestellt). $119^{\text {ra }}>$ De beata virgine a purificacione usque ad pasca, et ab octava penthecostes usque ad adventum domini. Introitus $<$. Salve sancta parens ... mit AH 50 Nr. 241, AH 54 Nr. 232 (2, 2-3: tollis a ve mutans vocem, 3, 3 - 4, 2 fehlt, 7 und 8 umgestellt), 216 (9, 3 und 10, 3: Que mater es), 218 (5, 1: Ave sponsa, 5, 2: lignum dumi) und 245 (23, 2: te ducente, 24, 2: salva servos). $220^{\mathrm{vb}}>$ De beata virgine. In tempore pascali<. Salve sancta parens ... mit AH 54 Nr. 18 (2, 2: quod Maria, 2, 3: agnum qui, 3, 1: Vis natura duello, 3, 2: conflixere mirando, 3, 3: dux vite mortuus, 3, 4: vivus, 4, 4: 
plasma ex te, 5, 3: Processit ex me, 7: Nunc credendum surrexisse ex mortuis vere, conserva mater nos et tuere). $221^{\mathrm{va}}-223^{\mathrm{rb}}$ Missa pro defunctis. $>$ Pro defunctis. Officium $<$. Requiem eternam ... $222^{\mathrm{va}}>$ In pascali tempore pro defunctis $<$. Si enim credimus ...

$223^{\text {rb }}-226^{\text {ra }}$ Collectae pro defunctis. $>$ In deposicione. Oracio <. Quesumus domine ut famulo tuo cuius primum $>$ vel< septimum >vel< tricesimum obitus diem commemoramus ... $10 \times 3$ Gebete: BRUYLANTs, Bd. 2, Nr. 931, Adesto domine suplicacionibus ... 223 va Omnipotens sempiterne deus collocare dignare ...; Nr. 233, 905, 1117; Nr. 161, 1119, 608; 223 vb >Pro laico<. Nr. 644, Annue ... Presta ...; Nr. 929, 606, 654; Nr. 407, 1134, 106; $224^{\mathrm{rb}}>$ Pro commendatis<. Nr. 217, Prosit ... Proficiat ...; Nr. 465, 217, 877; Nr. 214, 892, 223; Nr. 567, 620, 52.

$225^{\mathrm{ra}}-229^{\mathrm{ra}}$ Missae votivae. $>$ Sequntur nunc speciales misse, et primo De passione domini<. Humiliavit semetipsum ... 225 $5^{\mathrm{vb}}>$ De vulneribus Christi<. Gaudeamus omnes ... 226 $6^{\mathrm{va}}>$ De viginti quattuor senioribus missa<. Venite benedicti. > Cii. Oracio<. Deus qui ... 226vb $>$ Contra pestilenciam $<$. Recordare domine ... 227rb $>$ Pro salute vivorum <. Salus populi. $>$ Xlix. Oracio <. Pretende domine ... 227va $>$ Pro peccatis $<$. Si iniquitates. $>$ Cxlviii. Oracio<. Exaudi ... 227vb $>$ Pro pace<. Da pacem domine. $>$ Cxlv. Oracio<. Deus a quo ... $228^{\mathrm{ra}}>$ Pro infirmo <. De necessitatibus meis eripe me. $>x x x v$. Oracio <. Omnipotens ... $228^{\mathrm{va}}>$ In sollemnitate nupciarum pro sponso et sponsa $<$. Domine refugium. $>x x x i i i$. Oracio $<$. Exaudi ...

$229^{\mathrm{ra}}-231^{\mathrm{vb}}$ Collectae. $>$ Sacerdotis propria oracio $<$. Supliciter te deus pater omnipotens ... 229 ${ }^{\mathrm{rb}}>$ De sanctis quorum reliquie hic continentur oracio $<$. Concede ... $12 \times 3$ Gebete, darunter (anschliessend) BRUYLANTS, Bd. 2, Nr. 196, 1133, 1091; Nr. 30 und 902; Nr. 167, 353, 577; Nr. 229, 733, 168; Nr. 22, 881, 934; Nr. 739 und 791; $130^{\mathrm{rb}}>$ Pro hiis qui in magna pressura sive tribulacione sunt. Oremus<. Deus qui contritos ... $230^{\mathrm{va}}$ Deus qui tribulatos corde sanas ... Dimitte ...; Nr. 802, 209, 923; Nr. 1, 533, 687; zuletzt noch drei weitere, längere Orationes generales.

$231^{\mathrm{vb}}-232^{\mathrm{ra}}$ Missa votiva. $>V$. Ydus Novembris passio ymaginis domini nostri Ihesu Christi que crucifixa est a Iudeis in Iericho<. In nomine domini omne genu flectitatur. >Lxxix. Oracio<. Domine sancte pater ... - ... $>$ Clxviii. Completorium<. Repleti alimonio celesti ... proficiat nobis cottidie ad salutem corporis et anime. Per. Anschliessend Schreibervermerk, in Rot: Consumatur et feliciter completus est liber iste Anno incarnacionis dominice Millesimo Quadringentesimo Septuagesimo sexto, in profesto sanctorum decem milium martirum, quo factum est prelium inter confederatos et ducem Burgundie, ante civitatem Murten, et ut dicunt incole vallis Murteti qui eos sepelierunt, ultra sexaginta millium viros Burgundos perempti sunt, exceptis in lacu suffocatis, etc. 232rb Novum testamentum. Nachtrag. Mt 24,29-31 (mit Lücken und Fehlern). S. Matheum xxviiii Cap. In illo t.d. I. d. s. Statim post tribulationem dierum illorum ... - ... usque ad terminos eourum (sic). $232^{\mathrm{va}-\mathrm{vb}}$ leer.

$\mathrm{C}^{\mathrm{r}}-\mathrm{D}^{\mathrm{v}}$ leer. 

Die mittelalterlichen Handschriften in der Stiftsbibliothek 

PAULUS APOSTOLUS

Papier, 405 Blätter, 28,5-29 × 20,5 cm

$1430 ; 1469$

Wasserzeichen, Lagen, Foliierung: Aus sechs Teilen zusammengesetzt, Teile 5 und 6 Handschriften, die Wasserzeichen von Teil 5 und 6: Bl. 1-12 Traube, PICCARD, Wasserzeichenkartei Nr. 129231 (1428) und 129259 (1427); Bl. 13-194 Ochsenkopf, zwei Varianten von PICCARD, Wasserzeichenkartei Nr. 89789 (1472). Lagen, foliiert nach den kodikol. Einheiten: $\mathrm{IV}^{8}+\mathrm{VI}^{12}+\mathrm{IV}^{20}+\mathrm{III}^{26}+\mathrm{V}^{10}+12 \mathrm{IV}^{106}+(\mathrm{III}+1)^{113}$ $+\mathrm{III}^{119}+2 \mathrm{IV}^{135}+2 \mathrm{III}^{147}+3 \mathrm{~V}^{30}+10 \mathrm{VI}^{120}+\mathrm{V}^{130}+5 \mathrm{VI}^{190}+(\mathrm{IV}-4)^{194}$, Bl. 113 (Teil 3) ein Einzelblatt, nach Bl. 194 (Teil 6) vier Blätter herausgerissen, Reste von dreien (zu Bl. 192-194) erhalten, Bl. 191 lose. $3^{\mathrm{v}}$ (Teil 5) am oberen Rand ein Papierflicken. In Teil 6 Tintenfrass. In Teil 3 und Teil 6 Lagenzählung zu Beginn der Lagen am oberen Rand, in Teil 3: $6\left(43^{\mathrm{r}}\right)-19\left(142^{\mathrm{r}}\right)$, in Teil 6 von der Hand des Schreibers: $2^{u s}\left(25^{\mathrm{r}}\right)-x v i$ $\left(191^{\mathrm{r}}\right)$, z. T. beschnitten; in Teil 3 zudem $38^{\mathrm{r}}$ in der unteren Ecke eine doppelte Lagen- und Blattzählung sichtbar: 5d. Alte Foliierung in Teil 5: 1- 12. Neuere Foliierung, die Drucke einzeln: 1-8, 1 [9] - 26 [34], 1 [35] - 147 [181], 1 [182] - 30 [211], die beiden Hss. (Teile 5 und 6) doppelt foliiert: 186-379 (CMD-CH 2), sowie für die vorliegende Beschreibung gültig: 1 [212] - 194 [405].

\section{Einrichtung und Ausstattung:}

Teil 1 (Bl. 1-8, GW M41497) rubriziert, rote Unterstreichungen, 3-5zeilige rote Lombarden resp. Initialen, z. T. mit Punktverdickungen und Schaftaussparungen.

Teil 2 (Bl. 1-26, GW M47651) nicht rubriziert, Initialen 6richt ausgeführt.

Teil 3 (Bl. 1-147, GW 3077) rubriziert, rote Paragraphenzeichen und Unterstreichungen, 2-6zeilige rote Initialen. Die letzte Zeile auf $42^{\mathrm{v}}$ und die erste auf $75^{\mathrm{r}}$ und $83^{\mathrm{r}}$ sind von Hand (vom Drucker) ergänzt.

Teil 4 (Bl. 1-30, GW M51377) nicht rubriziert, ohne Initialen.

Teil 5 (Bl. 1-12): Vertikale Begrenzung des Schriftraums mit Tinte, Schriftraum 20-20,5 × 15, zweispaltig (6,5-7), 35-38 Zeilen. Jüngere gotische Buchkursive mit Schleifen von einer Hand. Rubriziert, rote Paragraphenzeichen und Unterstreichungen. $1^{\text {ra }} 8$ zeilige rote Initiale mit einem kleinen Dreipassmotiv, $1^{\mathrm{rb}}$ zweizeilig mit einer Punktverdickung, einfachen Schaftaussparungen und einem bescheidenen Ausläufer. Teil 6 (Bl. 13-194): Begrenzung des Schriftraums mit Tinte, Schriftraum 20,5-21,5 × 11-11,5, 15-18 Zeilen, zudem eine äussere Begrenzung für einen Rahmenkommentar, teilweise beschnitten. Flüssige jüngere gotische Buchkursive mit wenig Schleifen. Rubriziert, rote Überschriften und Paragraphenzeichen, $17^{\mathrm{r}}, 47^{\mathrm{r}}, 101^{\mathrm{v}}$ und $142^{\mathrm{r}}$ rote Kopftitel. 2-3zeilige, ab $26^{\mathrm{r}}$ nur noch einzeilige rote Lombarden (175 ${ }^{\mathrm{r}}$ nicht ausgeführt) mit Punktverdickungen, Konturbegleitstrichen und Schaftaussparungen, vereinzelt mit rudimentärem Fleuronné; 3-5zeilige, meist mit der Feder doppelt schwarz gerahmte Initialen mit den gleichen Gestaltungselementen, die Schaftaussparungen teilweise geometrisch abgetreppt, teilweise eher vegetabil, $172^{\mathrm{v}}$ mit Fadenranken im Binnenfeld.

Korrekturen und Nachträge: Korrekturen von der Hand der Schreiber (Teile 5 und 6), z. B. $1^{\text {ra }}, 12^{\text {ra }}, 32^{\text {r }}, 118^{\text {r }}$, $171^{\mathrm{r}}$ und $181^{\mathrm{r}}$; zeitgenössisch $1^{\mathrm{rb}}, 9^{\mathrm{va}}, 15^{\mathrm{r}}$ oder $19^{\mathrm{r}}$, aber auch ausserhalb der kommentierten Partien in Teil 6, z. B. $30^{\mathrm{v}}$ und $31^{\mathrm{r}}$. In Teil 5 Notazeichen des Schreibers, $2^{\mathrm{va}}$ mit Marginalie und Handweiser (zusätzlich rot nachgezogen), weitere Zeichen eingeritzt (blind), zudem Marginalien 16./17. Jh. $1^{\mathrm{v}}$ (Teil 1) Inhaltsübersicht, 
Nachtrag wohl von der Hand Ludwig Zellers, 15. Jh. In illo libro continentur: Seneca de forma ac honestate vite, Liber Senece de remediis fortuitorum. Tractatus de horis canonicis. Compendium Literalis sensus tocius biblie. Compendium super psalterium. Tractatus de communione Eukaristie. Textus Epistolarum beati pauli. Teil 6, 14r in der zweiten Initiale: $S S V$.

Einband: Einband aus der Werkstatt Uoldaricus (EBDB w000154, nachgewiesen um 1481-1490). Mit braunem Leder bezogene, an den Kanten abgefaste Holzdeckel, letztes Viertel 15. Jh.; Rücken erneuert. Streicheisenlinien, Einzelstempel (EBDB s011932, s011933, s011936, sowie ein weiterer: Schriftband teodericus, vgl. Erster datierter Schweizer Druck, Taf. 16, Nr. 1, 5, 7 und 11); ehemals zwei nach vorn greifende Kantenschliessen mit ziselierten Messingteilen, vgl. Johann Lindt, Der Buchbinder Uoldaricus, in: Berner Einbände, Buchbinder und Buchdrucker, Bern 1969, S. 22-26, Abb. 1, unten rechts (S. 25). Am Kopf rotblau-weisse, am Schwanz grün-rot-weisse geflochtene Kapitale. In den Fälzen Pergamentfragemente. Ehemals je ein grösseres Pergamentfragment einer liturgischen Hs. (Sanctorale), 12./13. Jh., um die erste und letzte Lage gebunden und in die Spiegel geklebt, daran angeklebt ein um die jeweils benachbarte Lage gebundener Pergamentstreifen; das Fragment im vorderen Spiegel ausgerissen. Im vorderen Spiegel Exlibris des Chorherrenstifts Beromünster (Wegmann, Exlibris, Nr. 619). Auf dem Vorderdeckel altes Papierschild: $S e$ [neca] de forma ac honestate vite cum variis opusculis io fol. signatis. Auf dem Rücken Papierschild mit Drucktypen: SENECA DE HONESTATE VITAE ET TRACT. VARII.

Herkunft: Teil 5 ist $197^{\mathrm{rb}}$ auf den 23. Juli 1430 datiert, Teil 6 wahrscheinlich im Auftrag von Ludwig Zeller geschrieben, 379v vom Schreiber auf 1469 datiert, siehe auch die Datierung Zellers (Besitzer). Die Drucke sind alle um 1474/5 zu datieren.

Besitzer: Teil 3, 147v Liber iste est Ludwici Zeller Capplani S. Magdalene in Arow. 1477, darunter Wappen (mit Fisch?). Teil 6, 194 in Rot: D. Ludwici Zeller de Brugg, 101 ${ }^{\mathrm{r}}$ in der Initiale: $L Z 1469$. Im vorderen Spiegel Exlibris des Chorherrenstifts Beromünster. Im vorderen Spiegel und 1r (Teil 1) neuere Signatur A 66, mit rotem Filzstift, 21. Jh. Auf dem Rücken gedrucktes Papierschild A 91 (Zahl durchgestrichen, daneben von Hand 66).

Literatur: [BÜChLER-]MATtMANN, Inkunabelverzeichnis der Stiftsbibliothek Beromünster, in: Erster datierter Schweizer Druck, Beromünster 1970, S. 108, Nr. 8, S. 131, Nr. 97, S. 134f., Nr. 113 und S. 136, Nr. 121; BüCHLER, Beromünster, S. 167; CDM-CH 2, Nr. 103.

Teil 1 (Bl. 1-8): Ps.-SENECA, De quattuor virtutibus, De remediis fortuitorum. Inkunabel GW M41497 [Strassburg: Heinrich Eggestein?, um 1475]. $1^{\mathrm{r}}$ leer, $1^{\mathrm{v}}$ siehe Nachträge, $8^{\mathrm{v}}$ leer. Auf Bl. $8^{\mathrm{rb}}$ Blinddruck.

Teil 2 (Bl. 1-26 [9-34]): ALBERTUS TROTTUS, De horis canonicis. Inkunabel GW M47651 [Basel: Martin Flach, um 1474].

Teil 3 (Bl. 1-147 [35-181]): PETRUS AUREOLI, Compendium sensus litteralis totius Sacrae Scripturae. Inkunabel GW 3077 [Strassburg: Georg Husner, nicht nach 1475].

Teil 4 (Bl. 1-30 [182-211]): WALAHFrIDUS STRABO, Scriptum compendiosum Psalterii intentionem declarans et exponens. Inkunabel GW M51377 [Basel: Johann Schilling, um 1473/74].

Teil 5:

$1^{\mathrm{ra}}-12^{\mathrm{rb}}$ MATTHAEUS DE CRACOVIA, Dialogus rationis et conscientiae. > Tractatus magistri Mathei de Cracovia doctoris sacre pagine super communione sacramenti Eukaristie etc. etc. $<$ Multorum tam clericorum 
quam laycorum querela est non modica ... - ... datum est nobis corpus domini nostri Ihesu Christi, qui cum deo patri et spiritu sancto vivit et regnat deus in secula seculorum benedictus, Amen. In translacione trium magorum 1430. Deo gracias. Amen. Stimmt überein etwa mit GW M21759. Bloomfield, Incipits, Nr. 3136; Franz Josef Worst вrock, Artikel Matthäus von Krakau, in: Verfasserlexikon², Bd. 6 (1987), Sp. $177 f$. $12^{\mathrm{va}-\mathrm{vb}}$ leer, am unteren Rand auf dem Kopf stehend, eingerahmt: Johannes Schnewli.

Teil 6:

13 $-194^{\mathrm{v}}$ PAULUS APOSTOLUS, Epistolae. Rm - Hbr (mit den Prologen RB 677, 685, 699/700, 707, 715, 728, 736, 747/748, 752, 765/766, 772, 780, 783 und 794). Epistole beati Pauli apostoli, darüber Preisangabe (?): i lib. iii s. Links und rechts davon Nachtrag: perspicuus, clarus, lucidus resp. autumo, affirmo, arbitror. 13 ${ }^{\mathrm{v}}$ Continuacio (zeitgenössischer Nachtrag). 14r Romani sunt partes Ytalie ... Paulus servus Christi Iesu vocatus apostolus ... - ... Salutant vos de Ytalie vestra cum omnibus vobis, Amen. $>$ Expliciunt epistole Pauli. $1469<$. Anschliessend Besitzeintrag, in Rot: D. Ludwici Zeller de Brugg. Von zwei Händen teilweise interlinear

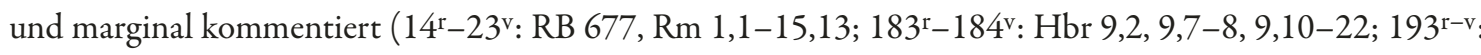
12,27-13,1 und 13,10-11): Sequitur continuacio post ewangelium in quo actum est de capite. Exposicio: Sequitur pars epistolarum in [qua] agitur de corpore ecclesie ...

Papier, 193 Blätter, $21,5 \times 14,5-15 \mathrm{~cm}$

Zweite Hälfte des 14. Jahrhunderts

Wasserzeichen, Lagen, Foliierung: Bl. 1-145 Horn, ähnlich BRIQUET, Nr. 7658 (1372); Bl. 171-193 ähnlich Nr. 7705 (1366); Bl. 147-168 zwei Kreise, ähnlich BRIQUET, Nr. 3233 (1368); Bl. 185/190 Ochsenkopf, ähnlich BRIQUET, Nr. 14461 (1373). Lagen: (VI-1) ${ }^{11}+$ VI $^{23}+$ VII $37+13$ VI ${ }^{193}$, vor Bl. 1 ein Blatt herausgerissen, Textverlust, Bl. 11 und die erste Lage fast lose. Wasserschaden am oberen Rand der Lage Bl. 158-169. Lagenzählung zu Beginn der Lagen: $5^{u s}\left(50^{\mathrm{r}}\right)-9^{u s}\left(98^{\mathrm{r}}\right), x\left(110^{\mathrm{r}}\right)-x i i\left(134^{\mathrm{r}}\right), x v\left(158^{\mathrm{r}}\right)$; nach [xiii] fehlt möglicherweise eine Lage. Die vorletzte Lage (B1. 170-181) hat ein kleineres, unregelmässigeres Format als die anderen: $14,5 \times 20,5-21,5 \mathrm{~cm}$. Alte Foliierung recto und verso, ab $8^{\mathrm{v}}$ in Rot: $2-108\left(1^{\mathrm{r}}-107^{\mathrm{r}}\right)$, neuere Foliierung 1-193.

\section{Einrichtung und Ausstattung:}

Bl. 1-140: Begrenzung des Schriftraums mit Tinte, Schriftraum 16,5-18 × 10,5-11,5, 26-40 Zeilen. Ältere gotische Buchkursive von einer Hand. Rubriziert, rote Überschriften, schwarz-rote Paragraphenzeichen, Stellenangaben unterstrichen, Zeilenfüller. 1-2zeilige rote sowie 2-4zeilige schwarze Initialen mit roten Konturbegleitstrichen. $1^{\mathrm{r}}-108^{\mathrm{r}}$ am Rand teils numerische, teils alphabetische Abschnittszählung, seltener texterschliessende Marginalien, meist in Tinte, teilweise auch rot, von der Hand des Schreibers (siehe auch Nachträge).

B1. 141-169: Begrenzung des Schriftraums mit Tinte, $141^{\mathrm{v}}-157^{\mathrm{v}}$ nur vertikal, Schriftraum $15,5-17,5 \times 9-11$, 29-42 Zeilen. Ältere gotische Buchkursive von mehreren Händen, Händewechsel 149r/149v, 157v/158r, $162^{\mathrm{r}} / 162^{\mathrm{v}}$ und $164^{\mathrm{r}} / 166^{\mathrm{r}} ; 141^{\mathrm{v}}-14^{\mathrm{r}}$ wohl von der Hand des Johannes Eggli, Pfarrer in Buochs und Schreiber 
der Handschrift C 53; 149v $-157^{\mathrm{v}}$ und $162^{\mathrm{v}}-164^{\mathrm{r}}$ von der Hand des Korrektors der ganzen Handschrift. Rubriziert, rote Überschriften und Paragraphenzeichen. 2-5zeilige rote Initialen mit Konturbegleitstrichen. $141^{\mathrm{v}}-149^{\mathrm{r}}$ texterschlissende Marginalien in Rot von der Hand des Schreibers.

Bl. 170-193: Begrenzung des Schriftraums mit Tinte, vertikal durch Doppellinien, Schriftraum 15-15,5 $\times$ 8,5-9, 31-38 Zeilen. Ältere gotische Buchkursive von einer Hand. Rubriziert, 2-3zeilige (170 r sechszeilige) rote, $\mathrm{ab} 182^{\mathrm{v}}$ schwarz-rote Initialen, $172^{\mathrm{r}}$ rote Überschrift. Texterschliessende Marginalien von der Hand des Schreibers.

Korrekturen und Nachträge: Zahlreiche Korrekturen wurden schon während des Schreibens vorgenommen,

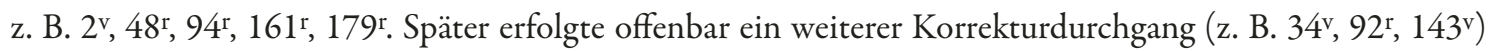
durch eine zeitgenössische Hand (den Schreiber von $149^{\mathrm{v}}-157^{\mathrm{v}}$ und $162^{\mathrm{v}}-164^{\mathrm{r}}$ ), bei dem an vielen Stellen unleserliche und blasse Buchstaben mit schwarzer Tinte nachgezeichnet und die Textgliederung, v. a. die Abschnittszählung, ausgebaut wurde. Wohl zu diesem Zeitpunkt wurden auch Notazeichen sowie zahlreiche schwarze und rote sechsfingrige Handweiser (bis 106 v), zudem das alphabetisch geordnete Register auf $162^{\mathrm{v}}-164^{\mathrm{r}}$, die Folierung und texterschliessende Marginalien auf $166^{\mathrm{r}}-168^{\mathrm{r}}$ eingefügt.

Einband: Mit hellem Leder bezogene Holzdeckel, 15. Jh., beide lose. Das Rückenleder ist grösstenteils abgerissen, so dass ein Streifen Leinengewebe freiliegt, der die Deckel miteinander verband. Ehemals eine nach hinten greifende Langriemenschliesse, Befestigung im Vorderdeckel mit einem aufgenagelten quadratischen Messingplättchen. Buchblock zu den Bünden hin abgefast, Kapitale mit ungefärbtem Garn umstochen. Spiegelblätter Papier, im Vorderdeckel Fragment eines Kommentars zu Mt 26,3-16, im Rückdeckel Quaestionen zum Wesen der Caritas, 14. Jh. Alle Lagen innen und aussen mit Pergamentstreifen verstärkt. Herkunft: $141^{\mathrm{v}}-149^{\mathrm{r}}$ kann durch Vergleich mit der namentlich gezeichneten Handschrift C 53 Johannes Eggli, Pfarrer in Buochs, zugewiesen werden, die Wasserzeichen weisen auf eine Entstehung in den 1360er bis 1370er Jahren. Die Textauswahl zeigt eine auffällige Nähe zu den Bettelorden.

Besitzer: $1^{\mathrm{r}}$ neuere Signatur: C 8, blauer Filzstift, spätes 20. Jh., mit Bleistift ergänzt: $4^{\mathrm{o}}$.

Literatur: BRUCKNER, Scriptoria, S. 21; BÜCHLER, Beromünster, S. 174.

$1^{\mathrm{r}}-107^{\mathrm{r}}$ Compendium virtutum et vitiorum. Tugend- und Lasterlehre in zwei Büchern, kompiliert aus verschiedenen älteren Werken (u. a. aus der Dekalog-Auslegung Ulrichs v. Pottenstein, dem Speculum Christiani, der Summa theologica des Antoninus Florentinus, der Summa virtutum des Guillelmus Peraldus und der Diaeta vel via salutis des Guillelmus de Lanicia). Die thematische Reihenfolge folgt keiner durchgehenden Ordnung, verschiedene Tugenden werden mehrfach behandelt. Gegen Ende von Buch 1 sind drei Adventspredigten eingefügt. //tudo peccati vel multitudo. Genesis: Maior est iniquitas mea, quam ut veniam merear. Sed fatuum est propter peccati multitudinem vel magnitudinem desperare ... $>$ De caritate $<$. Dicit Augustinus: Tene caritatem ... 50 $>$ Sermo prima dominica adventus $<$. Ecce rex tuus venit ... (Mt 21,5$)$. In verbis istis innuit nobis ewangelium tria: $1^{m}$ est advenientis dignitas ... 51 ${ }^{\mathrm{V}}$ SCHNEYER, Bd. 2, S. 483, Nr. 5 (Guilelmus de Malliaco). $53^{\mathrm{r}}>$ Dominica iiia in adventu<. Veniet dominus et illuminabit ... (1 Cor 4,5). Ista verba possunt exponi de adventu domini in mundum ... 53 $>$ De fide<. Queritur de sufficiencia fidei ... 54v viius est ad iudicium

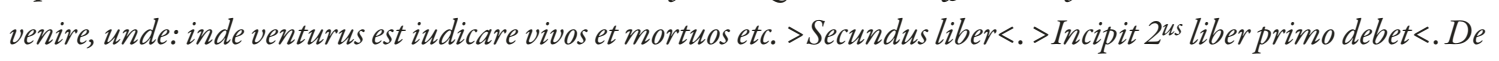
temperancia nota: Comparatur freno quo equus regitur, bisso quo caro tegitur, muro quo castrum cingitur ... - ... Sicut enim candor materialis est caput et fundamentum aliorum colorum secundum philosophum, sic candor spiritualis, hoc est castitas, est quasi caput omnium virtutum et honorum, unde dicit Gregorius: Non est bonum 
opus aliquod sine castitate. Anschliessend Kolophon: Explicit iste liber, scriptor sit crimine liber. Colophons Bd. 6, Nr. 21115.

$107^{\mathrm{r}}-108^{\mathrm{v}}$ Sermo. $>$ Sermo dominica xix<. Renovamini spiritu ... (Eph 4,23). Nota quod vi species renovacionis in creaturis inveniuntur, que ostendunt homini diversos modos sue renovacionis ... - ... ad cuius exemplar homo cottidie debet respicere, unde Iohannes: Ego dominus et magister exemplum dedi vobis ut et vos ita faciatis etc. etc. $108^{\mathrm{v}}-114^{\mathrm{r}}$ Notanda de cura animarum secundum ius canonicum. 51 Absätze. Nota quod propter hoc non tollitur alicui clerico potestas cantandi, si videt aliquem interfici ... Nota si infans vicinus morti mergeretur in aqua forte mo[re]retur ... - ... Enormia peccata sunt hec: homicidium voluntarium, symonia, heresis et huiusmodi. Anschliessend Merkverse zu verschiedenen Reservatsfällen: >De peccatis, que ad solum papam vel episcopum pertinent<. Crimina sunt quedam, que spectant presulis ad ius ... - ... Presulis arbitrio licet occulti subeant hii. Etc. [Jean Levesque de Burigny], Traité de l'autorité du pape, Bd. 3, 2. Aufl., Vienne 1782, S. $442 f$. Walther, Carmina, Nr. 3454. Danach: Item illi, qui in ecclesiis luxuriam commiserunt ... - ... Item mulier que de adulterio.

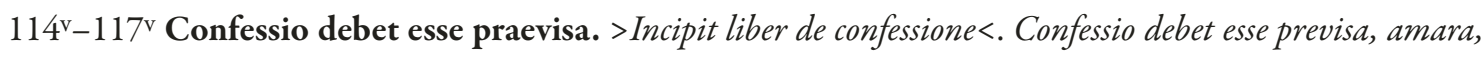
verecunda, discreta, integra, spontanea, frequens, obediens et subiecta ... - ... Nam super omnes sciencias maxima est sciencia scire confiteripeccata sua et modum confitendi. Pierre Michaud-Quantin, Deux formulaires pour la confession du milieu du XIII siècle, in: Recherches de théologie ancienne et médiévale 31 (1964), S. 43 62, hier besonders S. 48-51 (Hs. nicht erwähnt) und S. 52-57 (Edition). Bloomfield, Incipits, Nr. 878.

$117^{\mathrm{v}}-122^{\mathrm{r}}$ Summa poenitentiae Fratrum Praedicatorum. $>$ Sequitur alter liber $<$. Cum ad sacerdotem pro peccatis peccator accesserit, dicat sacerdos: Dominus nobiscum ... - ... 121 12 Et tunc ad arbitrium suum iniungat ei penitenciam, non passim sed (sic) indifferenter, sed si fieri possit penitenciam que deceat culpe. Joseph GoERING, Pierre J. PAYer, The «Summa penitentie Fratrum Predicatorum». A Thirteenth-Century Confessional Formulary, in: Mediaeval Studies 55 (1993), S. 1-50 (Hs. nicht erwähnt), hier besonders S. 25-39, Z. 249 (Edition). Bloomfield, Incipits, Nr. 1032.

$122^{\mathrm{r}}-124^{\mathrm{v}}$ De confessione. $>$ De speciebus $<$. Sequitur de speciebus confessionis, que multe sunt: Prima est confessio se excusancium ... $122^{\mathrm{v}}>$ Qualis debeat esse $<.123^{\mathrm{r}}$ Unde videndum est, qualis debeat esse confessio. Nota quod confessio primo debet esse voluntaria ... - ... 124 $4^{\mathrm{r}}$ ad consilium sacerdotis non vult abstinere quin ornetur se crinibus alienis, der zweite Abschnitt exzerpiert aus einer Predigt des Guilelmus Peraldus, Schneyer, Bd. 2, S. 551, Nr. 233: Guilielmi Alverni [...] Opera omnia, Paris 1764, Bd. 2, S. 158f. Zu beiden Teilen zusammen vgl. Melk, Stiftsbibliothek, Cod. 516, 135 $5^{\mathrm{rb}}-137^{\mathrm{vb}}$.

$124^{\mathrm{v}}-135^{\mathrm{v}}$ JOHANNES DE FRIBURGO, Tractatus de instructionibus confessorum. Exzerpte. $>D e$ clericis<. Circa alios clericos et canonicos seu alios beneficiatos querendum est, si per aliquam pravitatem symonicam ordines vel beneficia habuerunt ... - ... testamentum celerriter expediant frequencibus ammonicionibus impulsabis. $>$ Depenitencia in extremis<. GW M13586: [Erfurt: Drucker des Aristeas (?) / Magdeburg: Albert Ravenstein

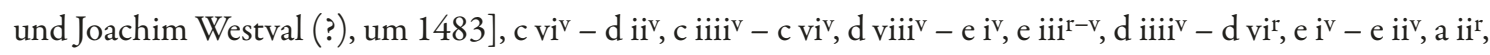
e iiiiv, e vir-v, e iiiir ${ }^{r}$ e viiiv. KaEppeli, Scriptores, Nr. 2346 (Hs. nicht erwähnt); Bloomfield, Incipits, Nr. 5755 (Hs. nicht erwähnt). Vgl. Marlies Hamm, Artikel Johannes von Freiburg, in: Verfasserlexikon², Bd. 4 (1983), Sp. 608.

$136^{\mathrm{r}}-137^{\mathrm{r}}$ Ad habendum salutiferae confessionis ordinem. Primo fiat confessio de puerilibus, utpote de inobediencia, de offensa parentum ... - ... maxime si in consuetudinem duxisti. Michaud-Quantin, Deux formulaires, S. 43-62, hier besonders S. 57-60 (Hs. nicht erwähnt) sowie S. 60, Z. 2 - S. 62, Z. 2 und 8-18 
(Edition). Bloomfield, Incipits, Nr. 222. Anschliessend Definitionen zu contritio, confessio und satisfactio: Contricio est dolor ex peccatis assumptus cum proposicio [ne] penitendi et confitendi ...

137r-140r JOHANNES DE FRIBURGO, Tractatus de instructionibus confessorum. Exzerpte. Dum aliquis petit suam confessionem audiri, quam antea numquam audivisti in foro confessionis, seu cuius status penitus tibi sit ignotus ... - ... Item si dicit se motus aliquos inordinatos habuisse scilicet talem vel talem, queras an perfectum fuerit peccatum an non. GW M13586, a iv - a iir $, \mathrm{a} \mathrm{iii}^{\mathrm{r}}, \mathrm{a} \mathrm{iii}^{\mathrm{r}}-\mathrm{a} \mathrm{iiii}^{\mathrm{r}}, \mathrm{a} \mathrm{iii}^{\mathrm{r}-\mathrm{v}}, \mathrm{a} \mathrm{v}^{\mathrm{r}}, \mathrm{a} \mathrm{v}^{\mathrm{v}}, \mathrm{a} \mathrm{v}^{\mathrm{v}}-\mathrm{a}$ viir $^{\mathrm{r}}$. $140^{\mathrm{v}}-141^{\mathrm{r}}$ leer.

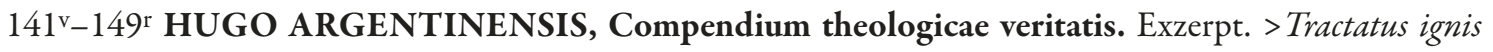
purgatorii<. Finale iudicium quedam sunt antecedencia, quedam quasi comitancia, et quedam sequencia ... - ... Notandum quoque quod predicare et docere, cum sint actus misericordie, inter spirituales elemosinas deputantur. B. Alberti Magni opera omnia, hrsg. v. Auguste Borgnet, Bd. 35, Paris 1899, S. 237-260. Kaeppeli, Scriptores, Nr. 1982 (Hs. nicht erwähnt); Bloomfield, Incipits, Nr. 6399 (Hs. nicht erwähnt). Vgl. Georg STEer, Artikel Hugo Ripelin von Straßburg, in: Verfasserlexikon², Bd. 4 (1983), Sp. 252-266.

$149^{\mathrm{v}}$ Miraculum. Accidit quod quidam sacerdos permultum dilexit unam mulierem Iudeam ... Bricht nach drei Zeilen unvollständig ab.

149v-153v NICOLAUS IV PAPA, Bulla «Supra montem». Nycolaus episcopus servus servorum dei ... Supra montem catholice fidei ... - ... Data etate (sic) quintodecimo Kalendas Septembris, pontificatus nostri anno secundo. Edith PAsztor, La «Supra montem» e la cancelleria pontificia al tempo di Niccolò IV, in: La «Supra montem» di Niccolò IV (1289): Genesi e diffusione di una regola, hrsg. v. Raffaele PAzzELLI / Lino Temperini, Rom 1988, S. 84-90. Anschliessend Inhaltsverzeichnis, Benedictio vestium und Professformel. 154 ${ }^{\mathrm{r}}-157^{\mathrm{v}}$ Sermo. Predigt zu Allerseelen, kompiliert aus Kirchenväterzitaten (zitiert werden: Augustinus, Beda, Cyprian, Gregor der Grosse und Julian von Toledo). >In come[mo]racione omnium fidelium defunctorum <. Frequenter, fratres karissimi, ac manifeste de dei dignacione preceptum nobis est ... - ... alibi iudicamur, ut aut pro peccatis penas aut pro bonis operibus premia consequamur eterna. Quod ipse prestare dignetur qui venturus est iudicare vivos et mortuos et seculum per ignem.

$158^{\mathrm{r}}-160^{\mathrm{r}}$ Sermones. Vier Osterpredigten. > Sermo bonus in festo pasche<. Maria Magdalena etc. (Mt 28,1 / Mc 16,1). Isti dies qui modo transacti fuerunt, pleni sunt dolore ... 158v SCHNEYER, Bd. 2, S. 722, Nr. 24 (Honorius Augustodunensis). 159r Schneyer, Bd. 4, S. 56, Nr. 92 (Lucas de Bitonto). 159v > Feria secunda<. Surrexit dominus vere etc. (Lc 24,34). In hoc verbo quod dominus dicit: O stulti ... - ... ut passio ipsius vobis in obitu vestro subveniat etc.

160 v leer.

$161^{\mathrm{r}}-162^{\mathrm{r}}$ Sermones. Zwei Predigten. $>$ Nota de sacerdotibus sermo bonus $<$. Vos estis genus electum ... (1 Pt 9). Et notandum est, quod glosa tangit hic iiiior: primo sacerdotis nobilitatem ... 161 ${ }^{\mathrm{v}}$ Daniel propheta vidit exire de mari

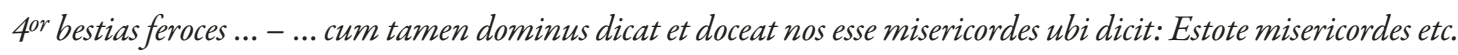

$162^{\mathrm{va}}-164^{\mathrm{ra}}$ Tabula. Nachtrag. Register zum Compendium virtutum et vitiorum $\left(1^{\mathrm{r}}-107^{\mathrm{r}}\right)$, beginnend mit $>$ Fides<, danach in alphabetischer Reihenfolge. > Tabulacio librorum prescriptorum<. Fides, 1. Fides, 34. Fides, 54, Fides, 56. Fletus, 76. Astucie serpentum, 5. Amor inordinatus, 6 ... - ... Virtus comparatur tribus, 61.

$164^{\mathrm{rb}}-165^{\mathrm{v}}$ leer.

166 $6^{\mathrm{r}}-168^{\mathrm{r}}$ Auctoritates. In neun Themenbereiche gegliedert: Caritas, humilitas, oratio, lacrimae, paenitentia, cogitationes, castitas, oboedientia, elemosyna. Zitierte Autoren: Ambrosius, Augustinus, Bernhard von Clairvaux, Clemens, Crisostomus, Gregor, Haymo von Auxerre, Hugo von St. Victor und Isidor. Eine erste 
Überschrift ist bis auf den Schluss de caritate aufgrund von Feuchtigkeit unleserlich. $>$ De caritate<. Augustinus: Sicut sine pane est mensa vilis, quia sicut panis est melior omnibus escis ... - ... istud scriptum est in exemplum nobis, ut propaciamur invicem, quod nobis prestare etc. Vgl. Stuttgart, Württembergische Landesbibliothek, HB III 45, 319r sowie Augsburg, Universitätsbibliothek, Cod. II. 1. 2º, $258^{\mathrm{vb}}$.

$168^{\mathrm{v}}-169^{\mathrm{v}}$ leer.

$170^{\mathrm{r}}-179^{\mathrm{r}}$ Miracula. In quodam cenobio erat quidam monachus secretarii officio functus ... PONCELET, Index, Nr. 468, 1357, 1651, 465, 1604, 480, 866, 384, 417, 646, 559, 495, 799, 545, 1674; $178^{\text {r }}$ BHL Nr. 1420. $178^{v}$ $>$ De assumpcione sancte Marie virginis <. Virgo Elizabeth monialis choetanea Hittegardis in Pinga ... - ... Sciat se ex hac singulare meritum a me et a filio meo in fine vite sue recepturum, vgl. Frankfurt (Main), Stadt- und Universitätsbibliothek, Ms. Barth. 4, 77rb und Ms. Praed. 43, 160 rb.

179v-182v Sermones. 3 Predigten. $>$ De nativitate domini Ihesu Christi<. Gloria in excelsis deo ... (Lc 2,14). Hec verba sunt magna ... SCHNEYeR, Bd. 8, S. 496, Nr. 3. 180 $0^{\mathrm{r}}>$ Nota de circumcisione domini nostri Ihesu Christi<. Cum consumati essent dies octo ... (Lc 2,21). Hec est [dies] domini, in qua ipse circumcidi voluit ... ähnlich SCHNEYER, Bd. 8, S. 496, Nr. 6. 181 Imnum cantate nobis ... (Ps 136,3). Quid hoc sit et quare hoc flat debetis scire ... - ... et cum domino ac sanctis eius in eternum gaudeamus. Quot ipse prestare dignetur ...

$182^{\mathrm{v}}-183^{\mathrm{r}}$ Symbolum. Glaubensbekenntnis mit dogmatischen Zusätzen. Credo in deum patrem omnipotentem, qui creator est celi et terre et omnis creature. Credo in eius unicum filium, dominum nostrum Ihesum Christum. Credo in spiritum sanctum. Credo quod iste tres persone unus verus deus est ... - ... Credo remissionem meorum peccatorum secundum veram penitentiam et secundum perfectam conversionem. Credo resurrectionem mee vite et credo eternam vitam. Amen.

$183^{\mathrm{r}}-185^{\mathrm{r}}$ Visio Pauli. Dies dominicus, dies electus. Interrogandum est, quis primus rogavit, ut anime requiem haberent in inferno ... - ... Nos autem, fratres karissimi, audientes ista mala convertamur ad dominum ut regnemus et vivamus cum ipso in secula seculorum. Amen. Lenka JiroušKová, Die Visio Pauli, Leiden 2006, S. 654-858, Textfassung der Gruppe C2. RB 276,7.2.

185r-186r ADALGERUS EPISCOPUS (?), Admonitio ad Nonsuindam reclusam. Exzerpt. Cum igitur de plurimis virtutibus te desiderem amonere, imprimis cupio, ut virtutem karitatis ante omnia studeas habere ... - .. lacrime generantur et multa mala per eam declinantur. PL 134, Sp. 920-923 (mit vielen Abweichungen). Bernard Lambert, Bibliotheca Hieronymiana Manuscripta, Bd. III A, Steenbrugge 1970, S. 235-241, Nr. 362 (Hs. nicht erwähnt); Bloomfield, Incipits, Nr. 6115; CPL Nr. 1219; Franz Josef Worstbrock, Artikel Adalger, in: Verfasserlexikon², Bd. 1 (1978), Sp. 42f. Vgl. Bordeaux, Bibliothèque municipale, 247, 59ra-74ra. Anschliessend: Ysidorus dicit: Neque iustus confidat de iusticia sua ... - ... ne per se incipiat quod postea peniteat.

$186^{\mathrm{v}}-187^{\mathrm{r}}$ De timore domini. $>$ De timore domini<. Principium nostre salutis est timor domini ... - ... ut puriores ante tribunal iudicis venire possimus. Vgl. Bordeaux, Bibliothèque municipale, 247, $81^{\text {ra-va }}$.

$187^{r}-188^{r}$ Exempla de fornicatione. Fünf Exempla. Discipulus unius heremite inpugnabatur a spiritu fornicacionis ... 187v Alius frater impugnabatur a spiritu fornicacionis ... Iterum beato abbati Moysi quodam tempore imposuit demon duram inpugnacionem fornicacionis ... Erat quidam frater habitans in heremo et multum in opere domini laborabat ... $188^{\mathrm{r}}$ Quo fratres monachi abierunt in civitatem ... - ... et ita frater bonus beatificavit proximum suum. Vgl. Bordeaux, Bibliothèque municipale, 247, 81 ${ }^{\mathrm{va}}-82^{\mathrm{vb}}$.

$188^{\mathrm{r}}-191^{\mathrm{r}}$ Vitae Sanctorum. Viten der Heiligen Euphrasia von Konstantinopel und Abraham von Kiduna. $>$ De Eufrasia<. Fuit quidam senator Antigous nomine, iustus ac timens deum ... - ... 190 Ideo quicumque 
legitime certaverit sicut virgo dei Eufrasia fecit, coronam habebit in celestibus regnis per eum, qui venturus est etc. Fuit quidam Abraham heremita et reclusus, serviens in oracionibus et ieiuniis domino ... - ... per dei graciam pervenerunt ad lucidas sedes sanctorum. Vgl. Bordeaux, Bibliothèque municipale, 247, 88vb_92 ${ }^{\mathrm{ra}}$.

$190^{\mathrm{r}}-192^{\mathrm{r}}$ Miracula. Zwei Wunderberichte. > De visione episcopi<. Legitur de quodam sancto episcopo, qui stabat solito more iuxta altare ad celebrandum divinum officium ... - ... nichil omnino reticuit iustos vero diligenter commonens, ut in bonis operibus persisterent, malos autem ut tantis peccatis penitenciam agerent. Vgl. Bordeaux, Bibliothèque municipale, $247,92^{\text {ra-va }} .191^{\mathrm{v}}$ Erat autem alter episcopus laborans in oracione et ieiunio ... - ... Sive manducetis, sive bibetis, sive aliud quid facitis, omnia in gloriam dei facite.

$192^{\mathrm{r}-\mathrm{v}}$ Ps.-BEDA, De quindecim signis. Quindecim signa invenit sanctus Ieronimus in animalibus (sic) libris Hebreorum ... - .. 192 ${ }^{\mathrm{r}}$ Quintadecima die ardebit terra usque ad inferni novissima. Post hec erit dies iudicii. PL 94, Sp. 555. Vgl. Hans Eg gers, Artikel 'Fünfzehn Vorzeichen des Jüngsten Gerichts', in: Verfasserlexikon², Bd. 2 (1980), Sp. 1013-1020. Zur Überlieferungsgemeinschaft mit der Visio Pauli vgl. Jiroušková, Die Visio Pauli, S. 418-420.

$192^{v}$ Notanda de avaro. Sentenzensammlung. Avarus homo similis est inferno ... - ... Avarus neque pro corpore suo neque pro anima numquam bene facit.

$192^{\mathrm{v}}-193^{\mathrm{r}}$ Physiologus. Exzerpte zu Schlange, Wiesel und Natter. Tres naturae serpentis. Estote ergo prudentes sicut serpentes et simplices sicut columbe (Mt 10,16). Serpens tres naturas habet ... Physiologus Latinus Versio Y, hrsg. v. Francis J. Carmody, Berkeley/Los Angeles 1941, S. 110f. 193 $3^{\mathrm{r}}$ Lex dicit: Non manducabis mustelam, quia inmunda est ... Physiologus Latinus: éditions préliminaires versio B, hrsg. v. Francis J. CARMody, Paris 1939 , S. $46 f$.

$193^{\mathrm{r}}$ Notanda astronomica. Dies quo vadit et nox et nubes quousque pergunt ... - ... Nomina septem celorum Alfrius, Glans, Alger et Alfner, Thothia, Iothia, Ioroch, in quo habitat deus.

$193^{v}$ Ps.-CYPRIAN, De duodecim abusivis saeculi. Nur die Capitula. Duodecim sunt abusiva huius seculi ... - ... Sic suffocatur iusticia. S. Thasci Caecilii Cypriani opera omnia, hrsg. v. Wilhelm Hartel, Bd. 3: Opera spuria, indices, praefatio, Wien 1871, S. 152, Z. 1-7. CPL Nr. 1106.

$193^{v}$ Physiologus. Exzerpt zum Fuchs. Vulpis dolosum et satis fraudulentum animal ... - ... introibunt in inferiores terre, tradentur in manus gladii partes vulpium erunt etc. Physiologus Latinus: éditions préliminaires versio B, hrsg. v. Francis J. CARMODY, Paris 1939, S. 29 f.

$193^{\vee}$ Versus. 9 Verse zur Heiligen Sippe. Anna tribus nupta tres sunt enixe Marias (sic) ... - ... Digna patri sobole Iacobo maiori Iohanne. WALTHER, Carmina, Nr. 1063.

Papier, 237 Blätter, $21 \times 14,5-15 \mathrm{~cm}$

Mitte des 15. Jahrhunderts; erste Hälfte des 15. Jahrhunderts; mittleres Drittel des 15. Jahrhunderts; erstes Viertel des 15. Jahrhunderts; zweites Viertel des 15. Jahrhunderts

Wasserzeichen, Lagen, Foliierung: Teil 1: Bl. 3-59 Ochsenkopf, PICCARD, Wasserzeichenkartei Nr. 76979 (1444) und eine Variante; Bl. 51-58 Ochse, Piccard, Wasserzeichenkartei Nr. 86011 (1447) und 86074 (1452). Teil 2: Bl. 63-70 Herz, ähnlich BriQuet Nr. 4336; Bl. 74-91 Ochsenkopf, Piccard, 
Wasserzeichenkartei Nr. 65798 (1426) und eine Variante. Teil 3: Bl. 99-112 Krone, PiCCARD, Wasserzeichenkartei Nr. 50105 (1440) und eine verwandte Form. Teil 4: Bl. 116-191 Ochsenkopf, PICCARD, Wasserzeichenkartei Nr. 78390 (1413), 78440 (1416) und zwei Varianten. Teil 5: Bl. 194-199 Ochsenkopf, Briquet Nr. 15233 (1437); Bl. 202-233 Horn, PicCARD, Wasserzeichenkartei Nr. 120341 (1437) und eine Variante. Lagen: $7 \mathrm{VI}^{84}+(\mathrm{VI}-1)^{95}+(\mathrm{IX}+1)^{114}+6 \mathrm{VI}^{186}+(\mathrm{I}+3)^{191}+(\mathrm{III}+3)^{200}+\mathrm{VI}^{212}+\mathrm{V}^{222}+\mathrm{VI}^{233}$, das letzte Blatt der letzten Lage in den Spiegel geklebt; nach Bl. 95 ein Blatt herausgeschnitten, B1. 96, 188190, 192, 193 und 200 Einzelblätter, Bl. 189 lose. Bl. 97 und 114 zu einem Doppelblatt zusammengeklebt, Bl. 96/97 möglicherweise zwei Hälften eines Doppelblattes (Wasserzeichen: Ochsenkopf). 12v-48v und 84v Reklamanten, 100v-112v (Teil 3) 14 Reklamanten. In Teil 4 Lagenzählung zu Beginn der Lagen am unteren Rand: 2-6 (127 $\left.7^{\mathrm{r}}-175^{\mathrm{r}}\right)$, Zählung der Doppelblätter in der ersten Lagenhälfte am oberen Rand: $1\left(127^{\mathrm{r}}\right)-6$ $\left(190^{r}\right)$, teilweise beschnitten. Neuere Paginierung in Teil 1: 1-118; neuere Foliierung: A-D. 1-233.

\section{Einrichtung und Ausstattung:}

Teil 1 (Bl. 1-60, Mitte des 15. Jhs.): Bl. 1-7 Begrenzung des Schriftraums mit Stift, Spaltenbegrenzung in Rot. Schriftraum 15-17 × 10,5-11,5, zweispaltig (4,5-6), 28-38 Zeilen. Jüngere gotische Buchkursive mit Schleifen von einer Hand. Rubriziert, rote Überschriften, $1^{\mathrm{r}}$ rote Initiale mit Schaftaussparung. Lemmata und Interpretamente mit Linien verbunden.

Teil 2 (Bl. 61-95, 1. Hälfte des 15. Jh.): Begrenzung des Schriftraums mit Blindlinien, 73 $-84^{\mathrm{v}}$ mit Tinte. Schriftraum 14-14,5 × 10,5-11, 26-29 Zeilen. Jüngere gotische Buchkursive mit Schleifen von einer Hand. Raum für zweizeilige Initialen ausgespart, teils mit Vorgaben des Schreibers. $91^{\mathrm{v}}$ rubriziert und Federzeichnung: Profilskizze, möglicherweise im Zusammenhang mit einer Textergänzung.

Teil 3 (Bl. 96-1 14, mittleres Drittel des 15. Jh.): Begrenzung des Schriftraums mit Tinte ab 99r. Schriftraum 15,5-16,5 × 9,5-10, 33-39 Zeilen. Jüngere gotische Buchkursive mit Schleifen von einer Hand. Rubriziert, Stellenangaben unterstrichen, rote Paragraphenzeichen, dreizeilige rote Lombarden. Marginalien zur Texterschliessung, hauptsächlich Abschnittsnummern.

Teil 4 (Bl. 115-191, 1. Viertel des 15. Jh.): Vertikale Begrenzung des Schriftraums mit Stift (bis $118^{\mathrm{v}}$ auch horizontal), $139^{\mathrm{v}}-188^{\mathrm{v}}$ mit Tinte. Schriftraum 13,5-15,5 × 10,5-11,5, zweispaltig (4-5). 21-27 Zeilen. Jüngere gotische Buchkursive mit Schleifen von einer Hand. $115^{\mathrm{r}}-140^{\mathrm{v}}$ und $144^{\mathrm{v}}-146^{\mathrm{v}}$ rubriziert, rote Überschriften und Paragraphenzeichen, zweizeilige rote Lombarden, sonst für die gleiche Rubrizierung eingerichtet, nicht ausgeführt. Stellenweise Abschnittsnummern, $185^{\text {va }}$ Notazeichen am Rand.

Teil 5 (Bl. 192-233, 2. Viertel des 15. Jh.): Begrenzung des Schriftraums mit Tinte, Schriftraum 15,5-17 × 10-11, 27-34 Zeilen. Raum für zweizeilige Lombarden ausgespart, mit Vorgaben des Schreibers. Marginalien zur Erschliessung des Inhalts.

Korrekturen und Nachträge: Wenige Korrekturen der Schreiber, z. B. 1 ${ }^{\mathrm{r}}, 70^{\mathrm{r}}, 102^{\mathrm{r}}, 195^{\mathrm{v}}$, in Teil 4 etwas häufiger, z. B. $115^{\mathrm{va}}, 144^{\mathrm{va}}, 173^{\mathrm{v}}$. Korrektur von anderer Hand: $91^{\mathrm{v}} .88^{\mathrm{r}-\mathrm{v}}$ Unterstreichungen. $102^{\mathrm{r}}$ rotes Schriftband, mit schwarzem Karomuster verdeckt. Nachträge, 15. Jh.: 93 ${ }^{\mathrm{r}}-94^{\mathrm{v}}$ von Ludwig Zeller 1461 (siehe unten), $138^{\mathrm{v}}$ schain åben ich waz nit vie im ist, $187^{\mathrm{r}}$ Probatio penne, $190^{\mathrm{v}}$ Nota ... $191^{\mathrm{r}}$ Oratio Christi in cruce (siehe Inhalt).

Einband: Mit hellem Leder bezogene Holzdeckel, 15. Jh., Reste von zwei nach hinten greifenden Langriemenschliessen, Befestigung im Vorderdeckel mit Eisennägeln. Buchblock zu den Bünden hin abgefast. Vorsatzblätter Papier (A-D), Wasserzeichen: Buchstabe A, ähnlich PICCARD, Wasserzeichenkartei Nr. 26500 (1418); Spiegelblätter vorne ein Streifen Papier und ein Pergamentfragment: Anfang eines (Muster-) Briefes 
an einen Papst, 15. Jh., hinten Papier. Im vorderen Spiegel Exlibris des Chorherrenstifts Beromünster (Wegmann, Exlibris, Nr. 619). Auf dem Vorder- und Hinterdeckel Spuren einer Beschriftung.

Herkunft: Die Wasserzeichen weisen auf eine Entstehung im Gebiet der Bistümer Basel bzw. Konstanz in der ersten Hälfte des 15. Jahrhunderts, wobei die verschiedenen Teile offenbar zu unterschiedlichen Zeitpunkten geschrieben wurden.

Besitzer: Ludwig Zeller von Brugg, siehe Nachtrag 94v. Zu ihm: Kopp, Stiftsbibliothek, I, S. 11, Clara Müller, Geschichte des aargauischen Schulwesens vor der Glaubenstrennung, Aarau 1917, S. 95 (Nr. 171) und 97 (Nr. 231); Erster datierter Schweizer Druck, S. 15f.; SIDLER, Bildungsverhältnisse, S. 175f. (Nr. 160). Im Catalogus von 1763 als Classis Nona Nr. 30 verzeichnet. Im vorderen Spiegel Exlibris des Chorherrenstifts Beromünster.

Literatur: Kopp, Stiftsbibliothek, II, S. 20; Bruckner, Scriptoria 9, S. 28; Heinrich Hänger, Mittelhochdeutsche Glossare und Vokabulare in schweizerischen Bibliotheken bis 1500, Berlin/New York 1972, S. 42f.; BüCHLER, Beromünster, S. 166; CMD-CH 2, Nr. 101; 'Liber ordinis rerum' (Esse-EssenciaGlossar), hrsg. v. Peter Schmitt, Tübingen 1983, Bd. 1, S. XXIf.

$\mathrm{A}^{\mathrm{r}}-\mathrm{D}^{\mathrm{v}}$ leer.

Teil 1:

$1^{\mathrm{r}}-59^{\mathrm{v}}$ Liber ordinis rerum. > Primo de deo et creaturis<. Res, Ens: Ding. Esse, Essencia: Wesen. Natura: Natur. Substancia: Substancz ... - ... > Metuitiva secuntur< At: hoho. At. Tat. Multa sunt hiis similia, ut 'a'vel clamatoria seu clamancia vectorum, venatorum, pastorum ad bestias, que tamen numquam vel raro reperiuntur ydiomate Latine, ergo pro fine Mariam virginem ponam, et sic est finis etc. Anschliessend in Rot: Ihesus Maria sint nobiscum hic et ubique. Thematisch geordnetes Vokabular. Schмiтt, S. 1-753 (Sigle Be1); Renward Brandstetter, Der Vocabularius Beronensis, in: Der Geschichtsfreund 41 (1886), S. 173-186 (auszugsweiser Abdruck und Untersuchung); Hänger, S. 42f.; Peter Schmitt, Artikel 'Liber ordinis rerum', in: Verfasserlexikon², Bd. 5 (1985), Sp. 765-767, Hs. erwähnt.

$60^{\mathrm{r}-\mathrm{v}}$ leer.

Teil 2:

$61^{\mathrm{r}}-92^{\mathrm{v}}$ Glossarium hymnorum. Lateinische Texte von 55 Hymnen in Prosawortordnung im Wechsel mit einer deutschen Übersetzung, enthaltene Hymnen: AH 51 Nr. 23; $61^{v}$ AH 50 Nr. 4; 62v AH 51 Nr. 24, 31;

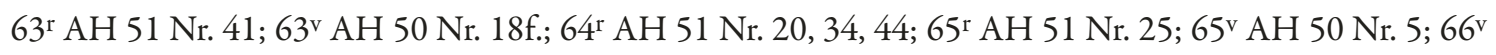
AH 51 Nr. 35, 26; 67r AH 50 Nr. 22; 67v AH 51 Nr. 36, 27; 68 AH 50 Nr. 23; 69r AH 51 Nr. 37, 28; 70r AH 50 Nr. 24; 70r AH 51 Nr. 38, 29, 32, 39, 30, 33, 40, 47-50; 75r AH 50 Nr. 53; 76r AH 51 Nr. 54f., 59, 61; 79r AH 50 Nr. 67, 66; 81v AH 51 Nr. 83, 2, 84, 89, 88; 84v AH 50 Nr. 144; 85r AH 51 Nr. 92, 91, 188 (4-6); 87r AH 50 Nr. 103 (5, 9); 87r AH 51 Nr. 188 (3); 87v AH 50 Nr. 96; 89r AH 51 Nr. 74 (3), 188 (1, 2, 6); 89v AH 50 Nr. 103 (4); 90r AH 51 Nr. 123; 90v AH 50 Nr. 72, 156; 92r AH 52 Nr. 195. [P] rimo dierum omnium etc. Exposicionem: Primo, suple 'die': An dem ersten tag. Omnium dierum: aller tag. Exstat: gewesen ... - ... Miseram prolem: das arm geschlecht. Eve: der frowen. A sompno: von dem schlaff. Mortis: des todes. Amen, daz werde war hüt und Ewenklich. Hänger, S. 43. Parallelüberlieferung: München, Bayerische Staatsbibliothek, Clm 13698, 28 r $-45^{\mathrm{r}}$, vgl. Nikolaus Henkel, Mittelalterliche Übersetzungen lateinischer 
Schultexte ins Deutsche, in: Poesie und Gebrauchsliteratur im deutschen Mittelalter. Würzburger Colloquium 1978, hrsg. v. Volker Honemann, Tübingen 1979, S. 168f., Anm. 11.

$93^{\mathrm{r}}-94^{\mathrm{v}}$ Octo species turpitudinis. Nachtrag (1461). Octo sunt turpitudines, quas coningales inter se exercere solent ... - ... nec hic nec in futuro dimittitur sed eternaliter dampnabitur. Ergo custodiat se unusquisque a talibus peccatis etc. Bloomfield, Incipits, Nr. 3589. Anschliessend Schreibervermerk: Hec sunt octo species luxurie per me Ludvicum Zeller de Brugg. 1461'. Ieronimus: Mulier pulchra et fatua.

$95^{\mathrm{r}-\mathrm{v}}$ leer.

Teil 3:

$96^{\mathrm{r}}-99^{\mathrm{v}}$ leer.

$100^{\mathrm{r}}-114^{\mathrm{v}}$ Sermones. $>$ De assumpcione virginis gloriose sermo bonus $<$. Elevata est magnificencia tua ... (Ps 8,2). Karissimi, pro introductione huius thematis dicit philosophus $4^{\circ}$ Phisicorum: Quanto unaqueque res est melius et perfectius, tanto sibi debetur locus altior ... $104^{\mathrm{r}}>$ In festo purificacionis sermo $<$. Viderunt oculi mei ... (Lc 2,30) Et sunt verba sancti Symeonis adventum filii in carnem desiderantis totum genus humanum alloquens ... $106^{\mathrm{r}}>$ In festo concepcionis virginis gloriose $<$. Anna concepit filium (I Sm 1,20). Karissimi, licet hoc verbum de matre Samuelis prophete sit dictum, tamen convenienter possunt dici de sancta Anna, matre matris Christi ... $109^{\mathrm{r}}$ $>$ Incipit sermo bonus de passione Christi<. O vos omnes, qui transitis ... (Lam 1,12). Karissimi, sicut scitis quod mos predicancium est in principio ad beatam virginem recurrere ... Anschliessend: Nota tres raciones, quare decuit beatam virginem a peccato originali preservari. Prima est quia peccatum originale excedit veniale ... Item in quinto decretalium tytulo de penitentia et remissione capitulo Omnis utriusque sexus dicitur ibidem quod omnis homo tenetur in anno semel confiteri ...

Teil 4:

$115^{\mathrm{ra}}-190^{\mathrm{vb}}$ Sermones. 1. Adventssonntag - Gründonnerstag. 44 Predigten, davon 4 auf Verweisen aufbauend. Initien im Register. > Prima dominica de adventu<. Benedictus qui venit ... (Mt 21,9). Verba proposita dicta sunt de adventu Christi in carnem. In adventu autem suo in carnem, attulit nobis Christus $x$ benedictiones ... 132 $2^{\text {ra }}$ Post consumati sunt ... (Lc 2,21). Hic notantur duo ... ähnlich SCHNEYER, Bd. 3, S. 378, Nr. 44; $141^{\text {va }}$ SChNeyer, Bd. 1, S. 473, Nr. 11 (Bertholdus Ratisbonensis), mit anderem Schluss; $145^{\text {rb }}$ SCHNEYeR, Bd. 1, S. 473f. Nr. 14 (Bertholdus Ratisbonensis); 147va [S] imile factum est regnum celorum ... (Mt 13,24). In hoc notantur quatuor ... ähnlich SCHNEYeR, Bd. 1, S. 752, Nr. 63; 150vb SCHNEYER, Bd. 1, S. 752, Nr. 67; 154vb SchneYer, Bd. 3, S. 224, Nr. 39 (mit anderem Schluss); 164vb SCHNEYer, Bd. 8, S. 750, Nr. 28; $167^{\mathrm{va}}[\mathrm{D}]$ uctus est Ihesus in desertum ... (Mt 4,1). De hoc inquire infra de confessore non pontifici, in sermone Beatus vir qui non sufferet temptacionem. 169 $9^{\text {ra }}$ SCHNEYER, Bd. 1, S. $482 \mathrm{f}$. Nr. 132 (Bertholdus Ratisbonensis), mit anderem Schluss; $177^{\mathrm{vb}}$ Mulier, magna est ... (Mt 15,28). Hodie de fide sancte ecclesie loqui proponimus ... Require autem de fide infra xii dominica post Pentecosten in sermone Beati oculi. $178^{\text {ra }}$ SCHNeyer, Bd. 1, S. 499, Nr. 338 (Bertholdus Ratisbonensis), mit anderem Schluss; 179vb [Q] ui non est mecum ... (Lc 11,23). Nota igitur, quod sicut tunc multi sequebantur dominum et curabantur ab eo ut hodiernus demoniacus, ita et nunc multi secuntur eum ... De timore autem et amore inordinato require infra de communi unius martiris in sermone Nolite timere. 180 ${ }^{\mathrm{ra}}$ [L]etatus sum ... (Ps 121,1) Hodiernum officium plenum est gaudio ... ähnlich SCHNeYer, Bd. 2, S. 370, Nr. 25. 189va [S] olvite et adducite michi ... (Mt 21,2) Mt xxi. Quis possit peccatorem absolvere? De hoc require in kathedra Petri in primo sermone. 
$191^{\mathrm{r}}$ Oratio Christi in cruce. Nachtrag. Sicio primo ad te, pater, ut respicias hodie de immenso solio glorie tue ... - ... Item sicio ad vos omnes qui transitis per viam, ut attendatis et videatis, si est dolor sicut dolor meus. $191^{\mathrm{v}}$ leer.

Teil 5:

192r-230r UDALRICUS DE CAMPO LILIORUM, Concordantiae caritatis. Temporale, unvollständig: 1. Adventssonntag - 1. Fastensonntag. Iohannes apocalipsi 4 vidit sedem positam in celo ... Sedes in celo posita est Christus ... - ... Experimentator dicit, quod cervus cornibus gloriatur //. Bricht am Ende der Seite ab. Herbert Douteil, Die Concordantiae caritatis des Ulrich von Lilienfeld. Edition des Codex Campililiensis 151 (um 1355). Bd. 1: Einführungen, Text und Übersetzung, hrsg. v. Rudolf SunTrup u. a., Münster 2010, S. 6-32, 36, 34, 38-72. Die Reihenfolge von Evangelium, Figura und Natura folgt meist dem Schema abdce(f), ab $195^{\mathrm{r}}$ werden die Verse zu den hier fehlenden Bildern in die jeweiligen Textabschnitte integriert (anfangs noch unsystematisch). Die deutschen Übersetzungen der lateinischen Tier- und Pflanzennamen werden im Text ausgelassen, aber vereinzelt am Rand angegeben. Dort werden ab $197^{\mathrm{r}}$ systematisch die Abschnitte mit der Bezeichnung des Sonntags, figura und natura gekennzeichnet. RB 8276; BLOOMFIELD Nr. 2811. $230^{v}-233^{v}$ leer. GREGORIUS MAGNUS; NICOLAUS MAGNI DE IAWOR

Papier, 311 Blätter, $21-21,5 \times 14-14,5 \mathrm{~cm}$

Drittes Viertel des 15. Jahrhunderts; 1470

Wasserzeichen, Lagen, Foliierung: Wasserzeichen: Bl. 1-47 Dreiberg, ähnlich PICCARD, Wasserzeichenkartei Nr. 151092, in zwei Varianten; B1. 48 und 59 Buchstabe P, ähnlich PICCARD, Wasserzeichenkartei Nr. 111950; Bl. 51-106 Ochsenkopf, PICCARD, Wasserzeichenkartei Nr. 79954 (1474) und 79957 (1474); Bl. 109-226 Nr. 74693 (1469) und eine Variante; Bl. 233-310 Nr. 77035 (1459) und eine Variante. Lagen: $3 \mathrm{VI}^{36}+(\mathrm{VI}-1)^{47}+21 \mathrm{VI}^{299}+(\mathrm{VI}-1)^{310}$, nach Blatt 47 und 310 jeweils ein Blatt herausgerissen. Zwei Lagenzählungen, Bl. 1-36 am Schluss der Lagen: primus sexternus - 3 ${ }^{u s}$, Bl. 240-288 zu Beginn der Lagen: $2^{u s}$-sextus. In Teil 2 (Bl. 108-299) Reklamanten sowie alte Foliierung: $1\left(108^{\mathrm{r}}\right)-4\left(111^{\mathrm{r}}\right)$. Neuere Foliierung: A. $1-310$.

\section{Einrichtung und Ausstattung:}

Teil 1 (Bl. 1-107, 3. Viertel 15. Jh.): Vertikale Begrenzung des Schriftraums mit Tinte. Schriftraum 13,5-15× 7,5-9,5, 28-39 Zeilen. Jüngere gotische Buchkursive mit Schleifen von der Hand des Jacobus Hilflin. Überschriften in vergrösserter Schrift. $1^{\mathrm{r}}-79^{\mathrm{r}}$ und $101^{\mathrm{v}}-106^{\mathrm{r}}$ rubriziert, 2-4zeilige rote Lombarden. Marginalien zur Erschliessung des Inhalts, z. T. beschnitten.

Teil 2 (Bl. 108-310, 1470): Begrenzung des Schriftraums mit Stift, 168 ${ }^{\mathrm{r}}-227^{\mathrm{v}}$ mit Tinte. Schriftraum 15-16× 8-9, 27-37 Zeilen. Jüngere gotische Buchkursive mit Schleifen von der Hand des Ludwig Zeller. 108 ${ }^{\mathrm{r}}-220^{\mathrm{v}}$ Namen der Dialogpartner und Zwischenüberschriften in vergrösserter Schrift, z. T. in Auszeichnungsschrift. Auf den Rectoseiten Buchzählung als Kopftitel; Kapitelzählung am Seitenrand. 228r $-310^{v}$ Überschriften und 
Bibelzitate in vergrösserter Schrift, Stellenangaben unterstrichen. Einzelne Marginalien zur Erschliessung des Inhalts. Raum für 2-4zeilige Initialen ausgespart. $108^{\mathrm{r}}, 112^{\mathrm{v}}, 123^{\mathrm{v}}$ und $196^{\mathrm{v}} 2-4$ zeilige schwarze Initialen mit Federverzierung, $123^{\mathrm{v}}$ und $196^{\mathrm{v}}$ fischförmig.

Korrekturen und Nachträge: Teil 1: Wenige Korrekturen des Schreibers Jacobus Hilflin, z. B. 1, 37v, 60v, 90v; von seiner Hand auch der Nachtrag 39v: Dum propter mimos celebras maledicte sacerdos, Defraudas stultos et deducis ad Tartara multos. 16v, 40v , 54v Handweiser. Nachträge von der Hand des Ludwig Zeller: Av, 72r-95 kurze Inhaltsangaben am oberen und seitlichen Rand, $101^{\mathrm{r}}$ Habetur etiam in forma summe Bysani, $101^{\mathrm{v}}-106^{\mathrm{r}}$ Ergänzungen zu beschnittenen Inhaltsangaben am Seitenrand, $106^{\mathrm{r}}$ Kaufvermerk. Teil 2: Korrekturen des Schreibers Ludwig Zeller, z. B. 117r, 156r $187^{\mathrm{r}}, 233^{\mathrm{r}}, 288^{\mathrm{v}}$; von seiner Hand auch der Nachtrag $224^{\mathrm{r}-\mathrm{v}}$ (siehe Inhalt). Notazeichen; 242v, 279v und 297v Handweiser.

Einband: Mit hellem Leder bezogene Holzdeckel, 15. Jh., Rückenleder grösstenteils abgerissen; auf dem Rückdeckel Streicheisenlinien. Zwei nach vorn greifende Kantenschliessen aus Messing und Eisen, Riemenbefestigungen hinten Vierpassblüten. Blau-rot-weisse geflochtene Kapitale. Vorsatzblatt (A) Papier, Wasserzeichen wie Bl. 1-47; Spiegelblätter Papier, Fragmente einer Abschrift von Petrus Lombardus, Sententiae, lib. 1, dist. 1, cap. 3 und lib. 1, dist. 2, cap. 3-4, Magistri Petri Lombardi Sententiae in IV libris distinctae, Bd. 1.2, Grottaferrata 197133, S. 58 und 63, von der Hand Ludwig Zellers, mit Marginalien. Jede zweite Lage mit Pergamentstreifen verstärkt, die erste und letzte Lage mit weiteren Streifen mit dem Deckel verbunden: Fragmente liturgischer Handschriften, u. a. eines neumierten Missale, sowie einer lat. Urkunde, 13./14. Jh. Im vorderen Spiegel Exlibris des Chorherrenstifts Beromünster (Wegmann, Exlibris, Nr. 619). Auf dem Vorderdeckel oben Spur eines verlorenen Titelschilds. Rückenschild: Lavacrum Conscientiae Sacerdotum Secularium, et Canonicorum in Regula viventium. No 6, entsprechend dem Catalogus von 1826.

Herkunft: Teil 1 geschrieben von Jacobus Hilfflin, siehe Schreibervermerke 52v, $57^{\mathrm{r}}$ und $100^{\mathrm{r}}$, gemäss Kaufvermerk $106^{\mathrm{r}}$ vor dem 6. 12. 1475; zu ihm CMD-CH 2, S. 224 . Teil 2 geschrieben von Ludwig Zeller und auf den 19. August 1470 datiert, siehe Schreibervermerk 220v.

Besitzer: Teil 1: Jacobus Hilflin, Ludwig Zeller, siehe Kaufvermerk 106r. Teil 2: Ludwig Zeller, 310v Besitzzeichen $L$ [udowic] $Z$., zu ihm: Kopp, Stiftsbibliothek, Bd. 1, S. 11, Clara Müller, Geschichte des aargauischen Schulwesens vor der Glaubenstrennung, Aarau 1917, S. 95 (Nr. 171) und 97 (Nr. 231); Erster datierter Schweizer Druck, S. 15f.; SIDLER, Bildungsverhältnisse, S. 175f. (Nr. 160). Im vorderen Spiegel Exlibris des Stifts Beromünster. Im Catalogus von 1763 als Classis Nona Nr. 27 verzeichnet, im Nachtrag dazu auf $53^{\mathrm{r}}$ ohne Nummer, im Catalogus von 1826 als Nr. 6.

Literatur: Kopp, Stiftsbibliothek, Bd. 2, S. 17f.; BrUCKner, Scriptoria 9, S. 30; BÜCHLER, Beromünster, S. 166f.; CMD-CH 2, Nr. 102.

Teil 1:

$\mathrm{A}^{\mathrm{r}-\mathrm{v}}$ Sententiae. 20 Sentenzen mit Zuschreibung an verschiedene Autoren. 8vo Ethicorum: Qui fingit se amicum et non est, peior est illo, qui facit falsam monetam ... Anschliessend, wohl von der Hand des Ludwig Zeller: xxiii q i. Militare non est delictum ... iure culpantur. Decretum Gratiani, C. 23, qu. 1, c. 4 und 5, Aemilius FrIedberg, Corpus iuris canonici, pars prior, Leipzig 1879, Sp. 892-893.

$1^{\mathrm{r}}-47^{\mathrm{v}} \mathrm{JACOBUS}$ DE GRUITRODE (?), Lavacrum conscientiae. > Incipit Lavacrum consciencie sacerdotum secularium et canonicorum regulariter vivencium cuiusmodi doc [trine $]<$ (Beschnitt). Lavamini, mundi estote. Yesaie. Ex quo non communem statum cum popularibus sed segregatim nos clerici ab eis habemus et longe 
digniorem ... - ... > Sequitur aliud exemplum<. Narrat Rabanus, quod in diocisi Monasteriensi erant duo fratres ... Quadam autem vice cum dictus Haymo in lecto cum concubina pausaret tonitruum de celo cum ingentifra//. Bricht am Seiten- und Lagenende ab. 14 Kapitel und zwei Exempla, stark gekürzt und umgestellt. GW M10700: [Jacobus de Gruytrode], Lavacrum conscientiae, [Leipzig: Gregor Boettiger, um 1495], die Exempla fehlen fast durchgehend. Bloomfield, Incipits, Nr. 2902; Dictionnaire de spiritualité, Bd. 8, Paris 1974, Sp. 38.

$48^{r}-52^{v}$ Speculum peccatoris. $>$ Speculum peccatorum a beato Augustino compilatum<. Quoniam karissime in via huius fugientis vite simus, dies nostri sicut umbre pretereunt ... - ... Superest igitur, ut diligenter discas, quomodo sane sapias, quomodo recte intelligas, quomodo novissima tua prudenter provideas, ut per hunc eternam dampnacionem evadas et cum domino nostro Ihesu vitam eternam possideas etc. Amen. PL 40, Sp. 983-992. Bloomfield, Incipits, Nr. 4918 (Hs. nicht erwähnt). Anschliessend Schreibervermerk: Jacobus Hilflin.

$52^{\mathrm{v}}-57^{\mathrm{r}}$ De dispositione ad celebrandum missam. >Incipit quoddam capitulum de disposicione ad celebrandum missam valde pulchrum, omni sanctitate et devocione repletum etc. etc. < Quia vero sacrificium corporis et sangwinis Christi, domini nostri Ihesu Christi, quod in missa conficitur et sumitur in memoriam eius veneracionis et excellentissime caritatis, qua dilexit nos, dignissimum est et preclarissimum ... - ... Est magna abusio et gravis iniuria et irreverencia circa altare, scilicet ibi deum offendere, ubi debet placari, ibi augere culpam, ubi debet defleri in presencia angelorum assistencium dei maiestati. Et hec hic dicta sufficiant. Amen. Vgl. Mailand, Biblioteca Ambrosiana, E 17 Sup., 145r-155r. Anschliessend Schreibervermerk: Jacobus Hilffin.

$57^{r}-59^{v}$ leer.

60r-100 ${ }^{\mathrm{r}}$ GUILLELMUS PARISIENSIS (?), Dialogus de septem sacramentis. > De baptismo. Gwido. Conclusiones de sacramentis $7^{\text {tem }}<$ Conclusiones sacramentorum de scriptis fratris Thome et aliorum doctorum extracte. Quoniam me sepius rogasti, Petre, postquam sacerdocii sacrum ordinem suscepisti ... - ... Pe. Multum difuse de singulis sacramentis dixistis, quapropter merito contentor. Deo gracias. GW 12028: Dialogus doctissimi viri Guillermi episcopi Parisiensis de septem sacramentis, Paris: Georg Mittelhus, 20. 9. 1489, stark gekürzt im hinteren Teil des Sacramentum penitentiae, das Sacramentum matrimonii und das Sacramentum ultimae unctionis sind umgestellt, das letztere zudem gekürzt. KaEppeli, Scriptores, Nr. 1618; Carmen Cardelle De Hartmann, Lateinische Dialoge 1200-1400. Literaturhistorische Studie und Repertorium, Leiden/ Boston 2007, S. 488-491 Nr. R38. Anschliessend Schreibervermerk: Jacobus Hilffin.

100v-101 ${ }^{\mathrm{r}}$ BARTHOLOMAEUS PISANUS, Summa de casibus conscientiae. Exzerpt. Ex Suma Bysani. $>$ De horis canonicis <. Utrum clerici teneantur ad horas canonicas ... - ... Clerici et religiosi commorantes cum cardinalibus aut cum episcopis possunt se coaptare illis in divinis officiis, ut ad alia tenentur, ut dicitur de cele. miss. dignum in Cle. Ex summa confessorum. GW 3450: Bartholomaeus de Sancto Concordio, Summa de casibus conscientiae, [Italien], 21. 10.1473, $73^{\mathrm{r}-\mathrm{v}}$.

$101^{\mathrm{v}}-106^{\mathrm{r}}$ De expeditione infirmorum. $>$ De procuracione infirmorum $<$. Quia circa infirmos maius est periculum, ideo cum ipsis consulcius procedendum ... - ... si est ibi aqua benedicta, aspergat infirmum et lectum ipsius circumquaque dicens: Exurgat Deus ... (Ps 67,2). Et sic domino committet infirmum etc. etc. Deo gracias. Rainer Rudolf, Ars moriendi. Von der Kunst des heilsamen Lebens und Sterbens, Köln/Graz 1957, 82 Anm. 1; Michaud-Quantin, Sommes de casuistique et manuels de confession au moyen âge, Louvain 1962, S. 93 und Index.

$106^{\mathrm{r}}$ Kaufvermerk. Iste liber venditus est Ludowico Zeller per dominus (sic) Jacobum Hilfin adiutorem in Aröw. $1475 \mathrm{Ny}$ [colay], siehe Nachträge.

$106^{\mathrm{v}}-107^{\mathrm{v}}$ leer. 
Teil 2:

108 ${ }^{\mathrm{r}}-220^{v}$ GREGORIUS I PAPA, Dialogi. Quadam die nimiis quorumdam secularium tumultibus depressus, insulis negociis quibus plerumque cogimur soluere etiam quod nos certum est non debere, secretum locum pecii amicum meroris ... - ... fidenter dico, quia salutaris hostie post mortem non indigebimus, si ante mortem deo hostia ipsi fuerimus. Deo gracias. Gregorii Magni Dialogi. Libri IV, hrsg. v. Umberto Moricca, Rom 1924, mit abweichender Kapiteleinteilung. Anschliessend Schreibervermerk: Explicit liber dyalogorum beati Gregorii pape urbis Romane per Ludowicum Zeller tunc adiutorem in Aröw. Anno incarnationis 1470, decimo quarto Kalendas Septembris. Sequitur tabula librorum.

$221^{\mathrm{r}}-223^{\mathrm{v}}$ Tabula. > Capitula primi libri dyalogorum <. 1. De Honorato abbate monasterii Fundensis ... - ... Capitulum ultimum. De laxandis culpis alienis ut nostre relaxentur. Anschliessend Schreibervermerk: Deo gracias. Orate pro scriptore. Manus mala, intensio bona etc. $L$ [udwig] $Z$ [eller].

$224^{\mathrm{r}-\mathrm{v}}$ Excerpta canonistica. Nachtrag. > Hiis interdicitur sacramentum divinissime eucharistie iuxta decreta et statuta sanctorum patrum. 1471<. Item excommunicatis, suspensis et interdictis ... - ... Item omnibus inimicicias retinentibus... Et cum hiis articulis, si que statuta ordinarii viduntur neccessaria, ut est statutum domini Burckhardi de parrochiis et parrochianis et similia etc.

$225^{\mathrm{r}}-227^{\mathrm{v}}$ leer.

$228^{r}-310^{v}$ NICOLAUS MAGNI DE IAWOR, Sermo super quattuor passionibus domini nostri Ihesu

Christi. > Passio domini nostri Ihesu Christi<. Vorangestellt: Item nota textum Danielis nono et invenies directe ad sensum probacionem contra Iudeos, si saltem bene computes 70 septimanas. Danielis nono: In anno primo ... - ... et usque ad consumacionem et finem perseverabit desolacio. Amen. Item nota ordinem per totam Bibliam: Primo Gen.... 229r Beginn des Sermo: [S]citis quia post biduum pasca fiet etc. Mt 26. Ubi nota quod passio domini nostri Ihesu Christi scribitur a $M^{t}$ capitulo octavo et Marci 14 et ... Matheus tamen diffusius et expressius pertractat et concordat cum eo Marcus ... - ... Cuius flius unigenitus est pro salute nostra passus, ut nos in eternam vitam revocaret. Quod nobis concedat Ihesus Christus, qui sine fine vivit et regnat, Amen. RB Nr. 6002, 1 und 9451.

Papier, 181 Blätter, $21,5 \times 15 \mathrm{~cm}$

Erste Hälfte des 15. Jahrhunderts

Wasserzeichen, Lagen, Foliierung: Wasserzeichen: Bl. 1-48, 61-72, 122-131 Rispe mit drei Trauben, Briquet Nr. 13023 (1430); Bl. 50 und 53 Ochsenkopf, Piccard, Wasserzeichenkartei Nr. 79339 (1432/33); Bl. 75-120 Säule, PiCCARD, Wasserzeichenkartei Nr. 100064 (1433); Bl. 134-168 Frau, PicCard, Wasserzeichenkartei Nr. 21232 (1432); Bl. 169-180 Schlüssel, Piccard, Wasserzeichenkartei Nr. 120947 (1426) und 120990 (1426). Lagen: 15 VI'180. Reklamanten. Alte Foliierung: 98 (169) - 109 (180). Neuere Foliierung: A. 1-180.

\section{Einrichtung und Ausstattung:}

Teil 1 (Bl. 1-132): Begrenzung des Schriftraums mit Stift, Schriftraum 15-16 × 9,5-10,5, 28-35 Zeilen. Jüngere gotische Buchkursive mit Schleifen von einer Hand. Rubriziert, rote Überschriften und Unterstreichungen. 2-4zeilige rote Lombarden, am Rand Vorgaben des Schreibers. 
Teil 2 (Bl. 133-168): Begrenzung des Schriftraums mit Stift, Schriftraum 15-15,5 × 10,5-11, 27-30 Zeilen. Jüngere gotische Buchkursive von einer Hand. Raum für 2-3zeilige Initialen freigelassen, nicht ausgeführt. Teil 3 (Bl. 169-180): Begrenzung des Schriftraums mit Stift, Schriftraum $16 \times 9,5$, 30-36 Zeilen. Jüngere gotische Buchkursive von einer Hand. Rubriziert, rote Überschriften. Zweizeilige rote Lombarden. Am Rand alphabetische Gliederung in 35 Textabschnitte.

Korrekturen und Nachträge: Korrekturen von der Hand der Schreiber, z. B. 10v $44^{\mathrm{v}}, 77^{\mathrm{v}}$ und $107^{\mathrm{r}}, 140^{\mathrm{r}}$ und $165^{\mathrm{r}}, 171^{\mathrm{v}}$ und $177^{\mathrm{r}}$. Gliedernde Marginalien $45^{\mathrm{v}}-48^{\mathrm{r}}, 62^{\mathrm{r}}-63^{\mathrm{r}}, 82^{\mathrm{v}}, 105^{\mathrm{r}}-106^{\mathrm{v}}, 135^{\mathrm{v}}, 141^{\mathrm{v}}$ und $^{\mathrm{s}} \mathrm{7}^{\mathrm{r}}$, zudem $93^{\mathrm{r}}$ ein Quellennachweis von der gleichen Hand wie der letzte Nachtrag auf $131^{\mathrm{v}}-132^{\mathrm{r}}$. Notazeichen $32^{\mathrm{v}}$, $35^{\mathrm{r}-\mathrm{v}}, 76^{\mathrm{r}} .131^{\mathrm{v}}-132^{\mathrm{r}}$ und $167^{\mathrm{r}}-168^{\mathrm{r}}$ zeitgenössische Nachträge.

Einband: Mit himbeerrotem Leder bezogene Holzdeckel, 15. Jh., Vorderdeckel lose, Leder des Rückdeckels teilweise abgerissen. Ehemals zwei nach hinten greifende Langriemensschliessen, Riemenbefestigung der oberen im Vorderdeckel erhalten. Geflochtene Kapitale aus Leder. Schnitt grünlich gelb gefärbt. Vorsatzblatt (A) Papier, Wasserzeichen: Buchstabe A, PICCARD, Wasserzeichenkartei Nr. 26501 (1418). Im Falz der ersten und der letzten Lage Pergamentfragmente einer glossierten Hs. des 14. Jhs. In den Spiegeln Abklatsch einer liturgischen Hs., 14. oder 15. Jh. Im vorderen Spiegel Exlibris des Chorherrenstifts Beromünster (WEGMANN, Exlibris, Nr. 619). Auf dem Vorderdeckel Spur eines Titelschildes. Auf dem Rücken (falsches) Titelschild: Tractatus de decem Praeceptis. No 10, 18. Jh.

Herkunft: Die drei Teile können aufgrund der Wasserzeichen zuverlässig noch in die erste Hälfte, wohl in das zweite Viertel des 15. Jahrhunderts datiert werden; Teil 3 ist möglicherweise ein paar Jahre älter als die anderen beiden.

Besitzer: Ludwig Zeller: Ar Liber Ludowici Zeller, Ad Bibliothecam pertinet dominorum. Im vorderen Spiegel Exlibris des Chorherrenstifts Beromünster. Das Rückenschild entspricht dem Eintrag als Nr. 10 im Catalogus von 1826, doch stimmt der Inhalt nicht damit überein, sondern mit C 13. Im Catalogus von 1763 als Classis Nona Nr. 34 verzeichnet.

Literatur: BRUCKNER, Scriptoria 9, S. 30, zu dieser Signatur, jedoch mit falschen Angaben (siehe Besitzer); BüCHLER, Beromünster, S. 167.

$\mathrm{A}^{\mathrm{r}}$ Besitzeintrag, sonst leer.

Av leer.

Teil 1:

$1^{\mathrm{r}}-131^{\mathrm{r}}$ Sermones. 1. Advent -24 . Sonntag nach Pfingsten. $>$ Dominica prima adventus<. Erunt signa in sole et luna et stellis etc. Istud ewangelium scribitur Luce $2^{\circ}$ (Lc 21,25). Legitur in eodem capitulo, quod dominus postquam vidit quid partarent divites et seniores populi vidit ibi unam viduam (Lc 21,1-2) ... $1^{\mathrm{v}}$ Istud est ewangelium in sensu suo: Nota quod Ysydorus dicit, quod in quolibet iudicio requiruntur $4^{\text {or }}$ persone ... $2^{\mathrm{v}}$ $>$ Dominica $2^{a}$ adventus $<$. Cum audisset Iohannes in vinculis opera Christi (Mt 11,2). Istud ewangelium scribitur $M^{t} x i$, quia legitur in precedenti capitulo quod Ihesus dixit ad discipulos suos: Ecce ego mitto vos ... $3^{\mathrm{v}}$ Istud est ewangelium in sensu suo: Hodie enim et isto tempore peragitur festum de adventu domini. Quare est notandum quod in sacra scriptura legimus de quadruplici adventu domini qui signatur per $4^{\circ}$ dominicas que sunt in adventu domini per ewangelia que leguntur illis dominicis diebus ... 60 Predigten, die Auslegung des Evangeliums «sensu suo» meist nach längerer Paraphrase des Bibeltextes, die einzelnen stereotyp eingeleiteten Initien im Register. 
$131^{\mathrm{v}}-132^{\mathrm{r}}$ Nachträge. Iste gladius quem Iohannes in Apocalipsi vidit exeuntem de ore dei ex utraque parte accutum ... Item rethorica scit persuadere iudici ... Hic nota: Si septem artes liberales faciunt hominem liberum a curis secularibus ... 132r Nota, Hugo libro de anima dicit: Frustra cordis oculos erigit ad cognoscendum deum ... $132^{\mathrm{v}}$ leer.

Teil 2:

133 $3^{\mathrm{r}}-166^{\mathrm{v}}$ Tractatus de adventu spirituali. [E]cce rex tuus venit tibi, $M^{t} 21$ (Mt 21,5). Hec verba licet ad literam dicta sunt de adventu Christi in carnem, tamen pro spirituali intellectu accipi possunt de adventu spirituali in devotam animam sive mentem ipsam videlicet exhortando ad preparacionem excitando per verba premissa: Ecce rex etc.... 137r [E]cce rex tuus venit etc. Visum est de tribus preambulis ante adventum verbi et eius ingressum in mentem requisitum ... $142^{\mathrm{v}}$ [E]cce rex tuus venit tibi. Visis primo preambulis quibus se anima devota ad adventum domini et verbi disponat et $2^{\circ}$ tribus aliis quibus ipsum verbum gratanter et honorifice suscipiat, videndum est nunc quid ipsi verbo in suo regno ostendere debeat ... $152^{\mathrm{r}}[\mathrm{E}]$ cce rex tuus venit tibi etc. Viso primo qualiter mens devota se ad adventum verbi disponat ... $157^{\mathrm{r}}[\mathrm{S}]$ uperius dictum de fontis mistica representacione $2^{\circ}$ de aque largiflua emanacione $3^{\circ}$ de ipsius fructifera degustacione ... - ... Ex gustu aque $3^{\circ}$ tribuitur mente devote virtutum //. Bricht am Ende der Seite ab.

$167^{\mathrm{r}}-168^{\mathrm{r}}$ Nachträge. Utrum ix peccata aliena quorum si unum in morte deprehenditur sic dampnarunt, ac si proprio peccato. Primum est iussio. Rest der Seite leer. $167^{\mathrm{v}}$ Karena dicitur a karencia hominum vel cibariorum. Nam illis quibus iniugitur (sic) karena debent xla diebus includi in aliquo loco secreto ... Darunter, von anderer Hand: Signum magnum ... (Apc 12,1). Quamvis verba ista per excellenciam communiter applicentur ad beatam virginem ... - ... de quibus habes in ultimo capitulo regule, considera diligencius regulam etc. Vgl. SCHNEYER, Bd. 9, S. 592, Nr. 135.

$168^{\mathrm{v}}$ leer.

Teil 3:

169 ${ }^{\mathrm{r}}-180^{\mathrm{v}}$ JOHANNES DE WERDENA, Sermones (Dormi secure). Ascensio domini - Nativitas Johannis Bapt. (Sanctorale, Serm. xxxii-xxxv) // deposita omni miseria in gloria resurrexit. Unde in signum buius dixit $M^{t}$ 26: Postquam autem resurrexero ... Corpora sanctorum resurgent sine ulla deformitate sine ulla corrupcione sine onere et difficultate propter quod spiritualia dicta sunt et resurgent fulgida sicut sol etc. $>$ De ascensione domini<. Dominus Ihesus postquam locutus est ... (Mc 16,19). Karissimi, dicit enim Philosophus 4. Phisicorum, quod quanto unaqueque res est melior et perfectior tanto debetur ei locus alcior et perfectior ... $176^{\mathrm{r}}$ Tres sunt qui testimonium dant ... (I Io 5,7). Karissimi, dicit enim Aristoteles primo Methaphisice, quod signum scientis est posse docere ... 179r Erit magnus coram domino ... (Lc 1,15). Karissimi, dicit enim Aristoteles 6 Ethicorum, quod omnis cognicio fit per similitudinem ... - ... quia magnificavit dominus misericordiam suam cum illa et congratulabantur ei. Ideo dixit //. Bricht ab. Stimmt überein mit GW M14900: [Johannes de Werdena], Sermones dormi secure de tempore et de sanctis, Basel: [Berthold Ruppel], 28. 6. 1489, N1 ${ }^{\mathrm{ra}}-\mathrm{O} 4^{\mathrm{ra}}$. SCHnEyer, 1350-1500, Johannes de Verdena Nr. 103-106. Vgl. Franz Josef Worstbrock, Artikel Johannes von Werden, in: Verfasserlexikon², Bd. 4 (1983), Sp. 811-813. 
Papier, 214 Blätter, $21 \times 14,5-15 \mathrm{~cm}$

Erstes Drittel des 15. Jahrhunderts

Wasserzeichen, Lagen, Foliierung: Ochsenkopf, PICCARD, Wasserzeichenkartei Nr. 78481 (1416), nebst einer Variante. Lagen: 18 VI214, das erste Blatt der ersten und das letzte Blatt der letzten Lage als Spiegelblätter in die Deckel geklebt. Von Bl. 185/186 ausgehend ein Wasserschaden im oberen Teil der Seiten. Reklamanten. Neuere Foliierung: 1-214.

Einrichtung und Ausstattung: Begrenzung des Schriftraums mit Tinte, Schriftraum 13,5-15 × 9-10,5, 28-31 Zeilen. Jüngere gotische Buchkursive mit Schleifen von zwei Händen (Handwechsel auf 210 r). Von der zweiten Hand durchgehend rubriziert, rote Überschriften und Paragraphenzeichen, zweizeilige rote Lombarden, $153^{\mathrm{r}}$ dreizeilig mit ornamentiertem Binnenfeld. Am Kopf der Rectoseiten Zählung der Viten in Rot, entsprechend den Inhaltsverzeichnissen: 1-99, $c 0-c 3$.

Korrekturen und Nachträge: Wenige Korrekturen der Schreiber, z. B. 2v $54^{\mathrm{v}}, 102^{\mathrm{r}}, 161^{\mathrm{v}}, 210^{\mathrm{v}}$; im Inhaltsverzeichnis $1^{\mathrm{r}}$ zwei Streichungen nachträglich wieder aufgehoben: non debet esse cancellatum. Zeitgenössisch: 38 v-39v (Vitusvita) und 103v. 153 ${ }^{\mathrm{r}-\mathrm{v}}$ Unterstreichungen im Inhaltsverzeichnis (Judocus, Ottilia, Valerius, Fridolin, Augustinus v. Canterbury, Ulrich, Oswald, Afra, Pelagius, Verena, Felix und Regula, Gallus, Othmar, Konrad). 1v (Inhaltsverzeichnis) und 213v Nachträge des zweiten Schreibers.

Einband: Mit himbeerrotem Leder bezogene Holzdeckel, 15. Jh.; Reste von zwei nach hinten greifenden Langriemenschliessen, Riemenbefestigungen aus Messing im Vorderdeckel sowie Messingstifte im Rückdeckel erhalten; B1. 211-214 vom unteren Stift durchbohrt. Spiegelblätter Papier (siehe Lagen), unter dem vorderen Spiegelblatt ein Pergamentfragment in Textualis (Lc 7,14), 14. Jh. Im vorderen Spiegel Exlibris des Chorherrenstifts Beromünster (WEgmann, Exlibris, Nr. 619). Im hinteren Spiegel Besitzeintrag: Iste liber spectat fratri Oswald ordinis fratrum minorum. Auf dem Vorderdeckel Spur eines verlorenen Titelschildes. Rückenschild: Vita et Passionale Sanctorum. No 11, entsprechend dem Catalogus von 1826.

Herkunft: Wasserzeichen und Schwerpunkte bei der Auswahl der Heiligen weisen auf eine Entstehung im Bistum Konstanz.

Besitzer: Oswald OFM, siehe Besitzeintrag im hinteren Spiegel; Ludwig Zeller von Brugg, siehe Besitzeintrag 213v. Zu ihm: Kopp, Stiftsbibliothek, I, S. 11, Clara Müller, Geschichte des aargauischen Schulwesens vor der Glaubenstrennung, Aarau 1917, S. 95 (Nr. 171) und 97 (Nr. 231); Erster datierter Schweizer Druck, S. 15f.; Sidler, Bildungsverhältnisse, S. 175f. (Nr. 160). Im Catalogus von 1763 als Classis Nona Nr. 32 verzeichnet, im Nachtrag dazu auf 53 ohne Nummer, im Catalogus von 1826 als Nr. 11.

Literatur: BRUCKNER, Scriptoria 9, S. 30; BüCHLER, Beromünster, S. 167.

$1^{\mathrm{r}-\mathrm{v}}$ Tabula. Die einzelnen Viten sind von 1-72 durchnumeriert, Nr. 6, 16, 22, 28, 33, 36, 38, 39, 42, 43, 48, 51, 59, 62, 63 und 69 doppelt vergeben, Nr. 20 im Inhaltsverzeichnis ausgelassen, im Kopftitel enthalten. $>$ Incipit tabula unius partis passionalis de sanctis<. De sancta Anastasia, 1. De sancto Paulo heremita, 2 ... Zuletzt Nachtrag: De sanctis Phylippo et Iacobo in fine libri. Anschliessend in Rot: Residuum quere 73 (vgl. 153 ${ }^{\mathrm{r}-\mathrm{v}}$ ).

$2^{\mathrm{r}}-213^{\mathrm{r}}$ JACOBUS DE VORAGINE, Legenda aurea. Gekürzte Fassung, mit Provincia-Anhang. >De sancta Anastasia<. Anastasia dicitur ab 'ana', quod est sursum, et 'stasis', quod est stans sive status, quia sursum stetit a viciis 
ad virtutes $\ldots-\ldots 152^{\mathrm{v}}$ Quo deposito et defuncto sedes imperii usque hodie vacat etc. etc. $2^{\mathrm{r}}$ Anastasia, $3^{\mathrm{r}}$ Paulus eremita, $4^{\mathrm{r}}$ Remigius, $5^{\mathrm{v}}$ Hilarius, $7^{\mathrm{r}}$ Macharius, $8^{\mathrm{v}}$ Felix in Pincis, $9^{\mathrm{v}}$ Marcellus, Antonius, $12^{\mathrm{v}}$ Julianus, $16^{\mathrm{v}}$ Septuagesima, 18 $8^{\mathrm{r}}$ Sexagesima, $19^{\mathrm{r}}$ Quinquagesima, 20 ${ }^{\mathrm{r}}$ Quadragesima, 21 ${ }^{\mathrm{v}}$ De ieiuniis quattuor temporum, 22

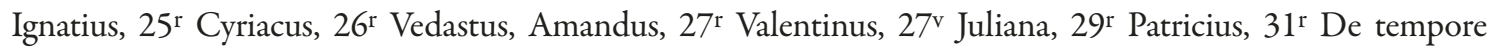
reconciliationis, Secundus, $32^{\mathrm{v}}$ Marcellinus, $33^{\mathrm{r}}$ Vitalis. $34^{\mathrm{r}}$ Qua[e] re sermonem de quadam virgine Anthyochie, qui sic incipit: Virgo quedam Anthiochie fuit ad tale signum etc. Gordianus und Epimachus, $34^{\mathrm{v}}$ Nereus und Achilleus, $35^{\mathrm{v}}$ Pancratius, $36^{\mathrm{v}}$ De tempore peregrinationis, Petrus und Marcellinus, 37v Primus und Felicianus, $38^{\mathrm{r}}$ Vitus und

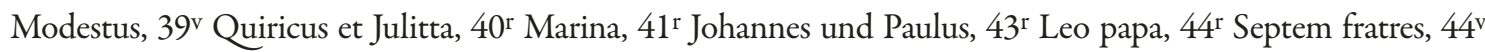

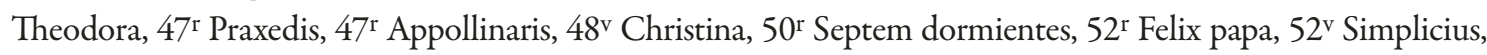
Faustinus und Beatrix, 52v Martha, 55v Abdon und Sennen, Germanus, $58^{\mathrm{v}}$ Sixtus, $59^{\mathrm{r}}$ Donatus, $61^{\mathrm{r}}$ Cyriacus, $62^{\mathrm{r}}$

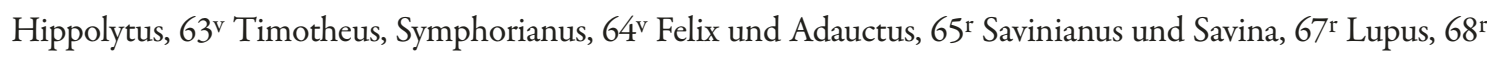
Mamertinus, 69v Aegidius, $71^{v}$ Adrianus, $75^{r}$ Gorgonius und Dorotheus, Protus und Hyacinthus, $77^{\mathrm{v}}$ Johannes Chrysostomus, 84v Cornelius und Cyprianus, 85v Lambertus, 86 Cosmas und Damianus, 88v Forseus, $90^{\mathrm{r}}$ Remigius, $91^{\mathrm{v}}$ Leodegarius, $93^{\mathrm{r}}$ Pelagia, $94^{\mathrm{v}}$ Margareta, $95^{\mathrm{v}}$ Thais, $97^{\mathrm{r}}$ Dionysius, $102^{\mathrm{v}}$ Calixtus, $103^{\mathrm{r}}$ Leonardus, $106^{\mathrm{v}}$ Chrysanthus, $107^{\mathrm{v}}$ Undecim mille virgines, $110^{\mathrm{v}}$ Quintinus, $111^{\mathrm{r}}$ Quattuor coronati, $111^{\mathrm{v}}$ Theodorus, $112^{\mathrm{r}}$ Brictius, $113^{\mathrm{r}}$ Chrysogonus, $114^{\mathrm{r}}$ Saturninus, $115^{\mathrm{v}}$ Jacobus intercisus, $118^{\mathrm{r}}$ Pastor abbas, $120^{\mathrm{r}}$ Johannes (Klimakos)

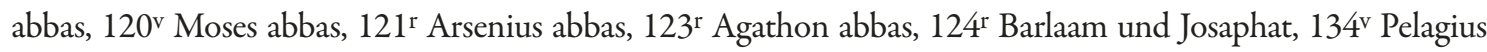
papa. Iacopo da Varazze, Legenda Aurea, hrsg. v. Giovanni Paolo Maggioni, 2. Auflage, Tavarnuzze/Florenz 1998, Bd. 1, S. 75-77, 141-160, 209-237; Bd. 2, S. 751-753 (mit längerem Schlussteil); Bd. 1, S. 262-269, 321-325, 355, 370-373, 411-414, 509-515, 519-522, 529-535, 552-557, 598f., 611-615, 627, 643-64861; Bd. 2, S. 670-675, 681-694, 745-753, 774-77762, 827-829, 886, 891-899, 887-890, 918-929, 939-950, 955f., 977-985, 1010-1015, 1033-1058, 1071-1078, 10889, 1130-1132, 1154f., 1203f., 1216-1282. KaepPeli, Scriptores, Nr. 2154. Anschliessend Provincia-Anhang: $153^{\mathrm{r}}$ Quoniam in prioribus fortassis propter defectum exemplarium nichil invenitur de sanctis, qui in hac provincia celebres habentur et sollempnes, libet aliqua disserere de ipsis et aliis quibusdam ... > Explicit prohemium. Incipit de sanctis, qui in priori non recoluntur opere et in provicia ista celebres habentur, nichilominus etiam alibi sunt famosi<. Die elsässische Legenda aurea, Bd. 2, hrsg. v. Konrad Kunze, Tübingen 1983, S. XXXIX, Anm. 73 (BHL 9035d). Anschliessend Inhaltsverzeichnis: De sancto Iodoco confessore, 74 ... 153 $3^{\mathrm{v}}$ Beatus Iodocus fuit Iudahelis regis Britonum filius ... - ...210 $>$ Passio sancte Barbare virginis et martiris<. Tenporibus inperatoris Maximiani erat quidam satrapas nomine Dyoscorus ... apud nos vero regnante domino deo atque salvatore nostro Ihesu Christo, cui est honor et gloria in secula seculorum. Amen. Jodocus, BHL 4514. 157 ${ }^{\mathrm{r}}$ Ottilia, 158v Eucharius, Valerius und Maternus, 159v Genovefa, 162r Brigida, Kunze, S. $311-$ 315 (BHL 6273a), 288-293, 63-77, 322-331 (vgl. BHL 1456). 165 Fridolinus, BHL 3171. 166r Gertrudis, Gangolfus, Kunze, S. 334,79-89.167v Servatius, BHL 7639d. 170 Guillelmus: Wilhelmus sanctissimus postquam ad honorem Christi missus ... vgl. Kunze, S. 105-115. 170v Augustinus Cantuariensis, 171'v Bonifatius martyr. $172^{\mathrm{r}}$ Bonifatius archiepiscopus (ohne Titel), 173v Onuphrius, KunZE, S. 335-338, 339-348 (BHL 6335c). $176^{\mathrm{v}}$ Decem milia martyrum, $177^{\mathrm{r}}$ Udalricus, BHL 8366c; $180^{\mathrm{v}}$ Goar. 182 ${ }^{\mathrm{r}}$ Anatolia und Victoria, Kunze, S. $316-$

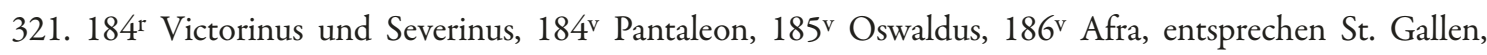
Stiftsbibliothek, Cod. Sang. 581, 280 vb $-282^{\mathrm{vb}}$. $188^{\mathrm{v}}$ Pelagius, BHL 6615c und 6615d. 190 ${ }^{\mathrm{r}}$ Verena, entspricht Cod. Sang. 581, 270 vb-272 ${ }^{\mathrm{vb}} .194^{\mathrm{r}}$ Felix und Regula, Cod. Sang. 581, 269vb-270vb. 196 Columban und Gallus, BHL 3252d. 199r Othmarus, entspricht Cod. Sang. 581, 285 ra-vb. 201 ${ }^{\mathrm{r}}$ Conradus Constantiensis, BHL 1919; 202v Theobaldus, BHL 8038f; 203 Carolus magnus, BHL 1611; 209 Christophorus: Hec dicta que secuntur 
pertinent ad passionale sancti Christoferi. Ambrosius autem in prefacione de hoc martire sic ait: Christoforo tantum virtutis cumulum et doctrine graciam contulisti ... 210 2 Barbara, BHL 0921d. Der Text des Provincia-Anhangs stimmt weitgehend überein mit Cod. Sang. 581, 263 ra $290^{\text {va }}$, dort jedoch Felix und Regula sowie Verena umgestellt (auch im Vergleich zum Inhaltsverzeichnis), zusätzlich Hilarion, ohne Barbara.

$213^{v}$ Nachtrag: > De sanctis Phylippo et Iacobo <. Iacobus minor fuit consobrinus Christi ... Post paucos annos due filie eius sepulte sunt iuxta sepulcrum eius. Anschliessend von anderer Hand Besitzeintrag: Liber Ludowici Zeller de Brugg.

$214^{\mathrm{r}-\mathrm{v}}$ leer.

Papier, 245 Blätter, 20,5-21 × 14,5-15 cm

Erste Hälfte des 15. Jahrhunderts

Wasserzeichen, Lagen, Foliierung: Wasserzeichen: Buchstaben MAD, darüber Kreuz, sowie ein weiteres, nicht identifiziertes Wasserzeichen. Lagen: 19 VI 228 + VII 241 , das letzte Blatt der letzten Lage in den Spiegel geklebt. Bl. 86f. an der unteren Ecke bis in den Schriftraum beschädigt. Neuere Foliierung: A-D. 1-241.

Einrichtung und Ausstattung: Begrenzung des Schriftraums mit Stift, Schriftraum 15-16 × 10,5-11, 26-34 Zeilen. Jüngere gotische Buchkursive mit Schleifen von einer Hand. Rubriziert, rote Überschriften und Explicits, rote Paragraphenzeichen, Stellenangaben rot unterstrichen, rote Zeilenfüller, 2-3zeilige rote Lombarden, häufig mit Punktverdickungen, Ausläufern und Konturbegleitstrichen. Am Kopf der Seiten Zählung der Texte 1-28, am äusseren Rand für jeden Text alphabetische Abschnittszählung.

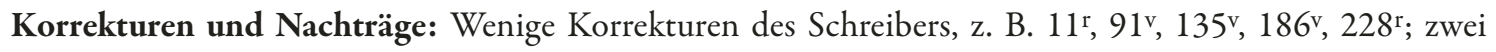
längere Streichungen in Rot 46 $115^{\mathrm{v}}$; zeitgenössische Ergänzung 105. Eine Korrektur auf $3^{\mathrm{v}}$ sowie Marginalien zur Texterschliessung auf $17^{\mathrm{v}}, 35^{\mathrm{r}}, 74^{\mathrm{v}}, 135^{\mathrm{v}}$ und $136^{\mathrm{r}}$ vermutlich von der Hand Ludwig Zellers, ebenso ein Nachtrag auf $\mathrm{A}^{\mathrm{r}}$ mit einer Gegenüberstellung der Zehn Gebote und der Zehn ägyptischen Plagen: 1 Non erunt dii alieni preter me - 1 Conversio aque in sanguinem ... - ... Hec omnia in glosa Colla super Exode in septimo capitulo super illud: Percussit aquam fluminis et versa est in sangwinem, usque ad xii capitulum sowie ein weiterer auf $173^{\text {r}}$ : Osee vii Omnes adulterantes quasi clibanus incensus a coquente.

Einband: Mit hellem Leder bezogene Holzdeckel, 15. Jh. Ehemals zwei nach hinten greifende Langriemenschliessen, nahezu loser Rest des unteren Riemens erhalten; Befestigung im Vorderdeckel mit Eisennägeln, hinten mit Messingstiften. Buchblock zu den Bünden hin abgefast. Der Einband entspricht dem von C 9. Vorsatzblätter (A-D) Papier, Wasserzeichen: Ochsenkopf, PICCARD, Wasserzeichenkartei Nr. 76985 (1445); Spiegelblätter: vorne ein Streifen Papier und ein um die Vorsatzblätter gelegtes, nur am Rand beschriebenes Pergamentfragment, hinten Papier. Im vorderen Spiegel Exlibris des Chorherrenstifts Beromünster (Wegmann, Exlibris, Nr. 619). Auf dem Vorderdeckel Titelschild: Decem precepta, cum aliis opusculis Ultimo folio Registratis, 15. Jh.

Herkunft: Das Wasserzeichen der Vorsatzblätter weist auf eine Entstehung vor der Mitte des 15. Jahrhunderts. Besitzer: Ludwig Zeller von Brugg, siehe Besitzeintrag 240v. Zu ihm: Kopp, Stiftsbibliothek, I, S. 11; Clara MüLlER, Geschichte des aargauischen Schulwesens vor der Glaubenstrennung, Aarau 1917, S. 95 (Nr. 171) und 97 (Nr. 231); Erster datierter Schweizer Druck, S. 15f.; SidLer, Bildungsverhältnisse, S. 175f. (Nr. 160). 
Im vorderen Spiegel Exlibris des Chorherrenstifts Beromünster. Im Catalogus von 1763 als Classis Nona Nr. 28 verzeichnet, im Nachtrag dazu auf 53 ohne Nummer, im Catalogus von 1826 als Nr. 10 (das entsprechende Rückenschild jedoch auf C 11). Im vorderen Spiegel und auf der Rectoseite des ersten Vorsatzblattes neuere Signatur: C 13, Kugelschreiber, spätes 20. Jh.

Literatur: Kopp, Stiftsbibliothek, II, S. 18; BRUCKNer, Scriptoria 9, S. 30; BÜCHLER, Beromünster, S. 167.

$\mathrm{A}^{\mathrm{r}}$ siehe Nachträge.

$\mathrm{A}^{\mathrm{v}}-\mathrm{D}^{\mathrm{v}}$ leer.

$1^{\mathrm{r}}-222^{\mathrm{r}}$ JOHANNES HEROLT, De eruditione christifidelium. $>$ De decem preceptis $<$. Si quis vult ad vitam ingredi ... (Mt 19,17). In verbis istis propositis ostendit Christus cuilibet homini viam vite eterne ... - ... 103 ${ }^{\mathrm{r}}>E t$ sic finita sunt decem precepta ad laudem dei omnipotentis $<.103^{v}>$ Nota de peccatis alienis $<$. Novem sunt peccata aliena, quorum si peccator in uno in morte deprehensus fuerit, sic dampnatur ac pro proprio ... 109r $>$ Nota peccatum mortale committitur iiiior modis<. Peccatum cum consummatum fuerit, generat mortem ... 180 $>$ De operibus misericordie corporalibus $<$. Opera misericordie corporalia sunt sex ... $184^{\mathrm{v}}>$ Et sic finis est de operibus misericordie sive corporalibus sive spiritualibus $<.185^{\mathrm{r}}>$ Nota de oracione $<$. Omnes unanimes in oracione ... 192 $2^{\mathrm{r}}$ bricht der Text ab: Sciendum quod in ista ultima clausula considerare debemus istam benedictionem, quam Ihesus Maria filius daturus est suis electis in novissimo die, cum dicet suis electis illud $M^{t} 25$ : Venite benedicti patris etc. Exemplum de beata virgine quere scilicet 4 etc. 192v $>$ Nota de articulis fidei<. Omnis, qui vivit et credit in me ... 199 19 bricht der Text ab: Veniet illuc Caym, qui proprium fratrem occidit, cum omnibus homicidis, Iudas cum traditoribus, Pilatus cum omnibus iniquis iudicibus, Lamech cum omnibus adulteris. Rogemus ergo dominum ut nobis etc. $>$ Amen etc.<. $199^{v}>$ Nota de vii sacramentis $<$. Sacramenta sunt vii, que deus instituit ... 216r $>$ Finem habent septem sacramenta $<.216^{\mathrm{v}}>$ De dignitate ordinis sacerdotalis $<$. Vos estis genus electum ... $219^{\mathrm{r}}>$ De sacramento matrimonii<. Matrimonium honoravit deus ... - ... 222 $2^{\mathrm{r}}$ Tercio parentes tenentur hereditare res iuste acquisitas fliis suis: Hoc quere 4 g. GW 12326: Johannes Herolt, De eruditione christifidelium [Strassburg: Georg Husner, um 1477], [2r-188r $188^{\mathrm{v}}$-196r , 199r-225r]. KAEPpeli, Scriptores, Nr. 2386 (Hs. nicht erwähnt); BLoomfield, Incipits, Nr. 5639 (Hs. nicht erwähnt), ohne den Tractatulus de septem donis sancti spiritus. Der Text entspricht bis auf die genannten Lücken im Wesentlichen dem Druck, auch das Verweissystem aus Textnummer und Abschnittsbuchstabe stimmt bis 199 r überein, danach wird es nicht mehr konsequent durchgeführt.

$222^{\mathrm{v}}-232^{\mathrm{r}}$ Tabula thematum. Perikopenverzeichnis für das ganze Kirchenjahr mit Verweisen auf die passenden Abschnitte im vorangehenden Text. > Tabula $<$. Ecce rex venit ... (Mt 21,5). Iam in presenti tempore celebratur adventus Christi ... Tercio quare Christus natus sit de virgine, hoc quere $22 k$... - ... Sermo communis de beata virgine, qualiter nos iuvat in vita, in morte et post mortem 4 y... Maria quamvis esset pulcerrima, tamen a nullo poterat concupisci, et hoc propter tres rationes 21 q. GW 12326: De eruditione christifidelium, [229v-239v]. $232^{\mathrm{r}}-240^{\mathrm{v}}$ Tabula alphabetica. Register. $>$ Item incipit tabula secundum alphabetum<. Abstinencia in cibo et potu est prolongacio vite, hoc quere $18 \mathrm{~b}$... - ... Ypocrisis octo modis committitur et quando est peccatum mortale, quere $13 v$. De eruditione christifidelium, 239v-247v. Anschliessend Kolophon und Inhaltsverzeichnis: Inde laudetur deus omnipotens. In isto volumine comprehenduntur prescripta, videlicet: Decem precepta, Novem peccata aliena, Septem peccata mortalia (nachträglich von anderer Hand: Opera misericordie, De oracione dominica), Decem articulos fidei, Septem sacramenta, Dignitatem ordinis sacerdotalis. Zwischen Kolophon und Inhaltsverzeichnis Besitzeintrag: Ister (sic) liber est Ludowici Zeller de Brugg.

$241^{\mathrm{r}-\mathrm{v}}$ leer. 
Papier, 266 Blätter, 20,5-21 × 13,5-14,5 cm

Zweites Viertel des 15. Jahrhunderts; erstes Viertel des 15. Jahrhunderts; Hitzkirch (?), um 1370.

Wasserzeichen, Lagen, Foliierung: Wasserzeichen: Bl. 2-113 Traube, Piccard, Wasserzeichenkartei Nr. 129272 (1431); Bl. 118-152 Dreiberg, PICCARD, Wasserzeichenkartei Nr. 150775 (1417); Bl. $153-176$ Mandel, Piccard, Wasserzeichenkartei Nr. 129838 (1370); Bl. 177-188 und 262 Horn, Piccard, Wasserzeichenkartei Nr. 119751 (1371) sowie eine kleinere Variante, ähnlich Nr. 119939; Bl. 190-224, 230/231, 239-259 zwei Kreise, darüber und darunter Stern, PICCARD, Wasserzeichenkartei Nr. 161862 (1371); Bl. 225229, 232-236 Kreis, darüber Stern, darunter Dreieck, PiCCARD, Wasserzeichenkartei Nr. 21817 (1371). Lagen: $9 \mathrm{VI}^{108}+(\mathrm{VI}-3)^{117}+2 \mathrm{VI}^{141}+(\mathrm{VI}-1)^{152}+9 \mathrm{VI}^{260}+(\mathrm{III}-1)^{265}$, nach Bl. 117 drei Blätter, nach Bl. 151 und 264 je ein Blatt herausgeschnitten. In Teil 1 Zählung der Lagen und der Doppelblätter in der ersten Lagenhälfte, z. T. beschnitten: $a 4\left(4^{\mathrm{r}}\right), B[1]\left(13^{\mathrm{r}}\right), C 5\left(29^{\mathrm{r}}\right)-k 6\left(114^{\mathrm{r}}\right)$; in Teil 2 Lagenzählung zu Beginn der Lagen am oberen Seitenrand in Rot: $1\left(118^{\mathrm{r}}\right)-3\left(142^{\mathrm{r}}\right)$; in Teil 3 Lagenzählung sichtbar am Schluss der ersten Lage: $1^{u s}\left(164^{\mathrm{v}}\right)$. Reklamanten. In Teil 3 (Bl. 153-265) alte Foliierung: 1 (153r) - 43 (195r). Neuere Foliierung: A. 1-265.

Einrichtung und Ausstattung:

Teil 1 (Bl. 1-117, 2. Viertel 15. Jh.): Begrenzung des Schriftraums mit (Stift und) Blindlinien, Schriftraum 15,5-16,5 × 9-9,5, 28-33 Zeilen. Schleifenlose jüngere gotische Buchkursive von einer Hand. Rubriziert, rote Paragraphenzeichen und Zeilenfüllungen. Zweizeilige rote Lombarden, z. T. mit Punktverdickungen und kurzen Ausläufern. $1^{\mathrm{r}}$ vierzeilige rot-schwarz ornamental gespaltene Initiale mit rotem und schwarzem Fleuronné.

Teil 2 (Bl. 118-152, 1. Viertel 15. Jh.): Begrenzung des Schriftraums mit Stift (und Blindlinien), Schriftraum 14,5 × 9-9,5, 25-28 Zeilen. Jüngere gotische Buchkursive mit Schleifen von einer Hand. Rubriziert, Überschriften rot gerahmt, rote Unterstreichungen; in Jean Gersons zweitem Traktat zudem rote Überschriften $\left(134^{\mathrm{v}}-141^{\mathrm{r}}\right)$ und Marginalien zur Erschliessung des Inhalts $\left(133^{\mathrm{v}}-141^{\mathrm{r}}\right)$, im Traktat des Bonaventura $\left(144^{\mathrm{r}}-148^{\mathrm{r}}\right)$ einzelne rote Paragraphenzeichen. 2-3zeilige rote Lombarden, z. T. mit Punktverdickungen und Konturbegleitstrichen.

Teil 3 (Bl. 153-265, um 1370): Begrenzung des Schriftraums mit Tinte, Schriftraum 16,5-17 × 9,5-10,5, 256v-261 zweispaltig (4-5), 33-39 Zeilen. Ältere gotische Buchkursive von zwei Händen, Händewechsel $178^{\mathrm{v}}$; Initien (Bibeltext der Postilla) in Textualis. Rubriziert, $183^{\mathrm{r}}$ und $200^{\mathrm{r}}$ rote Überschriften, rote Paragraphenzeichen. 1-2zeilige rote Lombarden, z. T. mit Punktverdickungen und Konturbegleitstrichen, $183^{\mathrm{v}}$ rot-schwarz ornamental gespalten, 256 ${ }^{\mathrm{va}}-257^{\mathrm{rb}}$ (Register) mit Schaftaussparungen. Marginalien zur Erschliessung des Inhalts, ab $178^{\mathrm{v}}$ rot unterstrichen, $182^{\mathrm{v}}$ in Rot.

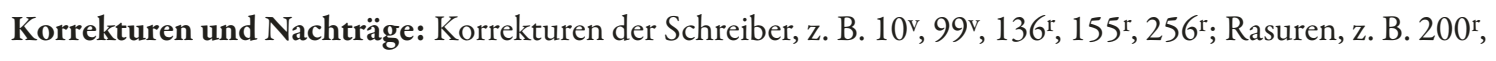
261 vb. Nachgetragene Titel am Rand: $1^{\mathrm{r}}$ Historia naturalis Volucrum, animalium etc. etc., $118^{\mathrm{r}}$ alias Opusculum tripartitum, de Preceptis decalogi, de Confessione, de Arte moriendi, 153 Postilla Super Evangel. S. Lucae et cetera, 17. Jh. Notazeichen wohl noch des 15. Jhs. 6 $6^{\mathrm{v}}, 38^{\mathrm{r}}, 97^{\mathrm{v}}$ und in Teil 3. In Teil 1 und 3 Notazeichen und Handweiser (in Teil 1 z. T. auch in Grün, zudem grüne Unterstreichungen) sowie Marginalien von einer Hand des 16. Jhs., z. T. auf Deutsch: 27v D [e] Basilisco (Basiliscus, zum Lemma 'Gallus'), 35r Amsel (Merula), 35 Dull (Monedula), 39v Rephin (Perdix), 49 Wildschwin (Aper silvester), 58v Murmelthier (Emtra), 59v ein 
Biber Otter (Fiber), 180v 4or Signa Leprosi (Constanti[n] us [Africanus] zu Lc 7,22); von einer Hand des 15. Jhs. $158^{\mathrm{v}}$ Worzelin die do hyessent hoy staffelen, ein Zusatz $168^{\mathrm{r}}$, sowie einzelne Interlinearübersetzungen $222^{\mathrm{r}}$.

Einband: Mit hellem Leder bezogene Holzdeckel, 15. Jh., Leder an der oberen Ecke des Rückdeckels teilweise abgerissen. Ehemals eine nach hinten greifende Langriemenschliesse, Riemenbefestigung aus Messing im Vorderdeckel erhalten, im Rückdeckel das Loch des Stifts; zudem Stümpfe der Messingnägel von zwei älteren Schliessen an den Rändern des Vorder- und Rückdeckels. Ein Loch am oberen Rand des Vorderdeckels, daneben Rest eines grösseren Eisennagels, im Rückdeckel zwei Löcher, am unteren und am oberen Rand, sowie Spuren oben an der Stelle, wo das Leder fehlt, möglicherweise von einer Kettenklammer: ehemals Catenatus. Ungefärbte Kapitale. Vorsatzblatt (A) Papier. Spiegelblatt im Rückdeckel Pergament, Fragment eines Anniversars (Frienisberg?), Monat Mai (17. - 25.) mit den rot eingetragenen Heiligenfesten $P[$ ot $]$ ent $[\mathrm{i}]$ ane virginis (19.5.) und Urbani pape et martiris (25. 5.), angelegt wohl im 14. Jh., die schwarzen Einträge jünger: Crett uxor Heinrici dicti Kneblis de Mochil (17. 5.), Ita ux[o]r Hymanis de Móchil und Anna u[x]or Chünradi dicti Swab de Mochil (20. 5.), Petrus dictus Kundigo und Iohannes flius Chionradi dicti Knaben de Grechwile (23. 5.), Petrus dictus Berri de Grechwile (24. 5.), Grächwil ist der Name eines Weilers bei Frienisberg, vgl. auch W. F. von Mülinen, Auszug aus dem alten Jahrzeitbuch von Frienisberg, in: Anzeiger für Schweizerische Geschichte, N. F. 8, Bern 1901, S. 408: «Immo von Mökilch Ita uxor» oder S. 407: «Conrad Bökli, Anna uxor». Die Lagen mit weiteren Fragmenten derselben Hs. verstärkt. Im vorderen Spiegel Abklatsch (Anniversar, unlesbar) sowie Exlibris des Chorherrenstifts Beromünster (Wegmann, Exlibris, Nr. 619). Rückenschild Historia Naturalis Volucrum Animalium etc. Ordine Alphabetico. No 9, entsprechend dem Catalogus von 1826.

Herkunft: Teil 1 lässt sich aufgrund des Wasserzeichens in das zweite, Teil 2 in das erste Viertel des 15. Jhs. datieren. Teil 3 wurde laut dem Schreibervermerk 261 vb von Albert von Münnerstadt, Konventuale der Deutschritterkommende Hitzkirch, an einem Mittwoch vor dem 19. Mai fertig abgeschrieben; die vier Wasserzeichen weisen auf die Zeit um 1370.

Besitzer: Ar Philippus Victoris, Johannes, sowie Ludigarius Hertenstein (1601-1646), vgl. Historischbiographisches Lexikon der Schweiz, Bd. 4, Neuenburg 1927, S. 202; wahrscheinlich gelangte die Hs. über Jakob von Hertenstein, 1551-1560 Hofmeister der Kommende Hitzkirch (Helvetia sacra IV/7.2, S. 729), in den Besitz der Luzerner Patrizierfamilie. Im vorderen Spiegel Exlibris des Stifts Beromünster. Im Catalogus von 1763 als Classis Nona Nr. 31 verzeichnet, im Nachtrag dazu auf 53 $3^{\mathrm{r}-\mathrm{v}}$ ohne Nummer, in den Antiquitates Beronenses, S. 691, als Nr. 26 (sowie möglicherweise Nr. 27: Tractatus de discretione spirituum, als Geschenk Ludwig Zellers), im Catalogus von 1826 als Nr. 9.

Literatur: Kopp, Stiftsbibliothek, II, S. 20 f.; BRUCKNER, Scriptoria 9, S. 30f. und 43; Bü CHLER, Beromünster, S. 174 und 246 (Anm. 156); CMD-CH 2, Nr. 542. Die Hs. ist seit dem 23.9.2014 online, mit Beschreibung von Eckhart Conrad Lutz: http://www.e-codices.ch/de/description/sbb/C0014.

$\mathrm{A}^{\mathrm{r}-\mathrm{v}}$ Besitzeinträge, darüber: Salus nostra in manu tua domine. Quis potest dicere: Mundum est cor meum, mundus sum a peccato. Darunter, von anderer Hand (Philippus Victoris): Chrisostomus. Peccatorem quem non salvat dei iustitia, salvat misericordia Marie infinita.

Teil 1:

$1^{\mathrm{r}}-99^{\mathrm{r}}$ Historia naturalis. Alphabetisch (zuerst 9 Lemmata Avis, dann Accipiter - Zelenchides; 9 Lemmata Animal/Anima/Animus, dann Agnus - Zibo). Aves secundum Ysidorum dicte sunt eo quod vias certas non 
habent sed per avia queque discurrunt. Sic anima stulte provocacionis plumis super alios se extollit ... - ... 47 Zelenchides aves sunt ut dicit philosophus sed nescitur unde veniant aut quo vadant ... cui deo sit laus et gloria in secula seculorum. Amen. Omne animal habens caudam pilosam habet parvum caput et mandibulas magnas ... - ... 98v Zibo habitat in sepulchris mortuorum ... de quorum proverbiorum septimo satis habetur, et sic est finis huius operis deo laus etc. Thorndike/Kibre, Incipits, Sp. 170. Drei französische Namen: 2v Accipiter qui Gallice

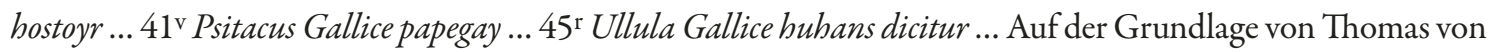
Cantimpré, vgl. Thomas Cantimpratensis, Liber de natura rerum. Editio princeps secundum codices manuscriptos, Teil I: Text, Berlin/New York 1973, S. 175-231 und 102-173, erweitert um zusätzliche Angaben nach Isidor und anderen Autoritäten, vereinzelt auch dem Physiologus, oft, aber nicht systematisch moralisierend; bis auf einzelne, z. T. durch Zeilensprünge erklärbare Auslassungen genau entsprechend der Hs. UB Basel, F II 10, $2^{\mathrm{r}}-67^{\mathrm{r}}$.

99v-117r HENRICUS DE LANGENSTEIN, De discretione spirituum. > Incipit tractatus de discrecione spirituum <. Sicut in philosophia motus et operaciones referre consueverunt ad formas ... - ... non nisi solo impossibilitatis freno posse retineri. > Explicit tractatus de discrecione spirituum a magistro Heinrico Langestein de Hassya conpilatus. Deo laus<. Thomas Hohmann, Heinrichs von Langenstein 'Unterscheidung der Geister', Lateinisch und Deutsch. Texte und Untersuchungen zu Übersetzungsliteratur aus der Wiener Schule, Zürich/München 1977, S. 52-122 (ohne diese Hs., vgl. S. 326).

$117^{\mathrm{v}}$ leer.

Teil 2:

118 ${ }^{\mathrm{r}}-142^{\mathrm{r}}$ JOHANNES GERSON, Opus tripartitum. >Incipit tractatus magistri Iohannis de Iersona cancellarii Parysiensis, sacre theologie professoris de generalibus nostre fidei principiis <. Cristianitatis suus qualiscumque zelator... Salubre duxi sequens opusculum tripartitum de preceptis, de confessione, de sciencia mortis, brevitate qua potui tradere ... Jean Gerson, CEuvres complètes, ed. Palémon GlorIEUx, Bd. 2, Paris etc. 1960, S. 74f. (Nr. 18). 118 Gloria sit ... > Primum capitulum affirmat mundum a deo fuisse creatum, quod ipse deus unus sit, et trinus. Cur etiam aut ad quem finem homo creatus sit<. Firmissime credendum est ... 133 ${ }^{\mathrm{v}}$ $>$ Incipit secundus tractatus de confessione sacramentali omnium peccatorum tempore debito presbitero faciendo $<$. Quisquis a morte peccati ad salutis et gracie statum volet resurgere ... 139r > Sequitur tractatus tercius de habendo modum circa constitutos in mortis articulo et noticia<. Si veraces fidelesque amici ... - ... laudabiliter observatur. Et sic est finis huius tractatus de generalibus nostre fidei principiis et de decem preceptis aliisque multis utilibus ad salutem. Joannis Gersonii Opera omnia, Antwerpen 1706, Bd. 1, Sp. 427-450; 140v ein Zusatz: Indulges ex corde ... - ... lesisti, vgl. Doctrinale de triplici morte, naturali, culpae, et Gehennae, Ioannis Raulini opus egregium, Venedig 1585, S. 82 (richtig: 72). RB 4491; BLOOMFIELD, Incipits, Nr. 734; vgl. zum dritten Traktat auch MADRE, Dinkelsbühl, S. 334.

142 $-151^{\mathrm{r}}$ BONAVENTURA, Tractatus de praeparatione ad missam. $>$ Sequitur tractatus Bonaventure de corpore Christi et preparacione ad devotam sumpcionem eiusdem ritamque celebracionem mysterii misse $<$. Ad honorem gloriose ac individue trinitatis et ad honorem excellentissimi sacramenti et preciosi corporis et sanguinis Ihesu Christi describam tibi formam, per quam potes leviter manuduci ad contemplacionem tanti mysterii et congrue diposicioni (sic) ad eius precepcionem ... Primo attendendo ad mensam celestis convivii iuxta apostolum proba te ipsum ... - ... Hoc autem non reputes posse tua virtute sed auxilio gracie eius, quod ipse tibi et michi prestare dignetur. Amen. Bonaventura, Opera omnia, Bd. 8, Quaracchi 1898, S. 99-106 (Hs. unbekannt, 
vgl. S. LI-LVII); auf 146r fehlen im Bibelzitat Nm 9,13 (Cap. I,9: «Ultimo» ...) die Worte «in itinere», stattdessen Lücke. Distelbrink, Bonaventurae scripta, S. 29f., Nr. 24.

$151^{\mathrm{v}-152^{\mathrm{v}} \text { leer. }}$

Teil 3:

153 $3^{\mathrm{r}}-256^{\mathrm{r}}$ FRANCISCUS GALVANUS, Collationes super Lucam. 8 Lektionen und 86 Kollationen. Lectio ia: > Hoc nomen 'Maria' quinque habet literas<. Ad denotandum quod ipsa est figurata per 5 dominas veteris testamenti quarum nomina incipiunt ab aliqua istarum literarum. Et etiam per $v$ lapides preciosos, et similiter incipiunt ab aliqua istarum litterarum ... $154^{\mathrm{v}}$ Lectio $2^{a}$, Origenes: $>$ Missus est angelus $<$, etc. Luce $i^{\circ}$. Origenes ponit ... 164 $4^{\mathrm{r}}$ Collacio ia: $>$ Nunc dimittis servum tuum $<$. Luce $4^{\circ}$. Doctores dicunt triplici de causa possunt fieri tripudia ... 169v Collacio 4a: $>$ Relictis omnibus secuti sunt eum <. Luce 5. Legitur in libro de vita philosophorum ... - ... Collatio lxxxv[i], a, Augustinus: Quem queritis viventem cum mortuis surrexit, non est hic. Luce ultimo. Beatus Augustinus ... lapsus palmam. Hunc illi celesti regi qui contra Iacob luctatus fuisse inscius aptare posse existimo ... Vult dicere Augustinus quod fabulose dictum est quod quidam gygas fuit fortissimus quod si aliquo casu ad terram fuisset prostratus ipse fiebat victor ... Christus quasi gygas venit in hunc mundum ... tamen in Parasceve fuit prostratus ad terram quando a Iudeis fuit interfectus et positus in sepulchro propter quod factus est forcior unde bene dicit verbum propositum: Quem queritis, ubi tria tanguntur ... Primo ergo etc. Sic est finis buius tractatus, deo gracias et omnibus sanctis. Finito libro sit laus et gloria Christo. Stimmt im Wortlaut mit UB Basel, A X 59, 47 ${ }^{\mathrm{r}}-151^{\mathrm{v}}$ weitgehend überein; viele zusätzliche Abschnitte (Auctoritates resp. Testimonia), die letzten 5 Seiten Text der Basler Hs. (der grössere Teil von Coll. 86 sowie Coll. 87 und 88) fehlen hingegen. Kaeppeli, Scriptores, Nr. 1103 (a, b und d); RB 2303 (Supplement).

$256^{\mathrm{va}}-261^{\mathrm{vb}}$ Tabula und Schreibervermerk. In Postilla illa continentur octo lectiones in principio<. Ia $:$ Hoc nomen 'Maria' habet v literas ... >Iste sunt collaciones que secuntur<. Prima collacio: Nunc dimittis ... 257 25 $>$ Incipiunt historie lectionum<. Quid denotatur per quamlibet litteram huius nominis Maria, leccione prima, a, $b, c, d, e, f \ldots 257^{\mathrm{rb}}>$ Incipiunt historie collacionum <. De eo quomodo sit licitum esse tripudia, collatione prima, a ... - ... De gygante qui quociescumque ad terram prosternebatur maiores virtutes recipiebat et forcior fiebat, sic fuit de Christo, collacio ultima et 86, a. Deo gracias. > Expliciunt moralitates super ewangelia sancti Luce et cetera<, per manus fratris Alberti de Mürstat conventualis in Hiczkilch ordinis Theutonicorum feria iiiia ante diem sancte Potentiane virginis.

262 ${ }^{\mathrm{r}}-263^{\mathrm{v}}$ JACOBUS DE CESSOLIS, Liber de ludo scaccorum. Auszug. De crudelitate regis vitanda: Tempore igitur Radach regis Babylonie hominis Chaldei et efferi iniusti et crudelis qui proprii patris corpus scilicet Nabuchodonosor in trecentas partes divisit et trecentis vulturibus ad devorandum dedit. Huic fuit similis pater suus Nabuchodonosor ... De iusticia regis: Valerius Maximus dicit Theodorus qui fuit Atheniensis cum cruci affixus fuisset ... Socratem enim ... De ocio vitando: Valerius dicit quod quidam miles ... Item: Physistartus Atheniensis dux ... 262v De veritate: Valerius Maximus dicit quod cum Allexander ... Orosius dicit quod quidam Percillus nomine ... De iusticia: Augustinus in libro De civitate dei dicit quod erat quidam nomine Dyonides ... $263^{\mathrm{r}} \mathrm{De}$ continencia: Refert Valerius quod Cipio Affricanus ... De constancia: Refert Ieronimus contra Iovinianum ... 263 ${ }^{\mathrm{v}}$ De continencia (von anderer, zeitgen. Hand: Regine): Refert Augustinus in libro De civitate dei ... - ... intravit hostis pro hospite. Tu autem //. Bricht am Seitenende ab. Das Schachzabelbuch Kunrats von Ammenhausen, Mönchs und Leutpriesters zu Stein am Rhein. Nebst den Schachbüchern des Jakob von Cessole und des Jakob Mennel, hrsg. v. Ferdinand VetTer, Frauenfeld 1892, Sp. 37-40, 47-50, 61-64, 87-90, 95-106, 111-114, 
131-134, 137-144. Kaeppeli, Scriptores, Nr. 2066; Anton Schwob, Artikel 'Schachzabelbücher', in: Verfasserlexikon², Bd. 8 (1992), Sp. 589-590.

$264^{\mathrm{r}}$ leer.

264v-265r PEREGRINUS DE OPPELN, Sermo de assumptione BMV. > [Q] ue est ista que ascendit de deserto deliciis affluens ... (Ct 8,5)<. Filius dei hodierna die matrem suam honorans secundum cursum huius mundi. Cum enim aliquis peregrinus in terra sua incognitus ab aliqua in hospitem recipitur ... - ... Cui Maria respondit: Si inveni graciam apud te obsecro ut nomen tuum mibi revelare digneris ... Hoc iterum peto et obsecro ut anima mea de corpore exiens nullum spiritum deterrimum videat nullaque mibi Sathane potestas occurrat. Cui angelus //. Bricht ab. Schneyer, Bd. 4, S. 561, Nr. 151; GW M30917: Peregrinus [de Oppeln] / Nicolaus [de Dinkelspuhel], Sermones de tempore et de sanctis, [Ulm, nicht nach 1479], K6 ${ }^{\mathrm{v}}-\mathrm{K} 7^{\mathrm{v}}$, gekürzt, die letzten Sätze mehr entsprechend der Legenda aurea.

$265^{\mathrm{V}}$ Federproben, sonst leer. CAELO ET MUNDO; JOHANNES DE SACROBOSCO

Papier, 240 Blätter, $29 \times 21 \mathrm{~cm}$

Heidelberg (?), 1452 (?); 1 . November 1451

Wasserzeichen, Lagen, Foliierung: Wasserzeichen: Bl. III-132 Ochsenkopf, PICCARD, Wasserzeichenkartei Nr. 74888 (1448), 75092 (1448) und 75123 (1449); Bl. 133-144, 157-180 und 193-216 Nr. 75508 (1451) und 75846 (1451), Bl. 145-156 und 181-192 Nr. 75145 (1452) und 75382 (1452); Bl. 217-226 Nr. 74880 (1450). Lagen: VXII +18 VI $^{216}+V^{226} \cdot 60^{v}$ Lagenzählung 6, beschnitten. 12v-108v Reklamanten. Neuere Foliierung: I-XII, 1-228.

\section{Einrichtung und Ausstattung:}

Teil 1 (B1. 1-198, 1452): Meist nur vertikale Begrenzung des Schriftraums mit Tinte. Schriftraum 21-22× 13,5-14, 42-58 Zeilen. Schleifenlose jüngere gotische Buchkursive von zwei Händen, Händewechsel $132^{\mathrm{r}} / 133^{\mathrm{r}}$. Rubriziert (ausser 43v $-48^{\mathrm{v}}, 68^{\mathrm{v}}-71^{\mathrm{r}}, 82^{\mathrm{v}}-84^{\mathrm{v}}, 91^{\mathrm{v}}-96^{\mathrm{v}}, 103^{\mathrm{v}}-104^{\mathrm{r}}, 105^{\mathrm{v}}-108^{\mathrm{v}}, 115^{\mathrm{v}}-120^{\mathrm{v}}$, $\left.127^{\mathrm{v}}-132^{\mathrm{v}}\right)$, Zitate unterstrichen. Überschriften in vergrösserter Schrift, durchgehend Raum für 1-2zeilige, $1^{\mathrm{r}}$ und $133^{\mathrm{r}}$ für 4zeilige Initialen ausgespart, nicht ausgeführt. Kopftitel: Buchzählung, $1^{\mathrm{v}}-131^{\mathrm{r}}$ und $181^{\mathrm{v}}-198^{\mathrm{r}}$ auf den Versoseiten $L$ [iber], auf den Rectoseiten $I-V I I I$ bzw. II, IIII, 34 ${ }^{\mathrm{v}}-36^{\mathrm{r}}$ in Rot; $133^{\mathrm{r}}-181^{\mathrm{r}}$ L I-L II. An vielen Stellen Raum für Ergänzungen ausgespart (siehe Nachträge), $172^{\mathrm{r}}$ Sphärendarstellung, $191^{\mathrm{r}}$ Planetenbahnen.

Teil 2 (Bl. 199-211, 1451): Vertikale Begrenzung des Schriftraums mit Tinte. Schriftraum 19-20 × 11,513,5, 25-29 Zeilen, 199r-204v durch Doppellinien mit zusätzlicher Spalte (2) für Marginalien und Grafiken am inneren Seitenrand. Schleifenlose jüngere gotische Buchkursive von zwei Händen, Händewechsel auf $201^{r}$. Rubriziert, Merkverse rot unterstrichen, Raum für ein- bis zweizeilige Initialen ausgespart, nicht ausgeführt. Marginalien zur Texterschliessung. 199 Raum für Sphärendarstellung ausgespart.

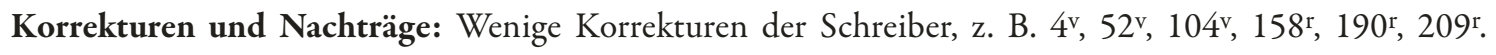
Handweiser 161v-197v. Zahlreiche Anmerkungen und Ergänzungen in kleinerer Schrift bis zum Umfang von 
einer halben Seite, öfters in Form von schematischen Darstellungen, in Teil 2 vor allem Interlinearglossen, wohl von der Hand Friedrichs von Lütishofen. Auf den Spiegelblättern verschiedene zeitgenössische Notizen, darunter vorne: Omnis revera meritrix est sicut Kymera ... WALTHER, Initia carminum, Nr. 13370; hinten: Profidentes unitatem veneremur trinitatem ... AH 54 Nr. 161. Ir Nachtrag 15. Jh., siehe Inhalt. XIIv Nachtrag 17./18. Jh., Inhaltsangabe: Tractatus Phisicus. Item De Coelo, et Mundo. De Sphera, et forma Mundi, de Ortu, et Occasu Signorum, de Calculis, et Motu Planetarum; de Causis Ecclipsium.

Einband: Mit hellem Leder bezogene Holzdeckel, 15. Jh., Streicheisenlinien und Einzelstempel, EBDB s025996 und s025999 (w003221: Vierblatt-Blüthe V) sowie ein weiterer: Lilienkreuz in umrandetem Quadrat. Ehemals zwei nach vorn greifende Kantenschliessen, die obere abgerissen, Beschläge Messing, Riemenbefestigungen hinten Vierpassblüten. Der untere Beschlag auf dem Vorderdeckel wurde möglicherweise zeitgenössisch ersetzt, die Aussparung im Deckel ist für diesen zu gross. Kapitale aus ungefärbtem Garn. Spiegelblätter Papier mit Notizen von verschiedenen Händen des 15. Jhs. Im vorderen Spiegel Preisangabe: xxviii solidum i florenum (?). Vor- und Nachsatz (I, II und 227, 228) jeweils ein Doppelblatt, Papier, Wasserzeichen: Ochsenkopf, PICCARD, Wasserzeichenkartei Nr. 75092 (1448) und Nr. 74880 (1450), vgl. oben; Rand von Blatt I abgerissen. Vorne und hinten je fünf Lagen mit Pergamentstreifen verstärkt: Fragmente von einem theologischen Traktat und einer weiteren Handschrift des 14./15. Jhs. Weitere Streifen um die erste und letzte Lage gebunden und in die Deckel geklebt, heute abgelöst und verloren, Abklatsch erkennbar: zwei Streifen aus einer Handschrift in karolingischer Minuskel mit roten Überschriften und Glossen; noch erhalten: zwei Fragmente der Abschrift einer deutschsprachigen Urkunde. Streicheisenlinien und Art der Bindung entsprechen C 41 und C 64 (siehe BüCHLER, Beromünster, S. 158 und 160), so dass von derselben Werkstatt auszugehen ist. Exlibris des Chorherrenstifts Beromünster (Wegmann, Exlibris, Nr. 619). Auf dem Vorderdeckel Spuren einer Beschriftung. Rückenschild: Tractatus Phisicus et De Coelo et Mundo etc. No 23, entsprechend dem Catalogus von 1826.

Herkunft: Möglicherweise für Friedrich von Lütishofen in Heidelberg hergestellt, Anmerkungen und Ergänzungen sowie der Beginn von Teil 2 stammen wohl von seiner Hand. Der erste Schreiber von Teil 1 ist vielleicht mit Konrad Menger zu identifizieren, welcher Teil 2 der Handschrift C 41 subskribierte. Teil $2 \mathrm{ab}$ $201^{\mathrm{r}}$ geschrieben von Johannes Schumacher aus Lenzburg und auf den 1 . November 1451 datiert (Schreibervermerk 211 r), zu ihm: BüCHLER, Beromünster, S. 158 und 242 (Anm. 95) und CMD-CH 2, S. 225. Der Band stimmt in Wasserzeichen, Ausstattung und Annotation mit C 41 überein, beide ergänzen einander inhaltlich.

Besitzer: Wahrscheinlich Friedrich von Lütishofen; im vorderen Spiegel Exlibris des Chorherrenstifts Beromünster. Im Nachtrag zum Catalogus von 1763 auf 48 vohne Nummer verzeichnet, Teil 2 im Catalogus von 1826 als Nr. 23. Ir neuere Signatur: C 40, dünner schwarzer Filzstift, spätes 20. Jh. Signatur ehemals C 20 fol.

Literatur: Kopp, Stiftsbibliothek, II, S. 20; Bruckner, Scriptoria 9, S. 28 sowie Taf. 46; Büchler, Beromünster, S. 143, 158, 160f., 165, 178; CMD-CH 2, Nr. 91; LoHr, Aristotelica Helvetica, S. 168.

Ir Nachtrag. Zwei naturphilosophische Quaestionen: Utrum motus sit de essentia sui termini ad quem. Notandum quod duplex est motus, scilicet ad ubi et ad formam ... Utrum motus est actus mobilis uel moventis. Notandum quod motus est actus mobilis in genere cause formalis et est actus moventis in genere cause efficientis ... Iv-XIIr leer.

XIIv Inhaltsangabe, Nachtrag (s. oben). 
Teil 1:

$1^{\mathrm{r}}-132^{\mathrm{r}}$ Quaestiones super Aristotelis libros Physicorum. > Queritur circa primum Phisicorum, utrum naturalis philosophia est omnium rerum mundi considerativa $<$. Pro illa questione est primo notandum, quod philosophia sic potest describi: Est divinarum humanarumque rerum cognicio ... $3^{\mathrm{r}}>$ Queritur secundo, utrum ens mobile est subiectum naturalis philosophie $<\ldots-\ldots 131^{\mathrm{r}}>$ Utrum primus motor sit indivisibilis et impartibilis nullam habens magnitudinem < ... attribuuntur sibi plura nomina, quare deus sic pluribus nominatur nominibus, et sic et primus motor. Et finito hoc octavo sit laus et gloria Christo in secula seculorum amen. Bis auf geringfügige Abweichungen übereinstimmend mit Karlsruhe, Badische Landesbibliothek, Aug. pap. 145, 2r $-190^{\mathrm{v}}$. $1^{\mathrm{r}}$ Buch

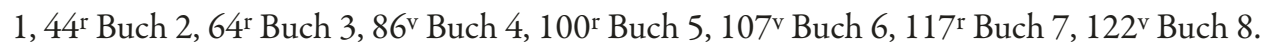

$132^{v}$ Nachtrag wohl von der Hand Friedrichs von Lütishofen: Verzeichnis der Quaestionen zu De caelo et mundo, Buch 1.

133 ${ }^{\mathrm{r}}-198^{\mathrm{r}}$ KILIANUS LUPI, Quaestiones super Aristotelis De caelo et mundo. $>$ De celo et mundo $<$. $>[$ C $]$ irca primum librum de celo et mundo<. Post librum Phisicorum, in quo determinatum est de principiis et passionibus rerum naturalium in communi, sequitur in ordine librorum naturalium secundus, scilicet presens liber De celo et mundo, in quo determinatur in speciali de rebus naturalibus ... > Utrum ens mobile ad ubi est subiectum scientie libri de celo<. Ista questio presupponit, quod de celo et mundo sit scientia ... 134 $4^{\mathrm{v}}>$ Utrum longitudo, latitudo et profunditas sint dimensiones realiter $<$ distincte ... - .. 197v > Utrum quatuor elementa determinant sibi aliquas figuras a natura <... Quod autem in superiori parte debilior sit quam in inferiori patet ex eo, quia in superioriparte plus distat a suo origine, scilicet combustibili, et sic superior debilior est quam inferius, quare superius plus diminuitur quam inferius. Et sic latior apparet quam (sic) inferius quam superius et sic apparet piramidalis figura etc. Et est finis. Anschliessend von anderer Hand: Anno 1452 in die Crispini et Crispiani magister K[ilian] L[upi] de Haslach finiuit De celo et mundo pro magistrandis circa nonam de mane. $133^{\mathrm{r}} \mathrm{Buch} 1,165^{\mathrm{r}} \mathrm{Buch} 2,191^{\mathrm{v}} \mathrm{Buch}$ 4, Buch 3 fehlt. Charles H. Lohr, Latin Aristotle Commentaries, I.1: Medieval Authors A-L, Florenz 2013, S. 359. Zu Kilian Wolf als dem wahrscheinlichen Autor des Werkes siehe BüCHLER, Beromünster, S. 158 und 241f., Anm. 94 sowie CMD-CH 2, S. 218. Die Werkdatierung dürfte zeitlich eng mit der Entstehung der Handschrift zusammenfallen (siehe Wasserzeichen).

$198^{v}$ leer.

Teil 2:

199r-211 ${ }^{\mathrm{r}}$ JOHANNES DE SACROBOSCO, Tractatus de sphera. [T] ractatum de spera quattwor cappitulis distingwimus, dicentes primo quid sit spera, quid eius centrum, quid axis spere, quid polus mundi, et quot sint spere, et que sit forma mundi ... [S]pera igitur ab Euclide sic describitur ... - ... Propter hoc legitur sanctum Dyonisium Ariopagitam in eadem passione dixisse: Aut deus nature patitur aut mundi machina dissolvetur. The Sphere of Sacrobosco and Its Commentators, hrsg. v. Lynn Thorndike, Chicago 1949, S. 76-117. Thorndike/Kibre, Incipits, Sp. 1577; Palémon Glorieux, La faculté des arts et ses maîtres au XIII ${ }^{e}$ siècle, Paris 1971, S. 235, Nr. 267a. Anschliessend Schreibervermerk: Et sic est finis spere materialis in die omnium sanctorum per me Iohannem de Lentzburg anno 1451.

$211^{\mathrm{v}}-228^{\mathrm{v}}$ leer. 
Papier, 227 Blätter, $29 \times 21 \mathrm{~cm}$

Heidelberg (?), Mitte des 15. Jahrhunderts; 1451 und 1452

Wasserzeichen, Lagen, Foliierung: Wasserzeichen: Bl. II-XIII und 198/207, 200-205 Ochsenkopf, PICCARD, Wasserzeichenkartei Nr. 75092 (1448); Bl. 2-184 Nr. 75508 (1451) und 75846 (1451); Bl. 1/14, 99/112, 113/126 und 197/208, 199/206, 210/214 Nr. 75123 (1449); Bl. 185-196 Nr.75238 (1450) und 75264 (1451). Lagen: VIXIII + (VI+I) ${ }^{14}+7 \mathrm{VI}^{98}+2(\mathrm{VI}+\mathrm{I})^{126}+\mathrm{VI}^{138}+\mathrm{V}^{148}+5 \mathrm{VI}^{208}+(\mathrm{V}-4)^{214}$, nach Bl. 213 drei Blätter herausgerissen, nach 214 eines. Die drei Septernionen waren ursprünglich als Sexternionen ausgeführt, um die nachträglich jeweils ein zusätzliches Doppelblatt gelegt wurde. Von Bl. I bis 125 Wasserschaden an der oberen Ecke, der auf den ersten Seiten bis in den Schriftraum reicht. Lagenzählung zu Beginn der Lagen in Teil 1: $6\left(63^{r}\right)-$ $8\left(87^{\mathrm{r}}\right)$; am Ende der Lagen in Teil 2: $2^{u s} 6^{u s}\left(138^{\mathrm{v}}\right)-7^{m u s} 6^{\text {nus }}\left(196^{\mathrm{v}}\right)$. Reklamanten. Neuere Foliierung: IXIII. $1-214$.

\section{Einrichtung und Ausstattung:}

Teil 1 (Bl. 2-112, Mitte 15. Jh.): Vertikale Begrenzung des Schriftraums mit Tinte, Schriftraum 20,5-21,5 × 13 13,5,40-51 Zeilen. Schleifenlose jüngere gotische Buchkursive von einer Hand. Rubriziert, rote Paragraphenzeichen und Unterstreichungen. Überschriften in Auszeichnungsschrift, an den Buchanfängen dreizeilige rote Lombarden. Teil 2 (Bl. 113-208, 1451 und 1452): Vertikale Begrenzung des Schriftraums mit Tinte, 161 r $-172^{\mathrm{v}}$ mit Stift, Schriftraum 21-22 × 13-13,5, 47-57 Zeilen. Jüngere gotische Buchkursive mit Schleifen von der Hand Konrad Mengers. Rubriziert, rote Unterstreichungen. Überschriften in Auszeichnungsschrift, selten rot; $178^{\mathrm{v}}$ und $194^{\mathrm{r}}$ in Schriftband, 200 ${ }^{\mathrm{r}}$ gerahmt. Durchgehend Raum für 1-3zeilige Initialen ausgespart, teilweise ausgeführt: meist rote, seltener rot-schwarze Lombarden, teilweise mit floralen Ausläufern; 164 ${ }^{\mathrm{r}}-170^{\mathrm{r}}, 197^{\mathrm{r}}$ und 200 ${ }^{\mathrm{r}}$ mit verziertem Binnenfeld (Knospenfleuronné, 166 $6^{\mathrm{r}}$ Gesichtsskizze); 203 ${ }^{\mathrm{r}}$ Cadelle. 201 ${ }^{\mathrm{v}}$ rotschwarze Profilzeichnung. Kopftitel: Buchzählung, auf den Versoseiten L[iber], auf den Rectoseiten I-III (für Buch I nicht durchgehend ausgeführt), teilweise in Rot. An vielen Stellen Raum für Ergänzungen ausgespart (siehe Nachträge).

Korrekturen und Nachträge: Korrekturen der Schreiber, z. B. 2v, $55^{\mathrm{r}}$, 94 $4^{\mathrm{r}}, 138^{\mathrm{r}}, 168^{\mathrm{v}}$, 200 , sowie zahlreiche Korrekturen wohl durch Friedrich von Lütishofen, z. B. $5^{\mathrm{r}}, 64^{\mathrm{v}}, 119^{\mathrm{r}}, 170^{\mathrm{r}}$. Auf $114^{\mathrm{r}}, 115^{\mathrm{r}}, 120^{\mathrm{v}}$, 157v und 199v Handweiser. Vorsatzblatt: Notizen zu Naturphilosophie und Grammatik von verschiedenen Händen des 15. Jhs. $1^{\mathrm{r}}$ Verzeichnis der Quaestionen zu De generatione et corruptione: Incipit registrum questionum libri Perigeneos, et erunt in numero primi libri 24 questiones, et $2^{i} 20$... wahrscheinlich von der Hand Friedrichs von Lütishofen, ebenso ein Verzeichnis der Quaestionen zum 1. Buch von De anima auf 113v: Utrum de anima est sciencia tamquam de subiecto. Utrum omnis noticia est bona. Utrum omnis noticia est honorabilis. Utrum sciencia libri de anima excedat omnes alias sciencias in nobilitate et perfectione. Utrum sciencia libri de anima est de numero difficilimorum. Utrum universalia nichil sunt aut posteriora singularibus. Utrum accidentia magnam partem conferunt ad cognoscendum quod quid est. Von ihm dürften auch die zahlreiche Anmerkungen und Ergänzungen stammen, die in kleinerer Schrift, öfters in Form von schematischen Darstellungen, auf den Seitenrändern und in Teil 2 zusätzlich auf ausgesparten Bereichen bis zum Umfang von einer halben Seite angebracht wurden. Dazu kommen eine Reihe von meist roten Memorialeinträgen: Intialen $H, E$ und $B(39$ r, $\left.116^{\mathrm{r}}, 118^{\mathrm{v}}, 121^{\mathrm{r}}, 125^{\mathrm{v}}, 128^{\mathrm{v}}, 139^{\mathrm{v}}, 141^{\mathrm{r}}\right)$, manchmal mit dem Zusatz requiescant $\left(47^{\mathrm{r}}\right)$ bzw. requiescant in pace 
$\left(115^{\mathrm{v}}, 120^{\mathrm{v}}, 122^{\mathrm{r}}-123^{\mathrm{r}}, 127^{\mathrm{r}}\right)$; Initialen $E\left(168^{\mathrm{r}}\right), E H Q\left(161^{\mathrm{r}}\right)$ und $K D L M\left(159^{\mathrm{r}}\right)$; $44^{\mathrm{r}}$ F. Karr requiescat in karritate; $102^{\mathrm{r}}$ Bussegg, $144^{\mathrm{v}}$ O. v. Buszeck, 196 ${ }^{\mathrm{v}}$ Ottilgg von bussegg (vgl. auch das Einbandfragment in C 44 sowie den Musterbrief $67^{\mathrm{r}}$ ); $184^{\mathrm{r}}$ dieb.

Einband: Mit hellem Leder bezogene Holzdeckel, 15. Jh., mit Streicheisenlinien und Einzelstempeln (EBDB s028074), ungefärbte Kapitale. Ehemals zwei nach vorn greifenden Kantenschliessen mit Messingteilen: Ösenbeschläge vorne mit ausgesparter Dreipassblüte, Riemenbefestigungen hinten 9- bzw. 10zählige Blüte, Reste von Lederriemen erhalten. Vorsatzblatt (I) Papier, ein zweites sowie ein Doppelblatt am Ende herausgerissen. Spiegelblätter Papier, abgerissen. Vorne und hinten je vier Lagen mit Pergamentstreifen verstärkt, Fragmente: Isaak ben Salomon Israeli, Liber de urinis, 13./14. Jh. und Petrus Hispanus, Summule logicales, Traktat VII: De fallaciis, 13. Jh. Weitere Streifen mit angeschnittenen kurzen Notizen des 15. Jhs. um die erste und letzte Lage gebunden und in die Deckel geklebt. Streicheisenlinien und Art der Bindung entsprechen C 40 und C 64 (siehe Bü CHLER, Beromünster, S. 158 und 160), so dass von derselben Werkstatt auszugehen ist. Im vorderen Spiegel Exlibris des Chorherrenstifts Beromünster (WEgmann, Exlibris, Nr. 619). Auf dem Vorderdeckel Aufschrift: Iste liber est magistrifride[rici] de lütishoffen. Darunter: Questiones librorum de generacione, de anima. Auf dem Rücken Titelschild, Papier: Epistolce S. Pauli Ap. Omnes. No 29, entsprechend dem Catalogus von 1826, doch stimmt der Inhalt nicht damit überein.

Herkunft: Möglicherweise für Friedrich von Lütishofen in Heidelberg hergestellt, Anmerkungen und Ergänzungen wohl von seiner Hand. Der Band bildet eine Einheit mit C 40, mit dem er in Wasserzeichen, Ausstattung, Annotation und Inhalt übereinstimmt. Teil 1 wohl von Johannes Schumacher aus Lenzburg geschrieben, vgl. C 40, Teil 2. Teil 2 geschrieben von Konrad Menger aus Sursee, siehe Schreibervermerke 184 ${ }^{\mathrm{r}}$ und $203^{\mathrm{r}} ; 125^{\mathrm{v}}$ auf 13 . November 1451, $184^{\mathrm{r}}$ auf 21 . Januar 1452 datiert, zu ihm: Paul BÄNZIGER, Beiträge zur Geschichte der Spätscholastik und des Frühhumanismus in der Schweiz, Zürich 1945, S. 112-119 sowie CMD-CH 2, Textband, S. 218f. mit weiterer Literatur. Menger schrieb auch einen Teil der Hs. Pal. lat. 1589 (Aristoteles, Rhetorica, $9^{\mathrm{r}}-68^{\mathrm{v}}$ ) in der Biblioteca Apostolica Vaticana, deren Fortsetzung $\left(69^{\mathrm{r}}-194^{\mathrm{v}}\right)$ die Vorlage für C 44 gewesen sein muss.

Besitzer: Vermutlich Friedrich von Lütishofen, siehe Besitznotiz auf dem Vorderdeckel, zu ihm: BüCHLER, Beromünster, S. 132-134 und 337f. mit weiterer Literatur; im vorderen Spiegel Exlibris des Chorherrenstifts Beromünster. Im Catalogus von 1763 als Classis Nona Nr. 9 verzeichnet. Ir neuere Signatur: C 41, dünner schwarzer Filzstift, spätes 20. Jh. Signatur ehemals C 21 fol.

Literatur: Kopp, Stiftsbibliothek, II, S. 14f.; BrUCKNER, Scriptoria 9, S. 31; SidLER, Bildungsverhältnisse, S. 164 (als Kollegheft aus Heidelberg angeführt mit Verweis auf Kopp); BüCHLER, Beromünster, S. 132, 143, 158, 160f.; CMD-CH 2, Nr. 92; LoHr, Aristotelica Helvetica, S. 168f.

Ir Nachträge, 15. Jh.

Iv-XIIIv leer.

$1^{\mathrm{r}}$ Nachtrag (s. oben).

$1^{\mathrm{v}}$ leer.

Teil 1:

$2^{\mathrm{r}}-111^{\mathrm{v}}$ MARSILIUS DE INGHEN, Quaestiones super libris de generatione et corruptione Aristotelis. $>$ Incipit liber Perigeneos Aristotilis<. Circa librum de generacione et corrupcione queritur primo, utrum ens 
mobile ad formam sit subiectum libri de generacione. Et arguiturprimo, quod non, quia anima est subiectum libri de generacione, ergo non ens mobile ad formam ... - ... tamen istum ex illa materia solum isto motu potest, et isto motu numero solum potest producere istum ignem. Ratio post oppositum est pro questionis ultima conclusione. Hec de questione et de omnibus aliis, et sic est finis huius tocius libri. GW M21158: Marsilius de Inghen, Quaestiones super libris de generatione et corruptione Aristotelis, Padua: Bonus Gallus, [um 1480]. 56v Buch 2. Bl. 14 und 99 leer.

$112^{\mathrm{r}-\mathrm{v}}$ leer.

Teil 2:

$113^{\mathrm{r}}$ leer.

$113^{\mathrm{v}}$ Nachtrag (s. oben).

$114^{\mathrm{r}}-203^{\mathrm{r}}$ Quaestiones super Aristotelis libros de anima. > [Q] ueritur circa primum de anima, utrum de anima est sciencia tamquam de subiecto proprio et adequato sciencie libri de anima etc. <. Pro illa questione est primo notandum, quod licet scientia multis modis capitur, hic tamen dicit capi communiter et agregative ... - ... $125^{\mathrm{v}}$ vel forte posset dici, quod staret forte: propter miraculum sensum sentire abstractive, naturaliter tamen semper sentit concretive etc. etc. Explicit primus liber de anima etc. Finitus sabato post Martini etc. 1451. Anschliessend Verse: De sancto spiritu: Tu spiras ubi vis tua munera dividis ut vis. Das cui vis quid vis quantum vis tempore quo vis. WAlther, Carmina Nr. 19536. $127^{\mathrm{r}}>$ Queritur primo circa $2^{m}$ de anima, utrum anima sit actus substancialis etc. <. Pro illa questione est primo notandum, quod ieus (?) anima capitur dupliciter ... - ... $184^{\mathrm{r}}$ tunc clauditur propter compressionem illarum viarum. Et tantum de illa questione et omnibus questionibus illius secundi de anima deo gracias etc. Menger. Et sic est finis secundi libri de anima crastino Fabiani et Sebastiani martirum anno 1452 etc. $184^{\mathrm{v}}>$ Circa inicium tercii libri de anima queritur primo, utrum intellectus est virtus passiva <. Pro illa questione est primo dicendum, quod intellectus capitur tripliciter ... - ... unde non semper potencia appetitiva ut sic solum facit admotum, sed semper prerequirit etiam cognicionem, ut dictum est in conclusionibus, igitur etc. etc. Deo gracias. Et sic est finis tercii de anima deo gracias etc. Per me Conradum Menger de Surse etc.

$203^{\mathrm{v}}-214^{\mathrm{v}}$ leer.

\section{JACOBUS DE PARADISO; SERMONES}

Papier, 313 Blätter, 28,5-29 × $21 \mathrm{~cm}$

Aargau (?), 1474-1475

Wasserzeichen, Lagen, Foliierung: Wasserzeichen: Bl. 1-147, 193-239 und 265-311 Ochsenkopf, PiCCARD, Wasserzeichenkartei Nr. 74354 (1472) und 74694 (1475); Bl. 155 Nr. 75132 (1475); Bl. 148-165 Nr. 75514 (1473) und eine Variante, Bl. 171-191 und 243-263 Nr. 74698 (1474) und ein weiterer desselben Typs. Lagen: $26 \mathrm{VI}^{312}$. Reklamanten. Neuere Foliierung: A. 1-312.

Einrichtung und Ausstattung: Zweispaltig, Spaltenbegrenzung mit Stift, häufig kaum sichtbar. Schriftraum 20-20,5 × 13,5-14 (6), 37-48 Zeilen. Jüngere gotische Buchkursive mit Schleifen von einer Hand. Rubriziert, rote Überschriften, Stellenangaben und einzelne Zwischenüberschriften rot unterstrichen, 2-4zeilige rote 
Lombarden, ausser im jünger datierten Teil $229^{\mathrm{ra}}-263^{\mathrm{vb}} ; 262^{\mathrm{va}}$ Initiale mit flüchtiger Profilskizze. $165^{\mathrm{vb}}$ $185^{\text {ra }}$ und $265^{\text {ra }}-302^{\text {ra }}$ Zwischenüberschriften in vergrösserter Schrift. Zitate häufig am Rand durch Anführungszeichen gekennzeichnet, stellenweise Marginalien zur Texterschliessung, z. B. $24^{\mathrm{va}}, 95^{\mathrm{va}}-97^{\mathrm{rb}}$, $199^{\mathrm{va}}, 251^{\mathrm{va}}-263^{\mathrm{rb}}$, teils in Rot oder rot angestrichen.

Korrekturen und Nachträge: Wenige Korrekturen des Schreibers, z. B. 1 ${ }^{\text {ra }}$, 75 ${ }^{\text {va }}, 149^{\mathrm{va}}, 233^{\mathrm{vb}}$, 309vb. Von seiner Hand ausserdem auf $310^{\mathrm{rb}}$ unten: Item dyaphanus interpretatur durschinig. Item spatula dicitur brustblech vergült. 44 $4^{\mathrm{ra}}$ Unterstreichung und Markierung neben der Spalte; $8^{\mathrm{rb}}, 20^{\mathrm{va}}, 229^{\mathrm{rb}}$, 268 ${ }^{\mathrm{va}}$ Notazeichen; durchgehend Handweiser. Marginalien zur Texterschliessung: $119^{\mathrm{rb}}, 121^{\mathrm{va}}$, 147va, 152 ${ }^{\mathrm{rb}} 16$. Jh.; $230^{\mathrm{va}}-248^{\mathrm{va}}$ 16./17. Jh.

Einband: Einband aus der Werkstatt Uoldaricus (EBDB w000154, nachgewiesen um 1481-1490). Mit hellem Leder bezogene Holzdeckel, Streicheisenlinien und Einzelstempeln (EBDB s011933 mit Spuren einer Vergoldung, s011932, s011933 und s011940 sowie ein weiterer: ein springender Hund in Rechteck, vgl. Johann LindT, Der Buchbinder Uoldaricus, in: Berner Einbände, Buchbinder und Buchdrucker, Bern 1969, S. 25, Abb. 1, Nr. 10); zwei nach vorn greifende Kantenschliessen mit ziselierten Messingbeschlägen, die untere abgerissen; rot-weiss-blaue geflochtene Kapitale. Vorsatzblatt (A) Papier, Wasserzeichen: Kreuz, ähnlich PICCARD, Wasserzeichenkartei Nr. 125816; nur vorne ein Spiegelblatt: Papier. Aussen um die zwei ersten und letzten Lagen Pergamentstreifen: Fragmente einer neumierten liturgischen Handschrift des 12. Jahrhunderts; in den Fälzen durchgehend Fragmente von zwei Hss.: Legenda minor S. Francisci Bonaventuras (III.3f., IV.2f. und VI.2f., Analecta Franciscana X, Quaracchi/Florenz 1926-1941, S. 663, 666 und 673) und Franziskusoffizium, 14. Jh., sowie Liber pontificalis (zu Martin I., Le Liber pontificalis, hrsg. v. Louis Duchesne, Bd. 1, Paris 1886, S. 336) und Brevier, 14./15. Jh. Im vorderen Spiegel Exlibris des Chorherrenstifts Beromünster (Wegmann, Exlibris, Nr. 619). Auf dem Vorderdeckel Besitzvermerk: domini iacobi vásen. Herkunft: Aargau (?), höchstwahrscheinlich geschrieben von Jacobus Väsen, vgl. Basel, Universitätsbibliothek, F V 5 mit seiner Schreibersubskription. An fünf Stellen datiert: 153 rb 22. Januar 1474, 302 ra 28. April 1474, $308^{\text {ra }}$ 1. Mai 1474; $310^{\text {ra }} 1474,263^{\text {vb }} 1475$.

Besitzer: Jacobus Väsen, Besitzvermerk auf dem Vorderdeckel. Zu ihm: BüCHLER, Beromünster, S. $393 \mathrm{f}$. (StiAB 01.01.600, S. 76, zum 11. Mai: Anno domini $m^{\circ}$ cccc $^{0}$ octuagesimooctavo obiit honorabilis dominus Iacobus Vasen ... S. 117, zum 30. Mai: Hac die peragitur Salus domini Iacobi Väsen ...) und CMD-CH 1, Text, S. 262. Im vorderen Spiegel Exlibris des Chorherrenstifts Beromünster. Im Catalogus von 1763 als Classis Nona Nr. 20 verzeichnet. Ir neuere Signatur: C 42, dünner schwarzer Filzstift, spätes 20. Jh. Signatur ehemals C 22 fol. Literatur: Kopp, Stiftsbibliothek, II, S. 18; BüCHLER, Beromünster, S. 143, 170; CMD-CH 2, Nr. 93.

$\mathrm{A}^{\mathrm{r}-\mathrm{v}}$ leer.

$1^{\mathrm{r}}-153^{\mathrm{rb}}$ JACOBUS DE PARADISO, Sermones. Sonntagspredigten, 1. Advent - 24. Sonntag nach Pfingsten, dazwischen zwei Festtagspredigten zu Weihnachten. > Dominica prima adventus<. Dicite filie Syon ... (Mt 21,5) $M^{t}$ xxi et originaliter Zacharie ix, licet sub aliis verbis eodem tamen sensu obtinuit. Ecce auctoritas spiritus sancti inspiratcione roborata $\ldots 12^{\mathrm{va}}>$ In vigilia nativitatis $<$. Cum esset desponsata $\ldots 15^{\mathrm{va}}>$ De nativitate domini<. Populus gencium ... 18 $8^{\mathrm{ra}}>$ Dominica infra octavas nativitatis<. Erat pater Ihesu ... - ... $153^{\mathrm{rb}} \mathrm{O}$ anima, tibi dico: Surge! Et statim ad imperium Christi anima nostra revivificet hic per graciam et in futuro per gloriam. Quod nobis prestare dignetur. GW M10869: Jacobus de Paradiso, Sermones dominicales notabiles et formales, [Straßburg: Georg Husner, ca. 1475], 2v $-15^{\mathrm{r}}$ und 15 $15^{\mathrm{r}}-185^{\mathrm{r}}$, dazwischen GW M10873: Jacobus de Paradiso, 
Sermones notabiles et formales de praecipuis festivitatibus, [Blaubeuren, nicht nach 1476], 21 ${ }^{\mathrm{v}}-26^{\mathrm{v}}, 36^{\mathrm{r}}-3^{\mathrm{v}}$. Ludger MeIER, Die Werke des Erfurter Kartäusers Jakob von Jüterbog in ihrer handschriftlichen Überlieferung, Münster 1955, S. 76f., Nr. 94 (Hs. nicht erwähnt). Anschliessend Schreibervermerk: Et sic finis huius operis in die Vincencii anno 1474.

$153^{\text {va }}-171^{\text {va }}$ JACOBUS DE PARADISO, Sermo de paenitentia. $>$ Sermo de penitentia $<$. Penitenciam agite ... (Mt 3,2). Licet vita cuiuslibet boni Christiani omni tempore debet esse penitencialis ... - ... Et quia episcopus scit et dissimulat, igitur videtur ratum habere etc. MEIER, Jakob von Jüterbog, S. 79.

$171^{\text {va }}-177^{v b}$ JACOBUS DE PARADISO, Sermo de solutionibus debitorum. $>$ Sermo de solutionibus debitorum <. Reddite omnibus debita ... (Rm 13,7). Beatus Paulus vas eleccionis certissimus de sua fide et doctrina, quam non ab homine nec per hominem se accepisse testatur, sed per revelacionem Ihesu Christi ... - ... et si illud invenerit, et per circumstancias certificetur, quod illius fuerit, illi restituet, alias erroget pauperibus vel idem ipse tenere potest, si est indigens. Et hoc si quosdam auctoritate penitenciarii sive sui diocesani si forte sibi retinuerit dispensacionem titulum vel etiam sui confessoris aut plebani (Ende offenbar gestört). MEIER, Jakob von Jüterbog, S. 88 .

$178^{\mathrm{ra}}-184^{\mathrm{vb}}$ JACOBUS DE PARADISO, Sermo de defunctis. $>$ Sermo pro deffunctis $<$. Sancta et salubris ... (2 Mcc 12,46). Paulus omnium doctor curans (sic) gerens Ad Romanos xiii hortatur omnes dicens: Reddite omnibus debita ... - ... In longum produxi sermonem non ea intencione, ut una vice coram populo recitaretur, sed potest dividi in $3^{s}$ sermones aut secundum complacenciam predicatoris maxime $3^{a}$ pars et ultima magis utiles viduntur (sic). MeIER, Jakob von Jüterbog, S. 81.

$184^{\mathrm{vb}}-192^{\mathrm{ra}}$ JACOBUS DE PARADISO, Sermones. Zwei Predigten zu Mariä Geburt und Ostern. $>$ Sequitur sermo de nativitate beatissime virginis Marie<. Nativitas tua, dei genitrix virgo, gaudium annunciavit universo mundo! iocundissime canit sancta mater ecclesia per orbem longe lateque diffusa in hodierna virginis Marie nativitate ... 189 $9^{\mathrm{rb}}>$ Sermo ut sequitur feria $3^{\text {a }}$ pasce $<$. Stetit Ihesus in medio ... (Lc 24,36). Ex quo hec festa pascalia pro sui veneracione exigunt a fidelibus, ut celeberrime peragantur ... - ... quo precipit predicare penitenciam et remissionem peccatorum in omnes gentes, que vocande erant ad fidem Christi, in quo Iudei deum credere noluerunt. Amen. GW M10873, 206 $-213^{\mathrm{r}}, 103^{\mathrm{v}}-107^{\mathrm{v}}$.

$192^{\mathrm{rb}-\mathrm{vb}}$ leer.

$193^{\mathrm{ra}}-220^{\mathrm{ra}}$ Sermones. Acht Predigten zu Pfingsten, davon sieben aufeinander aufbauend zu Io 10,1f. Initien im Register. $>$ Feria $2^{a}$ penthecostes $<$. Sic deus dilexit mundum ... (Io 3,16). Hoc ewangelium ideo legitur in festo penthecostes, quia filius datus est nobis in mundum per spiritus sancti donum ... 195 $>$ ra Sequntur sermones aliqui de festo penthecostes, et significant de donis spiritus sancti, et subsequentia omnia peroptime notantur $<$. > Primus sermo <. Qui autem intrat per ostium ... (Io 10,2). Hec verba dixit Christus ad Iudeos occasione ceci illuminati ...

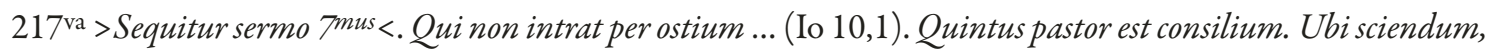
quod consilium quandoque causatur pro inquisicione ... - ... divinitatem conprehendere non convenit nisi illi, qui est deus, sed non est deus nisi pater et filius et spiritus sanctus, et sic tali visioni (sic) divinitatem videre solum convenit trinitati.

$220^{\mathrm{rb}}-228^{\mathrm{v}}$ leer.

$229^{\mathrm{ra}}-263^{\mathrm{vb}}$ Sermones. 11 Predigten zu verschiedenen Themen und Anlässen, darunter Kirchweih und Neujahr. >Sermo de dedicacione<. Ingressus Ihesus perambulabat ... (Lc 19,1). Proverbium est commune: Quisquis amat suum et rem invitus perdet ... 234 $4^{\mathrm{ra}}>$ De dedicacione $<$. Es ist ein kein dorff so klein, es werd alle Jar einest kilwi. Ita nulla reperitur villa, quin in anno ad minus semel fit dedicacio ... $234^{\mathrm{vb}}>$ Sermo de novo anno 
omnibus statibus<. Postquam consummati sunt dies octo ... (Lc 2,21). In hiis verbis duo tanguntur, que hodie solempnizat sancta mater ecclesia. Primum est circumcisio infantis, $2^{\text {um }}$ imposicio nominis ... $241^{\text {ra }} 2$ Predigten des Nikolaus von Dinkelsbühl zu Allerheiligen und St. Michael: MADre, Dinkelsbühl, S. 232-234 (Sermo II) und 235-237. 256 $6^{\mathrm{ra}}$ Alius sermo: Exiit qui seminat ... (Mt 13,3 / Lc 8,5). In istis etenim verbis innuitur varia disposicio agri, circa quod sciendum, quod $4^{\text {or }}$ sunt genera hominum, qui continue currunt ad predicacionem ... $257^{\mathrm{ra}} 6$ Predigten des Jordanes von Quedlinburg, Schneyer, Bd. 3, S. 859-861, Nr. 533-537 (mit anderem Schluss), 539, 546 (mit anderem Schluss), 554. Anschliessend Datierung: Finis huius 1475.

$264^{\mathrm{ra}}-264^{\mathrm{v}}$ leer.

$265^{\text {ra }}-302^{\text {ra }}$ JACOBUS DE PARADISO, Passio domini secundum quatuor evangelistas. $>$ Ablaturus in tabernaculo tuo, quod est ecclesia<. Indulgentissime domine Ihesu Christe, munus quo nullum preciosius, videlicet memoriale insigne tue sanctissime passionis ... - ... 302 ${ }^{\mathrm{ra}}$ Hanc mellis dulcedinem et olei pinguedinem opto et oro semper me una cum omnibus desiderantibus inpinguari. Amen. MeIER, Jakob von Jüterbog, S. 46, Nr. 51. Anschliessend Datierung: Anno domini $1474^{\text {to }}$ in die Vitalis martyris.

$302^{\text {ra }}-308^{\text {ra }}$ JACOBUS DE PARADISO (?), Devota passionis Christi meditatio. > Sequitur devota meditacio passionis Christi<. O preciosa Christi sponsa, id est quelibet devota anima Christi sponsi sanguine redempta et dei ymagine insignita, tibi ingeritur ... - ... non restat aliud nisi gaudiosa resurreccio cum Christo Ihesu, qui est benedictus in secula seculorum. Amen. MeIER, Jakob von Jüterbog, S. 85, Nr. 113 (unter «Zweifelhafte und unechte Werke»). Anschliessend Datierung: In vigilia Philippi et Jacobi anno 1474.

308 ${ }^{\mathrm{rb}}-311^{\mathrm{va}}$ Sermones. 2 Predigten zu Pfingsten. > De sancto spiritu<. Paraclitus autem spiritus sanctus ... (Io 14,26). Secundum sentenciam Aristotilis primum, quod cadit sub nostro appetitu, est esse ... $310^{\text {ra }}$ ut ydoitarum (sic) corda uno momento erudiret ad scienciam et eorum linguas formauit ad omnium linguarum facundiam. Quod nobis prestare dignetur 1474. Amen. $>2^{a}$ penthecostes<. Lux venit in mundum ... (Io 3,19). Quia adventu spiritus sancti mundus dicitur creatus et renovatus quantum ad mentes hominum ... - ... Sed nos debemus pro talibus spiritum sanctum rogare et dicere illud Luce 2: Illuminare hiis, qui in tenebris et in umbra mortis sedent. Quod nobis prestare dignetur Christus.

$311^{\mathrm{vb}}-312^{\mathrm{vb}}$ leer.

\section{ZACHARIAS CHRYSOPOLITANUS}

Papier, 301 Blätter, $28,5 \times 21 \mathrm{~cm}$

Zweite Hälfte des 15. Jahrhunderts

Wasserzeichen, Lagen, Foliierung: Wasserzeichen: Bl. 1-48 und 193-297 Waage, PiCCARD, Wasserzeichenkartei Nr. 116648 (1471) in 5 Varianten; Bl. 49-108 Krone, Nr. 50090 (1449) und 50224 (1452); Bl. 109-120 Traube, Nr. 128993 (1453) und eine Variante; Bl. 121-144 und 148/153 Ochsenkopf, Nr. 75196 (1462) und 75696 (1462); Bl. 145f./155f. und 149-152 Nr. 75140 (1462); Bl. 147/154 Nr. 74829 (1464); Bl. 157f./167f., 160/165 Nr. 79781 (1462), Bl. 159/166 Nr. 79782 (1462); Bl. 161-164 und 169-192 Nr. $74442(1464)$ in zwei Varianten. Lagen: $8 \mathrm{VI}^{96}+(\mathrm{VI}+4)^{108 \mathrm{a}}+15 \mathrm{VI}^{288}+(\mathrm{VI}-3)^{297}$, nach Bl. 102, 104, 107 und 108 jeweils ein kleineres Einzelblatt eingefügt, nach 297 drei Blätter herausgerissen, Bl. 289-291 fast lose. Buchblock beschnitten, wobei der Rand von Bl. 28 und 29 vorgängig umgefaltet 
wurde, um die Marginalien zu erhalten. Von den Deckeln ausgehend viele Wurmlöcher. Lagenzählung zu Beginn der Lagen: $5\left(49^{\mathrm{r}}\right)-17\left(193^{\mathrm{r}}\right)$. Reklamanten. Neuere Foliierung: 1-102. 102a. 103-104. $104 \mathrm{a}$. 105-107. 107a. 108. 108a. 109-297.

Einrichtung und Ausstattung: Begrenzung des Schriftraums mit Tinte, Schriftraum 19,5-20,5 × 13,5-14,5, zweispaltig (6-7), 14 $\mathrm{rb}^{\mathrm{b}}-19^{\mathrm{va}}$ vierspaltig; 34-58 Zeilen. Jüngere gotische Buchkursive von 4 Händen, Haupthand nahezu schleifenlos: $1^{\mathrm{ra}}-48^{\mathrm{ra}}, 11^{\mathrm{rb}}-160^{\mathrm{vb}}, 170^{\mathrm{ra}}-297^{\mathrm{vb}} ; 2$. Hand schleifenlos: 49 ${ }^{\mathrm{ra}}-108^{\mathrm{vb}}$; 3. Hand mit Schleifen: $109^{\mathrm{ra}}-111^{\mathrm{rb}} ; 4$. Hand (Friedrich von Lütishofen) nahezu schleifenlos: $160^{\mathrm{vb}}-169^{\mathrm{vb}}$. Von der letzten Hand stammen ausserdem zahlreiche Marginalien in der ganzen Handschrift (vor allem Bl. 49-108) und die vier eingebundenen kleineren Blätter. Weitere Marginalien zu Textgliederung und Erschliessung des Inhalts von der Hand des jeweiligen Schreibers. Rubriziert, rote Überschriften und Explicits, $24^{\mathrm{va}}-26^{\text {ra }}$ rote Abschnittsnummern, durchgehend rote Kanonnummern. 49 $-75^{\mathrm{r}}$ am Kopf, ab $75^{\mathrm{r}}$ am Fuss der Seiten Evangelistenkürzel, anfangs in Rot. Bibelzitate in vergrösserter Schrift, häufig rot unterstrichen, $113^{\text {ra }}-160^{\text {ra }}$ mit roten Anführungszeichen hervorgehoben. $1^{\mathrm{ra}}-14^{\mathrm{ra}}, 21^{\mathrm{v}}, 35^{\mathrm{ra}}-38^{\mathrm{ra}}$ und $293^{\mathrm{ra}}-297^{\mathrm{vb}}$ rote Versalien. Durchgehend Raum für 1-4zeilige Initialen ausgespart, $20^{\mathrm{ra}}$ für eine 6zeilige, $49^{\mathrm{ra}}-75^{\mathrm{rb}}, 81^{\mathrm{ra}}, 85^{\mathrm{rb}}-101^{\mathrm{ra}}, 157^{\mathrm{va}}-158^{\mathrm{rb}}, 163^{\mathrm{vb}}-164^{\mathrm{vb}}$ ausgeführt: rote Lombarden, öfters mit Punktverdickungen oder gespaltenen Schäften, $87 \mathrm{vb}$ mit flüchtiger Profilskizze.

Korrekturen und Nachträge: Wenige Korrekturen der Schreiber, z. B. 46 ${ }^{\mathrm{ra}}, 81^{\mathrm{va}}, 135^{\mathrm{ra}}, 203^{\mathrm{rb}}, 267^{\mathrm{va}}$. Handweiser und Markierungszeichen.

Einband: Mit braunem Leder bezogene Holzdeckel, 15. Jh., mit Streicheisenlinien und 9 verschiedenen Einzelstempeln: 1. Blume in umrandetem Kreis (vgl. Erster datierter Schweizer Druck, Taf. 18, Nr. 12), 2. Eichenblatt (ebd. Nr. 13), 3. Lilie (ebd. Nr. 14), 4. Lilie in umrandetem Quadrat (ebd. Nr. 9), 5. Stelzvogel in umrandetem Kreis (ebd. Nr. 10), 6. Blüte: Vierblatt mit zwei Blattkränzen in umrandetem Kreis (ebd. Nr. 11), 7. gegenständige Ranke mit Laub und Blüten in umrandetem Rechteck, 8. Quadratmuster (ebd. Nr. 5), 9. stehender geflügelter Greif über einem Band in Quadrat (ebd. Nr. 4). Vgl. C 65. Zwei nach vorn greifende Kantenschliessen mit Messingbeschlägen, Riemenbefestigungen hinten durch im Dreieck angeordnete Messingnägel. Weiss-blaue geflochtene Kapitale. Rückenleder oben und unten beschädigt, zum Rückdeckel hin gebrochen. Nach Bl. 12 Rest eines ausgerissenen Vorsatzblattes aus Papier. In den Spiegeln je ein Papierstreifen sowie Abklatsch von zwei herausgelösten Pergamentfragmenten: neumiertes Antiphonar, 12. Jh. Durchgehend Falzverstärkungen, Pergament, Fragmente derselben Handschrift. Im vorderen Spiegel auf dem Abklatsch Exlibris des Chorherrenstifts Beromünster (Wegmann, Exlibris, Nr. 619). Auf dem Vorderdeckel Titelschild, Pergament, 15. Jh.: Unum ex iiiior, Seu concordia evangelistarum cum expositione continua. Interpretaciones nominum quae in evangelio comperiuntur. Auf dem Rücken Titelschild, Papier: Zacharie Crisopolitani unum ex Quatuor, Seu Concordia Evangelistarum. No 5, entsprechend dem Catalogus von 1826; unter dem modernen Signaturschild Spuren eines früheren.

Herkunft: $160^{\mathrm{vb}}-169^{\mathrm{vb}}$ geschrieben von Friedrich von Lütishofen, das Übrige wohl in seinem Auftrag. Besitzer: Wahrscheinlich Friedrich von Lütishofen. Im Catalogus von 1763 als Classis Nona Nr. 13 verzeichnet, im Nachtrag dazu auf 46r als Nr. V, im Catalogus von 1826 als Nr. 5. $1^{\mathrm{r}}$ mit Filzstift neuere Signatur: C 43, spätes 20. Jh. Signatur ehemals C 23 fol.

Literatur: Kopp, Stiftsbibliothek, II, S. 14; BRUCKNER, Scriptoria 9, S. 27f.; BüCHLER, Beromünster, S. 143.

$1^{\text {ra }}-20^{\text {ra }}$ Capitula et canones evangeliorum. > Incipiunt capitula Mathei<. Liber generacionis Ihesu Christi: $i$, iii. Omnes ergo generaciones et cetera: $i$, $x \ldots-\ldots 14^{\mathrm{ra}}$ Amen dico tibi: cum esses iunior: ccxxx. $>$ Expliciunt 
capitula Iohannis<. Initienliste zu den Kapiteln der Evangelien, für Mt und Mc $\left(1^{\mathrm{ra}}-7^{\mathrm{rb}}\right)$ mit den jeweiligen Kanonnummern, danach nur noch sporadisch. $14^{\mathrm{rb}}-19^{\mathrm{va}}$ Kanontabelle, PL 29, Sp. 531-542. 19vb Ex ordine librorum iiiior ewangelistarum capitula necnon canones ante posuimus, ut vel sic lector directus in libris eciam non distinctis canonibus facile reperiat, quod quesierit ... - ... Igitur possibile fuit xii esse canones ewangelii, licet solummodo $x$ esse contigerit. Diese Zusätze in anderer Reihenfolge auch am Ende des Erstdrucks GW M52010: Zacharias Chrysopolitanus, In unum ex quattuor seu concordia evangelistarum, [Straßburg] 1473.

20 ${ }^{\text {ra }}-293^{\text {ra }}$ ZACHARIAS CHRYSOPOLITANUS, In unum ex quattuor. $>$ In nomine sancte trinitatis liber de concordia ewangelistarum incipit<. De excellencia ewangelii et differencia ipsius ad legem ... - ... novissime visus est et michi, hoc non post parvum tempus ascensionis. > Explicit Unum ex quattwor seu concordia Ewangelistarum, et desuper exposicio continua, exactissima diligencia edita a Zacharia Crisopolitano<. PL 186, Sp. 11-620. RB 8400; Trudo J. Gerits, Notes sur la tradition manuscrite et imprimée du traité In unum ex quattuor de Zacharie de Besançon, in: Analecta Praemonstratensia 42 (1966), S. 276-303 (Hs. nicht erwähnt). $33^{\text {ra }}$ Epilogus Brevis und Praefatio secunda, 34 ${ }^{\text {ra }}$ Praefatio tertia. Es fehlt die Admonitio lectori, stattdessen folgt 35 $5^{\text {ra }}$ direkt das Kapitelverzeichnis. 38 ${ }^{\text {vb }}$ Prologus Lucae, 96 va Buch 2, $138^{\text {rb }}$ Buch 3, $222^{\text {rb }}$ Buch 4. $293^{\mathrm{rb}}-297^{\mathrm{vb}}$ Interpretationes nominum, quae in evangeliis reperiuntur. > Incipiunt interpretaciones nominum, que in ewangeliis reperiuntur<. Abraham: Pater videns populum uel multitudinem, vel pater multarum (subaudis: gencium). Aminadab ... - ... Zebedei: Sunt memoria domini, vel memor domini, vel sacrificium, vel donatus, vel fluens iste etc. $>$ Expliciunt Interpretaciones nominum, que in ewangelio inveniuntur $<$. Weiterer Textzeuge: München, Bayerische Staatsbibliothek, Clm 4546, 264 $4^{\mathrm{ra}}-267^{\mathrm{ra}}$.

Wasserzeichen, Lagen, Foliierung: Wasserzeichen: B1. 2/13, 3/12 Ochsenkopf, PICCARD, Wasserzeichenkartei Nr. 75469 (1453), Bl. 14-63 Nr. 74786 (1452), 75431 (1453), 75515 (1453), 76840 (1452) und 76878 (1453); Bl. 112-136 Nr. 75489 (1452) und 75855 (1452); Bl. 138-197 Nr. 74465 (1472) und 74504 (1472); Bl. 199-232 Nr. 75888 (1438) und 76933 (1436), nebst drei weiteren Varianten, Bl. 233-280 Nr. 79331 (1436) und 79351 (1435); Bl. 4-11 Traube, PiccARD, Wasserzeichenkartei Nr. 129216 (1456) und eine Variante, Bl. 64-111 Nr. 129331 (1452) und 129342 (1452), sowie ähnlich Nr. 128999 (1452), Bl. 80/83 Nr. 128935 (1458); Bl. 126/137 Nr. 129327 (1457); Bl. 341-351 Nr. 129125 (1437/38) und 129243 (1436); Bl. 198/209 Hand (ohne Stern), PicCard, Wasserzeichenkartei Nr. 154381 (1432-1435), Bl. 281-340 (mit Stern) Nr. 155660 (1437) und 155662 (1435-1437).

Lagen: VI ${ }^{13}+\mathrm{VII}^{27}+7 \mathrm{VI}^{111}+\mathrm{VII}^{125}+(\mathrm{VII}-2)^{137}+6 \mathrm{~V}^{197}+12 \mathrm{VI}^{340}+(\mathrm{VI}-1)^{351}$, nach Bl. 135 zwei Blätter herausgerissen, nach Bl. 351 ein Blatt herausgeschnitten. In Teil 4 Wasserschaden, am unteren Rand bis in den

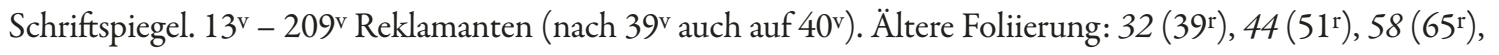
$59\left(66^{\mathrm{r}}\right), 61\left(68^{\mathrm{r}}\right), 63\left(70^{\mathrm{r}}\right), 64\left(71^{\mathrm{r}}\right), 67\left(74^{\mathrm{r}}\right)-73\left(80^{\mathrm{r}}\right)$. Neuere Foliierung: 1-219. 219a. 220-352. 


\section{Einrichtung und Ausstattung:}

Teil 1 (Bl. 1-111, 1453-1456): Vertikale Begrenzung des Schriftraums mit Tinte $\left(64^{\mathrm{r}}-65^{\mathrm{r}}\right.$ und $88^{\mathrm{r}}$ auch horizontal), $52^{\mathrm{r}}-53^{\mathrm{v}}$ und $60^{\mathrm{r}}-63^{\mathrm{v}}$ nur durch Falzung, $100^{\mathrm{r}}-108^{\mathrm{r}}$ mit Stift, Schriftraum $20-21,5 \times 12,5-14$, $32-35\left(2^{\mathrm{r}}-7^{\mathrm{v}}\right)$ resp. $40-60\left(8^{\mathrm{r}}-107^{\mathrm{r}}\right)$ Zeilen. $2^{\mathrm{r}}-7^{\mathrm{v}}$ jüngere gotische Buchkursive mit Schleifen von einer Hand, $8^{r}-107^{r}$ mit wenigen Schleifen, wohl von der Hand Friedrichs von Lütishofen. $2^{r}-7^{r}$ rubriziert, $3^{r}$ eine rote Marginalie (wohl von der Hand des Lütishofen); $2^{\mathrm{r}}$ Raum für eine dreizeilige Initiale freigelassen, nicht ausgeführt. $9^{\mathrm{r}}-12^{\mathrm{r}}, 14^{\mathrm{r}}-20^{\mathrm{r}}, 28^{\mathrm{r}}-34^{\mathrm{r}}, 40^{\mathrm{r}}-46^{\mathrm{r}}, 52^{\mathrm{r}}-58^{\mathrm{r}}, 64^{\mathrm{r}}-70^{\mathrm{r}}, 76^{\mathrm{r}}-80^{\mathrm{r}}, 81^{\mathrm{v}}-82^{\mathrm{r}}, 88^{\mathrm{r}}-94^{\mathrm{r}}, 100^{\mathrm{r}}-106^{\mathrm{r}}$ rubriziert, rote Unterstreichungen und Zeilenfüller, $17^{\mathrm{v}}, 30^{\mathrm{v}}, 65^{\mathrm{v}}-68^{\mathrm{v}}, 79^{\mathrm{v}}, 82^{\mathrm{r}}, 91^{\mathrm{r}}$ und $100^{\mathrm{r}}$ rote Überschriften. Marginalien. Raum für 2-4zeilige Initialen freigelassen, nicht ausgeführt. $16^{\mathrm{r}}$ die obere Hälfte der Seite freigelassen. Teilweise mit Schemata.

Teil 2 (Bl. 112-137, um 1453): Vertikale Begrenzung des Schriftraums mit Tinte (bis 134v ), 113v zusätzlich für Randglosse, Schriftraum 19-22 × 10,5-13, abschnittsweise abwechselnd Referenztext, 13-15 Zeilen, und Kommentar, 46-54 Zeilen. Nahezu schleifenlose jüngere gotische Buchkursive von zwei Händen, bis $124^{\mathrm{v}}$ von der gleichen Hand wie $8^{\mathrm{r}}-107$ (also wohl Lütishofen). Rubriziert, rote Unterstreichungen, Marginalien teilweise in Rot. Raum für 1-2zeilige Initialen ausgespart, nicht ausgeführt.

Teil 3 (Bl. 138-197, nicht nach 1472): Inkunabel. Rubriziert (Majuskeln), Initialen nicht ausgeführt. Teil 4 (Bl. 198-351, 1438): Begrenzung des Schriftraums mit Tinte, Schriftraum 20-22 × 13,5-14, zweispaltig (6-6,5), 37-47 Zeilen. Jüngere gotische Buchkursive mit Schleifen von der Hand des Thomas Ebinger. Rubriziert, einzelne rote Unterstreichungen. Ab 205 der jeweils aktuelle Buchstabe des Vokabulars in Rot am Kopf der Seiten. 2-5zeilige rote Initialen, z. T. mit ornamentalen Schaftaussparungen, 198 ${ }^{\text {ra }}$ mit schwarzem Quadratmustergrund. Einzelne Oberlängen der ersten Zeile mit Ausläufern und Banderolen verziert.

Korrekturen und Nachträge: Korrekturen von der Hand der Schreiber, z. B. $7^{\mathrm{r}}$, ab $8^{\mathrm{r}}$ sehr zahlreich in Teil 1, $31^{\mathrm{r} / \mathrm{v}}$ mehrere Korrekturen sowie Neuanfang eines Satzes auf neuer Seite, davor Hinweis: Verte folium, $42^{\mathrm{v}} / 44^{\mathrm{r}}$ wiederum Neuanfang, davor Verte folium, $51^{\mathrm{r}}, 100^{\mathrm{v}}, 198^{\mathrm{vb}}, 306^{\mathrm{rb}}, 334^{\mathrm{va}}$. Handweiser: $47^{\mathrm{v}}, 48^{\mathrm{v}}, 54^{\mathrm{v}}$ und $83^{\mathrm{v}}$. $116^{\mathrm{v}}$ und $117^{\mathrm{r}}$ Initialen $E H B($ ?) in Rot, von der Hand des Lütishofen, vgl. C 41. In der Inkunabel vereinzelt Marginalien (139 ${ }^{\mathrm{r}}$ auch einzelne Interlinearglossen) und Handweiser, 16. Jh. Im Vokabular Nachträge: zusätzliche Lemmata mit lateinischen, nur vereinzelt auch deutschen Erklärungen, möglicherweise von der Hand Friedrichs von Lütishofen. Im hinteren Spiegel: Haud facile emergunt quorum virtutibus obstat / Res angusta domi, 16. Jh.

Einband: Mit grösstenteils abgerissenem weissem Leder bezogene Holzdeckel, 15. Jh.; neuer dunkelbrauner Lederrücken, spätestens des 18. Jhs., wurmstichig und teilweise ebenfalls abgerissen. Ehemals eine nach vorn greifende Kantenschliesse, Messingraste im Vorderdeckel erhalten. Spiegel- und Vorsatzblätter (1,352) Papier, Wasserzeichen: Ochsenkopf, PICCARD, Wasserzeichenkartei Nr. 71723 (1478). Blau-weisse geflochtene Kapitale. Je zwei Pergamentfragmente einer grammatischen Hs., 13./14. Jh., um die Vorsatzblätter gebunden und in die Deckel geklebt. In den Fälzen Pergamentfragmente, darunter mehrere einer dt. Urkunde, darin genannt der Erwirdig wolgelert Meister Fridrich von Lütishoffen kilchber zü wangen (B1. 7/8), der seiner Tochter, der vorgemelden Otilien von Busegg (Bl. 298/299) etwas zu vermachen scheint (vgl. auch $67^{\mathrm{r}}$ und die Nachträge in C $41,144^{\mathrm{v}}$ bzw. 196 v). Auf dem Rücken Papierschild mit Drucktypen: CASPARINI EPISTOLAE CUM DUOBUS MSPT'S.

Herkunft: Die Teile 1 und 2 mehrheitlich $\left(8^{\mathrm{r}}-124^{\mathrm{v}}\right)$ geschrieben von Friedrich von Lütishofen und in Teil 1, einer gewiss in Heidelberg nach der heute im Vatikan aufbewahrten Hs. Pal. lat. Vat. 1589 angefertigten 
Abschrift, auf den 11. Okt. 1453 (Buch 1) resp. den 20. Aug. 1456 (Buch 2) datiert, vgl. BüCHLER, S. 158; Teil 2 auch aufgrund der Wasserzeichen um $1453 \mathrm{zu}$ datieren. Teil 4 gemäss Schreibervermerk 351 va geschrieben von Thomas Ebinger und auf den 23. Dez. 1438 datiert, zu ihm CMD-CH 2, S. 235 bzw. BÜCHLER, S. 338 (Nr. 202).

Besitzer: Teil 4 laut Schreibervermerk 351 va an Ludwig von Lütishofen (BüCHLER, S. 338, Nr. 202) verkauft, später anscheinend im Besitz Friedrichs von Lütishofen (BüCHLER, S. 337f., Nr. 201). Im vorderen Spiegel: Collegii Beronensis, darunter Spuren wahrscheinlich von dem üblichen gestochenen Exlibris des Chorherrenstifts Beromünster. In den Antiquitates Beronenses, S. 691, als Nr. 21, im Catalogus von 1826 als Nr. 28 verzeichnet. $1^{\mathrm{r}}$ neuere Signatur C 44, Filzstift, spätes 20. Jh. Signatur ehemals C 24 fol.

Literatur: Franz Xaver Bernhard Göldlin von TieffenAU: Konrad Scheuber von Altsellen, oder: Etwas über Politik und Cultur der Schweizer im fünfzehenten und sechszehenten Jahrhundert. Zweyter Theil: Konrad Scheubers Zeitgeschichte. Erste Abtheilung, Luzern 1813, S. 96f.; RiEdwEg, Beromünster, S. 491; Kopp, Stiftsbibliothek, I, S. 10 und II, S. 19f.; Theodor von Liebenau, Nachtrag zu der biographischen Skizze von M. E. Knab, in: Diözesanarchiv von Schwaben 22 (1904), S. 125f.; Renward BrandstetTER, Der Ebingersche Vokabularius 1438, in: Archiv für das Studium der neueren Sprachen und Litteraturen 72 (1884), S. 427-432 (über die Hs. S. 427) und 73 (1885), S. 99-105; BruCKnER, Scriptoria 9, S. 31 und Taf. 40; Heinrich Hänger, Mittelhochdeutsche Glossare und Vokabulare in schweizerischen Bibliotheken bis 1500, Berlin/New York 1972, S. 43f.; SidLER, Bildungsverhältnisse, S. 121; BüCHLER, Beromünster, S. 132135, 158-162, 165, 177, 232f. (Anm. 100-107), 243 (Anm. 106), 305f. (Nr. 119) und 336-338 (Nr. 200, 201 und 202); CDM-CH 2, Nr. 94; Kristeller, Iter Italicum 5, S. 99; Nigel F. PAlmer, Bibelübersetzung und Heilsgeschichte, Berlin/New York 2007, S. $135 f$.

Teil 1:

$1^{\mathrm{r}}$ Inhaltsübersicht. Nachtrag, 18. Jh. Aggregatorium Rhetoricae Magistri Erhardi Knab de Zwifalten in Alma Universitate Heydelberg: Anno Gratiae MCCCCLIII. ${ }^{\circ}$ in quo plurimae continentur Epistolae DD: Magistri Friderici de Lutishoven ad amicos, et praesertim ad Fratrem Suum DD. Burcardum de Lutishoven Canonicum Beronensem. Continetur etiam continetur Formula concessi Magisterii pro Joane de Gundelingen Beronense, postea eiusdem Collegii Canonico a Decano et Magistris Facultatis Artium Studii Heidelbergensis. 1453. 18 May. pag. 44.

1 v leer.

$2^{\mathrm{r}}-7^{\mathrm{v}}$ Compendium rhetoricum (Partes dictaminis). $[\mathrm{P}]$ ro aliquali intellectu in scientia rethoricali omnino deficientibus aliqua sub compendio dei adiutorio cooperante dicere attemptabo ... $3^{\mathrm{r}}$ Cum igitur inter partes dictaminis salutacio prima pars esse dinoscitur ... $3^{\mathrm{v}}$ Sequitur nunc de $2^{a}$ parte principali dictaminis que exordium nuncupatur ... $4^{\mathrm{v}}$ Nunc est determinandum de $3^{\circ}$ premisso scilicet de narracione que $3^{a}$ pars dictaminis fore dinoscitur ... $5^{\mathrm{v}}$ Nunc restat determinare de $4^{a}$ parte scilicet de peticione ... $6^{\mathrm{v}} \mathrm{Nunc}$ de subscripcione agendum est ... $7^{\mathrm{r}}$ Primo ponendum est nomen proprium persone mittentis ... $2^{\circ}$ ponatur meritum persone mittentis ut est 'miles tuus' vel consimilis. $3^{\circ}$ ponatur nomen loci in quo persona mittens moratur, ut Gregorius Vogt scolasticus scole Elwangensis ... Exemplum: Fridericus arcium baccalaureus Haydelbergensis ... Quantum ad $2^{m}$ scilicet de superscripcione ... $7^{\mathrm{v}}$ Exemplum de superscripcione: Honesto viro Friderico N. de Lutishoffen fautori suo ...

$8^{\mathrm{r}}-57^{\mathrm{r}}$ ERHARDUS KNAB DE ZWIFALTEN, Aggregatorium rhetoricum. Buch 1: Quemadmodum homo cum non individualiter perpetuetur sed fluxibilitati subiacens et continue instabilitati requirit pro successione 
sibi speciei similium et conformium ... $8^{\mathrm{v}}$ Ergo titulus agegatorium (sic) rethorice Magistri Erhardi Knab de Zwifalten editum ab eodem in alma universitate Hey [delbergensi] anno gracie $m$ cccc liii finis autem huius operis sive tractatus ut debito ordine dicendorum bene pensato novelli ac rudes possint in epistolando sive dictamine intenciones suas non nullis aliis melius et ornacius significare, ad laudemque omnipotentis dei et sue gloriose matris virginis intemerate eo sic uti ut sit eis ad meritum et universis proficiendi cedat in exemplum. $9^{\mathrm{r}} U$ t autem nunc

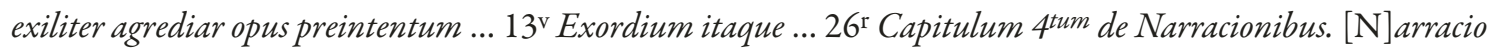
est rerum gestarum vel prout gestarum venusta explicacio ... $27^{\mathrm{r}}$ Divisio autem ... 30 $>$ Confirmacio, Confutacio $<$. [S] uperest nunc ... 36 $6^{\mathrm{r}}$ Adest nunc ponere formam oracionis ... ne illas brigas (Interlinearzusatz: schelttwort, vgl. Pal. lat. Vat. 1589, 115 ) distensionis (sic) in usus hominum seminaret ... 43 $3^{\mathrm{r}-\mathrm{v}}$ leer. $49^{\mathrm{v}}$ Peticio est oracio ... 50v Benivolencia est sermo ... $51^{\mathrm{r}}$ Ex hiis itaque omnibus prime partis huius mei libri iam innotescit satis ruditer que sunt partes et quales quibus componi habet eppistula et eciam oracio persuasiva ... 51 ${ }^{\mathrm{v}}$ «Forma magisterii» des Johannes von Gundeldingen, vgl. Pal. lat. Vat. 1589, 132 und Göldlin von Tieffenau, S. 96f.: Nos $H$ [enricus] videlicet facultatis arcium studii Heidelbergensis Wormaciensis dyocesis decanus ceterique magistri et regentes eiusdem facultatis, salutem in domino ... quod discretus vir Iohannes Gund. de Berona in nostra universitate in facultate supradicta ... anno domini millesimo quadringentesimo quinquagesimo $2^{\circ}$, vicesima die Februarii presidente sibi honorabili viro magistro Erhardo Knab de Zwiffälten rigoroso premisso examine, gradum baccalaureatus in artibus est adeptus. Qui quidem ... honorifice perfecit ita quod ... eum quantum est racione expressatorum birretalem magisterii efficeret susceptum ... Datum Heydelberge anno gracie $53^{\circ}$ decima $8^{v a}$ die May sub sigillo superexpresse facultatis arcium adimpresso ... - ... in secula seculorum. Sic finita est huius agegatorii pars prima Octobris undecima gracie anno in pprohemio annotato. Entspricht dem Autographen: Biblioteca Apostolica Vaticana, Pal. lat. 1589, 69 -139 v.

$57^{\mathrm{v}}-63^{\mathrm{r}}$ Compendium rhetoricum (Ars epistolandi et praedicandi). Rethorica est sciencia docens materiam invenire, inventam disponere, dispositam eloquere, elicitam commendare, commendatam pronunciare. Unter diesem ersten Schema als Textblock: Invencio est rerum verarum vel veresimilium excogitacio. Disposicio est ordo parcium epistolarum, ordinum alius naturalis alius artificialis ... Es folgen Ausführungen und Schemata zu den einzelnen Teilen eines Briefes (und/oder einer Predigt) anhand von Regulae, Status, Colores, Vitia. 58r Prima regula: Omnis suprascripcio ponenda est in dativo ... Status est locucio personarum in gradu secundum sub et supra ... 59v Exordium est sermo preambulus generalis preparans animum audientis ad infra dicenda ... 60 r Primus color exordii dicitur similiter cadens ... Viciatur autem exordium primo si est difficile, $2^{\circ}$ si puerile ... $62^{\mathrm{r}}$ Ars predicandi: Est sciencia docens de aliquo aliqua dicere, verbum dei est subiectum artis ... 62v Über den vierfachen Schriftsinn:

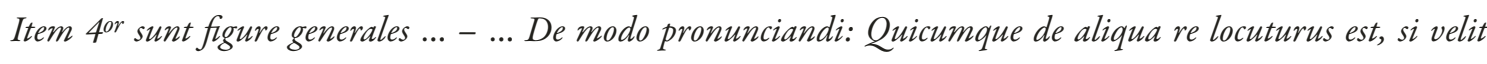
magistraliter de illa sermonem suum extendere ... vel plures.

63 leer.

64 ${ }^{\mathrm{r}}-107^{\mathrm{r}}$ ERHARDUS KNAB DE ZWIFALTEN, Aggregatorium rhetoricum. Buch 2: Prohemium partis $2^{e}$ huius operis. [Q]uia mulierem in suo esse perfectam et completam laceratis vestibus divagantem nemo tantum preconisabit ... Ex quo autem ... Expedit nunc iuxta promissum ad primam speciem coloris verborum accedere ... Repeticio ... 64v Exemplificabo autem illum colorem quodam dictamine in quo quidam ... Viro ... insignito Friderico de L. preceptori suo singulari Iohannes de Busseck ... (Pal. lat. Vat. 1589, 140v: Iohanni de M. ... R. de M.); Secundus autem verborum color est conversio ... Exemplificabo ... Iohannes de Buss [eck] ... viro O. de Lü. ... 65 ${ }^{\mathrm{r}}$ Tercius color rethoricus dicitur complexio ... Exemplificabo ... Ut sic et Fridericus de Lutishoffen religiosis ac devotis abbati et conventui monasterii in Muri ... Datum Hey[delberge] etc. (141v: Erhardus Knab de Zvivalten ... 
conventui monasterii in Zvivalten); 65 Fridericus de Lutishoffen ... Burchardo de Lütis[hoffen] (142r: Erhardus Knab de Zvivalten ... Iohanni Knab plebano in Emeringen); $66^{\mathrm{r}}$ Hein[ri]cus von Busseck ... religiosis viris conventualibus monasterii in Engelberg ... (143 ${ }^{\mathrm{r}}$ : Erh. K. de Z... R. de M.); 66 ${ }^{\mathrm{r}}$ Conradus de Buszeneck ...

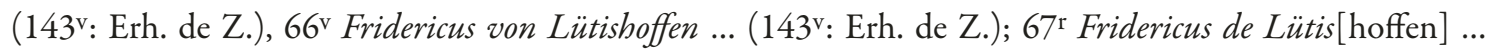
domine Otti[lie] ... (144v' : Erh. de Z.... domine K.); Erhardus K. de Zviff[alten] ... Die ausgetauschten Namen kommen in diesem Abschnitt mehrfach vor, zudem wieder: $73^{\vee}$ Fridericus de Lütis[hoffen] magistri Iohanni Gundell[inger] (156r: Er. de Z. ... N. de M.) ... 74 $4^{\mathrm{r}}$ Magister Iohannes Gundell[inger] rector scholarum Beronensium ... domino Friderico de Lut[ishoffen] ... $74^{\mathrm{v}}$ decano egregio totique generosi facultati arcium ... universitatis Heidelbergensis ... N. de Busseneck arcium magister et filius eius ... 76r Dictamen aliud ... Magister Iohannes de Gundell[inger] ... Datum Heydelberge 1456 Albani post quarta hora. Der letzte Name 84r $N$. de Z. $(169 \mathrm{v})$, Heidelberg kommt hingegen noch öfters in den folgenden Exempla vor. $76 \mathrm{v}$ Tractatus $2^{u s}$ iste $2^{e}$ partis de coloribus sentenciarum. Capitulum primum eius et est xvim tocius $2^{e}$ partis ... Expeditis ita coloribus verborum restat ag $[\mathrm{r}]$ edi colores sentenciarum ... $84^{\mathrm{v}}$ Tractatus $3^{\text {us }}$ et ultimus istius $2^{e}$ partis de coloribus transsumpcionis ... $85^{\mathrm{r}}$ Quia autem ... 90 $90^{\mathrm{v}}$ Capitulum ultimum tractatus $3^{i i}$ istius $2^{e}$ partis et xxiiii tocius partis $2^{e}$, in quo ponuntur exempla diversorum dictaminum ad diversas materias applicandorum. Quia usus ... 100 r $^{\mathrm{r}}>$ Epistole mixte $<$. Primum in quo cuidam regi fit regraciacio et laudacio de bonis impensis ... - .. $10^{\mathrm{r}}$ Et sic est finis $2^{e}$ partis istius agegatorii (sic) rhethorice. Heydelberge in die sancti Bernhardi anno lvito circa primam. Entspricht dem Autographen: Biblioteca Apostolica Vaticana, Pal. lat. 1589, 140r-194v (dort anschliessend: Buch 3), in den Exempla sind einzig Namen ersetzt, die Brieftexte sind ansonsten identisch. Colette JEUDY und Ludwig Schuba, Erhard Knab und die Heidelberger Universität im Spiegel von Handschriften und Akteneinträgen, in: Quellen und Forschungen aus italienischen Bibliotheken und Archiven 61 (1981), Hs. erwähnt S. 83; Ludwig Schuba, Artikel Knab, Erhard, von Zwiefalten, in: Verfasserlexikon², Bd. 4 (1983), Sp. 1264-1271, Hs. erwähnt Sp. 1269; Emil Joseph Polak, Medieval and Renaissance Letter Treatises and Form Letters, Leiden/New York/Köln 1994, S. 225, Hs. erwähnt ( $2^{\mathrm{r}}-107^{\mathrm{r}}$ als ein zusammenhängender Text betrachtet). $107^{\mathrm{v}}-111^{\mathrm{v}}$ leer.

Teil 2:

$112^{\mathrm{r}}-133^{\mathrm{r}}$ Ps.-BOETHIUS, De disciplina scholarium. Mit Kommentar, abschnittsweise und auch interlinear. Prolog: Tunc unum quodque arbitramur scire cum causas eius cognoscimus, ut ait Aristoteles in prohemio libri Phisicorum. Similiter dicit Plato in Thimeo ... Kommentar: Vestra novit etc. Iste liber cuius est subiectum attribucionis est (sic) aptitudo recippiendi cognitionem veritatis a doctore. Prima sui divisione dividitur in partes duas scilicet in partem probemialem et executivam ... $113^{\mathrm{r}}$ Text: [V]estra novit intencio de scolarium disciplina compendiosum postulare tractatum ... - ... Omnibus istis scola est postposita. 126 ${ }^{\mathrm{r}-\mathrm{v}}$ leer. $127^{\mathrm{r}}$ Hic Boethius ostendit impedimenta impediencia debitam subieccionem, et dividitur in quatuor secundum quod $4^{\text {or }}$ ponit impedimenta ... - ... Vinum autem modice sumptum intellectui videtur conferre acumen. Non autem modice sumptum racionem perturbat ... ignoranciam inducit, ubi enim ebrietas ibi furor. Bricht am Ende der Seite ab (in 2,11; Kap. 2,12 - 6,34 fehlen). Pseudo-Boèce, De disciplina scolarium. Édition critique, introduction et notes par Olga WeIJERs, Leiden/Köln 1976, S. 93-102; Hs. nicht erwähnt, der Kommentar scheint mit keinem der S. 18-30 aufgeführten 32 Kommentare übereinzustimmen. Theodor von LiebenAU, Nachtrag zu der biographischen Skizze von M. E. Knab, S. 125f. zitiert aus diesem Text, den er anscheinend vollumfänglich dem Erhard Knab zuschreibt; die einzelnen Stellen: 132v (Nullus amor ... Sampsonem ...), 133 
(Clerice sta fortis ... vgl. auch 130 am Rand, und Vinum autem ...), 128 $8^{\mathrm{r}-\mathrm{v}}$ (Quodam tempore ego Boethius ... und Parisius locus egregius, mala gens bona villa), die Liebesbriefe hingegen im Aggregatorium: 53 ${ }^{\mathrm{r}-\mathrm{v}}$ (vgl. Pal. lat. Vat. 1589, 134r - der Name: Katharina in der Abschrift aus Beromünster weggelassen), 57r (144v : Erh. de Z... refulgenti domine K.) und $89^{\mathrm{r}-\mathrm{v}}\left(179^{\mathrm{r}-\mathrm{v}}\right)$; worin der Hinweis auf die Rhetorica des Peter Luder gründet, ist unklar, vgl. C 61, 294v $-299^{v}$ (dort auf 296r jedoch Libra statt Bibra).

$133^{\mathrm{v}}-138^{\mathrm{r}}$ leer.

Teil 3:

138 ${ }^{\mathrm{v}}-197^{\mathrm{r}}$ GASPARINUS BARZIZIUS, Epistulae. Inkunabel GW 3676, Basel: Michael Wenssler und Friedrich Biel, [nicht nach 1. 12. 1472]. 197 ${ }^{\mathrm{r}}$ zwei blind geprägte Zeilen zu unbekannter Zeit mit Bleistiftabrieb kontrastiert, nicht vollständig lesbar.

197 v leer.

Teil 4:

$198^{\mathrm{ra}}-351^{\mathrm{va}}$ Vocabularium. A idest sine vel de. Versus: A sine significat, acephalus hoc tibi signat. Aaa est interieccio vagentis Ier $[\mathrm{em}] i[\mathrm{e}] i^{\circ}$. Aaron: arone. Abba idest pater: heiliger vatter. Abbas: apt ... - ... Zorobabel apud Hebreos sonat nomen compositum ex tribus nominibus integris, scilicet Zo idest iste, Ra idest magister, Babel proprie Babilonie unde ortus est, unde princeps existit. Zukera: zuker. Explicit vocabularium finitum per manus Thome Ebinger ordinis sancti Iohannis in anno domini $m^{o} c c c c c^{0} x x v i i$ feria $4^{t a}$ ante nativitatem Christi. $>$ Et vendidi domino Ludwico de Lütishofen pro duobus florenis<. Eine Auswahl (Wortlisten) veröffentlichte BRANDSTETTER.

$351^{\mathrm{vb}}-352^{\mathrm{v}}$ leer.

Papier, 273 Blätter, $28 \times 20,5-21 \mathrm{~cm}$

1464

Wasserzeichen, Lagen, Foliierung: Wasserzeichen: Bl. 1-62, 99-146, 159-170, 211-246 Ochsenkopf, PICCARD, Wasserzeichenkartei Nr. 76111 (1460) und vier weitere gleichen Typs in mehreren Varianten; Bl. 6398 Traube, PICCARD, Wasserzeichenkartei Nr. 128785 (1443); Bl. 147-158 Anker, PicCARD, Wasserzeichenkartei Nr. 117757 (1463); Bl. 171-210, 247-260 Buchstabe P, PicCARD, Wasserzeichenkartei Nr. 112152 (1465), 115719 (1473) und 115725 (1464); Bl. 261-273 Ochsenkopf, PICCARD, Wasserzeichenkartei Nr. 79772 (1465), 79778 (1464) sowie zwei Varianten. Lagen: 3 VI ${ }^{36}+$ VII ${ }^{50}+12$ VI ${ }^{194}+$ VIII $^{210}+3$ VI $^{246}+$ $\mathrm{VII}^{260}+(\mathrm{VII}-1)^{273}$, nach Bl. 273 fehlt ein Blatt; Bl. 261 ganz, Bl. 260, 262 und 273 fast lose. Bl. 1-86 Lagenzählung am Schluss der Lagen oben: $1^{u s}-4$, [5] $]^{t u s}, 7 ; 13^{\mathrm{r}}, 63^{\mathrm{r}}, 87^{\mathrm{r}}, 111^{\mathrm{r}}, 123^{\mathrm{r}}, 211^{\mathrm{r}}$ zu Lagenbeginn: $s[$ externio]. Bl. 135-182 Reklamanten. Neuere Foliierung: 1-273.

Einrichtung und Ausstattung: $1^{\mathrm{r}}-170^{\mathrm{v}}, 211^{\mathrm{r}}-260^{\mathrm{v}}$ und $262^{\mathrm{v}}-266^{\mathrm{r}}$ Begrenzung des Schriftraums mit Tinte, sonst mit Stift, Schriftraum 18,5-19 × 12,5-13, 31-43 Zeilen. Jüngere gotische Buchkursive mit Schleifen

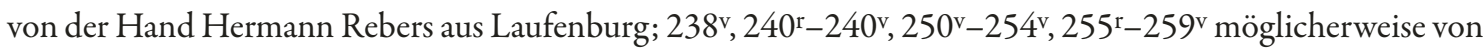


einer zweiten Hand, 100v jüngere gotische Buchkursive ohne Schleifen. Gedicht- und kleiner geschriebene Kommentarabschnitte wechseln ab. $1^{\mathrm{r}}-75^{\mathrm{r}}$ rubriziert $\left(64^{\mathrm{r}}-66^{\mathrm{r}}\right.$ in Ocker), rote Unterstreichungen, vereinzelt rote Zeilenfüller; $24^{\mathrm{v}}, 25^{\mathrm{r}}, 73^{\mathrm{v}}-84^{\mathrm{r}}, 184^{\mathrm{r}}$ rote Überschriften; Textgliederung durch Zwischenüberschriften in vergrösserter Schrift, $188^{\mathrm{r}}$ in Schriftband; $17^{\mathrm{v}}$ am Rand in Rot und gerahmt [...]cio, beschnitten. $2^{\mathrm{r}}-52^{\mathrm{v}}$ und $70^{\mathrm{v}}$ am Beginn von Gedichtabschnitten 2-3zeilige rote Lombarden, Binnenfeld Ocker, 40 mit Gesicht, 52r mit Wappenschild, ab 64r Raum für zwei- bis dreizeilige Lombarden ausgespart, nicht ausgeführt. 17v 7zeilige rote Lombarde mit Punktverdickung, rot ornamentiert auf ockerfarbenem und grünem Grund. 2v 5zeilige rote Initiale, beidseits je eine Figur: Maria (?) und Engel, $1^{\mathrm{r}}$ 9zeilige historisierte Initiale, Buchstabenkörper rot, im Binnenfeld Anbetung der Könige vor Flächenornament aus Dreipassblüten, ausserhalb drei menschliche Köpfe, kolorierte Federzeichnungen in Rot, Grün und Ocker.

Korrekturen und Nachträge: Wenige Korrekturen des Schreibers, z. B. 7v, 27r auf Rasur, 44v $106^{\mathrm{r}}, 183^{\mathrm{v}}$, $241^{\mathrm{v}}$; längere Einfügungen $233^{\mathrm{v}}-234^{\mathrm{r}}, 236^{\mathrm{v}}$; zeitgenössische Korrekturen von anderer Hand 67v, 259r; wenige Streichungen, z. B. 9v $48^{\mathrm{v}}$, 80 $\mathrm{r}$, 119v $179^{\mathrm{r}}$. Marginalien zur Gliederung des Textes $66^{\mathrm{r}}-69^{\mathrm{v}}$, danach vereinzelt, zum Inhalt 56 $6^{\mathrm{v}}, 132^{\mathrm{r}}, 174^{\mathrm{v}}, 199^{\mathrm{r}}$. Notazeichen, z. B. $5^{\mathrm{r}}, 119^{\mathrm{r}}, 151^{\mathrm{v}}, 163^{\mathrm{r}}$. Handweiser: $52^{\mathrm{r}}, 141^{\mathrm{r}}, 151^{\mathrm{v}}, 157^{\mathrm{v}}$, $188^{\mathrm{r}}$. Kopftitel $82^{\mathrm{v}}-83^{\mathrm{r}}$ l. IIII ${ }^{u s}, 188^{\mathrm{v}}-190^{\mathrm{r}} l$. Vus bzw. Quintus, 235 $\mathrm{v}-237^{\mathrm{r}}$ VIus bzw. Sextus von derselben Hand wie die Zählung der Bücher am Seitenrand und die Bucheinteilung im Spiegel hinten. 260r anschliessend

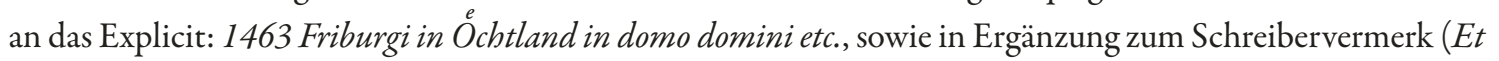
sic finis est huius floreti): Bernhardi doctoris eximii, per Hemannum Reber de Löffenberg Requies [cat?] oder zum Besitzeintrag: Requis[icione?] (Ludowici Zeller de Brugg) Capplani primi hospitalis ibidem in Brugg. $261^{\mathrm{r}}-266^{\mathrm{r}}$ Inhaltsverzeichnis von der Hand Ludwig Zellers.

Einband: Mit hellem Leder bezogene Holzdeckel, 15. Jh., Rückenleder fehlt. Ehemals zwei nach vorn greifende Kantenschliessen, Riemenbefestigungen im Rück- und Ösen im Vorderdeckel erhalten. Rot-grün-blaue Kapitale. Spiegelblätter Papier. Im vorderen Spiegel Exlibris des Stifts Beromünster (Wegmann, Exlibris, Bd. 1, Nr. 619). Auf dem Vorderdeckel oben Titelschild Floretus cum commento, 16. Jh. Lose einliegend ehemaliges Rückenschild Liber Floretis Bernhardi doctoris eximii $N^{\circ}$ 25, entsprechend dem Catalogus von 1826. Herkunft: Die Hs. ist dreifach datiert: $188^{\mathrm{r}}$ 1. Juli 1464, $210^{\mathrm{r}} 24$. Juli 1464, 260 1463.

Besitzer: Bl. 260r Besitzeintrag Ludowici Zeller de Brugg, 15. Jh., zu ihm: Kopp, Stiftsbibliothek, Bd. 1, S. 11, Clara Müller, Geschichte des aargauischen Schulwesens vor der Glaubenstrennung, Aarau 1917, S. 95 (Nr. 171) und 97 (Nr. 231); Erster datierter Schweizer Druck, S. 15f.; SidLER, Bildungsverhältnisse, S. 175 f. (Nr. 160); BüCHLER, S. 165-170, 410, Nr. 409. Im Catalogus von 1763 als Classis Nona Nr. 22 verzeichnet, im Nachtrag dazu auf $48^{\mathrm{v}}$ ohne Nummer, in den Antiquitates Beronenses, S. 691, als Nr. 23, im Catalogus von 1826 als Nr. 25. $1^{\text {r }}$ neuere Signatur: C 45, Kugelschreiber, spätes 20. Jh. Signatur ehemals C 25 fol.

Literatur: Kopp, Stiftsbibliothek, I, S. 11 und II, S. 15; Marc SIEBER, Die Universität Basel und die Eidgenossenschaft 1460-1529. Eidgenössische Studenten in Basel, Basel 1960, S. 104f.; BrUCKNER, Scriptoria 9, S. 29 sowie Taf. 40 und 41; BüCHLER, Beromünster, S. 143, 166, 177; CMD-CH 2, Nr. 95.

Spiegelblatt vorne: Notata. Item Numerum xxxii babetur notabile capitulum de voto uxorum filiorum viduarum. Item $3^{\circ}$ Regum ultimo habetur de rege Samarie ... Notizen zu verschiedenen Bibelstellen.

$1^{\mathrm{r}}-260^{\mathrm{r}}$ Liber Floretus mit dem Kommentar des JEAN GERSON. Nomine floretus liber incipit ad bona cetus ... - .. 244v Qui dat cuncta bona det nobis hec pya dona. Liber floretus, hrsg. nach der Hs. Utrecht,

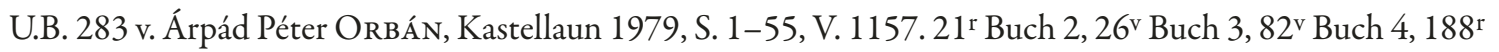


Buch 5, 235' Buch 6. Kommentar: $1^{\mathrm{r}}$ Antequam lectura commenti tam sublimis tamque profunde indaginis ingredi presumam, si lectura dici mereatur, tria seriatim habeo preponere ... - ... Corpora vero celestia habita quiete et lumine clariori dicuntur remunerari. GW 4016: Floretus ... una cum commento, Lyon: Johannes Fabri, 21. 6. 1494, a i ${ }^{\mathrm{r}}-[2 \text { vii] }]^{v}$. 188 ${ }^{\mathrm{r}}$ Finitur capitulum de matrimonio etc. feria $2^{a}$ in vigilia beate Marie visitacionis virginis, anno $1464^{\circ}$. Zum Schluss (vgl. auch Nachträge): Et sic est finis yalanō peragone (Lesung unklar), sowie von derselben Hand: Et sic finis est huius floreti und in anderer, grösserer Schrift, vielleicht von der Hand Zellers: Ludowici Zeller de Brugg.

260v Sententiae. Seneca: Si pulcher es, lauda naturam ... Aristotiles ad Alexandrum: O clemens imperator ... Seneca: Vir speculativus ... Sancti Thomae Aquinatis Opera omnia, Bd. 7: Aliorum medii aevi auctorum scripta 61, hrsg. v. Roberto BusA, Stuttgart/Bad Cannstadt 1980, S. 147 (Sp. 3), S. 148 (Sp. 2), S. 152 (Sp. 1). Tulius: Omnis sapiens liber, omnis stultus servus. Sancti Ambrosii Opera, epistulae et acta. Bd. 1: Epistularum Libri I-VII, hrsg. v. Otto FAller, Wien 1968, S. 45 Z. 32f. Theofolus: In mundo nichil iniquius quam iniuriam facere inpotenti ... 10 Sentenzen, angeblich nach Cassiodor, Augustin u. a. Abschliessend 4 Stellen aus Ps.-Bernardus Claraevallensis, Epistola 14a, PL 182, Sp. 650A, 649B, 649C, 650A, beginnend mit: Ut futurum inimicum famulum suis moribus plandientem repelle...

261 ${ }^{\mathrm{r}}-266^{\mathrm{r}}$ Tabula. Bücher 1-4, Nachtrag. $>$ Registrum libri primi< Quid credere explicite et quid inplicite ... - ... Quid iuris si papa indulgenciam plenariam a culpa et pena dumtaxat in articulo mortis.

266 $-273^{\mathrm{v}}$ leer.

Spiegelblatt hinten: Liber ille Symbolus Bernhardi intitulatur et dividitur in 6 libros parciales. In primo agitur de fide. Incipit ibi: Credere debemus etc. ... In sexto de morte et eius sequela ibi: Mordet mors cuncta que nascuntur etc. Bucheinteilung. Darunter wappenförmiger Besitzeintrag und Ämterverzeichnis Ludwig Zellers sowie Datierung: L. Zeller (darum herum): Capplanus primus hospitalis in Bruggper annum, Sancte Ursule in Berona per annum, Sancte Marie Magdalene in Arow modo, plebanus in Sur per trienium, Adiutor in Arow per byenium. 1475. 30. Laurencii. Numquam sine pena sunt vicia, numquam sine premia virtutes. Boecius. Boethius, De consolatione Philosophiae, hrsg. v. Ludwig BIEler, Turnhout 1984, Buch 4, Prosa 1, S. 98. Perversi dificile corriguntur et stultorum infinitus est numerus. Ecclesiastici 7timo (Ecl 1,15).

Papier, 345 Blätter, $28,5 \times 21-21,5 \mathrm{~cm}$

1455-1469

Wasserzeichen, Lagen, Foliierung: Wasserzeichen: Bl. 1-35 Ochsenkopf, PiCCARD, Wasserzeichenkartei Nr. 74852 (1456), 74864 (1455), 75527 (1457) und 75878 (1459), Bl. 36-107, Nr. 75353 (1466) und 75357 (1466), Bl. 108-155 Nr. 75107 (1457) und ähnlich Nr. 73940; Bl. 166-171 und 291-302 Nr. 75098 (1453), Bl. 167/170 Nr. 75404 (1453); Bl. 172-185 Nr. 65393 (1458); Bl. 186-197 BRIQUET Nr. 14382, in drei Varianten; Bl. 198-257 und 303-315 PICCARD, Wasserzeichenkartei Nr. 75527 und 75878 (vgl. Bl. 1-35); Bl. 269-290 Nr. 74759 (1459), 75058 (1454), 75440 (1454) und 75541 (1460); Bl. 338 Nr. 75353 (vgl. 
Bl. 36-107), Bl. 340-344 Nr. 74381 (1454); Bl. 156-165 Krone, PicCARD, Wasserzeichenkartei Nr. 51988 (1483) und 51990 (1484); Bl. 258-268 Mühlrad, ähnlich PICCARD, Wasserzeichenkartei Nr. 122849; Bl. 316/329 Schlange, ähnlich PICCARD, Wasserzeichenkartei Nr. 43210, Bl. 317-328 Blume, ähnlich PICCARD, Wasserzeichenkartei Nr. 126695, Bl. 332, 333 und 335 Drache, ähnlich PICCARD, Wasserzeichenkartei Nr. 124123.

Lagen: $13 \mathrm{VI}^{155}+\mathrm{V}^{165}+\mathrm{III}^{171}+\mathrm{VII}^{185}+6 \mathrm{VI}^{257}+(\mathrm{VI}-1)^{268}+\mathrm{VI}^{280}+\mathrm{V}^{290}+\mathrm{VI}^{302}+(\mathrm{VI}+1)^{315}+\mathrm{VII}^{329}+$ $(\mathrm{V}-2)^{337}+(\mathrm{V}-3)^{344}$, vor Bl. 258 ein Blatt, nach Bl. 337 zwei, nach Bl. 344 drei Blätter herausgerissen; das äusserste Doppelblatt der (wohl als Nr. 14 gezählten) Lage Bl. 281-290 (Quinternio, ehemals Sexternio) fehlt, eine unbekannte Anzahl Blätter fehlt zudem nach Bl. 155 (und möglicherweise auch vor Bl. 37 ), 257 und 268 (siehe den Hinweis auf eine fehlende Lage 268 ${ }^{\mathrm{vb}}$ ), Textverlust; 276r $294^{\mathrm{v}}$ und 337v hingegen Textabbruch beim Schreiben. Bl. 305 eingeheftetes Einzelblatt in quarto. Bl. 333 und 336 sowie 334 und 335 im Bund zusammengeklebt, ebenso Bl. 330 mit dem Rest seines verlorenen Gegenstücks. Lagenzählung am Schluss der Lagen, sichtbar (mit Lücken) $19\left(71^{\mathrm{v}}\right)-25\left(143^{\mathrm{v}}\right)$ sowie $4\left(171^{\mathrm{v}}\right)-16\left(315^{\mathrm{v}}\right)$. Reklamanten:

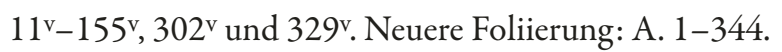

Einrichtung und Ausstattung: Begrenzung des Schriftraums mehrheitlich mit Tinte, Bl. 186-197 und 316-337 mit Stift, Bl. 269-280 durch Falzung; 318 r $-327^{\mathrm{v}}$ Tintenliniierung. Schriftraum 20-23,5 × 13,5-16,5, zweispaltig (6,5-8), 41-56 Zeilen; einspaltig: $246^{\mathrm{r}}-257^{\mathrm{v}}$ und $316^{\mathrm{r}}-337^{\mathrm{v}}(18-23 \times 10-15,32-41$ Zeilen); einspaltig, mit Raum für Interlinearglossen: $198^{\mathrm{r}}-245^{\mathrm{r}}\left(17-18,5 \times 11-11,5,12-14\right.$ Zeilen) und 269r $-276^{\mathrm{r}}$ (18,5-20 × 12, 18-22 Zeilen). Jüngere gotische Buchkursive mit Schleifen, von mehreren Händen; nicht zwingend zu unterscheiden die Teile $1^{\mathrm{ra}}-35^{\mathrm{rb}}, 37^{\mathrm{ra}}-155^{\mathrm{vb}}, 295^{\mathrm{ra}}-310^{\mathrm{va}}$ und $338^{\mathrm{ra}}-344^{\mathrm{ra}}$, ebensowenig die eher schleifenlosen $198^{\mathrm{r}}-245^{\mathrm{r}}$ und 269 $9^{\mathrm{r}}-276^{\mathrm{r}}$, doch 107v $/ 108^{\mathrm{r}}$ wohl ein Händewechsel; 246 ${ }^{\mathrm{r}}-257^{\mathrm{v}}$, 258 ${ }^{\mathrm{ra}}$ $268^{\mathrm{vb}}$ und $281^{\mathrm{ra}}-294^{\mathrm{vb}}$ von drei weiteren Händen; $172^{\mathrm{ra}}-184^{\mathrm{va}}$ und $316^{\mathrm{r}}-337^{\mathrm{v}}$ schleifenlose jüngere gotische Buchkursive von zwei Händen, letzterer Text mit Marginalien; $166^{\mathrm{ra}}-171^{\mathrm{va}}$ und $186^{\mathrm{ra}}-197^{\mathrm{rb}}$ schleifenlose Bastarda von einer Hand. 281 ${ }^{\mathrm{ra}}-294^{\mathrm{vb}}$ Lemmata in Auszeichnungsschrift. Raum für 3-5zeilige Initialen freigelassen, nicht ausgeführt, 37ra $-106^{\mathrm{va}}$ auch für Überschriften, Vorgaben am unteren Rand teilweise sichtbar, z. B. $44^{\mathrm{vb}}, 80^{\mathrm{rb}}$ und $93^{\mathrm{vb}} \cdot 172^{\mathrm{r}}-198^{\mathrm{r}}$ rubriziert, rote Überschriften und Marginalien zum Inhalt, Paragraphenzeichen und Unterstreichungen; 2-4zeilige rote Lombarden. 198 ${ }^{\mathrm{r}}$ dreizeilige rote Initiale mit schwarzem Fleuronné.

Korrekturen und Nachträge: Korrekturen von der Hand der Schreiber, z. B. $5^{\mathrm{vb}}, 109^{\mathrm{ra}}$, 150 ${ }^{\mathrm{ra}}, 203^{\mathrm{v}}$, 232v, $268^{\mathrm{va}}, 282^{\mathrm{ra}}, 295^{\mathrm{rb}}, 318^{\mathrm{r}}$ und $331^{\mathrm{v}} ; 189^{\mathrm{ra}}$ Streichung in Rot; $246^{\mathrm{r}}-257^{\mathrm{v}}$ auffällig viele Korrekturen; $288^{\mathrm{rb}}$ Nachtrag eines Lemmas: Plasphemia (ohne weiteren Text). Nachträge, 16./17. Jh.: $1^{\text {ra }}-35^{\text {rb }}$ Kapitelzählung am Rand und als Kopftitel, wohl von der gleichen Hand auch die Überschriften $246^{\mathrm{r}}$ De Vanitate Mundi, 295r 8 Questiones und 338 $\mathrm{r}$ De Arte moriendi Libellus Burcardi Madach Ord. Praedic. Convent. Nurnberg. 23 und $24^{\mathrm{r}}, 246^{\mathrm{r}}-249^{\mathrm{v}}$ und 298 $\mathrm{ra}-299^{\mathrm{rb}}$ Marginalien von anderer Hand, von einer dritten $37^{\mathrm{ra}}-149^{\mathrm{rb}}$ Überschriften, Marginalien, Unterstreichungen und vereinzelte Korrekturen. Handweiser.

Einband: Einband aus der Werkstatt Uoldaricus (EBDB w000154, nachgewiesen um 1481-1490), vgl. C 52. Mit hellem Leder bezogene Holzdeckel, letztes Viertel 15. Jh. Streicheisenlinien, Einzelstempel (EBDB s011932, s011933, s011936, s011937, s011940, s011942, sowie ein weiterer: Blattstrauss mit Bund, vgl. Erster datierter Schweizer Druck, Beromünster 1970, Taf. 16, Nr. 14); zwei nach vorn greifende Kantenschliessen mit ziselierten Messingteilen, vgl. Johann Lindt, Der Buchbinder Uoldaricus, in: Berner Einbände, Buchbinder und Buchdrucker, Bern 1969, S. 22-26, Abb. 1, unten rechts (S. 25). Grün-rot-weisse geflochtene Kapitale. 
Spiegelblätter Papier. Die Datierung der Wasserzeichen der unbeschriebenen Lage Bl. 156-165 in die 70er oder 80er Jahre kann als zusätzlicher Hinweis auf die Zeit der Zusammenstellung des Bandes gut ein oder zwei Jahrzehnte nach Abschrift der einzelnen (oft unvollständigen) Teile in Betracht gezogen werden. Die als 17-26 gezählten Lagen umfassen das Corpus der Sermones (Bl. 37-155), Bl. 166-315 bilden nach einer früheren Konzeption die Lagen 4-16; möglicherweise sind die ersten drei Lagen (Honorius von Autun) oder die letzten (Laktanz und Eberhard von Mardach) entsprechend als 1-3 zu zählen. In den Fälzen Pergamentfragmente einer Bibel (lesbar Stellen aus III Rg 1) sowie mindestens einer weiteren lat. Hs. des 14. Jhs.; um die erste und die letzte Lage weitere Fragmente grammatischen und scholastischen Inhalts gebunden, in den Spiegeln nur noch Abklatsch. Im vorderen Spiegel Exlibris des Chorherrenstifts Beromünster (WEgmann, Exlibris, Nr. 619). Auf dem Rücken Titelschild: Explanatio in Cantica Canticorum, entsprechend dem Catalogus von 1826.

Herkunft: $35^{\mathrm{rb}}$ auf den 21 . November $1461,170^{\mathrm{ra}}$ den 30 . April 1455, $184^{\mathrm{va}}$ den 19. November, $197^{\mathrm{rb}}$ den 8 . Juni 1459, 304 $4^{\mathrm{rb}}$ den 22. Sept. 1469, 310 rb den 6. Okt. 1469 datiert.

Besitzer: Im vorderen Spiegel Exlibris des Chorherrenstifts Beromünster. Im Nachtrag zum Catalogus von 1763 auf $49^{\mathrm{v}}-50^{\mathrm{v}}$ ohne Nummer verzeichnet, im Catalogus von 1826 als Nr. 8. A ${ }^{\mathrm{r}}$ neuere Signatur C 46, Kugelschreiber, spätes 20. Jh. Signatur ehemals C 26 fol.

Literatur: Kopp, Stiftsbibliothek, II, S. 16; BrUCKner, Scriptoria 9, S. 27; BüCHLER, Beromünster, S. 143, 170, 177 und 244 (Anm. 130); CDM-CH 2, Nr. 96; Kristeller, Iter Italicum 5, S. 99; Deutsche Reichstagsakten unter Kaiser Friedrich III., Abt. 5, Tl. 2, bearb. v. Johannes HeLmRath, München 2013, S. 471, $477 \mathrm{f}$.

$\mathrm{A}^{\mathrm{r}-\mathrm{v}}$ leer.

$1^{\mathrm{ra}}-35^{\mathrm{rb}}$ HONORIUS AUGUSTODUNENSIS, Expositio in Cantica canticorum. Epistula Honorii: [D]onum sapiencie cum Salomone poscenti et vero Pacifico postulanti consequi optas. Quia predecessori tuo ... Prologus I: [I]n principiis librorum tria requiruntur scilicet autor materia intencio ... Prologus II: $3^{\text {ra }}$ Imperator superne reipublice ... Tractatus I: $4{ }^{\mathrm{vb}}$ [F] ilius regis Ierusalem desponsavit sibifiliam regis Babilonis per internuncios ... Caput I: $5^{\text {ra }}$ Osculetur me osculo oris sui. Sacra scriptura iiiior modis intelligitur ... - ... sponso suo copulabitur. Hic autem liber ideo de festo sancte Marie legitur ... et matre sponsi intelligi. Finit feliciter a dominica usque proximum sequens sabathum post brandia dierum scriptum, et tunc vesperarum hora completum vicesima prima die Novembris anno lxi $i^{\circ} 11^{\mathrm{rb}}$ Caput II; $15^{\text {va }}$ Tractatus II, Caput III; $19^{\text {ra }}$ Caput IV; $25^{\text {ra }}$ Caput V; $30^{\text {rb }}$ Caput VI; 30vb Tractatus III; $31^{\text {va }}$ Caput VII; 34ra Tractatus IV; 34rb Caput VIII. PL 172, Sp. 347-446, 453-469, 471f., 476-479, 482-485, 493-496, 494, teilweise gekürzt und umgearbeitet (vgl. C 62, $\left.1^{\mathrm{ra}}-35^{\mathrm{vb}}\right)$. RB 3573.

$35^{\mathrm{v}}-36^{\mathrm{v}}$ leer.

37ra $-155^{\text {vb }}$ Sermones. 61 Predigten, häufig nach Jacobus de Voragine: Pfingsten - Dominicus. [C]or mundum crea in me ... (Ps 50,12). Qui spiritum sanctum vult recipere debet oracioni insistere ... SCHNEYER, Bd. 6, S. 67, Nr. 88; 39 ra Schneyer, Bd. 3, S. 256, Nr. 452 und 453, letztere Predigt mit anderem Schluss;

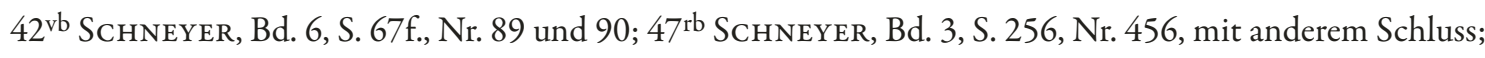
$50^{\mathrm{ra}}[\mathrm{A}]$ pparuerunt illis dispertite ligwe ... (Act 2,3). Circa istas ligwas in quibus apparuit spiritus sanctus tria videnda sunt ... 51 $1^{\mathrm{vb}}$ [S] i si quis diligit me ... (Io 14,23). Ante adventum filii dei eramus omnes servi dyaboli a divina salvacione exclusi ... 54 $4^{\mathrm{rb}}$ Trinitas: [O] altitudo diviciarum ... ( $\left.\mathrm{Rm} 11,33\right)$. Festum trinitatis olim ab ecclesia non fiebat ... 57 ra [B] enedicat nos deus ... (Ps 66,8). Sicut dicit Ieronimus ad Heliodorum: Grandis materie ingenia non sufferunt ... 59 $9^{\mathrm{ra}}$ [S] anctus sanctus sanctus ... (Is 6,3). In hoc cantico angelico seraphin primo glorificant beatam 
trinitatem et unitatem ... vgl. Schneyer, Bd. 8, S. 345, Nr. 38; 60va SchneYeR, Bd. 3, S. 257, Nr. 460, mit anderem Schluss; 63 ${ }^{\mathrm{rb}}[\mathrm{P}]$ otestas deus est ... (Ps 61,12). In divinis invenitur essencie unitas in tribus personis ... 66rb Barnabas: [I] oseph qui cognominatus est Barnabas ... (Act 4,36). Describit sanctus Lucas conversionem beati Barnabe apostoli ... 67rb [M] iserunt Barnabam ... (Act 11,22). Ex hiis verbis ostenditur quod ipse fuit dilectus in sermone strenuus in opere ... 68 $8^{\mathrm{ra}}[\mathrm{S}]$ egregate mihi Barnabam ... (Act 13,2). Duo sunt necessaria prelato et predicatori, scilicet sana doctrina et bona vita ... 69va [I] am non estis hospites ... (Eph 2,19). Apostolus de sanctis viris duo negat ... 72 $2^{\text {ra }}$ Gervasius et Prothasius (resp. Commune martyrum): [V] os amici mei estis ... (Io 15,14). Magna dignacio dei quia cum essemus indigni vocari servi suos nos vocat amicos ... $74^{\mathrm{ra}}[\mathrm{P}]$ reciosa in conspectu domini ... (Ps 115,15). Sicut dicit beatus Augustinus: Non potest male mori qui bene vixerit ... 75vb [I] ustorum autem anime ... (Sap 3,1). Magna consolacio sanctis viris quando habent securitatem de perseverantia gracie ... $78^{\mathrm{rb}}$ [C] um audieritis prelia et opiniones bellorum ne timueritis, $M^{t}$ (Mt 24,6 resp. Mc 13,7). Quia magnum periculum quando rex sive miles nescit que imminent ... 80 $0^{\mathrm{rb}}$ Johannes Bapt.: SCHNEYER, Bd. 3, S. 257, Nr. 464; 82 ${ }^{\mathrm{va}}$ [E]rit enim magnus ... (Lc 1,15). Angelus Gabriel qui nativitatem precursoris venit nunciare, primo Zachariam trepidantem confortavit ... vgl. SCHNEYER, Bd. 3, S. 257, Nr. 465; 85 ra [A]men dico vobis ... (Mt 11,11). Laudari potest aliquando homo a seipso aliquando ab homine ... 87 $7^{\mathrm{rb}}$ [E] rit magnus coram domino ... (Lc 1,15). Volens angelus magnitudinem et dignitatem Iohannis ostendere multipliciter hoc facit ... 89va [P]aravi lucernam ... (Ps 131,17). Verba hec sunt patris de filio volens eum mittere in hunc mundum ... 91 va SCHNEYER, Bd. 3, S. 257, Nr. 468, mit anderem Schluss; 93 ${ }^{\mathrm{vb}}$ Johannes et Paulus: [M] ulte tribulaciones iustorum ... (Ps 33,20). Ecclesia dei a principio passa est tribulaciones a Iudeis, demum a paganis, postmodum a hereticis ... 95 va SCHNEYER, Bd. 3, S. 257, Nr. 470, mit anderem Schluss; 97va [D] ico autem vobis amicis meis ... (Lc 12,4). Secundum autem Augustinum duo amores et duo timores sunt causa omnis boni et omnis mali ... 99vb Petrus et Paulus: SCHNEYER, Bd. 3, S. 257, Nr. 471, mit anderem Schluss; $101^{\mathrm{vb}}$ [D] ixit Simoni Petro ... (Io 21,15). In ceteros sanctos beatus Petrus quatuor magnas prerogativas habuisse videtur ... 104 $4^{\mathrm{ra}}$ SCHNEYER, Bd. 7, S. 571, Nr. 67 und S. 570 , Nr. 66; 109 ${ }^{\text {ra }}$ Commemoratio Pauli: [B] onum certamen certavi ... (II Tim 4,7). Ut aliqua pugna sit strenua debet ibi esse causa, constancia, sapiencia et victoria, respicit triumphum ... 110 va SCHNEYER, Bd. 3, S. 257, Nr. 474 (jedoch nur quatuor effectus); $112^{\text {va }}$ SCHNEYER, Bd. 9, S. 492, Nr. 55; $114^{\text {vb }}$ SCHNEYER, Bd. 7, S. 466, Nr. 74 / Bd. 9, S. 728, Nr. 74, mit anderem Schluss; $117 \mathrm{vb}$ Margaretha: [I]psa conteret caput ... (Gn 3,15). Deus dedit homini potestatem contra dyabolum ... 119vb SCHNEYER, Bd. 2, S. 744, Nr. 35, mit anderem Schluss; $121^{\text {va }}$ Schneyer, Bd. 9, S. 493, Nr. 72; 123 rb Sequitur Magdalene 1us: [E]go sto ad ostium ... SCHNEYER, Bd. 3, S. 258, Nr. 479; 125rb Sequitur 2us, 125 va Schneyer, Bd. 9, S. 493, Nr. 74; 127ra Schneyer, Bd. 3, S. 258, Nr. 481 (mit anderem Schluss) und 482; 131 ra [M] ulte filie congregaverunt divicias ... (Prv 31,29). Anime fidelium que sunt filie dei ... 132vb SCHNEYER, Bd. 3, S. 258, Nr. 483 (mit anderem Schluss); 134rb Jacobus maior: [V]idit Ihesus duos fratres ... (Mt 4,21). Magna dignitas istorum apostolorum qui ... 135 $5^{\mathrm{rb}}[\mathrm{O}]$ ccidit autem Iacobum ... (Act 12,2). Non solum beatus Iacobus multis privilegiis fuit dotatus in vita ... vgl. SCHNEYER, Bd. 3, S. 258, Nr. 484; 136 va Schneyer, Bd. 3, S. 258, Nr. 485 (mit anderem Schluss); 139rb Ad vincula Petri: [D] irrupisti domine vincula mea ... (Ps 115,17). Sancta mater ecclesia representat hodie quadruplex beneficium ... vgl. Schneyer, Bd. 3, S. 258, Nr. 487; 140va [E] rat Petrus dormiens ... (Act 12,6). Quamvis ad literam verum fuerit

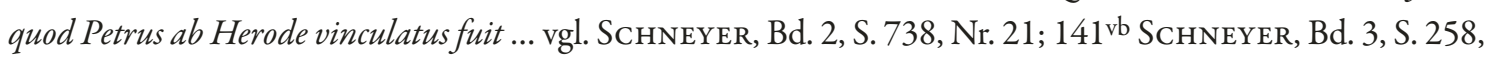
Nr. 488 (mit umformuliertem Schluss); 143 ${ }^{\text {rb }}$ Inventio Stephani: Schneyer, Bd. 3, S. 258, Nr. 489 (mit umformuliertem Schluss); 144viv Sequitur 2us, $145^{\text {ra }}$ Schneyer, Bd. 3, S. 258, Nr. 490; 146 vb Dominicus: [Q] uasi stella matutina ... (Sir 50,6). Celum spirituale sunt viri iusti et fideles in quibus deus inhabitat per graciam et 
quiescit ... vgl. SCHNEYer, Bd. 3, S. 259, Nr. 491; 149ra Sequitur 2us: [S]piritus meus qui est in te ... (Is 59,21). Verum et fructuosum predicatorem tria commendant, scilicet vita sancta, doctrina assidua, proles sapiens et iocunda ... vgl. SCHNeYeR, Bd. 3, S. 259, Nr. 492; $151^{\text {ra }}$ [L] ex veritatis fuit in ore eius ... (Mal 2,6). Vera perfectio hominis est quando quis habet ea que requiruntur ad seipsum, ad deum et ad proximum ... vgl. SCHNEYER, Bd. 3, S. 259, Nr. 493 (gleicher Schluss); 152vb [M] isit servum suum ... (Lc 14,17). Quantum deus desideret salutem homini patet ex multitudine missorum ... vgl. SCHNEYER, Bd. 4, S. 300, Nr. 674; 154 ${ }^{\mathrm{ra}}[\mathrm{M}]$ isit servum suum ... (Lc 14,17). Ista fuit magna ambaziata quam per servum suum beatum Dominicum pater familias fecit ... 155 ${ }^{\mathrm{rb}}[\mathrm{O}]$ pus fac ewangeliste ... (II Tim 4,5). Ewangelista idem est quod bonus nunciator, sed non sufficit quod sit bonus nunciator nisi sit eciam bonus operator ... Possumus eciam dicere quod in verbis premissis ostenditur quam laudabiliter beatus Dominicus se habuit ... quibus ad habitacionem regni ascendere debemus. Psalmus: Ascensiones //. Bricht am Seitenende ab, Reklamant: In corde suo. Vgl. Schneyer, Bd. 2, S. 834, Nr. 195 / Bd. 3, S. 259, Nr. 495. $156^{\mathrm{r}}-165^{\mathrm{v}}$ leer.

166 ${ }^{\text {ra }}-170^{\text {ra }}$ PIUS II PAPA, Oratio 'Constantinopolitana clades'. Frankfurt, 15. 10. 1454. Hanc oracionem sive proposicionem dominus Eneas natus de Senis episcopusque Senensis atque protunc cellerarius domini Friderici imperatoris ducis Austrie proposuit in Franckfordia coram electoribus regni ac aliis principibus ibidem occasione inserte materie congregatis. Et hec circa festum purificacionis beate virginis anno domini $1455^{\circ}$. [C] onstantinopolitana clades ... - ... Si hoc bellum ut imperator admonet papa petit Christus iubet pro divino honore et amore suscipiatis. Amen. Ultima Apprilis 55․ Helmrath, Deutsche Reichstagsakten, S. 494-565, mit den Varianten dieser Hs. (Sigle Be). Bertalot, Initia humanistica Latina, Bd. 2, Nr. 2586.

$170^{\mathrm{ra}}-171^{\mathrm{va}}$ LAURUS QUIRINUS, Epistula de urbis Constantinopolis iactura et capitivitate ad Nicolaum V papam. Kreta, 15. 7. 1453. Sequitur alia epistola occasione prescripte materie domino apostolico videlicet Nicolao quinto directa. Conquestio de eversione Grecorum et exhortacio contra Thurcos. Beatissimo Nicolao quinto pontifici maximo Laurus Quirinus salutem in domino qui est vera salus. 170 ${ }^{\mathrm{rb}}$ [Q] uamquam ingenium meum par materie non sit, simque usque adeo metu dolore meroreque confectus ut iuxta Grecorum proverbium sangwinem insudarim, conabor tamen beatissime pater accerbissimum casum infelicissime Constantinopolitane urbis describere ... - ... Credo enim reliquos Christianos fideles qui gloriosos spiritus possident illum ardorem animi hebere quem video habere Cretenses, qui pro fidei defensione emori gloriosissime cupiunt. Amen etc. etc. Giovanni Degli Agostini, Notizie istorico-critiche intorno la vita, e le opere degli scrittori viniziani, Bd. 1, Venedig 1752, S. 216-222. Bertalot, Initia humanistica Latina, Bd. 2, Nr. 17244.

$171^{\mathrm{vb}}$ leer.

$172^{\text {ra }}-184^{\text {va }}$ PIUS II PAPA, De curialium miseriis. Aeneas Silvius Piccolomini an Johann von Eich, Innsbruck, 30. 11. 1444. > Tractatus de miseria curialium pulcherrimus <. Eneas Silvius poeta salutem plurimam domino Iohanni de Aich perspicati et claro iusconsulto. Stultos esse ... - ... quin apud viros doctos et malus esse convincatur et stultus. Vale vir ... Ex Pruk pridie Kalendas Decembris anno domini millesimo quadringentesimo quadragesimo quarto, Indiccione septima. Explicit tractatulus de miseria curialium editus per preclarum et venerabilem virum dominum Eneam Silvium de Picolominibus de Senis poetam laureatum regium secretarium colendissimum, nunc vero antistitem Senesem predignum, favente tamen demum divina clemencia papam Pium secundum. In die Elizabeth vidue etc. Enee Silvii Piccolominei Epistolarium seculare, post Rudolf Wolkan iterum recognovit edidit Adrianus VAN HECK, Città del Vaticano 2007, S. 393-419, Nr. 166. Franz Josef Worstbrock, Artikel Piccolomini, Aeneas Silvius, in: Verfasserlexikon², Bd. 7 (1989), Sp. 643f. Bertalot, Initia humanistica Latina, Bd. 2, Nr. 22528. 
$184^{\mathrm{vb}}-185^{\mathrm{vb}}$ leer.

$186^{\mathrm{ra}}-197^{\mathrm{rb}}$ PIUS II PAPA, Epistula de legatione Bohemica ad cardinalem Johannem. Aeneas Silvius Piccolomini an Johannes de Carvajal, Wiener Neustadt, 21. 8. 1451. Reverendissimo in Christo et colendissimo patri, domino Iohanni de Carviali sacrosancte Romane ecclesie sancti Angeli dyacono cardinali Eneas episcopus Senensis salutem plurimam dicit. Quamvis aput Bohemos apostolice sedis legacionem obieris, et omnes illius gentis mores, opinionesque, tamen quia perversi quidam homines novos in dies errores cudunt ... - ... acri et gravi iudicio comprobatum. Vale nostri memor et amans. Quando deus et fata volent, veniemus ad te. Ex nova civitate xii Kalendas Septembris, sub anno domini mo quadringentesimo quinquagesimo primo etc. etc. $>$ Finis huius Medardi episcopi 1459<. Der Briefwechsel des Eneas Silvius Piccolomini, hrsg. v. Rudolf Wolkan, Abt. 3, Bd. 1, Wien 1918, S. 22-57, Nr. 12. Bertalot, Initia humanistica Latina, Bd. 2, Nr. 17421.

197 v leer.

198r-245v PAULUS APOSTOLUS, Epistolae. I Th - Hbr, kommentiert. Argumentum ad Thesalonicenses secundam scribit epistulam apostolus et notum facit eis de temporibus novissimis et de adversariis deiectione ... Paulus et Silvanus et Thimotheus ... - ... Salutant vos omnes de Ytalia fratres. Gracia cum omnibus vobis. Amen. Kommentar interlinear und am Rand, beginnend: Intencio apostoli in hac epistula est pravos et incorrectos corrigere et bonos ad perseveranciam aliorumque correctionem cohortari ... Kommentierung bricht am Schluss von $\operatorname{Hbr} 7(229 \mathrm{v})$ ab.

245v leer (bis auf einen Nachtrag: Epistolas Pauli, am unteren Rand auf dem Kopf stehend).

$246^{\mathrm{r}}-251^{\mathrm{r}}$ Tractatulus de quinque floribus mundi contemnendis. [Q] uicumque voluerit esse amicus huius mundi inimicus dei constituentur. Jacobi 4 (Iac 4,4). Tot sunt negocia buius mundi et tot in eo oblectamenta mali ut qui negotia eius exequi voluerit raro vel numquam peccatum grande vitare valebit ... Primus flos est bona disposicio corporis scilicet sanitas, fortitudo et pulchrituto ... - ... Ecce horribile exemplum sed valde utile ad ruminandum quia facit hominem huius mundi amiciciam declinare et ad amiciciam dei frequencius aspirare. Ad quam nos. Vgl. etwa Basel, Universitätsbibliothek, A X 131, 123 r $-128^{\mathrm{r}}$ und A XI 74, $111^{\mathrm{r}}-126^{\mathrm{v}}$, letztere Hs. im Wortlaut besser übereinstimmend. BlOOMFIELD, Incipits, Nr. 4761.

251 $1^{\mathrm{r}}-257^{\mathrm{v}}$ ANDREAS DE ESCOBAR, Lumen confessorum. [L] umen penitenciariorum seu confessorum ad revelacionem gencium fidelium et gloriam plebis christianorum lucem veram gloriam omni primo invocando qui illuminat ... - ... non tamen est absolutus ad debito penitentie //. Bricht am Seitenende ab. SCHULTE, Geschichte, Bd. 2, S. 440; BLOOMFIELD, Incipits, Nr. 2988.

$258^{\mathrm{ra}}-268^{\mathrm{vb}}$ Expositio hymnorum 'Conditor alme siderum' et 'Veni redemptor omnium'. AH $51 \mathrm{Nr} .47$ und AH 50 Nr. 8 (2-7). > [I]n lumine tuo videbimus lumen, etc. < Hanc proposicionem scribit propheta David et est theoloycalis ... 259 $9^{\mathrm{ra}}>[\mathrm{C}]$ onditor alme syderum, eterna lux, etc. $<$ Postquam visum est et de quibusdam notabilibus circa principium huius libri, nunc divisione et distinctione capitulorum videamus. Dividitur ergo iste liber in tot capitula quot sunt ymni in eo contenti ... Sed iste ymnus qui est adventu domini ... 264vb $>$ Questio quare Christus fuerit, etc. $<$ Circa materia adventus ... 265 $5^{\mathrm{rb}}>[\mathrm{V}]$ eni redemptor gencium ostende partum etc. $<$ Iste ymnus canitur in Adventu domini in Completorio ... - ... $>$ Equalis eterno patri etc. $<$ Hic auctor dirigit peticionem suam ... in corde fedelis ut pius adiutor. Et sic de aliis. Sequitur $2^{u s}$ sexternus. Nota auctor dicit infirma etc. //. Bricht am Seitenende ab, vgl. Olomouc, Vědecká knihovna, M II 138, $10^{\text {ra }}$ (ganzes Werk: $2^{\text {ra }}-111^{\text {ra }}$ ). 269r-276r Ps.-DIONYSIUS AREOPAGITA, De divinis nominibus. Caput I und II (Beginn) in der Übersetzung des Johannes Scotus Eriugena, teilweise mit Interlinear- und Randglossen $\left(270^{\mathrm{v}}-274^{\mathrm{v}}\right)$. Epigrama in beatum Dionisium in libro de divinis nominibus. [N] unc autem o beate post theologicos caracteres 
in divinorum nominum replicacionem quantum licet transeamus. Sit autem et nunc nobis eloquiorum lex prediffinita ... - ... ut cumque nobis bene conspiciens omnis ingenita est racio varium quidem omne et non manifestum //. Bricht ab. Dionysiaca, [Brügge/Paris] 1937, Bd. 1, S. 5-74. Martin Grabmann, Mittelalterliches Geistesleben, München 1926, S. 453 f. und 468.

$276^{\mathrm{v}}-280^{\mathrm{v}}$ leer.

$281^{\mathrm{ra}}-294^{\mathrm{vb}}$ THOMAS PALMERANUS, Manipulus florum. Accidia - Confessio, Consideratio sui Contritio. Vor Bl. 281 fehlt ein Blatt, Textverlust: die Artikel 'Abstinentia' und 'Abusio' sowie die ersten Zeilen zum Lemma 'Acceptio personarum': // facit. Yeronimus: Multa nos facere cogit affectus et dum propinquitatem respicimus ... Innocens libro $i i^{\circ}$ de utilitate condicionis humane: Clamat pauper er nullus exaudit, loquitur dives et quilibet applaudit. Gregorius: > Accidia< est de virtutum laudabili exercicio utriusque hominis langwida deiectio ... - ... 290 ${ }^{\mathrm{vb}}>[\mathrm{C}]$ onfidentia<. Augustinus: Adversaria est confidencia ... Nemo de suo corde presumat //. Nach Bl. 290 fehlt ein Blatt, Textverlust: der grösste Teil zu 'Confidentia', die beiden Artikel 'Coniugium’ und 'Conscientia' sowie die ersten zwei Zeilen zum Lemma 'Consideratio sui'. 291'ra // fallacia tegmina ... - ... $294^{\mathrm{va}}>[\mathrm{C}]$ onversatio <. Augustinus de doctrina christiana: In diversis observacionibus nulla disciplina melior gravi et prudenti christiano ... interdum turpis sermo demonstrat //. Bricht ab, es fehlen wohl vier Lagen (der grössere Teil zu 'Conversatio' sowie die Artikel 'Conversio' bis 'Usura'). Flores omnium fere doctorum, qui super sacris literis conscripserunt, necnon et quorundam aliorum doctissimorum, a Thoma Hibernico miro ordine collecti, Venetiis 1550, 5ㄴ $-90^{\mathrm{v}}$, 96v $-113^{\mathrm{r}}$. RB 8128,1; Richard H. Rouse, Mary A. Rouse, Preachers, Florilegia and Sermons: Studies on the Manipulus florum of Thomas of Ireland, Toronto 1979 (ohne diese Hs., vgl. S. 321 bzw. 457).

295 ${ }^{\mathrm{ra}}-304^{\mathrm{rb}}$ JACOBUS DE PARADISO, De apparitionibus animarum separatarum. Rogamus vos ne terreamini per spiritum. Verba sunt apostolica ad plebem Thessolonicam missa in epistola $2^{a}$ capitulo $i^{\circ}$. Que verba absurde assummi non possunt ... 295 $5^{\mathrm{rb}}$ Quantum igitur ad primum ... - ... 303 $3^{\mathrm{va}}$ Exclamacio autoris: In materia huius cupientes aliquid ... caritate ad hoc instigante. Pro quo deus ipse sit benedictus, Amen. Explicit feliciter Mauricii anno lxixno. Teilweise gekürzt und leicht umgearbeitet, vgl. Christoph Fasbender, Von der Wiederkehr der Seelen Verstorbener. Untersuchungen zu Überlieferung und Rezeption eines Erfolgstextes Jakobs von Paradies, mit einem Abdruck des Autographs, Heidelberg 2001, S. 32-100 (ohne diese Hs., vgl. S. 107/129 bzw. 374).

304 $4^{\mathrm{va}}-310^{\mathrm{rb}}$ MARQUARD VON LINDAU, De poenis inferni. [Q] uerebant eum inter cognatos et notos. Luce (Lc 2,44). Quamvis enim verbum istud de benedicta matre virgine et nutricio pueri sit dictum ... - ... dicentes illud Sapientie: Quid profuit nobis superbia aut diviciarum iactancia? Transierunt omnia sicut umbra. Avertat pius deus omne malum a nobis. Amen. Explicit feliciter Fidis virginis et martiris anno lxixno. Vgl. UB Basel, A VI 4, 175 ${ }^{\mathrm{r}}-182^{\mathrm{r}}$ und A VIII 8, 221 $1^{\mathrm{r}}-243^{\mathrm{v}}$, welche jedoch untereinander besser übereinstimmen. Nigel F. PAlmer, Artikel Marquard von Lindau, in: Verfasserlexikon², Bd. 6 (1987), Sp. 115, Hs. erwähnt. B1. 305 eingebundenes Zusatzblatt von der gleichen Hand, Rectoseite: Qui volunt divites fieri ... (I Tim 6,9). Que est ista aviditas cum ipse belue modum habeant? Tunc enim ... et perdere celum. Vgl. Augustinus, Sermo 367, gekürzt wie PL 186, Sp. 337 (Zacharias Chrysopolitanus), Rest der Seite leer. Verso: Secundum beatum Augustinum status hominis tripliciter consideratur: in vita, in morte et post mortem. Sic et hic et divitis et pauperis describitur triplex status ... - ... et vermes carnem propriam corrodentes. Auszug aus Jacobus de Voragine, Sermo I in dominica prima post festum Trinitatis, Schneyer, Bd. 3, S. 327, Nr. 86.

$310^{\mathrm{v}}-315^{\mathrm{v}}$ leer. 
316 ${ }^{\mathrm{r}}-337^{\mathrm{v}}$ LACTANTIUS, Divinae institutiones. Buch 1, Kap. 1-22. [M]agno et excellenti ingenio viri concessione doctrine penitus dedissent quidquid laboris poterat impendi ... - ... huc se remotis inferre consueverat et mentiri posset monitu dee coniugis //. Bricht nach Beginn von Kap. 22 mitten auf der Seite ab, Lücken für griech. Text freigelassen, nicht ergänzt. L. Caelius Firmianus Lactantius, Divinarum institutionum libri septem, Fasc. 1: Libri I et II, ed. Eberhard Heck et Antoine WLosok, München/Leipzig 2005, S. 1-101.

338 ${ }^{\text {ra }}-344^{\text {ra }}$ EBERHARD MARDACH (?), Speculum de arte moriendi. [C] um de presentis exilii miseria mortis exitus propter moriendi imperitia multum non solum laicis verum eciam devotis et religiosis difficilis nimis multumque periculosus ... [C] um omnium terribilium mors corporis sit terribilissima ... - ... ut prius antequam mors occupet discat mori. O vita secura ... cum nichil certius sit morte et nichil incertius hora mortis. Et sic finis est libelli de arte moriendi compositi per patrem Eberhardi Madach ordinis Predicatorum conventus Nurenbergensis. Stimmt überein mit GW 2603: Ars moriendi etc. [Paris, um 1485], a1 ${ }^{\mathrm{r}}$ - b5 ${ }^{\mathrm{v}}$, Zeile 5. MAdre, Dinkelsbühl, S. 292-295; Kaeppeli, Scriptores, Nr. 965, Hs. erwähnt; Bloomfield, Incipits, Nr. 1076; Werner Williams-Krapp, Artikel Mardach, Eberhard, in: Verfasserlexikon², Bd. 5 (1985), Sp. 1239.

$344^{\mathrm{rb}}$ und $344^{\mathrm{v}}$ leer.

Papier, 143 Blätter, $31,5 \times 21,5 \mathrm{~cm}$

Mittleres Drittel des 15. Jahrhunderts

Wasserzeichen, Lagen, Foliierung: Wasserzeichen: Bl. 1-132 Dreiberg, PICCARD, Wasserzeichenkartei Nr. 151289 (1455), Bl. 133-142 Nr. 151357 (1454). Lagen: 11 VI132 + V142, nach Bl. 12 zwei Lagen (Sexternionen) herausgerissen, Textverlust, Reste davon mit den Reklamanten erhalten. Am oberen Rand Wasserschaden, die ersten Zeilen des Textes auf jeder Seite, vor allem am Anfang und gegen den Schluss der Hs. leicht beeinträchtigt, aber gut lesbar. Reklamanten. Neuere Foliierung: A. 1-142.

Einrichtung und Ausstattung: Begrenzung des Schriftraums mit Tinte, Schriftraum 22,5-23,5 × 14-15, zweispaltig (6,5-7), 41-49 Zeilen. Jüngere gotische Buchkursive, $1^{\mathrm{ra}}-101^{\mathrm{rb}}$ ohne Schleifen von einer Hand, $101^{\mathrm{va}}-132^{\mathrm{rb}}$ mit Schleifen von einer anderen Hand. Der erste Schreiber gab die in Isidors Text ursprünglich griechischen Buchstaben und Begriffe lateinisch wieder, der zweite verwendete eigentümliche, halb griechische Buchstabenformen. Bis $101^{\mathrm{r}}$ Rubrizierung der Majuskeln, Lemmata oder wichtige Begriffe zusätzlich oft rot, teilweise auch schwarz unterstrichen; $1^{\mathrm{r}}, 2^{\mathrm{rb}}-3^{\mathrm{ra}}, 13^{\mathrm{r}}, 25^{\mathrm{r}}, 37^{\mathrm{va}}, 38^{\mathrm{ra}}, 51^{\mathrm{rb}}, 61^{\mathrm{va}}, 74^{\mathrm{ra}}, 97^{\mathrm{r}}, 109^{\mathrm{ra}}$ und $121^{\mathrm{r}}$ rote Überschriften; $13^{\mathrm{r}}, 23^{\mathrm{v}}-25^{\mathrm{r}}, 31^{\mathrm{v}}, 42^{\mathrm{v}}, 44^{\mathrm{v}}, 51^{\mathrm{r}}, 55^{\mathrm{v}}, 59^{\mathrm{v}}$ und $81^{\mathrm{r}}$ rote Marginalien. $3^{\mathrm{r}}-101^{\mathrm{r}}$ Zählung der Bücher am Kopf der Rectoseiten in Rot, mit Vorgaben (bis 102r); eine andere Zählung $1^{r}-55^{r}$ am Seitenfuss in Schwarz, siehe Inhalt. Raum für 2-4zeilige Initialen ( ${ }^{\text {ra }}$ für eine 11 zeilige, 47va 6zeilige, 67va 5zeilige) freigelassen, darin meist Vorgaben, z. T. in Rot, nicht ausgeführt. $81^{\text {vb }}$ Federskizze: OT-Karte (XIV,2,3), 35 ${ }^{\text {rb }}$ 11 Zeilen freigelassen (VII,4,2).

Korrekturen und Nachträge: Wenige Korrekturen von der Hand der beiden Schreiber, z. B. $3^{\mathrm{va}}, 72^{\mathrm{vb}}, 82^{\mathrm{vb}}$, $119^{\mathrm{rb}}, 127^{\mathrm{vb}}$; zeitgenössisch z. B. $1^{\mathrm{rb}}, 24^{\mathrm{rb}}, 68^{\mathrm{rb}}, 115^{\mathrm{rb}}$. Marginalien zur Erschliessung des Inhalts (Kapitelzählung in Buch 1, Wiederholung der Lemmata, auch Notazeichen und Handweiser), überwiegend von einer zeitgenössischen Hand, andere z. T. auf Deutsch, z. B. 66v labrum underleffen, $112^{\mathrm{r}}$ Tyrsus leydtstab 
mit blumen ... 48 $8^{\mathrm{va}}-89^{\mathrm{rb}}$ Notazeichen und Handweiser, letztere auch $112^{\mathrm{r}}-115^{\mathrm{r}}$, 15. Jh. Marginalien von einer Hand des 17. Jhs., vgl. $7^{\mathrm{r}}$ (zu Etym. I,21) Has scripturarum notas cum expressis caracterib[us] egregie describit frater Sixtus Senensis Domincanus profundissimus theologus in libello qui inscribitur Ars interpretandi sacras scripturas absolutissima fol. 122 impressionis Coloniens. a Ludovico Alectorio anno 1577(VD 16 S 6598). 39va im für die Initiale freigelassenen Raum Federskizze eines Sterns (Stella maris) mit Beischrift Maria (zu VII,10,1).

Einband: Mit hellem Leder bezogene Holzdeckel, 15. Jh. Streicheisenlinien. Zwei nach vorn greifende Kantenschliessen mit Messingteilen, der Haken der oberen abgerissen. Ehemals fünf runde Metallbuckel auf dem Vorder- und Rückdeckel, ausser den zwei Stiften am unteren Rand vorne nur noch Löcher und Abdrücke vorhanden. Ungefärbte Kapitale. Das nahezu lose Vorsatzblatt (A) und das hintere Spiegelbl. Papier. Im vorderen Spiegel zwei Pergamentfragmente, beide wohl von einer lat. Urkunde des 14. Jhs.; die äussere, davon nicht abgedeckte Hälfte mit zwei Stücken Papier überklebt, auf dem oberen aufgelistet Ingredienzien für ein medizinisches Rezept: Rossbein gebröndt unn gebulffert, Wisstannenrinden die in win gesotten ... Ein weiteres Pergamentfragm. (lat., 15. Jh.) um die letzte Lage gebunden und in den hinteren Deckel unter das Spiegelbl. geklebt. Im Falz der ersten Lage ein Pergamentstreifen. Am oberen Rand des Rückdeckels [Ysid] orus sowie In Etymologys, 16./17. Jh. Auf dem Vorderdeckel oben weitere, unlesbare Spuren von Handschrift sowie eines Titelschildes. Im vorderen Spiegel Exlibris des Chorherrenstifts Beromünster (WEgmann, Exlibris, Nr. 619). Auf dem Rücken Titelschild: S. Isidori Episcopi Hispalensis Liber Etymologiarum ad Braulion. Cesar Augustanum Episcop., entsprechend dem Catalogus von 1826.

Herkunft: Aufgrund der Wasserzeichen ist die Handschrift in das mittlere Drittel des 15. Jahrhunderts zu datieren.

Besitzer: Im vorderen Spiegel Exlibris des Chorherrenstifts Beromünster. Im Nachtrag zum Catalogus von 1763 auf 46 $\mathrm{r}$ als Nr. VI verzeichnet, im Catalogus von 1826 als Nr. 1. A ${ }^{\mathrm{r}}$ neuere Signatur C 49, Kugelschreiber, spätes 20. Jh. Signatur ehemals C 29 fol.

Literatur: Kopp, Stiftsbibliothek, II, S. 12; BRUCKNER, Scriptoria 9, S. 26; BüCHLER, Beromünster, S. 159 , 162.

$\mathrm{A}^{\mathrm{r}-\mathrm{v}}$ leer.

$1^{\mathrm{ra}}-132^{\mathrm{rb}}$ ISIDORUS HISPALENSIS, Etymologiarum libri XX. Einschub: De natura rerum (40,3-43,2; 45,1-47,4; 15,1-21,3). > Incipit prologus Ysidori episcopi in librum ethymologiarum ad Braulionem episcopum<. Domino meo et dei servo Braulioni efpiscopo Ysidorus episcopus. Omni desiderio ... 5 weitere Briefe, $2^{\text {va }}$ $>$ Determinabit igitur Ysidorus in libro primo <. De gramatica et partibus eius. $>i i<$. De rethorica et dyalectica. $>$ iii<. De mathematica, cuius partes sunt arismetica geometria musica et astronomia ... $2^{\mathrm{vb}}>$ Capitula primi libri<. De disciplina et arte ... > Incipit liber ethymologiarum Ysidori episcopi de disciplina. Capitulum primum<. Disciplina a discendo nomen accepit ... - ... 12 $2^{\mathrm{vb}}$ Hoc autem vix omnino constat, a quo sit inventum. Non quia aput nos //. Bricht ab (zwei Lagen herausgerissen), Reklamant: nos Ennius eo prior. Isidori Hispalensis episcopi etymologiarum sive originum libri XX, hrsg. v. Wallace Martin LindsaY, Oxford 1911, Briefe I-VI, Index und Capitula (zu Buch 1), Lib. I,1,1 - I,39,15; der Rest von Buch 1 (39,15-44,5) sowie die Bücher 2 und 3 fehlen. 13 ${ }^{\text {ra }}$ De natura rerum: // latitudo perhibetur. Quod eciam Clemens discipulus apostolorum visus est indicare ... -.. 15 va in toto orbe diffuderit. Isidore de Séville, Traité de la nature, hrsg. v. Jacques FonTAINE, Bordeaux 1960, S. 307-313, 317-325, 227-253. Anschliessend: De chronice vocabulo. De momentis et horis ... 
[C] bronica dicitur Grece que Latine temporum series appellatur ... - ... ut vis morbi ignis ardore siccetur etc. Et sic est finis libri ethymoloyarum Ysidori. Isidori Hispalensis episcopi etymologiarum sive originum libri XX, Lib. V,28,1 - V,39,42; IV,1,1 - V,27,38; VI,1,1 - IX,6,22; IX,7,1 - XX,16,8 (Capitula meist zu Beginn der einzelnen Bücher, manchmal auch von Begriffszusammenhängen); $54^{\mathrm{vb}}$ bis auf drei Zeilen leer, es fehlt der Text IX,6,23-29 (kleine Lücken zudem 82 va XIV,3,25; 83 ${ }^{\text {ra }}$ XIV,3,34; $111^{\text {rb }}$ XVII,9,77; XIX,16,7, wohl aufgrund von Unklarheiten in der Vorlage). $15^{\text {va }}$ Buch 5 (Kap. 28-39), 18 ${ }^{\text {va }}$ Buch 4, $21^{\text {va }}$ Buch 5 (Kap. 1-27), $25^{\mathrm{ra}}$ Buch 6, mit Überschrift: >Incipit liber sextus de sacris scripturis $<, 32^{\mathrm{rb}}$ Buch 7, 40vb Buch 8, 47va Buch 9, 55 va Buch 10, 61 va Buch 11, mit Überschrift: >Incipit liber xi de homine et partibus eius $<, 67^{\text {va }}$ Buch 12, $76^{\text {va }}$

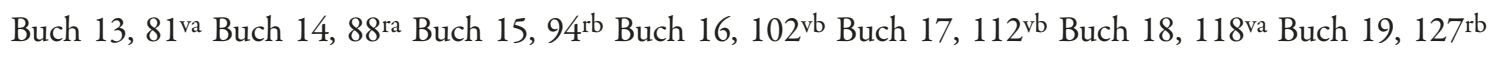
Buch 20. Zwei nicht mit einander (und auch nicht mit den Überschriften $25^{\text {ra }}$ und $61^{\text {va }}$ ) übereinstimmende Zählungen der Bücher, am Kopf der Rectoseiten (siehe Einrichtung): 1 (Buch 1), 3 (aus De natura rerum), 4 (Buch 5, Kap. 28-39), 5 (Buch 4), 6 (Buch 5, Kap. 1-27), 8 (Buch 6, Kap. 1-8), 9 (Buch 6, Kap. 9-19), 10 (Buch 7), 11 (Buch 8), 12 (Bücher 9-12), 13 (Buch 13, Kap. 1-11), 14 (Buch 13, Kap. 12-22), 15 (Buch 14 ) 19 (Buch 18), 20 (Buch 19, Kap. 1-19), 21 (Buch 19, Kap. 20-34), 22 (Buch 20); 18-22 nachträgl. wohl von der gleichen Hand wie die folgende, zweite Zählung in der rechten Ecke am Fuss der Seiten: 1 (Buch 1), 7 (aus De natura rerum), 8 (Buch 5, 2. Hälfte), 9 (Buch 4), 10 (Buch 5, 1. Hälfte), 11 (Buch 6) - 14 (Buch 9), zudem $25^{\mathrm{r}}$ am unteren Rand in der Mitte 6 , entsprechend der roten Überschrift.

$132^{\mathrm{va}}-142^{\mathrm{v}}$ leer.

Papier, 186 Blätter, $28 \times 20-21 \mathrm{~cm}$ 1449

Wasserzeichen, Lagen, Foliierung: Wasserzeichen: Bl. 1-96 und 145-185 Ochsenkopf, PICCARD, Wasserzeichenkartei Nr. 76658 (1449) und 76659 (1449), Bl. 97-144 Nr. 75095 (1449) und 75242 (1451). Lagen: $15 \mathrm{VI}^{180}+(\mathrm{V}-5)^{185}$, nach Bl. 185 fünf Blätter sowie ein Sextern und ein Quintern herausgerissen. Bl. 1 und B1. 12 zu einem Doppelblatt verbunden. Bl. 13 beinahe lose, an das in den Spiegel geklebte Pergamentfragment geklebt (siehe Einband). Reklamanten, sichtbar ab 72v. Neuere Foliierung: A. 1-185.

Einrichtung und Ausstattung: Begrenzung des Schriftraums mit Tinte, Schriftraum 19,5-21 × 14,5, zweispaltig (6-6,5), 34-46 Zeilen. Schleifenlose jüngere gotische Buchkursive, möglicherweise alles von der Hand des Henmannus Murer, jedoch mit auffälligem Wechsel 86 va zu kalligrafischer Ausführung (Haarstriche). Rubriziert, rote Überschriften, Paragraphenzeichen, Unterstreichungen und Zeilenfüller. Zählung der Sermones in Rot am Kopf der Seiten. Oberlängen der ersten Zeile bisweilen verziert. 2-4zeilige rote Lombarden mit Punktverdickungen. $1^{\text {ra }} 10$ zeilige rote Initiale. Marginalien zur Erschliessung des Inhalts, rubriziert.

Korrekturen und Nachträge: Korrekturen von der Hand des Schreibers, z. B. $1^{\mathrm{ra}}, 28^{\mathrm{rb}}, 86^{\mathrm{rb}}, 118^{\mathrm{vb}}, 181^{\mathrm{vb}}$; zeitgenössische Korrekturen, z. B. $4^{\mathrm{va}}$, 37rb. Zeitgenössische Ergänzung der Marginalien. 47v ein Handweiser und ein Notazeichen.

Einband: Mit weissem Leder bezogene Holzdeckel, 15. Jh., Leder teilweise abgerissen, v. a. am Rückdeckel. Ehemals eine nach vorne greifende Kantenschliesse, Messingraste im Vorderdeckel erhalten. Kapitale am Kopf 
vom Rückenleder verdeckt, am Schwanz das Leder abgerissen. Spiegelblätter und Vorsatzblatt (A) Papier. Zwei Fragmente einer Pergamenths. in (später) karolingischer Minuskel um die erste und die ehemals letzte Lage gebunden und unter die Spiegelblätter in die Deckel geklebt. Im vorderen Spiegel Exlibris des Chorherrenstifts Beromünster (Wegmann, Exlibris, Nr. 619). Auf dem Vorderdeckel Spuren von einer Beschriftung. Auf dem Rücken Titelschild: Pars Aestivalis Sermonum Discipuli. No 21, 18. Jh., entsprechend dem Catalogus von 1826; darunter älteres Rückenschild, 15. oder 16. Jh.

Herkunft: Geschrieben von Henmannus Murer und auf den 28. Oktober 1449 datiert, zu ihm CMD-CH 2, S. 223.

Besitzer: Im vorderen Spiegel Exlibris des Chorherrenstifts Beromünster. Im Catalogus von 1763 als Classis Nona Nr. 23 verzeichnet, im Nachtrag dazu auf 48r als Nr. VII[bis], in den Antiquitates Beronenses, S. 691, als Nr. 22 (und als Geschenk des Ludwig von Lütishofen), im Catalogus von 1826 als Nr. 21. Signatur ehemals C 30 fol.

Literatur: Kopp, Stiftsbibliothek, II, S. 14; BrUCKner, Scriptoria 9, S. 27; Bü CHLER, Beromünster, S. 143f., 177 und 236 (Anm. 31); CDM-CH 2, Nr. 97.

$\mathrm{A}^{\mathrm{r}-\mathrm{v}}$ leer.

$1^{\mathrm{ra}}-185^{\mathrm{rb}}$ JOHANNES HEROLT, Sermones de tempore. Pars aestivalis. >Incipit pars estivalis sermonum Discipuli. Et primo in festo sancte pasce. Sermo quinquagesimus <. Hec est dies quam fecit dominus ... (Ps 117,24). Sciendum quod festivitas presens precellit alias festivitates in sollempnitate et iocunditate ... - ... audientes hoc quem vivum querebant, mortuum inveniebant. Amen. Et sic est finis. $>$ Explicit pars estivalis sermonum Discipuli per me Henmannum Murer protunc plebanus in Kolliken die quinta Kalendas Novembris anno domini $1449<$. Sermones Discipuli de tempore et sanctis, Mainz 1612, S. 293-771 (Sermo 50-136); der Text stimmt mit dem Druck weitgehend überein, die Zählung und Reihenfolge der Sermones ist dieselbe, einzelne Begriffe sind zusätzlich auf Deutsch übersetzt. SCHNEYER, 1350-1500, Johannes Herolt (Discipulus) Nr. 56-64, 67, 68, 71, 72, 75-99, 101-125, 127-156; KAEPpeLI, Scriptores, Nr. 2387, Hs. erwähnt.

$185^{\mathrm{va}-\mathrm{vb}}$ leer.

Papier, 221 Blätter, $28,5 \times 21 \mathrm{~cm}$

Ende 14. Jh.; 1408; 1460 (?)

Wasserzeichen, Lagen, Foliierung: Wasserzeichen: Bl. 1-24 Ochsenkopf, PICCARD, Wasserzeichenkartei Nr. 66639 (1394), nebst zwei Varianten; Bl. 25-36 Nr. 78873 (1395/96), Bl. 29/32 und Bl. 7a Nr. 78871 (1394/95); Bl. 142-151 Nr. 78587 (1410); Bl. 37-48 Kreuz, ähnlich PICCARD, Wasserzeichenkartei Nr. 125760, in zwei Varianten; Bl. 49-62 und 122-133 Horn, PICCARD, Wasserzeichenkartei Nr. 119989 (1395) und 120038 (1394); Bl. 63-98 Lilie, BRIQUET Nr. 16037 (1396); Bl. 100-121 und 134-139 Buchstabe G, Piccard, Wasserzeichenkartei Nr. 27584 (1395) und 27597 (1395); Bl. 143/150 Ochse, ähnlich PiCCARD, Wasserzeichenkartei Nr. 86245 (1409). Bl. 152-163 und 188-199 Mühlrad, PiCCARD, 
Wasserzeichenkartei Nr. 122848 (1435-1437), 122870 (1440) und 122902 (1438); Bl. 164-187 Traube, PICCARD, Wasserzeichenkartei Nr. 129131 (1439) und 129318 (1440). Lagen: $(\mathrm{VI}+1)^{12}+(\mathrm{VI}+2)^{24}+2 \mathrm{VI}^{48}+\mathrm{VII}^{62}+(\mathrm{VI}+1)^{74}+2 \mathrm{VI}^{98}+(\mathrm{V}+1)^{109}+2 \mathrm{VI}^{133}+(\mathrm{VI}-4)^{141}+$ $(\mathrm{VI}-2)^{151}+4 \mathrm{VI}^{199}$, Bl. 7a, 14a, 23a und 71a eingebundene Zettel; Bl. 99 Einzelblatt (an Pergamentfalz), nach Bl. 140 vier Blätter herausgeschnitten, vor Bl. 142 und nach Bl. 151 je ein Blatt (Doppelbl.) herausgerissen. $1^{\mathrm{r}}-110^{\mathrm{r}}$ Lagenzählung zu Beginn der Lagen, $1^{u s}-3^{u s}$ und $8^{v u s}$ am unteren, $4^{u s}$, $5^{u s}$, $7{ }^{u s}$ und $10^{u s}$ am oberen Rand. $175^{\mathrm{v}}$ und $187^{\mathrm{v}}$ Reklamanten, beschnitten. Die Rectoseite von Bl. 1 teilweise abgeschabt und schwer lesbar, die Versoseite des letzten Blatts von Teil 1 (141) verschmutzt. In Teil 2 am oberen Rand Wasserschaden, die ersten Zeilen des Textes auf jeder Seite leicht beeinträchtigt, aber gut lesbar. Alte Foliierung in Teil 2: zuerst $i\left(152^{\mathrm{r}}\right)$, ii $\left(153^{\mathrm{r}}\right)$, dann $i\left(157^{\mathrm{v}}\right)$ - vii $\left(163^{\mathrm{r}}\right)$, schliesslich in Übereinstimmung mit der Tabula auf den Verso- und den Rectoseiten: $i\left(158^{\mathrm{r}}\right)$ - xxxxii (199) $)$. Neuere Foliierung: A-D. 1-7. 7a. 8-14. 14a. 15-23. 23a. 24-71. 71a.72-213.

\section{Einrichtung und Ausstattung:}

Teil 1 (Bl. 1-141, Ende 14. Jh.): Bis $121^{\mathrm{v}}$ doppelte Begrenzung des Schriftraums mit Tinte, für den Haupttext und die Randglosse, danach bis $128^{\mathrm{r}}$ nur Einstichlöcher; $128^{\mathrm{v}}-140^{\mathrm{r}}$ Begrenzung des Schriftraums mit Stift, z. T. zweispaltig, danach mit Tinte. Schriftraum $1^{\mathrm{r}}-128^{\mathrm{v}}$ und $129^{\mathrm{v}}-132^{\mathrm{r}}$ (Haupttext): 12,5-20,5 × 10-15, 9-15 Zeilen; $128^{\mathrm{v}}-129^{\mathrm{r}}$ und 132v-139v: $24-25,5 \times 16-17$, zweispaltig (7-8,5), 46-58 Zeilen. Jüngere gotische Buchkursive mit Schleifen. Rubriziert, rote Überschriften und Paragraphenzeichen. Einzeilige rote und schwarze Initialen, meist ornamentiert; $17^{\mathrm{r}}$ dreizeilige schwarz und rot umrissene Initiale, der Buchstabenschaft gespalten: Fisch und vegetabile Ornamente; $17^{\mathrm{v}}$ zweizeilig, im Binnenfeld Hirsch und Jagdhund; $42^{\mathrm{r}}$ zweizeilig, zwei Fische bilden den Schwanz (Q), im Buchstabenkörper ein Stelzvogel im Schilf; weitere, kleinere Initialen mit Fischen und Vögeln, 103 $\mathrm{v}$ Fisch und Menschenkopf im Profil; 106 ${ }^{\mathrm{r}}$ dreizeilig: Profilbild, auf dem Hut der Figur ein aus der Flasche trinkender Teufel, Unterteilung von Ps $118\left(106^{\mathrm{r}}-113^{\mathrm{v}}\right)$ durch einfache Flechtbandinitialen.

Teil 2 (Bl. 142-151, 1408): Ein-, zwei- oder dreispaltige Einrichtung mit Tinte, $151^{\mathrm{r}}$ liniiert; Schriftraum 18-20 × 15-16,5 (6-7,5), die Rectoseiten 142 und 144-148 mit einer nur $2 \mathrm{~cm}$ breiten Mittelspalte für den Haupttext: 22-26 Zeilen, Kommentar 32-62. Bastarda (Haupttext sowie Überschriften im Kommentar) und jüngere gotische Buchkursive mit Schleifen von der Hand des Heinricus Goltz. Rubriziert, rote Paragraphenzeichen. 2-3zeilige rote Initialen im Haupttext.

Teil 3 (Bl. 152-199, 1460): Begrenzung des Schriftraums mit Tinte, Tabula $\left(152^{\mathrm{r}}-157^{\mathrm{v}}\right)$ liniiert, rechts zwei Spalten für Zählung der Abschnitte (rote Buchstaben) und Folia (schwarze Ziffern). Schriftraum 20,5-22× 13,5-14,5, 37-45, in der Tabula 29-37 Zeilen. Jüngere gotische Buchkursive mit Schleifen von zwei Händen, Händewechsel 159v/160r. Rubriziert, rote Überschriften. Rote Foliierung (römisch) am Kopf der Seiten; die Zählung der Abschnitte am linken Rand entspr. der Tabula (Minuskeln) nur bis 160 ${ }^{\mathrm{r}}$, kurz nach dem Wechsel der Hand. 2-3zeilige rote Lombarden, in der Tabula 1-4zeilig. 152 6 zzeilige rote Spaltleisteninitiale.

Korrekturen und Nachträge: Korrekturen von der Hand der Schreiber, z. B. 1 ${ }^{\mathrm{r}}$, 95 ${ }^{\mathrm{r}}, 140^{\mathrm{vb}}$, 160 , $198^{\mathrm{r}}$. In Teil 3 $158^{\mathrm{r}}-174^{\mathrm{r}}$ Marginalien, 16./17. Jh., $160^{\mathrm{v}}$ und $181^{\mathrm{v}}-188^{\mathrm{v}}$ Marginalien und Notazeichen von der Hand Friedrichs von Lütishofen, 15. Jh. $80^{\mathrm{r}}$ und $80^{\mathrm{v}}$ sowie $162^{\mathrm{v}}, 167^{\mathrm{r}}$ und $172^{\mathrm{v}}$ Handweiser. $140^{\mathrm{r}}-141^{\mathrm{v}}$ Nachträge, 15. Jh. Dv Nachtrag, 17. Jh.

Einband: Einband aus der Werkstatt Alberthus (EBDB w000043, nachgewiesen in Heidelberg um 14651482), vgl. auch C 62. Mit hellem Leder bezogene Holzdeckel, 15. Jh. Streicheisenlinien, Einzelstempel 
(EBDB s002521, s002523, s002527, s002529, s002530, s002532, s002533 und s002536). Zwei nach vorn greifende Kantenschliessen mit Messingbeschlägen, die obere abgerissen. Mit ungefärbtem Garn umstochene Kapitale. Schnitt gelb gefärbt. Spiegel- und Vorsatzblätter (A-D, 200-213) Papier, Wasserzeichen: Dreiberg, PicCARD, Wasserzeichenkartei Nr. 151357 (1454) und 151358 (1455). Bl. 152 Ledersignakel, an Bl. 142 ausgerissen. Je zwei Pergamentfragmente einer neumierten Hs. um die Vorsatzblätter gebunden und in die Deckel geklebt, vom einen der beiden im hinteren Deckel nur noch der Abklatsch. In den Fälzen Fragmente u. a. einer Rechtshandschrift, 14. Jh. (Bl. 6/7): convenit me super centum racione mutui coram archiepiscopo Parisiensi ... Im vorderen Spiegel Exlibris des Chorherrenstifts Beromünster (Wegmann, Exlibris, Nr. 619). Titelschilder, auf dem Vorderdeckel Pergament: Psalterium glosatum, 15. Jh.; auf dem Rücken Papier: Liber ymnorum vel Soliloqu[i] orum Prophetae David. No 4, 18. Jh., entsprechend dem Catalogus von 1826.

Herkunft: Teil 1 lässt sich aufgrund der vielen übereinstimmend datierbaren Wasserzeichen dem Ende des 14. Jhs. zuweisen. Teil 2 geschrieben von Heinricus Goltz, gen. Biegger und auf Ostern 1408 datiert (150r), zu ihm CMD-CH 2, S. 223. Teil 3 ist 199r datiert auf den 28. Januar 1460, doch sind die Vergleichsbeispiele für die Wasserzeichen zwei Jahrzehnte älter.

Besitzer: Friedrich von Lütishofen, vgl. auch die in der gleichen Werkstatt eingebundene, durchgehend auf dem hier nur als Vorsatz gebrauchten Papier geschriebene Hs. C 62. Im vorderen Spiegel Exlibris des Chorherrenstifts Beromünster. Im Catalogus von 1763 als Classis Nona Nr. 19 verzeichnet, im Nachtrag dazu auf $47^{\mathrm{v}}$ als Nr. VII, im Catalogus von 1826 als Nr. 4. A ${ }^{\mathrm{r}}$ neuere Signatur C 51, Filzstift, spätes 20. Jh. Signatur ehemals C 31 fol.

Literatur: Kopp, Stiftsbibliothek, II, S. 13; BruCKner, Scriptoria 9, S. 27 sowie Taf. 39 und 46; BüCHLER, Beromünster, S. 159, 161f., 165, 177 und 242 (Anm. 98); CDM-CH 2, Nr. 98.

$\mathrm{A}^{\mathrm{r}}-\mathrm{D}^{\mathrm{r}}$ leer.

Dv Inhaltsübersicht. Nachtrag, 17. Jh.

Teil 1:

$1^{\mathrm{r}}-128^{\mathrm{v}}$ Psalterium glossatum. Ps 1-150, durchgehend am Rand und interlinear glossiert. In Rot: Regem magnum adoremus dominum. Text: Beatus vir ... Randglosse: Tytulus tocius libri ympnorum vel soliloquiorum propheti dei: Notandum, Esdras propheta notanter dicit liber ympnorum propter aliquos qui dixerunt quod essent 5 libri propter hoc quod dividitur in quinque partes ... Queritur quare non apponatur titulus huius psalmus (sic) Beatus vir etc. [Respondetur ...] quod huic primo psalmo ideo tytulus non apponitur qui[a] psalmus iste principium est et capud libri ... Interlinearglossen, Beatus vir: puta Christus, qui non abiit: id est non peccavit voluntarie sicud Adam qui consentit uxori a dyabolo deceptum ... - ... Omnis spiritus laudet dominum. Glosse: Scilicet sine fine et in perpetuum, laudemus igitur et nos dominum ... qui cum spiritu sancto in gloria dei patris vivit et regnat, Amen. Am oberen Rand: > Explicit exposicio psalterii<. Teilweise nach Petrus Lombardus (oder der Glossa ordinaria), vgl. PL 191, Sp. 60f. resp. 1292. RB 6637. Nachträglich ergänzte derselbe Schreiber Antiphonen, Versikel sowie Hymnen: AH 50 Nr. 4, AH 51 Nr. 25, AH 50 Nr. 5, AH 51 Nr. 26, AH 50 Nr. 22, AH 51 Nr. 27, AH 50 Nr. 23, AH 51 Nr. 28, AH 50 Nr. 24, AH 51 Nr. 29, 32, 30, 33-39, AH 50 Nr. 7 (1-5), entsprechend der liturgischen Einteilung (Psalterium feriatum); damit nicht ganz übereinstimmend die Gliederung durch zwei- oder mehrzeiligen Initialen: Ps $25\left(17^{\mathrm{r}}\right), 26\left(17^{\mathrm{v}}\right), 34\left(24^{\mathrm{v}}\right), 51$

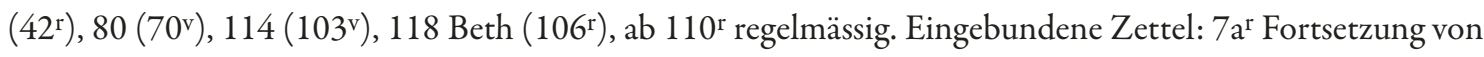


6v (Ps 14): iusticiam, qui loquitur ... 7av Antiphon (Respice et exaudi me ... aus Ps 12) und Versikel (Memor fui ... aus Ps 118). $14 \mathrm{a}^{\mathrm{r}}>$ Hic vero ymnus legitur ad laudes ab octava Pentecostes usque ad primam dominicam Octobris<. Ecce iam noctis ... 14av Glosse zu Ps 22: Et ideo magister Nicolaus Delira recitat omnipotentem ... vgl. Biblia sacra cum Glossa ordinaria, Venedig 1603, Bd. 3, Sp. 586. $23 \mathrm{a}^{\mathrm{r}}$ Fortsetzung der Glosse zu Ps 33 (Verso leer). $71 \mathrm{a}^{\mathrm{ra}-\mathrm{va}}$ Glosse zu Ps 81: Deus stetit in synagoga. Notandum, Glossa ordinaria dicit quod psalmus iste sit de duabus naturis in Christo ... vgl. Bd. 3, Sp. 1069.

$128^{\mathrm{v}}-132^{\mathrm{v}}$ Symbolum Athanasii glossatum cum expositione. > Inicipit symbolum Athanasii<. In nomine Iesu Christi amem. Ad explicacionem ergo fidei nostre tria symbola principaliter tradita sunt ... 129v Quicumque vult salvus esse ... - ... Nota hic queritur que sit differentia inter ista duo: firmiter et fideliter ... confessio fit ad salutem. Der Kommentartext ab 129v abschnittsweise am Rand um den glossierten Text, Parallelüberlieferung mit Nennung von Johannes Müntzinger als Autor: Basel, Universitätsbibliothek, A VI 4, 118v-122v. Im Text des Symbolum zusätzlich Interlinearglossen, Quicumque: id est omnis homo habens usum racionis et annos discrecionis, vult: id est cupit vel desiderat ... Der zweitletzte Abschnitt der Expositio fehlt, 132v Sequitur 'Asscendit ad celos' ultra quem textum notabilia scripta sunt in cedula proxima precedenti ubi posui tale signum (Zeichnung eines Knotens, sowie Kreuz).

132 va $135^{\text {ra }}$ Expositio symboli Apostolorum. > Incipit symbolum appostulorum<. Istud symbolum: Credo in deum recipimus tamquam ab appostolis traditum ... - ... et stabilis usque in finem vite. Parallelüberlieferung mit Nennung von Johannes Müntzinger als Autor: Basel, Universitätsbibliothek, A VI 4, 107r-110v.

135 ${ }^{\mathrm{ra}}-139^{\mathrm{v}}$ Expositio symboli Nicaeni. >Symbolum antiquorum patrum et Credo in unum deum<. Istud symbolum traditum est in civitate Nicena ubi fuerunt 318 patres congregati ... - ... Et ergo dicitur Pylato in symbolo nulla mencione facta de aliis. Et sic dei misericordia finita est exposicio symboli. De quo sit Christus in seculum seculi benedictus. Parallelüberlieferung mit Nennung von Johannes Müntzinger als Autor: Basel, Universitätsbibliothek, A VI 4, 110v-118 .

$140^{\mathrm{r}}-141^{\mathrm{v}}$ Moralia dogmata philosophorum. Nachtrag. Ysta sunt moralie dogmata phylosophorum multum utilia. Iuvenis stans in timore et parentum in honore, ac divino servicio, pauperum amore pio, et ad mala timorosus, si vita longa vixerit, magno in honore erit ... WALTHER, Proverbia 13337, 956, 24952, 24802, 9923 , 25968, 3934, 18359, 6257, 7921, 5162, 27164, 3432, 17515, 24017, 16672, 21988, 15629, 1172, 2750, 6060a und 17498, 24671a, 24503, 21677d/21754 (7836b), 1330, 2129, 27159, 19108, 30489, 14896, 15450, 11095b und 1408a, 10178; die einzelnen Verse z. T. auch mit grösseren Abweichungen, darüber Zuschreibungen an mehrheitlich antike Autoren. $140^{\mathrm{r}}$ Verse auf zwei langen Zeilen, $140^{\mathrm{v}}-141^{\mathrm{r}}$ zweispaltig, je vier Zeilen, insgesamt 33 Einträge. Nach B1. 140 vier Blätter herausgeschnitten, kein Textverlust ersichtlich. $141^{\mathrm{v}}$ Audite populi universi et videte dolorem meum. Verba premissa Treni primo sunt scripta et sunt verba salvatoris ad nos de cruce clamantis et ad memoriam suam ...

Teil 2:

$142^{\mathrm{ra}}-151^{\mathrm{r}}$ Lectura capituli ‘Omnis utriusque sexus' de poenitentia. Concilium Lateranense IV, Constitutio 21, mit Kommentar des Henricus de Odendorp sowie weiteren Erörterungen (Zweifelsfragen) zu den einzelnen Abschnitten und dem Gesamttext. Text (Bl. 142, 144-148, jeweils Rectoseiten, mittlere Spalte): Omnis utriusque sexus fidelis ... Glosse: Istud capitulum dividitur in 6 partes ... 'Omnis' capitur distributive, non collective, quia hoc statutum non ligat universitatem ... 142 $2^{\text {va }}$ Dubia zu Teil 1: Circa hanc partem dubitatur, primo quid de suspecto non communicet in anno semel, numquid cogi potest ad communicandum. Respondetur quod non, quia forte indignus est, 
sed cogendum est ut faciat se dignum ... - ... 1499ra Circa illum totum textum dubitatur, quare penitencia sit adinventa. Respondet dominus Iohannes de Lignano quod aliquod ut fiat $2^{a}$ tabula post naufragium, item dicit $2^{o}$ ut fiat medicina contra peccata ... 150 ${ }^{\mathrm{rb}}$ Nota concordancias littere intuitu brevitatis. Primo quod solifideles ligantur statutis ecclesie editis, quia fideles ... > Explicit optimum capitulum de confessione a magistro $H[$ enrico] per manus Heinrici Goltz provisoris scole Paronensis scriptum anno $m^{\circ} c c c c^{\circ}$ viiio in Pascha<. Vgl. GW 12255: Hainricus de Odendorff, Repetitio Capituli Omnis utriusque sexus de penitentiis et remissionibus, Memmingen: Albrecht

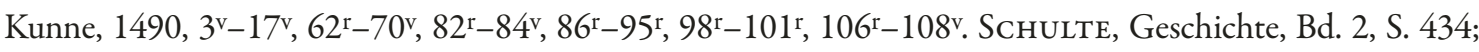
Bloomfield, Incipits, Nr. 3684 und 5180. Kopps Lesung «h. r.» für den Autor des Kommentars ist in Bezug auf die zweite Initiale nicht haltbar. $150^{\mathrm{v}}$ leer. $151^{\mathrm{r}}$ Wiederholung des Konzilsbeschlusses: [O]mnis utriusque sexus fidelis postquam ad annos discretionis pervenerit ... - ... detrudendum. Explicit textus illius cappituli. Conciliorum oecumenicorum decreta, hrsg. v. Giuseppe Alberigo u. a., 3. Ausg., Bologna 1973, S. 245.

$151^{\mathrm{v}}$ leer.

Teil 3:

$152^{\mathrm{r}}-199^{\mathrm{r}}$ Speculum clericorum. Tabula: > Primo de sacramento baptismatis et aliorum sacramentorum scilicet Eukaristie et unccionis etc.<. De sciencia et ignorancia sacerdotum, a 1. Quod fideles sciant oracionem dominicam et symbolum, b1 ... - .. 157v Quomodo beata Maria Magdalena non solum fuerit peccatrix in mente, sed eciam in opere, h 52. Nota prespiter ocultam penitenciam potest et debet iniungere pro ocultis peccatis eciam enormibus nec oportet quod remittat ad episcopum penitentem ... 158 [ [I]gnorancia est erroris mater, Apostolus. Si quis ignorat sacerdotibus vero est periculosa ... - ... Ecce qualiter sancti doctores Mariam Magdalenam non solum mentaliter, sed actualiter peccasse testantur... Deo gracias. Anno $m^{\circ} c c c c^{\circ} l x^{\circ}$ in die octavo Agnetis. Gleiches Incipit mit Nennung von Albertus de Diessen als Autor: Freiburg, Kantons- und Universitätsbibliothek, Ms L 16, $84^{\mathrm{r}}-150^{\mathrm{r}}$. Ausser der Gesamtstruktur im Vergleich mit anderen Hss. jedoch wenig Übereinstimmungen. Karl LANGosch, Artikel Albert von Diessen, in: Verfasserlexikon², Bd. 1 (1978), Sp. 120. Anschliessend: Item quinque filie sunt luxurie scilicet fornicacio que est cum muliere soluta ... quod est contra naturam.

$199^{v}-213^{v}$ leer.

\section{SERMONES; ZACHARIAS CHRYSOPOLITANUS}

Papier, 247 Blätter, $28 \times 20-20,5 \mathrm{~cm}$

Beromünster (?), Mitte des 15. Jahrhunderts

Wasserzeichen, Lagen, Foliierung: Bl. 1-12, 146-156 sowie 215/226 und 216/225 Ochsenkopf, PICCARD, Wasserzeichenkartei Nr. 74381 (1454) und eine Variante; Bl. 25-36, 139/144 sowie 140/143 Nr. 74856 (1455) und 74864 (1455); Bl. 37-120 Nr. 74734 (1459) und eine Variante; Bl. 121-132 sowie 134-136 Nr. 75085 (1457) und eine Variante; Bl. 157-214 Nr. 75200 (1455) und 75258 (1450); Bl. 217-246 Nr. 75878 (1459) und eine ähnliche Form; Bl. 13-24 sowie 141/142 Krone, PICCARD, Wasserzeichenkartei Nr. 50094 (1450) und 50223 (1452). Lagen: $11 \mathrm{VI}^{132}+(\mathrm{III}-3+1)^{136}+(\mathrm{V}-2)^{144}+2 \mathrm{VI}^{168}+\mathrm{V}^{178}+5 \mathrm{VI}^{238}+$ $(\mathrm{VI}-4)^{246}+(\mathrm{III}-6)^{246}$, vor 133 ein Einzelblatt eingefügt; nach 136 drei, nach 144 zwei, nach 246 vier Blätter, am Ende eine ganze Lage ausgerissen. Reklamanten, häufig stark beschnitten. Neuere Foliierung A. 1-246. 
Einrichtung und Ausstattung:

Teil 1 (1-144): Vertikale Begrenzung des Schriftraums durch Faltung, Schriftraum 22-24× 13,5-14,5, 4352 Zeilen. Gotische Buchkursive mit Schleifen, meist mit doppelstöckigem a, 124 $4^{\mathrm{v}}-132^{\mathrm{v}}, 134^{\mathrm{r}}-136^{\mathrm{v}}$, $142^{\mathrm{r}}-143^{\mathrm{v}}$ konsequent mit einstöckigem a, aber wohl von der gleichen Hand; $109^{\mathrm{v}}-110^{\mathrm{v}}$ jüngere gotische Buchkursive von zwei anderen Händen, Händewechsel 109v. Texterschliessende Marginalien, $4^{\mathrm{r}}-6^{\mathrm{r}}$ auch längere Anmerkungen von der Hand des Schreibers; 51 ${ }^{\mathrm{v}}, 72^{\mathrm{r}}$ und $107^{\mathrm{r}}$ Nota (in Monogrammform); Paragraphenzeichen. Über die Zeile erhöhte, flüchtig ornamentierte 1-3zeilige Initialen in Tinte. Nach BüCHLER, Beromünster, S. 244 (Anm. 130) vom gleichen Schreiber wie C 46, 281 r $-310^{\text {r }}$.

Teil 2 (145-246): Begrenzung des Schriftraums mit Tinte, Schriftraum 20-20,5 × 13,5-14,5, zweispaltig (66,5), 37-56 Zeilen. 145 ${ }^{\mathrm{r}}-215^{\mathrm{r}}$ ältere gotische Buchkursive mit Schleifen, wohl von derselben Hand wie das meiste von Teil 1 (hier durchgehend mit doppelstöckigem a), 215 $\mathrm{v}-246^{\mathrm{v}}$ jüngere gotische Buchkursive ohne Schleifen von anderer Hand. Am Rand Autor- und Stellenangaben sowie vereinzelt Anmerkungen von der Hand des jeweiligen Schreibers; Handweiser, teilweise rot bzw. schwarz-rot. $145^{\mathrm{r}}-226^{\mathrm{r}}$ rubriziert, rote Evangelistenkürzel und Unterstreichungen. Evangelienstellen durchgehend in vergrösserter Schrift. 2-5zeilige rote Lombarden, häufig mit ornamentalen Schaftaussparungen und Punktverdickungen, 186rb Raum für eine 12zeilige Initiale ausgespart, nicht ausgeführt, Initium in abwechselnd roten und schwarzen Buchstaben vertikal daneben; 226v -246r Raum für 1-3zeilige Initialen (186 rb 10zeilig, 229ra 7zeilig) ausgespart, nicht ausgeführt. Korrekturen und Nachträge: In Teil 1 zahlreiche Korrekturen der Schreiber, z. B. $1^{\mathrm{r}}$, 45 ${ }^{\mathrm{r}}$, 97v, 142 ${ }^{\mathrm{r}}$; in Teil 2 deutlich weniger, z. B. $145^{\mathrm{ra}}, 203^{\mathrm{va}} .54^{\mathrm{v}}-55^{\mathrm{r}}$ blassrote Unterstreichungen; Handweiser. 12v, $24^{\mathrm{v}}, 26^{\mathrm{v}}$ einzelne texterschliessende Marginalien von zeitgenössischen Händen, $43^{\mathrm{v}}-46^{\mathrm{v}}$ und $82^{\mathrm{v}}$ 16. Jh. $\mathrm{A}^{\mathrm{r}}$ Inhaltsangaben: Hii sermones continentur in libro isto: Spiritu sancto, Homo quidam faecit caenam magnam ... 17. Jh. Item plurimi sermones dicti in Concilio Constantiensi anno 1416. Item Concordantia Evangelistarum, 18. Jh. $47^{\mathrm{v}}$ und $84^{\mathrm{v}}$ historische Angaben, $84^{\mathrm{r}}$ und $86^{\mathrm{v}}$ Überschriften, $11^{\mathrm{v}}$, $87^{\mathrm{v}}$ texterschliessende Marginalien von derselben Hand des 18. Jhs. $144^{\mathrm{r}}$ zeitgenössischer Nachtrag.

Einband: Einband aus der Werkstatt Uoldaricus (EBDB w000154, nachgewiesen um 1481-1490), vgl. C 46. Mit hellem Leder bezogene Holzdeckel mit Streicheisenlinien und Einzelstempeln (EBDB s011932, s011933 und s011936 sowie ein weiterer: Blattstrauss mit Bund, vgl. Erster datierter Schweizer Druck, Taf. 16, Nr. 14); zwei nach vorn greifende Kantenschliessen mit ziselierten Messingbeschlägen, vgl. Johann LindT, Der Buchbinder Uoldaricus, in: Berner Einbände, Buchbinder und Buchdrucker, Bern 1969, S. 25 o. Nr. (unten rechts); grün-weiss-rot geflochtene Kapitale. Vorsatzblatt (A) Papier, Wasserzeichen: Krone, PiCCARD, Wasserzeichenkartei Nr. 51987 (1483); Spiegelblätter Papier und Pergamentstreifen: Fragment eines Kommentars zu Priscians Institutiones grammaticae, Buch 18, 13./14. Jh.; in den Fälzen mehr Fragmente derselben (?) Handschrift mit weiteren Texten (Eadmer Cantuariensis, De beatitudine coelestis patriae; Thomas Cisterciensis, Commentaria in Cantica canticorum) sowie einer anderen Handschrift des 12. Jhs. Im vorderen Spiegel Exlibris des Chorherrenstifts Beromünster (WegmanN, Exlibris, Nr. 619). Auf dem Rücken Titelschild: Sermones Sacri No 16 entsprechend dem Catalogus von 1826.

Herkunft: Die Predigten zu Patronatsfesten in Eich und Römerswil lassen auf eine Entstehung mindestens von Teil 1 im Umfeld von Beromünster schliessen. Alle Wasserzeichen datieren in die 1450er Jahre.

Besitzer: Im vorderen Spiegel Exlibris des Chorherrenstifts Beromünster. Im Catalogus von 1763 als Classis Nona Nr. 21 verzeichnet, im Nachtrag dazu auf $51^{\mathrm{r}}-52^{\mathrm{r}}$ ohne Nummer, im Catalogus von 1826 als Nr. 16. A ${ }^{\mathrm{r}}$ neuere Signatur C 52, mit dünnem schwarzem Filzstift, spätes 20. Jh. Signatur ehemals C 32 fol. 
Literatur: Kopp, Stiftsbibliothek, II, S. 13f.; BRUCKNeR, Scriptoria 9, S. 27 (beide mit unzutreffender Datierung); BüCHLER, Beromünster, S. 143f. und 244 (Anm. 130).

$\mathrm{A}^{\mathrm{r}}$ Inhaltsangabe. Nachtrag, 17. Jh. (s. oben).

$\mathrm{A}^{\mathrm{v}}$ leer.

Teil 1:

$1^{\mathrm{r}}-143^{\mathrm{v}}$ Sermones. 56 Predigten und Predigtanfänge zu verschiedenen Anlässen (Sonn- und Feiertage des Kirchenjahres, Heiligenfeste, Gelegenheitspredigten), davon 36 erstmals gehalten am Konstanzer Konzil und drei weitere zu Patronatsfesten mit deutlichem lokalem Bezug nach Beromünster $\left(5^{\mathrm{v}}\right.$ und $142^{\mathrm{r}}$ St. Laurentius in Eich, $11^{\mathrm{r}}$ St. Bartholomäus in Römerswil). Initien im Register. > Sancti spiritus assit nobis gracia<. Spiritus domini replevit ... (Sap 1,7). In huius recolendissime festivitatis capituli officio et eiusdem introitu biis verbis, quod flii lucis et non tenebrarum simus, pignus accepimus ... 11 $1 \mathrm{v}^{\mathrm{v}}>$ Sermo cancellarii Parisiensis factus Constantie de nativitate Marie anno mcccc $x v i^{\circ}<$. Iacob genuit Ioseph ... (Mt 1,16). Originaliter $M^{t} i^{0}$ et recitative in ewangelio presentialiter lecto. Invocandam te iudicamus imprimis, o Maria ... Konzilspredigten, darunter sechs von Jacobus Arrigoni, vier von Mauritius Rvačka und drei von Dietrich von Münster, je zwei von Jean Gerson, Alessio da Seregno, Johannes de Rocha und Johannes Zachariae, je eine von Johannes Mombaer, Johannes Huguonetti, Pierre d'Ailly, Johannes de Serravalle, Matthäus von Königsaal, Antonius Caxal, Gérard du Puy, Petrus de Pulka, Stephanus de Palecz und möglicherweise Theobaldus de Saxonia. Schneyer, 1350-1500, J.G. 27; Con.Con. 242; Finke, Acta 2, Nr. 493; Schneyer, 1350-1500, Con.Con. 57 und 242; Ja.Ar. 4; Con.Con. 73; 38 $>$ Sermo venerabilis patris, domini Iohannis de Castrodurantis in festo sancti Augustinipredicatus<. Reverendissimi in Christo patresceleberrimique domini mei metuendisacrosancte Romane ecclesie cardinales benemeriti ... Nam teste philosopho ethicorum io sermones sunt exquirendi ... 43 ${ }^{\mathrm{r}}$ SCHNEYER, 1350-1500, P.d.A. 23; Con.Con. 64, 88, 72; Ja.Ar. 3; Con.Con. 92, 114, 81, 63, 185 und 84. 80r Fiet unum ovile ... (Io 10,16). Iohannis xviii ${ }^{\circ}$ et in ewangelio instantis dominice. Ingeniti potencia, patris sapiencia et procedentis ab utroque infinita gracia ... 84r SCHNEYER, 1350-1500, Ja.Ar. 8; Con.Con. 97 und 49. 89v Bene omnia fecit ... (Mc 7,37) Mt vito et in ewangelio currentis dominice verba hec habentur. Salutiferum dire pressure victorem ... ähnl. SCHNEYER, 1350-1500, Con.Con. 123.91v Obsecro vos in caritate ... (Ephes 3,17). Ex epistola istius dominice presens suscipitur exhortacio, quam Paulus apostolus in Romane urbisteterrimo scripsitet adpartes Asiriorum Ephesiis ... 94v SCHNEYER, 1350-1500, Con. Con. 119, 133, 176 und 125.107v > Sermo de anno iubileo <. Sanctificabis annum ... (Lv 25,10). Domini mei reverendi, ex dictis sanctorum colligo evidenter quod gracia est auxilium divinum ... Johann Baptist SCHNEYER, Konstanzer Konzilspredigten: Texte, in: Zeitschrift für die Geschichte des Oberrheins 120 (1972), S. 125-214, hier 133-140.

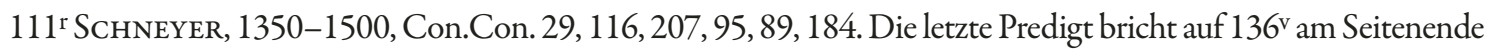
ab, anschliessend drei Seiten ausgerissen, Textverlust. Darin eingeschaltet ein Einzelblatt mit dem grössten Teil der Predigt, die auf $137^{\mathrm{r}}$ endet: $133^{\mathrm{r}}>$ De omnibus sanctis anno lv $v^{\text {to }}<$. Beati qui persecucionem patiuntur ... (Mt 5,10). Originaliter $M^{t} v^{t o}$, et recitantur usualiter in instantis celeberrime solempnitatis ewangelio. Tristicia vestra vertetur in gaudium ... (Io 16,20). Hiis verbis secundum communes doctores invitamur ad perseveranciam ... 137 ${ }^{\mathrm{r}}$ Beati mundo corde ... - ... et beatitudinem nobis paratam festinanter bonis et iustis operibus attingere studeamusprestante Ihesu Christo domino nostro qui cum patre etc. Es folgt eine Reihe von deutlich kürzeren Predigten bzw. Predigtanfängen. $139^{\mathrm{r}}$ leer. Zum Schluss: $143^{v}$ Hoc facite in meam commemoracionem (Lc 22,19). Originaliter leguntur verba ista Luce 22 $2^{\circ}$ et in currenti octava persepe et sedulo recitantur. Verbis istis exhortatur nos dominus ad crebram sui memoriam habendam ... Preparacio autem ad hoc est penitenciam pro peccatis agere. 
$144^{\mathrm{r}}$ Miraculum. Nachtrag. > Miraculum magnum de festo annunciacionis beate Marie virginis bene memoria dignum<. Vivente papa Honorio eius cognatus nomine Manfridus cardinalis, filius sororis sue, tituli sanctorum Johannis et Pauli martirum adeo lubricus extitit ... - ... Et sic mortuus est cardinalis in pace. Vgl. Köln, Historisches Archiv der Stadt Köln, W 235, $1^{\text {r-v }}$ und Bibliotheca Apostolica Vaticana, Vat. lat. 10499, $41^{\mathrm{r}}$.

Teil 2:

145 ${ }^{\mathrm{ra}}-246^{\mathrm{vb}}$ ZACHARIAS CHRYSOPOLITANUS, In unum ex quattuor. > Liber generacionis Ihesu Christi filii David filii Abraham <. Mathei liber dictus est liber generacionis secundum consuetudinem Hebreorum ... $186^{\mathrm{ra}}>$ Exposicionis in Unum ex quatuor liber primus explicit. Incipit secundus feliciter $<.186^{\mathrm{rb}}$ Et factum est ... - ... et post iudicii remuneracionem duplicem stolam habebunt. Denarium igitur accipientes non ex //. Beginnt mit Kap. 5, bricht ab in Kap. 109. PL 186, Sp. 63B-347C. RB 8400; Trudo J. Gerits, Notes sur la tradition manuscrite et imprimée du traité In unum ex quattuor de Zacharie de Besançon, in: Analecta Praemonstratensia 42 (1966), S. 276-303 (Hs. nicht erwähnt).

\section{53 EXPOSITIO HYMNORUM; HENRICUS DE FRIMARIA; SERMONES}

Papier, 188 Blätter, $29 \times 21,5-22 \mathrm{~cm}$

Buochs, 1388-1389

Wasserzeichen, Lagen, Foliierung: Wasserzeichen: Bl. 3-78 Hut, PICCARD, Wasserzeichenkartei Nr. 31879 (1387) und vier weitere desselben Typs; Bl. 79-106 Horn, ähnlich PICCARD, Wasserzeichenkartei Nr. 120057 und ein weiteres desselben Typs; Bl. 2 und 107-188 zwei weitere Hörner desselben Typs, Bl. 1 grösser. Lagen: $(\mathrm{II}-2)^{2}+4 \mathrm{VI}^{50}+9 \mathrm{VII}^{176}+\mathrm{VI}^{188}$, nach Bl. 2 zwei Blätter herausgerissen, Textverlust. Lagenzählung zu Beginn der Lagen: $i^{u s}\left(15^{\mathrm{r}}\right)-x i i i\left(177^{\mathrm{r}}\right) .120^{\mathrm{v}}$ Reklamant. Alte Foliierung: $1\left(3^{\mathrm{r}}\right)-10\left(12^{\mathrm{r}}\right), 12\left(13^{\mathrm{r}}\right)-175$ $\left(176^{\mathrm{r}}\right)$, recto und verso, entsprechend den Verzeichnissen, $\mathrm{ab} 4^{\mathrm{v}}$ in Rot; neuere Foliierung: 1-188.

Einrichtung und Ausstattung: Vertikale Begrenzung der Spalten mit Tinte, ebenso obere Begrenzung des Schriftraums (ausser Bl. 3-14), erste Zeile meist darüber geschrieben. Schriftraum 19-22,5 × 13-16,5, zweispaltig (7-9 bzw. 5,5-6,5), 28-50 Zeilen. Ältere gotische Buchkursive von der Hand des Johannes Eggli. Rubriziert, Überschriften, Explicits und Paragraphenzeichen meist in Rot. $3^{\mathrm{r}}$ und $\mathrm{ab} 15^{\mathrm{ra}} 1-3 z e i l i g e$ rote Lombarden mit Konturbegleitstrichen. Marginalien zur Texterschliessung von der Hand des Schreibers, teils in Rot.

Korrekturen und Nachträge: Wenige Korrekturen des Schreibers, z. B. $5^{\mathrm{va}}$, 64 $4^{\mathrm{vb}}, 125^{\mathrm{rb}}, 185^{\mathrm{ra}}$. Von seiner Hand ausserdem eine Reihe von teils umfangreichen Nachträgen auf den Seitenrändern ( $47^{\mathrm{v}}-49^{\mathrm{r}}$ eine ganze Predigt, 67v und 68v-69r Ergänzungen, jeweils mit Quellenangabe: hec Heymo), sowie in den Registern, zudem wohl auch die zahlreichen Handweiser und Notazeichen. $131^{\mathrm{v}}$ Rasuren. 56 $6^{\mathrm{vb}}-57^{\mathrm{ra}}$ eine Pfingstpredigt durchgestrichen. In den Spiegeln zahlreiche Einträge des Schreibers. Vorderdeckel: Nota. [Nox] principaliter dividitur in 4 partes. Prima dicitur crepusculum ... Sic in peccato 4 gradus invenimus methaforice... Anschliessend 12 Verse zu Verben, die den menschlichen Körper betreffen, mit deutschen Interlinearglossen: Ossito (gemon), sternuto (nisson), singulcio (iessen), nauseo (vnwillen), screto (snuten) ... - ... Scarrificor vel inungo, pastillo flebetomoque (lassen). WALther, Carmina 13526. Nux, oleum, nudumque caput, pomum quoque crudum, 
Vinum non paucum faciunt hominem fore raucum. Dann: Ad fontem cicius festinat currere cerwus, Ad largum merito tendit egenus homo. Dann: Ach, crucior corde ... (2 Verse), Walther, Carmina 284. Dann: Drensat olor, anser clingit, crocitat quoque corwus ... (11 Verse), WALTER, Carmina 4744. Eberhard von Béthune, Graecismus 19, 32-41. Rückdeckel: Uxori parcens iunctus alii mulieri, Ille suam formam turpi vult laude tueri. Er hat sin wib nüt wol bewart, Der si mit einer andern spart. Dann Glossar zu Kräuternamen: Eufrasia, ögentrost. Liquaricia, süsshölcz ... 10 Einträge. Dann: Dyna, Caim, Corwus, Esau, Iepte, Semeyque, Egrediendo foras fecisse feruntur inique. Dann: Non sic ambirent prelati ... (2 Verse), Walther, Carmina 12169. Dann drei Merkverse zur Grammatik: >Composita a cubo<. Dormit a-, d-languet, obit ob-, quo numen adorat, Con-violat ...

Einband: Mit himbeerrotem Leder überzogene Holzdeckel mit abgeschrägten Kanten, 14./15. Jh., ehemals zwei nach hinten greifende Langriemenschliessen, vorne Spuren von quadratischen Riemenbefestigungen, Eisenstifte im Rückdeckel erhalten. Auf den beiden ersten und letzten Blättern Rostflecken. Spiegelblätter Pergament, innerer Rand um die erste bzw. letzte Lage geschlagen. In den Fälzen Pergamentstreifen. Buchblock zu den Bünden hin abgefast. Im vorderen Spiegel Exlibris des Chorherrenstifts Beromünster (Wegmann, Exlibris, Nr. 619). Rückenschild: Summa 10. Praeceptorum. No 18 , entsprechend dem Catalogus von 1826.

Herkunft: Geschrieben zwischen 20. Februar 1388 und 8. oder 9. April 1389 von Johannes Eggli, Pfarrer in Buochs, siehe Schreibervermerke $1^{\mathrm{r}}, 14^{\mathrm{v}}, 43^{\mathrm{r}}$ und $176^{\mathrm{r}}$. Bei dem letzten Datum stimmen der angegebene Wochentag und das Heiligenfest nicht überein. Von seiner Hand wohl auch 141 ${ }^{\mathrm{v}}-149^{\mathrm{r}}$ der Handschrift C 8. Besitzer: $1^{\mathrm{r}}$ Iste liber est ecclesie Beronensis, 15./16. Jh. Im Catalogus von 1763 als Classis Nona Nr. 24 verzeichnet, im Nachtrag dazu auf $51^{\mathrm{r}}$ ohne Nummer, in den Antiquitates Beronenses, S. 690, als Nr. 19, im Catalogus von 1826 als Nr. 18. Auf dem Spiegelblatt neuere Signatur C 53, Filzstift und Kugelschreiber, spätes 20. Jh. Signatur ehemals C 33 fol.

Literatur: Kopp, Stiftsbibliothek, II, S. 11f.; BRUCKNER, Scriptoria 9, S. 20f. und 33 sowie Taf. 39; BÜCHLER, Beromünster, S. 174; CMD-CH 2, Nr. 99; KRISTELLER, Iter Italicum 5, S. 99.

$1^{\mathrm{ra}-\mathrm{rb}}$ HERMANNUS DE SCHILDIS, Introductorium iuris. Nur der Modus legendi. Si quis desiderat studio iuris operam dare, omnia observare debet, que Hostiensis ponit in principio summe sue ... - ... Ista autem hic posita pro noviter incipientibus studere sufficiant. Adolar ZuMkeLLER, Schrifttum und Lehre des Hermann von Schildesche, Würzburg 1959, S. 89. Anschliessend Schreibernotiz: Anno $M^{\circ}$ ccc ${ }^{\circ}$ lxxxviii ${ }^{\circ}$ in octava Johannis Baptiste.

$1^{\text {va }} 2^{\text {ra }}$ Tabula. Inhaltsverzeichnis zur Summa decem praeceptorum mit Blattangaben. > Tabulacio Summe 10 preceptorum $<.14$, Divina precepta sunt hylariter audienda propter $3^{a} \ldots-\ldots 41$, Tria sunt que puritatem mentis conservant.

$2^{\text {rb leer. }}$

$2^{\text {va }}$ Hymnus cum glossis. Hymnus mit Interlinearglossen und Scholien, unvollständig. > Hymnus $<$. Inventor rutili dux bone luminis ... - ... Lignis ac facibus passimus aridis, quin //. AH 50 Nr. 31 (1-3, 7, 9f., 4). Scholien: Nota, quod in igne inveniuntur plures proprietates, que deo methaforice possunt comparari ... Nota quod cum deus sit digna res, nobilis et perfectissima, huius probacio ostenditur racione ...

$3^{\mathrm{ra}}-14^{\mathrm{vb}}$ Expositio hymnorum. Fortlaufender Kommentar zu den Hymnen AH 51 Nr. 47; AH 50 Nr. 8 (2-7), 226 (8); AH 2 Nr. 20; AH 50 Nr. 53 (1-7); AH 12 Nr. 184 (6); AH 50 Nr. 26; AH 51 Nr. 123; AH 27 Nr. 1081 (4-6); AH 52 Nr. 2. Super salutem et omnem pulchritudinem dilexi sapienciam et cetera. Hec proposicio scribitur in 
libro sapiencie, et licet in se sit lucida, tamen in ea due commendaciones ... $3^{\mathrm{va}}>$ Exposicio ymni et primo exponitur primus versus etc. Conditor<. Iste liber prima sui divisione dividitur in tot partes, quod sunt ymni ... - ... si tunc consenciebant, tunc tenebatur pro lege. Vgl. Mainz, Stadtbibliothek, Hs I 80, $1^{\mathrm{ra}}-23^{\mathrm{rb}}$ und München, Bayerische Staatsbibliothek, Clm 11475, $3^{\mathrm{r}}-56^{\mathrm{r}}$. 14 $4^{\mathrm{va}}$ Datierung: Anno $m^{\circ} c c c^{\circ}$ lxxxviii ${ }^{\circ}$ in octava Johannis Baptiste. $14^{\mathrm{va}}-43^{\mathrm{ra}}$ HENRICUS DE FRIMARIA, De decem praeceptis. $>$ Incipit liber decem preceptorum<. $15^{\mathrm{ra}}$ Audi Israhel precepta domini dei ... (Dt 4,1). In verbis istis spiritus sanctus circa divina precepta tria facit ... - ... Quod vinum meritis gloriose virginis prestare dignetur eius filius benedictus, qui cum patre regnat in secula seculorum. Amen. Henricus de Frimaria, De decem preceptis, hrsg. v. Bertrand-G. Guyot und Loris

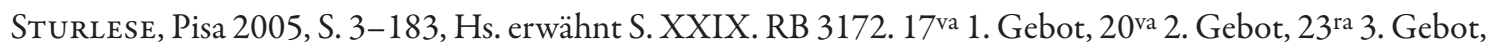
26ra 4. Gebot, 29 ${ }^{\text {ra }}$ 5. Gebot, 32 ra 6. Gebot, 34 $4^{\text {ra }}$ 7. Gebot, 38 ra 8 . Gebot, 40 ra 9. Gebot, 41 rb 10. Gebot. Anschliessend Schreibervermerk: Explicit tractatus de decem preceptis finitus per manus Johannis dicti Eggli, incuratus in Buchs anno domini $M^{\circ} c c c^{\circ}$ lxxxviii $i^{\circ}$ proxima feria 5. ante festum Mathie apostoli.

$43^{\mathrm{ra}}-43^{\mathrm{va}}$ Notanda. Nota: Opera misericordie sunt xiiii, videlicet vii corporalia et vii spiritualia ... $43^{\mathrm{rb}}$ Sanctus Arsenius flectit genua coram scala Christi ... - ... renunciacio perfecta huius mundi. Mit Zeichnung einer Leiter und Handweiser: Scala virtutum.

$43^{\mathrm{vb}}-71^{\mathrm{va}}$ Sermones dominicales Trianguli. 54 Predigten, Advent - 24. Sonntag nach Pfingsten. Initien im Register. $>$ Sermo in adventu domini. Dominica prima $<$. 44ra Pacientes estote ... (Iac 5,8). Karissimi, tempus quod hodie incipit omni sanctitate plenum est ... 47v-49r am Rand nachgetragen: > Sermo Heymonis<. Confitebor ... (Mt 11,25). Beatus Mattheus, qui hoc scribit evangelium, non dicit ad quid pertineat hec responsio. Lucas autem narrat ... - ... et levius iugo legis. Hec Heymo. 52 ${ }^{\text {rb }}$ SCHNEYER, Bd. 8, S. 719, Nr. 31 (mit anderem Schluss). 52 va $>$ De resurrectione $<$. Hec est dies quam fecit dominus ... (Ps 117,24). Fratres karissimi, modo peregimus cum devocione dies tristicie ... 54 va SCHNEYER, Bd. 8, S. 719, Nr. 37 (mit anderem Schluss). 55 ra >Dominica 3 post Pascha<. Vado ad eum qui misit me etc. (Io 16,5). Quasi diceret: Ascensio mea ita manifesta erit, quod nulli licebit me interrogare quo vadis ... 66 $6^{\text {ra }}$ SCHNEYER, Bd. 9, S. 436, Nr. 101 (mit anderem Schluss). 66 $6^{\mathrm{vb}}>$ Dominica 16<. Ibat Ihesus in civitatem Naym ... (Lc 7,11). Per Naym intelligitur mundus, in quem intravit, quando de Maria natus fuit ... 69vb SCHNEYER, Bd. 9, S. 721, Nr. 70. 70 rb >Dominica 23<. Magister scimus quod verax es ... (Mt 22,16). In hoc verbo, quod dixit dominus: Reddite que sunt Cesaris Cesari ... 71 $1^{\mathrm{ra}}$ $>$ Dominica 24<. Est puer unus hic ... (Io 6,9). In verbis istis notare debemus quid puer, quid 5 panes significent, et quid duo pisces ... - ... Duo pisces significant timorem Iehenne et spem celestis premii. Oremus ergo etc.

$71^{\mathrm{va}}-162^{\mathrm{rb}}$ Sermones. 81 Predigten, überwiegend für Heiligen- und Feiertage, darunter mindestens 15 Predigten Bertholds von Regensburg. Keine durchgehende Ordnung. Initien im Register. > Hic incipiunt aliqui sermones de sanctis seu festis<. Sermo de cena domini vel corpore Christi. $71^{\mathrm{vb}}>$ De cena domini $<$. Ad eum veniemus ... (Io 14,23). Hiis verbis consolatur dominus discipulos suos ... SCHNEYER, Bd. 9, S. 326, Nr. 68. 72vb eingeschaltete Genealogie der Heiligen Sippe: >De generacione Anne et Ysmarie<. De generacione Anne et Ysmarie multe opiniones leguntur, unde Ieronimus, qui transtulit hanc generacionem et psalterium in primis de Hebreo in

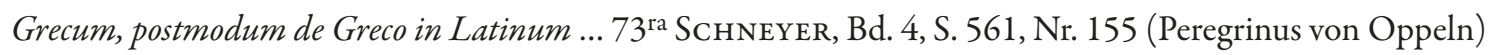
mit anderem Schluss. 74 ${ }^{\mathrm{ra}}>$ De sancta Katherina<. Ingressa regina Saba ... (3 Rg 10,2). Regina Saba mistice intellegitur sancta Katherina, que naturaliter est regina ... 74 $4^{\mathrm{rb}} 6$ Predigten zur Kirchweihe: > Sermo de dedicacione<. Domus mea domus oracionis vocabitur ... (Mt 21,13). Verba ista sunt scripta in Matthaeo. In quibus duo notare possumus, scilicet loci sanctitatem et dei largitatem ... 77 rb SCHNEYER, Bd. 2, S. 721, Nr. 20 (Honorius Augustodunensis). $78^{\mathrm{va}}>$ De nativitate domini sermo <. Hodie Christus natus est nobis, gaudeamus igitur non 
carnaliter, sed spiritualiter ... 79 $\mathrm{rb}$ SCHNEYeR, Bd. 9, S. 47, Nr. 24. 79vb $>$ De sancto Iohanne sermo $<$. Valde honorandus est beatus Iohannes, qui suprapectus domini in cena recubuit ... $81^{\text {ra }}$ SCHNEYER, Bd. 2, S. 151, Nr. 6 (Galfredus Babio), mit anderem Schluss. $81^{\mathrm{vb}}>$ Sermo in annunciacione Marie $<$. Hec est dies ... (Ps 117,24). In ista proposita materia hodie spiritus sanctus per os David ostendit laudem et gloriam virginis Marie ... $85^{\mathrm{vb}}$ $>$ Sermo de nativitate beate Marie virginis $<$. Notandum, quod iste sermo non videtur michi ex toto esse predicandus, quia bic sunt (ut presumitur) inserta aliqua apocrifa etc., scilicet sermo qui sequitur et sic incipit: In diebus illis etc. ... 90 $90^{\mathrm{rb}}>$ Sermo de missa et eius prerogativis<. Prerogativas plurimas habet missa: Primo quia celebratur a ieiunis, $2^{\circ}$ quia tantum in ecclesia ... Exzerpt aus dem Compendium theologicae veritatis des Hugo Ripelin von Strassburg (Buch 6, Kap. 18). B. Alberti Magni opera omnia, hrsg. v. Auguste BorgnET, Bd. 35, Paris 1899, S. 217f. 90 ${ }^{\mathrm{vb}}>$ Quare corpus Christi elevatur<. Corpus Christi multis de causis elevatur a sacerdote in missa: Prima causa est, quia graciam dei patris peccatis nostris offendimus ... Vgl. u. a. Basel, Universitätsbibliothek, B IX 32, 132 rb. 98va SChNeyer, Bd. 2, S. 488, Nr. 69 (Guilelmus de Malliaco) mit anderem Schluss. 99vb SChneyer, Bd. 1, S. 482, Nr. 124. 101 $1^{\mathrm{rb}}>$ Sermo de 7 nunciis $<$. Pater noster celestis ... (Lc 6,36). Nam deus facit 7 magna ad conversionem peccatoris, et ista 7 signata sunt per 7 nuncios, quos misit rex Asswerus pro Vasti ... $102^{\mathrm{ra}}$ $>$ De penitencia sermo bonus $<$. Reddet deus mercedem ... Am Ende der Seite Text unterbrochen, unter der Spalte: hic defficit, $103^{\mathrm{ra}}$ leer, 103 ${ }^{\mathrm{rb}}$ Fortsetzung. 106 ${ }^{\mathrm{vb}}$ SCHNEYER, Bd. 9, S. 883, Nr. 142. 109 ${ }^{\mathrm{vb}}>$ De religiosis sermo bonus et communis<. Que habitas in ortis ... (Ct 8,13). Anima dei potest facere prostibulum dyaboli ex se per luxuriam ... $111^{\mathrm{rb}}>$ Sermo de apostolis $<$. Vos estis cives ... (Eph 2,19). Aliter vivunt cives demonum, aliter cives

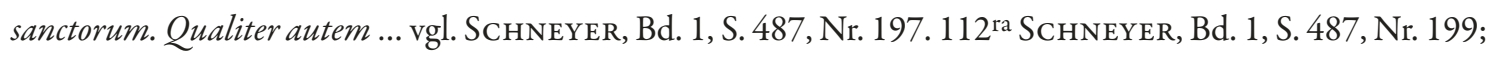
S. 488, Nr. 208; S. 489, Nr. 224 und 230 (Berthold von Regensburg), die letzte mit anderem Schluss. 119 va $>$ De 5 lapidibus et de martyribus<. Lapidaverunt Stephanum ... (Act 7,58). Aliud thema: Nolite arbitrari ... (Mt 10,34). Preliatur dominus contra peccatores, ut convertantur, mittens bellatores suos, id est predicatores ... $121^{\text {ra }}$ SChneyer, Bd. 1, S. 489, Nr. 218 (Berthold von Regensburg). 123 $3^{\text {rb }}>$ De uno martyre sermo $<$. Gloria et honore etc. (Ps 8,6). Verba proposita sunt verba psalmiste, et possumus ea dicere domino de martyre, cuius festum celebramus ... 124va SCHNeYer, Bd. 1, S. 488, Nr. 211; S. 491, Nr. 252 mit anderem Schluss (Berthold von Regensburg). 128va Iustus cor suum dabit ... (Sir 39,6). Inter alia que describit sapiens facere dicitur etiam iustus ... 130 rb SCHNEYer, Bd. 1, S. 491, Nr. 253 mit anderem Schluss (Berthold von Regensburg). 132 rb SCHNEYeR, Bd. 4, S. 799 , Nr. 234 (Petrus de S. Benedicto). 133 $3^{\text {va }}>$ De sancta Margaretha<. Venit sponsus ... (Mt 25,10). Una ex hiis virginibus, que parate erant, fuit beatissima Margaretha ... 135 ${ }^{\text {rb }}$ SCHNEYER, Bd. 2, S. 781, Nr. 350 (Hugo de S. Caro). 137 rb SCHNEYeR, Bd. 1, S. 495, Nr. 277 mit anderem Schluss (Berthold von Regensburg). $140^{\mathrm{rb}}>$ Sermo communis et bonus $<$. Nescit homo utrum amore ... (Ecl 9,1). Quia omnia in futurum reservantur incerta ... 142 $2^{\mathrm{rb}}$ Zusammenstellung von Auctoritates zur Gottesfurcht: Timete dominum ... (Ios 24,14). Fili,

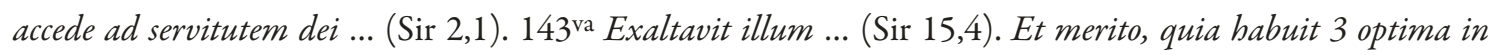

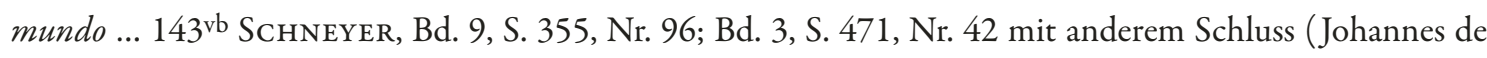
Forda). $145^{\mathrm{rb}}>$ De sancto Francisco $<$. Factum est autem ut morietur mendicus ... (Lc 16,22). Sanctus Franciscus mendicus fuit, quia omnia que habuit propter Christum reliquit ... 148 vb SCHNEYER, Bd. 7, S. 487, Nr. 69; Schneyer, Bd. 1, S. 495, Nr. 279 mit anderem Schluss; S. 480, Nr. 99, Nr. 101 mit anderem Schluss, Nr. 103 mit anderem Schluss; S. 481, Nr. 106 mit anderem Schluss, Nr. 111 (Berthold von Regensburg). 154 va $>$ De sancta Agatha<. Mulierem fortem ... (Prv 31,10). Responderi potest, quod Quincianus scilicet beatam Agatham ... $155^{\mathrm{vb}}$ vgl. SCHNeYer, Bd. 1, S. 637, Nr. 674. $156^{\mathrm{va}}>$ Sermo de annunciacione<. Ave gratia plena etc. (Lc 1,28). In verbis propositis annunciat celestis nuncius plenitudinem gracie virgini Marie ... 159 ra SCHNEYER, Bd. 1, 
S. 484, Nr. 150 (Berthold von Regensburg). 159vb SCHneYer, Bd. 1, S. 767, Nr. 297 (Conradus Holtnicker). $160^{\mathrm{va}}>$ Sermo de Iohanne et Paulo<. Donum et pax ... (Sap 3,9). Deus dedit hominibus tria dona, quibus possunt eterna gaudia promereri ... 162 $2^{\mathrm{ra}}>$ De assumpcione $<$. Maria optimam partem elegit (Lc 10,42). In hiis verbis altissime commendatur beata virgo, quod patet dupliciter ... - ... Prima ergo virtus de qua commendatur beata virgo est humilitas, licet enim tante dignitatis esset etc.

$162^{\mathrm{va}-\mathrm{vb}}$ Notanda de Sanctis. $>$ Nota de Anna et beata virgine<. Anne 5 fuerunt: Prima mater Samuelis ... $>$ Versus <. Anna solet dici tres concepisse Marias ... WALther, Carmina 1060. > Nota de passione apostolorum <. Apostoli totum mundum circuierunt ... - ... Et anno 43 Marcus ewangelium edidit, et fames valida fuit.

$163^{\mathrm{ra}}-176^{\mathrm{rb}}$ Sermones vel tractatuli. 13 Predigten bzw. kurze Abhandlungen zu Themen wie Jungfräulichkeit, Beichte, Vaterunser usw. Initien im Register. > Sermo de 12 signis amoris<. Signa servos dei in frontibus eorum (Apc 7,3). Sunt enim 12 signa amoris Christi, que quicumque habuerit, omnipotens fit cum omnipotente ... $174 \mathrm{vb}>$ Octo sunt raciones, quare homo debet averti a peccatis <. Octo sunt, que compellunt hominem ad conversionem: Primum est mortis incertitudo ... - .. 176 $16^{\mathrm{ra}}$ nec alia adversitas potest nocere, si homo a peccato caverit ipso prestante ... Amen. Anschliessend Schreibervermerk: Finitus est liber iste per me Iohannem Eggli, incuratum in Buchs, in die sancte Marie que dicitur Maria Egypciaca, hora quasi $6^{a}$. Et erat feria 5 diesque lucida ac clara sub anno domini $M^{\circ} c_{c}{ }^{\circ}$ lxxxix ${ }^{\circ}$.

$176^{\mathrm{rb}}-176^{\mathrm{va}}$ Versus, Notandum. 7 ein- bis dreizeilige Merkverse. Anglorum regi scribit scola tota Salerni (1 Vers), WALther, Carmina 1039, dann 6423 (2 Verse). Nota per sompnum intelligitur peccatum ... > De templis iterato consecrandis<. Ignis, adulterium, destructio, mensa remota ... WALTHER, Carmina 8674, dann 16031. Quinque dies venie lucraris, quando Marie ... (2 Verse). Missa, preces, dona, ieiunia, quatuor ista ... WALTHER, Carmina 11107. Rex ad iudicium veniens hec dicet in ira ... (3 Verse). Si missam dicis post amplexus meretricis ... (2 Verse). $176^{\text {va }}$ Virgo dei vixit 60 tribus annis ... (4 Verse), Walther, Carmina 20497; PL 81, 831. Ora virgo pia pro nobis virgo Maria. Sexaginta quinque Christus paciebatur in se ... (2 Verse).

$177^{\mathrm{vb}}$ leer.

$178^{\mathrm{ra}}-181^{\mathrm{ra}}$ Tabulae. $>$ Nota contenta in hoc libro<. Primo exposiciones ymnorum. Secundo de 10 preceptis. Tercio sermones Trianguli, et hoc de tempore per totum annum. Quarto collaciones sanctorum cum insercione aliorum sermonum diversorum. Anschliessend Inhaltsverzeichnis von $71^{\mathrm{vb}}-176^{\mathrm{rb}}$ : Sequitur tabulacio ex collacione sanctorum et primo sermonum. Primo sermo de cena domini, 70 ... 177vb Inhaltsverzeichnis von $44^{\mathrm{ra}}-71^{\mathrm{va}}$, alphabetisch geordnet von A bis F: > Tabulacio Trianguli<. Paciencia tria bona operatur in homine, $43 \ldots 179^{\mathrm{rb}}$ Inhaltsverzeichnis von $71^{\mathrm{vb}}-176^{\mathrm{rb}}$, alphabetisch geordnet von A bis D: > Tabulacio ex colleccione sanctorum ac eorum festorum <. Alique bestie in nocte turbantur, 72 .. - ... De conversione a peccatis, 174. Anschliessend Nachträge zur Tabula, dann: Verte 3 folia et invenies tabulacionem plene.

$181^{\text {rb }}$ Versus. Nachtrag. $>$ Septem mortalia peccata<. Ut tibi sit vita semper s.a.l.i.g.i.a. vita. WALTHER, Carmina 19899. > Decem precepta<. Solum crede deum nec vane iura per ipsum ... (4 Verse), WALTHER, Carmina 18425. $>$ Quinque sensus <. Hos sensus rege, quos signat dictio v.a.g.o.t. > Septem sacramenta <. Sacramenta quidem sunt septem, scilicet ista, Unctio, crisma, thorus, contricio, fons, cibus, ordo. >Opera misericordie corporalia<. Vestio, cibo, poto, tectum do, visito, solvo. WALTHER, Carmina 20271. >Opera misericordie spiritualia<. Oro, remitto, docens, ferio, fero, consulo, solos. >Circumstancie<. Aggravat ordo, locus, persona, sciencia, tempus, Etas, condicio, numerus, mora, copia, causa. WALTHER, Carmina 680. > Septem dona spritus sancti<. Insere ti. cum. pi. sci. for. con., Spiritus in. sa. septem dona spiritus sancti.

181 $1^{\mathrm{va}-\mathrm{vb}}$ HONORIUS AUGUSTODUNENSIS, Hexaemeron. Nachtrag. Nur das vierte Kapitel, unvollständig. >Nota dicta Honorii de sex diebus, de quibus Genesis primo dicitur<. Quid Augustinus senciat de 
hiis sex diebus, quam brevissime studiosis dicemus ... - ... creatorem laudantes diligebant. Et divisit //. PL 172, Sp. 260f. RB 3566.

$182^{\text {ra }}-183^{\text {va }}$ Versus, Notanda. Nachtrag. 7 liquores. In Iano claris calidisque cibispociaris ... (49 Verse), Walt Her, Carmina 8953; Thorndike/Kibre, Incipits, Sp. 683; Gundolf KeIL, Artikel 'In Jano claris', in: Verfasserlexikon², Bd. 4 (1983), Sp. 373-375. > Gramatica<. Quidquid agunt artes ego semperpredico partes ... (7 Verse), WALTHER, Carmina 15973. Galangum calidum et siccum dicitur esse ... - ... 182 vb Clarificat lumen extollunt vocis acumen (69 Verse), Walther, Carmina 6995; Thorndike/Kibre, Incipits, Sp. 575. Sudor, apostema, ventris solucio, sputum ... (4 Verse). 183 ra Molesta. Sume cibum modice, modico natura fovetur ... (6 Verse), Walther, Carmina 18740. 183 $3^{\mathrm{rb}}$ Oracio dominicalis. Dominica oracio continet 7 peticiones ... $183^{\mathrm{r}}$ Virginitas flos est et virginis aurea dos est ... (7 Verse), WALTHER, Carmina 20475. 183 $3^{\text {ra }}$ Oracio dominica. O pater alme tuum nomen sit sanctificatum ... (7 Verse), Walther, Carmina 12835. Ave Maria. Hoc Gabrielis Ave genus Eve sustulit a ve ... (8 Verse). 183 ${ }^{\mathrm{rb}}$ Symbolum apostolorum, et primo articuli fidei de humanitate. Conceptus, natus, passus descendit ad yma ... (9 Verse). $183^{\text {ra }}-183^{\text {va }}$ Decem precepta. Plures sperne deos, unum tantummodo credes ... (6 Verse). Ista merentur veniam. Martyrium, baptizmus, amor, conversio fratris ... (4 Verse). 7 vicia. Luxus, ava. super... WALTHER, Carmina 10531. 7 virtutes. Sis humilis, mitis, carus, fortis quoque largus, Sobrius et castus: sic fugit omne scelus.

$184^{\mathrm{ra}-\mathrm{rb}}$ Tabula. Nachtrag. Fortsetzung von $181^{\mathrm{ra}}$ : Amor privatus et libertas deformant cor, 173 ... - ... De lylio exemplum. Sic et vita tua, 173.

$184^{\mathrm{va}}$ Versus. Nachtrag. > Exposicio alphabeti Hebreorum <. Aleph doctrinam notat et doctrina vocatur ... (27 Verse), Walther, Carmina 751. RB 6825. Vgl. Greti Dinkova-Bruun, Liber Ecclesiastes. An Anonymous Poem Incorporated in Peter Riga's Aurora (Ott. Lat. 399), in: Miscellanea Bibliothecae Apostolicae Vaticanae 8 (2001), S. 161f.

$184^{\mathrm{vb}}-186^{\mathrm{ra}}$ Notanda. Nachtrag. Notizen zu Divination, Geographie und Indulgenzen. Nota in nativitate domini sol videtur letare sereni diei ... Nobilis tibi cancer, aries, caper quoque libra ... (3 Verse). Nota de fetu ... 185 ${ }^{\mathrm{ra}}>$ Nota de die dominica<. Nota die dominica qui nascitur ... 185 $5^{\mathrm{rb}}>$ Nota provincias partis terre Assyrie inter septentrionem et orientem<. Nota provincia Litua, provincia Armenie ... 185 $5^{\mathrm{vb}}>$ Nota indulgencie inhibitarum< (sic). Primo quingentos annos et 58 annos ... > Ymago Christi<. Nota deus apparuit sancto Gregorio sub forma martirii ... 186 $6^{\mathrm{ra}}$ $>$ Nota de primis denariis <. Primi denarii fabricati sunt ad peticionem et ordinacionem regis Nini ...

$186^{\text {rb }}$ leer.

$186^{\mathrm{va}}-188^{\mathrm{vb}}$ Sententiae. Nachtrag. Vir qui festinat ditari et aliis invidet ignorat, quod egestas superveniet ei ...

- ... 188 $8^{\mathrm{ra}}$ Non res amate, sed anime perverse amantes culpande sunt. Anschliessend $188^{\mathrm{vb}} 22$ Verse zu Heilkräutern: Anglorum regi scribit scola tota Salerni ... - ... Esa solent gratum conferre papavera sompnum. Walther, Carmina 1039, dann 6423 (2 Verse).

\section{54 AMALRICUS AUGERIUS}

Papier, 150 Blätter, 29,5-30 × 20,5-21 cm

Birndorf(?), 1402

Wasserzeichen, Lagen, Foliierung: Bl. 1 und 107-139 Glocke, ähnlich PICCARD, Wasserzeichenkartei Nr. 40753 in vier verschiedenen Formen; Bl. 3-46 und 60/69 Nr. 40812 (1400) und 40815 (1400) sowie eine 
Variante; Bl. 49-56, 84/93 und 97-104 Nr. 40543 (1401) und 40549 (1400); Bl. 61-68, 73-80, 83-94 und 100/101 Nr. 40529 (1400) und 40530 (1400); Bl. 13/20 Buchstabe, unziales d, ähnlich PICCARD, Wasserzeichenkartei Nr. 27545; Bl. 59/70 Horn, ähnlich PiCCARD, Wasserzeichenkartei Nr. 119428; Bl. 47/58, 48/57, 72/81, 95/106, 96/105, 143/148 und 145/146 Ochsenkopf, PICCARD, Wasserzeichenkartei Nr. 78540 (1402), Bl. $71 / 82$ und 142 Nr. 78356 (1400), Bl. 140/150 Nr. 78534 (1401), Bl. 141/149 und 144/147 Nr. 78546 (1403). Lagen: $(V I-2)^{10}+10 \mathrm{VI}^{130}+(\mathrm{VI}-3)^{139}+(\mathrm{VI}-1)^{150}$, nach Bl. 10 zwei Blätter, nach Bl. 148 ein Blatt herausgeschnitten, nach Bl. 139 drei Blätter herausgerissen, Textverlust. Lagenzählung zu Beginn der Lagen: primus $\left(2^{\mathrm{r}}\right)-x i i^{u s}\left(131^{\mathrm{r}}\right) \cdot 22^{\mathrm{v}}$ und $23^{\mathrm{r}}$ Verweiszeichen als Reklamanten. 58 $8^{\mathrm{v}}-130^{\mathrm{v}}$ Reklamanten. Alte Foliierung $i\left(11^{\mathrm{r}}\right)-c x x v i i\left(137^{\mathrm{r}}\right), i\left(141^{\mathrm{r}}\right)$. Neuere Foliierung: 1-150.

Einrichtung und Ausstattung: Vertikale Begrenzung des Schriftraums mit Stift, Schriftraum 19-21,5 $\times$ 12-13, 30-38 Zeilen; $1^{\mathrm{v}}$ und $141^{\mathrm{v}}-145^{\mathrm{v}}$ dreispaltig (3-4,5), $2^{\mathrm{r}}-6^{\mathrm{r}}$ und $141^{\mathrm{r}}$ zweispaltig (4-6). Ältere gotische Buchkursive mit wenig Schleifen von der Hand Ulrich Wachters. Rubriziert, Überschriften in den Tabulae teils rot oder rot unterstrichen, $2^{\mathrm{r}}$ schwarz-rot alternierend (am unteren Seitenrand Hinweis für die Rubrizierung), Bl. 141-145 rot mit Platzhaltern, teilweise nicht ausgeführt; Kaisernamen mit roten Paragraphenzeichen und Unterstreichungen. 1-4zeilige rote Lombarden, teilweise mit Ausläufern, Punktverdickungen und Zierstrichen, im Hauptteil für jeden neuen Papst; $2^{\mathrm{r}}$ schwarz-rote Lombarde, $5^{\mathrm{v}}$ schwarz-rot mit Schaftaussparungen und Konturbegleitstrichen.

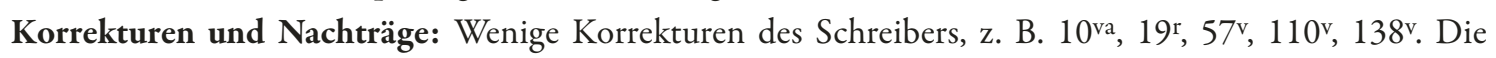
texterschliessenden Marginalien von seiner Hand sind teils mit anderer Tinte, also wohl nachträglich geschrieben. $32^{\mathrm{v}}$ eine falsche Lombarde (A) in Schwarz (zu D) korrigiert. 101 ${ }^{\mathrm{r}}$ Marginalie Item anno secundo sui pontificatus confirmavit ordinem Carmelitarum ipse Honorius tercius rot hervorgehoben. $3^{\mathrm{v}} \mathrm{zu}$ Johannes VIII. feminam fuisse false fingunt sectarum chronographi, in humanistischer Kursive des 16. Jhs. 135 ${ }^{\mathrm{r}}$ Aufzählung der römisch-deutschen Könige von Heinrich VII. bis Friedrich III., 15. Jh. Nachträge: $147^{\mathrm{v}}-148^{\mathrm{r}}$ (15. Jh.), 149v (1470) und 150v (1451).

Einband: Mit hellem Leder bezogene Holzdeckel mit abgeschrägten Kanten, 15. Jh. Ehemals zwei nach hinten greifende Langriemenschliessen, Riemenbefestigungen im Vorderdeckel Eisennägel mit Unterlegscheiben aus Buntmetall, im Rückdeckel zwei Kupferstifte. Am Vorderdeckel Rest eines an den Bezug genähten Lederstreifens, der ursprünglich den Schnitt schützte. Mit ungefärbtem Garn umstochene Kapitale. Im Vorderdeckel Abklatsch von einem um die erste Lage geführten, nur noch im Bund als Rest erhaltenen Spiegelblatt aus Pergament: kirchenrechtliche Summe, 13./14. Jh. Spiegelblatt hinten Pergament, um die letzte Lage geführt: Makulatur mit liturgischen Versatzstücken und Federproben, 14./15. Jh., das Mittelstück ausgeschnitten. In den Fälzen zwei Fragmente eines monats- bzw. jahresweise angelegten Festtagsverzeichnisses, 14. Jh., und ein weiteres, sehr klein geschriebenes und stark abgeriebenes Fragment des 13./14. Jhs. Auf dem Vorderdeckel Aufschrift Vitae Pontificum, 17./18. Jh. Im vorderen Spiegel Exlibris des Chorherrenstifts Beromünster (Wegmann, Exlibris, Nr. 619). Rückenschild: Actus Romanorum Pontificum. No 19, entsprechend dem Catalogus von 1826.

Herkunft: Geschrieben von Ulrich Wachter von Laufenburg und datiert auf den 2. Januar 1402, siehe Schreibervermerk 150\%. Wachter ist als Leutpriester von Birndorf für 1415 urkundlich erwähnt, siehe Moriz Gmelin, Urkundenbuch der Deutschordens-Commende Beuggen, in: Zeitschrift für die Geschichte des Oberrheins 28 (1876), S. 206, Nr. 379. Er schrieb auch die Handschrift F IV 12 der Universitätsbibliothek Basel. 
Besitzer: Im Catalogus von 1763 als Classis Nona Nr. 25 verzeichnet, im Nachtrag dazu auf $45^{\mathrm{v}}-46^{\mathrm{r}}$ als Nr. II, in den Antiquitates Beronenses, S. 691, als Nr. 20, im Catalogus von 1826 als Nr. 19. Auf dem ersten Blatt neuere Signatur C 54, Tintenschreiber über Filzstift, spätes 20. Jh. Signatur ehemals C 34 fol.

Literatur: Kopp, Stiftsbibliothek, II, S. 12f.; BruCKner, Scriptoria 9, S. 26; Bü CHLER, Beromünster, S. 174; CMD-CH 2, Nr. 100.

$1^{\mathrm{r}}$ Tabula ordinum. $>[\mathrm{S}]$ equitur de supradictis ratio $<$. Anno $x x x i^{\circ}$ nativitatis Christi incepit predicare. Anno cclo cepit ordo monasticus sub beato Anthonio in Thebadia ... Chronologisch geordnete Aufzählung: Cluniazenser, Regularkanoniker, Benediktiner, Kongregation von Arrouaise, Kartäuser, Zisterzienser, Prämonstratenser, Norbertiner, Templer, Trinitarier, Deutschordensritter, Prediger und Minoriten.

$1^{\mathrm{v}}$ Tabula linguarum. $>$ De tribus filiis Noe $l x x^{a}$ et due gentes procreate sunt et totidem lingwe, quarum nomina sunt hec<. Hebrea, Assiria, Caldea ... - ... Alamanica siue Theutonica. Aufzählung von 72 Sprachen.

$2^{\mathrm{r}}-9^{\mathrm{v}}$ Tabulae pontificum Romanorum. > Incipit tabula ad inveniendum de facili per numerum alphabeti ac folia omnia nomina Romanorum pontificum in hoc libro descriptorum, et quot de ipsis sancti martires, intrusi, cardinales et religiosi fuerunt, et sub quibus ipsorum passagia ultra et circa marina incepta et prosecuta extiterunt, et quibus imperatoribus regnantibus, ut infra sequitur. Et primo<. Adrianus papa primus, xlvii. Adrianus papa secundus, liii ... - ... Tempore eciam huius Clementis pape quinti Fulco et magister generalis Hospitalariorum sive Ordinis Sancti Johannis cum magna Christianorum sanguinis effusione cepit insulam Rodarum, quam Turcorum gens tunc in sua potestate habuit. Zuerst alphabetisches Gesamtverzeichnis, anschliessend Papstlisten von 1. Märtyrern (ohne Blattangaben), 2. Bekennern, 3. ehemaligen Kardinälen, 4. Mönchen (überwiegend ohne Blattangaben), 5. Usurpatoren (ohne Blattangaben), 6. Schismatikern (ohne Blattangaben), 7. Veranstaltern von Konzilien (ohne Blattangaben) und 8. von Kreuzzügen (regestenartig, ohne Blattangaben). Die Indices stimmen zu grossen Teilen überein mit der Handschrift Paris, Bibliothèque nationale de France, lat. 5146, $1^{\mathrm{r}}-5^{\mathrm{v}}$ (ohne 2, 6 und 7 , Abweichungen in 5 und 8).

$10^{\mathrm{ra}-\mathrm{vb}}$ Tabula titulorum ecclesiae. In civitate Romana sunt $v^{e}$ ecclesie que dicuntur patriarchie, videlicet ecclesia Sancti Johannis Lateranensis ... - ... Dyaconus cardinalis tituli Sanctorum Sergii et Bachi. Anschliessend zwei Blätter herausgeschnitten, Reste mit Namen italienischer Bistümer erhalten.

11 $1^{\mathrm{r}}$-139v AMALRICUS AUGERIUS, Actus Romanorum pontificum. Beatissimo patri in Christo et vicario glorioso ac domino nostro precipuo Urbano, digna dei providencia pape quinto, vester devotus cappellanus Amalricus Augerii de Biteris ... $11^{\mathrm{v}}$ qui est benedictus et summe urbanus in actibus suis per infinita seculorum secula, amen. $>$ Explicit probemium Actus Romanorum pontificum <. $12^{\mathrm{r}}$ Ad honorem et eternam huius librimemoriam sanctissimi in in (sic) Christo patris et domini, domini Urbani quinti ... Incipit liber qui intitulatur Actus Romanorum pontificum computando a primo usque ad Iohannem papam xxiim. Ihesus Christus dei filius ... $14^{\mathrm{r}}$ Petrus Ihesu Christi gloriosus apostolus, Andree apostoli germanus, nacione Gallileus ... - ... Illi autem, qui culpabiles inventi non fuerunt, in domibus suis propriis perpetuo inclusi fuerunt, et coniunges et filii ipsorum in alia domo ab eis //. Rerum Italicarum scriptores, hrsg. v. Lodovico Antonio Muratori, Bd. 3,2, Mailand 1734, S. 5 - Sp. 9D (in der Hs. Zusatz zu Jesus Christus), 9D-10E (Zusatz zu Petrus), 10E-20E (Lücke für fehlenden Text zu Zephirinus), 20E-40E (Zusatz zu Leo I.), 40E-44D, 48A-54D (Auslassung bei Gregor I.), 55D, 54E-55D, 55D-68A (Auslassung bei Gregor II.), 68B, 70C (Auslassung bei Gregor III.), 70D-71B, 88E-89B (Zusatz zu Stephan II.), 89B-89C, 115E-116B, 170D-E, 187C-188A, 282D-283C, 285C-D, 286D-287A, 288E-290E, 293A-294D, 298D-299B, 305B-D, 307B-D, 309D (Martinus = Marinus II., etwas ausführlicher), 310D-311C, 313B-D, 317D-318D, 
319C-320C, 321C-323E, 325E-326B (Lücke für fehlenden Text zu Agapet II.), 326C-327B, 329B-330C, 332B-C, 332D-334C, 335D-336C (Zusatz zu Silvester II.), 336D-337D, 338C-339B, 339D, 339C, 339E-340D, 341A, 340E-341A, 342B-344C, 345A-D, 355C-D, 355E-357B, 358D-367D (Zusatz zu Innozenz II.), 367E-371E (Auslassung bei Adrian IV.), 373A-374D, 374E, 374D, 375A-377D (Auslassung bei Clemens III.), 377E-378D (Zusatz zu Innozenz III.), 378E, 379C, 378E-379B, 379D-380C, 380D (Auslassung bei Innozenz III.), 380C (Zusatz zu Innozenz III.), 380E-381C (Auslassung bei Innozenz III.), 381E-387B (Auslassung bei Innozenz III.), 387D-388A (Auslassung bei Honorius III.), 388B-D (Auslassung bei Honorius III.), 389A-B (Auslassung bei Honorius III.), 389D-391A, 391C, 391A, 391D-395A (Auslassung bei Gregor IX.), 395E-396A (Auslassung bei Gregor IX.), 396B-C (Auslassung bei Gregor IX.), 397D-399D (Auslassung bei Innozenz IV.), 400C, 400B, 400C-403D (Auslassung und Zusatz zu Innozenz IV.), 403E-405D (mit Umstellungen), 421A-C (D-E verkürzt), 422A-435E, 436D-437B (Auslassung und Zusatz zu Bonifaz VIII.), 437D, 435E-436C, 437E-441A (Auslassung bei Benedikt XI.), 441C-446B (Auslassung bei Clemens V.), 446C-D, 447A, 446E-447A, 447B (Auslassung bei Clemens V.), 447C-448B (Auslassung bei Clemens V.), 448C-449B (Auslassung bei Clemens V.), 449E-451A, 470D-E (Auslassung bei Johannes XXII.), 471C-E (Auslassung bei Johannes XXII.), 471E-472D, 472E, 472D, 472E-473A (Auslassung bei Johannes XXII.), 473C-D (Auslassung bei Johannes XXII.), 474B, 474D-E, 474C, 474E-476B (Auslassung bei Johannes XXII.), 476C-E. Auslassungen betreffen vor allem Namenslisten. Leo III. hier im Gegensatz zum Druck in der Zählung konsequent berücksichtigt. Adolar Zumkeller, Manuskripte von Werken der Autoren des AugustinerEremitenordens in mitteleuropäischen Bibliotheken, Würzburg 1966, S. 53f. (Hs. erwähnt).

$140^{r}$ Excerpta ex Isidori Etymologiarum libris. Esdras scriba post incensam legem ... Panphilus cuius vitam Eusebius Cesariensis episcopus conscripsit //. Isidori Hispalensis episcopi Etymologiarum sive Originum libri XX, Wallace Martin Lindsay, Bd. 1, Oxford 1911, III.2-VI.1.

140 v leer.

$141^{\mathrm{r}}-145^{\mathrm{v}}$ Tabula archiepiscopatuum cum suffraganeis. $>$ Sciendum est, quod in subscriptis inveniuntur omnes archiepiscopatus nec non et patriarchatus sedes cum suis suffraganeis, qui sunt ab antiquo ordinati per universum orbem, qui protunc vel adhuc tenent fidem catholicam cum sancta Romana ecclesia<. Et nota quod primo sunt vii episcopi sub Romano pontifice ... Hostiensis, Portuensis, Albanensis ... - ... Tripolitanum, Bibliensem. Huius civitas Bibelec dicitur. Vgl. GW M29815: Patriarchatus, archiepiscopatus et episcopatus totius ecclesiae catholicae, Augsburg [14]94, mit zahlreichen Abweichungen und Umstellungen.

$146^{\mathrm{r}}-147^{\mathrm{r}}$ leer.

147v-148 ${ }^{\mathrm{r}}$ CAESARIUS ARELATENSIS, Sermo. Nachtrag. > Sermo beati Maximini<. Leccio actuum apostolorum que nobis hodie lecta est, dilectissimi fratres, cum plurimum habuit in ipsa specie ammiracionis, non minus continet in mysterio dignitatis ... - ... ut cito ad emendacionem vite per penitencie medicamenta confugiant. Quam rememorantibus voluntatem ipse prestare dignetur, qui cum patre et spiritu sancto vivit et regnat in secula seculorum. CC 104, S. 867-870, Nr. 219.

$148^{\mathrm{v}}-149^{\mathrm{r}}$ leer.

149v Festa sanctorum. Nachtrag. >Anno lxxmo, g littera dominicali<. Reverendissimus dominus noster Constantiensis ... disposuit ... ut festa subscripta diebus subnotatis peragantur. Item primo festum annunciacionis beate Marie virginis ... - ... Scriptum feliciter in vigilia annunciacionis Marie anno prescripto, presidente tunc domino Hermanno de Landenberg. Ausweichtermine für die Feste Mariä Verkündigung sowie der Heiligen Georg, Markus, Barnabas, 10`000 Märtyrer, Johannes der Täufer, Johannes und Paulus, Petrus und Paulus. 
$150^{r}$ Explicit und Schreibervermerk. Explicit huiusmodi nova compilacio edita aput Avinionem per Amalricum Augerii de Biteris, prior monasterii sancte Marie de Spirano ordinis sancti Augustini, anno domini $M^{0} c_{c c}{ }^{0}$ et lxiii $^{\circ}$ in die sancte (sic) Michahelis mensis Septembris, et tempore sanctissimi in Christo patris et domini, domini Urbani pape quinti et anno sui pontificatus primo. Quam ego ülricus wachter de löffenberg Basiliensis dyocesis et plebanus in Byrdorff Constanciensis dyocesis rescripsi et complevi anno domini $M^{\circ}$ cccc $^{\circ}{i i^{\circ}}^{\circ}$ iiii ${ }^{\circ}$ Nonas Ianuarii. Anschliessend Liste der Kurfürsten mit deutschen Übersetzungen ihrer Titel.

$151^{\mathrm{v}}$ Festa sanctorum. Nachtrag. $>M c c c c$ li $^{\circ}$, c littera dominicali<. De mandato reverendissimi ... patris et domini $H$ [einrici de Hewen] ... episcopi Constanciensis ... festa sanctorum predicta ordine subscripto statuit in choro et foro celebranda ... Ausweichtermine und Ausführungsanweisungen für die Feste der Heiligen Georg, Markus, Philipp und Jakob, Johannes des Täufers, Petrus und Paulus, 10’000 Märtyrer, Johannes und Paulus.

Papier, 208 Blätter, $28 \times 20-20,5 \mathrm{~cm}$

Mittleres Drittel des 15. Jahrhunderts

Wasserzeichen, Lagen, Foliierung: Wasserzeichen: Ochsenkopf, Bl. 1/8 PiCCARD, Wasserzeichenkartei Nr. 75457 (1446), Bl. 2/7 Nr. 76103 (1447), Bl. 3-6 Nr. 75880 (1447), Bl. 9-20 Nr. 75769 (1446), Bl. 21-32 Nr. 75844 (1446), Bl. 33-92 Nr. 75788 (1445/46), 75853 (1446) und 75935 (1446), Bl. 93-116 Nr. 62156 (1447) und 62160 (1446), Bl. 117-206 Nr. 75456 (1446) und 75457 (1446). Lagen: IV + 16 VI $^{200}+$ III $^{206}$. Vor Bl. 125 ein an Bl. 121 geklebtes Einzelblatt herausgerissen (Kanonbild). Zählung der Blätter innerhalb der einzelnen Lagen in der unteren rechten Ecke der Rectoseiten, zuerst sichtbar: 2 (118 r) und 11 (127r), vollständig erhalten $141^{\mathrm{r}}-152^{\mathrm{r}}$ : 1-12, zuletzt 194 ${ }^{\mathrm{r}}-200^{\mathrm{r}}$ : 6-12. Reklamanten in der Mitte des unteren Randes, teilweise beschnitten. Auf den Blättern 10-20 starker Tintenfrass. Alte, fehlerhafte Foliierung: $1\left(10^{\mathrm{r}}\right)-66\left(75^{\mathrm{r}}\right) .61$ $\left(76^{\mathrm{r}}\right)-109\left(124^{\mathrm{r}}\right) .111\left(125^{\mathrm{r}}\right)-124\left(138^{\mathrm{r}}\right) .126\left(139^{\mathrm{r}}\right)-193\left(206^{\mathrm{r}}\right)$. Neuere Foliierung: A. 1-207.

Einrichtung und Ausstattung: Begrenzung des Schriftraums (der Spalten) mit Stift, für die Nachträge $1^{\mathrm{v}}, 8^{\mathrm{r}-\mathrm{v}}$ und $205^{\mathrm{v}}-206^{\mathrm{v}}$ mit Tinte, das Kalendar $\left(2^{\mathrm{r}}-7^{\mathrm{v}}\right)$ und die beiden nachgetragenen Sequenzen auf $9^{\mathrm{v}}$ mit

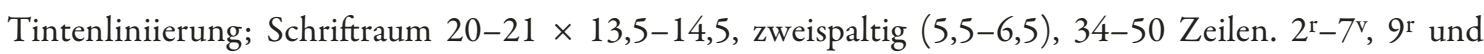
$10^{\mathrm{r}}-204^{\mathrm{v}}$ schleifenlose Bastarda von einer Hand; die Nachträge $1^{\mathrm{r}-\mathrm{v}}, 8^{\mathrm{ra}-\mathrm{vb}}$ und $9^{\mathrm{rb}-\mathrm{va}}$ von einer zweiten Hand (B), die auch den Text des Hauptschreibers mehrfach ergänzte, $9^{\mathrm{va}-\mathrm{vb}}, 124^{\mathrm{va}-\mathrm{vb}}$ und $205^{\mathrm{r}}-206^{\mathrm{v}}$ von einer dritten, weniger kursiven, ebenfalls ergänzenden Hand (C), siehe Nachträge. An den Rändern Vorgaben für die Rubrizierung sichtbar, z. B. 31 v $59^{v}$ und 68r. Rubriziert, rote Überschriften von der Hand des Schreibers, die Nachträge und Ergänzungen rubriziert von den beiden jeweiligen Händen. 1-3zeilige (127rb 5zeilig, $133^{\text {va }}$ 4zeilig) rote und blaue Lombarden, meist abwechslungsweise, z. T. mit Punktverdickungen; $20^{\mathrm{rb}}$ und $63^{\text {va }}$ schwarze Lombarden mit ornamentaler Schaftaussparung. $10^{\text {ra }}$ 6zeilige rote Initiale mit schwarzem Fleuronné (Binnenfelder leer), 125 ra 8 zeilig (Te igitur).

Korrekturen und Nachträge: Korrekturen von der Hand des Schreibers (A), z. B. 33 $3^{\mathrm{ra}}$, 75 ${ }^{\mathrm{va}}$, 98 $8^{\mathrm{va}}, 185^{\mathrm{rb}}$. Zahlreiche zeitgenössische Korrekturen von der Hand B, z. B. 64 ${ }^{\mathrm{ra}}, 118^{\mathrm{va}}$, 187va, vielleicht auch im Hymnus $75^{\mathrm{rb}}$ (samt Rasur), grössere Ergänzungen am unteren Rand auf $7^{\mathrm{v}}-8^{\mathrm{r}}, 16^{\mathrm{v}}-17^{\mathrm{r}}, 80^{\mathrm{v}}-81^{\mathrm{r}}, 95^{\mathrm{v}}, 144^{\mathrm{r}-\mathrm{v}}, 146^{\mathrm{v}}$, $152^{\mathrm{r}}, 154^{\mathrm{r}}, 156^{\mathrm{v}}-157^{\mathrm{r}}, 159^{\mathrm{v}}, 177^{\mathrm{v}}, 179^{\mathrm{r}}, 185^{\mathrm{v}}, 200^{\mathrm{r}-\mathrm{v}}$ und $202^{\mathrm{r}}-203^{\mathrm{r}} ; 147^{\mathrm{rb}}$ Nota festum Corone Christi in fine 
libri (vgl. auch die beiden Hinweise zu Anna und Martha im Kalendar 5r). Von der Hand C die Ergänzungen $165^{\mathrm{v}}-166^{\mathrm{r}}$ und $181^{\mathrm{r}}$. Zu den Nachträgen von B und C siehe oben (Einrichtung). $27^{\mathrm{ra}}, 30^{\mathrm{va}}, 74^{\mathrm{vb}}$ und $125^{\mathrm{va}}$ Handweiser.

Einband: Mit hellbraunem Leder bezogene Holzdeckel, wohl erst 20. Jh. Streicheisenlinien, auf den Schmalseiten der Kanten Rollenstempel: vierzählige Blüte alternierend mit rechteckiger Kartusche. Grüne, maschinell gefertigte Kapitale. Spiegel- und Vorsatzblätter (A, 207) Papier, aus der Zeit des neuen Einbandes. Auf $1^{\mathrm{r}}$ und 206v Spuren von den Lederumschlägen eines älteren Einbandes. 15 rote Ledersignakel (Bl. 10, 17, 30, 47, 57, 75, 90, 113, 123, 125, 126, 146, 173, 183, 194), der Rand der betreffenden Blätter mit Pergament verstärkt, zwei weitere auf Bl. 133 und 197 abgerissen. In den Fälzen (ausser 62/63) Pergamentverstärkungen, z. T. auch im äussersten Doppelbl. (57/68 und 69/80 unten). Im vorderen Spiegel Exlibris des Chorherrenstifts Beromünster (WEgmanN, Exlibris, Nr. 619), wohl vom alten Einband abgelöst.

Herkunft: Zürich, nach den Heiligenfesten im Kalendar. Die Wasserzeichen weisen alle auf eine Zeit kurz vor Mitte des 15. Jahrhunderts.

Besitzer: 206v Dis Mes-Buoch gehortt Is Ror: Den Goldlinen, 15/16. Jh. Darunter: Jochim góldli verkouft das Rorr Im Iar da man Zalt: 1527 anno uff denn: 13: dag: hornung und geschach mit gunst mins vatters In desselbigen By wessens. Darunter: Dono datum a Reverendissimo, ac Magnific: Domino Renwardo Göldlin a Tieffenau Decano Eccl: Cathedr. Basileens, et Canonici, Quotid, et Eleemosin: Eccl. Colleg. Beronens, nach Kopp (und BrUCKNER) von der Hand des Propstes Franz Bernhard Göldlin (HLS Bd. 5, S. 522, Nr. 2). Zu Joachim Göldlin von Tiefenau und dem Verkauf der Burg im Rohr bei Rümlang siehe Historisch-biographisches Lexikon der Schweiz, Bd. 3, Neuenburg 1926, S. 582 (I. A 14), zu seinem Vater Georg ebd. (I. A 9); zu Renward Göldlin von Tiefenau (vgl. Bd. 3, S. 583, II. A 3; Chorherr seit 1551, Mitglied des Basler Domstifts seit 1578) siehe Paul BoEsCH, Renward Göldlin von Tiefenau und der Glasmaler Hans Sur von Basel, in: Zeitschrift für schweizerische Archäologie und Kunstgeschichte 14 (1953), S. 91-96. Das Geschlecht der Göldlin war zu Beginn des 15. Jhs. von Pforzheim nach Zürich übergesiedelt, von wo die katholisch gebliebenen Zweige hundert Jahre später wieder wegzogen, vgl. auch HLS Bd. 5, S. 521. $1^{\mathrm{r}}$ Missale Thuricens: Ad Familiam Goldlin de Tieffenau. Collegii Beronensis, wohl 17. Jh. Im vorderen Spiegel Exlibris des Chorherrenstifts Beromünster. In den Antiquitates Beronenses, S. 692, als Nr. 34 verzeichnet, im Catalogus von 1826 als Nr. 12. Auf dem Exlibris A $^{r}$ : C 35, blauer Kugelschreiber; $A^{r} z^{2}$ dem die neuere Signatur: C 55, mit drei verschiedenen Stiften (blau, schwarz und Silber) übereinander, spätes 20. Jh. Signatur ehemals C 35 fol.

Literatur: Estermann, Sehenswürdigkeiten, S. 66-70; Kopp, Stiftsbibliothek, II, S. 7f.; Wolfgang IRTENKAUf, Das Missale speciale Constantiense - wieder einmal nach seiner liturgischen Seite untersucht, in: Archiv für Geschichte des Buchwesens 15 (1959), S. 1333-1343, besonders S. 1342 (Nr. 8, Sigle Be 1); BRUCKNer, Scriptoria 9, S. 28; BüCHLER, Beromünster, S. 174 und 246 (Anm. 155).

$\mathrm{A}^{\mathrm{r}-\mathrm{v}}$ leer.

$1^{\mathrm{r}-\mathrm{v}}$ Lectiones et sequentiae. Nachtrag. $>$ Sabbato ante dominicam Iudica, post propheciam sequitur inmediate leccio Esaye prophete $<$. Hec dicit dominus deus: Omnes sicientes ... > Feria secunda post Palmarum, leccio Esaye prophete $<$. In diebus illis dixit Esayas: Dominus deus aperuit michi aurem ... > Feria tercia post Palmarum, leccio libris Sapiencie<. In diebus illis dixerunt impii Iudei apud semetipsos: Venite circumveniamus ... $1^{\mathrm{v}}>$ In visitacione Marie<. Lauda sponsa genitricem ... AH 54 Nr. 196 (20, 3: Sed in medio collocandum). > De Hylario vel alio pontifice<. Ad laudes salvatoris... AH 54 Nr. 88. 
$2^{\mathrm{r}}-7^{\mathrm{v}}$ Kalendar. Goldene Zahl, Sonntagsbuchstaben, Kalenden, Nonen, Iden, Angaben zu Länge von Tag und Nacht sowie Ekliptik (Locus solis in Graden und Minuten). Rot hervorgehoben u. a. Karoli magni imperatoris et confessoris (28. 1.), Augustini episcopi (28. 8.), Felicis et Regule (11. 9.), Fidis virginis et martiris (6. 10.), Dionisii cum sociis (9. 10.), Undecim milia virginum (21. 10.), Kunradi episcopi (26. 11.); Luzius, der Patron der Diözese Chur (Lucii regis Britanie, 3. 12.), ist nicht hervorgehoben, Basilla (Basille virginis, 20. 5.) und Wunnebald (Wunibaldi, 18. 12.) erscheinen im Sanctorale nicht wieder. Nachträge: Anne matris Marie officium in principio libri und Marthe virginis officium in principio libri (26. und 29. 7.), vgl. $8^{\mathrm{r}}$.

$8^{\mathrm{ra}}-9^{\mathrm{vb}}$ Officia et sequentiae. Nachträge, mit Ausnahme von 9ra-rb (Officium Fidis). > De sancta Anna officium $<$. Gaudeamus omnes in domino diem festum celebrantes ... $8^{\mathrm{rb}}>$ De sancta Martha $<$. Gaudeamus omnes ... mit $\mathrm{AH}$ 55 Nr. 246 (als Nachtrag des Schreibers zum Nachtrag). $8^{\mathrm{va}}>$ In commemoracione Felicis et Regulae<. Sapienciam sanctorum ... mit AH 55 Nr. 129 (8, 2-3: Portant capita beati Karoli collegio, sonst wie der ed. Text). $8^{\mathrm{vb}}>$ In divisione apostolorum, sequencia<. Celi enarrant ... AH $50 \mathrm{Nr} .267 .9^{\mathrm{ra}}>$ Fidis virginis officium $<$. Gaudeamus omnes ... >Sequentia $<$. Cantemus de sancta Fide cum sonora cordis fide fideles magnalia ... $9^{\mathrm{rb}}>$ De sancto Dyonisio, sequencia<. Vas electum Greciam ... AH 8 Nr. 150. $9^{\mathrm{va}}>$ De sancto Luca, sequentia<. Plausu chorus letabundo ... AH 55 Nr. 6 (14, 1: Voce patris suscitatus). 9vb > De sancto Francisco, sequentia<. Letabundus Francisco decantet... AH 55 Nr. 131.

$10^{\mathrm{r}}-123^{\text {ra }}$ Proprium de tempore. 1. Sonntag im Advent - 25. Woche nach Pfingsten. Ad te levavi animam meam ... > Collecta $<$. Excita domine quesumus ... 16 vb Weihnachten mit AH 53 Nr. 16 und 15, 19va Stephanus mit Nr. 215 (11, 2: elegit), $20^{\text {ra }}$ Nativitas Johannis Ev. mit Nr. 168, $20^{\text {va }}$ Innocentes mit Nr. 157, 22 ${ }^{\text {rb }}$ Epiphanie mit Nr. 29, 30 $0^{\mathrm{ra}}>$ In capite ieiunii super cineres $<$. Concede ... $47^{\mathrm{ra}}>$ Dominica in medio quadragesime $<$. Letare ... 67va Karfreitag mit AH 50 Nr. 66 (8 [3-6: Nulla silva telem profert, fronde flore germine, Dulce lignum dulces clavos, dulce pondus sustinet], 1-7 [5, 2: positus presepia], 9, 10, S. 73: Sit patri ...), 75 ${ }^{\text {ra }}$ Ostern mit AH 53 Nr. 36 (7, 3: lavit, 9, 2: saporem), 75vb Ostermontag mit Nr. 47 (2, 2-3: pugnaturus immortalem, 6, 1: Et stabile), 76vb Dienstag mit Nr. 48, 77va Mittwoch mit Nr. 50, $78^{\mathrm{rb}}$ Donnerstag mit Nr. 52, 79rb Freitag mit Nr. 54, 80va Osteroktav (Quasimodo), als Nachtrag 80v Nr. 56, 85 vb Auffahrt mit Nr. 67, 90va Pfingsten mit Nr. 70.

$123^{\text {ra }}-124^{\mathrm{va}}$ Ordinarium missae, praefationes. $>$ Credo in unum. Legitur vel cantatur $<$. Credo in unum deum ... $123^{\mathrm{rb}}>$ Legitur de quovis sancto $<$. Gloria in excelsis deo ... > De beata virgine <. Gloria in excelsis deo ... Quoniam tu solus sanctus Mariam sanctificans ... 123 va Per omnia secula seculorum ... Vere dignum et iustum est ... >In Nativitate domini<. O eterne deus ... Praefationes zu Weihnachten, Epiphanie, 123 vb Quadragesima, Ostern, Auffahrt, 124ra Pfingsten, Trinitas, 124rb BMV (Assumptio), Apostel und Crux sancta; am Schluss jeweils Sanctus. Anschliessend Nachtrag: 124 $4^{\mathrm{ra}}>$ Missa contra infideles hereticos $<$. Iudica domine nocentes me ... - ... $>$ Completorium <. Protector noster aspice ... liberis tibi mentibus deserviant per dominum.

$125^{\mathrm{ra}}-127^{\mathrm{ra}}$ Canon missae. Te igitur ...

$127^{\mathrm{rb}}-133^{\mathrm{va}}$ Missae votivae. > Incipiunt misse speciales primo de sancta trinitate $<$. Benedicta sit sancta trinitas ... mit AH 53 Nr. 81 (1, 4-5: scilicet unitas equalis gloria, 6, 3: spiritusque sanctus, 9, 3: arva fretum, 15 und 16 umgestellt), $128^{\mathrm{ra}}>$ Missa de sancto spititu $<, 128^{\mathrm{rb}}>$ Missa pro peccatis $<, 128^{\mathrm{va}}>$ Missa pro pace $<, 129^{\mathrm{ra}}>$ Missa pro salute $<, 129^{\mathrm{va}}>$ Missa contra pestilenciam<, 130 ra $>$ De corpore Cristi<, mit AH 50 Nr. 385 (1b, 1: gaude, 3a, 5: prima colitur, 3b, 1: summi regis, 6a, 2: Signis tamen, 6b, 2: tamen Cristus), 131 ra $>$ De sancta cruce $<$, $131^{\mathrm{rb}}>$ De sancta Maria officium<, mit AH 54 Nr. 219 (3, 2: Hanc adora et implora, 9, 1: Salve splendor firmamenti), 132 $\mathrm{ra}>$ De sancta Maria in adventu<, 132 va $>$ De sancta Maria, a nativitate domini usque ad 
purificacionem <, mit AH 54 Nr. 2 (4, 3: Valde clara, 8, 1: ens altissimi), 133 ${ }^{\text {rb }}>$ De sancta Maria a septuagesima usque ad pascha $<,>$ De sancta Maria tempore paschali officium $<$.

$133^{\text {va }}-183^{\text {ra }}$ Proprium de sanctis. Lucia - Conceptio BMV. > Incipit liber de sanctis per circulum anni, primo de beata Lucia virgine<. Dilexisti iusticiam ... >Psalmus <. Eructavit cor meum ... > Oracio<. Exaudi nos deus salutaris noster ut sicut de beata Lucie festivitate gaudemus ... Ottilia, 133 vb Jodocus, 134 ra Thomas mit AH 55 Nr. 323 (3, 2: Et a Christo vocitatus, 4, 2: reformatus), 134va Thomas von Canterbury, >Silvestri papa<. Sacerdotes tui ... 134 $4^{\mathrm{vb}}>$ Pauli primi heremite collecta<. Deus qui nos .... Hilarius (am unteren Seitenrand in Rot: Sequenciam habet in principio libri, vgl. $1^{\mathrm{v}}$ ), $135^{\mathrm{ra}}$ Felix in pincis, $135^{\mathrm{rb}}$ Ignatius (normalerweise erst Anfang Februar), Marcellus, 135 va Antonius mit AH 55 Nr. 72 (8, 3: qui rigat omnia, 9, 2: Nobis hoc, 12, 2: quod optamus), 136 ${ }^{\mathrm{ra}}$ Prisca, 136 $\mathrm{vb}$ Agnes mit AH 55 Nr. 51, 137 rb Vincentius, 137va Timotheus, 137vb Conversio Pauli mit AH 50 Nr. 269 (4b, 4: contra christianos, 7b, 1: Collegit universas, 8a und 8b umgestellt, 9b, 2-3: rediens de profundo, danach eingefügt: viciorum), 138 vb Johannes Chrysostomus, Octava Agnetis, 139ra Karl der Grosse mit AH 55 Nr. 201 (Urbs Thuregum, urbs famosa ... 1-14 entsprechend Hs. J, vgl. S. 226; 15, 3: vacillantes), 139 ${ }^{\mathrm{vb}}$ Brigida, Purificatio BMV mit AH 53 Nr. 99, 140 vb Blasius, $141^{\text {ra }}$ Agathe, $141^{\mathrm{rb}}$ Dorothea mit AH 55 Nr. 116 (13,3-4: Ut sociemur beatis condigno premio), 141 va Scholastica, $141^{\mathrm{vb}}$

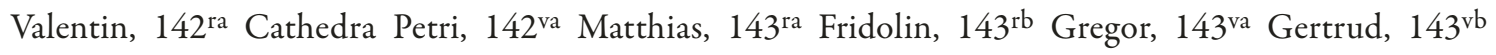
Annuntiatio BMV, 144va Georg, als Nachtrag AH 34 Nr. 238 (5a und 5b umgestellt, 6a, 1-4: Ignis de celo exusit ydolum, plebs Daciani sprevit Georium, 7, 1-2: Et Sueviensibus incolis veniam), Adalbert, $145^{\text {ra }}$ Lancea et clavis mit AH 54 Nr. 140, 146 $6^{\text {ra }}$ Anaklet, Vital, 146 rb Philipp und Jacob, Walpurga, 146 $6^{\mathrm{rb}}$ Inventio crucis, $147^{\mathrm{rb}}$ Johannes ante portam Latinam, als Nachtrag 146v AH 55 Nr. 192 (1-4, 6 [6, 3: excellentis curie ], 5, 7, 8a-10a), 149 ${ }^{\mathrm{rb}}$ Barnabas, 149vb Antonius v. Padua (vgl. auch die Sequenz 135 vb), 150vb Johannes Bapt. mit AH 53 Nr. 163, 152 ra Johannes und Paul, als Nachtrag AH 53 Nr. 151 (entsprechend Hs. B, in 9. fehlt «artubus sanitatis», 14. hingegen vollständig), 152 rb Peter und Paul mit Nr. 210 (8, 1: Doctilogosphilosophos, 10, 5: Romanos discordes), 154ra Visitatio BMV mit AH 54 Nr. 193 (154rb $>$ Sequencia dicitur<, daneben am Rand ebenfalls in Rot: alia in principio libri ante Kalendarium, vgl. 1 1 ), 154 vb Udalricus, 155 $5^{\text {ra }}$ Octava

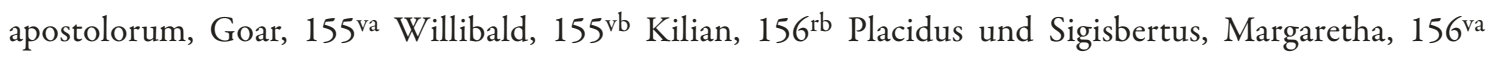
Andeolus, Alexius, als Nachtrag 156 v-157r Divisio apostolorum, 157ra Maria Magdalena mit AH 50 Nr. 268 (2b, 3: et hominem, 9b, 2: resurgentem, 11a, 1-2: ... tangit peccatrix, 11b, 3: si non medicus esset), 158 Jacobus ap., 158 va Pantaleon, Nazarenus und Celsus, 158 vb Felix papa, 159 ${ }^{\text {ra }}$ Abdon und Sennen, 159rb Vincula Petri, 159va Stephanus papa, 159vb Inventio Stephani, als Nachtrag AH 55 Nr. 313, Oswald, 160rb Sixtus, Felicissimus und Agapitus, rot unterstrichen: Et in ista missa circa finem canonis ante locum ubi dicitur: Per quem hec omnia, nove uve a sacerdoti benedici consueverunt per hanc oracionem: > Oracio<. Benedic domine et hos novos uve fructus ... vgl. FrAnz, Benediktionen, Bd. 1, S. 372f.; 160va Afra mit AH 53 Nr. 119 (26: Zacheus dat dimidium bonorum, fraudem redemit in quadruplum), 161 rb Laurentius mit AH $53 \mathrm{Nr} .173,162^{\mathrm{va}}$ Assumptio BMV mit AH 53 Nr. 104, 163 vb Theodul, Arnulf, 164 va Bernhard mit AH 55 Nr. 93 (1-5, 7-12; 10, 1-2: Quod non vidit, quod non fatur humilis), 165 $5^{\text {ra }}$ Bartholomaeus mit AH 54 Nr. 34, 165 $5^{\text {vb }}$ Augustinus, als Nachtrag 165 $166^{\mathrm{r}}$ AH 55 Nr. 75 (9, 1-2: «formam» und «normam» vertauscht), Pelagius mit AH 54 Nr. 72, 166 va Decollatio Johannis mit AH 50 Nr. 270 (3b, 2: sonando, 5b, 1: Non tamen, 8a, 2: puella saltet, 12, 2-4: quo mensa altaris cui mensa te ipsum dum sumimus semper tibi canamus), 167va Felix und Adauctus, Paulinus, 167vb Aegidius, 167vb Verena mit AH 55 Nr. 336, 168 rb Nativitas BMV mit AH 53 Nr. 95, 169va Felix und Regula mit AH 55 Nr. 128, 170 ra Exaltatio crucis mit AH 54 Nr. 120 (2, 1: pulsat, 10, 2: Si non 
cruce, 21, 1: Quos nunc cruci vis servire, 3: Sed, cum dies adest ire), 170 ${ }^{\mathrm{vb}}$ Matthaeus, $171^{\mathrm{rb}}$ Mauritius mit $\mathrm{AH}$ 53 Nr. 186 (5, 1: celestes), 172 ${ }^{\text {ra }}$ Michael mit AH 53 Nr. 190 (16, 5: demus huic per liricas cytheras), 172 Hieronymus, Ursus und Victor, $173^{\text {ra }}$ Remigius, $173^{\text {rb }}$ Leodegar, $173^{\text {va }}$ Franciscus $\left(173^{\text {va }}\right.$ am Rand in Schwarz: Item Fidis virginis in principio libri, in Rot: similiter sequentia Francisci, vgl. 9 ${ }^{\mathrm{ra}}$ resp. 9vb), 173 ${ }^{\mathrm{vb}}$ Dionysius $\left(174^{\mathrm{rb}}>\right.$ Sequencia<, am Rand in Rot: in principio libri, vgl. 9 $\left.{ }^{\mathrm{rb}}\right), 174^{\mathrm{rb}}$ Gereon, 174 ${ }^{\mathrm{va}}$ Gallus mit AH 53 Nr. 149, 175 va Ursula, 176 ${ }^{\text {va }}$ Allerheiligen mit AH 53 Nr. 112, Wolfgang, 178 rb Martin mit AH 53 Nr. 181, $178^{\mathrm{vb}}$ Brictius, 179 ${ }^{\mathrm{ra}}$ Othmar, Florinus, 179 ${ }^{\mathrm{rb}}$ Elisabeth, als Nachtrag 179r AH 55 Nr. 120 (1, 3: splendor seculi, 8, 2: demonstratur), 179va Caecilia, 180 ${ }^{\mathrm{rb}}$ Katharina mit AH 55 Nr. 208 (6, 4: sempiterna gloria), 180va Konrad, als Nachtrag 181 ${ }^{\mathrm{r}}$ AH 55 Nr. 108, 180vb Andreas mit AH 53 Nr. 122 (6, 1: Istum), 182 ${ }^{\text {ra }}$ Lucius, 182 ${ }^{\mathrm{rb}}$ Barbara, Nicolaus mit AH 54 Nr. 66 (1-22; 4, 1: Ad mamillas, 15, 3: Ad vestra subsidia, 20, 3: Ubi pax et gaudia), 182 vb Conceptio BMV mit AH 54 Nr. 188 (1, 1: Concepcio, 10, 3 und 4 fehlen).

$183^{\text {ra }}-185^{\text {va }}$ Commune sanctorum. $>$ Sequuntur alleluia, et primo de apostolis $<$. Alleluia. $>$ Versus. $<$ Nimis honorati sunt ... $183^{\mathrm{va}}>$ Sequitur commune sanctorum. Et primo vigilia apostolorum $<$. Ego autem sicut oliva ... Apostel, 184 $4^{\text {ra }}$ Märtyrer, $184^{\text {va }}$ Bekenner, $185^{\text {rb }}$ Jungfrauen.

$185^{\mathrm{va}}-186^{\mathrm{va}}$ Dedicatio ecclesiae et altaris. $>$ In anniversario dedicacionis ecclesie, officium <. Terribilis est locus iste ... mit AH 53 Nr. 247 als Nachtrag (185'v). 186 ra >In dedicacione altaris<. Dicit dominus: Sermones meos quos dedi ...

$186^{\mathrm{va}}-195^{\mathrm{rb}}$ Lectiones communis sanctorum. $>$ In nativitate apostolorum, Ephesios $<$. Fratres, iam non estis ... $190^{\text {va }}$ Märtyrer, 192 rb Bekenner, 194rb Jungfrauen.

$195^{\mathrm{rb}}-197^{\mathrm{rb}}$ Collectae. $>$ Missa de sanctis quorum reliquie in ecclesia continentur, oracio $<$. Concede quesumus omnipotens, ut sancta dei genitrix Maria, sanctique tui apostoli martires confessores virgines atque omnes sancti quorum reliquie in ista continentur ecclesia nos ubique adiuvent ... $15 \times 3$ Gebete, darunter BRUYLANTS, Bd. 2, Nr. 201, 318, 204; Nr. 1168, 472, 484; Nr. 753, 602 sowie 196 ${ }^{\text {ra }}$ Per hoc ... vgl. Bd. 1, S. 195, Nr. 590; Bd. 2 , Nr. 759, 397, 1069 (beginnend Libera nos ...); Nr. 229, 733, 168; Nr. 22, 881, 669/934 (Maiestatem tuam ... deprecamur, ut per hec sacramenta que sumpsimus inundantiam coherceas ...); Nr. 804, 903, 234; Nr. 802, 209 , 923; Nr. 1, 533, 687.

$197^{\mathrm{rb}}-198^{\mathrm{va}}$ Missa pro defunctis. $>$ Sequitur missa pro defunctis. Officium <. Requiem eternam ... $198^{\mathrm{va}}>$ In pascali tempore missa pro defunctis $<$. Si enim credimus ...

$198^{\mathrm{va}}-199^{\mathrm{vb}}$ Collectae pro defunctis. $>$ Collecta $<$. Deus indulgenciarum domine da famulis tuis quorum aniversarium deposicionis diem conmemoramus refrigerii sedem ... $10 \times 3$ Gebete, darunter BRUYLANTS, Bd. 2, Nr. 233 und 905, Nr. 931, sowie Nr. 407, 1134, 106; Nr. 929, 606, 654; Nr. 465, 217, 877; Nr. 214, 892, 223; Nr. 567, 603, 52 .

$199^{\mathrm{vb}}-204^{\mathrm{va}}$ Sequentiar. > Tempore pascali, Sequencia<. Victime pascali ... AH 54 Nr. 7; 200 ra $>$ Alia sequencia<, AH $50 \mathrm{Nr}$. 240; 200 rb > De resurreccione <, AH 54 Nr. 148 (mit allen Varianten von p und q, vgl. S. 226), sowie 200 r-v als Nachtrag Nr. 230 (2, 2: seram porte, 4, 2: Magdalenam consumebat, S. 366: 5-8, 1114) und wiederum Nr. 7 (6-7); > De spiritu sancto<, AH 54 Nr. 153 (6, 2: Nibil est in homine, 7, 3: Sana quod est sanctium, dann [vor 8, 1] 8, 2: Fove quod est langwidum); 200va > Sequencia de sacramento<, AH 54 Nr. 169; $>$ Conmemoracio Pauli<, AH 55 Nr. 281 (10, 2: munda prece); 200vb > De sancta Afra, sequencia<, AH 53 Nr. 119 (1-14, 16-25, 26: Zacheus dat dimidium bonorum fraudem reddidit in quadruplum, 27); 201 ${ }^{\mathrm{ra}}>D e$ sancto Blasio<, AH 54 Nr. 36; 201 $1^{\mathrm{rb}}>$ De sancta Margaretha <, AH 54 Nr. 64; 201 $1^{\mathrm{va}}>$ Oswaldi regis<, AH 53 Nr. 201; 201 $1^{\mathrm{vb}}>$ Undecim milium virginum<, AH $55 \mathrm{Nr} .333$ (1, 1: Virginalis turme sexus, bis auf 9, 4 nach I, 
vgl. S. 870); 202 $2^{\mathrm{ra}}>$ De sancto Cuinrado episcopo <, AH $55 \mathrm{Nr} 107$ (8, 1: In qua tria templa fundat); 202 $2^{\mathrm{rb}}>$ De sancto Othmaro sequencia<, AH 53 Nr. 203; 202 va Sequentiae de communi sanctorum: AH 53 Nr. 228, AH 54 Nr. 27 (3, 4: est per mundi climata, 9, 3: vocatus per dominum), AH 55 Nr. 14 (9, 1: Dum sint), AH 53 Nr. 229, AH 39 Nr. 239 (11a und 11b) und AH 55 Nr. 37 (23-26), AH 54 Nr. 90 (1-8 und 10; 3, 2: et qui tenuerit) und AH 50 Nr. 271, als Nachträge 202r: Ave virgo (resp. N.) gloriosa, Sponsa Christi generosa ... AH 55 Nr. 79 (4,1: Ave virgo plus serena, 5,1: Ave virgo iam beata), $202^{\mathrm{v}} \mathrm{Nr} .10$ (2, 3: N. memoria, 5, 1: Ave martir vel confessor preciose) und $203^{\mathrm{r}}>$ De confessore pontifice $<$. Ihesu bone rex cunctorum, dulcis pater orphanorum, tibi laus et gloria ... 203 $3^{\mathrm{rb}}$ de BMV: AH 50 Nr. 241 (2b, 1: Virgo salus mundi), AH 54 Nr. 245 (1-8, 10, 9, 11-24), 232 (1-6, 8, 7, 9-10, zudem 3, 1-2 und 4, 1-2 vertauscht), 218 (5, 1: Ave sponsa regis summi), 216 und 21 (4, 1-2: Da nobis Maria, tua per suffragia, 7, 1-2: Scimus Christum processisse, ex virgine vere).

$204^{\mathrm{va}}-206^{\mathrm{vb}}$ Missae votivae. Ab 205 ${ }^{\mathrm{ra}}$ Nachtrag. > Festum Corone domini, officium $<$. Gaudeamus omnes ... $205^{\mathrm{ra}}>$ Missa de passione Cristi, introitus $<$. Humiliavit semetipsum ... > De eterna sapiencia $<$. Lex domini irreprehensibilis ... 205 $5^{\mathrm{vb}}>$ Missa de angelis $<$. Adorate deum ... 206 $6^{\mathrm{ra}}>$ De caritate $<$. Deus in loco sancto suo ... $206^{\mathrm{rb}}>$ Missa propria sacerdotis<. Respice in me et miserere mei ...

$207^{\mathrm{r}-\mathrm{v}}$ leer. PARADISO; JOHANNES ANDREAE; JOHANNES DE DEO; JOHANNES DE FONTE; JOHANNES HISPALENSIS; WALTER MAP; EXCERPTA

Papier, 207 Blätter, $31 \times 21 \mathrm{~cm}$

Leipzig, 1468 und Beromünster (?), 1469

Wasserzeichen, Lagen, Foliierung: Wasserzeichen: Bl. 1-24 Ochsenkopf, ähnlich Piccard, Wasserzeichenkartei Nr. 81277 in zwei Formen; Bl. 25-74, 100/107, 110-135, 139/146 und 174-206 Nr. 70270 (1465) und eine weitere Form; Bl. 98-109, 136-173, 186/197 und 187/196 ähnlich Nr. 65964 in zwei Formen; Bl. 111/122, 112/121 und 203/204 ähnlich Nr. 70284; Bl. 75-97 Schlüssel, PICCARD, Wasserzeichenkartei Nr. 121278 (1468) und 121284 (1468). Lagen: $4 \mathrm{VI}^{48}+\mathrm{VII}^{62}+\mathrm{VI}^{74}+(\mathrm{VII}-1)^{87}+\mathrm{V}^{97}+\mathrm{VI}^{109}+\mathrm{VII}^{123}+$ $\mathrm{VI}^{135}+(\mathrm{VI}+\mathrm{I})^{149}+4 \mathrm{VI}^{197}+(\mathrm{VI}-3)^{206}$, nach Bl. 84 und 206 je eines, nach 203 zwei Blätter herausgerissen, nach Bl. 139 ein Doppelblatt eingeklebt. Bl. 97 mit Pergament geflickt. Wasserschaden am oberen Rand innen, teilweise bis in den Schriftraum. Zählung der Doppelblätter in der ersten Lagenhälfte: $1\left(63^{\mathrm{r}}\right)-6\left(68^{\mathrm{r}}\right)$ am oberen Rand in Rot; 1 (110 $)$ - $7\left(116^{\mathrm{r}}\right)$ am unteren Rand in Schwarz. Reklamanten, $61^{\mathrm{v}}$ auf dem vorletzten Blatt der Lage. Neuere Foliierung: 1-207.

Einrichtung und Ausstattung: $1^{\mathrm{v}}-24^{\mathrm{r}}$ Spaltenbegrenzung mit Tinte, $1^{\mathrm{v}}-2^{\mathrm{r}}$ auch Linierung, Bl. 1-12 Einstichlöcher für Linierung erhalten; Bl. 25-206 Blindlinierung. Schriftraum 21,5-24 × 14-14,5, zweispaltig (6-6,5), 45-58 Zeilen. Jüngere gotische Buchkursive mit Schleifen von mehreren Händen: $1^{\mathrm{r}}-10^{\mathrm{va}}, 25^{\mathrm{ra}}-62^{\mathrm{va}}, 74^{\mathrm{va}}-134^{\mathrm{v}}, 162^{\mathrm{ra}}-169^{\mathrm{va}}$ und $174^{\mathrm{ra}}-203^{\mathrm{vb}}$ Ludwig Zeller; 63 $3^{\mathrm{ra}}-74^{\mathrm{rb}}$ Rudolf Grünli; $10^{\mathrm{va}}-$ $24^{\mathrm{ra}}, 136^{\mathrm{ra}}-161^{\mathrm{vb}}$ und $169^{\mathrm{va}}-173^{\mathrm{vb}}$ drei weitere zeitgenössische Schreiber. $1^{\mathrm{ra}}-2^{\mathrm{vb}}, 11^{\mathrm{ra}-\mathrm{rb}}, 12^{\mathrm{ra}-\mathrm{vb}}, 63^{\mathrm{ra}}-74^{\mathrm{rb}}$, $98^{\mathrm{r}}-103^{\mathrm{va}}, 136^{\mathrm{ra}-\mathrm{rb}}, 138^{\mathrm{r}}-139^{\mathrm{v}}, 148^{\mathrm{va}}-149^{\mathrm{vb}}$ rubriziert, rote Überschriften, Unterstreichungen und 2-5zeilige Lombarden, sonst Raum für Initialen ausgespart, teilweise mit Platzhaltern; $103^{\text {va }}$ grosser Fleck von verschüttetem Rubrum. $3^{\mathrm{rb}}-10^{\mathrm{vb}}, 25^{\mathrm{ra}}-62^{\mathrm{va}}, 76^{\mathrm{rb}}-84^{\mathrm{va}}, 105^{\mathrm{rb}}-115^{\mathrm{rb}}, 127^{\mathrm{rb}}-133^{\mathrm{va}}, 140^{\mathrm{vb}}-147^{\mathrm{ra}}, 149^{\mathrm{va}}-162^{\mathrm{vb}}$ 
und $174^{\mathrm{va}}-201^{\mathrm{v}}$ Überschriften und Stellenangaben in vergrösserter Schrift, teilweise in Auszeichnungsschrift, Unterstreichungen und Paragraphenzeichen. $25^{\mathrm{ra}}-29^{\mathrm{rb}}, 58^{\mathrm{vb}}-62^{\mathrm{ra}}$ und $83^{\mathrm{rb}-\mathrm{va}}, 85^{\mathrm{ra}}-88^{\mathrm{ra}}$ textgliedernde Marginalien. 25r $-48^{\mathrm{r}}$ Buchzählung im Kopftitel. $1^{\text {ra }}$ schwarz-rote Initiale in Form eines Fischs, $175^{\text {va }}$ kleiner in Schwarz; $79^{\mathrm{rb}}$ und $181^{\mathrm{ra}}$ schwarze Initiale mit gespaltenem Schaft, die erste flüchtig ausgeführt. $174^{\mathrm{vb}}$ und $175^{\text {va }}$ kleiner Wappenschild mit den Initialen $L . Z$. in Tinte. $138^{\mathrm{r}}$ Arbor consanguinitatis aus Kreisen und Linien, $138^{\mathrm{v}}-139^{\mathrm{v}}$ weitere ähnliche Grafiken zu verschiedenen Verwandtschaftsverhältnissen. 193 ${ }^{\mathrm{r}}$ schematische Skizze von einem Herz.

Korrekturen und Nachträge: Korrekturen der Schreiber, z. B. 11 ${ }^{\mathrm{ra}}, 65^{\mathrm{vb}}, 100^{\mathrm{rb}}, 136^{\mathrm{ra}}, 169^{\mathrm{vb}}, 200^{\mathrm{vb}}$. Durchgehend Korrekturen und Annotationen von der Hand Ludwig Zellers, $1^{\text {r }}-10^{\text {va }}$ alle Überschriften, $127^{\text {va }}$ texterschliessende Marginalien, 38 , $51^{\mathrm{va}}$, 56 , $133^{\mathrm{ra}}$, $184^{\mathrm{v}}$ etwas längere Nachträge. $65^{\mathrm{ra}}-72^{\mathrm{rb}}$ Handweiser. $117^{\mathrm{r}}$ Libellus penitentialis Ioanis de Deo, doctore decretorum Hispano, scriptore saeculi XIII., 17./18. Jh.

Einband: Mit hellem Leder überzogene Holzdeckel mit abgeschrägten Kanten, 15. Jh. Streicheisenlinien, Einzelstempel: Vierblattblüte in Quadrat, gefiedertes Dreiblatt, Eichel. Blau-weiss-rote, geflochtene Kapitale. Reste von zwei nach vorn greifenden Kantenschliessen, Beschläge Messing, Befestigungen hinten Vierpass (Blüten). Schnitt ehemals gelb gefärbt. Spiegel und Vorsatz (207) jeweils ein zusammenhängendes und zusammen mit den darunter eingeklebten Pergamentstücken um die benachbarte Lage geführtes Doppelblatt, Papier, vorderes Vorsatzblatt herausgerissen; Makulatur: vorne zwei Predigten zu Io 7,33, hinten Predigt zu Lc 15,10, 15. Jh. Eines der beiden vorderen Pergamentstücke Fragment einer Urkunde, 14./15. Jh. In den Fälzen weitere Fragmente eines Breviers, einer kanonistischen Handschrift und eines Kommentars, 14. Jh. Im vorderen Spiegel Exlibris des Chorherrenstifts Beromünster (Wegmann, Exlibris, Nr. 619). Auf den Deckeln Beschriftung, vorne: Collegii Beronensis, 16./17. Jh., am unteren Rand zwei Zeilen abgewaschen, 15. Jh.; hinten: Ludwicus, 15. Jh., und Abklatsch. Auf dem Rücken verwischte Beschriftung, $E[$ nchiri] $d[$ ion], 16. Jh. Rückenschild: Enchiridion S. Augustini, starker Tintenfrass, der Rest nicht mehr lesbar.

Herkunft: Der Grossteil dieser Handschrift wurde im Jahr 1468 während eines Studienaufenthalts an der Universität Leipzig von und für Ludwig Zeller geschrieben. Ausser ihm waren an der Arbeit Rudolf Grünli und zwei weitere Schreiber beteiligt. Die Aufteilung der Texte auf die Lagen und die zahlreichen Besitzeinträge lassen vermuten, dass die einzelnen Faszikel zunächst separat vorlagen. Die ersten zwei Lagen schrieben Ludwig Zeller und eine weitere Person ein Jahr später, nach den Wasserzeichen zu schliessen in Beromünster. Besitzer: Ludwig Zeller von Brugg, siehe Besitzeinträge $24^{\mathrm{ra}}, 48^{\mathrm{vb}}, 74^{\mathrm{rb}}, 75^{\mathrm{rb}}, 88^{\mathrm{ra}}, 116^{\mathrm{vb}}, 133^{\mathrm{ra}}, 148^{\mathrm{va}}, 189^{\mathrm{rb}}$, 192 va, 201 rb, 203 vb. Zu ihm: Kopp, Stiftsbibliothek, I, S. 11, Clara Müller, Geschichte des aargauischen Schulwesens vor der Glaubenstrennung, Aarau 1917, S. 95 (Nr. 171) und 97 (Nr. 231); Erster datierter Schweizer Druck, S. 15f.; SIDLER, Bildungsverhältnisse, S. 175f. (Nr. 160). Im Catalogus von 1763 als Classis Nona Nr. 12 verzeichnet, im Nachtrag dazu auf 46 ${ }^{\mathrm{r}}$ als Nr. I, in den Antiquitates Beronenses, S. 691, als Nr. 25 und im Catalogus von 1826 als Nr. 27. Im vorderen Spiegel Exlibris des Chorherrenstifts Beromünster und mit Filzstift neuere Signatur C 57, spätes 20. Jh. Ehemals C 6 fol.

Literatur: Estermann, Stiftsschule, S. 15; Kopp, Stiftsbibliothek, II, S. 17; BruCKner, Scriptoria 9, S. 29f.; BÜCHLER, Beromünster, S. 123, 165f., 169; CMD-CH 2, Nr. 86, JANnER/Jurot/WebER, Handschriftliche Überlieferung, Bd. IX/2, S. $71 f$.

$1^{\text {ra-va }}$ Tabula. Kapitelverzeichnis zum Enchiridion. >Incipiunt capitula libri Encheridion beati Augustini<. Interrogacio per epistolam, capitulum $1^{m}$. Quid intersit inter sperare et timere, capitulum $2^{m} \ldots-\ldots$ De quatuor 
perfectuum differenciis, 87. De caritate etc., 89. Explicit tabula libri Encheridion beati Augustini habens 89 capitula. Encheridion est manualis.

1 vb leer.

$2^{\mathrm{ra}}-24^{\mathrm{ra}}$ AURELIUS AUGUSTINUS, Enchiridion. > Incipit liber Hencheridion beati Augustini episcopi ad Laurencium primicerium Romane ecclesie de fide, spe et caritate <. Dici non potest, dilectissime fili Laurenti, quantum tua erudicione delectar ... - ... utinam tam commodum quam prolixum de fide et speret (sic) caritate conscripsi. Amen. CC 46, S. 49-114 (mit abweichender Kapiteleinteilung). CPL 295; Janner/Jurot/ WeBer, Handschriftliche Überlieferung, Bd. IX/1, S. 51. Anschliessend: L. Z. Et sic est finis 1469. $24^{\mathrm{rb}-\mathrm{v}}$ leer.

$25^{\mathrm{ra}}-48^{\mathrm{vb}}$ JOHANNES DE FONTE, Conclusiones super quattuor libros Sententiarum. > Conclusiones libri sentenciarum < [v] eteris ac nove legis. Distinccio prima, conclusio prima est, quod tractatus sacre pagine sive continencia veteris ac nove legis versatur precipue circa res et signa ... - ... Duodecima conclusio est etc. Egredientur electi ... visa impiorum ineffabili calamitate. A qua nos custodiat deus omnipotens, qui vivit et regnat deus in secula seculorum. Amen. 29vb Buch 2, 33 vb Buch 3, 38 rb Buch 4. Vgl. GW M13568: Johannes [de Fonte], Compendium librorum Sententiarum, [Augsburg: Günther Zainer, 1475-76], mit zahlreichen Auslassungen, Paraphrasen und geänderter Zählung. Friedrich STEGMÜLLER, Repertorium Commentariorum in Sententias Petri Lombardi, Bd. 1, Würzburg 1947, S. 217-218, Nr. 446. Anschliessend: Explicunt excerpta conclusionum sentenciarum magistri Petri Longobardi collecta per Iohannem de Fonte ordinis fratrum minorum pro informacione studentum minus peritorum. Scripta per me Ludowicum Zeller, studentem Lipsensem et Basiliensem in Liptzig anno sexagesimo octavo, quarto Idus octobris (12. Oktober 1468) etc. Deo gracias. Darunter in anderer Tinte: Eodem anno Schwitenses devastarunt Alsaciam.

$49^{\mathrm{r}-\mathrm{v}}$ leer.

50 ra_51 va Ps.-AUGUSTINUS, Sermo de contemptu mundi. > Sequitur libellus beati Augustini de contemptu mundi<. [A] udite, fratres karissimi, salutiferam patris vestri doctrinam ... - ... ut de suis beneficiis perhennes sibi reddamus gracias Ihesu Christo domino, qui cum patre etc. Explicit libellus beati Augustini de contemptu mundi. Deo gracias. PL 40, Sp. 1215-1218. Bloomfield, Incipits, Nr. 548; Janner/Jurot/Weber, Handschriftliche Überlieferung, Bd. IX/1, S. 234, Sermo 59 fr. er.

51 $1^{\mathrm{vb}}-62^{\mathrm{va}}$ FULGENTIUS RUSPENSIS, De fide ad Petrum. > Incipit epistola beati Augustini ad Petrum de fide<. Epistolam, fili Petre, tue caritatis accepi, in qua te signifficasti Ierosolimam pergere ... - ... Et si quis aliter sapit, hoc illi quoque deus revelavit. Amen. 55 ra 2. Teil. CC 91A, 711-760 (Regula III und IV, XXX und XXXI jeweils in umgekehrter Reihenfolge). CPL Nr. 826; JANNER/Jurot/WEBER, Handschriftliche Überlieferung, Bd. IX/1, S. 57. Anschliessend: Beati Augustini de fide ad Petrum explicit. 1468 in Liptzg.

$62^{\mathrm{vb}}$ leer.

$63^{\mathrm{ra}}-74^{\mathrm{rb}}$ HONORIUS AUGUSTODUNENSIS, De cognitione verae vitae. > Prefacio Augustini in librum de cognicione vere vite<. Sapiencia, que os muti apperuit ... $63^{\mathrm{rb}}>$ Incipit liber. Fratres $<$ gracias deo persolvimus ... - ... et omnium beate vivencium faciet te deus participem, qui nos omnes ad summum bonum perducat. Amen. PL 40, Sp. 1005-1032. Janner/Jurot/Weber, Handschriftliche Überlieferung, Bd. IX/1, S. 35. Anschliessend in Rot: Ludowici Zeller de brugg. Darunter von der Hand des Schreibers: Rudolfus Grünli. Augustinus de cognicione vere vite explicit feliciter, finitus in alma universitate Lipzensi 1468.

$74^{\mathrm{va}}-75^{\mathrm{rb}}$ CAESARIUS ARELATENSIS, De indigna familiaritate extranearum mulierum et de martyrio. >Incipit Augustinus de fuga mulierum<. Nemo dicat, fratres, quod temporibus nostris martirum 
certamina esse non possunt ... - ... ipso domino nostro Ihesu Christo mediatore dei et hominum largiente, cuius misericordia plena est terra. Amen. CC 103, S. 180-184. Janner/Jurot/Weber, Handschriftliche Überlieferung, Bd. IX/1, S. 220. Anschliessend: Explicit tractatus beati Augustini de fuga mulierum 1468 L. Zeller.

$75^{\mathrm{rb}}-76^{\mathrm{rb}}$ CAESARIUS ARELATENSIS, Ammonitio ut iugalis castitas conservetur et concubinae non habeantur. > Incipit tractatus beati Augustini de continencia<. [Q] uando castitas (sic) bonum, fratres carissimi, secundum quod decet et expedit commendamus ... - ... ut ad eternam mereamur felicitatem unanimiter pervenire prestante domino nostro Ihesu Christo, cui est honor et gloria in perpetuum et in secula seculorum. Amen. Explicit tractatus beati Augustini de continencia. CC 103, 189-192, 194 (6. bis 8. ausgelassen). BLOomfIELD, Incipits, Nr. 4387; Janner/Jurot/Weber, Handschriftliche Überlieferung, Bd. IX/1, S. 219, Sermo app. 289.

76 ${ }^{\mathrm{rb}}-79^{\mathrm{ra}}$ Ps.-AUGUSTINUS, De vera et falsa poenitentia. Erster Teil und Schluss des Textes (nachträglich ergänzt auf 79 ${ }^{\mathrm{ra}}$ ), mittlerer Teil siehe $80^{\mathrm{ra}}-84^{\mathrm{vb}}$. $>$ Incipit liber de vera et falsa penitencia beati Augustini, quem fecit ad preces Redilinde sororis sue necnon ad instanciam aliarum mulierum sanctimonialium sibi mutuo suplicancium. Incipit prefacio<. [Q] uantum sit appetenda gracia penitencie, omnis autoritas clamat ... $76^{\text {va }} \mathrm{Et}$ finita prefacione incipit liber. $>$ De fide catholica capitulum $i^{m}<$. Sicud fides est fundamentum boni ... $78^{\mathrm{vb}}$ Sine penitencia nulli profuit //. Anschliessend Verweiszeichen a und Reklamant baptisma qui. 79ra Verweiszeichen b, anschliessend Text: // in alterius crimine, discrecionem in varietate ... - ... et sui luminis prerogativam contulit dignitatis et ideo stabilitatis, modo rem sanitatis. Deo gracias. Explicit Augustinus de vera et falsa penitencia etc. PL 40, Sp. 1113-1119, 1130. BLOOMFIELD, Incipits, Nr. 4419; CPL, S. 153; CPPM 2B, Nr. 3081; JANNER/ Jurot/Weber, Handschriftliche Überlieferung, Bd. IX/1, S. 105.

79 ${ }^{\mathrm{rb}-\mathrm{vb}}$ AURELIUS AUGUSTINUS, Sermo de paenitentibus. > Incipit tractatus alius brevis beati Augustini depenitencia<. Penitentes, penitentes, penitentes si tamen estis penitens (sic) et non estis irridentes, mutate vitam ... - ... ergo dimitte incertum et tene certum. Amen. Éric Rebillard, Étude critique du sermon 393 de saint Augustin: de paenitentibus, in: Recherches augustiniennes 28 (1995), S. 82f. (Textfassung A). BLOomfIELD, Incipits, Nr. 3835; CPL, Nr. 285, Sermo 393; Janner/Jurot/Weber, Handschriftliche Überlieferung, Bd. IX/1, S. 190, Sermo 393. Anschliessend: Explicit tractatus beati Augustini de penitencia. 1468 in Liptzg. $80^{\mathrm{ra}}-84^{\mathrm{vb}}$ Ps.-AUGUSTINUS, De vera et falsa poenitentia. Mittlerer Teil des Textes beginnend mit Verweiszeichen a, erster Teil und Schluss siehe $76^{\mathrm{rb}}-78^{\mathrm{vb}}$. // baptisma, qui peccat spontaneus ... - ... habet dulcedinem in affectione, pietatem //. PL 40, Sp. 1119-1130. Anschliessend Verweiszeichen b und Reklamant in alterius crimine. Dann: Quere ante in sexto folio huius. Das folgende Blatt herausgerissen, noch während des Schreibens durch das eingeschobene Bl. 79/84 ersetzt.

$85^{\mathrm{ra}}-88^{\mathrm{ra}}$ GENNADIUS, De ecclesiasticis dogmatibus. >Incipit tractatus beati Augustini de ecclesiasticis dogmatibus, hoc est de symbolo<. Credimus unum esse deum, patrem et filium et spiritum sanctum. Patrem eo quod habet filium ... - ... et sine reprehensione consciencie certe mobilitate et mutabilitate peccatricis anime. Amen. Beati Augustini de eclesiasticis dogmatibus tractatus explicit. L. Z. Cuthbert H. Turner, The Liber ecclesiasticorum dogmatum attributed to Gennadius, in: The Journal of Theological Studies 7 (1905), S. 8999. RB 2446; CPL 958; Janner/Jurot/Weber, Handschriftliche Überlieferung, Bd. IX/1, S. 45.

$88^{\mathrm{rb}}-92^{\mathrm{rb}}$ Ps.-AUGUSTINUS, Dialogus quaestionum. Veni sancte spiritus. >Incipit dyalogus beati Augustini ad Orosium <. Licet multi et probatissimi viri diverso quidem stilo, sed non diversa fide innumerabilia opuscula ediderunt ... - ... Totam terram aqua tegebat sicut rarissima nebula, que postea in unum redacta //. PL 40, Sp. 733-743. CPL 373a; Janner/Jurot/Weber, Handschriftliche Überlieferung, Bd. IX/1, S. 40. Am unteren Rand: Defficit media pars illius. 
$92^{\mathrm{v}}-97 \mathrm{v}$ leer.

98 $8^{\mathrm{ra}}-116^{\mathrm{vb}}$ JACOBUS DE PARADISO, De potestate daemonum. > De potestate demonum, arte magica, supersticionibus et illusionibus eorundem <. Doctrinis variis et peregrinis nolite abduci, ad Hebreos ultimo. Hec doctrina appostolica et saluberrima hortatur fideles ... - ... ut omnibus erroribus seclusis in veritatis et salutis via omnes ambulare possimus ad ipsum, qui via est, veritas et vita, Ihesum Christum, qui est super omnia deus benedictus in secula. Amen. Ludger MeIER, Die Werke des Erfurter Kartäusers Jakob von Jüterbog in ihrer handschriftlichen Überlieferung, Münster 1955, S. 28f., Nr. 26 (Hs. nicht erwähnt); Dieter MERTENS, Iacobus Carthusiensis, Göttingen 1976, S. 278, Nr. 26 (Hs. nicht erwähnt). Anschliessend: Deo gracias L. Z[in anderer Tinte:]eller. Hanc materiam collegi in Liptzg a devoto sacerdote de Dacia ibi studente 1468. Orate pro.

$117^{\mathrm{ra}}-127^{\mathrm{ra}}$ JOHANNES DE DEO, Liber poenitentiarius. Ohne Buch 5-7. [A]d honorem summe trinitatis et individue unitatis patris et fllii et spiritus sancti et gloriose virginis genitricis domini nostri Ihesu Christi et omnium agminum angelorum omniumque sanctorum dei et ad utilitatem sacerdotum confessiones audiencium ego Iohannes de Deo presens opusculum de regulis penitencialibus composui ... - ... Et hoc attestatur Gregorius xi q. 3. Qui recte iudicat, qui excuttit manus suas ab omni munere, spem habitet (sic) in excelsis etc. $120^{\text {ra }}$ 2. Buch, 122 ra 3. Buch, 124ra 4. Buch. Bloomfield Nr. 238; Michaud-Quantin, Sommes de casuistique et manuels de confession au moyen âge, Louvain 1962, S. 26f.; Giovanna MurAno, La tradizione delle opere di Iohannes de Deo ed il ms Roma, Biblioteca Casanatense 1094 (A.II.10), in: Mediaevalia. Textos e estudos 26 (2007), S. 54f. Anschliessend: Sequitur quintus liber continens de penitencia pape usque ad ultimum, sequitur etiam $6^{\text {tus }}$ liber de penitencia imperatoris etiam ad ultimum statum secularium, et septimus de his, qui[bus] peccata favente domino vitare possunt etc. Quos obmittere oportet propter deffectum temporis, exemplar non possum amplius tenere etc. Tamen aliquos titulos ex septimo ascribam utiliores etc. Dann Verse: Diviciis uti res adversa saluti, WALther, Carmina, Nr. 6145. Paucos credo bonos, quo[s] beat eris onus. Mollicies vestis, coytus, gula, cura quietis, Possunt luxurie quattuor esse rote.

$127^{\mathrm{rb}}-128^{\mathrm{va}}$ Excerpta ex Libro poenitentiario. > De hiis que abusive fiunt a quibusdam <. Legitur in canone sancti Augustini quod ea, que ultimo dicuntur, melius memorie commendantur ... Primum est, quod mulieres deo dicate attingunt sacra vasa, quod eis nulla licuit racione ... - ... et alios a peccatis similibus probibeatis quantum valeatis. Amen. Explicit hoc opus.

$128^{\mathrm{vb}}$ BONAVENTURA, Breviloquium. Exzerpt. > Hec sequencia dicit Bonaventura in Breviloquio parte sexta de matrimonio capitulo ultimo versus finem, que bene notanda sunt, quia verba eius sunt in forma<. Postremo quia dicta coniunctio matrimonialis debet esse ex libero consensu ... - ... et propter morbum annexum etc. Hec Bonaventura. Doctoris seraphici S. Bonaventurae S. R. E. episcopi cardinalis opera omnia. Bd. 5, Opuscula varia theologica, Quaracchi 1891, S. 280a-b. DistelBRINK, Bonaventurae scripta, Nr. 1.

129 ra-133 ${ }^{\text {ra }}$ BONAVENTURA, Breviloquium. Exzerpt. > Bonaventura in Breviloquio habens septem partes, incipit tercia pars de corruptela peccati habens xi capitula, primum capitulum de origine mali, ut patebit in processu<. Predeterminatis aliquibus breviter de trinitate dei et creatura mundi, restat nunc aliqua breviter tangere de corruptela peccati ... - ... et ideo incarnacionem eius desiderabat universitas salvandorum. Cui mediatori domino nostro sit omnis honor et gloria in secula seculorum. Amen. L. Z. Bonaventura, Opera omnia, Bd. 5: Opuscula varia theologica, Quaracchi 1891, S. 231a-241b. DistelBrink, Bonaventurae scripta, Nr. 1. Anschliessend: Et sic est finis $3^{e}$ partis Boneventure devote (sic) doctoris in Breviloquio, in Liptzig 1468. Deo gracias. 
$133^{\text {rb }}$ AEGIDIUS ROMANUS, Theoremata de corpore Christi. Exzerpt. > Teremata Egidii 50. et ultimum de hostia consecrata, et est quasi conclusio tocius<. Totus Christus sub utraque specie panis et vini a fidelibus sumitur ... - ... sub accidentibus panis et vini totus Christus existit etc. GW 7209: Theoremata de hostia consecrata Egidij de Roma ordinis heremitarum sancti Augustini, Köln: Koelhoff, 14. 10. 1490, [n vi] ${ }^{v}$-[n vii] . Anschliessend: Nunc concludit Egidius de Roma ordinis heremitarum sancti Augustini.

$133^{\text {va }}$ Notanda theologica. Sechs Notizen. Hec tria designantur per baculum episcopalem, que continentur in hiis versibus ... Collige per primum, medio rege, punge per ymum, Atrahe, sustenta, stimula vaga, morbida, lenta ... Item nota ...

$134^{\mathrm{ra}-\mathrm{rb}}$ Fragmentum operis de poenitentia. Ausgestrichen. // desinat peccare aliter excommunicet eum uel denunciet superiori ... - ... sacerdotes populi peccata comedunt et suis precibus ea delent.

$134^{\mathrm{v}}$ Notanda de impedimentis matrimonii. Querformat, Langzeilen. Uxoricida 33 q. 5. Interfectores et $1^{a}$ 37, capitulo ultimo. Aut interficit propter culpam ... Hec sunt impedimenta matrimonii ... Versus: Vincula coniugium casus bis quinque resolvunt, Condicio dispar, cultus, vis, error, honestas, Fri [gi] ditas, habitus, ordo, congregacio, votum ... Augustinus: Est coniugium aliud legitimum et non ratum ...

$135^{\mathrm{r}-\mathrm{v}}$ leer.

$136^{\mathrm{ra}}-140^{\mathrm{vb}}$ JOHANNES ANDREAE, Lectura super arboribus consanguinitatis et affinitatis. $>$ Textus compositus a Iohanne Andree super arborem consanguinitatis<. Circa lecturam arboris diversis olim diversum modum tenentibus ... - ... sed si alium habes patrem, alium socerum numerosius se caritas protendit. In qua universi fideles et precipue studentes per graciam eius, qui est benedictus in secula secula (sic) seculorum. Amen. Auf dem Doppelblatt 138/139 die in den Text eingeschalteten schematischen Darstellungen (s. Lagen und Ausstattung). GW 1676: Johannes Andreae, Lectura super arboribus consanguinitatis et affinitatis, [Nürnberg, ca. 1473]. Vgl. Helko EIs, Artikel Andreae, Johannes, in: Verfasserlexikon², Bd. 1 (1978), Sp. $336 f$. Anschliessend von der Hand Ludwig Zellers: Et finitus in Liptzg est textus 1468. L. Z.

$140^{\mathrm{vb}}-148^{\mathrm{rb}}$ Commentarius in Iohannis Andreae Lecturam super arboribus consanguinitatis et affinitatis. > Circa lecturam arboris consanguinitatis nondum ibi attendens lectio modo sic<. Triplex est recommendatio seu laus: quod (sic) est necessaria, quedam utilis et quedam levis seu voluntaria ... - ... deficit causa probibicionis et per consequens effectus facit, capitulo Cum cessante de appellacione. Hoc etiam clarius patet perfiguram hic proxime postpositam.

$148^{\mathrm{va}}-160^{\mathrm{rb}}$ GERARDUS MONACHUS, Defensorium iuris. $>$ L. Z. Defensorium iuris. $1468<$. Quia bone rei dere (sic) consilium presentis vitte presentis (sic) subsidium et eterne remuneracionis premium expectatur, xii q. iic. Bone rei, ideo ego Gerardus Monachus de Rivo Sancte Marie Cisterciensis ordinis, videns regulas propter maleficiam actoris fatigari laboribus et expensis, presens opusculum de corpore canonum, decretalium ac legum collegi ... - ... Si autem lis non fuerit, contestata perit instancia. Explicit defensorium iuris canonici compositum per me, [Ge]rardum de Rivo Sancte Marie ordinis Cistersiensis, collectum ex diversis tractatulis iuristarum ... quem composuit de Deo Hyspanus. GW M47366: Tractatus plurimi iuris, [Basel: Johann Schilling(Solidi), nicht nach 1476], [190] ${ }^{\mathrm{ra}}$ - [210]vb mit kleineren Abweichungen. Schulte, Geschichte, S. 314-316. Anschliessend: Scriptor erat sanus, non tamen apta manus. 160va $161^{\text {ra }}$ Errores Graecorum. >Errores Grecorum<. Primus: Ab ipsa maiestate divina negant terciam personam ... - ... quia utitur mitris, anulis et preciosis lapidibus in sacrificio et cum pompa prelati incedunt contra Christi exemplum etc. Vgl. Freiburg i. Br., Universitätsbibliothek, Hs. 26, $5^{\mathrm{r}}-8^{\mathrm{r}}$ mit abweichendem Schluss. $161^{\mathrm{rb}}-173^{\mathrm{vb}}$ ALBERTUS DE FERRARIIS, De horis canonicis. [I]n nomine domini, Amen. Hec est tabula composita a domino Alberto de Secrtariis (sic), iuris utriusque doctoris de Placentia, super infrascripto op [usc] ulo [de] 
horis canonicis ... 162 $16 \mathrm{vb}$ et de multis aliis vide in questione incipiente: Quero quomodo debeat se habere etc. Et est questio finalis in ordine. > Incipit tractatus de horis canonicis <. Materiam horarum quas canonicas appellavimus sub brevi stilo divina oppitulante gracia tractandum (sic) assumpsi ego Albertus de Ferrariis ... - ... intra in gaudium domini, domini tui. Ad quod quidem gaudium ille nos perducat qui est trinus et unus semper benedictus in secula seculorum. Amen etc. Entspricht GW M47661: Albertus de Ferrariis, De horis canonicis, [Rom: Bartholomäus Guldinbeck, nicht vor 1476, nicht nach 1480], Quaestio 31 (in der Hs. irrtüml. 24) und 33 (26) mit längeren Zusätzen am Ende, Quaestio 35 (28) am Anfang und in der Mitte, Quaestio 41 (33) in der Mitte und am Ende. $174^{\mathrm{ra}}-185^{\mathrm{va}}$ Tractatus de peccatis. Sicut dicit philosophus $2^{\circ}$ Ethicorum: Malum non vitatur nisi precognitum. Quia autem vicia sunt mala, idcirco vitari non possunt nisi congnoscantur ... $176^{\mathrm{rb}}$ circa que nisi occurrat racio et consensus restringatur. Peccabit homo mortaliter etc. Sequitur de peccatis mortalibus in speciali per L. Z. de Brugg. $>$ Peccata mortalia sunt ista: superbia, avaricicia (sic), luxuria, invidia, gula, ira, accidia<. Et vocantur ista septem peccata mortalia capitalia ... 176 va $>$ Superbia igitur est< appetitus proprye excellencie ... $180^{\text {ra }}$ et isti sunt rami ex superbia communiter ebulientes. >Sequitur de remedio superbie. L. Z.< Superbie remedium est consideracio proprye vilitatis ... - ... Nam uxorem cognoscere contra naturam est gravius quam cum proprya matre incestum facere, xxii ${ }^{a}$ q. vii ${ }^{\mathrm{a}}$ per Augustinum ut eciam dictum. 180vb Avaricia, 184 ${ }^{\mathrm{va}}$ Luxuria. Möglicherweise von Ludwig Zeller selbst abgefasst. Von den aufgezählten sieben Todsünden werden nur drei behandelt, gegen Ende nimmt der Text immer mehr den Charakter einer Quellensammlung an.

$185^{\mathrm{va}-\mathrm{vb}}$ Forma confitendi in articulo mortis. >Pro exhortacione in agone iacentis. Sanctus Wilhelmus beate virginis < assignatus capellanus hanc sequentem scribit pro infirmorum excitanda devocione exhortacione $[\mathrm{m}] . . .-\ldots$ pone mortem Ihesu Christi inter nos et iram tuam, et miserere mei. Ego commendo in manus tuas spiritum meum. Amen.

$186^{\mathrm{ra}}-187^{\mathrm{ra}}$ Commentarius in Orationem dominicam. [P] ater non dominus, quia amari appetit, non timeri ... - ... et dimite nobis debita nostra //. RB 9763. Bernd ADAM, Katechetische Vaterunserauslegungen. Texte und Untersuchungen zu deutschsprachigen Auslegungen des 14. und 15. Jahrhunderts, Zürich 1976, S. 182-192, Z. 189.

$187^{\mathrm{rb}-\mathrm{vb}}$ leer.

188 ${ }^{\mathrm{ra}}$-189rb JOHANNES HISPALENSIS, Ps.-Aristoteles, Secretum secretorum. >Incipit libellus de regimine sanitatis<. $[\mathrm{N}]$ omine vel gracia dei Yspane regine Iohannes Yspanus salutem. Cum de utilitate corporis olim tractaturus ... 188 $8^{\mathrm{rb}}$ Alexander, cum sit corpus corruptibile ... - ... Hec omnia et multa alia corpus debilitant. Hermann Suchier, Denkmäler provenzalischer Literatur und Sprache, Halle 1883, S. 473-480, Z. 182. Thorndike/Kibre, Incipits, S. 291; Charles B. Schmitt, Dilwyn Knox, Pseudo-Aristoteles latinus, London 1985, S. 54f. (Hs. nicht verzeichnet); LoHr, Aristotelica Helvetica, S. 167. Anschliessend: Deo gracias 1468. Explicit regimen sanitatis per Ludowicum Zeller de Brugg.

189'rb-192 va JOHANNES HISPALENSIS, Costa Ben Lucae, De differentia spiritus et animae. >Incipit libellus de differencia spiritus et anime collectus ex diversis libris<. Interrogasti me, honoret te deus, de differencia, que est inter spiritum et animam ... - ... et det tibi gloriam in hoc seculo et in futuro. Amen. Carl Sigmund BARACH, Excerpta e libro Alfredi Anglici De motu cordis item Costa-Ben-Lucae De differentia animae et spiritus, Innsbruck 1878, S. 120-139. Thorndike/Kibre, Incipits, S. 771; Charles H. Lohr, Medieval Latin Aristotle commentaries, in: Traditio 23 (1967), S. 323, Nr. 22 (Hs. nicht verzeichnet); LoHR, Aristotelica Helvetica, S. 167 (zu dieser Hs.). Anschliessend: Quia tu es de Yorc. Skite Ualter etc. Explicit liber de differencia spiritus et anime per L. Z. 1468. Et hec de textu sequitur glosa. 
$192^{\mathrm{va}}-201^{\mathrm{rb}}$ Commentarius in De differentia spiritus et animae. Circa initium libri de spiritu et anima sumitur hec proposicio: Opportet nos speclari in rebus ... - ... Sed spiritus naturalis est tantummodo incrementum omnium, que sunt in humano corpore naturali etc. Deo gracias. LoHr, Aristotelica Helvetica, S. 167. Anschliessend: In die Iohannis baptiste in Liptzig 1468. Et composita sunt Barisius originaliter hec dicta. L. Z. de brugg in ergwe. 201va_203vb WALTER MAP, Dissuasio Valerii. > Valerii Maximi oratoris primarii epistola ad Ruffinum<. Loqui prohibeor et tacere non possum ... - ... Sed ne Horestem scripsisse videar vale. Walter Map, De Nugis Curialium, hrsg. v. M. R. James, C. N. L. Brooke und R. A. B. Mynors, Oxford 1983, S. 288-312. Anschliessend: Deo gracias L. Z. et finita in alma universitate Lipsensi in bursa Missnensium anno 1468. Die ersten zwei Seiten intensiv marginal kommentiert: Valerius Maximus volens disswadere Ruffino amico suo ne uxorem duceret...

$204^{\mathrm{r}}-206^{\mathrm{v}}$ leer.

$207^{\mathrm{r}}$ Excerpta. 16 Bibelstellen, Nachtrag. > De muneribus non acipiendis<. Exodi 23. Non accipies munera ... $207 \mathrm{v}$ leer.

Papier, 319 Blätter, 30,5 × 21,5-22 cm

Drittes Viertel des 15. Jahrhunderts

Wasserzeichen, Lagen, Foliierung: Wasserzeichen: Ochsenkopf, PICCARD, Wasserzeichenkartei Nr. 72656 (1466) und 72724 (1468). Lagen: $(V I-1)^{11}+20 \mathrm{VI}^{251}+(\mathrm{V}-1)^{260}+(\mathrm{VI}-1)^{271}+4 \mathrm{VI}^{319}$, Bl. 11 lose, ein Rest des ersten Blatts der Lage an das vordere Spiegelblatt geklebt; nach Bl. 260 (bzw. vor Bl. 261) zwei Blätter herausgerissen. Im hinteren Teil der Hs. Zählung der Doppelblätter in der ersten Lagenhälfte: 1-6, vereinzelt sichtbar zwischen $231^{\mathrm{r}} 4$ und 299r 4. Reklamanten, 83 $239^{\mathrm{v}}$ und 295 vertikal; $10^{\mathrm{v}}$ ein Reklamant: Sive hec te (Versanfang der 13. Zeile auf derselben Seite). Neuere Foliierung: 1-319.

\section{Einrichtung und Ausstattung:}

$1^{\mathrm{r}}-203^{\mathrm{v}}$ vertikale Begrenzung des Schriftraums mit Stift, links doppelt (Versinitialen abgesetzt), B1. 72-83 zusätzlich Blindliniierung; Schriftraum 19-21,5 × 11-12, 30-35 (Prosa) resp. 18-21 Zeilen (Verse, Hand A), 12-18 Zeilen (Verse, Hand B). Schleifenlose jüngere gotische Buchkursive von zwei Händen, Händewechsel $72^{\mathrm{r}}$ und 83v/84r ; Hand A möglicherweise Johannes Remishůb von Feldkirch, vgl. C 64. Initialen der einzelnen Verse in Zierschrift, z. T. mit Cadellen. Rubriziert, rote Überschriften, Sprecher und deren Kürzel in Rot. 1-2zeilige rote Lombarden, z. T. mit Konturbegleitstrichen und Ausläufern, $7^{\mathrm{r}}$ und $17^{\mathrm{v}}$ mit menschlichen Gesichtern im Profil, $145^{\vee}$ mit schwarzem Fleuronné.

$204^{\mathrm{r}}-260^{\mathrm{r}}$ vertikale Begrenzung des Schriftraums mit Stift, ab Bl. 230 zusätzlich Blindliniierung und ab Bl. 232 eine äussere Begrenzung für (nicht vorhandene) Marginalien; Schriftraum 19,5-21 × 10-12, 17-19 Zeilen, ab 230v $18 \times 9-10,21$ Zeilen. Schleifenlose jüngere gotische Buchkursive von zwei Händen (A und B), Händewechsel 229v/230r. Rubriziert. 233 ${ }^{\mathrm{r}}$ zwei einzeilige rote Lombarden, 204r zweizeilig, mit schwarz gefüllter Schaftaussparung, schwarz-rotem Fleuronné und einem kurzen schwarzen-rot Fleuronnéstab.

$261^{\mathrm{r}}-283^{\mathrm{v}}$ vertikale Begrenzung des Schriftraums mit Stift, links doppelt, 261 ${ }^{\mathrm{v}}-271^{\mathrm{v}}$ mit Tinte, Schriftraum 19-20,5 × 10-12, 17-21 Zeilen. Schleifenlose jüngere gotische Buchkursive von einer Hand (A). Initialen 
der einzelnen Verse in Zierschrift. Rubriziert, rote Überschriften, Sprecher und deren Kürzel in Rot. 1-2zeilige Lombarden.

284r-299v Blindliniierung, Schriftraum 21,5 × 13,5, 42 Zeilen. Schleifenlose jüngere gotische Buchkursive von einer Hand (B). 284 $4^{\mathrm{r}}-286^{\mathrm{r}}, 288^{\mathrm{v}}-290^{\mathrm{r}}$ und $296^{\mathrm{r}}-297^{\mathrm{r}}$ rubriziert, $284^{\mathrm{r}}$ zweizeilige rote Initiale mit leicht verziertem Binnenfeld. Marginalien von der Hand des Schreibers.

$300^{r}-319^{v}$ Blindliniierung, Schriftraum $18 \times 11,5,21$ Zeilen. Schleifenlose jüngere gotische Buchkursive von einer Hand (B). Die Initialen der einzelnen Briefe etwas vergrössert und vereinzelt mit Verzierungen, ansatzweise auch die Adresszeilen (Super- resp. Adscriptio, meist abgekürzt), 307v Zierschrift. Bis auf $305^{\mathrm{r}}-307^{\mathrm{v}}$ rubriziert, 300 $\mathrm{r}$ eine einzeilige rote Initiale. Interlinearglossen von der Hand des Schreibers.

Korrekturen und Nachträge: Korrekturen von der Hand der Schreiber, z. B. 1v, 83r $133^{\mathrm{r}}$, $218^{\mathrm{v}}$ (Vers ergänzt), $262^{\mathrm{r}}$ (siehe Inhalt), 282 ${ }^{\mathrm{r}}$ (Vers ergänzt), 286r $316^{\mathrm{v}} ; 235^{\mathrm{r}}$ der Name Amyclaeus in Georgica 3,89 radiert, in 3,345 hingegen ausgelassen (mit Lücke). 244v an der Stelle des fehlenden Verses Georgica 3,499 von einer Hand wohl des 17. oder 18. Jhs. deest versus. Von der Hand Friedrichs von Lütishofen auf dem vorderen Spiegelblatt: Conicere est per coniecturam seuper sumpcione [co]gnoscere. Daneben: Salvum te advenisse gaudeo, in Eunuch [o]: ex meo propinquo ... $1^{\mathrm{v}}$ Roma suo more tanto me donat honore ... - ... quem nolit Roma perisse. Auch der grösste Teil der Glossen stammt von der Hand des Lütishofen, zudem wohl am Fuß der Seiten im Terenz die Angaben des Komödientitels (recto), in den Andria vereinzelt auch von Akt und Szene. Mindestens zwei weitere Hände noch des 15. Jhs., vgl. 50v, die eine davon möglicherweise der Schreiber A, jeweils am Szenenanfang bei Terenz, zur Hauptsache in den Georgica und den Eklogen; zudem in der Hecyra und zu Beginn des Phormio eine Hand des 16. oder 17. Jhs., z. B. $137^{v}$ Donatus: Acta sane est ludis Megalensibus ... Handweiser, Nota- und Anführungszeichen.

Einband: Mit dunkelbraunem, grösstenteils abgerissenem Leder bezogene Holzdeckel, 15. Jh., Rücken fehlt (seit langem, siehe Titelschild). Auf den beiden erhaltenen Stücken an den äusseren oberen Ecken, das grössere vorne, Streicheisenlinien und Einzelstempel, drei davon abgebildet bei Helene MATTMANN, Inkunabelverzeichnis der Stiftsbibliothek Beromünster, in: Erster datierter Schweizer Druck, Beromünster 1970, Taf. 14, Nr. 3 (EBDB s014709) sowie Nr. 4 und 5; zudem eine sehr kleine fünfzählige Blüte, ein Vierblatt in Quadrat, eine Ranke in rechteckigem Feld und ein Tier (Hund). Ehemals zwei nach vorn greifende Kantenschliessen, Riemenbefestigungen im Rückdeckel erhalten, ebenso die beiden Messingrasten im Vorderdeckel, darauf je zweimal ziseliert: Osan. Spiegelblätter Papier. Kapitale mit ungefärbtem Garn umwickelt. In der Mehrzahl der Fälze Pergamentfragmente, zwischen Bl. 5 u. 6 einer dt. Urkunde, danach Teile einer Buchhandschrift mit den Synonyma des Johannes de Garlandia und dem Kommentar des Ps.Vitalis de Furno zum Liber de sex principiis, 14. Jh. Im vorderen Spiegel Exlibris des Chorherrenstifts Beromünster (Wegmann, Exlibris, Nr. 619). Auf dem Rücken Papierschild: [Tere]ntius Afer, entsprechend dem Catalogus von 1826, die untere Hälfte jedoch mit dem Signaturschild C 10 überklebt.

Herkunft: Die Handschrift ist aufgrund des durchgehend verwendeten Wasserzeichens in das 3. Viertel des 15. Jahrhunderts zu datieren. Auffällig ist die Nähe mehrerer Texte zu der Hs. Freiburg im Breisgau, Universitätsbibliothek, Hs. 89. Der Glossator Friedrich von Lütishofen kam Anfang der 1470er Jahre an die Universität Freiburg.

Besitzer: Im vorderen Spiegel Exlibris des Chorherrenstifts Beromünster. Im Catalogus von 1763 als Classis Nona Nr. 7 verzeichnet, im Nachtrag dazu auf $48^{r}$ als Nr. VIII, im Catalogus von 1826 als Nr. 2. Im vorderen Spiegel neuere Signatur: C 61, Kugelschreiber, spätes 20. Jh. Ehemals C 10 fol. 
Literatur: Liebenau, Urkundenbuch, Bd. 1, S. 60f.; Kopp, Stiftsbibliothek, II, S. 19; BrUCKner, Scriptoria 9, S. 31; BÜCHLER, Beromünster, S. 167, 169, 244 (Anm. 126); KRISTEllER, Iter Italicum 5, S. 99.

$1^{\mathrm{r}}-203^{v}$ P. TERENTIUS AFER, Comoediae. Andria, Eunuchus, Heautontimorumenos, Adelphoe, Hecyra, Phormio, in der Calliopius-Rezension, gemäss dem Hinweis jeweils am Ende der einzelnen Komödien, mit Interlinearglossen und Scholien, z. T. nach Donat, vereinzelt leicht beschnitten. Vita Terentii (Ambrosiana): Terencius nacione Afer genere Carthaginensis puer captus a quodam Terencio Lucano emptus litteris Grecis Latinisque instructus ... - ... nemo acceperat. August ReIfFerscheId, C. Suetonii Tranquilli praeter Caesarum libros reliquiae, Leipzig 1860, S. 535f. Comediarum nomina ex quatuor rebus sumuntur ... Andria prima fabula ideo vocatur, quia ... $1^{\mathrm{v}}$ Exorto Athenis bello ... $2^{\mathrm{r}}$ Epitaphium Terencii: Natus in excelsis ... Walther, Carmina 11627.2v Argumentum in Andria: Sororem falso creditam ... Walt Her, Carmina 18456. Prologus: Poeta cum primum animum ad scribendum appulit ... $3^{\mathrm{v}}$ Vos istec intro auferte ... P. Terentii Afri Comoediae sex, ed. Paulus Iacobus Bruns, Halle 1811, Bd. 1, S. 5-146. 31 Eunuchus: Quo tempore aut in

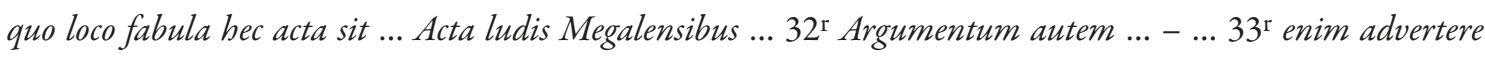
quibit. Nunc tamen de prologo ... >Incipit Eunuchus. Acta ludis Megalensibus ... BRUns, Bd. 1, S. 146, 153-156, 153. Incipit argumentum Eunuchi<. Meretrix adolescentem ... P. Terenti Afri Comoediae, ed. Sextus PRETE, Heidelberg 1954, S. 178. 33 > Eunuchi prologus incipit et Caliopius loquitur<. Si quisquam ... BRUNs, Bd. 1, S. 149-153. 34v > Explicit prologus. Incipit argumentum<. Sororem falso iam dictitatam Taidis ... vgl. PRETE, S. 178, am Schluss ganz abweichend: ... viciatam ephebo, Phedria amator Thaidis exclusus, Ab ista esterna die et iterum revocatus, Loquitur audiente Parmenone servo suo, vgl. Scholia Terentiana, collegit et disposuit Fridericus SCHLEE, Leipzig 1893, S. 96.35 ${ }^{\mathrm{r}}$ Quid igitur faciam ... BRUNS, Bd. 1, S. 157-266. 70 r $>$ Eunuchus explicit. Incipit Heautontimerumenos, lege feliciter $<$. Acta id est recitata est ... $70^{\mathrm{v}}>$ Incipit argumentum $<$. In miliciam proficisci ... $>$ Incipit prologus <. Ne cui vestrum ... BRUNS, Bd. 1, S. 269-366. 105 $>$ Terencii Affri Heautontimeromenos explicit. Incipit Adelpho, lege feliciter $<.106^{\mathrm{r}}$ Acta est ista fabula ... Postquam poeta ... 106 ${ }^{\mathrm{v}}>$ Sequitur argumentum $<$. Duos cum haberet ... BRUns, Bd. 2, S. 3-91. 137 $>$ Explicit Adelphe. Incipit Hechyra $<$. Hechira est nomen huic fabule, dicta est Hechira a loco ... 138 ${ }^{\mathrm{r}}>$ Terencius Affri argumentum Hechire incipit<. Adolescens qui meretricis amore tenebatur ... Catalogue général des manuscrits des bibliothèques publiques de France, Bd. 14, Paris 1890, S. 460, die vier Zeilen «Ad cogendam ...» - «Domum abiit ...» fehlen. $138^{\mathrm{v}}>$ Aliud argumentum <. Uxorem duxit ... Bruns, Bd. 2, S. 97-170. 166v > Hechira explicit. Incipit Phormio<. Argumentum istius fabule istud est: Duo senes fratres ... 167v > Aliud argumentum <. Ex duobus fratribus ... Catalogue général, Bd. 14, S. 461. $168^{\mathrm{v}}$ $>$ Aliud argumentum compendiosius <. Cremetis frater ... 169 $\mathrm{r}>$ Prologus $<$. Postquam poeta ... - ... Vos valete et plaudite. Caliopius recensui. > Et finis<. BRuns, Bd. 2, S. 173-268. Am Ende von der Hand des Glossators Friedrich von Lütishofen: Qui cupit obstrusam frugem gustasse Terenti, Donatum querat noscere gramaticum.

204r-260r P. VERGILIUS MARO, Georgica. Quid faciat letas segetes, quo sidere terram ... - ... Titere tu patule cecini sub tegmine fagi. Vers 1,467 vor 1,465; 3,229 und 3,499 fehlen, ebenso die zweite Hälfte von 3,510 resp. die erste von 511 (die beiden Verse zusammengezogen); die Bücher 2-4 mit den Argumenta des Ps.Ovid. 218 ${ }^{\mathrm{r}}>$ Secundus liber $<, 233^{\mathrm{r}}$ Buch 3, 246v Buch 4. Bis zum Ende der zweiten Lage 227v (Vers 2,341) interlinear und am Rand in nachlassender Dichte glossiert, der Text $204^{\mathrm{r}}$ am oberen Rand beschnitten. $260^{v}$ leer.

$261^{\mathrm{r}}-283^{v}$ P. VERGILIUS MARO, Eclogae. P. Virgilii Maronis poete Mantuani Carmen buccolicum incipit. $>$ Melibeus, Titirus<. Titire tu patule recubans sub tegmine fagi ... - ... Ite domum sature venit Hesperus ite 
capelle. > Et finit Buccolicon Virgilii<. Nach 1,17 der interpolierte Vers: Saepe sinistra cava predixit ab ilice cornix (1,17a); Vers 1,52 fehlt (1,51 zuerst Fortunate senex frigus captabis opacum, dann nur die eine Hälfte ergänzt); 3,104/105 und 106/107 umgestellt; 8,28a nicht vorhanden. Mit Ausnahme von 271 ${ }^{\mathrm{r}-\mathrm{v}}$ am Rand und interlinear glossiert.

284r-289v AUGUSTINUS DATUS, Elegantiolae. Bearbeitete Fassung. Cum omnis dicendi conficiendique Latini sermonis modus sola imitacione, ac coaptacione acquiratur ... Plerumque qui oratorie artis floribus student ... - ... Ego vero ad $8^{\text {vum }}$ Ydus Ianuas (sic) ad te scripseram. Habet enim vim temporis vehemenciorem hoc posteris. Stimmt überein mit Freiburg im Breisgau, Universitätsbibliothek, Hs. 89, 14 $4^{\mathrm{r}}-20^{\mathrm{r}}$ und auszugsweise mit GW 8123: [Augustinus Datus], De variis loquendi regulis sive poetarum praeceptis, [Köln: Ulrich Zell, um 1470, $\left.1^{\mathrm{v}}-34^{\mathrm{v}}\right] .284^{\mathrm{r}}$ wenige Randglossen von einer anderen Hand. Emil Joseph POLAK, Medieval and Renaissance Letter Treatises and Form Letters, Leiden/New York/Köln 1994, S. 224.

289v-290r AUGUSTINUS DATUS, Summula praeceptorum. Bearbeite Fassung, unmittelbar an das Vorangehende anschliessend. Summa preceptorum ad partem composicionis pertinencia que ad ordinem et collacionem spectantur. Sequitur regula. Quod se oratio augeat ut nobilis et egregius magnificus et illustris ... - ... quoniam a summis poetis et oratoribus sunt reperta. Stimmt überein mit Freiburg im Breisgau, Universitätsbibliothek, Hs. 89, 20v-21v' nur auszugsweise (Regulae 1-3 und 10-13) mit GW 8123, [35', 36v-37r]. 289v am Rand: 4a et ultima species est eloquencia (wie Hs. 89, 20v).

290r-294v PETRUS LUDER, Modus epistolandi et orandi. Unmittelbar anschliessend. Modus epistolandi et orandi sequitur. Peticiones loci sunt quatuor. Primus locus peticiones (sic) quidem ex honestate constat ... - ... facile existamabis (sic). Vale. Vgl. wiederum UB Freiburg, Hs. 89, 21 $1^{\mathrm{v}-27^{\mathrm{r}}}$ und GW 8123, [37 $\left.7^{\mathrm{r}}-46^{\mathrm{v}}\right]$. $291^{v}-294^{v}$ Marginalien zur Textgliederung von der Hand des Schreibers. Frank BARON, Artikel Luder, Peter, in: Verfasserlexikon², Bd. 5 (1985), Sp. 957.

294v-299v PETRUS LUDER, Rhetorica. Unmittelbar anschliessend. Si quid rethorice dicere volumus atque auditoribus ita ostendere ut nobis assenciant ... - ... omnino eis bellum indixisse videar. Stimmt überein mit GW 2667 ( a ii $^{\mathrm{r}}$ - a viiir ${ }^{\mathrm{r}}$ ), enthält jedoch zwei zusätzliche Abschnitte: $295^{\mathrm{r}-\mathrm{v}}$ Incipit oratio ut cives dicordias et simultates pretermittant in genere deliberativo. Eximius enim ... - ... iam dudum esse arbitror. 297v-298 ${ }^{\mathrm{r}}$ Qui morem hunc instituere ... - ... et laudabile et facile esse ostendemus. Die «Alia conclusio» auf a iiir des Druckes und der Epilog hingegen fehlen. Marginalien zur Textgliederung von der Hand des Schreibers. Vgl. wiederum UB Freiburg, Hs. 89, 38 vㄴ 44v , die Randglossen z. T. übereinstimmend. Frank BARON, Artikel Luder, Peter, in: Verfasserlexikon², Bd. 5 (1985), Sp. 957.

300r-319v M. TULLIUS CICERO, Epistulae ad familiares. Buch 1: 1-6, 11, 7, 14, 18, 19 (Ep. 45-50, 90, 107, 89, 115, 116); Buch 3: 1, 2, 13 (Ep. 64, 65, 76); Buch 4: 5, 6, 8, 10-12 (Ep. 248, 249, 229, 233, 232, 253); Buch 5: 5, 7 (Ep. 5, 3); Buch 4: 15 (Ep. 241); Buch 5: 3, 9, 11, 15, 18 (Ep. 11, 255, 257, 252, 51). Die Briefe 2,1 und 4,5 mit (wenigen) Glossen, v. a. interlinear. $M$ [arcus] $C$ [icero] $S$ [alutem] $D$ [icit] Curioni. Quamquam me nomine negligencie suspectum tibi esse ... - ... M. T[ullius] C[icero] S. D. Tyto Fabio. Et si egoment ... Vale. Octavo Kalendas Februarias. Vgl. wiederum UB Freiburg, Hs. 89, 54r-71'v. 
Papier, 244 Blätter, $31 \times 22 \mathrm{~cm}$

Drittes Viertel des 15. Jahrhunderts

Wasserzeichen, Lagen, Foliierung: Wasserzeichen: Dreiberg, PICCARD, Wasserzeichenkartei Nr. 151357 (1454) und 151358 (1455). Lagen: $(\mathrm{VI}-3)^{9}+\mathrm{VI}^{21}+\mathrm{VII}^{35}+17 \mathrm{VI}^{239}+(\mathrm{VI}-9)^{242}$, vor dem zu mehr als der Hälfte herausgeschnittenen Bl. 1 ein ganzes Blatt herausgeschnitten, danach zwei Blätter herausgerissen; nach B1. 242 zuerst sechs Blätter herausgerissen, danach drei Blätter herausgeschnitten. Reklamanten, meist stark beschnitten. Neuere Foliierung: A-B. 1-242.

Einrichtung und Ausstattung: Begrenzung des Schriftraums (der Spalten) mit Stift, Schriftraum 22-23 × 15, zweispaltig (6,5-7), 45-57 Zeilen. Schleifenlose jüngere gotische Buchkursive von einer Hand. Rubriziert, rote Überschriften (zuerst 38 ra), Paragraphenzeichen und Unterstreichungen, möglicherweise von Friedrich von Lütishofen, siehe auch Nachträge. 1-4zeilige rote Lombarden, z. T. mit Punktverdickungen und Konturbegleitstrichen, $2^{\mathrm{vb}}$ (und 132 vb) mit ein wenig Fleuronné, 139va mit menschl. Profil, teilweise und nach $144^{\mathrm{r}}$ überhaupt nicht ausgeführt. 36 ${ }^{\mathrm{ra}}$ 8zeilige Initiale in brauner Tinte, mit Halbpalmetten im Binnenfeld, umrahmt von Blattwerk und kopfstehendem Gesicht im Profil, darüber Federzeichnung (18 Zeilen) von der gleichen, geübten Hand: Gott, im Busch thronend auf dem Berg Sinai, übergibt dem knienden Moses (mit Rinderhörnern) die Gesetzestafeln (Diptychon mit Griff), 36rb 4zeilige spiegelverkehrte Initiale im Umriss von ders. Hand.

Korrekturen und Nachträge: Korrekturen von der Hand des Schreibers, z. B. 29va, 89 ${ }^{\mathrm{rb}}$, 132 ${ }^{\mathrm{ra}}$, 236rb. Wohl von der Hand des Friedrich von Lütishofen: 48 ${ }^{\mathrm{r}}-72^{\mathrm{r}}$ rote Kopftitel, 92v $-110^{\mathrm{r}}, 173^{\mathrm{v}}-178^{\mathrm{r}}$ Zählung der Praecepta und Capitula in Schwarz am Kopf der Seiten, $36^{\mathrm{r}}-231^{\mathrm{r}}$ am Fuss; Marginalien zur Gliederung des Inhalts in Rot, $\mathrm{ab} 61^{\mathrm{r}}$ auch am Fuss der Seiten; vereinzelt auch Nota- und Anführungszeichen. Von Lütishofen auch zahlreiche ausführlichere Marginalien ( $54^{\mathrm{rb}}$ oder $131^{\mathrm{va}}$ auch Korrekturen), z. T. auch rubriziert, z. B. 26r Nota: An lapsus angelorum sit causa creacionis hominis, 26v Nota: An lapsus hominis sit causa incarnacionis Christi, 54 $4^{\mathrm{v}}$ Nota unde quod lupi comedunt homines, z. T. auch deutsche Übersetzungen, z. B. $54^{\mathrm{ra}}$ pigmeus: zwerg, homo semicubitalis, $71^{\mathrm{vb}}$ lascivia: unkünschbeit, tragheit. Vielleicht von anderer Hand 31 va: Hic est magnus deffectus viciose pretermissus ut vide in textu notabiliter (Ct 6,4-9 bleiben unkommentiert, gleich auch in C 46, 31 va). Weitere zeitgenössische Marginalien, 20vb von einer Hand des 16. Jhs. Handweiser. 36 ${ }^{\mathrm{r}}$ Titel, 17./18. Jh.: Distinctiones Super Praecepta Decalogi.

Einband: Einband aus der Werkstatt Alberthus (EBDB w000043, nachgewiesen in Heidelberg um 1465-1482), vgl. auch C 51. Mit hellem Leder bezogene Holzdeckel, 15. Jh. Streicheisenlinien, Einzelstempel (EBDB s002521, s002523, s002527, s002529, s002530, s002532 und s002533). Ehemals zwei nach vorn greifende Kantenschliessen, ziselierte Messingteile an den Deckeln erhalten, blütenförmige Riemenbefestigungen im Rückdeckel; ehemals vorne und hinten je fünf Metallbuckel. Spiegel- und Vorsatzblätter Papier, Vorsatzbll. A-B Wasserzeichen: Dreiberg, PICCARD, Wasserzeichenkartei Nr. 151358 (1455); vier weitere Bll. herausgerissen. Am Schluss der Hs. eine Dreierlage herausgerissen. Hinteres Spiegelblatt: Wasserzeichen Traube, Piccard, Wasserzeichenkartei Nr. 129327 (1457). Rot-weisse Kapitale. Bis 65/66 und ab 209/210 Pergamentfragmente in den Fälzen; zudem (ehemals) je zwei Stücke einer neumierten Hs. (Graduale) um die erste und die letzte Lage gebunden und in die Deckel geklebt, vom grösseren Stück vorne nur noch Abklatsch. 
Im vorderen Spiegel Exlibris des Chorherrenstifts Beromünster (WEGMANN, Exlibris, Nr. 619). Rückenschild: Expositio super Cantica Canticorum, N. 7, entsprechend dem Catalogus von 1826.

Herkunft: Aufgrund der Wasserzeichen und der Datierung durch den Vorbesitzer $\left(\mathrm{B}^{\mathrm{r}}\right)$ ist die Handschrift in das 3. Viertel des 15. Jahrhunderts zu datieren. Friedrich von Lütishofen war möglicherweise auch der Auftraggeber und Rubrikator der Hs.

Besitzer: $\mathrm{A}^{\mathrm{r}}-\mathrm{B}^{\mathrm{v}}$ und Marginalien von der Hand des Friedrich von Lütishofen, $\mathrm{B}^{\mathrm{r}}$ 1473. In universitate Fryburgensi, feria $2 a$ ante Appolonie (8. Februar). Im vorderen Spiegel Exlibris des Chorherrenstifts Beromünster. Im Nachtrag zum Catalogus von 1763 auf 51 ${ }^{\mathrm{r}}$ ohne Nummer, im Catalogus von 1826 als Nr. 7 verzeichnet. Im vorderen Spiegel neuere Signatur C 62, mit blauem Farbstift, spätes 20. Jh. Ehemals C 11 fol. Literatur: BRUCKNER, Scriptoria 9, S. 28; BüCHLER, Beromünster, S. 134, 159, 161 und 233 (Anm. 112).

Spiegelblatt, $\mathrm{A}^{\mathrm{r}}-\mathrm{B}^{\mathrm{v}}$ Schemata. Peticiones dominice oracionis pro removendo multo ... Septem Peticiones, Dona, Beatitudines ... $\mathrm{A}^{\mathrm{r}}$ Peticiones dominice oracionis pro adipiscendo bona ... Disposicio hominis per spiritum sanctum ... $\mathrm{B}^{\mathrm{r}}$ Actus hominis ...

$1^{\mathrm{ra}}-35^{\mathrm{vb}}$ HONORIUS AUGUSTODUNENSIS, Expositio in Cantica canticorum. Prologus I: // domino. Quedam graciarum a [ccionis] // ... // [Can]tica, Liber sapiencie, Eccle [siasticus] // $1^{\mathrm{vb}} / /[\mathrm{P}]$ haraonis ab orientem // ... // quia sapiencia et ornamento //. Prologus II: $2^{\text {ra } / / ~ r e c e p t u m ~ r e d d i d i t ~ b a p t i s m a t e ~ a ~ s o r d i b u s ~ a b l u i t ~ . . . ~}$ Tractatus I: $2^{\text {va }}$ Filius regis Ierusalem desponsavit sibi filiam regis Babilonis per internunccios ... Caput I: $3^{\text {ra }}$ Osculetur me osculo oris sui. Sacra scriptura quatuor modis intelligitur ... - ...35 $5^{\text {va }}$ ut eam ad me perferant. Ut labor noster fiat omnibus fructuosus brevi epilogo ab exordio cuncta repetamus. Hic liber ibi incipit ubi humanum genus ... Hic autem liber ideo de festo sancte Marie legitur ... possunt eciam de ipsa virgine sponsa et matre sponsi intelligi. Amen. Caput II: 10b , Tractatus II: 15 ${ }^{\mathrm{ra}}$, Caput III: $15^{\mathrm{rb}}$, Caput IV: 19 ${ }^{\mathrm{ra}}$, Caput V: $25^{\mathrm{vb}}$, Caput VI: $31^{\mathrm{ra}}$. Tractatus III: 31 va, Caput VII: 32rb, Tractatus IV: 34 $4^{\mathrm{va}}$, Caput VIIIra: 36 ${ }^{\mathrm{ra}}$. PL 172, Sp. 350, 352, 356-446, 453-469, 471f., 476-479, 482-485, 493-496, 494, teilweise gekürzt und umgearbeitet (31 rb-va Auslegung von Ct 6,3 nach Beda Venerabilis und Gregor, Hom. VIII in Ezechielem, vgl. Nachträge). RB 3573.

$36^{\mathrm{ra}}-242^{\mathrm{vb}}$ JOHANNES NIDER, Praeceptorium divinae legis. Decalogi legem sacratissimam primum divinitus prothoplastorum insertam cordibus ... 36 $6^{\mathrm{rb}}$ Sunt igitur tria principaliter prenotanda ... - ... 241 24 [G]audia superiora anime ... Si amicicia, diligent//. Stimmt überein mit GW M 26931: Johannes Nider, Praeceptorium divinae legis sive Expositio decalogi, Paris: Ulrich Gering, 20. 4. 1478, a2 ${ }^{\mathrm{r}}-S 12^{\mathrm{r}}$. Auf $76^{\mathrm{v}}$ in Kapitel I,20 (vor Quintus est dilacio ... vgl. im Druck i8 ${ }^{\mathrm{r}}$ ) eine Aufstellung von 20 Begriffen zur Accidia mit dt. Übersetzungen: Tepiditas: lewikeit. Mollicies: zartheit ... Praeceptum II: 82 ${ }^{\mathrm{rb}}$, Praeceptum III: $93^{\mathrm{ra}}\left(111^{\mathrm{rb}}\right.$ $112^{\mathrm{va}}$ in Kap. III,11 umgestellt), Praeceptum IV: 117vb, Praeceptum V: 128 ${ }^{\mathrm{ra}}$, Praeceptum VI: 156rb, Praeceptum VII: 171 rb Praeceptum VIII: 198vb, Praeceptum IX: 205 ${ }^{\mathrm{ra}}$, Praeceptum X: 218 ${ }^{\mathrm{ra}}$. RB 4832; Kaeppeli, Scriptores, Nr. 2540 (Hs. nicht erwähnt); Bloomfield, Incipits, Nr. 1488 (Hs. nicht erwähnt). Vgl. Eugen Hillenbrand, Artikel Nider, Johannes, in: Verfasserlexikon², Bd. 6 (1987), Sp. 971-977. 
Papier, 145 Blätter, 29,5-30 × 21,5 cm

1432

Wasserzeichen, Lagen, Foliierung: Bl. 1-122 Frau, PICCARD, Wasserzeichenkartei Nr. 21230 (1432) und 21243 (1434), jeweils in drei Varianten; Bl. 123-145 Ochsenkopf, PiCCARD, Wasserzeichenkartei Nr. 75968 (1433) und 76247 (1433). Lagen: 9 VI ${ }^{108}+$ VII ${ }^{122}+2$ VI ${ }^{145}$, letztes Blatt der letzten Lage in den Spiegel geklebt. Zählung der Lagen am Lagenende: primus $\left(12^{v}\right)$ - viiius $(96 \mathrm{v})$, ausserdem alphabetische Zählung auf dem zweitinnersten und innersten Blatt jeder Lage, gut erkennbar: $h$ ( $89^{\mathrm{vb}}$ und $\left.90^{\mathrm{ra}}\right)-m$ (139vb und $140^{\mathrm{ra}}$ ), davor bis auf die Oberlängen beschnitten. Bl. 98-145 Wasserschaden, stellenweise bis in den Schriftraum. Neuere Folierung: 1-145.

Einrichtung und Ausstattung: Zweispaltig, Spaltenbegrenzung mit Tinte, Schriftraum 21-22 × 15 (6,5-7), 42-52 Zeilen. Jüngere gotische Buchkursive mit Schleifen von einer Hand. Rubriziert, rote Überschriften ( $5^{\mathrm{rb}}-97^{\mathrm{rb}}$ jeweils mit Vorgaben an den Rändern) und Paragraphenzeichen, zweizeilige rote Lombarden, $\mathrm{z}$. T. mit Punktverdickungen. Die letzte Zeile öfters mit ausgezogenen Unterlängen. $16^{\mathrm{r}}-19^{\mathrm{r}}$ Buchnummer $2 \mathrm{im}$ Fusstitel.

Korrekturen und Nachträge: Korrekturen des Schreibers, z. B. $3^{\mathrm{rb}}, 10^{\mathrm{ra}}, 33^{\mathrm{ra}}, 72^{\mathrm{vb}}, 112^{\mathrm{vb}}, 142^{\mathrm{va}}$. Notizen von der Hand des Schreibers: $9^{\mathrm{va}}$ nota quomodo deus est in anima, $111^{\mathrm{ra}}$ hic nota bunc sermonem, $120^{\mathrm{va}}$ nota miraculum. $17^{\mathrm{ra}}-18^{\mathrm{va}}$ und 59vb Notazeichen, wohl von einer weiteren zeitgenössischen Hand. 82v Nachträge von der Hand Friedrichs von Lütishofen: Est vitis agrestis vel sterilis, que producit fructus inmaturos et amaros. wilder win stock, und: Reatus accipitur pro pena, pro oblicione temporalis pene vel eterne, pro peccato (scilicet quando peccatum ad eternam penam obligatur), pro culpa. schuldt vel pin. Lesezeichen nach Bl. 110 und 111: Papier, 15. Jh. $3^{\text {ra }}$ Titel von einer Hand des 17./18. Jhs nachgezogen.

Einband: Mit hellem Leder überzogene Holzdeckel mit abgeschrägten Kanten, 15. Jh. Rücken oben lose. Am hinteren Deckel unten Reste von vier Eisenstiften, vielleicht von der Befestigung eines Titelschilds. Kapitale mit ungefärbtem Garn umstochen. Spiegelblätter Papier, das hintere mit Wasserzeichen (siehe Lagen). In den Fälzen Fragmente einer anscheinend für das Kloster Saint Sauveur (Dép. Meurthe-et-Moselle) ausgestellten lateinischen Urkunde von 1435 mit Erwähnung eines frater Iacobus de Thiacuria (Thiaucourt) abbas. Im vorderen Spiegel Exlibris des Chorherrenstifts Beromünster (Wegmann, Exlibris, Nr. 619). Auf beiden Deckeln Aufschrift: Conpendium Theologice Veritatis, 15./16. Jh. Ein wohl zeitgenössisches Rückenschild aus Pergament ist nicht mehr lesbar. Rückenschild von 1826: [Lib]er Theologicae Veritatis, der Rest verblasst. Im Catalogus von 1826 unter Nr. 20 verzeichnet.

Herkunft: $98^{\mathrm{ra}}$ auf den 17. April 1432 datiert.

Besitzer: Im 15. Jh. wahrscheinlich im Besitz Friedrichs von Lütishofen, von dessen Hand zwei Anmerkungen auf $82^{\mathrm{v}}$ stammen. Im Nachtrag zum Catalogus von 1763 auf 46r ohne Nummer verzeichnet. Im vorderen Spiegel Exlibris des Chorherrenstifts Beromünster und mit blauem Farbstift neuere Signatur C 63, spätes 20. Jh. Ehemals C 12 fol.

Literatur: Kopp, Stiftsbibliothek, II, S. 14; BRUCKNER, Scriptoria 9, S. 27; BÜCHLER, Beromünster, S. 143; CMD-CH 2, Nr. 88. 
$1^{\text {ra-va leer. }}$

$1^{\mathrm{vb}}-2^{\mathrm{vb}}$ Tabula. Buchweise durchgezähltes Kapitelverzeichnis zum Compendium theologicae veritatis. $>D e$ natura divinitatis liber primus<. Quod deus est, 1. Quod unus deus est, 2 ... - ... De aureolis in specie, 28. Enumeracio celestium gaudiorum, 29.

$3^{\text {ra }}-98^{\text {ra }}$ HUGO ARGENTINENSIS, Compendium theologicae veritatis. >Incipit prologus theologice veritatis $<$. Veritatis theoloyce sublimitas cum superni sit splendoris radius ... $3^{\mathrm{rb}}>$ Explicit prologus, incipit liber primus de nativitate domini. Capitulum primum: Quod deus est<. Deum esse multis modis ostenditur ... - ... 97vb Denique de gaudibus celestibus nota versus: Mens cognoscendo dotatur, amando, fruendo ... 11 Verse, WALTHER, Carmina 10896. Ex omnibus premissis collige quedam spectare gaudia solum ad animam, quedam ad corpus, quedam ad coniunctum. Que tamen felici fine quisque beatus secundum merita recipiet sine fine. B. Alberti Magni opera omnia, hrsg. v. Auguste Borgnet, Bd. 34, Paris 1895, S. 1-34b, 34b-35a, 35b-43a, 43b-44a, $44 a-57 b, 58 a-59 a, 59 a-71 b, 72 a-76 a, 76 b-155 a, 155 b-251 b, 251 b-261$, mit kleineren Auslassungen und einem zusätzlichen Lehrgedicht am Ende. $16^{\text {rb }}$ Buch 2, 35 va Buch 3, 48 ${ }^{\text {ra }}$ Buch 4, 59va Buch 5, $75^{\text {ra }}$ Buch 6, 88vb Buch 7. Kaeppeli, Scriptores, Nr. 1982 (Hs. nicht erwähnt); Bloomfield, Incipits, Nr. 6399 (Hs. nicht erwähnt); Friedrich STEgmülleR, Repertorium commentariorum in sententias Petri Lombardi, Würzburg 1947, Bd. 1, S. 172f., Nr. 368. Vgl. Georg SteER, Artikel Hugo Ripelin von Straßburg, in: Verfasserlexikon², Bd. 4 (1983), Sp. 252-266. Anschliessend Datierung: Explicit liber etc. finitus in cena domini anno etc. $x x x i i^{\circ}$.

$98^{\mathrm{rb}}-108^{\mathrm{vb}}$ leer.

109 ${ }^{\mathrm{ra}}-143^{\mathrm{ra}}$ AEGIDIUS ROMANUS, Sermones de sanctissima eucharistia. $>$ Modus procedendi in sermones de sacramento corporis domini<. De sacrosancto corporis domini locuturi sacramento proponimus ... $109^{\mathrm{rb}}>$ Tituli sermonum. Primus <. De tribus causis institucionis sacramenti corporis Christi, que sunt memoria salvatoris, sacrificium altaris, cibus hominis. De prima causa institucionis per se ... 109 $9^{\mathrm{vb}}>$ De sacramento corporis domini sermones. De tribus causis institucionis huius sacramenti. Thema generale de sacramento corporis Christi vel aliud simile<. Venite comedite panem meum ... (Prv 9,5). Hiis verbis dominus nos invitat ad salutare convivium ... - ... 142 $2^{\mathrm{rb}}$ Promissionem habes vite, que nunc est, et future. Ad quam nos perducat qui est benedictus in secula. Amen. B. Alberti Magni opera omnia, hrsg. v. Auguste Borgnet, Bd. 13: Sermones, Paris 1891, S. 668f., 801-805, 669-717b, 719-743a, 744-797, mit wenigen kleineren Auslassungen. ZuMkELLER, Manuskripte, S. 18, Nr. 14 (Hs. nicht erwähnt); SCHneyer, Bd. 5, S. 608-611, Nr. 412-444 (Zuschreibung an Thomas von Aquin); John R. Eastman, Die Werke des Aegidius Romanus, in: Augustiniana 44 (1994), S. 223, Nr. 63. Anschliessend eine weitere, offenbar zu diesem Corpus gehörige Predigt: Nisi manducaveritis carnem ... (Io 6,54). Nota proprietates hostie, in quibus collige indigne et digne communicantes ... - ... Item quia non habent vim retentivam, sed totum reiciunt et evomunt, quod contingit vel ex nimia replecione vel ex stomachi debilitate, Iob xx: Divicias, quas donavit, evomit. > Expliciunt sermones de sacramento dominici corporis <. $143^{\mathrm{rb}}-145^{\mathrm{vb}}$ leer. 
Papier, 276 Blätter, $29 \times 21 \mathrm{~cm}$

1451

Wasserzeichen, Lagen, Foliierung: Wasserzeichen: Ochsenkopf, Bl. 1-36, 130/131 und 137-183 PICCARD, Wasserzeichenkartei Nr. 75508 (1451), in zwei Varianten, sowie eine Variante von Nr. 75846 (1451); Bl. $37-136$ Nr. 75238 (1450) mit einer Variante; Bl. 62/73 Nr. 75151 (1451); Bl. 104/105 Nr. 75509 (1453); Bl. 115/120 und 202/205 eine Variante von Nr. 75096 (1455/56); Bl. 161/172, 173/184 und 185-234 ähnlich Nr. 74794 , in zwei Varianten; Bl. 239-242 und 249/258 Nr. 76440 (1451); Bl. 235-272 Nr. 75723 (1450), in zwei Varianten, sowie 75724 (1454). Lagen: $5 \mathrm{VI}^{60}+\mathrm{VII}^{74}+3 \mathrm{VI}^{110}+\mathrm{VII}^{124}+6 \mathrm{VI}^{196}+\mathrm{VII}^{210}+5 \mathrm{VI}^{270}+$ $(I V-6)^{272}$, nach Bl. 272 sechs Blätter herausgerissen. Reklamanten. Wasserschaden, vor allem unten vom Rücken ausgehend, stellenweise bis in den Schriftspiegel. Bl. 1-6 und 37 unten ein Riss mit Papier geflickt, 223 ein weiterer geklebt. Neuere Folierung: I. 1-274.

Einrichtung und Ausstattung: Begrenzung des Schriftraums mit Tinte, aussen durch Doppellinien, $1^{\mathrm{r}}-13^{\mathrm{r}}$ und öfters zusätzlich Rahmen (für Marginalien?), Schriftraum 17,5-18,5 × 11-13, 15-18 Zeilen; Bl. 267272 zweispaltig, Schriftraum 22-23,5 × 16-17 (7-8,5), 21-23 Zeilen (267 $\left.{ }^{\mathrm{ra}}-270^{\mathrm{rb}}\right)$ bzw. 44-48 Zeilen $\left(270^{\mathrm{va}}-272^{\mathrm{vb}}\right)$. Einstichlöcher für die Liniierung, meist auf der äusseren Textfeldgrenze, seltener auch am Rand (z. B. in der Lage Bl. 25-36). Schleifenlose Bastarda von der Hand des Johannes Remishůb, 270va_272vb schleifenlose jüngere gotische Buchkursive, wohl von derselben Hand. Rubriziert, Reklamanten und Kapitelüberschriften am Kopf der Seiten häufig rot unterstrichen, letztere teils in vergrösserter Schrift oder in Auszeichnungsschrift, 56 ${ }^{\mathrm{r}}, 65^{\mathrm{r}}, 71^{\mathrm{v}}$ und $201^{\mathrm{v}}$ in Rot; $71^{\mathrm{v}}$ Überschrift, $119^{\mathrm{v}}$ Explicit in Kapitalis. In der ersten Zeile häufig vergrösserte Initialen in Tinte und Rot, oft mit Flechtbandornamenten, Kadellen und Konturbegleitstrichen (116 $6^{\mathrm{r}}$ fischförmig, $212^{\mathrm{r}}$ mit Grün). Einzeilige (270va $272^{\text {va }}$ dreizeilige) Lombarden in Rot, Dunkelrot, Blau, Grün und Schwarz mit farblich abgesetztem Fleuronné; 6v, 20v $69^{\mathrm{v}}$ und ab $127^{\mathrm{r}}$ regelhaft am Kapitelanfang zweizeilig; Fleuronné zunehmend mehrfarbig, ab $119^{\mathrm{v}} \mathrm{z}$. T. mit Profilzeichnungen. Fleuronné-Initialen in gleicher Gestaltung, 270 va dreizeilig, $1^{\mathrm{r}}, 71^{\mathrm{v}}, 218^{\mathrm{v}}$ und $263^{\mathrm{r}}$ vierzeilig, $201^{\mathrm{v}}$ sechszeilig, im blauen Buchstabenkörper gelbe Ähren und Fadenranken, Fleuronné in Rot und Dunkelrot. Fünf3-6zeilige Initialen in Deckfarbenmalerei in Rot, Blau, Grün und Grau mit einfachen Blatt- und Blumenornamenten sowie Tierdarstellungen ( $38^{\mathrm{r}}$ Fisch, $74^{\mathrm{r}}$ und $122^{\mathrm{v}}$ Hunde), z. T. mit wenig Fleuronné.

Korrekturen und Nachträge: Korrekturen des Schreibers, z. B. 51 v $106^{\mathrm{v}}, 175^{\mathrm{v}}$, $272^{\mathrm{rb}}$. Korrekturen von anderer Hand z. B. $1^{\mathrm{r}}, 50^{\mathrm{v}}, 132^{\mathrm{r}}, 262^{\mathrm{r}}$, öfters auf Rasur. Interlinearglossen von einer zeitgenössischen Hand, z. B. $1^{\mathrm{r}}-2^{\mathrm{r}}$. Interlinearglossen und Marginalien von der Hand Friedrichs von Lütishofen, vor allem $36^{\mathrm{r}}, 43^{\mathrm{v}}, 128^{\mathrm{r}}-130^{\mathrm{v}}$,

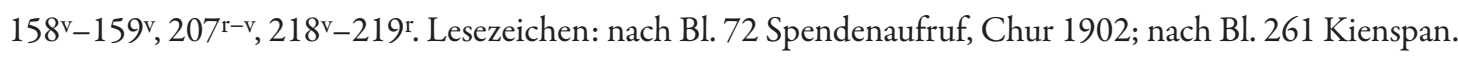

Einband: Mit hellem Leder bezogene Holzdeckel, 15. Jh., Streicheisenlinien und Einzelstempel: Lilienkreuz in umrandetem Quadrat, kleine fünfzählige Blüte und sehr kleine vierzählige Blüte. Streicheisenlinien und Art der Bindung entsprechen C 40 und C 41 (siehe BüCHLER, Beromünster, S. 158 und 160), so dass von derselben Werkstatt auszugehen ist. Kapitale aus ungefärbtem Garn, mit blau-weiss-gelb-rotem Band umstochen und mit dem Rückenleder verbunden. Ehemals zwei nach vorn greifende Kantenschliessen, Reste von Lederriemen erhalten, Beschläge Messing. Spiegelblätter Pergament: Fragment der Abschrift einer päpstlichen Littera, die das Domkapitel von Zürich zur Aufnahme eines gewissen Conradus oder dessen 
Stellvertreters verpflichtet, Datierung: Datum Rome apud sanctum Petrum Idus Novembris, pontificatus nostri anno primo (evtl. Konrad Schmid, der 1410 an der Kurie von Johannes XXIII einen Prozess um eine Chorherrenpfründe am Grossmünster führte, vgl. Andreas Meyer, Zürich und Rom, Tübingen 1986, S. 229f.); innerer Rand um die Vorsatzblätter geschlagen. Vorsatzblätter (I, II und 273, 274) Papier, Wasserzeichen: Ochsenkopf, vorne eine Variante von PiCCARD, Wasserzeichenkartei Nr. 75096 (1455/56), hinten Nr. 75723 (1450), vgl. oben. In den Fälzen der Vorsatzblätter sowie der vier ersten und drei letzten Lagen Fragmente einer Pergamenthandschrift, 14. Jh. Bl. 71, 121 und 200 Reste von Signakeln aus Pergament, himbeerrot. Im vorderen Spiegel Exlibris des Chorherrenstifts Beromünster (Wegmann, Exlibris, Nr. 619). Auf dem Vorderdeckel Spuren eines Titelschilds. Rückenschild: Evangelia Quattuor Evangelistarum $N^{o} 22$, entsprechend dem Catalogus von 1826, das erste Wort mit Kugelschreiber nachgezeichnet.

Herkunft: Die Wasserzeichen (PICCARD, Wasserzeichenkartei Nr. 75238, 75508 und 75846) und der Einband weisen auf einen Zusammenhang mit den Handschriften C 40 und C 41 hin. Geschrieben von Johannes Remishůb aus Feldkirch und auf den 18. Dezember 1451 datiert, siehe Schreibersubskription 265r.

Besitzer: Im 15. Jh. wahrscheinlich im Besitz Friedrichs von Lütishofen, von dessen Hand zahlreiche Anmerkungen stammen. Am 8. Mai 1467 von seinem Bruder Burkhard dem Kapitel geschenkt, siehe Nachtrag 272 vb. Im Catalogus von 1763 als Classis Nona Nr. 15 verzeichnet, im Nachtrag dazu auf 46v als Nr. IV, in den Antiquitates Beronenses, S. 690, als Nr. 24 und im Catalogus von 1826 als Nr. 22. Im vorderen Spiegel Exlibris des Chorherrenstifts Beromünster. Auf Ir mit blauem Farbstift neuere Signatur: C 64, spätes 20. Jh. Ehemals C 13 fol. Literatur: Kopp, Stiftsbibliothek, I, S. 10f. und II, S. 15; BRUCKNER, Scriptoria 9, S. 31 sowie Taf. 40 und 43; Helene [Büchler-]Mattmann, Das Stift Beromünster zur Zeit des Helias Helye, in: Erster datierter Schweizer Druck, S. 14; BüCHLER, Beromünster, S. 143, 158, 160, 177; CMD-CH 2, Nr. 89.

Ir-IIv leer.

$1^{\mathrm{r}}-265^{\mathrm{r}}$ Evangelia. > Capitulum primum<. Liber generacionis Ihesu Christi filii David, flii Abraham. Abraham autem genuit $Y_{\text {saac }} . . .2^{\mathrm{v}}>$ Capitulum $2^{m}$ ad Matheum<. Cum ergo natus esset Ihesus ... $71^{\mathrm{r}}$ usque ad consummacionem seculi etc. $>$ Et sic est finis secundum Matheum <. Daneben in Rot: Deo gracias Marie och das. Amen. $71^{\mathrm{v}}>$ Incipit prefacio secundum Marcum <. Marcus ewangelista dei electus et Petri in baptismate filius ... Donatien DE BRUYne, Préfaces de la Bible Latine, Namur 1920, S. 171f. RB 607. $74^{\mathrm{r}}$ Inicium sancti ewangelii Ihesu Christi filii dei. Sicud scriptum est in Ysaia propheta ... 121 $1^{\mathrm{r}}$ Lucas Syrus nacione et Anthyocensis, arte medicus ... DE Bruyne, Préfaces, S. 172. RB 620. 122 $2^{\mathrm{r}}$ Prevacio secunda. Quoniam quidem multi conati sunt ordinare narracionem ... 200v Sic est Iohannes ewangelista unus ex discipulis dei ... DE BRUYNE, Préfaces, S. 173. $\mathrm{RB} 624.201^{\mathrm{v}}>$ Capitulum primum secundum Iohannem <. In principio erat verbum ... - ... 265 $5^{\mathrm{r}}$ non ipsum mundum arbitror capere eos qui scribendi sunt libros etc. Anschliessend Schreibernotiz: Conpletus est iste liber per me Iohannem Remishüb de Veltkilch sabato ante festum Thome apostoli anno domini 1451 etc. Fünf Blätter vielleicht für Illustrationen freigelassen: Bl. 62 (Ölberg), 73 (Beginn Markus), 115 (Pilatus), 120 (Beginn Lukas), 202 (Beginn Johannes).

$265^{\mathrm{v}}-266^{\mathrm{v}}$ leer.

$267^{\mathrm{ra}}-270^{\mathrm{va}}$ Versus de canonibus evangeliorum. $>$ Matheus $<$. A generat, B magos vocat, Egyptum petit, exit ... $267^{\mathrm{vb}}>$ Marcus $<$. A Christum baptisans predicat ante Iohannes ... 268 $8^{\mathrm{rb}}>$ Lucas $<$. A Zacharie Gabriel venit, inde Marie ... 269 $9^{\mathrm{rb}}>$ Iohannes $<$. A de puero testis baptisa probatur ... - ... Christus sepelitur valde mane. WALTHER, Carmina, Nr. 37. Interlinear die Parallelstellen der verschiedenen Evangelien von der Hand des Schreibers. 
$270^{\mathrm{va}}-272^{\mathrm{vb}}$ NICOLAUS DE DINKELSPUHEL, Casus missae. > Hec sunt collecta per venerabilem doctorem Nicolaum de Dinckelspuel alme universitatis studii Winensis<. Hinc signantur quedam dubia circa defectus sacramenti altaris contigencia et preceptis domini aut ecclesie constitutis obuiancia. $>$ Primum dubium $<$. Si contingit quod sacerdos ante consecracionem vel post moritur ... - ... 272 va $>$ Decimum dubium <. In (sic) quotidie sit celebrandum ... 272 $22^{\mathrm{vb}}$ inter omnia opera missa tenet primatum meritorium. Hec Gregorius. MADRE, Dinkelsbühl, S. 267f. (Hs. nicht verzeichnet). Anschliessend Datierung: Et sic est finis huius operis 1451.

$272^{\mathrm{vb}}$ Schenkungsvermerk. Ego Burcardus de Lütishoffen, canonicus necnon custos huius ecclesie, legavi hunc librum predicte ecclesie pro remedio omnium fidelium defunctorum atque omnium meorum superstitum sub anno incarnacionis domini $M^{\circ} \operatorname{cccc}{ }^{\circ}$ lx $7^{\circ}$ Michaelis May.

\section{65 FÜNF INKUNABELN; CONRADUS DE SAXONIA}

Papier, 370 Blätter, $28,5 \times 20-21 \mathrm{~cm}$

Um 1460

Wasserzeichen, Lagen, Foliierung: Aus sechs Teilen zusammengesetzt, nur der letzte Teil (Bl. 321-366) Handschrift. Wasserzeichen: Bl. 321-346, 359/366 und 362/363 Ochsenkopf, PICCARD, Wasserzeichenkartei Nr. 74387 (1460) in zwei Varianten und 74723 (1461) in drei Varianten; Bl. 347-358 Nr. 75196 (1462) und eine Variante; Bl. 360/365 Krone, ähnlich PiCCARD, Wasserzeichenkartei Nr. 51365; Bl. 361/364 ähnlich Nr. 51362. Lagen: $(\mathrm{VI}+\mathrm{I})^{334}+2$ VI $358+\mathrm{IV}^{366}$, ein Doppelblatt nachträglich um die erste Lage der Handschrift geschlagen. Lagenzählung: $1\left(1^{\mathrm{r}}\right)-37\left(359^{\mathrm{r}}\right)$. Zählung der Blätter in der ersten Lagenhälfte: $a\left(323^{\mathrm{v}} / 324^{\mathrm{r}}\right)-s$ $\left(352^{\mathrm{v}}\right) \cdot 333^{\mathrm{v}}, 346^{\mathrm{v}}$ und $358^{\mathrm{v}}$ Reklamanten. Von den Deckeln ausgehend viele Wurmlöcher; im hinteren Teil des Bandes Wasserschaden, von oben ausgehend bis in den Schriftspiegel. Alte Foliierung (ganzer Codex): $i\left(2^{\mathrm{r}}\right)-l$ $\left(51^{\mathrm{r}}\right)$. lii $\left(52^{\mathrm{r}}\right)-C x x\left(120^{\mathrm{r}}\right) \cdot i\left(133^{\mathrm{r}}\right)-l\left(182^{\mathrm{r}}\right)$. lii $\left(183^{\mathrm{r}}\right)-C l x v i\left(297^{\mathrm{r}}\right)$; neuere Foliierung: auf der Blattmitte durchgehend I-IV. 1-366, aussen nach kodikologischen Einheiten 1-52. 1-68. 1-10.1-168. 1-22. 1-38 (ohne Bl. 321 und Bl. 360-366).

Einrichtung und Ausstattung: Durchgehend rubriziert, rote Paragraphenzeichen. $299^{\mathrm{ra}}-300^{\mathrm{rb}}$ rote Initialen. $1^{\mathrm{r}}$ sechszeilige rote Initiale mit grünem Blattmuster auf quadratischem, rot gerahmtem Grund. Zu Teil 4 siehe Nachträge.

Teil 6 (B1. 321-366): Begrenzung des Schriftraums mit Tinte, Schriftraum: 19-19,5 × 13,5-14,5, zweispaltig (5,5-7), 41-52 Zeilen. Jüngere gotische Buchkursive mit Schleifen von einer Hand. Rubriziert, rote Paragraphenzeichen und Unterstreichungen. $322^{\mathrm{rb}}-323^{\mathrm{va}}$ am Rand Quellenangaben von der Hand des Schreibers, rot unterstrichen. Durchgehend Raum für dreizeilige Initialen ausgespart, nicht ausgeführt.

Korrekturen und Nachträge: Teil 6 (Bl.321-366): Wenige Korrekturen von der Hand des Schreibers, z. B. 324va, $346^{\text {ra }}$. Im vorderen Spiegel ein Inhaltsverzeichnis, vielleicht von der Hand Friedrichs von Lütishofen: Manuale confessorum, Tractatus De morali lepra: Nider. Exposicio magistri de Hassia super dominicam oracionem. Sophilogium, cuius finis est amare sciencias. Opusculum Enee Silvei De duobus amantibus. Eppistola Enee Silvei poete sive Pii De amoris remedio. Tractatum De beata virgine super Ave Maria. Sicher von seiner Hand in Teil 6 Lemmata als Fusstitel und eine Reihe von Marginalien am unteren Rand, sowie auf 359vb die Datierung Simonis et Iude lxi. In den Teilen 4 und 5 fügte er an verschiedenen Stellen Marginalien, Nota- und Anführungszeichen sowie Handweiser ein. 
$133^{\mathrm{ra}}-258^{\mathrm{vb}}$ (Teil 4) Initialen in Federzeichnung, vor allem zu Beginn florale Formen, Tierdarstellungen und menschliche Gesichter, ab $144^{\mathrm{vb}}$ schlichter; $133^{\mathrm{ra}}$ Jüngling mit Blatt- und Blütenornamenten, braun und grün koloriert. Von derselben Hand auch zwei Handweiser (140 va und 166 va). 30 ${ }^{\mathrm{r}}-31^{\mathrm{r}}$ Marginalien 16./17. Jh. 131 ${ }^{\mathrm{r}}$ F. Jacobi Ord. Erem. S. Augustini Sophilogium, 17/18. Jh. Ein Lesezeichen (Papierfetzen) nach Bl. 292.

Einband: Mit hellem Leder bezogene Holzdeckel, 15. Jh., mit Streicheisenlinien und 8 verschiedenen Einzelstempeln: 1. Jakobsmuschel in umrandetem Quadrat (vgl. Erster datierter Schweizer Druck, Taf. 18, Nr. 1), 2. Blüte: Vierblatt in gemustertem quadratischem Rahmen (ebd. Nr. 3), 3. stehender geflügelter Greif über einem Band in Quadrat (ebd. Nr. 4), 4. Quadratmuster (ebd. Nr. 5), 5. gegenständige Ranke mit Laub und Blüten in umrandetem Rechteck (ebd. Nr. 7), 6. Stelzvogel in umrandetem Kreis (ebd. Nr. 10), 7. Blüte: Vierblatt mit zwei Blattkränzen in umrandetem Kreis (ebd. Nr. 11), 8. Blume in umrandetem Kreis (ebd. Nr. 12). Fast alle Stempel auch auf dem Einband von C 43, so dass von derselben Werkstatt auszugehen ist. Zwei nach vorn greifende Kantenschliessen, beide Lederriemen ohne die Haken erhalten, Beschläge Messing. Blau-rot-weisse, geflochtene Kapitale. Spiegelblätter Pergament, das hintere Makulatur (Exzerpte aus Cicero, De officiis), darüber je ein Papierstreifen. Vorsatz: zwei Doppelblätter (A-D), Papier, Wasserzeichen: ähnlich PICCARD, Wasserzeichenkartei Nr. 51362 und 51365 (siehe oben). Durchgehend Falzverstärkungen, Pergament. Im vorderen Spiegel Exlibris des Chorherrenstifts Beromünster (Wegmann, Exlibris, Nr. 619). Auf dem Vorderdeckel Spur eines Titelschilds, ebenso auf dem Rücken, darauf: Sophilogium F. Jacobi. Aeneae Sylvii de 2. Amantibus. Item Amoris Remedium [...] 1473, 18. Jh. Ausserdem gedrucktes Titelschild, Papier: F.J. NYDERI O.P. MANUALE CONFESSORUM.

Herkunft: Teil 6 wohl für Friedrich von Lütishofen geschrieben und 359vb von ihm auf den 28. Oktober [14]61 datiert. Der Einband weist auf einen Zusammenhang mit C 43.

Besitzer: Der Band war im 15. Jh. wahrscheinlich im Besitz Friedrichs von Lütishofen, der ihn annotierte. 320 rb (Teil 5) möglicherweise ein Besitzeintrag aus dem Jahr 1473: J. Morff (oder M. F. ?) d. l. l. lxxiii. Im vorderen Spiegel Exlibris des Chorherrenstifts Beromünster. Im Nachtrag zum Catalogus von 1763 auf 46 ${ }^{\mathrm{r}}$ ohne Nummer verzeichnet. $\mathrm{A}^{\mathrm{r}}$ mit blauem Farbstift neuere Signatur: C 65, spätes 20. Jh. Darunter mit Bleistift: Msc. 13, 20. Jh. Ehemals C 14 fol.

Literatur: Kopp, Stiftsbibliothek, II, S. 29; BRUCKNER, Scriptoria 9, S. 28 sowie Taf. 47; Erster datierter Schweizer Druck. Teil 2, Nr. 61, 66, 75, 78 und 108; BüCHLER, Beromünster, S. 163f., 177; CMD-CH 2, Nr. 90.

$\mathrm{A}^{\mathrm{r}}-\mathrm{D}^{\mathrm{v}}$ leer.

Teil 1 (B1. 1-52):

JOHANNES NIDER, Manuale confessorum. Inkunabel GW M26875, [Basel: Michael Wenssler, nicht nach 1474].

Teil 2 (B1. 53-120):

JOHANNES NIDER, Tractatus de morali lepra. Inkunabel GW M26867, [Basel: Michael Wenssler, nicht nach 1475].

Teil 3 (Bl. 121-130):

HENRICUS DE LANGENSTEIN, Expositio super orationem dominicam. Inkunabel GW 12242, [Basel: Michael Wenssler, nicht nach 1474]. 
Teil 4 (Bl. 131-298):

JACQUES LEGRAND, Sophilogium. Inkunabel GW M17639, [Basel: Johann Schilling (Solidi), nicht nach 29. 9. 1473].

Teil 5 (Bl. 299-320):

PIUS II PAPA, De duobus amantibus. De remedio amoris. Inkunabel GW M33482, [Basel: Johann Schilling (Solidi), um 1473/74].

Teil 6 (B1. 321-366):

$321^{\mathrm{r}-\mathrm{v}}$ leer.

$322^{\mathrm{ra}}-359^{\mathrm{vb}}$ CONRADUS DE SAXONIA, Speculum Marie. [Q]uoniam, ut ait Ieronimus, nulli dubium est, quin totum ad gloriam laudis dei pertineat ... 322 $2^{\mathrm{vb}}$ [A] ve Maria ... Audi, dulcissima virgo Maria, audi nova, audi mira ... - ... Adiuva, o dulcissima, ut sine fine nobis concedat dulcedine sua frui ille liberalissimus communicator sui, benedictus fructus ventris tui, qui cum patre et spiritu sancto vivit regnat deus per omnia secula seculorum. Amen. Bl. 334 leer. Conradus de Saxonia, Speculum seu salutatio beatae Mariae virginis ac sermones Mariani, hrsg. v. Petrus de Alcantara Martinez, Grottaferrata 1975, S. 141-504 (Hs. im Verzeichnis der Schweizer Textzeugen S. 131 nicht erwähnt). RB 2017.

$360^{r}-366^{v}$ leer.

Papier, 203 Blätter, $30-31 \times 21-22 \mathrm{~cm}$

Ende des 14. Jahrhunderts

Wasserzeichen, Lagen, Foliierung: Wasserzeichen: Ochsenkopf, PICCARD, Wasserzeichenkartei Nr. 78715 (1394), 78743 (1395), 78831 (1392/93) und eine weitere Variante. Lagen: 9 VI ${ }^{108}+\left(\right.$ VI-1)119 +7 VI $^{203}$, vor Bl. 112 ein Blatt herausgeschnitten. Reklamanten bis 84v Bl. 89-95 am unteren Rand Wasserschaden, z. T. bis in den Schriftraum. Bl. 167-191 an der unteren Ecke (Bl. 25 an der oberen) Mäusefrass, Bl. 167, 175 und 189-191 bis in den Schriftraum. Neuere Foliierung: 1-203.

Einrichtung und Ausstattung: Begrenzung des Schriftraums mit Tinte, Schriftraum 22-24 × 15-15,5, zweispaltig (5,5-8,5), 36-57 (190va 31) Zeilen. Jüngere gotische Buchkursive mit Schleifen von zwei Händen, Händewechsel 89 rb Rubrizierung siehe Nachträge. Raum für zweizeilige Initialen ausgespart, meist am Rand vorgegeben, $1^{\text {ra }}$ für eine 7 zeilige, $2^{\text {rb }}$ eine 4 zeilige, $2^{\mathrm{vb}}-3^{\mathrm{rb}}$ drei dreizeilige, nicht ausgeführt. Vereinzelt Kolumnentitel am unteren oder oberen Rand $\left(37^{\mathrm{r}}-44^{\mathrm{r}}\right.$ und $\left.89^{\mathrm{rb}}-95^{\mathrm{va}}\right)$.

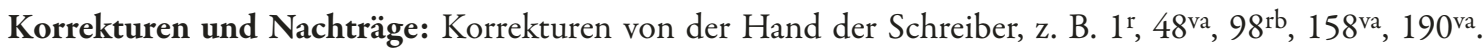
$31^{\mathrm{ra}}-33^{\mathrm{rb}}$ und $195^{\mathrm{va}}-197^{\mathrm{rb}}$ Paragraphenzeichen und Handweiser, 197 $7^{\mathrm{rb}}$ ein Gesicht, alles in Rot; $198^{\mathrm{r}}-199^{\mathrm{r}}$ Marginalien und Notazeichen sowie 199va eine längere Anstreichung mit Gesicht von der gleichen Hand, in Schwarz. 201 ${ }^{\mathrm{r}}$ Nachtrag, 15. Jh. $1^{\mathrm{r}}$ Titel: Comentarius in Quinque libros Decretalium Heinrici Boich de Britania doctoris Parisiensis de anno 1349, Nachtrag 18. Jh.

Einband: Mit Pergamentfragmenten und himbeerrotem Leder bezogene Pappdeckel, 14./15. Jh., in den vorderen Spiegel eingeklappt eine übergreifende Klappe zum Schutz des Schnittes. Ehemals zwei 
Verschlussbänder, Befestigungsschlitz des oberen am Ansatz der Klappe erhalten. Sehr steife Bindung, das Buch lässt sich nicht weit öffnen. Im Spiegel vorne und hinten eingebunden ein durchgehendes grosses Fragment einer Urkunde vom 5. Juli 1394: Statuten für ein Kapitel wohl in Colmar (dicte ecclesie Colmariensis), darin erwähnt nebst dem Basler Bischof Konrad ein prepositus Iacobus und Nicolaus de Hagenbach scolasticus als Zeugen, Datum et actum anno domini Millesimo [trecentesimo nona]gesimoquarto, dominica post festum beatorum Petri et Pauli apostolorum (teilweise mit Exlibris überklebt). Ein Fragment einer anderen Hs. (14. Jh.) sichtbar auf dem Vorderdeckel. In den Fälzen weitere Urkundenfragmente, das erste mit einer Datierung vielleicht auf Ende 1392: Pontificatus dicti domini nostri domini Bon[ifacii] Anno quarto Indiccione decimaquinta, auf einem zweiten, dazugehörigen sind genannt die beiden in dem Pfründenstreit des Oswald Pfirter bezeugten päpstlichen Legaten [Gerlacus decanus sancti Petri] extra muros Maguntin[os] Executor ad infrascripta unacum Reverendo patre in Christo domino Turibio episcopo Tudensi (zw. Bl. 54 u. 55); zwei weitere nennen Stadt und Bischof von Basel (zw. Bl. 78 u. 79) sowie die Namen [Fr] oweler, Heinricum et Lu[told?] um de Ratzenhusen fratres, Wernerum Schaler und wiederum dominum Turibium episcopum (zw. Bl. 90 u. 91); zuletzt noch zwei Streifen desselben Schriftstücks auf Deutsch (erwähnt sind ein brieffder geben und das Datum an Sant Georien tag des heiligen marterers). Im vorderen Spiegel Exlibris des Chorherrenstifts Beromünster (Wegmann, Exlibris, Nr. 619). Auf dem Vorderdeckel Pergamentschild: Heinricus Boich super io decretalium, darunter (mehrheitlich verdeckt) in Schwarz Boi[ch]. Auf dem Rücken der Rest eines weiteren mittelalterlichen, von anderer Hand geschriebenen Pergamentschildes: Heinricus $B$ [oich] super $i^{\circ}$ decr [etalium] sowie ein neueres aus Papier: Commentarius in quinque Libros Decretalium $N^{o}$ 17, 18. Jh., entsprechend dem Catalogus von 1826.

Herkunft: -

Besitzer: Im vorderen Spiegel Exlibris des Chorherrenstifts Beromünster. Im Nachtrag zum Catalogus von 1763 auf 49v ohne Nummer verzeichnet, im Catalogus von 1826 als Nr. 17. $1^{\mathrm{r}}$ neuere Signatur: C 67, Kugelschreiber, spätes 20. Jh. Ehemals C 17 fol.

Literatur: Kopp, Stiftsbibliothek, II, S. 11; BrUCKNER, Scriptoria 9, S. 26; BüCHLER, Beromünster, S. 174 und 246 (Anm. 153).

$1^{\text {ra }}-200^{v a}$ HENRICUS BOHICUS, Distinctiones super primo decretalium. [V] enerabilibus et discretis viris doctoribus licenciatis bacalariis, et aliis scolaribus auditorium suum lecture decretalium ... $2^{\text {rb }}$ Gregorius: Super verbo doctoribus ... $4^{\mathrm{ra}}$ De constitucionibus. Rubrica. Canonum Si queratur ... - ... Et quid si moritur prelatus qui de rebus ecclesie compromisit, vide in dicto 5 Finitur, versus Quid si prelatus. Stimmt überein mit GW 4964: Henricus Bohicus, Distinctiones super quinque libris decretalium, Lyon: Johann Siber für Jacques Buyer, 1498, Super primo decretalium, 2ra_-90vb. SCHUlte, Geschichte, Bd. 2, S. 266-270 (68, Nr. 2); NöRR, Kanonistische Literatur, S. 378.

$200^{\text {vb }}$ leer.

$201^{\mathrm{r}}$ Ex actibus concilii Pisani. Nachtrag. Hec subsequencia sunt ordinata et pronunciata in consilio Constanciensi: Sacro approbante consilio omnes et singulas promociones translaciones confirmaciones collaciones et quascumque provisiones ... de novo providemus. Ubi autem ... - ... a die tercia Mai quo ad Angelum Corario et a die xv Iulii quo ad Petrum de Luna anno domini Mo ccc viii placet consilio quod dictus dominus noster provideat ut sibi iustum videbatur etc. Joannes Dominicus MANsI, Sacrorum conciliorum nova, et amplissima collectio. Editio novissima, Bd. 26, Venedig 1784, Sp. 1154 (Sessio XXII).

$201^{\mathrm{v}}-203^{\mathrm{v}}$ leer. 
Papier, 384 Blätter, $28,5 \times 21 \mathrm{~cm}$

Mitte des 15. Jahrhunderts

Wasserzeichen, Lagen, Foliierung: Wasserzeichen: Bl. 1-48, 61-84, 90/91, 97-100, 105-182, 191-276, 291-298 und 301-348 Traube, PiCCARD, Wasserzeichenkartei Nr. 128864 (1451); Bl. 49-60, 64/69, 85-96, 101-104, 183-190, 277-288, 289/300 und 290/299 Nr. 129168 (1449); Bl. 349-360 und 373-384 Schlange, PiCCARD, Wasserzeichenkartei Nr. 42087 (1439), in zwei Varianten; Bl. 361-372 Ochsenkopf, PiCCARD, Wasserzeichenkartei Nr. 79061 (1448), nebst einer Variante. Lagen: 32 VI ${ }^{384}$. Zwischen Bl. 295 u. 296 ein Zettel (6,5 × 21) eingebunden (295a). Risse in Bl. 1 und Bl. 384 alt mit Papier geflickt. Lagenzählung zu Beginn der Lagen: ius $\left(1^{\mathrm{r}}\right)$ - xviius $\left(193^{\mathrm{r}}\right), 18\left(205^{\mathrm{r}}\right)$ - 29us $\left(337^{\mathrm{r}}\right)$. Reklamanten. Am oberen und (inneren) unteren Rand Wasserschäden, die Schrift teilweise beeinträchtigt aber gut lesbar, Lagenzählung und Reklamanten überwiegend verblasst. $325^{\mathrm{v}} / 326^{\mathrm{r}}$ grossflächig mit (verwässertem) Rubrum verschmiert (die Kopfzeilen hier in Schwarz), rote Flecken auch im Bund von B1. 335/336. Alte Foliierung in Rot, recto und verso, entsprechend der Tabula, z. T. alt korrigiert, modern ergänzt: [1]. 2-13. [14r]. 14-295. [295a]. 296-383. [384].

Einrichtung und Ausstattung: Begrenzung des Schriftraums (der Spalten) mit Tinte, Bl. 189-360 am äusseren Rand Punkturen für eine Liniierung (38 Zeilen, nicht umgesetzt) sichtbar. Schriftraum 20-22 × 14-14,5, zweispaltig (6,5), 34-46 Zeilen. Jüngere gotische Buchkursive mit Schleifen von zwei Händen, Händewechsel $188^{\mathrm{vb}}$. Rubriziert, rote Überschriften und Paragraphenzeichen. Am Kopf der Seiten Buchzählung (und Foliierung) in Rot; am Fuss Zählung der Distinktionen in Schwarz. 2-4zeilige rote Lombarden, z. T. mit Punktverdickungen und Konturbegleitstrichen, $76^{\mathrm{rb}}$ und $77^{\mathrm{rb}}$ mit Schaftaussparungen (Spaltleiste resp. Würfelmuster). $17^{\mathrm{rb}}$ 5zeilige rote, anspruchslos verzierte Initiale. Maginalien zur Textgliederung von der Hand des ersten Schreibers und Rubrikators.

Korrekturen und Nachträge: Wenige Korrekturen von der Hand der beiden Schreiber, z. B. $1^{\mathrm{ra}}$, 17rb $24^{\mathrm{va}}$, $150^{\mathrm{va}}, 193^{\mathrm{v}}, 294^{\mathrm{vb}}, 372^{\mathrm{va}}$; auf dem Zettel 295a eine Ergänzung des zweiten Schreibers; zahlreiche Korrekturen von der Hand des ersten Schreibers im Text des zweiten, z. B. $188^{\mathrm{vb}}, 301^{\mathrm{v}}$, 383 ${ }^{\mathrm{ra}} \cdot 170^{\mathrm{r}}$ eine umfangreiche marginale Ergänzung von einer weiteren, zeitgenössischen Hand. 383 ${ }^{\text {va }}$ Nachtrag von der Hand Ludwig Zellers: Iste liber est Wernheri de Selden caplani S. crucis Beronensis ecclesie. Si autem ante sacerdotium moritur dari debet ecclesie in Arow, prout ab ava et matre eius michi Ludwico commissum est anno lxxvi ${ }^{\circ}$.

Einband: Mit hellem, teilweise abgerissenem, auf dem Rückdeckel aus zwei Stücken zusammengenähtem Leder bezogene Holzdeckel, 15. Jh., Rücken fehlt. Ehemals zwei nach hinten greifende Langriemenschliessen, die Riemenbefestigungen im Vorderdeckel und der obere, ganz umgebogene Messingstift im Rückdeckel erhalten. In den Deckeln vereinzelt Abklatsch ehemaliger Spiegelblätter in Textualis formata. In den Fälzen Pergamentverstärkungen, darunter drei Fragmente aus drei verschiedenen lat. Hss., 13./14. Jh.; zudem je ein Pergamentstück um die erste und die letzte Lage gebunden und in die Deckel geklebt. Im vorderen Spiegel Exlibris des Chorherrenstifts Beromünster(Wegmann, Exlibris, Nr. 619). Auf dem Vorderdeckel Titelschild aus Pergament: Questiones ex Bonaventura super libros sentenciarum, 15. Jh. Zwischen zwei der offenliegenden Doppelbünde Reste und Spuren eines Titelschildes.

Herkunft: $147^{\mathrm{r}}$ am unteren Rand eine Datierung des (ersten) Schreibers: In die Iacobi 1449 (25. Juli). Dazu passt auch die Datierung der Wasserzeichen in die Mitte des 15. Jhs. 
Besitzer: Gemäss dem Eintrag 383 va von der Hand Ludwig Zellers gehörte die Hs. 1476 Werner von Selden, gen. Oeristein, seit 1474 Kaplan am von seinem Onkel Johann von Gundoldingen gestifteten Kreuzaltar und nunmehr dessen Erbe, vgl. Der Geschichtsfreund 10 (1854), S. 45f.; Estermann, Stiftsschule, S. 31; BüChleR, S. 243f. (Anm. 117) und 378f. (Nr. 321). Der Band dürfte also vorher dem Onkel und nachher Zeller gehört haben. Im vorderen Spiegel Exlibris des Chorherrenstifts Beromünster. Im Catalogus von 1763 als Classis Nona Nr. 17 verzeichnet, im Nachtrag dazu auf 49r ohne Nummer, in den Antiquitates Beronenses, S. 691, als Nr. 28, im Catalogus von 1826 als Nr. 3. $1^{\text {r }}$ N. 3. Msc, Bleistift, sowie neuere Signatur: C 69, Kugelschreiber, zudem auf dem oberen Schnitt doppelt mit rotem Filzstift: 69, spätes 20. Jh. Ehemals C 19 fol. Literatur: Kopp, Stiftsbibliothek, II, S. 18 (I, S. 11); BRUCKNER, Scriptoria 9, S. 30; Bü CHLER, Beromünster, S. 166, 177, 243f. (Anm. 117) und 379.

$1^{\text {ra-vb leer. }}$

$2^{\mathrm{ra}}-17^{\mathrm{rb}}$ Tabula. Am oberen Rand: Suscipe placatus rex bone de virgine natus, Exiguum munus qui regnas trinus et unus. Amen. Tabula zu der Abbreviatio Bonaventurae, mit teilweise fehlerhaften Blattverweisen und Vermerken zur gestörten Textfolge: Quid sit subiectum in hoc libro, 17. Utrum modus tractandi sit inquisitivus $\ldots 14^{\mathrm{ra}}$ Utrum restitucio sit pars satisfaccionis, 280. 16. Distinccio: Quid sit contricio secundum suam substanciam, $180 \ldots 14^{\mathrm{rb}}$ Utrum contra voluntatem proprii sacerdotis possit quis confiteri alii discreciori, 188. Nota defectum: Utrum proprio sacerdoti debeat quis confiteri in manifesto vel in occulto, $364 \ldots 14^{\mathrm{vb}}$ Utrum peccata dimissa redeant quantum ad reatum, 383. Post defectum: Utrum sacramentum penitencie fuerit institutum, 289 ... - ... $17^{\mathrm{ra}}$ Utrum vermis ille sit invariabilis, 364. Explicit tabula questionum sive distinctionum in quartum sentenciarum cum suis problematibus. Summa vero omnium distinccionum in omnes libros hec est: 182, que in opere hoc locis reperiuntur suis et hoc foliis per numerum certum signatis.

17 $7^{\mathrm{rb}}-383^{\mathrm{va}}$ HENRICUS DE TUREGO, Abbreviatio Bonaventurae. >Veritates questionum ex opere Bonaventure super libros sentenciarum brevi sub forma sine forma argumentali<. Veritates questionum ex opere Bonaventure super librum sentenciarum pro modico intelligencie mee ad instanciam fratrum extrahere cupiens brevitati studui in hunc modum ... 17 $7^{\mathrm{vb}}$ Habitis preambulis accedendum est ad librum ... - ... non tamen ita quod faciat equivalenciam. Ad tercium dicendum quod de penitencia est loqui dupliciter, aut prout est etc. ut supra habetur. > Notandum quod hic deffectus qui post finem libri scriptus est pertinet ad folium $289 \mathrm{~m}$ ad tale signum ut hic<. Daneben ein Herz mit drei roten Punkten, ut supra in vicesimo quinto sexterno habetur hoc signum. In der fünften Zeile der Spalte 289rb fehlt das 364 ${ }^{\mathrm{va}}-383^{\mathrm{va}}$ nachgetragene mittlere Stück von Buch 4: $289^{\mathrm{rb}}$... quia de aliis absoluti sunt. Ad tercium dicendum quod de penitencia ... Daneben: Hic est defectus, invenies in fine libri inquire hoc signum: das Herz mit den drei roten Punkten. > In folio 364 in principio<. $364 \mathrm{rb}$... et nos apparebimus cum ipso in gloria ad quam ... per infinita seculorum secula, Amen. Tibi Christe sit, cum patre, ayoque pneumate ... Amen. 364va wiederum das Herz: Incipit defectus dimissus. Ad tercium dicendum quod confessio ... $77^{\mathrm{rb}} \mathrm{Buch} 2$, $166^{\mathrm{rb}}$ Buch 3, $231^{\mathrm{vb}}$ Buch 4. B1. 295a ein Zusatz zu Buch 4, Dist. 24.1.2.4: Totum virtuale differt a toto universali et a toto integrali quia totum virtuale est tantum perfecte in uno, in aliis autem incomplete ... 90v leer; $332^{\mathrm{r}}$ leer bis auf eine Notiz von der Hand des ersten Schreibers: Hic nichil deficit sed conatus scriptoris defecit. BONAVENTURA, Opera omnia, Bd. 1, S. LXVa $(\$ 6.2)$; Friedrich STEGmüLlER, Repertorium commentariorum in sententias Petri Lombardi, Würzburg 1947, Bd. 1, S. 150, Nr. 320 (Henricus Goeckelmann de Isny); Volker HonemanN, Artikel H(einrich) von Zürich, in: Verfasserlexikon², Bd. 3 (1981), Sp. 927f.; Hs. nicht genannt. $383^{\mathrm{vb}}-384^{\mathrm{v}}$ leer. 

Die mittelalterlichen Buchhandschriften im Stiftsarchiv 
Papier, 252 Blätter, $17,5 \times 13,5 \mathrm{~cm}$

Beromünster (?), Ende 15. / Anfang 16. Jahrhundert

Wasserzeichen, Lagen, Foliierung: Wasserzeichen: Bl. I-VI und 205-238 Baselstab, Variante von PicCARD, Wasserzeichenkartei Nr. 33116 (1574), Bl. X-XIII und 128-143 Waage, PicCARD, Wasserzeichenkartei Nr. 117398 (1501); Bl. 2-88, 95-104, 108/117, 145-154 und 195-202 Kopf, PicCard, Wasserzeichenkartei Nr. 20832 (1496) und Variante von Nr. 20818 (1488-1492) jeweils mit einer verwandten Form; Bl. 89/92 Buchstabe P, Variante von PICCARD, Wasserzeichenkartei Nr. 115698 (1499), Bl. 112/113 Variante von Nr. 115697 (1496), Bl. 110/115 eine weitere verwandte Form; Bl. 119127 Ochsenkopf, Variante von Piccard, Wasserzeichenkartei Nr. 76479 (1499); Bl. 159-190 Buchstabe M, Piccard, Wasserzeichenkartei Nr. 28925 (1496).

Lagen: $\mathrm{III}^{\mathrm{V}}+\mathrm{VI} \mathrm{XVII}+\mathrm{VII}^{14}+\mathrm{VI}^{26}+(\mathrm{IV}-1)^{33}+2 \mathrm{VI}^{59}+\mathrm{V}^{69}+(\mathrm{IV}-1)^{76}+\mathrm{VI}^{88}+\mathrm{II}^{92}+\mathrm{VII}^{106}+\mathrm{VI}^{118}+$ $\mathrm{V}^{127}+(\mathrm{VIII}-3)^{143}+4 \mathrm{VI}^{191}+(\mathrm{VII}-1)^{204}+3 \mathrm{VI}^{239}$, erstes Blatt der ersten und letztes Blatt der letzten Lage in die Spiegel geklebt, nach Bl. 29, 73 und 204 je ein Blatt, nach Bl. 131 drei foliierte Blätter herausgeschnitten, dort Textverlust. Bl. VI/XVII, 27/33, 29/31, 50/55, 51/52, 70/76 sowie 72/74 aufgrund der Wasserzeichen aus zwei Hälften zusammengeklebt, aufgeklebte Papierstreifen im Falz von weiteren Doppelblättern derselben Lagen. Die Blätter 53 und 54 fehlen (Textverlust), doch scheint die Lage intakt. Bl. VII an den Rändern mit Papierstreifen verstärkt. Buchblock beschnitten, Rand von Bl. 76 zum Schutz der Schrift umgeknickt, an vereinzelten anderen Stellen Textverlust, z. B. 110v. Bl. VII-XVII und 201-204 mit Wasserschaden. $144^{\mathrm{r}}$ unten Lagenzählung (?) 1. Alte Foliierung von zwei Händen, ergänzt: [I-XVII]. 1-52. 55-121. 121 [bis]-131. 135-146, bei der Anlage; 147-202. [203-239], um 1575.

Einrichtung und Ausstattung: Vertikale Begrenzung des Schriftraums mit Stift, meist kaum sichtbar, 64v $-69^{\mathrm{r}}$ mit Tinte; VIIr $-X V I I^{r}$ Schriftraum $11 \times 14-16,5$, zweispaltig (5), 20-26Zeilen; $1^{\mathrm{r}}-204^{\mathrm{v}}$ Schriftraum 9,5 $\times 11,5$ - über 16 (Beschnitt), 18-28 Zeilen. Jüngere gotische Buchkursive mit Schleifen, wohl von einer Hand.

Korrekturen und Nachträge: Wenige Korrekturen von der Hand des Schreibers, z. B. VIIva $44^{\mathrm{v}}, 87^{\mathrm{r}}$, 125 , $180^{\mathrm{v}} ; 88^{\mathrm{v}}$ ein Eintrag zum Eherecht ausgestrichen, weitere Streichungen $93^{\mathrm{r}}$ und $101^{\mathrm{r}}$. Notazeichen, z. B. $14^{\mathrm{r}}$, $90^{\mathrm{v}}, 148^{\mathrm{v}}, 201^{\mathrm{v}} ; 62^{\mathrm{v}}$ Handweiser, 93 ${ }^{\mathrm{r}}$ Unterstreichung. 1v, 22v, 56v, 90v (Bestimmung zum Vorkaufsrecht, Nachtrag: Dis ist geprucht gegen meister andriss und herr hanss zey von Lucia huss wegen oben Im dorff), $125^{\mathrm{r}-\mathrm{v}}$ (Überschriften), $192^{\mathrm{r}}$ und $196^{\mathrm{v}}$ Nachträge des Schreibers. $111^{\mathrm{r}}$ Nachträge des 15. und 16. Jhs. und Lesezeichen; einzelne beschnittene Wörter nachgeschrieben, z. B. 106v, 16. Jh.; 47v Nachtrag von einer Hand des 17. Jhs.: vid. fol. 57. An vielen Stellen Anstreichungen und Bleistiftnotizen, 19. Jh., z. B. $78^{\mathrm{v}}-80^{\mathrm{r}}, 104^{\mathrm{r}}, 131^{\mathrm{r}}$. Beilage: Transkription der Spitalordnung 127r-v, Kugelschreiber 20. Jh.

Einband: Mit braunem Leder bezogene Holzdeckel, Kanten im mittleren Bereich abgeschrägt, 16. Jh. Streicheisenlinien sowie Einzelstempel (Quadrat, Krone, Lilie, kleine sechszählige Blüte, kleine fünfzählige Blüte mit gebuchteten Blättern, Ringlein, Staude, Rautengerank) und ein Rollenstempel (Blumenranke). Ehemals zwei nach vorn greifende Kantenschliessen mit Messingteilen, Lederriemen erhalten; ziselierte Eckund Mittelbeschläge mit blütenförmigen Buckeln, auf der Kante des einen Eckbeschlags eingepunzt: VIII. Kapitale mit weissem und blauem Garn umstochen. Rückenleder am vorderen Gelenk gebrochen. Spiegelblätter Papier, Wasserzeichen siehe dort. Auf dem Rücken ein unter die oberen Eckbeschläge reichendes Titelschild: 
Der Probst [ei] RoothBuch anno 1578 (Datum des Einbands?), Pergament; darunter drei weitere Schilder: Propstei: Roth-Buch 1578, Papier, 19. Jh., 22a Pergament, 18. Jh. (?), 463 Papier, gedruckt, 20. Jh. Reste von einem abgerissenen Papierschild auf dem vorderen Deckel. Im vorderen Spiegel Bleistiftnotiz, 19./20. Jh.

Herkunft: Nach Inhalt und Datierung der enthaltenen Abschriften sowie der Wasserzeichen sukzessive Ende 15. bis Anfang 16. Jh. in Beromünster geschrieben ( $47^{\mathrm{r}}$ Nachtrag mit Jahreszahl 1496, $131^{\mathrm{v}}$ jüngste Jahresangabe [150]8), nach Estermann, Stiftsschule, S. 87 und 212 vom Scholasticus Niklaus Weidmann. Wohl 1578 neu eingebunden.

Besitzer: -

Literatur: Estermann, Stiftsschule, S. 87, 212 und 222; BüCHLER, Beromünster, S. XIV.

Ir-VIv leer.

VIIra-XIVrb Inhaltsverzeichnis. > Register dis buchs $<$. Was man zü dem stouff der dotten geben müss und wz man einem darum thiun solle, folio $1^{\circ}$. Fryheit und gerechtikeit des gotzhus um ein dot schlag, folio $2^{\circ}, 3^{\circ} \ldots-\ldots$ XIII' ${ }^{r b}$ Ordnung eines Capplan[s] zu Santsteffen, folio 131. XIII ${ }^{v}$ leer (die Lücke beginnt mit den ausgeschnittenen Blättern 132-134). XIVra Miner herren von lutzern statt rechtt nach ordnung als $d z$ im rodel stat, folio 144 / 145 etc. XIVrb Ein form eines land gerichtes um [b] dot schleg und der glich sachen hie zümünster wie man das brucht, folio. Insgesamt 128 Einträge.

XIVv-XVIIr leer.

XVIIv Ordo rationis generalis. Nachtrag. > Racio generalis dominorum Beronensium <. Sciendum, quod racio generalis in diem proximum ante Cosme et Damiani ... Verordnung über die Anwesenheitspflicht der Kanoniker bei der jährlichen Generalabrechnung bis Kirchweih.

$1^{\mathrm{r}}$ Notizen. Nachtrag. Nota: Item Ein schüposs die hett xii iucharten ... Item: de ecclesia núdorff pro primis fructibus dantur xxxifl.

$1^{\mathrm{v}}-131^{\mathrm{v}}$ Ordnungen, Eidformeln, Stiftungen, Verträge, Gerichtsbeschlïsse, Zeugenaussagen. Abschriften zu Verwaltungs-, Zivil- und Strafrecht im Herrschaftsgebiet des Stiftes St. Michael, insgesamt 134 Stücke. $>$ Der stouff und was man einem mönschen darum schuldig ze thïn sy, der den stouff gitt<. Item des ersten So git man $v i j[=61 / 2]$ pfund wachs zü den kertzen ... $52^{\mathrm{r}}>$ Dis sind die alten harkomenheiten des meyer hoffs züpfeffiken $<$. Des ersten, so sol ein meyer ze pfeffikon ein wücher stier han ... 52v Aber Im Summer sol er es lassen louffen under den gemeinen swinen pfäfken und rinach. Und umb solichs hat er //. Bricht am Ende der Seite ab, Bl. 53f. fehlen. $55^{\mathrm{r}} / /$ des rechten zü benügen lassen ... by dem eid ouch zü halten und dar wider nit zü thün. 55v leer. 56 $\mathrm{r}$ $>$ Ein richtung von der höfen wegen wile und blasenberg anno lxxii<. Item von der der hofen wegen wile und ober blasenberg ist ein richtung der gütter halb geschechen ... - ... 131 $1^{\mathrm{r}}>$ Ordnung eines Capplans zü sant steffen $<$. Item Er sol uff all donstag, all Samstag, all unsre frowen tag, alle vierhohzit, uff aller selen tag, ouch uff de patronen, so uff unsre frowen altar patronen sind, da selbst mess han ... sol der capplan dem lútpriester hilflich sin. Actum feria $2^{a}$ post Iohannis baptiste anno $8^{v o}$. Nach dem Inhaltsverzeichnis (VIIIva und VIIva) sind für die fehlenden Blätter $53 \mathrm{f}$. drei Texte zu erschliessen: Schluss des Hofrechts für den Meierhof in Pfäffikon, Ordnung des Weinschenkenamts, Formel des Eides, den ein Chorherr dem Rat von Luzern zu schwören hatte (Schluss erhalten). Mehrere Stücke sind nicht im Inhaltsverzeichnis enthalten: 68 ${ }^{\mathrm{r}}-69^{\mathrm{r}}$ Ordnung für den Amtmann in Langnau, 75ㄴ-76 ${ }^{\mathrm{r}}$ Eidformeln für Fürsprecher und Weibel, $76^{\mathrm{v}}$ Verzeichnis der Ämter, die am Johannistag besetzt werden, $111^{\mathrm{r}}$ Feuerordnung, $113^{v}$ Ordnung über Abgaben und Reisekosten, 120v Stiftung des Hans Schumacher, 121v Verbot von nichtöffentlichem Handel. 55v , 64v , 69v , 92v , 99v-100v leer. Bl. 132-134 herausgeschnitten (Textverlust). 
$135^{\mathrm{r}}-143^{\mathrm{v}}$ leer.

$144^{\mathrm{r}}-184^{\mathrm{r}}$ Luzerner Stadtrecht. $>$ Dis ist miner herren von Lutzern stat Rechtt<. $>$ Morgengab $<$. Ein yetlicher So siner elichen fröwen ein morgen gab verheist, Als einer wol tün mag, Die selb fry morgen gab sol dann gantz fry sin In all weg ... - ... 183 ${ }^{\mathrm{r}}>$ Was ein Richter von erben zü lon zü gehoren sol<. Item es hand redt und hundert geordnet ... oder das verbott sol nitt krafft haben. Die Rechtsquellen des Kantons Luzern, Bd. 1.3: Stadt und Territorialstaat Luzern. Satzungen, Eidbuch, Stadtrechtbuch und andere normative Quellen (1461-1489), hrsg. v. Konrad Wanner, Basel 2005, S. 446-450, Nr. 12; S. 450, Nr. 14 - S. 455, Nr. 29; S. 455, Nr. 31 S. 457, Nr. 36; S. 459 Nr. 41 - S. 460, Nr. 43; S. 460, Nr. 46 - S. 461, Nr. 50; S. 462, Nr. 54 - S. 471, Nr. 83; S. 472 , Nr. 85 - S. 473, Nr. 87; S. 473, Nr. 89 - S. 475, Nr. 95; S. 476, Nr. 97-99; S. 477, Nr. 101 - S. 481, Nr. 108; S. 481f., Nr. 111f.; S. 481, Nr. 109f.; S. 500, Nr. 165; S. 505, Nr. 178a.

$184^{\mathrm{v}}-191^{\mathrm{v}}$ leer.

$192^{\mathrm{r}}-201^{\mathrm{r}}$ Landgerichtsordnung. $>$ Ein form Eines land gerichtes umb dot schleg und der glich sachen wie man darum [b] richten sol nach landt recht<. Item des ersten so sol man dem dot schleger oder úbeldetter den rechttag ver künden ... - ... und usrüffe als recht ist zum dritten mal ob yeman des gerichtz witter begere.

201v Nachtrag: Nota. Wenn einer gegenwertig Im Land gricht stat ... - ... und den dot verschult habe.

$202^{\mathrm{v}}-239^{\mathrm{v}}$ leer.

\section{StiAB 01.01.599 ROTES JAHRZEITBUCH}

Pergament, 84 Blätter, 39-40 × 26-27 cm

Beromünster (?), 1323 und 1324

Lagen, Foliierung: Lagen: VII ${ }^{14}+5 \mathrm{VI}^{74}+\mathrm{IV}^{82}$. Untere Hälfte von Bl. 1 und 68 herausgeschnitten, bei Bl. 1 alt ersetzt, dort auch Textverlust; in Teil 1 alte Pergamentflicken an der unteren Ecke der meisten Blätter. Zwei Risse in Bl. 12 genäht (davon einer mit blauem Garn), einer in Bl. 34. 37v/38 ${ }^{\mathrm{r}}$ Flecken. Neuere Paginierung in Abschnitten auf den Rectoseiten in Teil 2 (wohl anlässlich der Edition im QW): $1\left(51^{\mathrm{r}}\right)-21\left(61^{\mathrm{r}}\right), 1\left(62^{\mathrm{r}}\right)-11$ $(67 \mathrm{r}), 1\left(69^{\mathrm{r}}\right), 1\left(70^{\mathrm{r}}\right)-19\left(79^{\mathrm{r}}\right), 1\left(81^{\mathrm{r}}\right)-3\left(82^{\mathrm{r}}\right)$. Neue Foliierung A. 1-83.

\section{Einrichtung und Ausstattung:}

Teil 1 (Bl. 1-50, 1323): Tintenliniierung, Schriftraum 28,5-29,5 × 20-20,5, fünfspaltig (Textspalte 15,5-16), 53-55 Zeilen. Anlagehand: Textualis, Festtage in vergrösserter Auszeichnungsschrift. Rubriziert, Ortsangaben rot unterstrichen (analog zur Unterstreichung der Daten im Anniversarurbar); Monatsnamen, Angaben zur Brotverteilung, Goldene Zahl und Tageszahl in Rot; Sonntagsbuchstabe alternierend rot und blau; Festa fori mit einzeiligen roten und blauen Lombarden und Fleuronné in der Gegenfarbe; Abkürzung für Nonas/Idus/ Kalendas 8-10zeilig in Rot mit lila Fleuronné; KL stark vergrössert, rot und blau mit Fleuronné in der jeweiligen Gegenfarbe, auf $2^{\mathrm{r}}$ mit einem kleinen Fabeltier, $18^{\mathrm{r}}$ mit blauem Blatt im Binnenfeld.

Teil 2 (Bl. 51-82, 1324): Tintenliniierung, Schriftraum 28-28,5 × 19,5, zweispaltig (9), 36 Zeilen. Anlagehand: Textualis. Rubriziert, rote Überschriften, 51 $1^{\mathrm{ra}}-61^{\mathrm{rb}}$ (Anniversarurbar) Daten rot unterstrichen (analog zur Unterstreichung der Ortsnamen in Teil 1). Zweizeilige rote Lombarden zu Beginn der einzelnen Abschnitte (61 ${ }^{\mathrm{r}}$ in Schwarz). 


\section{Korrekturen und Nachträge:}

Teil 1: Korrekturen von der Anlagehand, z. B. $4^{\mathrm{r}}, 11^{\mathrm{r}}$ (teilweise auf Rasur), viele weitere zeitgenössische Änderungen und Aktualisierungen auf Rasur. Zahlreiche Nachträge von verschiedenen Händen des 14. und 15. Jahrhunderts, vor allem Anniversarstiftungen, Weiteres siehe Inhalt. Auf den Rectoseiten Monatsnamen als Kopftitel nachgetragen.

Teil 2: Zahlreiche Rasuren, Änderungen und Nachträge von verschiedenen Händen des 14. und 15., vereinzelt auch des 16. bis 18. Jhs., z. B. $65^{\mathrm{rb}}$.

Einband: Neuer mit rotem, teilweise abgeschabtem Leder bezogener Einband mit abgeschrägten Kanten und Streicheisenlinien, möglicherweise unter Verwendung der alten Holzdeckel; Kapitale ungefärbtes Garn. Neue Spiegel- und Vorsatzblätter (A, 83), Pergament. Buchblock im Rücken mit einem weissen Textilstreifen verstärkt. Der Band wurde im 20. Jh. unsachgemäss restauriert, viele Blätter unten mit aufgeklebten Streifen aus Transparentpapier so fixiert, dass sie beim Trocknen zusammengezogen wurden. Auf dem vorderen Spiegel Aufkleber J. Kronenberg Buchbinderei Münster (Luzern). Gedrucktes Rückenschild: 599.

Herkunft: Geschrieben für das Stift Beromünster, sicherlich vor Ort; der Ostertermin am 27. März und Gedenkeinträge der ersten Hand weisen auf eine Entstehung von Teil 1 im Jahr 1323, die Namen in Teil 2 auf 1324, siehe QW II, 1, S. 18.

Besitzer: In den Antiquitates Beronenses, S. 690 als Nr. 16 verzeichnet. Auf dem Vorsatzblatt Bleistifteintrag Stiftsarchiv Beromünster, auf dem ersten Blatt Besitzstempel Stiftsarchiv Beromünster, beides 20. Jh.

Literatur: Das Jahrzeitbuch des Chorherrenstiftes Beromünster, hrsg. v. Ignaz Vital Herzog, in: Der Geschichtsfreund 5 (1848), S. 83f.; Josef Leopold Brandstetter, Das Alter der Urbarien des Stifts Münster, in: Der Geschichtsfreund 24 (1869), S. 301-304; Josef Ludwig AEBI, Hube und Schuposen, in: Anzeiger für Schweizerische Geschichte, N. F. Bd. 1 (1870-1873), S. 10f.; EstermanN, Sehenswürdigkeiten, S. 66 und 77; Riedweg, Beromünster, S. 171-216; LiebenaU, Urkundenbuch, Bd. 1, S. 25-27; Rudolf HeNGGELER, Das Schlachtenjahrzeit der Eidgenossen nach den innerschweizerischen Jahrzeitbüchern, Basel 1940, S. 235 und 255; QW II, 1, S. 18; Bruckner, Scriptoria 9, S. 18f. sowie Taf. 35 und 38f.; BüCHLER, Beromünster, S. 194 (Anm. 10); Hugener, Buchführung, S. 151-158.

$\mathrm{A}^{\mathrm{r}}$ Besitzeintrag, sonst leer.

Av leer.

Teil 1:

$1^{\mathrm{r}-\mathrm{v}}$ Nachträge, 14. und 15. Jh. // de bonis in Ezzelwil, quos colit Rüdinus Hennio ... Teil einer Urkunde vom 3. Sept. 1369 über den Wiederaufbau eines abgebrannten Hauses sowie zwei Abrechnungen: Summa pauperum anni $m^{\circ} c c c c^{\circ}$ huius libri und Summa pauperum istius libri, die letzte unvollständig. QW II, 1 , S. 263f., Nr. 21. 1 ${ }^{v}$ Ista sunt bona, que dominus Iacobus de Rinach prepositus ecclesie Beronensis vendidit de suo patrimonio ... QW II, 1, S. 103, Nr. 12.

$2^{\mathrm{r}}-49^{\mathrm{v}}$ Liber anniversariorum. Jahrzeitbuch. Goldene Zahl, Sonntagsbuchstaben, Kalenden, Nonen, Iden. >iii. A. KL. Ianuarius. Circumcisio Domini<. > Hac die dantur tres panes et de camera i<. Hesso an dem Brüle obiit. De cuius anniversario dantur $x$ quartalia spelte de decima in Leimbach, in vino et in pane canonicis presentibus ministranda ... - ... >xiii. A. ii. K Silvestri pape<. Das Jahrzeitbuch des Chorherrenstiftes Beromünster, hrsg. v. Ignaz Vital Herzog, in: Der Geschichtsfreund 5 (1848), S. 84-157; Monumenta 
Germaniae Historica, Necrologia Germaniae, Bd. 1, ed. Franciscus Ludovicus Baumann, Berlin 1888, S. 347-356 (auszugsweise Edition). $6^{\mathrm{r}}$ Februar, 10 ${ }^{\mathrm{r}}$ März, 14 $4^{\mathrm{r}}$ April, $18^{\mathrm{r}} \mathrm{Mai}, 22^{\mathrm{r}}$ Juni, 26r Juli, 30 ${ }^{\mathrm{r}}$ August, $34^{\mathrm{r}}$ September, 38 $8^{\mathrm{r}}$ Oktober, $42^{\mathrm{r}}$ November, $46^{\mathrm{r}}$ Dezember. Nachgetragene Heiligenfeste: Ignacii episcopi et martiris (1. Februar), Dorothee virginis et martiris (7. Februar, gestrichen und am 6. neu eingetragen) und Fortunate virginis et martiris (12. Oktober). Zu Hieronymus (30. September): Huius festum in crastinum transferatur. Am 17. Oktober wurde der Eintrag für Johannes von Trostberg ausgestrichen und am Rand vermerkt: Illa ordinacio revocata est [per] heredes.

49v-50v Nachträge, 14. Jh. Fünf Urkunden. Wir, Jacob von Rynach, Probst, und das Capitel gemenilich des Gotzhus sant Michels ze Münster in Ergo ... Urkundenbuch, Bd. 2, S. 315-317, Nr. 514. Urkundenbuch, Bd. 1, S. 236f., Nr. 198; S. 202f., Nr. 156; S. 366f., Nr. 309. Urkundenbuch, Bd. 2, S. 309f., Nr. 503.

Teil 2:

$51^{\mathrm{ra}}-61^{\mathrm{rb}}$ Census anniversariorum. Anniversarurbar. Hec est summa spelte, que de granario dominorum ministratur camare ad anniversaria per circulum anni celebranda ... 53 $3^{\mathrm{rb}}$ sechs Merkverse: Omnibus hec panis ad festa datur cameralis ... Estermann, Stiftsschule, S. 12 bzw. Urkundenbuch, Bd. 1, S. 11 (vgl. StiAB 01.01.600, S. 313 und StiAB 01.01.634a, 35 rb). 53 va $>$ In villa Beronensi<. Isti sunt census pertinentes ad anniversaria ... QW II, 1, S. 19-45, Nr. 5.

$61^{\mathrm{v}}$ Nachtrag, 14. Jh. In nomine domini, amen. Nos Iacobus de Rinach prepositus totumque capitulum ecclesie Michahelis in Berona ... Urkunde von 1346. Urkundenbuch, Bd. 2, S. 273-275, Nr. 474.

$62^{\mathrm{ra}}-67^{\mathrm{vb}}$ Census camerae. Kammeramtsurbar. $>$ Incipit liber camere $<$. Isti sunt census specialiter ad cameram pertinentes... QW II, 1, S. 45-60, Nr. 6.

$68^{\mathrm{ra}-\mathrm{rb}}$ Nachtrag, 16. Jh. > Iuramentum canonicorum <. Ego N. ex hac dieprohinc fidelis ero ... $68^{\mathrm{rb}}>$ Iuramentum prebendariorum <. Ego N. ab hac hora probinc fidelis ero ...

$68^{\mathrm{va}-\mathrm{vb}}$ Census panis celebrantium. $>$ Hec est annona, de qua ministrari debet singulis diebus per circulum anni sacerdoti missam publicam celebranti unus panis prebendalis vulgariter dictus Singbrot<. In Nüdorf de bono quod colit P. dictus Heiden ii modios spelte mensure curie ... QW II, 1, S. 102, Nr. 11.

$69^{\mathrm{ra}-\mathrm{vb}}$ Census fabricae. Fabrikamtsurbar. $>$ Isti sunt census pertinentes ad fabricam ecclesie Beronenis $<$. In villa Beronensi Wernherus de Kütingen viii solidos denariorum ... QW II, 1, S. 91-93, Nr. 9.

$70^{\mathrm{ra}}-79^{\mathrm{va}}$ Census cellarii. Kelleramtsurbar. $>$ Isti sunt census pertinentes ad cellarium ecclesie Beronensis $<$. In Berona uxor Wernheri de Erlosen vii denarios de area ... QW II, 1, S. 61-85, Nr. 7.

$79^{\mathrm{vb}}-80^{\mathrm{ra}}$ Decimae. $>$ Iste sunt decime ecclesie Beronensis<. > In Hochdorf<. Decima in villa Hochdorfsecundum communem estimacionem reddit lxvi malteras et duas libras in arra ... QW II, 1, S. 85-87, Nr. 7.

$80^{\mathrm{va}-\mathrm{vb}}$ Nachtrag, 14. Jh. Isti sunt census sive redditus altaris omnium sanctorum in ecclesia Beronensi ... QW II, 1, S. $105 f .$, Nr. 14.

$81^{\mathrm{ra}}-82^{\mathrm{rb}}$ Census custodie. Kusteramtsurbar. $>$ Isti sunt census custodie ecclesie Beronensis $<$. In Göchusen census auri ... QW II, 1, S. 87-90, Nr. 8.

$82^{\mathrm{vb}}$ Nachträge, 14. Jh. In Gottes namen, amen. Wir Jacob von Rinach Probst und das Capitel gemenilich des Gotzhuses von Münster ... Urkundenbuch, Bd. 2, S. 271-273, Nr. 473. Anschliessend von anderer Hand, teilweise ganz abgerieben: [Nos Iacobus] de Rinach prepositus totumque capitulum ecclesie Beronensis ... Urkundenbuch, Bd. 2, S. $290 f .$, Nr. 487. 
Pergament, 203 Blätter, 36-36,5 × 24,5-25 cm

Beromünster (?), 1345 und 1346/47

Lagen, Foliierung: Lagen: $2 \mathrm{I}^{8}+8 \mathrm{VI}^{200}+(\mathrm{I}+\mathrm{I})^{208}+(\mathrm{VI}+\mathrm{I})^{234}+2 \mathrm{VI}^{282}+(\mathrm{VI}+\mathrm{III})^{318}+(\mathrm{VI}+1)^{344}+$ $2 \mathrm{VI}^{392}+\mathrm{II}^{400}$, die Lage S. 201-208 besteht aus zwei nachträglich hinzugefügten, hintereinander angeordneten Doppelblättern; nach Bl. 223/224 ein Doppelblatt, nach 293/294 drei Doppelblätter eingefügt; das Einzelblatt 327/328 an S. 329 geklebt. Letzte Lage kleiner: $35 \times 24,5$. Buchblock beschnitten, vereinzelt mit Textverlust; für einzelne längere Einträge am Rand von S. 129, 253 und 297 wurden kurze überstehende Streifen belassen. Teil 1 in schlechtem Zustand, vor allem die unteren Ecken stark angegriffen, mit Wurmfrass und Schimmel. Grössere Risse in den Blättern 19/20, 21/22, 69/70, 77/78 (mit grünem Seidengarn geflickt), 151/152, 159/160, 169/170 und 181/182; ein Stück von Blatt 185/186 von der unteren Ecke ausgehend abgerissen. Einzelne Einträge stark abgerieben; jeweils ein Eintrag auf S. 20f. mit einer heute braun verfärbten Chemikalie behandelt. Alte Foliierungen: $i(210)-v i i i(224)$. ix (228) - xlii (294). xliii (308) - xlvi (314). 1 (329) - 23 (373). 14 (375). 25 (377, korrigiert aus 15) - 30 (387). 31 (391). Paginierung des 16. Jhs., ergänzt: [A]. 1-6, fortgesetzt durch neuere Paginierung: 7-225. [225a, 225b]. 226-400. [401].

Einrichtung und Ausstattung:

Teil 1 (S. 1-200, 1345): Tintenliniierung, Schriftraum 27,5-29 × 19,5-20, vierspaltig (Textspalte 15,5-16), 49-51 Zeilen; S. 200 23,5 × 18,5, zweispaltig (8-9,5), 39 Zeilen. Anlagehand: Textualis, Festtage in vergrösserter Auszeichnungsschrift. Rubriziert, rote und blaue Paragraphenzeichen, Ortsangaben rot unterstrichen (analog zur Unterstreichung der Daten im Anniversarurbar); Monatsnamen, Angaben zur Brotverteilung und Tagesangaben in Rot; Sonntagsbuchstabe alternierend rot und blau; Festtage z. T. mit einzeiligen roten oder blauen Lombarden (festa fori und festa duplicia), sonst mit schwarzer Initiale, diese ab S. 113 häufig mit Binnenfeldornament in Schwarz und Rot, S. 114-121 zusätzlich mit Blau, S. 192 mit Gesichtskizze im Binnenfeld; KL stark vergrössert, rot und blau, z. T. mit Fleuronné.

Teil 2 (S. 201-400, 1346/47 und spätere Ergänzungen): Tintenliniierung, Schriftraum $26 \times 20$, dreispaltig (mittlere Spalte 8, links und rechts 5), in der Mitte 24, seitlich 48 Zeilen; in den nachträglich hinzugefügten Teilen nur die Mittelspalte liniiert. Anlagehand: Textualis von derselben Hand, die auch StiA Bm 709 schrieb. Rubriziert, rote Überschriften, S. 209-328 (Anniversarurbar) Daten rot unterstrichen (analog zur Unterstreichung der Ortsnamen in Teil 1). Zweizeilige rote Lombarden zu Beginn der einzelnen Abschnitte, S. 209 zweizeilige rote Initiale mit schwarz-rotem Quadratmuster im Binnenfeld.

\section{Korrekturen und Nachträge:}

S. 1-8 und 393-397 Nachträge des 16. Jhs., siehe Inhalt.

Teil 1: Vereinzelte Korrekturen der Anlagehand S. 95, 123 und 197, selten spätere Änderungen an ihren Einträgen, z. B. S. 37, 115, 193 (Name, auf Rasur); zahlreiche zusätzliche Einträge und Streichungen von verschiedenen Händen des 14. bis frühen 17. Jhs., vor allem Anniversarstiftungen, häufig auch prom $(p)$ ten bzw.prom (p)tum neben einzelnen Einträgen. Grössere Rasuren auf S. 26, 161, 174, 183 und 185. Durchgehend Daten, vereinzelt Jahreszahlen und kurze Transkriptionen mit Bleistift eingetragen, Spiegel vorne: Ostern am 27. März Anno 1239, 1250, 1323, 1334, 1345, 1407, 1418, 1429, 1440 (die Daten 1334 und 1345 unterstrichen, 1323 doppelt), alles 19./20. Jh. Nach S. 84 kleineres, lose einliegendes Blatt Papier mit Notiz 
des 17./18. Jhs. zu einer weiteren Jahrzeit: Dominus Renw. Göldlin ordinavit dari singulis annis 16 florenos de bonis Conr. Seebacher in Oberrinach ... - ... Ita Liber anniversariorum major ad diem 28 May.

Beilage: Heft aus 12 Doppelblättern, 20,5 × 16,5, Papier, 17. Jh. S. 1-10 alphabetisches Ortsnamenregister, wohl zu einer Karte der South West Peninsula und der Bretagne: A. Abrirac, C.h. Audierne, i. Absburton [sic], D.c. ... - ... Z. Zime E.c. S. 11-[30] monatsweise geordnetes Anniversarverzeichnis, am Ende jeder Seite Abrechnung: > Januarius<. Joannes de Bütikon dedit bonum in Mulwyl, spelte 2 quarteria, 3 immi (?). Hug de Jegenstorff, tritici, 1 ... - ... Richenza de Winon, spelte $8=$ spelte 1. tritici -, 2, 11/2.

Teil 2: Wenige spätere Änderungen an den Einträgen der Anlagehand in der mittleren Spalte, z. B. S. 213 (Streichung), 233 (Mengenangabe), 287 (Rasur), 365 (Streichung); viele Nachträge des 14. und 15. Jhs., z. B. S. 216 f., 276, 327f., 387; 333 ein Nachtrag radiert. S. 209-309 und ab 329 zahlreiche Nachträge und Änderungen von verschiedenen Händen des 14. und 15. Jhs. in den beiden randlichen Spalten, z. T. auf Rasur; S. 247 Balmer, 18. Jh. Zu den nachträglich (spätestens zum Zeitpunkt der Neubindung im 16. Jh.) in den fertig geschriebenen Text eingefügten Blättern mit den Seitenzahlen 201-208, 225-226 sowie 295-306 siehe Inhalt. Nach S. 268 Lesezeichen, Papier, mit Resten von Schrift, 16. Jh. (?).

Einband: Mit hellem Leder überzogene Holzdeckel, Kanten jeweils im mittleren Bereich abgeschrägt, 16. Jh., Streicheisenlinien und Rollenstempel (Blumenranken). Ehemals zwei nach vorn greifende Kantenschliessen, Reste von Lederriemen erhalten, Beschläge Messing. Auf dem hinteren Deckel oben zwei ziselierte Eckbeschläge, in der Mitte ein rhombischer Beschlag, alle aus Messing mit blütenförmigen Buckeln und Blattausläufern; an den unteren Ecken und auf dem vorderen Deckel Spuren ebensolcher Beschläge. Rücken Pergament, unten und zum hinteren Deckel hin fast lose, oben rechts mit Papier geflickt. Buchblock hinten mit mehreren Pergamentstreifen verstärkt: Fragmente einer Handschrift mit Hufnagelnotation im Vierlinienschema. Spiegel- und Vorsatzblätter (A, 401) Papier, Wasserzeichen mit Zürcher Wappen, ähnl. Wasserzeichen-Informationssystem (WZIS) CH9500-Ms_C5_Y; der Einband steht dem Kodex Zürich, Zentralbibliothek, Ms C 5 nahe (Zurichtung der Holzdeckel, Beschläge, Wasserzeichen der Spiegel- und Vorsatzblätter) und könnte wie dieser aus der Zürcher Werkstatt des Heirich Meosli stammen. Auf S. 1 und 400 Spuren von älteren Einbanddeckeln, B1. 399/400 ehemals Spiegelblatt mit Resten von Klebstoff und zwei Fragmenten: Pergament, 13./14. Jh. (Priscian. Inst. 14,3) und Papier, 15. Jh. (Druck). S. 368 zum Falz hin mit einem aufgeklebten Pergamentstreifen (Fragment) verstärkt. Auf dem vorderen Deckel Titelschild, Papier, 19. Jh.: Anniversarium de circa 1325. Darunter mit Bleistift: der Stift. 2. Auf dem Rücken Aufschrift: Anniversarium c. 1325.

Herkunft: Geschrieben für das Stift Beromünster, sicherlich vor Ort; der Ostertermin am 27. März weist auf eine Entstehung von Teil 1 im Jahr 1345 (falls das Datum nicht aus dem Roten Jahrzeitbuch übernommen wurde), die Namen in Teil 2 auf 1346/47, siehe QW II, 1, S. 114. Teil 2 wurde von derselben Hand geschrieben wie das Kelleramtsurbar StiA Bm 709.

Besitzer: In den Antiquitates Beronenses, S. 690 wohl als Nr. 17 verzeichnet.

Literatur: Estermann, Sehenswürdigkeiten, S. 66 und 77; Liebenau, Urkundenbuch, Bd. 1, S. 27-29;

Rudolf Heng geler, Die Jahrzeitbücher der fünf Orte. Ein Überblick, in: Der Geschichtsfreund 93 (1938),

S. 51; QW II, 1, S. 113f.; BRUCKNER, Scriptoria, Bd. 9, S. 19 sowie Taf. 36 und 38; Bü CHLER, Beromünster, S. 194 (Anm. 10); Hugener, Buchführung, S. 158-162.

$\mathrm{A}^{\mathrm{r}-\mathrm{v}}$ leer. 
Teil 1:

S. 1-7 Abschriften und Kapitelsbeschlüsse des 16. Jhs. Zü wüssen, allsdann bishar yewëlten der bruch gwesen das die Zins vor Martini vallende, dem allten Camerer ynzäziehen ... zur Einkünfteverteilung bei Wechsel des Amtsinhabers, anschliessend Rentenkauf und Jahrzeitstiftung Agatha Halters von 1540 und Statuten für die Abhaltung von Messfeiern. S. $3>$ Ordinacio fraternitatis beatissime virginis Marie ecclesie collegiate Beronensis <. Nos prepositus totumque capitulum ... mit Nachträgen von verschiedenen Händen des 16. Jhs. S. 5 Wir Custos unnd Capittel gemeinlich ... Ordnung für die Fronleichnamsprozession, Jahrzeitstiftung Propst Wilhelm Rycharts von 1575.

S. 8 leer.

S. 9-198 Liber anniversariorum. Jahrzeitbuch. Sonntagsbuchstaben, Kalenden, Nonen, Iden. > A. KL. Ianuarius. Circumcisio Domini<. > Hac die dantur iii panes et de camera $i<$. Hesso an dem Brüle obiit. In cuius anniversario dantur x quarteria spelte de decima in Leinbach, canonicis presentibus in pane et vino ministranda ... - ... $>$ A. ii. $K$ Silvestri pape<. S. 25 Februar, S. 39 März, S. 55 April, S. 71 Mai, S. 87 Juni, S. 103 Juli, S. 119 August, S. 135 September, S. 151 Oktober, S. 167 November, S. 183 Dezember. Nachgetragenes Heiligenfest: Erhardi episcopi (8. Januar). S. 70 Nachtrag, 15. Jh.: Anno domini Millesimo quadringentesimo octuagesimo tercio in vigilia annunciacionis beate Marie virginis obiit spectabilis vir magister Fridericus de Lútishoven ... Anniversarstiftung der Brüder Friedrich und Burkhard von Lütishofen für den 9. Februar, vgl auch Bü CHLER, Beromünster, S. 248 (Anm. 16).

S. 198f. Nachträge, 15. Jh. Zwei Urkunden: Wir, Türing von Arburg Probst und dz Cappittel gemeinlich der Stifft ze Münster im Ergow ... Jahrzeitstiftung der Anna von Küssenberg von 1422, anschliessend Gebetsbruderschaft zwischen den Michaelsstiften Aschaffenburg, Beromünster, Rheinau und Lautenbach von 1402, letztere ediert im Codex diplomaticus Alemanniae et Burgundiae Trans-Juranae intra fines dioecesis Constantiensis, hrsg. v. Trudpertus Neugart, Bd. 2, St. Blasien 1795, S. 487.

S. 200 Abrechnung, 14. Jh. In Berona, i. Hergisperg, Ludingen, v. Richartswile, Nunwil, v ...

Teil 2:

S. 201f. Nachträge zum Anniversarurbar, um 1400. Item bonum dictum das oberbucholcz reddit i modium tritici, qui datur ad anniversarium L. de Irklikon v Kl. May ... Daneben: Coluit Petrus phung. Nunc tantum iii quarteria tritici. S. 202-204 Nachträge, 15. Jh. Wir Niclaus von Gundelffingen Probst und gemein Cappitel der Stiffe ze Münster in Ergow ... Jahrzeitstiftung des Anton Russ und seiner Frau Anna von Küssenberg von 1453, anschliessend Terminänderung für die Generalabrechnung von 1464.

S. 205 Nachtrag, 16. Jh. > Anno 1524<. Nos, Ůldricus Martinus totumque capitulum ecclesie collegiate Sancti Michaelis Beronensis ... Statuten für die Abhaltung von Messfeiern.

S. 206f. leer.

S. 208 Nachtrag, 16. Jh. Nota quod anno domini $M^{\circ}$ cccccxx $x^{\circ}$ honestus Thüringus Scherer ordinavit decem libras denariorum annui census ... Jahrzeitstiftung.

S. 209-328 Census anniversariorum. Anniversarurbar. > Hii sunt census pertinentes ad anniversaria per circulum anni celebranda in Berona<. Area et domus contigua granario dominorum reddit xx solidos denariorum ... In der rechten Spalte: Quam possidet Iohannes Ravensp [urc] (Name auf Rasur) buius ecclesie canonicus. Nunc magister C. Schappel. Nunc dominus Ymerius Hori. Nunc dominus Iohannes Wiczig. In der linken Spalte: Desuper dantur de eadem domo et area i libra iiii solidi denariorum, que dantur ad anniversarium Iohannes Schiterberg xii 
Kalendas Iunii. S. 310 leer, danach keine Einträge mehr in den seitlichen Spalten. S. $311>$ Decima in Leinbach<. De decima in Leimbach dantur singulis annis ad anniversaria ... S. 313 De censibus camere dantur viii maltera spelte canonicis omnibus in pane ad festa infrascripta ... Anschliessend sechs Merkverse: Omnibus hic panis ad festa datur cameralis ... Estermann, Stiftsschule, S. 12 bzw. Urkundenbuch, Bd. 1, S. 11 (vgl. StiAB 01.01.599, 53 $3^{\mathrm{rb}}$ und StiAB 01.01.634a, 35 ${ }^{\mathrm{rb}}$ ). S. $315>$ De granario dominorum<. Item de granario dominorum ministrantur camere singulis annis ad anniversaria ... - ... S. 326 Item i modium siliginis datur pro cera ad candelas super coronam in choro pendentem. Anschliessend Nachträge, 14. Jh.: Item vi modios spelte et ii maltera avene ad anniversarium Dietrici de Fonte ii Idus Marcii ... S. 225-[225b], 295, 297-304 Nachträge auf den später eingefügten Blättern (um 1400), S. 226, 296 und 305f. leer. QW II, 1, S. 115-156, Nr. 17.

S. 329-392 Census camerae. Kammeramtsurbar. $>$ Hii sunt census camere speciales $<$. $>$ Elmengrin $<$. In Elmengrin bonum Uf dem Büle reddens xii solidos ... In der rechten Spalte: Quod colit H. Martis de Remerswile ... - ... S. 391 Item bonum Hemme de Staden reddit xi denarios. Anschliessend S. 392 Nachträge. Anno domini Millesimo ccc mo computatum est salarium camerarii ... Summa pauperum in anno $M^{\circ}$ ccco buius libri ... Abrechnungen. QW II, 1, S. 157-182, Nr. 18. Danach Urkundenabschrift: Ich, Hans zem Tor, Ein burger ze nüwenburg ... alle zum Jahr 1400.

S. 393-396 Nachtrag, 16. Jh. Wir, Johann heinrich schümacher, propst unnd das Capitel der Stifft sant Michael ze Münster inn Ergow ... > Wie man der Jarziten tegliche presents verdienen sol<. Ein ietlicher herre caplan ... Statuten über die Amtsplichten der Stiftsherren von 1562.

S. 397 Nachtrag, 16. Jh. Uf sambstag vor Palmarum, Anno 1590. Ist von herren Probste und Capitel beschlossen, Wan ein herr Probst, Custos, old Chorher sterbe, söl man ibm mit allen glogen lüten ...

\section{StiAB 01.01.602 JAHRZEITBUCH DES SCHOLASTICUS}

Papier, 118 Blätter, $31 \times 21,5 \mathrm{~cm}$

Beromünster (?), zwischen 1534 und 1537

Wasserzeichen, Lagen, Foliierung: Wasserzeichen: Bl. 1-104 Bär, PICCARD, Wasserzeichenkartei Nr. 83933 (1539), 83944 (1536) und 84069 (1533) sowie eine Variante; Bl. 85/96 und 105-118 Variante von Nr. 83905 (1541); Bl. 106/113 und 107/114 Variante von Nr. 84646 (1537). Lagen: (VI+1) $)^{12}+7 \mathrm{VI}^{96}+\mathrm{IV}^{104}+\mathrm{V}^{114}+$ III $^{118}$, B1. 4 Einzelblatt, das erste und die zwei letzten Blätter in den Spiegel, die äusseren Blätter der einzelnen Lagen jeweils aneinander geklebt. Erste Lage fast lose. Lagenzählung zu Beginn der Lagen: $C\left(25^{\mathrm{r}}\right)-H\left(85^{\mathrm{r}}\right)$. Alte Paginierung: $A\left(97^{\mathrm{r}}\right)-S\left(105^{\mathrm{v}}\right)$. Neuere Foliierung 1-11, neu fortgesetzt bis 118 .

Einrichtung und Ausstattung: $2^{\mathrm{r}}-96^{\mathrm{v}}$ vertikale und horizontale Begrenzung des Schriftraums mit Tinte, Breite 18-19,5, fünfspaltig (Textspalte 10,5-11,5), horizontal zweigeteilt (zwei Tage pro Seite), Zeilenzahl stark schwankend. Anlagehand: Kursive des 16. Jhs., Festtage und Monatsnamen in vergrösserter Auszeichnungsschrift. Monatsnamen, Sonntagsbuchstabe, Tageszahl und Kalenden, Nonen, Iden sowie Festa fori in Rot. Bl. 97-101 durch Falten in vier gleiche Spalten unterteilt. Bl. 1 und 102-118 ohne Vorgaben für die Seiteneinrichtung.

Korrekturen und Nachträge: Wenige Schreiberkorrekturen, z. B. 6r $32^{\mathrm{r}}, 76^{\mathrm{r}}, 100^{\mathrm{v}}$; einige spätere Änderungen an den Einträgen der ersten Hand, z. B. 9 ${ }^{\mathrm{r}}$ (Ergänzung auf Rasur), 26v $68^{\mathrm{v}}$. 13 $3^{\mathrm{r}}, 14^{\mathrm{v}}$ und $31^{\mathrm{v}}$ Nota, 40 
Handweiser. Zahlreiche Nachträge des 16. bis frühen 17. Jhs., vor allem Jahrzeitstiftungen, seltener auch promptum oder vacat, an mehreren Stellen von verschiedenen Händen Listen der tatsächlichen Einnahmen aus einzelnen Stiftungen über einen längeren Zeitraum, z. B. $5^{\text {r }}: 37$ spelte, 46 spelte, 51 nibil, 61 spelte, 69 nibil, 73 spelte, 84 nibil, 91 spelte, 1600 spelte, 1604 spelte, 1605 nibil, 1606 spelte, 1610 avene. Längere Nachträge siehe Inhalt. Zwischen Bl. 23 und 24 ein lose einliegender kleinerer Zettel mit Bleistiftnotizen zu den Beromünsterer Jahrzeitbüchern, 19. Jh.

Einband: Flexibler brauner Ledereinband, hinten mit Klappe, 16. Jh., Streicheisenlinien, Roll- und Einzelstempel (bewohnte Ranke und Vierblatt in konkavem Karo). Leder des Einbands steif und spröde. Auf dem Vorderdeckel und in der Klappe Löcher für zwei Verschlussbänder. In der Klappe Pergamentfragment, 13./14. Jh.: Pandekten, D. 2, 14, 40-49, am Vorderdeckel zum Rücken hin und im Rücken mehrere Streifen derselben Handschrift. Rücken oben und unten gebrochen, vorderer Deckel zum Buchblock hin lose.

Herkunft: Geschrieben für das Stift Beromünster, sicherlich vor Ort. Einen Terminus post quem bietet das $38^{v}$ von der Anlagehand geschriebene und auf 1534 datierte Obiit des Johannes Feer, Deutschordenskomtur in Hitzkirch, einen Terminus ante quem ein auf 1537 datierter Eintrag von anderer Hand auf 96v, siehe Inhalt. Besitzer: $1^{\mathrm{r}}$ Besitzstempel Stiftsarchiv Beromünster, mit Kugelschreiber handschriftlich ergänzt: 602, 20. Jh.; $118^{\mathrm{r}}$ zwei weitere gleiche Besitzstempel.

Literatur: BRUCKNER, Scriptoria, Bd. 9, S. 33 (mit Datierung auf 1525, wohl aufgrund des Nachtrags im Spiegel); Hugener, Buchführung, S. 314.

Spiegelblatt: Nachträge, 16. Jh. Per anni circulum peraguntur heęoctave inchoanturque: videlicet Lucię sequenti die proximo ... Anno 1525 cuilibet canonicorum residentium ex presentiis libri vite cessit ...

$1^{\mathrm{r}-\mathrm{v}}$ Nachträge, 16. Jh. >Corpus seu annua pensio ex dominorum cellari[o] Beronensi atque canonicorum scholastico cedens <. Avene vii modios Beronensis mensure ... Liste der Einkünfte des Schulmeisters, anschliessend Hinweise für die Benutzung des Jahrzeitbuches: Ubicumque inveneris signaturam crucis ad ordinationes sive anniversaria sive festivitates in hoc libro, spectat divisio cano[nicis] residen[tibus] tantum ... $1^{\mathrm{v}}>$ Verglychung des Mess<. Item 18 quarteria Zürichmess facit 1 malterum hofmäs ...

$2^{\mathrm{r}}-96^{\mathrm{v}}$ Liber anniversariorum. Jahrzeitbuch. Sonntagsbuchstaben, Kalenden, Nonen, Iden. $>A$. KL. Ianuarius. Circumcisio Domini<. Item ad anniversarium Hessonis an dem Brül de decima in Leimbach vii quarteria spelte inter canonicis dividenda ... - ... $>$ A. ii. K Silvestri pape $<$. In der randlichen Spalte zu jedem Eintrag die Anteile der Kanoniker und Präbendeninhaber: $2^{\mathrm{r}}$ Canonicis vii quarteria spelte ... Anschliessend von anderer Hand: Absolutus est hic anniversariorum liber per me Abrahamum Schat huius collegii notarium anno a nativitate domini Millesimo quingentesimo tricesimo septimo mense Septembri. $10^{\mathrm{r}}$ Februar, $17^{\mathrm{r}}$ März,

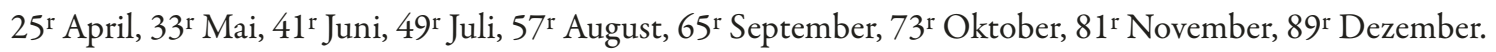
Nachgetragene Heiligenfeste: $8^{\mathrm{r}}$ Conversio Pauli, $13^{\mathrm{r}}$ Valentin, $15^{\mathrm{v}}$ Matthias, $43^{\mathrm{v}}$ Barnabas.

97r-99v Quotidianae, pretia frugum, divisiones. $>1537<$. Mehrung der quottidian, Vnder heren propst Martin. Qui totum generat cuilibet 16 solidos 2 denarios. $>$ Anno 1546<. Das qui totum cuilibet 39 solidos 4 denarios ... von zwei verschiedenen Händen fortgesetzt bis $1597.97 \mathrm{v}>$ Index venditionis siliginis $<$. Anno 1530 siliginis modius venditus est florenis 41/2 (?) ... Anschliessend Preislisten für Dinkel, Hafer und Weizen sowie für Wein, von verschiedenen Händen fortgesetzt bis 1622. 99 ${ }^{\mathrm{r}}>$ Divisiones a dominis Lucernensibus strenuis prudentibusque viris anno 1563 emptae iuxta ordinem seniorum capitularium et in perpetuum observandae iuxta litterarum desuper tenorem admissarum<. Praepositus Schumacher, Rathenhoffer, Wirts ... quelibet divisio 
continet 91 malteras. Unamquanque pro 100 coronatis Francorum ... von verschiedenen Händen fortgesetzt bis 1570.

$100^{r}$ leer.

$100^{\mathrm{v}}-103^{\mathrm{r}}$ Index canonicorum. >Index eorum, qui quandoque sunt praesentati installatique canonici<. Dominus Jacobus Haas successit in canonicali praebenda domino magistro Johanni Zimmermann anno $x \times v^{\circ}$ mense septembri ... von verschiedenen Händen fortgesetzt bis 1586.

$103^{v}$ Verzeichnis von Amtsinhabern. > Ordnung unnd namen der fünff ämpter<. Weibel. Jost Amrein. 1565 obiit 8 die Decembris. 1566, 29. Tag Jenners ist Adam Amrein Weibel worden ... Schenk ... koch ... pfister ... der ander pfister ... Anschliessend: Cammerer. Stoffel feer ist abgesetzt worden uf 13 tag novembris ...

$104^{\mathrm{r}}-105^{\mathrm{r}}$ leer.

105 Abrechnungen von 1566. > Summarum was ein cammerer uss dem jarzitbuch von jarziten jerlichen ussgen müssen thut<. Spelte iic lxxi maltera, iii mütt, vii immi (?) ... Mit Ergänzungen.

$106^{\mathrm{r}}-114^{\mathrm{r}}$ leer.

$114^{\mathrm{v}}$ Index canonicorum. > Nomina canonicorum 1567<. Praepositus schumacher. Onofrius wissenbach custos ... Geordnet nach Priestern, Diakonen, Subdiakonen und tacentes.

$115^{\mathrm{r}}-116^{\mathrm{r}}$ leer.

$117^{\mathrm{r}}-118^{\mathrm{r}}$ Notizen zu Begräbnissen. Item uff den 14 tag decembris hat man zu vesper zu zwo lyhen gericht mit crüts ... 1564. 117v leer. $118^{\mathrm{r}}$ Item wan ein chorlych ist, so singt am morgen ein gsungne vigilg mit dem Invitatorio ... Item wan eins priesters jungfrow stirbt ... Beide 1561. Anschliessend Ergänzung und Nachtrag von 1562.

$118^{\mathrm{v}}$ leer.

\section{StiAB 01.01.603 JAHRZEITBUCH UND URBARE}

Papier, 265 Blätter, 30,5 × $21 \mathrm{~cm}$

Beromünster (?), Anfang 16. Jahrhundert

Wasserzeichen, Lagen, Foliierung: Wasserzeichen: Traube, PICCARD, Wasserzeichenkartei Nr. 129360 (1503) und 129374 (1501), Bl. 223/224 (nachträglich eingeklebt) Löwe. Lagen: 15 VI ${ }^{182}+(\mathrm{VI}-1+\mathrm{I}+\mathrm{I})^{197}+$ $(\text { VIII-4+II })^{213}+\left(\right.$ VI+I+1) $228+(\text { VIII-2+I })^{244}+\left(\right.$ VIII-1) $259+$ III $^{265}$, nach Bl. 185, 191, 222 und 240 je ein Doppelblatt, nach 200 zwei Doppelblätter eingefügt; nach 197, 210, 232, 240 und 250 je ein Blatt herausgeschnitten, nach 204 drei Blätter (die nach 204 und 210 herausgeschnittenen bildeten ein Doppelblatt); Bl. 214 Einzelblatt. Die ganze erste Lage ist im Falz gebrochen und mit Papierstreifen geflickt, das erste Blatt ausserdem mit Faden angeheftet und an den Vorsatz geklebt; alle Lagen sind miteinander verklebt. Von oben ausgehend Wasserschaden. Alte Foliierung: 1 (183) - $36(218) .38(219)$ - 52 (233). $54(234)$ - $57(237) .59$ (238) - 85 (264). Neuere Foliierung, ergänzt: 1-12. [13-265].

Einrichtung und Ausstattung: Vertikale Begrenzung des Schriftraums mit Tinte, Breite 19-20, Kolumnenhöhe und Zeilenzahl stark schwankend. $1^{\mathrm{r}}-134^{\mathrm{v}}$ fünfspaltig (Textspalte 9,5-10, Anmerkungsspalte 6,5-7); $135^{\mathrm{r}}-162^{\mathrm{v}}$ zweispaltig $(9,5-10) ; 164^{\mathrm{r}}-170^{\mathrm{r}}$ zweispaltig mit beidseitiger Spaltenbegrenzung $(8) ; 171^{\mathrm{r}}-265^{\mathrm{r}}$ dreispaltig $(3,5 ; 10 ; 6,5)$. Anlagehand: jüngere gotische Kursive mit Schleifen. Rubriziert, rote Unterstreichungen. Bl. 1-97 (Kalendar): horizontal zweigeteilt (zwei Tage pro Seite). Festtage in vergrösserter Schrift. 
Monatsnamen, Sonntagsbuchstabe, Tageszahl und Kalenden, Nonen, Iden sowie Festa fori in Rot. Kopftitel mit Kalenden, Nonen, Iden und Monatsnamen, rot unterstrichen. Bl. 98 ${ }^{\mathrm{r}}-264^{\mathrm{r}}$ (Urbare): rote Überschriften in vergrösserter Schrift; $184^{\mathrm{r}}-255^{\mathrm{r}}$ auf den Rectoseiten rote Kopftitel: Ortsnamen in vergrösserter Schrift.

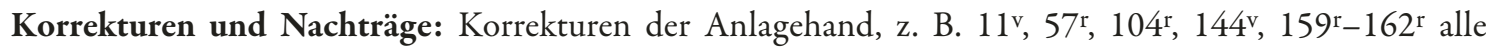

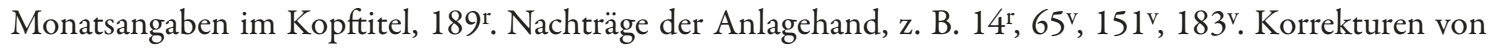
anderer Hand, z. B. 12v', 49r (auf Rasur), 77r, 129v, 208v. Viele Streichungen. Notazeichen, $14^{\mathrm{r}}$ Handweiser zu einem Nachtrag: Plus exposuit quam census contineant. Zahlreiche Nachträge des 16 . bis frühen 17 . Jhs.: Jahrzeitstiftungen und Ergänzungen zu bestehenden Einträgen, öfters promptum; $6^{\mathrm{r}}, 2^{\mathrm{v}}$, $58^{\mathrm{r}}$ Listen der tatsächlichen Einnahmen aus einzelnen Stiftungen von verschiedenen Händen über einen längeren Zeitraum, z. B. 6r: Anno 1615 spelte, anno 1616 avene, Anno 1617 nibil, Anno 1626 00. Zu den Auszahlungen an die Armen $\left(123^{\mathrm{r}}-156^{\mathrm{v}}\right)$ nach jedem Monat eine Abrechnung, am Schluss eine Gesamtrechnung sowie Angaben über die Art der Verteilung von einer Hand des 16./17. Jhs. 223 ${ }^{\mathrm{r}}-224^{\mathrm{v}}$ auf einem zusätzlich eingeklebten Doppelblatt Nachträge von Johannes Hitzmann, 1565: Item rudi kerren guetli, danach das wüstengütli genant. Bereinigung findestu im schwartzenbuch ... Lateinische Stücke mit deutschen Übersetzungen. 224r $\mathrm{Zu}$ wissen, alsdann ein mütt kernen uff und ab zweyen acheren, so hans houri demnach wellti houri besessen hand, ierlichs bodenzins gat ... Johannes Hitzman prothonotarius Beronensis subscripsit anno 1565.

Einband: Flexibler brauner Ledereinband, ehemals mit Klappe am Hinterdeckel (abgerissen), 16. Jh., Streicheisenlinien und Rollenstempel. Deckel mit Papier- und Pergamentfragmenten verstärkt, darunter ein neumiertes Graduale, Pergament, 13. Jh. (Commune sanctorum mit AH 50 Nr. 21) und mehrere Blätter eines juristischen Traktats, Papier, 14./15. Jh. Auf dem Vorderdeckel Spuren von zwei Verschlussbändern und einer Riemenbefestigung. Über die Deckel verlaufen mehrere Schnitte, der Rücken ist am vorderen Gelenk fast ganz, am hinteren oben und unten lose. Vorsatzblätter $(1,2)$ Papier, Wasserzeichen Löwe (wie das nachträglich eingeklebte Doppelblatt). Auf dem Rücken zwei Papierschilder, das obere handschriftlich in Tinte, nicht mehr lesbar, das untere mit gedruckter Signatur 603.

Herkunft: Geschrieben für das Stift Beromünster, sicherlich vor Ort. Das Kalendar steht in engem Zusammenhang mit StiAB 01.01.602. Ein Eintrag zu Getreide- und Weinpreisen von der Anlagehand auf $98^{\mathrm{v}}$ bezieht sich auf das Jahr 1502; Terminus ante quem ist 1517, da ein Eintrag zu diesem Jahr auf $15^{\mathrm{v}}$ von anderer Hand stammt.

Besitzer: -

Literatur: Hugener, Buchführung, S. 314 (dort irrtümlich mit der Angabe «Perg., 85 Bl.»).

$1^{\mathrm{r}}-2^{\mathrm{v}}$ leer.

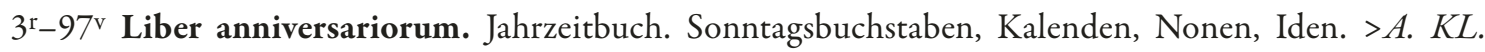
Ianuarius. Circumcisio Domini<. Item ad anniversarium Hessonis Ambrül dantur de decima in Leimbach vii quarteria spelte inter canonicis dividenda ... - ... $>$ A. ii. K Silvestri pape $<$. In der randlichen Spalte zu jedem Eintrag die Anteile der Kanoniker und Präbendeninhaber: Canonicis vii quarteria spelte ... $11^{\mathrm{r}}$ Februar, $18^{\mathrm{r}}$

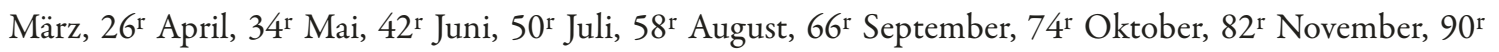
Dezember. Nachgetragene Heiligenfeste: $22^{\mathrm{v}}$ Joseph, $76^{\mathrm{v}}$ Fortunata, $91^{\mathrm{r}}$ Nikolaus.

98 ${ }^{\mathrm{r}}$ Donatio. > Ordinacio domini de Grünenberg<. Anno domini $M^{o}$ cccc ${ }^{o}$ in proxima feria sexta ante festum nativitatis gloriose virginis Marie dominus Hemannus de Grüenberg miles donavit huic ecclesie dotem cum ecclesia ad ipsam pertinente in Rickenbach ... Vgl. RIEDwEG, Beromünster, S. 150. 
$98^{v}$ Pretia. Item anno cccc $i^{\circ}$ siligo vendita est camerario pro xxxiii solidis monete Lucernensis. Item pocculum vini pro viii angster.

99r-168v Redditus anniversariorum. Verzeichnisse über die Auszahlungen aus Anniversarstiftungen an verschiedene Empfängergruppen, jeweils chronologisch geordnet. >Item de granario dominorum ministrantur camere singulis annis ad aniversaria per circulum anni celebranda etc. ut sequitur $<$. > Januarius $<$. Item ad anniversarium Kathrine de Rüda dantur iiii modii tritici de granario, iiii Nonas Januarii ... 100v Februar, 102v

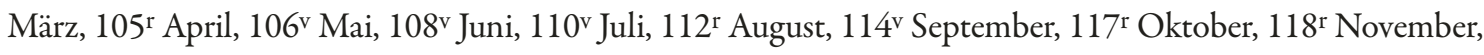
$120^{\mathrm{r}}$ Dezember. $122^{\mathrm{v}}$ leer. $123^{\mathrm{r}}>$ Subsequentia dantur de anniversariis pauperibus ex libro vite seclusis (?) prompte<. $>$ Ianuarius <. Item de anniversario Iohannis de Búttiken dantur pauperibus ii quarteria iii fiertel spelte et xviii denarii ... Daneben bis $162^{v}$ eine Spalte für Anmerkungen: De octava Iohannis evangelistae ex ordinacione domini Iohannis Meyers cedit pauperibus in prompto ere xv solidi ... Nachtrag, 16./17. Jh. 125 $5^{\mathrm{v}}$ leer. 126r Februar, $128^{\mathrm{r}}$

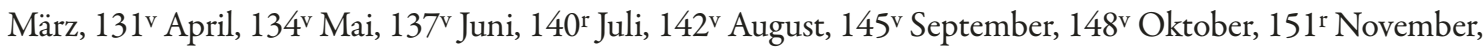
$153^{\mathrm{v}}$ Dezember. $157^{\mathrm{r}}>$ Subsequentia dantur fabrice. Ex libro vite $<.>$ Ianuarius $<$. Item de anniversario domini $H$. Gartner dantur vi quarteria avene fabrice ... Daneben: Item ad salutem Ia [cobi] ann der Almend i libra v solidi ... Nachtrag, 16./17. Jh. 163 leer. Anschliessend Auszahlungen an einzelne Amtsträger: $164^{\text {ra }}$ Inhaber der Marienpräbende, 164 $4^{\mathrm{rb}}$ Organist, $164^{\mathrm{va}}$ Kustos, $165^{\mathrm{ra}}$ Kaplan des Johannesaltars, $165^{\mathrm{rb}}$ Inhaber der Martinspräbende, $165^{\text {va }}$ Inhaber der Allerheiligenpräbende, $165^{\text {vb }}$ Inhaber der Andreaspräbende, $166^{\text {ra }}$ Kaplan des Nikolausaltars, $166^{\mathrm{rb}}$ Kaplan des Mauritiusaltars, 166 $6^{\mathrm{va}}$ Inhaber der Katharinenpräbende, 166 ${ }^{\mathrm{vb}}$ Zelebrant der öffentlichen Messe, 167ra Zelebrant der Totenmesse, 167 rb Diakon, 167va Subdiakon und Kantoren, 167vb Rezeptoren, $168^{\mathrm{ra}}$ Offiziale, $168^{\mathrm{rb}}$ Ausrufer und die Kirche von Lezöw, 168 va Sakristane, 168 vb St. Stephanskirche.

$169^{\mathrm{ra}}-182^{\mathrm{v}}$ leer.

$183^{\mathrm{r}}-264^{\mathrm{r}}$ Census anniversariorum. Verzeichnisse über die Abgaben zugunsten von Anniversarstiftungen, geographisch geordnet. > Hii sunt census pertinentes ad anniversaria per circulum anni celebranda. In Berona $<$. Item domus et area apud cameram reddit ii libras iiii solidos ad cameram ... Zu vielen Gütern auf der inneren Spalte Angaben über die Inhaber: 183 Possidet magister Erhardus Batman ... 186 $6^{\mathrm{v}}-187^{\mathrm{v}}$ und 193v leer. $194^{\mathrm{r}}$ $>$ Hergensperg<. Item bonum ibidem reddit $i$ modium spelte primo anno, i modium avene secundo anno, tercio anno nichil ... 194 $>$ Ludingen <. Item advocacia in Ludingen reddit x solidos, qui dantur ad anniversarium

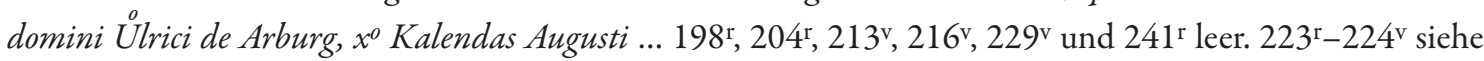
Nachträge. $256^{\mathrm{r}}>$ Hii sunt census camere speciales. Elmegrin <. Item in Elmegrin bonum Uff dem Büle reddens xii solidos ... 264 26 De cellari<. Item i libram ex parte bonorum venditorum in Oberrinach ... Anschliessend Abrechnung: >Summarum censuum specialium <. In spelta viii maltera iii modios ... $265^{\text {r-v }}$ leer.

\section{StiAB 01.01.615 JAHRZEITBUCH VON SCHWARZENBACH}

Pergament, 59 Blätter, $37-37,5 \times 27 \mathrm{~cm}$

Beromünster oder Schwarzenbach, um 1479-1492 (?)

Lagen, Foliierung: Lagen: $(\mathrm{V}-1)^{20}+2 \mathrm{~V}^{60}+(\mathrm{IV}-1)^{74}+\mathrm{IV}^{90}+\mathrm{III}^{102}$, vor Bl. 3/4 und 67/68 je ein Blatt herausgeschnitten (ersteres nach dem Paginieren, letzteres mit Textverlust, offenbar vor dem Paginieren), 
zudem der untere Rand von Bl. 97/98. Bl. 69/70 von unten her eingerissen; in Bl. 89/90 ein Loch, im folgenden Blatt ein Schnitt an entsprechender Stelle. Die Tinte teilweise zersetzt und abgefallen, besonders auf der unteren Hälfte von S. 56-61. Reklamanten auf S. 60 (Tinte zersetzt) und 74 (beschnitten). Alte Paginierung (zwei Hände, Wechsel vor S. 56), ergänzt: [I-VIII]. 3-104. [105-112].

Einrichtung und Ausstattung: Vertikale Begrenzung des Schriftraums mit Tinte, horizontal im Anniversar (Tageseinteilung) teilweise mit Stift, ab S. 57 Tintenliniierung. S. 3-66: Schriftraum 26-30,5 × 15,5-16, bis 60 dreispaltig (Textspalte 13,5-14), 7 Tage pro Seite, ab S. 578 Zeilen im Notenschema, mit eingeschalteten Textblöcken; S. 67-100 Schriftraum 27-33,5 × 21,5-23, bis 94 dreispaltig, teilw. mit Zwischenspalten (in der Mitte 7,5-8,5, seitlich 6-6,5), der fortlaufende Text auf einer und derselben Seite teils spaltenweise, teils in ornamentalen Blöcken unterschiedlicher Zeilenlänge angeordnet, 35-41 Zeilen (Textualis); S. 87-98 nur noch Kursive, ab S. 94 in Langzeilen: 33-36 × 22, 58-62 Zeilen. Textualis und jüngere gotische Buchkursive mit Schleifen von der Hand des Johannes Dörflinger. Rubriziert, rote Überschriften; ab S. 67 rote Paragraphenzeichen und 1-2zeilige rote Lombarden mit Punktverdickungen; schwarz-rote Initialen. Monatsnamen, Sonntagsbuchstabe, Tageszahl und Kalenden, Nonen, Iden sowie Festa fori in Rot. Im Officium dedicationis (S. 57-66) einzeilige rote Lombarden im Text, sowie rote und schwarz-rote Initialen im Notenschema, Hufnagelnotation auf vier Linien, eine davon jeweils rot nachgezogen.

Korrekturen und Nachträge: Korrekturen des Schreibers, z. B. S. 21, 34, 54, 69, Ergänzungen, z. B. S. 70; S. 69, bei dem Stiftungseintrag zu Dörflingers Onkel Heinrich, am Rand ein Querverweis auf S. 97: Copia instrumenti legacionis huius et donacionis quere infra in fine libri ab hinc folio xvii computandum, ähnlich auch S. 68. S. 70 am Rand ein Nachtrag von Stiftsnotar Andreas Erni betr. Kassation der Jahrzeit des Johannes Dörflinger, von Erni auch noch weitere Einträge. Zahlreiche Nachträge im Anniversar von verschiedenen Händen bis in das 18. Jh., darunter Christoph Zacharias Göldin, z. B. S. 27, 50, 52, vgl. auch StiAB 01.01.616. Notazeichen. S. 14 Gesicht im Binnenfeld einer Initiale, darauf ein Hut. S. 15 zum Ostertermin am 27. März ein Datierungsversuch, S. 98-104 Nachträge, 1554-1795.

Einband: Mit braunem Leder bezogene Holzdeckel, 15. Jh., an den Seiten im mittleren Bereich abgeschrägt, mit Streicheisenlinien, Rollen- und Einzelstempeln (Rautenblüte und Blütenstaude); der Rücken aus weissem Leder, mit anderem Rollenstempel. Ehemals zwei nach vorn greifende Kantenschliessen, Messingteile im Vorderdeckel und ein Rest des oberen Riemens erhalten. Ehemals je vier ziselierte Eckbeschläge mit flachen Buckeln, vorne drei, hinten zwei davon erhalten. Spiegel- und Vorsatzblätter (S. I-VIII, 105-112) Papier, aus Einzelblättern zusammengefügte Doppelblätter, Wasserzeichen: Doppeladler mit Balken im Adlerherzschild. Vorderes Spiegelblatt abgelöst, das dazugehörige (Vorsatz-)Blatt herausgerissen. Auf dem Rückdeckel Reste von rotem Siegellack, vorne nur in Spuren. Auf dem Vorderdeckel Papierschild: Anniversarium Schwarzenbach, gleiche Hand wie StiAB 01.01.616. Gedrucktes Rückenschild: 615.

Herkunft: Geschrieben wohl ganz von Johannes Dörflinger, aufgrund des Schriftvergleichs mit dem Hochdorfer Missale (C 5 fol.), dem Jahrzeitbuch von Neudorf (Pfarrarchiv Neudorf), sowie dem Reliquienverzeichnis im Evangelistar (II C 1, 107v -114v ), dem Nachtrag $1^{\mathrm{r}}$ im Epistolar (II C 3) und weiterer, auch inhaltlicher Merkmale: S. 86 etwa ein Eintrag: Sciendum quod ego Iohannes Dörffinger fui prebendarius ... S. 29 zudem ein Nachtrag wohl von Dörflingers Neffe und Nachfolger Georg (zum 26. Juni): Anno domini $15[0] 4$ obiit dominus Iohannes Dörffinger rector huius eclesie in Schwarzenbach et capplanus ecclesie Beronensis altaris s. Mauricii qui hunc conscripsit librum. Cuius anima requiescat in pace, am Rand: Annotato obitu $m$. Georgii d. Siehe dazu und zu den eigenen Jahrzeiteinträgen auf S. 54 (zum 12. Dezember) und S. 70 die 
Einleitung, S. 19f. Zur Datierung: S. 4 ein auf das Jahr 1484 datierter Eintrag von der Anlagehand; auf S. 18 der Eintrag zum 15. April: Proxima feria sexta post Octavam pasce celebratur festum clavorum et lancee domini, vgl. Suter, S. 84. Auf S. 38 jedoch ein Eintrag in der Kursive Dörflingers: Nunc vero videlicet Anno domini Mo $^{\circ}$ ccc $^{\circ}$ lxxix ... S. 39 und S. 71 Einträge in gleicher Schrift von 1489, aus dem gleichen Jahr S. 21 in Textualis, rubriziert, aber ein Nachtrag; S. 95 schliesslich, in Kursive: Nunc autem videlicet anno domini $M^{o} \operatorname{cccc}^{\circ}$ lxxxxii ${ }^{\circ}$...Wenn allerdings der Eintrag S. 70 eigenhändig ist, kann er kaum vor 1500 geschrieben sein.

Besitzer: S. VIII Bibliotheca Beronensis, 17./18. Jh.

Literatur: Joseph Schneller, Jahrzeitbücher des Mittelalters, 2: Der Kirche zu Schwarzenbach, Cantons Lucern, in: Der Geschichtsfreund 3 (1846), S. 195-213 (auszugsweise Edition); EstermanN, Stiftsschule, S. 88 und 138; Konrad LÜtolf, Dörflingers Reliquienverzeichnis von Beromünster, in: Zeitschrift für Schweizerische Kirchengeschichte 12 (1918), S. 157 (und 185, Anm. 3), 161; Rudolf Henggeler, Das Schlachtenjahrzeit der Eidgenossen nach den innerschweizerischen Jahrzeitbüchern, Basel 1940, S. 240 und 274f.; BruCKner, Scriptoria, Bd. 9, S. 28; Robert Ludwig Suter, Johannes Dörflinger, der Illuminator des Helias Helye, in: Erster datierter Schweizer Druck, S. 81 (Tabelle 3b) und 82, 84; BüchleR, Beromünster, S. 141; Hugener, Buchführung, S. 89 und 373.

\section{S. I-VII leer.}

S. VIII Besitzeintrag, sonst leer.

S. 3-56 Liber anniversariorum. Sonntagsbuchstaben, Kalenden, Nonen, Iden. $>$ KL. Ianuarius habet dies xxxim. A. Jan. Circumcisio domini<. Hemma de Rinfelden obiit que dedit casulam eclesie. $>B$. IIII (Nonas). Octava S. Stephani (schwarz, darüber in Rot: Reliquie eius sunt hic.) Berchte regine Burgundie< ... - ... > A. II. Silvestri pape, Columbe virginis<. S. 7 Februar, S. 12 März, S. 16 April, S. 21 Mai, S. 25 Juni, S. 30 Juli, S. 34 August, S. 39 September, S. 43 Oktober, S. 48 November, S. 52 Dezember. S. 37 zum 20. August Bero und Ulrich, S. 38 zum 25. August Dedicatio ecclesiae, mit Einträgen von J. Dörflinger, S. 43 Dedicatio eccl. Beronensis, mit Eintrag zu den Reliquien der Thebäer, S. 49 zum 9. November eine längere historische Notiz zu den Guglern: Anno domini $M^{o} c c c^{o}$ lxxv. venerunt Anglici wulgariter die engellender ... SCHNELLER, Jahrzeitbücher des Mittelalters, S. 195-205 (auszugsweise Edition), die Notiz zu den Guglern S. 203f. oder bei HengGeler, Schlachtenjahrzeit, S. 275.

S. 57-66 Officium dedicationis. Presta domine ut quisquis hoc templum beneficia petiturus ingreditur cuncta se impetrasse letetur ... S. $58>$ Hymnus $<$. Urbs beata Hierusalem ... S. $59>$ Ad missam, introitus $<$. Terribilis est locus iste ... S. 63 > Sequencia<. Clara chorus dulce pangat ... - ... voce pura Flagitamus da //. Bricht ab, AH 54 Nr. 94 (Strophe 13 fehlt; 4: celi fastidia, 9: paria pagina, 10: elegit, 12: lapidibus ornata, 14: inter filias, 21: ipsamque mediatricem), das Blatt mit dem Schluss (den letzten Wörtern von Strophe 22) herausgeschnitten. S. 67-93 Conspectus benefactorum, possessionum, privilegiorum etc. Verzeichnis der Guttäter, der Einkünfte und Rechte der Kirche von Schwarzenbach und der Mauritiuspfründe sowie sämtlicher Liegenschaften. // quia idem prebenda altaris in cripta eclesiam in Swarzenbach in officia re tenetur ... $>$ Benefactores eclesie in Swarzenbach seu prebende altaris in cripta, et augmentatores censuum eorundem<. Mechthildis de Winnon obiit v. Ydus Martii, que dedit ad prebendam constitutam per predictum magistrum Burkardum de Winnon suum fratrem predium in Kulmbe ... SCHNELLER, Jahrzeitbücher des Mittelalters, S. 205f. S. 68 >De loco habitationis sue in Berona uff dem stalden situate<. S. 69 Anno domini Millesimo quadringentesimo sexagesimo sexto, iii Ydus Decembris obiit Heinricus Dórflinger rector eclesie in Swarzenbach ... 
S. $70>$ De loco habitationis sue in Swarzenbach situate<. Anno domini Millesimo quingentesimo. Obiit Iohannes Dorfflinger rector eclesie in Swarzenbach ... > Hec sunt possessiones ad predictum bonum pertinentes <. Item ... S. 71 $>$ Hii sunt census annuales ad prebendam altaris in cripta pertinentes $<$. Decima tota et totalis et minuta eclesie parrochialis in Swarzenbach. Demptis agris ... Text am unteren Seitenrand beschnitten. S. $87>$ Bona in Swarzenbach ad eclesiam Beronensem pertinentia cum possessionibus suis. Et primo de predio cuius habitacio propinquior est ville Beronensi<. Predium seu bonum cum certis scoposis insertis dictum meyers gü sive des friesen güt est ecclesie Beronensi ... SCHNELler, Jahrzeitbücher des Mittelalters, S. 206-210 (Auszüge und Zusammenfassungen).

S. 94-98 Chartae. Ablässe, Reliquien und Schenkungen. Sequitur copia de indulgenciis infra octavam corporis Christi consequendis rescripta a vero originali iuxta eucharistiam in ecclesia in Filmeringen constituto. Sacrosancta synodus generalis Basiliensis in spiritu sancto legitime congregata ... S. 95 > Copia indulgentiarum eclesie in Swarczembach<. Nos Iohannes dechanus eclesie Constanciensis ... > Subscripte reliquie continentur in eclesia in Swarczenbach<. De ligno sancte crucis valde approbato. De casula sancti Petri. Reliquie sancti Stephani ... Sciendum quod Anno domini Mo cccc lxxix ... S. 97 > Copia instrumenti donationis ac legationis Heinrici Dorfflinger domus uff dem stalden<. In nomine domini Amen. Per hoc presens publicum instrumentum ... 27. 10. 1460 (vgl. S. 69 bzw. Nachträge). S. 98 Nicolaus episcopus ... Sixtus episcopus ... Schneller, Jahrzeitbücher des Mittelalters, S. 210-213 (Regesten sowie der Text zu den Reliquien von 1479). Anschliessend Nachträge zur Kirchenausstattung, 1607-1628.

S. 99-104 Nachträge. Benefactor altaris noviter exstructi ex parte muliebri ... S. 101 leer.

S. 105-112 leer.

\section{StiAB 01.01.616 SCHONGAUER JAHRZEITBUCH}

Pergament und Papier, 55 Blätter, $33 \times 23,5-24 \mathrm{~cm}$

Beromünster (?), letztes Viertel 15. des Jahrhunderts

Wasserzeichen, Lagen, Foliierung: Bl. 1-8, 15-22, 30-37 sowie 45 und 46 Pergament, ansonsten (Nachträge) Papier, Wasserzeichen: Bl. 9, 10, 24, 25 und 39-41 Schild mit Löwen, eine Variante von PICCARD, Wasserzeichenkartei Nr. 25771 (1634); Bl. 12-14, 26-29, 42-44 und 47-49 gekröntes Schild, viergeteilt, oben steigende Löwen, unten Buchstaben V und S, ähnlich PICCARD, Wasserzeichenkartei Nr. 85505 (1680), jedoch viel schmaler. Lagen: IV $8+(I I-2)^{10}+(I V-4)^{14}+(I I I+2)^{22}+3^{25}+(I V-4)^{29}+$ IV $^{37}+$ $4^{41}+\left(\right.$ III-3) ${ }^{44}+2^{46}+3^{49}$, nach Bl. 10 zwei, nach Bl. 44 drei, nach Bl. 14 und 29 je vier (Papier-)Blätter herausgeschnitten; Bl. 16, 21, 23-25 (Bl. 24/25 zu einem Doppelblatt zusammengeklebt), 38-41 (zu zwei Doppelblättern zusammengeklebt) und 45-49 Einzelblätter. Neue Foliierung: I-II. 1-53.

Einrichtung und Ausstattung: Bl. 1-8, 15-22 und 30-37: Schriftraumbegrenzung und Seitenaufteilung mit Tinte, Schriftraum 23,5-25,5 × 14-14,5, zweispaltig (Textspalte 13,5-14), 5-9 Tage pro Seite. Anlagehand: Nahezu schleifenlose jüngere gotische Buchkursive, Festtage in vergrösserter Auszeichnungsschrift (Textualis). Rubriziert, Monatsnamen, Festa fori sowie die Angaben zu Länge von Tag und Nacht in Rot; Sonntagsbuchstabe A rot, sonst schwarz. $1^{r}$ Kalenden (KL) in Blau. Kalenden und Sonntagsbuchstaben mit Punktverdickungen, Konturbegleitstrichen und Ausläufern, $5^{\mathrm{r}}$ Schaftaussparungen, $18^{\mathrm{v}}$ und $19^{\mathrm{r}}$ mit einem Gesicht (beschnitten). Auszeichnungsschrift mit Kadellen, $18^{\mathrm{r}}$ und $20^{\mathrm{r}}$ schwarz-rot. 
Korrekturen und Nachträge: Zeitgenössische Korrekturen, z. B. $35^{\mathrm{v}}$ und $45^{\mathrm{r}}$. Von einer zeitgenössischen Hand, jeweils am unteren Rand der Seiten: $4^{\mathrm{r}}$ Dedicacio dextri altaris peragitur semper dominica Invocavit, $15^{\mathrm{r}}$ Patrocinium altaris sinistri lateris (i. e. Inventio sancte crucis, 3. Mai), 16v Notandum est singulis annis celebrandum esse dedicacionem altaris sinistri lateris dominica proxima ante festum ascensionis domini (zum 31. Mai), $18^{\mathrm{r}}$ Patronorum altaris sinistri lateris (i. e. Decem milium martirum, 22. Juni), 19 ${ }^{\mathrm{r}}$ Notandum quod proxima dominica post festum sancti $U^{o} d a l$ rici celebranda est dedicacio huius ecclesie, 20v Patrone dextri altaris (i. e. Anne matris Marie, 26. Juli), 30r Patrone dextri altaris (i. e. Verene virginis, 1. Sept.), 30 Patrocinium altaris sinistri lateris (i. e. Exultacio S. crucis, 14. Sept.), 36r Patroni dextri altaris (i. e. Nicolai episcopi, 6. Dezember). Zahlreiche nachgetragene Jahrzeitstiftungen und Ergänzungen bis Anfang 18. Jh. $45^{\mathrm{r}}-46^{\mathrm{v}}$ beigebundene ergänzende Materialien auf Pergament, 1489, 1504 und 1505 bzw. 16. Jh. Monatsnamen als Kopftitel, Tageszählung am Rand nachgetragen, 16./17. Jh. Notazeichen. Die Nachträge auf Papier von Ende 17., Anfang 18. Jh., siehe unten (Inhalt). Einlage zwischen Vorsatz und Bl. 1: ein gefaltetes Doppelblatt, Wasserzeichen Horn und Monogramm IM, 27 × 39,5: Quod ex antiquioribus Collegii Documentis, Observatum olim fuisse, facile convincendum; Idipsum iam aliquot ab annis, esse denuo restauranda, pie meditatum; nunc tandem ... Actum Beronae die ia Augusti 1710. Christoph. Zachar. Göldin Dr. Can. et Secretarius. Kapitelsbeschluss über die Feier der Gründerjahrzeit. Von der Hand des Göldin auch Nachträge auf $10^{\mathrm{r}}-11^{\mathrm{r}}$ und $13^{\mathrm{v}}$.

Einband: Mit braunem Leder bezogene Holzdeckel, Ende 17., Anfang 18. Jh., mit Rollen- (u. a. vier Köpfe mit Blattwerk und Engelskopf) und Einzelstempeln (zentral im Mittelfeld des Rückdeckels Mondsichelmadonna im Strahlenkranz). Zwei nach vorn greifende Kantenschliesse, die obere fehlt (Stift an der Kante und ein Teil des Riemens erhalten), die Messingöse am unteren Riemen mit einem gefiederten Blatt. Spiegel- und Vorsatzblätter (I/II, 50/51 und 52/53) Papier, Wasserzeichen vorne: Wappen (siehe oben), hinten: Traube (16 Beeren), mit Krone, dazwischen in Kartusche AS, ähnlich PICCARD, Wasserzeichenkartei Nr. 129428 (1711), bzw. Löwe mit Krone und Reichsinsignien sowie Initialen IM, vgl. StiAB 01.01.709. 46v Spuren von einem früheren Einband. Auf dem Rückdeckel Spuren von rotem Siegellack. Auf dem Vorderdeckel Papierschild: Schongauer Jahrzeitbuch sowie 7, gleiche Hand wie StiAB 01.01.615. Gedrucktes Rückenschild: 616.

Herkunft: Möglicherweise angelegt von Johannes Dörflinger, vgl. Suter, Johannes Dörflinger, S. 82 bzw. Einleitung S. $19 \mathrm{f}$.

Besitzer: -

Literatur: Rudolf HengGeLER, Die Jahrzeitbücher der fünf Orte. Ein Überblick, in: Der Geschichtsfreund 93 (1938), S. 55; Robert Ludwig Suter, Johannes Dörflinger, der Illuminator des Helias Helye, in: Erster datierter Schweizer Druck, S. 79 (Tabelle 2) und 82; Büchler, Beromünster, S. 141; Hugener, Buchführung, S. 89 und 373.

Ir-IIv leer.

$1^{\mathrm{r}}-8^{\mathrm{v}}$ Jahrzeitbuch. Sonntagsbuchstaben, Kalenden, Angaben zu Länge von Tag und Nacht. Januar - April. $>$ KL. Ianuarius habet dies xxxi luna xxx<. Nachtrag: Anno 1701 hat Fr. Magdalena Stadler von Rüodickon geben ... >D. Octava sanctorum innocentium <. Item hans In gassen hatt gesetzt iiii $d n$. (Pfennig) von eynem acker Im geblismos ii dem lütpriester und ii der kilchen ... - ... $>$ A. Nox habet horas $x$. dies xiiii. $<.3^{\mathrm{r}}$ Februar, $5^{\mathrm{r}}$ März, $7^{\mathrm{r}}$ April. Geschwärzt 5r (zu Fridolin, 6. März): Celebratur non ubique (schwarz), Sed hic (rot).

$9^{\mathrm{r}}-12^{\mathrm{v}}$ Nachträge (bis 1713): Zu wüssen dass der Ehrsam und bescheiden Baschi Kretz säl. vom Metmenschongl welcher zuo Bärgholz in dem Elsas gestorben an ein ewiges Jahrzit hinderlassen 5 gulden ... Anno 1663 den 24 ten 
Jenner starb der Ehrsam, fromb und bescheiden Geöri Kretz von Oberschongen ... $11^{\mathrm{v}}$ wieder von der ersten Hand: Andechtige, geliebte in Christo etc. Es lasst Jahrzeit halten der Ehrwürdige, geistlich unnd Woblgelehrte Herr Johann Adam Sutter gebürttig zu Münster alss Notarius Apostolicus, Secretarius dess Ehrwürdigen Capitul Hochdorff Leutpriester albie zuo Schongaw ... Subskription unleserlich gemacht. $12^{\mathrm{v}}-13^{\mathrm{r}}$ leer.

13v Nachträge: Anno 1694 den 3. tag Febr. starb in Gott die Ehr-unde Tugendreiche Fr. Barbara steiner zu Rüodickon ... Anno 1693 den 26. Jänner starb in Gott der Ehrenveste pfleger hans martin kottmann zu Mettmenschongen ... Christoffen Zacharias Göldin Secretarius.

$14^{\mathrm{r}-\mathrm{v}}$ leer.

15 $5^{\mathrm{r}}-22^{\mathrm{v}}$ Jahrzeitbuch. Fortsetzung, Mai - August. $>$ KL. Maius habet dies xxxi. l. xxx.<. Kein Eintrag. $>$ B. Philippi et Iacobi. Walpurge virginis<. Nachtrag: Anno 1652 ... >D. Invencio s. crucis. $<$ Alexandri Evencii et Theodoli. Item Ita Sobrostin von bettwil hett gesetzt der kilchen ii dn. (Pfennig) von dem acker vor dem hage ... - ... $>$ E. Nox habet horas $x$. dies xiiii. <. $15^{\mathrm{r}}$ Mai, $17^{\mathrm{r}}$ Juni, 19 $\mathrm{r}$ Juli, 21 ${ }^{\mathrm{r}}$ August. Nachgetragene Heiligenfeste: 19v Pii papae

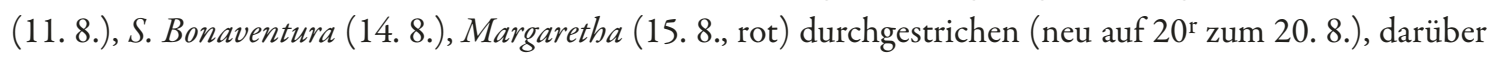
S. Heinrici Imperatoris (gestrichen am 13. 8.); $16^{\mathrm{r}}$ In die Ascensionis domini fit processio ad Collegium Beronense (zum 20. Mai) sowie am unteren Rand: Anno 1630. 19. Mai in quem diem incidit festum pentecostes ab hora $3^{a}$ matutina usque ad meridiem, nix irato coelo decidit quae fruges adbuc teneras humi deiecit. Quis talia videndo temperet a lacrimis? 20 Ex voto totius communitatis singulis annis fit processio ad $S$. Wendelinum pro peste animalium avertenda: Homines et iumenta servabis domine, alles von derselben Hand, die sich noch mehrmals findet.

23 ${ }^{\text {r-v }}$ Nachträge: Anno 1678. den 21. Ougsten hat herr Franz Pfyffer Chorher unnd Inspictor der Stifft Münster, In naamen probst unnd capitul daselbsten ... ein accord getroffen ... Zuwüssen, dass anno 1678 auf Ostern der Eersame Mr. Wilhelm Walthert ... gestifftet 50. gl. ...

$24^{\mathrm{r}}-25^{\mathrm{r}}$ leer.

25 Nachträge: Anno 1635. den Weinmonat starb der Ersam Sebastian trueb ... 5 Einträge von Oktober 1635, anschliessend noch je ein Nachtrag von 1671 und 1681.

$26^{\mathrm{r}}-29^{\mathrm{v}}$ leer.

$30^{\mathrm{r}}-37^{\mathrm{v}}$ Jahrzeitbuch. Fortsetzung, September - Dezember. $>$ September habet dies xxx. l. xxix<. Item Ridolff hasler von nider schongow hat gesetzt der kilchen i fiertel kernen von einer mattem genant geblismos unn von einer matten ze velwen da von dem lút priester iiii dn. (Pfennig) das úbrig an die kertzen. $>$ F. Verene virginis. Egidii confessoris<. Nachtrag: Anno $1664 \ldots-\ldots>$... Silvestri pape. Columbe virginis et martiris<.

$30^{\mathrm{r}}$ September, $32^{\mathrm{r}}$ Oktober, $34^{\mathrm{r}}$ November, 36 ${ }^{\mathrm{r}}$ Dezember.

38r-40v Nachträge (1635-1685). Anno 1635 starb den xv. Septembris zue Oberschongouw die Erbare Wittfrow Margaretha Leimbacherin, welche der Killchen allhie an ein Ewig Jahrzeyt verehrt V. gl. Erstlich für sich selbsten, für ihre Eemäner S. Thoman Weybel unndt Baschi Keller, für ibre Kinder, etc. ...

$41^{\mathrm{r}}-44^{\mathrm{r}}$ leer.

44v Nachtrag: Anno 1701, den 8.ten Octobris in festo S. Brigitae, Ist die Neüwe Pfarrkirchen, Kirchhoof, 3. Altär gewiehen, Consecriert und renoviert worden ... Mit Verzeichnis der in den Grundstein eingelassenen Objekte. $45^{\mathrm{r}-\mathrm{v}}$ Drei Urkunden. Nachträge. Item es ist Zewüssen das Eucharius liebetzer Zü denen ziten lippriester des erwirdigen gotzhuss ze Schongöwe gekouft hät ein huss hofstat lid under des lippriesters garten und stost an weg und hinden über den bach und den geküft umm x lib. genger unn geber wërung ... Factum anno domini M. cccc. 89. Darunter, von anderer Hand: Anno domini $M^{\circ} c c c c c^{0}$ quarto, mensis vero Octobris, die octavo, summum altare 
buius ecclesie beate Marie virginis unacum cimiterio eiusdem reconciliata: Et duo altaria unacum eadem ecclesia denovo consecrata sunt; per reverendum patrem Balthazar Episcopum Troyanum: suffraganeum Constantiensem cuius quidem ecclesie anniversarius dedicacionis dies constitutus est dominica proxima post festum Ůdalrici. Dedicacio autem altaris dextri lateris statuta est dominica Invocavit ... 45 1505. Zewüssen Syge menklichem das Uff donrstag nach dem sonnentag Invocavit des Iars als man zalt Tusentfünfhundert und fünff Iar Ein Rechtlicher spruch und urteyl durch einen Probst und Capittel der Stifft Münster als recht lehenherren der kilchen unser lieben frowen ze Schongow zwüschent gemeynen kilchgnossen ze Schongow von wegen des Buws und der opfer genanter kilchen Eins, und herr Ülrichen feyl der zyt lütpriester ze Schongow anders teyls geben und gsprochen ist ... Andreas Erny notarius Beronensis subscripsit.

$46^{\mathrm{r}}$ Osterlied. Nachtrag. Das lobgsang von der Ufferstehung Christi Unsers liebven hern von den thotten. 1. Christ ist erstanden von der marter allen, des sollend mir alle fron sein, Christ wel unseren trost sein alleluia. 2. Und wer er nit erstanden, so wer die welt zergangen, sitt dz er Erstanden ist, so loben mir den herren Iesum Christ, Alleluia ... 16 numerierte Strophen, anschliessend: Geschriben durch heeren Georgium Kromer kilcheer do zemal (?) albie ze Schongauw.

$46^{\mathrm{v}}$ Formeln und Gebete. Nachträge. Concione finita modus promulgandi. Heilige zit und tag so uns uf dise kunftig wochen fallen, Alls uf heutt ist uns gefallen der Sontag ... Si nullae sint feriae, Dicat: Keine sonderliche fest feyrtag ... Recitate mecum orationem dominicam ... Vater unser, Ave Maria, Glaubensbekenntnis und Zehn Gebote, deutsch. $47^{\mathrm{r}}$ leer.

47v_49v Amtsordnungen und Verwaltungsbeschlïsse. Nachträge. > Eines Sigristen Ampt der Pfarrey Schongaw<. 1. Sol erstlicher dess gottshauss unnd eines läutpriesters nutzen unnd Ehr fürden unndt schaden wenden noch mugligkeit ... 8 Punkte. 48r > Lohn Iährlich eines Sigristen zue Schongaw<. Erstlich: Fronfasten geltt gibt kirchmeyer 4 gl. ... 10 Punkte. 48v > Kirchmeyers Ambt zue Schongaw<. Erstlich: eines Kirchmeyers Innemmen geht an auff St. Martini Inclusive ... > Belohnung<. Erstlich: Hat er zue geniessen die klein buochmatt ... > Pflegen der hl. hl. bruederschaften des hl. Rosenkrantz St. Franncissi Xaverii<. Erstlich wird er alle Jahre Rechnung geben ... 49 $>$ Anno 1688< den 17ten Tag May, Zue Wüssen daß allhie zur Schongow erschienen der Ehrnveste herr Renwardt Troshler Amptman dess Hochwürdigen Adellichen Stüfft Münster ... Actum Capitulariter Beronae die 7. et 14. Xbris 1696. Christoph. Zachar. Göldin Dr. Can. et decret. Capituli Iurati. $50^{\mathrm{r}}-53^{\mathrm{v}}$ leer.

\section{StiAB 01.01.617 JAHRZEITBUCH VON HÄGGLINGEN}

Pergament, 47 Blätter, $29 \times 25,5 \mathrm{~cm}$

Beromünster (?), erstes Viertel des 16. Jahrhunderts

Lagen, Foliierung: Lagen: 3 IV $^{24}+V^{34}$. Beschnitt mit geringfügigem Textverlust, unterer Rand von Bl. 1 abgeschnitten. Neue Foliierung: A-F. 1-41.

Einrichtung und Ausstattung: Bl. $3^{\mathrm{r}}-34^{\mathrm{r}}$ Schriftraumbegrenzung und Seitenaufteilung mit Stift, Schriftraum 23,5-25,5 × 21,5-22,5, zweispaltig (Textspalte 20,5-21), je sechs Tage pro Seite. Anlagehand: Bastarda, Festtage in vergrösserter Auszeichnungsschrift. Rubriziert, Monatsnamen, Tageszahl und Festa fori in Rot; Sonntagsbuchstabe A rot, sonst schwarz. 
Korrekturen und Nachträge: Keine Korrekturen an den Einträgen der ersten Hand; 8v $12^{v}$, 22v $2^{v} 6^{r}, 28^{v}, 9^{r}$ und 32v Schreiberkorrekturen an Nachträgen; $11^{\mathrm{r}}$ und $33^{\mathrm{v}}$ Korrekturen von anderer Hand. Häufig Unterstreichungen; $6^{\mathrm{r}-\mathrm{v}}, 8^{\mathrm{r}}$ und $17^{\mathrm{r}}$ Notazeichen. Zahlreiche nachgetragene Anniversarstiftungen von verschiedenen

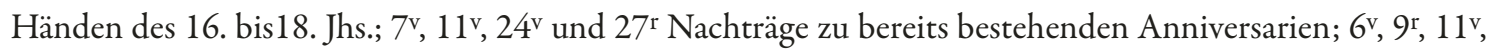
$14^{\mathrm{r}}, 15^{\mathrm{v}}, 22^{\mathrm{v}}$ und $26^{\mathrm{r}}$ neben einzelnen Einträgen von einer Hand des 16. Jhs.: promptum; zu Heiligentagen öfters von verschiedenen Händen: sub praecepto feriatur. Monatsnamen als Kopftitel nachgetragen, 16. Jh.; $9 \mathrm{r}$ der 31. März nachgetragen: F Pridie Kalendis, 16./17. Jh. Weitere Nachträge siehe Inhalt.

Einband: Mit braunem Leder bezogene Holzdeckel, 17. Jh., oben und unten im mittleren Bereich abgeschrägt, mit Rollen- und Einzelstempeln (zentral im Mittelfeld Madonna mit Kind, Halbfigur in Vierpass). Eine nach vorn greifende Kantenschliesse aus Messing mit der Aufschrift mir. Schnitt rot gesprenkelt, Kapitale mit weissem und blauem Garn umstochen. Spiegel- und Vorsatzblätter (A-F, 35f. und 38-41) Papier, drei Wasserzeichen: Variante von Lindt, Nr. 113 (1625) und zwei Formen ähnlich wie Nr. 188 (1637-1641), dazwischen ein Einzelblatt Pergament (37); E/F im Falz mit Pergament verstärkt. Im vorderen Spiegel ein aufgeklebtes Blatt Papier mit Angaben zur Kopie von Wilhelm Dörflinger von 1778, in Tinte geschrieben von Kaplan Karl Ab Egg, 1935. Auf beiden Deckeln Reste von rotem Siegellack, auf dem Rücken zwei Signaturschilder, Papier: 10 (handschriftlich), 19. Jh., sowie 617 (gedruckt), 20. Jh.

Herkunft: Geschrieben wohl in Beromünster. Datierte Einträge der Anlagehand (vielleicht des Notars Andreas Erni): $12^{\mathrm{r}}$ Anno $19 v$ Nonas May; $27^{\mathrm{r}}$ im jar als zalt von der gepurt cristi $x v^{c}$ unnd xviii uff den tag dess grossen jartzitz; 28r Anno 1513, $15 \mathrm{Kl}$. Decembris; 30r Anno 1498. Der Ostertermin am 27. März passt auf die Jahre 1502, 1513 und 1524. Die jüngsten datierten Nachträge auf $14^{\mathrm{v}}$ und 20r stammen aus dem Jahr 1708.

Besitzer: -

Literatur: Karl Aв EGG, Jahrzeitbuch der Kirchgemeinde Hägglingen-Dottikon, in: Unsere Heimat. Jahresschrift der historischen Gesellschaft Freiamt 11 (1937), S. 15-159; HugEnER, Buchführung, S. 334.

$\mathrm{A}^{\mathrm{r}}$ Nachtrag, 17. Jh. Sine fine, fine sine dicentes, legentes, scribentes sunt homines et regentes. Von anderer Hand angefügt: Sint mortuorum memores. Amen. Anschliessend Pentameter: Soli debetur gloria vera deo. Ausserdem Bleistiftnotizen zur Datierung des Jahrzeitbuches von verschiedenen Händen des 19./20. Jahrhunderts.

$\mathrm{A}^{\mathrm{v}}-\mathrm{C}^{\mathrm{v}}$ leer.

$\mathrm{D}^{\mathrm{r}}$ Nachtrag. Wir, Wilhelm Meier, der Probst und das Capitel gemeinklich Löbl. Stifft St. Michael zu Münster im Ergow ... Beschluss über die Einrichtung einer wöchentlichen Messe in der St. Agathen-Kapelle zu Dottikon vom 22. Dez. 1671.

$\mathrm{D}^{\mathrm{v}}-\mathrm{F}^{\mathrm{v}}$ leer.

$1^{\mathrm{r}}$ Nachtrag, 16./17. Jh. [...] mit disem jarzeitbuch der kilchen zu begglingen darin alle jarzeit e (?) begreifen sein et (?) actum [15]16 jabrs, Anfang radiert und abgewaschen.

$1^{\mathrm{v}}$ Verzeichnis über Besitzungen und Einkünfte der Kirche von Hägglingen. Item es ist ze wussen das hennsli wildi hatt geben ze kouffen dem gotzhus zu hägglingen ... AB EGG, Jahrzeitbuch, S. 102.

$2^{\mathrm{r}}-31^{\mathrm{v}}$ Jahrzeitbuch. Sonntagsbuchstaben, Kalenden, Nonen, Iden. $>$ KL. Ianuarius habet xxxi dies. Luna xxx. 1. A. Festum circumcisionis domini<. >2. B. iiii Nonas. Octava sancti Steffani<. Heini weber genant lentz gitt 1 f. $k$. der kilchen, hat gesetzt uly wyg uff die matten zu langen embden umb siner sele heyl willen ... - ... $>$ A. ii. Kl. Silvestri pape<. AB EGG, Jahrzeitbuch, S. 23-88 (In der Edition wurden die Einträge von drei Jahrzeitbüchern zusammengeführt, aber bei Doppelungen anscheinend jeweils nur der ausführlichste wiedergegeben). 


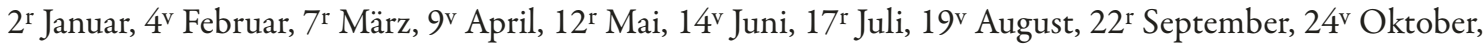
$27^{\mathrm{r}}$ November, 29v Dezember.

$32^{\mathrm{r}-\mathrm{v}}$ Verzeichnis über Zinspflichten gegenüber der Kirche von Hägglingen. Item Múller von diebfurt gitt disen Zinss ... Aв EGG, Jahrzeitbuch, S. 88, Nr. 30 und 31, Abs. 1. Anschliessend zwei Nachträge über Stiftungen zum Glockenläuten von 1651 (von zwei Händen) und 1688.

$33^{\mathrm{r}}$ leer.

$33^{\mathrm{v}}-34^{\mathrm{r}}$ Nachträge, 16./17. Jh. > Canticum pascale ad laudem et honorem gloriosissimae resurrectionis domini nostri Iesu Christi pie compositum, quo etiam nos hic in nostra ecclesia parochiali uti solemus a festo dominicae resurrectionis usque ad diem assensionis. Et ut deo placeat et nobis fiat meritorium dicant singuli Amen<. 1. Christus resurrexit, mala nostra texit etc. Des sollend wir alle fro sin, Christ wil unser trost sin. Alleluia ... 18 Strophen. Anschliessend Vaterunser, Englischer Gruss und Glaubensbekenntnis, alles auf Deutsch. AB EGG, Jahrzeitbuch, S. 91-94.

$34^{\mathrm{v}}$ Nachtrag, 17. Jh. Anno millesimo sexcentissimo undecimo in hac parochia Hegcklingensi peste obyerunt sub parocho domino Andrea Keller, qui eadem hac lue extinctus est, centum quinquaginta circiterplus minus utriusque sexus, curati et non curati. Mit Tinte nachgezeichnet, anschliessend: Renovatum anno 1681. Bei AB EGG, Jahrzeitbuch, S. 76 unter dem 31. Okt. verzeichnet.

$35^{\mathrm{r}}-36^{\mathrm{v}}$ leer.

$37^{\mathrm{r}-\mathrm{v}}$ Nachtrag, 1. Hälfte 17. Jh. Tabellarisches Verzeichnis über Spenden zur Kirchenrenovation. Verzeichnus der Jenigen, welche ihre stür, gaben, schankungen, allmuesen unndt handtreichung an dises lobwürdige gottshaus gethan haben, da man solches grösser gemacht unndt mit neüwen altären, brusttafelen unndt anderen zieraden gezieret ... Andreas Mattmann, Ritter von Jerusalem unndt Leütpriester allhier: 50. Undervogt Hans Hochstrasser: 90 ... Summa in totto 1196. 36. 3. AB EGG, Jahrzeitbuch, S. 113-115, dort mit der Datierung $1638-1642$.

$38^{\mathrm{r}}-41^{\mathrm{v}}$ leer.

\section{StiAB 01.01.634a LIBER CRINITUS}

Pergament, 67 Blätter, $42-45,5 \times 28-30$ bzw. $39 \times 26,5-27 \mathrm{~cm}$

Beromünster (?), erste Hälfte des 14. Jahrhunderts

Lagen, Foliierung: Aus zwei Teilen (B1. 1-34; 35-65) unterschiedlichen Formats zusammengesetzt. Lagen: $4 \mathrm{IV}^{31}+1^{32}+2 \mathrm{I}^{36}+(\mathrm{I}+1)^{39}+\mathrm{I}^{41}+(\mathrm{I}+3)^{46}+(\mathrm{VIII}+3-1)^{65}, \mathrm{Bl} .32,39,42 \mathrm{f} ., 46$ und $48-50$ Einzelblätter, vor Bl. 44 fehlt ein Einzelblatt, Textverlust; Bl. 48f. mit einem Pergamentstreifen verbunden (siehe Einband), Rand von Bl. 50 darumgeführt. Zweite und dritte Lage fast, Bl. 12/13 und 19/20 ganz lose. Risse in Bl. 33/34, 36 und 47 mit Pergament geflickt, in 36 und 43 genäht. Die untere Hälfte der inneren Spalte von Bl. 38 wurde ausgeschnitten und durch einen eingenähten Zettel ersetzt. Blattränder beschmutzt, rissig und z. T. eingerollt oder verknickt, Bl. 28-32 Mäusefrass, 65 stark abgerieben. Wasserschaden, von der rechten unteren Ecke ausgehend, in Teil 1 bis in den Schriftspiegel. In Teil 1 Reklamanten; 39v Lagenzählung (?) iii. Zwei alte Foliierungen, oben mittig: 1-35. 55 (35) - 61 (41).36(47) - 54 (65), 14./15. Jh.; oben am Rand: [A]. 1-18. 18 [bis]-65. [66], 16. Jh., das fehlende Blatt zwischen Bl. 43 und 44 nicht berücksichtigt. 
Einrichtung und Ausstattung:

Teil 1 (Bl. 1-34): Tintenliniierung, 33-34,5 × 18,5-19, 38 Zeilen $\left(1^{\mathrm{r}}-9^{\mathrm{v}}\right), 45-56\left(10^{\mathrm{r}}-32^{\mathrm{r}}\right), 61-70\left(32^{\mathrm{v}}-\right.$ $34^{v}$ ). Urkundenschrift, wohl von einer Hand, teilweise mit kursiven Zügen; 18(bis) ${ }^{r}$ jüngere gotische Buchkursive mit Schleifen von einer anderen Hand. Rote Überschriften. Vergrösserte Initialen in Tinte zu Beginn der einzelnen Stücke; $1^{\mathrm{r}}$ eine rote ornamental gespaltene Initiale (I), 17v eine schwarze. Monogramme der Königsurkunden nachgezeichnet.

Teil 2 (Bl. 35-65): Häufig wechselnde Seitenanlage, z. T. mit Schriftraumbegrenzung und Liniierung mit Tinte, $35^{\mathrm{r}}-38^{\mathrm{v}}, 47^{\mathrm{r}}-50^{\mathrm{r}}$ und $65^{\mathrm{r}}$ zweispaltig. Textualis, Urkundenschrift und ältere gotische Kursive von verschiedenen Händen. 37rb_-38 va neumiert. 35 va rubriziert; 65 ra-rb Paragraphenzeichen. Zu Beginn der einzelnen Stücke vergrösserte Initialen in Tinte, z. T. mit Schaftaussparungen. Längere zusammengehörige Abschnitte: $42^{\mathrm{r}}-46^{\mathrm{v}}: 27 \times 18,30$ Zeilen. Urkundenschrift von einer Hand. Monogramme der Königsurkunden nachgezeichnet. 47r-50r $28 \times 19,5$, zweispaltig (8,5-9), 33-35 Zeilen. Textualis von einer Hand. Rote Überschrift, alphabetische Zählung der Präbenden mit einzeiligen roten Lombarden. 50v-64v: $27 \times 19,33-34$ Zeilen. Ältere gotische Buchkursive, überwiegend von einer Hand, zwei weitere auf $56^{\mathrm{v}}$ und $64^{\mathrm{r}-\mathrm{v}} \cdot 52^{\mathrm{r}}$ einzeilige Initiale mit Fleuronné, $55^{\mathrm{v}}$ zweizeilig mit ornamentiertem Binnenfeld. Monogramme von drei Königsurkunden nachgezeichnet.

\section{Korrekturen und Nachträge:}

Teil 1: Wenige Korrekturen des Schreibers, z. B. 7v, 16v, 33v. Korrekturen einer anderen zeitgenössischen Hand, z. B. $3^{\mathrm{r}}$, 32 $2^{\mathrm{r}} 3^{\mathrm{v}}$, $4^{\mathrm{r}}$ und $8^{\mathrm{v}}$ Handweiser. Zu Beginn der einzelnen Stücke am Rand kurze Regesten von einer Hand des 14./15. Jh., z. B. $1^{\mathrm{r}}$ Prima ordinacio et donacio diversorum bonorum facta per comitem Ulricum, primo fliiv et nepotibus suis et deinceps ecclesie Beronensi. 32v unten eine ganze Urkunde von einer Hand des 15. Jhs. nachgetragen, Urkundenbuch, Bd. 1, S. 204, Nr. 158. Immer wieder Datierungen und zusätzliche Informationen, 16. bis 18. Jh., z. B. $3^{\mathrm{v}}$ Anno 1217 imperatore Federico 2. papa Honorio 3. Haec bulla habetur integra in archivo dominorum. $34^{\mathrm{v}}$ von einer Hand des 16. Jh. historische Notiz zur Gefangennahme eines päpstlichen Legaten durch Ulrich von Lenzburg, siehe Urkundenbuch, Bd. 1, S. 10 .

Teil 2: $35^{\mathrm{va}}$ und 36rb Rasuren. Zahlreiche Nachträge von verschiedenen Händen des 15. (selten des 16. bis 18.) Jhs., 47ra_49vb Aktualisierungen der Namen von Pfründeninhabern, durchgehend auf den Seitenrändern ganze Urkunden nachgetragen: 35v (Urkundenbuch, Bd. 1, S. 270f., Nr. 229), 38va-vb (S. 358-360, Nr. 301), 40v (S. 318, Nr. 266), 41ㄴ-42r (S. 330, Nr. 278), 44r (Urkundenbuch, Bd. 2, S. $187 f$., Nr. 395, nur das Ende, davor Blattverlust), 44v-45r (Urkundenbuch, Bd. 1, S. 172f., Nr. 127 bzw. 358, Nr. 300), 46r (S. 188, Nr. 137, ausgestrichen), $47^{\mathrm{r}}$ (Urkundenbuch, Bd. 2, S. 291, Nr. 487), 50 rb (S. 189, Nr. 397), 53 ${ }^{\mathrm{v}}$ (Urkundenbuch, Bd. 1, S. 204, Nr. 158), 62r (Urkundenbuch, Bd. 2, S. 297f., Nr. 493) und 65rb (S. 311f., Nr. 507). 37r Agnus dei, Sanctus und Benedictus, 37vb-38 ra Perikope zu Kirchweih, alles neumiert; der Teil der Perikope auf $38^{\text {ra }}$ auf einem eingenähten Pergamentstück, Fragment: auf der Rückseite Protokoll über Besitzungen und Einkünfte des Stifts Beromünster, 14. Jh., siehe Urkundenbuch, Bd. 1, S. 13f. $51^{\mathrm{r}}$ letzter Absatz ausgestrichen, darunter: Istud statutum, quod sic incipit: Nunc autem de novo statutum est etc. revocatum est et fuit per predictum dominum Iacobum, prepositum et capitulum ecclesie Beronensis, sicut apparet per statutum super eius revocacione factum et sigillatum sigillo domini prepositi et capituli, cuius forma eciam infra continetur.

Einband: Koperteinband aus stark abgeschabtem, rotbraunem Fell (Reste der Behaarung nur auf der Vorderseite erhalten) mit nach vorn übergeschlagener, trapezförmiger Klappe, 14./15. Jh. Längsheftung, Heftstelle am Kopf und am Schwanz ausgerückt. Vorsatzblätter (A, 66) Pergament: ein Doppelblatt, das um alle Lagen 
geschlagen wurde. Das Doppelblatt 33/34 wurde (vielleicht im 16. Jh.) repariert und anschliessend mit einem anderen Faden wieder eingeheftet, einer der Flicken Makulatur: Blütenranke in Deckfarbenmalerei (grün, türkis, blau, rot, rosa, ocker, weiss und gelb) mit Silberplattierung, 15./16. Jh. In Teil 2 wurden die äusseren Blätter der einzelnen Lagen aneinandergenäht; Bl. 48 und 49 mit einem Pergamentstreifen verbunden: Fragment, 15./16. Jh. Die ältere Foliierung lässt darauf schliessen, dass Bl. 47-65 ehemals vor Bl. 35-41 eingeordnet war, Bl. 42-46 wurde nachträglich dazwischen eingeschaltet; der Abdruck eines eisernen Beschlags auf der Versoseite von B1. 46 zeigt, dass diese Blätter ehemals am Ende eines fest gebundenen Kodex mit Schliesse standen. Auf der Rückseite des Einbandes zwei Aufschriften: Das Geharte Buch d[er] Stifft Münster [...] Register aller Alten Instrumenten und gwarsamen 1341, 17. Jh. (nur unter UV-Licht lesbar); Liber Crinitus, 18. Jh. Gedrucktes Rückenschild 364, mit rotem Filzstift ergänzt $a$.

Herkunft: Offenbar in Beromünster selbst angelegtes Kopialbuch, aus zwei Teilen mit unterschiedlichem Format zusammengesetzt, von denen der hintere wiederum mehrere separat entstandene Stücke umfasst. Auf Bl. 18(bis)/19 Abdruck eines braunen Ledereinbandes mit Blindstempeln, der längere Zeit in dem Band gelegen haben muss.

Besitzer: In den Antiquitates Beronenses, S. 689, als Nr. 9 verzeichnet. Auf dem Vorsatzblatt mit Bleistift Stiftsarchiv Beromünster, 20. Jh., darunter mit rotem Farbstift Signatur 634, mit rotem Filzstift ergänzt $a$. Eine 1619 angelegte Kopie des Bandes unter der Signatur StiAB 01.01.634b, Konkordanz in den Antiquitates Beronenses.

Literatur: EstermanN, Sehenswürdigkeiten, S. 74f.; Riedweg, Beromünster, S. VI; Liebenau, Urkundenbuch, S. 9-18 (die Blattangaben in der Edition sind z. T. fehlerhaft); BRUCKNER, Scriptoria 9, S. 15 und 19 f. sowie Taf. 2 und 35.

A ${ }^{\mathrm{r}}$ Nachtrag: An einer Kommission des Bezirksgerichts Münster aufgelegt d. 22ten Mai 1837. Der Gerichtespräsident J. Ant. Kopp. Beistiftnotizen in Kurrentschrift, 19./20. Jh.

Av leer.

Teil 1:

$1^{\mathrm{r}}-34^{\mathrm{v}}$ Diplomata. >Incipit registrum instrumentorum ecclesie Beronensis super donacionibus, privilegiis, sentenciis horumque confirmacionibus ac super aliis diversis contractibus confectorum, infra per diversas rubricas iuxta diversitatem materie distinctorum, et sub rubricis secundum successionem temporis seu etatis ordinem subscriptorum. Sic igitur ordinantur rubrice: Prima de donacionibus et privilegiis <. In nomine sancte et individue trinitatis ego Ullricus dei gracia comes ... Urkundenbuch, Bd. 1, S. 65-68, Nr. 1; S. 69-71, Nr. 3; S. 71f., Nr. 5; S. 75-79, Nr. 8; S. 87f., Nr. 17; S. 106f., Nr. 30; S. 100-103, Nr. 24-26; S. 107f., Nr. 32; S. 111f., Nr. 37; S. $114 f .$, Nr. 41; S. 155f., Nr. 97; S. 171, Nr. 126; S. 159, Nr. 102; S. 173f., Nr. 128; S. 241, Nr. 204; S. 249f., Nr. 212; S. 270f., Nr. 229; S. 303f., Nr. 257; S. 290, Nr. 248; S. 318, Nr. 266; S. 358-360, Nr. 301. Urkundenbuch, Bd. 2, S. 28f., Nr. 332. $8^{\mathrm{v}}>$ De donacionum et privilegiorum confirmacionibus<. In nomine sancte et individue Trinitatis Fridericus secundus ... Urkundenbuch, Bd. 1, S. 91-93, Nr. 20; S. 86f., Nr. 16; S. 183-185, Nr. 134f.; S. 322f., Nr. 270. $10^{v}>$ De sentenciis <. Omnibus fidelibus ad quos littere iste pervenerint C. abbas Lucellensis monasterii ... Urkundenbuch, Bd. 1, S. 82f., Nr. 13; S. 79f., Nr. 9; S. 108, Nr. 33; S. 84, Nr. 14; S. 124, Nr. 59; S. 140-142, Nr. 83; S. 88f., Nr. 18; S. 94-98, Nr. 22; S. 104f., Nr. 28; S. 115f., Nr. 42; S. 132-134, Nr. 75; S. 147-149, Nr. 86; S. 222-224, Nr. 181; S. 255f., Nr. 217; S. 286f., Nr. 243; S. 355-357, 
Nr. 298. Urkundenbuch, Bd. 2, S. 13-17, Nr. 320; S. 20f., Nr. 323. 16 -17r Abschrift einer Urkunde vom 19. Mai 1317 zu einem Streitfall in Hochdorf, inhaltlicher Zusammenhang mit dem folgenden Stück: Universis presentem inspecturis magister Ullr. thesaurarius ecclesie Thuricensis ... 17r Urkundenbuch, Bd. 2, S. 26f., Nr. 330. $17^{\mathrm{v}}>$ De confirmacionibus sentenciarum <. Innocencius episcopus servus servorum dei ... Urkundenbuch, Bd. 1, S. 138-140, Nr. 81f. Urkundenbuch, Bd. 2, S. 21f., Nr. 324. Urkundenbuch, Bd. 1, S. 142-144, Nr. 84; S. 280-284, Nr. 240. 18(bis) v $^{2}$ De empcionibus<. Omnibus presens scriptum intuentibus Rüdolfus dictus comes de Habsburch ... Urkundenbuch, Bd. 1, S. $110 f .$, Nr. 36; S. 158, Nr. 101; S. 164f., Nr. 115; S. 170f., Nr. 125; S. 193f., Nr. 142; S. 230, Nr. 192; S. 238f., Nr. 199; S. 245f., Nr. 209; S. 277-279, Nr. 238f.; S. 325f., Nr. 273; S. 331, Nr. 279; S. 343f., Nr. 284; S. 352f., Nr. 296. Urkundenbuch, Bd. 2, S. 45f., Nr. 351. 22r > De empcionum a dominis vendencium approbacionibus<. Universis presens scriptum inspecturis $R$. comes de Habsburg ... Urkundenbuch, Bd. 1, S. 154, Nr. 94; S. 152f., Nr. 92; S. 155, Nr. 96; S. 175, Nr. 130; S. 229f., Nr. 191; S. 232, Nr. 194; S. 81, Nr. 11; S. 360f., Nr. 303; S. 365f., Nr. 307. Urkundenbuch, Bd. 2, S. 25f., Nr. $328 f$. Urkundenbuch, Bd. 1, S. 99f., Nr. 23. $23^{\mathrm{v}}>$ De transactionibus sive pactis <. Dietricus Beronensis ecclesie prepositus ... dieselbe Urkunde wie unmittelbar davor. Anschliessend Urkundenbuch, Bd. 1, S. 162, Nr. 110; S. 194f., Nr. 143; S. 227f., Nr. 188; S. 234f., Nr. 196; S. 257f., Nr. 218; S. 286f., Nr. 243; S. 289, Nr. 247; S. 295f., Nr. 252; S. 298-300, Nr. 254. Urkundenbuch, Bd. 2, S. 32f., Nr. 336. Urkundenbuch, Bd. 1, S. $347 f .$, Nr. 292. Urkundenbuch, Bd. 2, S. 12f., Nr. 319; S. 22f., Nr. 325; S. 24f., Nr. 327; S. 42, Nr. 347; S. 6, Nr. 312. $27^{r}>$ De precariis $<$. Noverint universi presentem paginam inspecturi, quod ego Wernherus prepositus et capitulum Beronensis ... Urkundenbuch, Bd. 1, S. 109f., Nr. 34f.; S. 195, Nr. 144; S. 188, Nr. 137; S. 166f., Nr. 119; S. 270f., Nr. 229; S. 314, Nr. 262; S. 316-318, Nr. 265; S. 357f., Nr. 299; S. 266, Nr. 227; S. 250-252, Nr. 213. $28^{v}>$ De emphitheosibus<. Wir, Jacob von Rinach, der Probst unn das Capitel ... Urkundenbuch, Bd. 2, S. 29f., Nr. 333; S. 111, Nr. 377. 29r > De testamentis<. Ab humana facilius elabuntur memoria ... Urkundenbuch, Bd. 1, S. 112f., Nr. 40; S. 179-182, Nr. 132f.; S. 247-249, Nr. 21 1; S. 252f., Nr. 214; S. 273f., Nr. 232; S. $312 f .$, Nr. 261; S. 315f., Nr. 264; S. 321f., Nr. 269; S. 346f., Nr. 290; S. 172f., Nr. 127 und 358, Nr. 300; S. 358-360, Nr. 301. Urkundenbuch, Bd. 2, S. 104f., Nr. 374 (in der Hs. nur ein Auszug). Urkundenbuch, Bd. 1, S. 168170, Nr. 124; S. 175-179, Nr. 131; S. 190-192, Nr. 140; S. 157, Nr. 100; S. 185-187, Nr. 136; S. 202, Nr. 156; S. 268-270, Nr. 228[bis]; S. 361-363, Nr. 304; S. 348-351, Nr. 293. Urkundenbuch, Bd. 2, S. 10f., Nr. 318; S. 80f., Nr. 361.

Teil 2:

$35^{\mathrm{ra}}-37^{\mathrm{rb}}$ Statuta, versus. Hec est ordinacio testamenti pie recordacionis Hugonis dicti de Jegistorf ... Hii sunt redditus, per quos expediri debent ... $35^{\mathrm{rb}}$ Item hec est annona, de qua ministrari debet ... Anschliessend: Hii sunt ergo dies quibus hunc panem dare debes ... neun Merkverse mit Interlinearglossen. Darüber Nachtrag von anderer Hand: Vide versus novos magis planos infra. 35 $5^{\text {ra }}$ unten sechs Verse: Omnibus hec panis ad festa datur cameralis ... Urkundenbuch, Bd. 1, S. 11f. (vgl. StiAB 01.01.599, 53 $3^{\mathrm{rb}}$ und StiAB 01.01.600, S. 313). 35 ${ }^{\mathrm{va}}$ Hec est summa annone, que de cellario camere ministratur ad anniversaria ... QW II, 1, S. 8f., Nr. 1. Anschliessend mehrere Stücke: Urkundenbuch, Bd. 1, S. 185-187, Nr. 136. QW II, 1, S. 9, Nr. 2. Urkundenbuch, Bd. 1, S. 246f., Nr. 210 (aus einem ursprünglichen Eintrag und zwei Nachträgen vom Editor ohne Kennzeichnung der einzelnen Teile zusammengefügt); S. 308-311, Nr. 260 (aus drei Teilen vom Editor zusammengefügt, der fünfte Absatz der Edition in der Hs. gestrichen). $37^{\mathrm{rb}}$ Cottidie duplicem prebenda dat hec tibi panem ... 15 Merkverse mit Interlinearglossen, Urkundenbuch, Bd. 1, S. 12. Anschliessend Urkundenbuch, Bd. 2, S. 31, Nr. 334. 
37va $38^{\mathrm{va}}$ Liturgica. Dominus vobiscum. Et cum spiritu tuo. Sequencia sancti evangelii secundum Lucam ... Tropierte und neumierte Perikope zu Kirchweih (Lc 19,1), anschliessend Nachtrag: dieselbe Perikope mit Abweichungen in Tropen und Neumierung. 38 $8^{\text {ra }}$ tropierte Perikope (Io 21,20) und Epistel (Apc 12,7) zu Michaelis, neumiert.

$38^{\mathrm{vb}}-41^{\mathrm{v}}$ Statuta, diplomata, iuramenta. Noverint universi quod ego, Hugo de Ratberg ... Urkundenbuch, Bd. 1, S. 321, Nr. 269. Anschliessend Urkundenbuch, Bd. 2, S. 7, Nr. 313; S. 18f., Nr. 322 (mit den Nachträgen); S. 10f., Nr. 318; S. 4-6, Nr. 311. Urkundenbuch, Bd. 1, S. 250-252, Nr. 213; S. 254f., Nr. 215; S. 252f., Nr. 214; S. 166f., Nr. 119; S. 190-192, Nr. 140; S. 266, Nr. 227.

$42^{\mathrm{r}}-46^{\mathrm{v}}$ Diplomata. Älteste Besitzausstattung und vier Königsurkunden. In nomine sancte et individue trinitatis. Ego Ůdalricus comes ... Urkundenbuch, Bd. 1, S. 65-68, Nr. 1; S. 69-71, Nr. 3; S. 78f., Nr. 8 (nur das Ende, davor Blattverlust, 44r // habeant quam ceteri regales ...); S. 90f., Nr. 19; S. 86f., Nr. 16.

$47^{\mathrm{ra}}-50^{\mathrm{ra}}$ Redditus prebendarum. $>$ Hec est divisio porcorum et castr [at] orum $<$. Prebende A debetur huba in Guntzwil ... QW II, 1, S. 94-102, Nr. 10.

$50^{\mathrm{r}}-64^{\mathrm{v}}$ Diplomata. In nomine domini amen. Noverint universi quorum interest vel intererit in futurum quod ego magister Petrus dictus de Thurego ... Urkundenbuch, Bd. 2, S. 188f., Nr. 396; S. 153-159, Nr. 387; S. $182-$ 187, Nr. 393f. Urkundenbuch, Bd. 1, S. 185-187, Nr. 136; S. 183f., Nr. 134; S. 308-311, Nr. 260 (Abs. 1-4). Urkundenbuch, Bd. 2, S. 31, Nr. 334. Urkundenbuch, Bd. 1, S. 322f., Nr. 270. Urkundenbuch, Bd. 2, S. 109f., Nr. 376; S. 18, Nr. 322 (ohne die Nachträge); S. 239f., Nr. 440; S. 4-6, Nr. 311 . Urkundenbuch, Bd. 1, S. 6568, Nr. 1; S. 69-71, Nr. 3; S. 75-79, Nr. 8; S. 90f., Nr. 19; S. 86f., Nr. 16; S. 136f., Nr. 77; S. 135, Nr. 76. Urkundenbuch, Bd. 2, S. 248-250, Nr. 449.

$65^{\mathrm{ra}-\mathrm{rb}}$ Redditus coquinae. Isti sunt castrati et agni pertinentes ad coquinam ... QW II, 1, S. 104f., Nr. 13.

65 Diploma. In nomine domini amen. Universis Christi fidelibus ad quos presentes littere pervenerint Ullricus de Landenberg prepositus ... Urkundenbuch, Bd. 1, S. 250-252, Nr. 213.

$66^{\mathrm{r}-\mathrm{v}}$ leer.

\section{StiAB 01.01.635 ERNIS BUCH}

Pergament, 39 Blätter, 36-40 × 29-31 cm

Beromünster (?), 1504

Lagen, Foliierung: Lagen: $\mathrm{III}^{6}+4 \mathrm{IV}^{38}+1^{39}$. Doppelte Lagenzählung, Bezeichnung der Doppelblätter in der ersten Lagenhälfte (auf den Rectoseiten in der unteren Ecke): $2 a\left(2^{\mathrm{r}}\right), 1 b-4 b\left(7^{\mathrm{r}}-10^{\mathrm{r}}\right), 1 c-4 c\left(15^{\mathrm{r}}-18^{\mathrm{r}}\right)$, $d 1-d 4\left(23^{\mathrm{r}}-26^{\mathrm{r}}\right)$. Alte Foliierung: 1-39.

Einrichtung und Ausstattung: Vertikale Begrenzung des Schriftraums mit Stift, Schriftraum 24-27 × 19-20, 42-51 Zeilen. Bastarda mit Schleifen von der Hand des Andreas Erni. Unterstreichungen. Kadellenartige Zierinitialen und vergrösserte Initien. $2^{\mathrm{v}}, 7^{\mathrm{r}}$ und am ausgeprägtesten $8^{\mathrm{v}}$ schwarze ornamental gespaltene Initialen. $2^{\mathrm{r}}, 2^{\mathrm{v}}, 3^{\mathrm{v}}$ und $4^{\mathrm{r}}$ Monogramme sowie $2^{\mathrm{r}}$ und $2^{\mathrm{v}}$ die Bienenkörbe der Königsurkunden nachgezeichnet. Am Rand zu Beginn jeder Urkundenabschrift ein kurzer Regest.

Korrekturen und Nachträge: Korrekturen von der Hand des Schreibers, $2^{\mathrm{r}}, 3^{\mathrm{r}}, 7^{\mathrm{r}}, 10^{\mathrm{r}}, 10^{\mathrm{v}}, 14^{\mathrm{v}}, 18^{\mathrm{r}}, 19^{\mathrm{r}}, 20^{\mathrm{r}}, 22^{\mathrm{r}}$, $24^{\mathrm{r}}, 27^{\mathrm{r}}$ und $29^{\mathrm{r}}$; wohl von anderer, vielleicht zeitgenössischer Hand $1^{\mathrm{v}}$, $30^{\mathrm{r}}$. Notazeichen. Marginalien von einer 
Hand des 17. oder 18. Jhs. (vgl. Einband); z. T. auch Ergänzungen zu Datierungen, numerierte Querverweise (nicht übereinstimmend mit der heutigen Zählung der Urkunden im Stiftsarchiv), z. B. Bull. pont. n. 7 ( $\left.8^{\mathrm{v}}\right)$, oder Kommentare, z. B. über Clemens VII.: Antipapa fuit (9v). Eine spätere Hand hat auf $1^{\mathrm{r}}$ einzelne Wörter nachgezogen, auch dem 'e' in pagine (erste Zeile) eine Cauda beigefügt. Vereinzelte Notizen mit Bleistift, 19./20. Jh.

Einband: Kopert aus zwei auf einer Seite beschnittenen Doppelblättern einer Pergamenthandschrift (wohl das zweite und dritte des zweiten Quaterns), nur durch die Heftung miteinander verbunden, das vordere an der unteren Heftstelle ausgerissen und wohl im 20. Jh. mit einem Papierstreifen geflickt: Missale, 14. Jh., Tintenliniierung, 23,5 × 16, zweispaltig (7), 30 Zeilen, Textualis, rubriziert, rote Überschriften, 2-3zeilige Lombarden; alte Foliierung in Rot. Je drei von vier Spalten sind auf jeder Seite des Umschlags erhalten, die vier vollständigen Seiten bieten einen fortlaufenden Text $\left(\mathrm{x}^{\mathrm{ra}}-\mathrm{xi}^{\mathrm{vb}}\right)$, beginnend auf dem vorderen Deckblatt: // salvum me fac et in virtute tua ... Dienstag - Freitag, innen die Fortsetzung, Samstag und Palmsonntag: $>A d$ processionem<, auf dem zweiten Blatt (Rückseite, teils abgeschabt) weiter Palmsonntag mit AH 50 Nr. 117

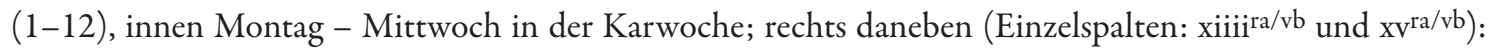
Exsultet mit den Rubriken $>$ Hic inprimantur quinque grana thuris in modum crucis $<$ und $>$ Hic accendatur propria manu legentis<, aussen (Rückseite): AH 50 Nr. 183 (5-7, 9, 10); vorne innen: > Ad stacionem<. Salve festa dies ... aussen: // nunc qui redempti sunt ... Dienstag - Donnerstag nach Ostern. Vorne auf dem Umschlag: Ernis-Büch, sowie (in Richtung der Zeilen des Fragments) doppelt, von einer älteren (15./16. Jh.) und einer jüngeren Hand: Maioribus obedientiam, paribus concordiam, minoribus compassionem und (um $180^{\circ}$ gedreht) von einer Hand des 17. oder 18. Jhs. Concordia res parvae crescunt, discordia maxime dilabuntur (Sallust).

Herkunft: Angelegt am 6. Juli 1504 von Stiftsnotar Andreas Erni, vgl. 1'r, der jedoch nicht namentlich genannt ist; Schriftvergleich, Subscriptiones in StiAB 01.01.714 und 715; die jüngste Urkunde ist datiert 28. 5.1506 $\left(32^{v}\right)$. Zu ihm vgl. Riedweg, Beromünster, S. 88 und Bü CHLER, Beromünster, S. 109.

Besitzer: In den Antiquitates Beronenses, S. 689, als Nr. 10 verzeichnet.

Literatur: Estermann, Stiftsschule, S. 88; Estermann, Sehenswürdigkeiten, S. 74; Riedweg, Beromünster, S. VI; Liebenau, Urkundenbuch, Bd. 1, S. 18 (B); Sidler, Bildungsverhältnisse, S. $191 \mathrm{f}$. (Nr. 241).

$1^{\mathrm{r}}-39^{\mathrm{v}}$ Diplomata. Einleitung: In nomine sancte et individue trinitatis, Amen. Cunctis presentis pagine seriem inspecturis evidenter pateat et sit notum, quod sub anno domini Millesimoquingentesimoquarto ... die vero sexta ipsius mensis Iulii, venerabiles et circumspecti viri domini prepositus et capitulum insignis ecclesie collegiate sancti Michaelis Beronensis Constanciensis diocesis has subinsertas litteras ... michi subscripto notario exhibuerunt ... Ego itaque notarius subscriptus ad exhortacionem et iussum dictorum dominorum meorum Beronensium litteras prelibatas ... de verbo ad verbum transsumpsi et copiavi ... titulis ac rubricis. Tenor talis est ut ecce: Sequitur Titulus primus. Incipit registrum instrumentorum ecclesie Beronensis super donacionibus privilegiis sentenciis horumque confirmacionibus ... Urkunden: In nomine sancte et individue trinitatis. Ego Ulricus dei gracia comes ... LiebenaU, Urkundenbuch, Bd. 1, S. 65-68, Nr. 1; S. 69f., Nr. 3; S. 71f., Nr. 5; S. 75-79, Nr. 8; S. 86f. Nr. 16;

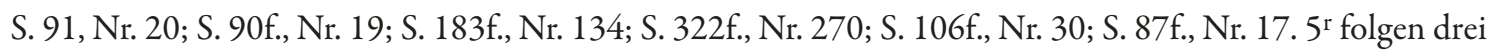
(lat.) Papsturkunden: Innocentius VIII, 22. 11. 1484; Martinus V, 18. 4. 1418; Sixtus IV, 13. 1. 1480 (nicht diejenige gleichen Datums im Geschichtsfreund 18, S. 266-270, sondern betr. das Tragen von Almutien etc.). 5 Liebenau, Urkundenbuch, Bd. 1, S. 122, Nr. 56 und Bd. 2, S. 39f., Nr. 344. 6r zwei weitere (lat.) Papsturkunden: Paulus II, 20. 12. 1465 und 2. 3. 1466. 6v Liebenau, Urkundenbuch, Bd. 1, S. 184f., Nr. 135; 
S. 88-90, Nr. 18; S. 139f., Nr. 82; S. 138f., Nr. 81, inseriert Nr. 22 (S. 94-98); S. 147-149, Nr. 86; S. 136f., Nr. 77, inseriert Nr. 75 (S. 132-134); S. 135, Nr. 76. 9v > Nunc sequitur de incorporacionibus et unionibus ecclesiarum ad mensam capitularem Beronensem necnon iure instituendi et destituendi eiusdem etc. $<$. Clemens episcopus servus servorum dei ... zuerst vier (lat.) Papsturkunden (betr. Neudorf, Hägglingen, Rickenbach und Suhr): Clemens VII, 6. 9. 1388; $10^{\mathrm{r}}$ Bonifatius IX, 15.7. 1399 und 7. 4. 1400; $11^{\mathrm{r}}$ Innocentius VIII, 30. 11. 1484. $11^{\mathrm{r}}$ Bernhard Öuglin, 7.3. 1485 (lat.), mit Subscr. des Johannes Salzmann (vgl. StiAB 01.01.718 und 719); 12r Petrus, Propst von Basel, inseriert eine (lat.) Papsturk.: Innocentius VII, 7. 5. 1405, Subscr. des Johannes Binder aus Schaffhausen, 26. 3. 1406; $15^{\mathrm{r}}$ Johannes (III), Bischof von Basel (lat.), 22. 9. 1375 (betr. Kilchberg). 15 $5^{\mathrm{r}}$ LiebenAU, Urkundenbuch, Bd. 2, S. 279-281, Nr. 477; S. 294-297, Nr. 492; Bd. 1, S. 302-304, Nr. 257. 16v eine weitere (lat.) Papsturkunde: Sixtus IV, 13. 1. 1479. 17v Bartholomaeus, Bischof von Città di Castello (lat.), 1. 8. 1483. $18^{\mathrm{r}}$ drei (lat.) Urk. Bischof Ottos (IV) von Konstanz, 9. 12. 1483 und zweimal 12. 9. 1486. 19r Thüring von Arburg, Propst von Beromünster (lat.), 16. 1. 1412. $19^{r}$ Liebenau, Urkundenbuch, Bd. 1, S. 202-204, Nr. 156. 19v > De donacionibus ecclesiarum Beronensi collegio attinentium. Núwdorff $<$. Wir Rüdolf der vierd von gots gnaden Ertzhertzog zu Ö Osterrich ... 23. 5. 1365; Albrecht (III) und Leopold (III) von Österreich, 30. 12. 1366; $20^{\mathrm{r}}$ Leopold (III) von Österreich (dt.), 18. 5. 1380. 20 $>$ Sur<. Wir Albrecht und Ott von gots gnaden hertzogen ze Osterrich ... Liebenau, Urkundenbuch, Bd. 2, S. 230f., Nr. 435. $20^{\mathrm{r}}$ Leopold (IV) von Österreich (dt.), 22. 1. 1400; 20v Friedrich (IV) von Österreich (lat.), 10. 11. 1408; $21^{\mathrm{r}}$ Thüring, Rudolf der Ältere und Rudolf der Jüngere von Arburg (dt.), 7. 5. 1414. $21^{\mathrm{r}}>$ Dos, et donacio ecclesie Rickenbach unacum advocatia ac alys bonis ibidem<. Ich hemman von Grünenberg Ritter ... (dt.), 10. 9. 1400. 22 $2^{\mathrm{r}}>$ Composicio ex parte ecclesie Sarnon super iure collacionis<. Wir diss nachbenempten heinrich von hynwil Schultheiss Hans Ritzi alt Schultheis Caspar von hertenstein und Rüdolf schiffman des Rates der statt lutzern Thünd kund ... 5. 1. 1464; 23 Bernhard Müller, Probst, und das Kapitel des Stifts Schönenwerd (dt.), 4. 8. 1498. 24 Friedrich von Lütishofen sowie Burkart (II), Rudolf (II), Leonhard und Rudolf (beide Bürger von Luzern), 19. 3. 1479, Der Geschichtsfreund 18 (1862), S. 262-266. 25 ${ }^{\mathrm{r}}$ Schultheiss und Rat von Luzern (dt.), 27. 3. 1489. 26v Bd. 1, S. 132-135, Nr. 75. 27v >Quarta in Sur<. Wir Otto von gottes genaden Bischoff ze Costenz ... Otto (III) von Konstanz (dt.), 14. 6. 1417; $28^{\mathrm{r}}$ Heinrich (IV) von Konstanz (dt.), 19. 4. 1437; 29r Jost von Silenen (dt.), 4. 8. 1469; 30v Heinrich Rosenschilt, Bürger und des Rats von Luzern (dt.), 15. 5. 1506; 32 ${ }^{\mathrm{r}}$ Schultheiss und Rat der Stadt Luzern (dt.), 18. 3. 1506; Peter Habermacher, Stiftsweibel von Beromünster (dt.), 28. 5. 1506; $32^{v}$ Eidgen. Räte zu Baden (dt.), 14. 6. 1486; $33^{\mathrm{r}}$ Heinrich Tolder von Glarus (dt.), 28. 6. 1487; 34r Bernhard Öuglin, 7. 3. 1485 (lat.), mit Subscription des Johannes Salzmann; 35r Johannes Bůchholtzer, Propst von St. Leodegar in Luzern (lat.), 24. 10. 1501; 36r Konrad Winterberg (?), Vikar des Bischofs von Konstanz (lat.), 25. 8. 1488, Subskription des Georg Loser von Zwiefalten; 38r Schultheissen und Räte der Städte Bern und Luzern (dt.), 29. 9. 1498.

\section{StiAB 01.01.663 JAHRZEITBUCH DES KAMMERAMTS}

Papier, 91 Blätter, $40 \times 29,5 \mathrm{~cm}$

Beromünster (?), Ende 15. Jahrhundert

Wasserzeichen, Lagen, Foliierung: Wasserzeichen: Kopf, je eine Variante von PiCCARD, Wasserzeichenkartei Nr. 20816 (1488/91) und 20838 (1490). Lagen: $(V-8)^{2}+(V I-1)^{13}+V^{25}+3 V^{55}+3 I^{79}+V^{89}$, von der 
ersten Lage fehlen 8 Blätter (Textverlust), die verbleibenden zwei Einzelblätter wurden vorne an die zweite Lage geklebt, deren erstes Blatt ebenfalls fehlt (Textverlust). Äußere Blätter der einzelnen Lagen teilweise aneinandergeklebt. Papierflicken auf Bl. 43 (16./17. Jh.), Ränder von Bl. 1 f., 13 und 73f. modern verstärkt. Beschnitt mit Textverlust. Neue Foliierung: A. 1-90.

Einrichtung und Ausstattung: Begrenzung des Schriftraums mit Stift, Breite bis 29, siebenspaltig (Textspalte 11-15, je eine Anmerkungsspalte am inneren und äusseren Seitenrand 6-7), horizontal zweigeteilt (zwei Tage pro Seite), Kolumnenhöhe und Zeilenzahl stark schwankend. Anlagehand Bastarda, Monatsnamen (nur am Monatsanfang angegeben) und Festtage in vergrösserter Schrift. 60 Michaelis archangeli in Ziermajuskeln. Rubriziert, rote Unterstreichungen, Monatsnamen, Sonntagsbuchstabe, Tageszahl und Kalenden, Nonen, Iden sowie Festa fori in Rot.

Korrekturen und Nachträge: Wenige Korrekturen der Anlagehand, z. B. 25 ${ }^{\mathrm{r}}$, 38 $8^{\mathrm{v}}$ und 46 $\mathrm{r}$ (auf Rasur), öfters

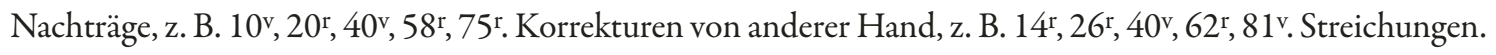
$33^{r}$ ein kleines Herz mit Pfeil, 58 ${ }^{r}$ Handweiser. Zahlreiche Nachträge des 16. bis 17. Jhs.: Jahrzeitstiftungen und Ergänzungen zu bestehenden Einträgen, öfters promptum. Am Ende jeder Seite von einer Hand des 17. Jhs. Abrechnung über die Anteile der verschiedenen Empfängergruppen, z. B. $1^{\mathrm{r}}$ Canonicis: spelt [e] 13 qrt. (quarteria) $2 f$. (Viertel) - tritt [ici] 9 qrt. $2 f$. den[ariorum] $1 f l$ [orenum] 3 ang[ster]. Praebendariis: spelt. 2 qrt. $3 f$. - tritt. 4 qrt. $2 f$ - den. 1 fl. 3 ang. Pauperibus: spelt. 2 qrt. $3 f$ - tritt. 5 qrt. - den. 1 fl. 3 ang. Daneben von einer anderen, etwa gleichzeitigen Hand jeweils eine Gesamtabrechnung, hier: Spelt. 1 mltr. (Malter) trit. 4 mltr. 3 qrt. - den. 6 s[olidi]. Am Ende jedes Monats von derselben Hand Summa mensis, vierteljährlich ausserdem Summa trium mensium. $10^{\mathrm{r}}, 10^{\mathrm{v}}$ und $45^{\mathrm{r}}$ Listen der tatsächlichen Einnahmen aus einzelnen Stiftungen von verschiedenen Händen über einen längeren Zeitraum, z. B. $10^{\mathrm{r}}$ von der Anlagehand: Anno [149]9o dedit avene, anschliessend von mehreren anderen Händen: [1]501 spelte. 54 spelte. 84 spelte. 1612 anvene. 1616000 (überschrieben). 1619000.1627 avene. 1633 avene. 1638 spelte. Anno 1642 avene. Anno 1645 avene. Anno 1647 spelte. 48 avene. Anno 1652 avene. 59 nibil. Zum Schluss von derselben Hand, die auch die Gesamtrechnungen geschrieben hat: 1666 spelte.

Einband: Mit rot gemasertem Papier überzogene Pappdeckel, 20. Jh., Rücken und Ecken braunes Leinen. Spiegel und Vorsatzblätter (A, 90) modernes Industriepapier. Schnitt grün gesprenkelt. Auf dem Rücken drei Papierschilder, zuoberst: Altes Jahrzeitbuch. Papier 1498, 18. Jh. (vom alten Einband abgelöst), darunter gedrucktes Signaturschild 663, zuunterst handschriftliches Signaturschild 33 (?).

Herkunft: Geschrieben für und sicherlich auch in Beromünster selbst. 10r Nachtrag der Anlagehand mit Bezug auf das Jahr 1499, 89v Nachtrag einer anderen Hand (wohl des Notars Andreas Erni) zu 1498.

Besitzer: Vorne und hinten im Spiegel und auf den Vorsatzblättern Stempel: Stiftsarchiv Beromünster, 20. Jh. Literatur: Estermann, Sehenswürdigkeiten, S. 77; Egloff, Herr in Münster, S. 224 (mit Anm. 144) und 298; Hugener, Buchführung, S. 314 (dort irrtümlich mit der Angabe «Anhang mit Urbar»).

$1^{\mathrm{r}}-84^{\mathrm{v}}$ Liber anniversariorum. Sonntagsbuchstaben, Kalenden, Nonen, Iden. $>$ A. KL. Ianuarius. Circumcisio Domini<. Item ad anniversarium Hessonis am Brül dantur de decima in Leimbach vii quarteria spelte inter canonicos dividenda ... $2^{\mathrm{v}}>$ A. vi. Idus. Erhardi episcopi<. Ut festum sancti Erhardi festive celebretur, datur $i$ malterum eque de granario inter canonicos dividendum, deducto pro quolibet prebendario i pane. // Danach acht Blätter (9. Januar bis 20. Februar) verloren. $3^{\mathrm{r}}>A$. ix. K<. Item ad anniversarium Cünadi Hagnower dantur xii solidi de cellario ... - ... $>$ A. ii. K Silvestri pape <. In der randlichen Spalte zu jedem Eintrag die Anteile der 
Kanoniker und Präbendeninhaber: $1^{\mathrm{r}}$ Canonicis vii quarteria spelte ... $5^{\mathrm{r}}$ März, $13^{\mathrm{r}}$ April, $21^{\mathrm{r}}$ Mai, $29^{\mathrm{r}}$ Juni, $37^{\mathrm{r}}$ Juli, $45^{\mathrm{r}}$ August, $53^{\mathrm{r}}$ September, $61^{\mathrm{r}}$ Oktober, $69^{\mathrm{r}}$ November, $77^{\mathrm{r}}$ Dezember. Nachgetragene Heiligenfeste: $6^{\mathrm{v}}$ Thomas von Aquin, $41^{\mathrm{v}}$ Christophorus, $45^{\mathrm{r}}$ Vincula Petri und Stephanus (Papst), $48^{\mathrm{v}}$ Theodul. $85^{\mathrm{r}}-89^{\mathrm{r}}$ leer.

89v Gesamtrechnung. Nachtrag, 15. Jh. Nota das uff donrstag vor Simonis et Iude Apostolorum Anno domini etc. Im lxxxx viii jare ein überschlag alles des korns, habers, kernens und gelts och Roggens so dann järlichen jn die kamer der jartzitten und zinsen halb von einem Cammrer in ze zyehent sind Pringt ... an einer summ in stucken tusent füftzig und siben stück ... - ... jn bysin der Erwirdigen herren hern wernher hagens, her niclaus von winckel, her hansen pfiffers und her hansen meygers und och peter Rosenschilts der zyt kellers ze múnster etc.

Pergament, 62 Blätter, $38 \times 25,5-26 \mathrm{~cm}$

Beromünster (?), um 1346/47

Lagen, Foliierung: Lagen: $3(\mathrm{VI}+1)^{76}+\mathrm{VI}^{100}+(\mathrm{IV}+1)^{118}$, Bl. III/IV an Bl. 1/2 und Bl. 101/102 an Bl. 103/104 geklebt, Bl. 47/48 an Bl. 45/46 und Bl. 65/66 an Bl. 63/64 genäht. Alte Zählung der Doppelseiten: $i$ (S. 2) - xxiii (S. 46). xxiiii (S. 50) - xxxi (S. 64).xxxii (S. 68) - lvi (S. 116). Paginierung wohl des 17. Jhs., schon für die Edition im QW (siehe Literatur) benutzt, ergänzt: [I-IV], 1-117, [118-120].

Einrichtung und Ausstattung: Tintenliniierung, bis S. 108 dreispaltig (S. 47 und S. 77-81 zweispaltig), Schriftraum 26,5 × 20 (mittlere Spalte 7,5-8, links und rechts 5), in der Mitte 24, seitlich 48 Zeilen; S. 111 118 zweispaltig, $26 \times 18$ (8-8,5), 24 Zeilen; Einstichlöcher für die Liniierung am inneren und äusseren Rand. Textualis von einer Hand, die auch StiAB 01.01.600, Teil 2 schrieb. Rubriziert, rote Überschriften (S. 9-10 ohne Rubrikation); rot-schwarze Versalien, gehäuft S. 78-81, ansonsten v. a. als zweiter Buchstabe der Präposition In am Beginn der einzelnen Einträge. Rote Initialen, meist mit eingerollten Schaftenden, S. 1 und 23 zusätzlich eine kleine Palmette, ansonsten mit wenigen Punktverdickungen oder Konturbegleitstrichen, S. 78 und 111 zweizeilig.

Korrekturen und Nachträge: Korrekturen des Schreibers S. 77 und 103, von anderer Hand z. B. S. 64. Nachträge in der Mittelspalte S. 5, 8-10, 12, 25 und 52. Nachträge in den Seitenspalten, vereinzelt auch an den Rändern, zu den jeweils aktuellen Besitzverhältnissen, von mehreren, meist wiederkehrenden Händen, die jüngsten auf der (ursprünglich leeren) inneren Spalte, in unterschiedlicher Dichte, mit Datum auf S. 15: Anno 1418, S. 16: Anno lxxv und Anno domini lxxvi, S. 42: $m^{\circ} c c c c^{\circ} x v i i^{\circ}$, S. 68: anno domini $m^{\circ} c c c c^{\circ} x v i i^{\circ}$ und S. 75: 1416, datierte Serien von Einträgen zu Hochdorf (S. 25-31) 1418, Aesch und Schongau (S. 37-43) 1422, zuletzt Buttisholz (S. 74f.) 1452. Die beiden angenähten Blätter S. 47/48 und 65/66 von zwei verschiedenen Händen wohl noch des 14. Jhs., beide rubriziert, ersteres zu Gundoltzwil (Gunzwil?) und Pfeffikon, letzteres zu Richenthal. S. 83-107 nahezu keine Nachträge, einzig auf S. 102 (deutsch) und 104 (lat.); S. 91-105 Einträge numeriert, zudem in den die Spalten trennenden Zwischenkolonnen Referenzzahlen zu einem Novus liber (links) und dem älteren Liber aniversarius (rechts), vgl. S. 91 bzw. Hugener, Buchführung, S. 162. Streichungen in allen drei Spalten, in der äusseren Spalte vereinzelt auch Rasuren; S. 118 a ein grösserer Abschnitt radiert und auf der leeren rechten Spalte neu verfasst, mit Nachtrag. S. 30 ein Nachtrag anno 1400 
vixit, 18. Jh., zu dem Eintrag nunc greta filia petri gerwers von sempach, von der gleichen Hand auch weitere Lebensdaten auf S. 115.

Einband: Mit (weissem) Pergament bezogene Pappdeckel, 18./19. Jh. Spiegel- und Vorsatzblätter (I-II, 119120) Papier, Wasserzeichen: Löwe mit Krone und Reichsinsignien sowie Initialen IS, vgl. StiAB 01.01.616. Blau-weisse Kapitale. Auf S. III Leimspuren und Abdrücke der Lederumschläge von einem früheren Einband. Auf dem Vorderdeckel mit Tinte: Census Ad Cellarium Ecclesiae Beronensis a 1303, 18./19. Jh., sowie mit Bleistift u. a. Stiftsarchiv Beromünster und 1303. (c. 1325) 1350, das erste Datum nachträglich durchgestrichen, das mittlere einfach unterstrichen und eingeklammert, das letzte doppelt unterstrichen und wiederum durchgestrichen, 20. Jh. Auf dem Rücken: Census ad Cellarium. C. 1350, sowie Signaturschild: 709, 20. Jh.

Herkunft: Geschrieben für das Stift Beromünster, sicherlich vor Ort, in Zusammenhang mit StiAB 01.01.600; vgl. zur Datierung QW II, 1, S. 114. Vgl. das ältere Kelleramtsurbar StiAB 01.01.599, 70ª_79va.

Besitzer: -

Literatur: Joseph BöLSTERLI, Die Urbarien der Stift Beromünster: A. Das Zinsbuch des Kelleramts, in: Der Geschichtsfreund 23 (1868), S. 235f.; Josef Leopold Brandstetter, Das Alter der Urbarien des Stifts Münster, in: Der Geschichtsfreund 24 (1869), S. 301-304; EsTERMANN, Sehenswürdigkeiten, S. 77; LiEBENAU, Urkundenbuch, Bd. 1, S. 24 (H); QW II, 1, S. 114 und 182; BruCKnER, Scriptoria 9, S. 19; Hugener, Buchführung, S. 71, 158-165.

S. I Angaben zu den Masseinheiten, 19./20. Jh.: Frustum = Stück enthält 10 Viertel Korn ...

S. II leer.

S. III Sepono semen domini fomen, secundum rem tuam ... (unsichere Lesung).

S. IV Tabula. Die Angaben beziehen sich auf die ältere Zählung der Doppelseiten. In Berona, i. Adelswile, $v$. Swartzenbach, $v$... - ... Conswetudinalia, liii. QW II, 1, S. 183, Nr. 19.

S. 1-108 Census cellarii. Kelleramtsurbar. > Isti sunt census pertinentes ad cellarium ecclesie Beronensis<. In villa Beronensi cellarium sub camera dominorum cum porticu prope fontem que reddunt annuatim xxviii solidos, de quibus dantur xii solidos ad anniversarium Marchwardi de Rüda $i i^{\circ}$ Kalendas Februarii ... In der rechten Randspalte: De quo Uliricus de Růda dat xxviii solidos denariorum (vgl. BüCHLER, Beromünster, S. 363, Nr. 276) ... S. 78 a $>$ Iste sunt decime Capituli Ecclesie Beronensis secundum summam taxationem estimate<. Decima in Hochtorf reddit aliquando lxviii. maltera et ii. libras denariorum in arra ... S. $83>$ Magthon<. In Magton ... S. $91>$ Ogghein<. In Oghein ... S. $103>$ Iste sunt vites quas capitulum colit suis expensis<. Primo ... - ... Item habemus domum in Friburgo ... pro ii. libris denariorum. S. 48 und 82 leer. BölsTERLI, Zinsbuch, S. 236278; QW II, 1, S. 183-235, Nr. 19.

S. 109-110 leer.

S. $111^{\mathrm{a}}-118^{\mathrm{b}}$ Dividenda. Verteilung der Einnahmen. Notandum quod ab antiquo dabantur et adbuc dantur Pistoribus de Cellario dominorum singulis diebus per circulum anni ii. modii spelte mensure curie ... BöLSTERLI, Zinsbuch, S. 278-283; QW II, 1, S. 235-239, Nr. 19.

S. 119-120 leer. 
Papier, 140 Blätter, $28-28,5 \times 21-21,5 \mathrm{~cm}$

Beromünster, 1479-1520

Wasserzeichen, Lagen, Foliierung: Wasserzeichen: Abt oder Bischof, BRIQUET Nr. 7553 (1475), in mehreren Varianten. Lagen: (VIII-1) ${ }^{16}+6$ VIII ${ }^{112}+$ VII ${ }^{126}+\left(\right.$ VIII-3) ${ }^{140}$, Bl. 3 grösstenteils herausgeschnitten, nach Bl. 131 ein Blatt herausgeschnitten, nach Bl. 137 ein Blatt herausgerissen, Bl. 138 grösstenteils herausgerissen; Bl. 5, 7-11, 15, 29, 81, 128 und 134 teilweise (meist oben) beschnitten. Textverlust. Zwischen B1. 21 und 22 ein Zettel lose eingebunden. Die erste Seite (Mitte) und die zweite Hälfte der letzten Lage vom mittleren Lederriemen des Einbands her (gegen den Bund) beschädigt. Neu foliiert: 1-140.

Einrichtung und Ausstattung: $18^{\mathrm{r}}-32^{\mathrm{v}}$ Schriftraum durchgehend vertikal mit Tinte begrenzt, danach unregelmässig. Kursive von mehreren Händen. Keine Rubrizierung, kein Buchschmuck.

Korrekturen und Nachträge: Der grösste Teil der Einträge ist (nach Erledigung des Geschäfts) jeweils gestrichen.

Einband: Kopertband aus Pergament mit umgeschlagenen Rändern und übergreifender Klappe. Über den Rücken drei braune Lederriemen als Verstärkung für die indirekte Schnürung der Knotenheftung, bis zur Hälfte über die Deckel reichend, der mittlere vorne mit einer Schnalle, von hinten um die Klappe geführt, das Ende mit dem Loch abgerissen; mit feinen weissen Lederstreifen ornamental im Kreuzstich angenäht. In den freien Ecken vorne und auf der Klappe je ein mit ebensolchen Lederbändern gestickter Davidsstern (sechs Stiche, auf der Innenseite als Sechseck erscheinend mit einem Knoten). Feuchigkeitsschäden. Auf dem Vorderdeckel zweizeilige Aufschrift, auf der Innenseite: Item maltera spelte i malterum pro ii libris xiii solidis, in gleicher Schrift wie mehrfach in der Hs., der Einband also nicht viel später.

Herkunft: Das Wasserzeichen und die ersten Einträge weisen auf eine Entstehung des Bandes zu Beginn des letzten Viertels des 15. Jahrhunderts, gewiss in Beromünster. Die früheste Jahreszahl lautet 1479, die Mehrheit der Einträge erfolgten zwischen 1498 und 1518, der vielleicht letzte Nachtrag (51 $)$ ist auf 1520 datiert. Zu Heinrich Gartner vgl. Bü CHLER, Beromünster, S. 65 (S. 215, Anm. 62 und 64) und S. 297 (Nr. 98).

Besitzer: -

Literatur: -

$1^{\mathrm{r}}-140^{\mathrm{v}}$ Abrechnungen, Notizen über Schulden und Aussenstände, Abgabenverzeichnisse. Im Folgenden die Anfänge von einzelnen herausragenden bzw. charakteristischen Stücken. Iacobus (folgt ein Schmierfleck) de Amurco - xviii maltera spelte ... xv maltera avene ... i malterum leguminis ... Iorg Iberg tenetur (gestrichen: iii lib.) post computacionem adhuc v libras viii solidos $x$ denarios tenetur $5^{\text {ta }}$ post Nicolai ... $2^{\mathrm{r}}$ Ihesus filius virginis Marie, die iii mensis Octobris 1479: Item Marchexius de Tremenicho debet dare pro speziebus sibi venditis ... Ulli blüwel der schüchmacher: Item ich han gerechnet mit ülli blüwel uff fritag in der frofasten züpfingsten im lxxxxviii Iar und nach aller rechnung so blipt mir blüwel schuldig xii sol. und sind iiii Iar verrechnet schüch und speczery gegen einander ... 2 $2^{v}$ Item Hans buggy hat köfft min gütt min spicher korn und haber uff donstag nach onufrii, dz korn i modium umb xii sol., den haber i modium umb viii sol ... Item ich herr Bartholome feller Capplan Sant peters zu zovingen han gerechnet mit Iacoben sonnentag von iii Iaren har und blib Im schuldig xxxvi sol. umb pulver ... $6^{\mathrm{r}}$ Pro petro famulo meo die xxiii mensis Ianuarii 1480. Darunter, neben einer Liste von Spezereien: 
Herr Caspar. Item ich han gerechnot mit sunnentag uf dunstag vor keysers heinrichs tag Im lxxxx 8 Iar und belib ich Im schuldig nach aller rechnung xiii sol. minus $i$ h. ... $8^{\mathrm{v}}-9^{\mathrm{r}}$ leer. $10^{\mathrm{r}}$ Item uff sunentag vor conversionis Pauli han Ich dunget min knächt hansen keller um uff liechtmes uber ein Iar und gib im ein Iar zü lon, iii par schüch und die bletzer i par stifflen ein gefüettert Iuppe i par gescharn hosen und i par zylchen hosen ii hemd und xiii lib. Presentibus domine sebastiano Rüger schnypffer und hans buggy. Item ligen hosen und wamsel und $i$ rock am Camerer ... 10 10er. $12^{\mathrm{r}}$ Die xxvi mensis novembris 1479. Item gaspar de buochs parens stefany de la petra debet dare pro speziebubus sibi venditis per fratrem meum ... 12 $2^{\mathrm{v}}$ leer. $13^{\mathrm{r}}$ Item Ego H. Gartner teneor Iohanni Decker a republica Lucerne xiii libras et duos solidos (?) monete beronensis. Iterum dedit michi specie ungeferwt i lot negeli $i$ lott zimet iii lott ymber ... 13 $3^{\mathrm{v}}-14^{\mathrm{r}}$ leer. $14^{\mathrm{v}}$ Item uff zinstag nach martini han ich gerechnatt mitt minem schwager hansen schärer... Item Ich heinricus gartner sol nach aller rechnung minem schwager hansen scherer xxiiii lib. xxii sol. actum $6^{a}$ eiusdem temporis sed ante thome 1518 ut habetur in libro suo dedi sibi iiii kronen eodem die. Solutum totum ... 17r Min herr propst von Erlach Sol Jacob Sunntagen nach aller rechnung dryssig und fünfpfund haller und xi sol. ii den. Gerechnet uff mittwoch vor Sant keiser heinrichs tag Inn xcviii Iar ... 17v leer. $18^{r}$ Divisio des Andreas von Luternau, zu ihm BüCHLER, Beromünster, S. 339f. (Nr. 206); Helvetia sacra II/2, S. 560f.: Divisio domini Andree de Luternow 1504: Iben moss i malter spelt, pfefficon iii malter spelt ... 27v Zewüssen das uff sampstag nach sanctorum Innocentium Anno $M^{\circ} c c c c v^{\circ}$ ein endtliche rechnung beschechen ist zwüschen den Erwirdigen herren heinrichen gartneren und herrn Andressen von Luternow ... Andreas Erny notarius subscripsit. 30 Item uff fritag nach michaehelis im xii han ich gerechnett mitt her heinrich gartner und die abgeschriben rechnung harin vergriffen ... blipt mir her heinrich schuldig xxviii libra $x$ solidos. Actum die ut supra. Andreas de luternow manu mea propria. 30v-31v leer. $32^{\mathrm{r}}$ Spelta curie ... 32v leer. $33^{\mathrm{r}}$ Divisio des Johann Rudolf von Hallwyl, 1508-1518, zu ihm BüCHLER, Beromünster, S. 307f. (Nr. 127); Helvetia sacra I/1, S. 201f. und 308; HLS Bd. 6, S. 72: Anno m ccccc viiio divisio domini de Hallwyl. Baldeck viiii maltera spelte ... Anno $x v^{c}$ nono uff mentag post Michaelis hab ich rudolf von halwile mit dem wirdigen herren her heinrich gartner gerechnat und min division unn umm all sachen nutzig uss genommen wz sich vormals erlouffen hatt biss hütt uff disen tag ... unn beschechen in gegenwertikeit heinrich winterhalder capplan aller heilgen. Rudolfus de Hallwile prepositus ecclesie Basiliensis ... 49 $9^{\mathrm{r}}$ Camerarius de Hertenstein. Zewüssen das ein rechnung beschehen ist zwüschent herr Heinrichen Gartnern und Iunckher Hansen von Hertenstein der presentz halb ... Zuletzt als Nachtrag: Facta conputacione inter kamerarium et hans dotiker et heredes domini heinrici gartner de singulis etc.

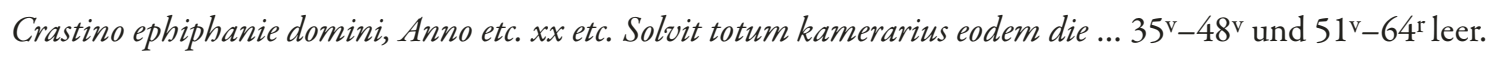
$64^{\mathrm{v}}$ Item $4^{\text {ta }}$ post reminiscere han Ich gelichen maryz kubn iiii libra x solidi ... Item dedi minem gevatter rugg $v$ libra xv solidi was er In schulden umb rind fleysch eadem die anno 1509 ... 65ㄴ-93v leer. 94r Anno 1517: Sequuntur debita cellerarii. Item ... scolastico. Sequuntur cantorii: Pancracii ... 94v $-95^{\mathrm{r}}$ leer. 95v Item uff samstag vor reminiscere anno 1518 han ich gerechnat mit minem knecht Üli Forster von ii Iaren lón und dz Ich Im daran gewert han und eins gegen den andren abzogen so blib ich Im schuldig vii libra ii solidi $i$ denarum und ii fuder und die Iuppen bin Ich Im ouch schuld ... 96v Abgabenverzeichnisse, 1504-1508: Anno 1504, divisio h. gartner. Spelt curie: Langnow 1 malterum, Pfeff [ik] en iii maltera ... 99v leer. 100r Abgabenverzeichnisse, 1511-1518: Anno 1511. Abersol x malter spelt, Pfeff $[\mathrm{ik}]$ en v malter, Schongow ii modii ... 103 $3^{\mathrm{v}}-126^{\mathrm{v}}$ leer. $127^{\mathrm{r}}$ Item $2^{a}$ post oculi anno 1510 hab ich dinget martin schällenbärg, unz uff primus purificacionis, und ich hat Im ouch vergriffen das hat so er bii mir ist gesin vor ob er zu mir hat dinget und sol Im gen vir schü und kleyder und all an sprach xvi libra. Item ... 127v leer. $128^{\mathrm{r}}$ Item hans buggy tenetur ... 129 $122^{\mathrm{r}}-132^{\mathrm{v}}$ und $136^{\mathrm{v}}-137^{\mathrm{r}}$ leer. Zuletzt $137^{\mathrm{v}}-140^{\mathrm{v}}$ nochmals 26 Abrechnungen, bis auf die erste alle durchgestrichen und undatiert: Item uff $5^{a}$ feria scilicet 
anthonii anno 1516 han Ich gerechnat mitt andres Husser mines gevatter Iakobs vatter vor sinen wäggen und blib Im schulden nach aller rechnung iii libra iiii solidi ... Item uff invocavit han Ich gerechnat mitt bernhard meyger umb fleysch und nach ab zug scilicet allen so blib Ich schuld dem bernhard xvi lib. xiii sol. 5 den. Unmittelbar anschliessend: Hans buggy dedit sibi et est solutus. Überwiegend Abrechnungen zwischen Hans Gartner und einer Reihe von verschiedenen anderen Personen, dazwischen vereinzelt Abrechnungen Dritter, 1479-1520. Die Einträge beziehen sich teils auf persönliche Ausgaben und Einnahmen Gartners, teils auf das Stift St. Michael. Unter den Personen sind Tagelöhner, Diener, Handwerker und Händler, Verwandte Gartners sowie Chorherren und Amtsträger des Stiftes. Eine Reihe von Namen erscheinen mehrfach, deutlich am häufigsten Hans Buggy.

\section{StiAB 01.01.715 SCHWARZBUCH}

Papier, 287 Blätter, 26,5 × 19,5-20 cm

Beromünster (?), zweite Hälfte des 15. Jahrhunderts bis um 1650

Wasserzeichen, Lagen, Foliierung: Wasserzeichen: Bl. I-IX, 237-281 Baselstab, PICCARD, Wasserzeichenkartei Nr. 32975 (1570) und 32977 (1569); Bl. 1-235 Mond mit Kreuz, ähnlich PiccARD, Wasserzeichenkartei Nr. 41414 (1450), nebst einer höheren Variante; Bl. $57 / 58$ Bär, ähnlich PICCARD, Wasserzeichenkartei Nr. 84896 (1524) oder Tschudin Nr. 368 (1522); Bl. 138a Löwe mit Monstranz, darunter BB. Lagen: VIX + $\mathrm{I}^{2}+\mathrm{XI}^{25}+\mathrm{X}^{45}+(\mathrm{XI}+\mathrm{I}+1)^{71}+(\mathrm{X}+3)^{96}+\mathrm{XII}^{120}+\mathrm{XII}^{144}+\mathrm{X}^{164}+\mathrm{X}^{183}+\mathrm{XII}^{208}+\mathrm{XII}^{232}+\mathrm{II}^{236}+\mathrm{V}^{246}+$ $\mathrm{VI}^{258}+\mathrm{VI}^{270}+\mathrm{IV}^{278}+\mathrm{II}^{281}$, das erste Blatt der ersten und das letzte Blatt der letzten Lage als Spiegelblätter in die Deckel geklebt; Bl. 57/58 Doppelblatt, an Bl. 59 geklebt; Bl. 46 und 72 Einzelblätter (beide ohne Wasserzeichen), an Bl. 47 und 73 geklebt; Bl. 86 und 96 Einzelblätter (beide mit Wasserzeichen), an Bl. 85 bzw. 95 geklebt; Bl. 233/236 aus zwei Einzelblättern zusammengeklebt. Bl. 1-25 und 47/71 zu einem späteren Zeitpunkt (siehe auch Einband) im Falz mit weissen Papierstreifen verstärkt oder zusammengeklebt, Bl. 26, 45, 71 und 95 am unteren Rand mit gleichen Papierstreifen verstärkt, Bl. 103-114 teilweise im Bund. Bl. 6771 mit z. T. rund zugeschnittenen Papierflicken, Bl. 121 mit kreisrundem Loch; Riss in Bl. 122 mit einem Randstück eines Briefmarkenbogens geflickt; die untere Ecke von Bl. 46 mit modernem Papier wiederangeklebt, die untere Ecke von Bl. 4 und 232 alt mit Makulatur ersetzt. Auf Bl. 139 ein gefalteter Zettel (138a. $138 b)$ eingeklebt. Seitenreklamanten $242^{\mathrm{r}}-246^{\mathrm{v}}$. Alte, fehlerhafte Foliierung, ergänzt: [I-IX], 1-2. 4-54. 56-75. 78-138, [138a. 138b], 139-165. 165 [bis]. 166-187. 189-250, [251-281].

Einrichtung und Ausstattung: Nicht liniiert, kein einheitlicher Schriftraum. Kursive des 15. bis 17. Jhs. von verschiedenen Händen, darunter Abraham Schatt: $1^{\mathrm{r}}-2^{\mathrm{r}}$, 56 $6^{\mathrm{r}}$ (Nachtrag), 89v-90v $105^{\mathrm{r}-\mathrm{v}}, 112^{\mathrm{v}}-113^{\mathrm{r}}, 121^{\mathrm{v}}$, $\left.123^{\mathrm{v}}-124^{\mathrm{v}}, 126^{\mathrm{r}}-138^{\mathrm{r}}, 139^{\mathrm{r}}-143^{\mathrm{v}}, 146^{\mathrm{r}}-148^{\mathrm{r}}, 165^{\mathrm{v}}-165^{[\mathrm{bis}}\right] \mathrm{v}, 194^{\mathrm{r}}-195^{\mathrm{r}}, 219^{\mathrm{v}}-222^{\mathrm{r}}, 233^{\mathrm{r}}$; Andreas Erni: $7^{\mathrm{v}}-8^{\mathrm{r}}, 10^{\mathrm{r}}, 11^{\mathrm{v}}, 19^{\mathrm{r}}-23^{\mathrm{v}}, 25^{\mathrm{r}-\mathrm{v}}, 29^{\mathrm{v}}-56^{\mathrm{r}}, 59^{\mathrm{r}}-81^{\mathrm{r}}, 83^{\mathrm{r}}-85^{\mathrm{r}}, 88^{\mathrm{r}}-89^{\mathrm{r}}, 104^{\mathrm{v}}, 121^{\mathrm{r}-\mathrm{v}}, 125^{\mathrm{r}-\mathrm{v}}, 127^{\mathrm{r}}, 190^{\mathrm{r}}-191^{\mathrm{r}}$, $198^{\mathrm{v}}-201^{\mathrm{v}}, 216^{\mathrm{r}}-219^{\mathrm{v}}, 223^{\mathrm{v}}-225^{\mathrm{r}}$; Sebastian Gauch: 91 $\mathrm{r}$; Leodegar Schinbein: 92 $, 138^{\mathrm{v}}, 144^{\mathrm{r}}-145^{\mathrm{v}}$, $148^{\mathrm{v}}-151^{\mathrm{r}}, 153^{\mathrm{r}}-155^{\mathrm{v}}, 171^{\mathrm{r}}-172^{\mathrm{r}}, 202^{\mathrm{r}}$; Johannes Hitzmann: 92 $-94^{\mathrm{r}}, 157^{\mathrm{v}}-158^{\mathrm{v}}, 160^{\mathrm{r}}, 165^{\mathrm{v}}-166^{\mathrm{v}}$, $167^{\mathrm{v}}-170^{\mathrm{r}}, 172^{\mathrm{v}}-173^{\mathrm{v}}, 182^{\mathrm{v}}, 202^{\mathrm{r}}, 222^{\mathrm{v}}, 227^{\mathrm{v}}, 233^{\mathrm{v}}-234^{\mathrm{r}}$; Fer: 151 $-152^{\mathrm{v}}(1545)$; Rochus Baumgartner: $174^{\mathrm{v}}-175^{\mathrm{r}}, 176^{\mathrm{r}}(1608,1613)$; Jacob Ott: 237 ${ }^{\mathrm{r}}-250^{\mathrm{r}}$. Ohne Rubrizierung oder Buchschmuck.

Korrekturen und Nachträge: Korrekturen der verschiedenen Schreiber, z. B. 25rr, 60v $91^{\text {r }} 128^{\mathrm{r}}, 202^{\mathrm{r}}, 237^{\mathrm{v}}$. Streichungen, gehäuft $8^{\mathrm{v}}-10^{\mathrm{r}} .46^{\mathrm{v}}$ Handweiser, $45^{\mathrm{v}}$ und $60^{\mathrm{v}}$ Notazeichen, öfters Unterstreichungen. $11^{\mathrm{v}} / 22^{\mathrm{r}}$, 
50v/54 und 56r/105 ${ }^{\mathrm{r}}$ Verweiszeichen. $4^{\mathrm{r}}, 13^{\mathrm{r}}$ Überschriften von einer Hand des 17. Jhs., von derselben Hand: $16^{\mathrm{v}}$ Videtur hic folium desiderari, quia sequens folium non cohaeret sowie $229^{\mathrm{r}}$ Habes quoque superius fol. 37. $46^{\mathrm{v}}-47^{\mathrm{r}}$ Nota Anno 1664 in generali capitulo custodia fuit reformata taliter ... 47 ${ }^{\mathrm{r}}$ Reformationem huius officii aliam vide protocollum 17. Aug. Anno 1674. Auf dem nachträglich eingeklebten, gefalteten Blatt 138bv Dorsalnotiz: Ussmarchung dess Hoofs jm Wyerhuss. Anno 1644. 138 $\mathrm{a}^{\mathrm{r}}>$ Wierhuss <. Erstlich huss, schür und krutgarten ... Einband: Mit dunkel gefärbtem Leder bezogene Holzdeckel, Kanten in der Mitte abgeschrägt, 16. Jh. (nach EGLOFF, Urbar, S. 375, von Johann Hitzmann um 1570 veranlasst), Rücken und Heftung (siehe auch Lagen) erneuert. Streicheisenlinien und Rollenstempel. Ehemals zwei nach vorn greifende Kantenschliessen mit Messingteilen. An den äusseren, ursprünglich auch den inneren Ecken der beiden Deckel ziselierte und durchbrochene Beschläge aus Messing mit Buckeln. Blau-weisse Kapitale. Spiegelblätter Papier (siehe Lagen); im vorderen Spiegel ein Pergamentstück sichtbar, vorne und hinten Papierstücke aus der Zeit der Restaurierung des Einbandes. Auf dem Vorderdeckel weiss aufgemalt Das schwartz buch 1571, sowie Reste des Wappens des Stifts Beromünster in Rot und Gold. Darauf ein grösstenteils abgerissenes Papierschild: Das [Schwarzbuch], 17. Jh. (?). Auf dem Rücken zwei Papierschilder, das untere grösstenteils abgerissen, ohne Reste von Schrift; darüber Signaturschild: 715, 20. Jh.

Herkunft: Fast alle namentlich unterzeichneten Schreiber (siehe Einrichtung und Ausstattung) waren Stiftsangehörige. Zu Andreas Erni siehe Estermann, Stiftsschule, S. 88; Abraham Schatt ebd., S. 89 und Büchler, Beromünster, S. 109; Sebastian Gauch und Leodegar Schinbein siehe EsTERmanN, Stiftsschule, S. 89; Johannes Hitzmann ebd. S. 89f.; Jacob Ott ebd. S. 91f. Nach Egloff, Herr in Münster, S. 292f., liess Notar Johann Hitzmann die einzelnen Hefte binden, als er seit 1567 ein erstes neues Bereinurbar anlegte. Eine Abschrift befindet sich in der Bibliothek unter der Signatur C 68 (ehemals: C 18 fol.).

Besitzer: In den Antiquitates Beronenses, S. 690, als Nr. 14 verzeichnet. Ar und 281v Stempel: Stiftsarchiv Beromünster, 20. Jh., darunter mit Kugelschreiber Signatur 715.

Literatur: Je ein detailliertes Inhaltsverzeichnis zum sog. Schwarzbuch in der Zentral- und Hochschulbibliothek Luzern, Bürgerbibliothek, Ms 304.a.4o (um 1570) und im Staatsarchiv Luzern, AKT 19D/405 (um 1650), vgl. Egloff, Herr in Münster, S. 293. Estermann, Stiftsschule, S. 30, 32, 56, 87-89, 134f. und 147; Estermann, Sehenswürdigkeiten, S. 75; Riedweg, Beromünster, S. VII; Liebenau, Urkundenbuch, Bd. 1, S. 24 (G); BüCHLER, Beromünster, S. XV, 141 und 388 (Anm. 14 zu Joh. Teller); Egloff, Urbar, S. 375, 383, 388, 390 (Anm. 20), 394 (Anm. 104 u. 105); Egloff, Herr in Münster, S. 31, 256f., 268, 293, 310, 314, 316 , 326, 355f. und 447 (die beiden im Register, S. 472, weiter angeführten Stellen S. 35 und 366 gehören zum dort folgenden Eintrag 'Schwarzenbach').

$\mathrm{Ir}^{\mathrm{r}}-\mathrm{VI} \mathrm{I}$ leer.

VIIr Statut. > A. Erlütherung, im Capitel beschlossen. Wie ein aberstorbner Chorherr mit dem dryssgist, In den paren, und unparen presentzen, välen und Erschätzen, ouch Quotidian solle gehalten werden<. Namblich so ein Chorher mit tod abgaat ... Actum Donstags vor Palmarum Anno Christi 1582 ... Darunter Nachtrag (mit Einfügezeichen): Zuo wüssen, das ufDonstag vor Reminiscere Anno 1589 ...

VIIv-IXv leer.

$1^{\mathrm{r}}-250^{\mathrm{r}}$ Statuten, Eide, Verträge, Urkunden, Beschlüsse, Abrechnungen, Notizen, Konzepte. Zahlreiche Einträge unterschiedlichen Umfangs, nur abschnittsweise in thematischer Ordnung. Im Folgenden nur die Anfänge von einzelnen herausragenden bzw. typischen Stücken: $1^{\mathrm{r}}-2^{\mathrm{r}}>$ Von dess keller ampts verpflichtigung<. 
Diss sind die artickel so ein yeglicher keller schulldig ist globen oder schwerrn zehallten. Item zu dem ersten, so soll er zu münster husshäblich syn ... - ... Item Er soll öch uff sant Michelstag zu herpst, oder so die Rechnung beschlossen ist, komen jnn ein gmein Capitel ... Abraham Schatt Beronensis Notarius subscripsit. $2^{\mathrm{v}}$ leer, Bl. 3 bei

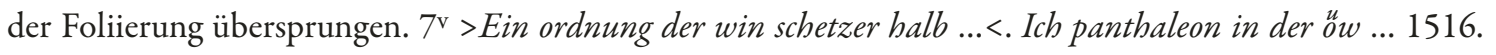
$8^{\mathrm{r}}-10^{\mathrm{r}}$ Item computatione facta ... inter dominos de capitulo et Rüggerum Gassman cellerarium ... 1458-1463. Darunter Statut: > Statutum capituli generalis ex parte locacionis decimarum <. Anno domini ... 1516. 10v leer. $11^{\mathrm{r}}>$ Hec sunt consuetudines introducte et per prius in ecclesia Beronensi per eiusdem ecclesie prepositos observate<. Prepositus qui eciam canonicus fuerit ... 13 $3^{\mathrm{r}}-16^{\mathrm{r}}>$ Iuramentum domini praepositi<. Wir, Jos von Silinon ... Vertrag von 1469 anlässlich der Amtseinsetzung des Propstes Jost von Silenen. 18v leer. 19r $-21^{\mathrm{v}}>$ Compositio inter clerum de nacione confederatorum et episcopum Constanciensem ... $<$. Wir nachbenempter Gerold meyer ... 1493. $24^{\mathrm{v}}$ leer. $25^{\mathrm{r}}$ Iuramentum domini Michaelis segesser: Anno domini ... Konzept, 1502. 26v leer. 27r $>$ Recognicio iuris nominandi ad ecclesias per dominos de Lutishofen collegio Beronensi datas <. Wir Jos von Silinon ... 1479. 29v-32r Iuramentum quatuor officialium et preconis ... vier Eidformeln: Amtmänner, Leutpriester, Kapläne und Lehrer. $33^{\mathrm{v}}-35^{\mathrm{v}}>$ Dis sind die Artickel so in dem bericht Zwüschen minen herren von münster und denen von Gundelswil begriffen stond etc. $<$ Zum ersten ... Anschliessend Bericht zwischen dem Meier von Pfäffikon und dem von Reinach von 1456, Hofrecht von Pfäffikon sowie Bericht zwischen Leutpriester und Meier von Pfäffikon. 38v leer. 39r $-41^{\mathrm{r}}>$ Diss sind die artickel So dann ein yeder Cammrer ze Münster sines ampts halb ze volfuren pflichtig ist<. Des ersten sol er hushäblich ze Münster sin ... $41^{\mathrm{v}}-43^{\mathrm{r}}$

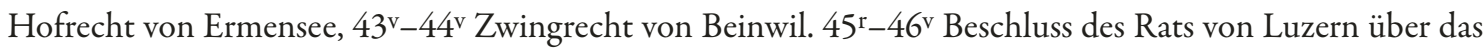
Fallrecht, $1453.47^{\mathrm{r}}-48^{\mathrm{v}}>$ Diss sind die Artickel so ein Custor ze Münster By geswornem eyd zehalten pflichtig ist ungevarlich<. Item des ersten ... letzter Artikel geschwärzt. 49 ${ }^{\mathrm{r}-\mathrm{v}}$ Grenzsetzung für die Zehnten von Homberg, Pfäffikon und Leimbach, 1498. 50 ${ }^{\mathrm{r}-\mathrm{v}}$ Bussenkatalog für die Herrschaft Kungstein. 52r leer. 52v-53 ${ }^{\mathrm{r}}$ Grenzsetzung für die Zehnten von Münster und Reinach, 1475, sowie Gondiswil und s Feld ab 1589. 53v leer. $54^{\mathrm{r}-\mathrm{v}}$ Amtseid des Meiers von Küttigen. $56^{\mathrm{r}}>$ Hienach volgt das lehenn des hoffs ze Hägglingen, cum insercione iuramenti per villicum servandum<. Item des ersten swert er ... Anschliessend Erblehenurkunde, 1506. 58 $8^{\mathrm{r}-\mathrm{v}}$ leer. 59r-61 ${ }^{\mathrm{r}}>$ Bericht zwüschent Beyden stetten Bern und Lutzern, der gotzhuss lüten halb der stiffe ze Münster zügehorig, So in der graffschafft Lentzburg gesessen sind, etc.<. Wir nachbenempten von stetten und lendern Botten ... 1458, Die Rechtsquellen des Kantons Argau. Zweiter Teil: Rechte der Landschaft. Erster Band: Amt Arburg und Grafschafft Lenzburg, bearbeitet und hrsg. v. Walther Merz, Aarau 1923, S. 185-188, Nr. 21 (ohne Nennung dieser Abschrift). 61 ${ }^{\mathrm{v}}$ leer. 62r $-64^{\mathrm{r}}$ Güterverzeichnis und Hofrecht des Amtes Hochdorf. $64^{\mathrm{v}}-65^{\mathrm{v}}$ Grenzsetzung für die Zehnten von Münster und Junker Hans Trüllerey. 66r Privilegienbestätigung des Grossen Rats von Luzern, 1516. 66v $-67^{\mathrm{v}}$ Bestimmungen von Probst und Kapitel über die Hochwälder und Hölzer, 1518. 68 ${ }^{\mathrm{r}}$ leer. 68v $-69^{\mathrm{r}}$ Protokoll über eine Erbschaft und den Erschatz, 1510. 69v leer. 70 $-74^{\mathrm{r}}$ Protokolle und Amtseide von 1519.74v leer. 75 ${ }^{\mathrm{r}-\mathrm{v}}$ Wartnerurkunde für Johannes Lang von Winterthur, 1519. $78^{\mathrm{r}-\mathrm{v}}$ Amtseid des Amtmanns von Langnau. 79r $-80^{\mathrm{r}}$ Vergleich über die St. Afra-Pfründe, 1519. 80v Abrechnung, 1520.81 $81^{\mathrm{v}}-82^{\mathrm{r}}$ zwei Bereinigungen, 1612.82 leer. $83^{\mathrm{r}}-85^{\mathrm{r}}>$ Hienach volgt der Zend zü Pfäffiken wie man den geteilt, licht etc.<. Item des grossen Zenden ... 85 $5^{\mathrm{v}}$ leer. 86 $6^{\mathrm{r}}-89^{\mathrm{r}}$ Zeugenaussagen und Verzeichnis zu den Zehnten in Suhr, 1505. 89 $9^{\vee}$ Zwei Einträge über die Verleihung des Schaffneramtes von Aarau, 1525 und 1528. 90 ${ }^{\mathrm{r}-\mathrm{v}}$ zwei Eidformeln für Priester und Kapläne. 91 ${ }^{\mathrm{r}}$ Protokoll, 1540. $91^{\mathrm{v}}$ leer. $92^{\mathrm{r}}$ Protokoll, 1542. $92^{\mathrm{v}}$ zwei Einträge über zinspflichtige Güter in Hochdorf, 1567. 93 $\mathrm{r}-94^{\mathrm{r}}$ Ordnung Eins schaffners zu Arow, ernüweret 1571. Fol. 247.pag. 2.94v leer. 95 $5^{\mathrm{r}}-96^{\mathrm{v}}>$ Urkund Von Wegen des Zwings Pfeffikon<. Wir, nachbenanten 
poten von beiden Stetten Bern und Lucern ... - ... Usszug uss dem Rechten Original, so hinder minem g[nedigen] b[errn] zuo Lucern ligt. 97 $7^{\mathrm{r}}-120^{\mathrm{r}}>$ Secuntur locationes bonorum ecclesie Beronensis cellaris et camere sive bonorum censuum specialium <. A. Item bonum quoddam in Altwys ... Alphabetisch angelegtes Güterverzeichnis mit Einträgen von verschiedenen Händen des 15. und 16. Jhs. $120^{\mathrm{v}}$ leer. $121^{\mathrm{r}}-156^{\mathrm{v}}$ weitere ungeordnete Einträge über Güterkauf, -tausch und Handwechsel sowie Zehntpflichten, darin eingeschaltet $133^{\mathrm{v}}-134^{\mathrm{v}}$ eine Ordnung zur Rekatholisierung von Hägglingen: > Hägglingen <. Zü wüssen: Allsdann ein missverstand unnd desshalb ein abfal von Christenlicher ordnung erwachsen ... 1532. Zu 139r (Weiherhaus im Wynental) vgl. EgLOFf, Herr in Münster, S. 355f. 128v $132^{\mathrm{r}}$, 133 ${ }^{\mathrm{r}}, 136^{\mathrm{v}}, 146^{\mathrm{v}}, 147^{\mathrm{v}}, 156^{\mathrm{r}}$ und $157^{\mathrm{r}}$ leer. $157^{\mathrm{v}}-163^{\mathrm{v}}$ mehrere Einträge zum Bruderhaus auf dem Erlosen, Sempach und Hochdorf, datiert 1561-1678, darin eingeschaltet $162^{\mathrm{r}}$ ein Eintrag zu verschiedenen Masseinheiten, 1589. $162^{\mathrm{v}}$ und $164^{\mathrm{r}-\mathrm{v}}$ leer. $165^{\mathrm{r}}>$ Iuramentum D.D. praepositi Beronensis<. Ego N.N. dominus et praepositus Beronensis ... 165 $5^{\mathrm{v}}-170^{\mathrm{r}}>$ Von den nüwen Chorhöfen $<$. Zü wüssen: Allsdenn her hans Meyer sälig ... Verzeichnis über die Neuvergabung von Chorhöfen, angelegt 1537, letzter Eintrag 1571. 170 leer. 171 ${ }^{\mathrm{r}}-172^{\mathrm{r}}$ Brief des Rates von Luzern über die Gründung einer höheren Schule, 1546. 172v-176r Einträge zum Weiherhaus im Wynental, vgl. EgLoff, Herr in Münster, S. 356; darin eingeschaltet $173^{v}$ ein Beschluss über den Chorhof des Kustos, 175 Einträge zur Försterei in Rickenbach, $175^{\mathrm{v}}$ Beschluss über die Kirchenrechnung, 1591. 176 v $-178^{\mathrm{r}}$ Bereinigung des Zehnten in Ballwil. 178 $8^{\mathrm{v}}-182^{\mathrm{r}}$ leer. $182^{\mathrm{v}}-183^{\mathrm{v}}>$ Brüder huss Münster $<$. Zü wüssen, das ein yetlicher brüder ... Statuten und Einträge zu den Inhabern des Bruderhauses in Münster. $184^{\mathrm{r}}-192^{\mathrm{v}}$ Item dominus helyas canonicus Beronensis hant verkoufft diss nachgeschribnen güter ... Abrechnungen mit verschiedenen Kanonikern, Leutpriestern und anderen. 189v 191 v und $193^{\mathrm{r}-\mathrm{v}}$ leer. $194^{\mathrm{r}}-195^{\mathrm{r}}$ Schlichtungsurkunde für die Priester von Grossdietwil, 1530. 195 $\mathrm{v}-197^{\mathrm{r}}$ leer. $197^{\mathrm{v}}-200^{\mathrm{r}}$ zwei Urkunden über eine Auseinandersetzung mit Jost Kiel, 1523 und 1516. 200 leer. 201 ${ }^{\mathrm{r}-\mathrm{v}}>$ Copia statutorum a capitulo Beronensi noviter editorum <. Nos Heinricus Fer prepositus ... 1504. Anschliessend zwei Einträge über die Schenkung silberner Becher. 202v-203 ${ }^{\mathrm{r}}$ leer. $203^{\mathrm{r}}-208^{\mathrm{v}}$ Verzeichnis über Stiftungen und die Verwendung der Mittel, beginnend mit dem Ulrichs-Altar in Aarau, 1480. 206v leer. 209 $-214^{\mathrm{v}}$ Abrechnungen, datiert von 1461-1474, 209v und 212 ${ }^{\mathrm{r}-\mathrm{v}}$ leer. $215^{\mathrm{r}-\mathrm{v}}$ Statuten und Amtseid für den Kaplan von Pfäffikon. $216^{\mathrm{r}}-217^{\mathrm{v}}$ zwei Urkunden über die Stiftung des Marienaltars in Wangen durch Burkhard von Lütishofen, 1456. $218^{\mathrm{r}}-219^{\mathrm{v}}$ zwei Urkunden über Stiftung und Verleihung der Kapelle in Gormund, 1509 und 1519.219v-222r zwei Urkunden über die Stiftung einer Predigerstelle auf der Heiligkreuz-Präbende, 1527, vgl. Ignaz Vital Herzog, Die St. Peter- und Pauls-, die hl. Kreuz-Caplanei und die Predigerpfründe zu Beromünster, in: Der Geschichtsfreund 10 (1854), S. 53-57 (Nr. 14 und 15). 222v Beschluss über die Einrichtung einer neuen Ziegelhütte, 1566. 223 $3^{\mathrm{r}}$ leer. 223 ${ }^{\mathrm{v}}$ Lehensvertrag über eine ältere Ziegelhütte, 1507. 224 $4^{\mathrm{r}}-225^{\mathrm{r}}>$ Die Ordnung und satzung von des gotzhus zü Münster höltzer wegen von probst und Capittel uffgesetzt als hernach volgt<. Anno domini etc. ... 1497. 225 leer. 226 ${ }^{\mathrm{r}-\mathrm{v}}$ Güterverzeichnis für den Hünerbül, 1522. Anschliessend diverse kleinere Stücke unterschiedlichen Inhalts. $229^{\mathrm{r}}-230^{\mathrm{v}}>$ Dis ist die gerechtikeit dess meiger hofes ze pfeffikon<. Item des ersten: so man den tzwing besetzet ... Anschliessend diverse kleinere Stücke unterschiedlichen Inhalts, 235v leer. 238 ${ }^{\mathrm{r}}-240^{\mathrm{r}}$ $>$ Wyngältt<. Dass Wyngält ist jerlich drühundert sächtzig gulden ... 1602. 240v leer. 241 ${ }^{\mathrm{r}}-247^{\mathrm{r}}>$ Copia dess Contracts zwüschen herrn probst holdermeyer und dem Capitul lobwürdiger Stifft zuo Münster inn Ergöuw etc. <. Wir nachbenanter Jost pfiffer ... 1603. 247 $-250^{\mathrm{r}}>$ Ordnung und Amptspflicht eines Schaffners zuo arouwe, ernüwert Anno 1605 den 2. Augusti<. So offt ein Schaffner oder Amptsmann zuo Arouw mit tod abgaht ... $250^{\mathrm{v}}-281^{\mathrm{r}}$ leer.

281 Bleistiftnotizen, 19./ 20. Jh. 
Papier, 348 Blätter, 29-31,5 × 21,5-22 cm

Basel, drittes Viertel des 15. Jahrhunderts

Wasserzeichen, Lagen, Foliierung: Wasserzeichen: Teil 1, Bl. i-lxvi (Lagen 1-7): Traube (am Rebstock), PICCARD, Wasserzeichenkartei Nr. 129524 (1460) und 129531 (1459); Teil 1, Bl. lxvii-lxxxxii und Teil 2, Bl. i-xxxix (Lagen 8-10 und 15-19): Buchstabe P, PICCARD, Wasserzeichenkartei Nr. 112005 (1461) und 112011 (1462); Teil 1, Bl. lxxxxiii-C (Lage 11): Kreis (Reichsapfel), PICCARD, Wasserzeichenkartei Nr. 161512 (1458); Teil 1, Bl. Ci-118 (Lagen 12 und 13): Buchstabe P, PiCCARD, Wasserzeichenkartei Nr. 112943 (1462) und 112954 (1462) in zwei Varianten; Teil 1, Bl. 119-122 und Teil 3, Bl. ii-lv (Lagen 14 und 27-32): Buchstabe P, Piccard, Wasserzeichenkartei Nr. 112593 (1464/65) und 112603 (1463); Teil 2, Bl. xxxix ${ }^{\text {bis }}$ Cxiii (Lagen 20-26): Ochsenkopf, PicCard, Wasserzeichenkartei Nr. 75563 (1462) und 75681 (1462); Teil 4, Bl. A/lv: Ochsenkopf, eine Variante von PICCARD, Wasserzeichenkartei Nr. 74442 (1464), Bl. i-xlv (in Lage 33): Nr. 76888 (1465), so auch Bl. xxxvii/liiii, und 77019 (1467); Teil 4, Bl. xlvii-lii (in Lage 33): Buchstabe D, Piccard, Wasserzeichenkartei Nr. 27073 (1475), Bl. xlvi/liii eine Variante von Nr. 27079 (1479), vgl. StiAB 01.01.719.

Lagen: $6 V^{l x}+2 I^{\text {lxxii }}+2 V^{\text {lxxxxii }}+\mathrm{IV}^{\mathrm{C}}+\mathrm{V}^{\mathrm{Cx}}+\mathrm{IV}^{118}+\mathrm{II}^{122}+\mathrm{V}^{\mathrm{x}}+\mathrm{IV}^{\mathrm{xvii}}+\mathrm{I}^{\mathrm{xx}}+2 \mathrm{~V}^{\mathrm{xxxix}}+5 \mathrm{VI}^{\mathrm{lxxxxix}}+$ $\mathrm{V}^{\mathrm{Cix}}+\mathrm{II}^{\mathrm{Cxiii}}+(\mathrm{IV}+2)^{\mathrm{ix}}+\mathrm{II}^{\mathrm{xiii}}+\mathrm{V}^{\mathrm{xxiii}}+\mathrm{VII} \mathrm{Ixxvii}^{\mathrm{V}} \mathrm{V}^{\mathrm{xlvii}}+\mathrm{IV}^{\mathrm{lv}}+(\mathrm{I}+3 \mathrm{VI}+[\mathrm{I}+2 \mathrm{IV}])^{\mathrm{lv}}, \mathrm{Bl}$. A und Bl. i in Teil 3 Einzelblätter; die Blätter A und lv sowie xxxvii und liiii in Teil 4 sind Doppelblätter, ersteres ist um den ganzen Teil 4 geführt, letzteres um dessen letzte zwei (Binnen-)Lagen. In Teil 3 auf xxxvii und xlvii Reklamanten. Alte Foliierung in vier Teilen, ergänzt: i-Cxiii. 114-121. [122]. i-xxxii. xxxii[bis]-xxxix.

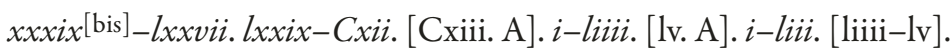

Einrichtung und Ausstattung: Vertikale Begrenzung des Schriftraums durch Falzung, 22-25,5 × 11-12, 23-31 Zeilen. Jüngere gotische Buchkursive mit Schleifen von zehn Händen. Hand 1: Teil 1, $\mathrm{i}^{\mathrm{r}}-\mathrm{v}^{\mathrm{v}}, \mathrm{xxix}^{\mathrm{r}}-$

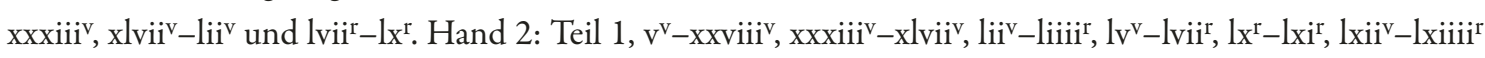
und lxviiv-lxx ${ }^{\mathrm{r}}$; Teil 3, liv-liiii ${ }^{\mathrm{v}}$; Teil 4, $\mathrm{xlv}^{\mathrm{v}}-\mathrm{xlvii}^{\mathrm{v}}$ und $\mathrm{xlix}^{\mathrm{r}}-\operatorname{liii}^{\mathrm{v}}$. Hand 3: Teil 1, liiii ${ }^{\mathrm{v}}-\mathrm{lv}^{\mathrm{v}}$, $\operatorname{lxi}^{\mathrm{r}}$, $\operatorname{lxx}^{\mathrm{r}}-\operatorname{lxxxix}^{\mathrm{r}}$ und möglicherweise Civ $\mathrm{C}^{\mathrm{v}}-\mathrm{Cxii}^{\mathrm{v}}$; Teil 2, $\mathrm{xx}^{\mathrm{v}}-\mathrm{xxxvi}^{\mathrm{r}}$; Teil 3, $\mathrm{l}^{\mathrm{r}}-\mathrm{li}^{\mathrm{r}}$; Teil 4, $\mathrm{i}^{\mathrm{r}}-\mathrm{v}^{\mathrm{r}}, \mathrm{vi}^{\mathrm{v}}-\mathrm{viii}^{\mathrm{r}}, \mathrm{ix}^{\mathrm{r}}-\mathrm{x}^{\mathrm{r}}, \mathrm{x}^{\mathrm{v}}-\mathrm{xiiii}^{\mathrm{r}}, \mathrm{xxi}^{\mathrm{v}}-\mathrm{xxv}^{\mathrm{v}}$, $x_{x x}{ }^{r}-x_{x x i i i}{ }^{r}$ und $x_{x x v^{v}-x l i v}$. Hand 4: Teil 1, lxir ${ }^{r}-x_{i i}{ }^{r}$; Teil 2, $i^{r}-x^{v}$ und $x_{x x i x}{ }^{r}-C x i i^{r}$. Hand 5: Teil 1, lxiiiiv lxviiv. Hand 6: Teil 1, lxxxix ${ }^{\mathrm{r}}-\mathrm{lxxxxix}^{\mathrm{r}}$. Hand 7: Teil 1, lxxxxix ${ }^{\mathrm{r}}-\mathrm{Ci}^{\mathrm{r}}$; Teil 2, $\operatorname{xxxvi}^{\mathrm{r}}-\mathrm{xxxviii}^{\mathrm{r}}$; Teil 3, $\mathrm{i}^{\mathrm{r}}-\mathrm{xx}^{\mathrm{r}} \mathrm{und}^{\mathrm{r}}$ xxiiir $^{\mathrm{r}}-\mathrm{xlix}^{\mathrm{v}}$. Hand 8: Teil 1, Cxii ${ }^{\mathrm{v}}-121^{\mathrm{v}}$. Hand 9: Teil 2, xxxix ${ }^{\mathrm{r}}$. Hand 10: Teil 3, $\mathrm{xx}^{\mathrm{r}}-\mathrm{xxii}^{\mathrm{v}}$ und lir-v; Teil 4, $\mathrm{v}^{\mathrm{r}}-\mathrm{vi}^{\mathrm{v}}$, viii $^{\mathrm{r}}-\mathrm{ix}^{\mathrm{r}}, \mathrm{x}^{\mathrm{r}-\mathrm{v}}, \mathrm{xiii}^{\mathrm{v}}-\mathrm{xxi}^{\mathrm{v}}, \mathrm{xxv}^{\mathrm{v}}-\mathrm{xxx}^{\mathrm{r}}, \mathrm{xxxiii}^{\mathrm{v}}-\mathrm{xxxv}^{\mathrm{v}}, \mathrm{xli}^{\mathrm{v}}-\mathrm{xlv}^{\mathrm{v}}$ und $\mathrm{xlviii}^{\mathrm{r}-\mathrm{v}}$. Siehe $\mathrm{zu}$ den Schreibern unten (Herkunft). Kadellenartig verzierte Initialen. In Teil 2 Kopftitel. Marginalien, in Teil 1 und Teil 4 wohl von Hand 7, in Teil 3 von Hand 2 ( $x_{x x v}{ }^{r}$ jedoch Hand 7$)$, sowie Absatzgliederung. Teil 2, lxxv ${ }^{v}$ Profilskizze.

Korrekturen und Nachträge: Korrekturen von der Hand der Schreiber, z. B. Teil 1, iv, vv , lxiiiiv etc.; in Teil 2, $\mathrm{Cv}^{\mathrm{r}}$, zudem zahlreiche Korrekturen und Marginalien von der Hand, die auch die Kopftitel beisteuerte, z. B. xlviir ${ }^{\mathrm{r}}$, wohl Hand 5, oder auch von Hand 9, z. B. lxxxxix ${ }^{\mathrm{r}}$. Teil 1, iv ${ }^{\mathrm{v}}$ ein (zweiteiliger) Nachtrag vielleicht von der Hand des Jo. Salzmann (Hand 3), von Jo. Friderich (doppelt) unterschrieben, vgl. StiAB 01.01.719 4v Vereinzelt Marginalien zum Inhalt von einer Hand des 16./17. Jhs., z. B. Teil 1, xiiiir; von der gleichen Hand auch eine Einlage in Teil 3 zw. Bl. xliiii und xlv, ein beschriebenes Blatt (Oktav) in einem gefalteten leeren Quartblatt: Regesten zu einzelnen Stellen sowie Angaben zu beteiligten Personen, auf Deutsch und Latein; 
in Teil 1, xlvii ${ }^{\mathrm{v}}$ auch eine Marginalie auf Deutsch: Dise artickel all werffen die von honrein denen von münster dar. Ss. 31 (i. e. i-xxxi, xlvii ${ }^{-}-$lii $^{v}$ ). Zuerst $x$ iir $^{\mathrm{r}}-\mathrm{xviiiv}$ und dann öfter in beiden Bänden Marginalien zum Inhalt von einer Hand wohl des 18. Jhs., z. B. xviii ${ }^{\mathrm{r}}$ : Joannes Hort Commendator in Hohenrein pretendit certas terras et vineas ad Suam domum sitas et Iure proprietatis ad eandem domum spectantes a Decimarum solutione exemptas esse und xviii ${ }^{v}$ Accusantur DD. Canonici Beron. quod nibilominus easdem Decimas invadant et diripiant. In Teil 1, xxxii ${ }^{r}$ ein frühneuzeitliches Notazeichen. Vereinzelt Inhaltsangaben in der oberen oder unteren (geknickten) Ecke, wohl von der gleichen Hand, die den Band (Teil 1 bis Ci) foliierte: Teil 1, xvii ${ }^{\mathrm{v}}$ Libellus actorum (unten), $\mathrm{xxv}^{\mathrm{v}}$ Excepciones partis reorum contra libellum (oben), $\mathrm{xxxix}^{\mathrm{v}}$ Libellus reconvencionis reorum (oben), xlvii ${ }^{\mathrm{v}}$ Articuli actoris (unten), liiii Excepciones partis ree in causa convencionis contra articulos

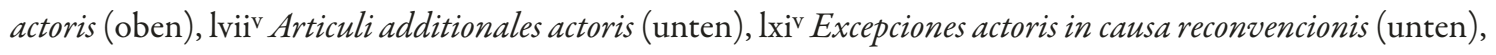
Ixxvii ${ }^{v}$ Excepciones contra testes et articuli pro parte reorum in causa convencionali (oben) und $\mathrm{xxxv}^{\mathrm{v}}$ Articuli additionales in causa reconvencionis (oben); Teil 2, $1^{\mathrm{v}}$ Testes pro parte actoris domini Hort (unten), $\mathrm{xxxix}^{\mathrm{v}}$ Testes pro parte dominorum Beronensium in causa convencionis et eciam reconvencionis (oben) und $\mathrm{xxv}^{\mathrm{v}}$ Remissio dominorum reorum (oben); Teil 3, ix ${ }^{\mathrm{v}}$ Appellacio dominorum Beronensium (oben) und $\mathrm{xxv}^{\mathrm{v}}$ Libellus dominorum Beronensium in $2^{a}$ instancia (oben). Die Hauptbeschriftung des Einbands und die Titelblätter von Teil 3 und 4 stammen von einer Hand noch des 15. Jhs.

Einband: Pergamentumschlag: Urkunde, Basel, 4. Juni 1443, Text vollständig (Innenseite): Johannes Wirtz, Leutpriester (incuratus) in Hagenbach, vertreten durch Leonhard Tetikofer, klagt (erneut) vor dem Basler Offizial gegen Heintzin Ruhe aus Wattwiller, vertreten durch Jacob Vogel, der ihm den alleinigen Nutzen seines Gartens streitig macht. Heftung am Kopf und am Schwanz auf zwei doppelte Pergamentstreifen; in den einzelnen Teilen zudem weitere Pergamentfragmente zur Verstärkung, 15. Jh. Ein Teil der Lagen an den Heftstellen im Falz mit schmalen Pergamentstreifen verstärkt. Die Lagen sind unten gegen den Bund hin einmal durchstochen und durch das Loch (nur noch teilweise) mit einer (gerissenen) ehemals roten Schnur verbunden und verknüpft. Auf der Vorderseite des Umschlags von versch. Händen: Coram venerabili viro domino decano ecclesie Basiliensis. Registrum Inter Religiosum fratrem dominum Iohannem hort, Conmendatorem domus ordinis sancti Iohannis In hohenrein Actorem ex una, Et ven. viros dominos prepositum, et capitulum ecclesie Collegiate sancti Michahelis Beronensis Reos, de et super reconventione decimarum ecclesie In Wangen etc. ex alia partibus habitum, et factum. Friderich notarius, sowie $N^{o} I$ (vgl. StiAB 01.01.719), Registrum sive Regestum in den Acta, sowie (teilweise kaum noch lesbar) folia quadringenta et octuaginta octo in causis convencionis et congure porcionis. In causa vero reconvencionis quinquaginta folia. Zuletzt: Registrum dominorum Reorum, darunter ein Papierschild, 18. Jh.: Acten des baselschen bischöfl. Decans im Streite zwischen Stift Münster und Ritterhaus Hohenrain, sowie eine alte Signatur: $N^{\circ} 30$ and $b$. Auf dem Rücken: Acta et Instrumenta coram Decan. Basiliens. sowie No 30 a.

Herkunft: Die Akten des Prozesses um Zehntrechte zwischen dem Stift Beromünster und der Johanniterkommende Hohenrain bilden eine Einheit mit dem Band StiAB 01.01.719, den Akten eines parallel geführten anderen Rechtsstreits; es handelt sich um Kopien der Basler Behörde (Dekanat) zuhanden der Gewinner, dem Michaelsstift. Johannes Friderich von Münnerstadt, domini decani scriba et notarius (Teil 4, $\mathrm{xxi}^{\mathrm{r}}$, vgl. Teil 1, $\mathrm{i}^{\mathrm{r}}$ etc. und xiiiir ${ }^{\mathrm{r}}$ ), war wohl der Schreiber 2, seine Subscriptiones in Teil 1, iiii $^{\mathrm{v}}$, xiiiir $^{\mathrm{r}} \mathrm{xvi}^{\mathrm{v}}-\mathrm{xvii}^{\mathrm{r}}$, $\mathrm{x}^{\mathrm{r}}$ und $121^{\mathrm{v}}$, vgl. auch die Nachträge in StiAB 01.01.719, wo allerdings auch eine nicht übereinstimmende Subscriptio vorkommt (Hand 3), wie auch hier in Teil 1, lxxxxvir (Hand 7); zu ihm Peter-Johannes Schuler, Notare Südwestdeutschlands, Stuttgart 1987, Nr. 364. Hand 1 wäre der Subcriptio vv nach Heinricus Ruwe, 
entsprechend auch StiAB 01.01.719, Teil 1, 6r. Hand 3 gehört wohl Johannes Salzmann, vgl. die Subscriptiones Teil 1, lxxiiiir ${ }^{r}$ Teil 3, liiii ${ }^{v}$ und Teil 4, liii ${ }^{v}$ bzw. StiAB 01.01.719 (dort Hand 3), Schuler, Nr. 1117. In Teil 2, Cxiir ${ }^{r}$ Subscriptio des Johannes Ytelclaus von Münnerstadt, wohl Hand 9 (vgl. jedoch Subscr. in Teil 1, lxvi ${ }^{\mathrm{r}-\mathrm{v}}$ = Hand 5), Schuler, Nr. 619. Acht der (mindestens) zehn Schreiber (bis auf die Hände 5 und 10) finden sich auch im anderen Band, zudem noch ein weiterer. Zu Friderich und Salzmann siehe auch Rudolf Wackernagel, Geschichte der Stadt Basel, Bd. 2.2, Basel 1916, S. 542 und Schuler, Registerband S. 252 (Stammtafel 14).

\section{Besitzer: -}

Literatur: Melchior Estermann, Geschichte der alten Pfarrei Hochdorf des Johanniter-Ordenshauses Honrein wie der Tochterpfarreien: Honrein, Wangen, Ballwil und Rein und der Filialkapellen innerhalb der alten Pfarreigrenzen und Geschichtliche Mittheilungen über die alten bürgerl. Verhältnisse, Luzern 1891, S. 172-180; BüCHLER, Beromünster, S. XV (Erwähnung).

Teil 1:

$\mathrm{i}^{\mathrm{r}}-121^{\mathrm{v}}$ Acta causae inter domum S. Johannis in Hohenrein et capitulum S. Michaelis Beronensis. Akten des Basler Offizials in dem von Johannes Hort, Komtur der Johanniterkommende Hohenrain, angestrengten Verfahren gegen das Stift Beromünster um bestimmte Zehntansprüche und Privilegien. 26. 1. 1459 - 26. 9. 1464. In nomine domini amen. Nos Laurentius Kron in decretis licenciatus, curie episcopalis Basiliensis officialis iudex in hac parte a venerabili et circumspecto viro domino Iohanne Wernhero de Flachslanden decano ecclesie Basiliensis et iudice ac conservatore iurium et privilegiorum venerabilium et religiosorum in Christo dominorum prioris generalis ac conmendatorum preceptorum fratrumque et domorum ordinis sancti Iohannis Iherusolimitani ... notum facimus ... v $\mathrm{v}^{\mathrm{v}}$ Et ego Heinricus Ruwe clericus Maguntinensis diocesis publicus apostolica et imperiali auctoritatibus notarius ... presens interfui etc. Ideo presens publicum documentum manu mea propria scriptum et subscriptum confeci et publicavi in fidem et testimonium omnium et singulorum premissorum. Mutantur annus ... Anno domini millesimoquadringentesimosexagesimo ... die vero Mercurii proxima post festum sancti Hilarii episcopi ... vi ${ }^{\mathrm{r}}$ Comparuerunt coram nobis officiali et iudice antedicto in iudicio predicto religiosus in Christo frater dominus Iohannes Hort ... personaliter unacum provido Wilhelmo Spüll curie nostre Basiliensis causarum iurato et suo asserto procuratore ex una, et honorabilis vir dominus Helias canonicus ecclesie Beronensis supradicte, et supradictorum dominorum prepositi, et capituli eiusdem ecclesie procurator constitutus ut dixit, similiter personaliter unacum perito viro magistro Iohanni Mittelbusen, in decretis licenciato curie archidyaconi Basiliensis officiali et suo ut dixit procuratore ex alia partibus ... xiiiir Et ego Iohannes Friderich de Münderstat clericus Herbipolensis dyocesis publicus imperiali auctoritate et venerabilis curie episcopalis Basiliensis collateralis notarius iuratus et prespecificate cause scriba deputatus ... presens interfui ... xviii ${ }^{\mathrm{r}}$ Iohannes Hort ... privilegiis gaudere volens et desiderans, certas terras, possessiones et vineas, prope dictam suam domum sitas, et iure proprietatis ad eandem domum spectantes, de anno domini Millesimo quadringentesimo quinquagesimo nono, quasdam suis sumptibus et expensis coluerit ... - ... 120 ${ }^{\mathrm{r}}$ Tenor itaque sentencie diffinitive ... sequitur et est talis ... 120 pronunciamus decernimus et declaramus, decimas et ius percipiendi colligendi levandi et exigendi easdem, provenientes de bonis ad curiam dictam Meygerhoff in actis cause specificatam pertinentibus, necnon decimas et ius percipiendi levandi et exigendi easdem, provenientes de viginti diurnalibus pratorum ad curiam Sennhoff spectancium et aput acta presentis cause similiter descriptis, ad prefatos dominos propositum et capitulum ecclesie collegiate sancti Michaelis predicte spectasse et pertinuisse, spectare et pertinere de iure ... $121^{\mathrm{r}}$ Teno $[\mathrm{r}]$ itaque 
cedule papiree sentencie diffinitive in causa reconvencionis ... Pari nostra sentencia prononciamus decernimus et declaramus molestaciones vexaciones perturbaciones et impeticiones per dominos prepositum et capitulum pretactos prefato domino commendatori in causis reconvencionis factas et prestitas, fuisse et esse temerarias indebitas et iniustas, atque defacto presumptas ... ad premissa vocatis pariter et rogatis. Anschliessend, wohl wieder von eigener Hand: Iohannes Friderich de Münderstat notarius hic subscripsit.

$122^{\mathrm{r}-\mathrm{v}}$ leer.

Teil 2:

$\mathrm{i}^{\mathrm{r}}-\mathrm{Cxii}{ }^{\mathrm{r}}$ Depositiones testium. Dicta et attestaciones testium in causa coram nobis Caspare de Reno custode et thesaurario ecclesie Basiliensis et iudice ... Deposicio primi testis: Iohannes Holtzach de villa Wangen ... Sechs Zeugenaussagen zugunsten der Kläger (Hohenrain). xxxviii ${ }^{-x x x i x}{ }^{v}$ leer. xxxix ${ }^{[b i s] r}$ Sequntur dicta et attestaciones testium ... Deposicio primi testis: Rudinus Fugli de superiori Ebersol ... Vier Zeugenaussagen zugunsten der Angeklagten (Beromünster). 1xxiiii leer. $\mathrm{xxv}^{\mathrm{r}}$ Venerabili et circumspecto viro domino Caspari ze Rin custodi ecclesie Basiliensis iudici ... lxxviv Deposicio primi testis: Henslinus Hug de villa Hochdorff debilis sui corporis, et ad ambulandum non dispositus sed compos racionis ... lxxxxiiii ${ }^{\mathrm{r}}$ Deposicio tercii testis: Dominus Iohannes Teller plebanus in Hochdorff satis annosus ... - ... conscripta anno domini et die quibus supra. Sechs weitere Zeugenaussagen zugunsten der Angeklagten. Anschliessend, wohl von eigener Hand: Johannes Ytelclaus de Munderstatt notarius curie Basiliensis hec audi. In StiAB 01.01.719 dieselben Zeugenreihen; die hier letzte dort jedoch noch um zwei erweitert.

Cxiiv-Cxiiiv leer.

Teil 3:

$\mathrm{A}^{\mathrm{r}}$-liiiiv Acta causae appellationis. Akten des vom Komtur der Johanniterkommende Hohenrain angestrengten Appellationverfahrens. Titelblatt: Custos ecclesie Sancti Petri Basiliensis iudex surrogatus. Daneben: Duplicatum. Darunter: Registrum in causa appellacionis conventionis decimarum inter honorabilem et religiosum in Christo fratrem Iohannem Hort conmendatorem domus ordinis sancti Iohannis in Hohenrein actorem et convenientem ex una, et venerabilem et honorabiles viros dominos prepositum et capitulum ecclesie Sancti Michaelis Beronensis de et super certis decimis etc. et reos et conventos ex alia partibus. Johannes Friderich notarius. Darunter: Registrum dominorum Beronensis ecclesie. $\mathrm{A}^{\mathrm{v}}$ Federproben, sonst leer. $\mathrm{i}^{\mathrm{r}}$ Akten, 31. 10. 1463 - 13. 9. 1465. Registrum in causa ... In nomine domini amen. Nos Iohannes Wernherus de Flachslanden ... - ... liii ${ }^{\mathrm{v}}$ Tenor itaque sentencie diffinitive sequitur et est talis: Christi nomine invocato pro tribunali ... pronuciamus decernimus et declaramus per venerabilem virum dominum Laurencium Kron officialem curie Basiliensis iudicem subdelegatum in causa que coram eo, inter religiosum fratrem Iohannem Hort, conmendatorem domus in Hohenrein ordinis sancti Iohannis Ierusolimitani, ex una, et venerabilem et honorabiles viros dominos prepositum et capitulum ecclesie collegiate sancti Michaelis Beronensis Constanciensis dyocesis reos, de et super certis decimis seu privilegio, de decimis non solvendis et eorum occasione ex altera in prima vertebatur instancia in ea parte, qua ipsos dominos prepositum et capitulum reos ab impeticione domini Iohannis Hort, actoris per suam sentenciam absolvit, ius decimandi ipsis adiudicando prout ex tenore ipsius sentencie diffinitur, clare continetur, bene fuisse et esse processum sentenciatum et diffinitum, et pro parte ipsius domini Iohannis Hort, actoris male et perperam ab ipso domino officiali et eius sentencia provocatum et appellatum ipsamque sentenciam in ea parte confirmandam fore et confirmamus. In ea vero parte, qua prefatos dominos prepositum et capitulum ecclesie Beronensis ad solvendum 
decimas de dictis duobus iugeribus in actis cause specificatis, condempnavit, nulliter et defective seu saltim male inique et iniuste sentenciasse atque diffinisse, dictamque pretensam sentenciam in ea parte revocandam fore et revocamus ... Wohl von eigener Hand: Nomine Iohannis Friderich notarii Iohannes Salzman notarius hic subscripsi.

$\mathrm{lv}^{\mathrm{r}-\mathrm{v}}$ leer.

Teil 4:

$\mathrm{A}^{\mathrm{r}}$-liii ${ }^{\mathrm{v}}$ Acta causae appellationis. Akten des vom Kapitel Beromünster angestrengten Appellationverfahrens. Titelblatt: Custos ecclesie Sancti Petri Basiliensis iudex subdelegatus etc. Registrum in causa appellacionis reconvencionis decimarum inter venerabilem et honorabiles viros dominos prepositum et capitulum ecclesie Sancti Michaelis Beronensis appellantes et reconvenientes ex una et honorabilem ac religiosum in Christo fratrem dominum Iohannem Hort conmendatorem domus sancti Iohannis in Hohenrein Constanciensis diocesis appellatum et reconventum ex alia partibus. Johannes Friderich notarius. Daneben: Duplicatum, sowie Registrum dominorum appellantium. $\mathrm{A}^{\mathrm{v}}$ leer. $\mathrm{i}^{\mathrm{r}}$ Akten, 31. 10. 1463 - 13. 9. 1465. Registrum in causa ... In nomine domini amen. Nos Iohannes Wernherus de Flachsslanden ... - ... liiv Tenor itaque sentencie diffinitive unde supra fit mencio sequitur et est talis: Quia ex novis coram nobis, et in secunda instancia productis iuribus et munimentis ... pronunciamus decernimus et declaramus per venerabilem virum dominum officialem curie Basiliensis male iniuste et defective sentenciatum atque diffinitum, eandemque suam sentenciam revocandum et cassandum fore ac cassamus et revocamus, ab eademque sentenciam proparte prefatorum dominorum prepositi et capituli ecclesie Beronensis bene fuisse et esse provocatum et appellatum, necnon spoliacionem denegacionem recusacionem et condicionem per dictum fratrem Iohannem Hort, factas fuisse et esse temerarias illicitas indebitas et iniustas, sibique minime licuisse neque licere ... Wiederum wohl von eigener Hand: Nomine Iohannis Friderich notarii Iohannes Salzman notarius hic subscripsi.

liiiv $-\mathrm{lv}^{\mathrm{v}}$ leer.

\section{StiAB 01.01.719 ACTA DECANI BASILIENSIS}

Papier, 194 Blätter, 30-30,5 × 22-23 cm

Basel, drittes Viertel des 15. Jahrhunderts

Wasserzeichen, Lagen, Foliierung: Wasserzeichen: Teil 1, Bl. 1-38 (Lagen 1-4), 42/45 (in Lage 5), sowie Teil 2, Bl. 1-16 (Lagen 10 und 11): Buchstabe P, PicCARD, Wasserzeichenkartei Nr. 112005 (1461) und 112011 (1462); Teil 1, Bl. 39-58 (Lagen 5 und 6): Kreis (Kugel), PiCCARD, Wasserzeichenkartei Nr. 161512 (1458); Teil 1, Bl. 59-76 (Lagen 7-9): Buchstabe P, PicCARD, Wasserzeichenkartei Nr. 112954 (1462); Teil 2, Bl. 17-53 (Lagen 12-14): Ochsenkopf, PicCARD, Wasserzeichenkartei Nr. 75563 (1462) und 75681 (1462); Teil 3, Bl. A, i-xliiii (Lagen 15-18): Ochsenkopf, entfernt ähnlich PICCARD, Wasserzeichenkartei Nr. 76533 , in zwei Varianten; Bl. xlv-xlviii, li-liiii (Lage 19): Sonne, PICCARD, Wasserzeichenkartei Nr. 41140 (1459); Bl. xlix/l (in Lage 19), lv und lviii-lxi (Lage 20): Karren, PiCCARD, Wasserzeichenkartei Nr. 122792 (1459); B1. lxii und lxiv (in Lage 20): Buchstabe D, eine Variante von PICCARD, Wasserzeichenkartei Nr. 27079 (1479), vgl. StiAB 01.01.718. 
Lagen: $3 \mathrm{~V}^{30}+\mathrm{IV}^{38}+2 \mathrm{~V}^{58}+2 \mathrm{IV}^{74}+\mathrm{I}^{76}+2 \mathrm{IV}^{16}+2 \mathrm{VI}^{40}+(\mathrm{VII}-1)^{53}+(\mathrm{VI}-1)^{\mathrm{x}}+\mathrm{V}^{\mathrm{xx}}+2 \mathrm{VI}^{\mathrm{xliiii}}+\mathrm{V}^{\text {liiii }}+$ $(\mathrm{II}+\mathrm{I}+4)^{\text {lxiiii }}$, vor Bl. 41 (Teil 2) und nach Bl. $\mathrm{x}$ (Teil 3) je ein Blatt herausgerissen; Bl. lxiii und lxiiii ein mit den Einzelblättern lv, lvi und lvii zusammengeklebtes Doppelblatt, Bl. lxii ein weiteres, an Bl. lxi geklebtes Einzelblatt. $1^{\mathrm{r}}$ verschmutzt. Alte Foliierung in drei Teilen, ergänzt: $1-75$. [76]. 1-53. [A]. i-lx. [lxi-lxiiii].

Einrichtung und Ausstattung: Vertikale Begrenzung des Schriftraums durch Falzung, 21,5-25 × 11-12, 22-29 Zeilen. Jüngere gotische Buchkursive mit Schleifen von neun Händen. Hand 1: Teil 1, $1^{\mathrm{r}}-10^{\mathrm{v}}, 18^{\mathrm{v}}-28^{\mathrm{v}}$ und $31^{\mathrm{r}}-35^{\mathrm{r}}$. Hand 2: Teil 1, $11^{\mathrm{r}}-18^{\mathrm{v}}, 45^{\mathrm{v}}-53^{\mathrm{v}}$ und 59v-62r ; Teil 2, $1^{\mathrm{v}}-5^{\mathrm{v}}$ und $7^{\mathrm{r}-\mathrm{v}}$; Teil 3, 1xii ${ }^{\mathrm{r}}-\mathrm{lxiiii}^{\mathrm{v}}$. Hand 3: Teil 1, 29 $-30^{\mathrm{v}}, 53^{\mathrm{v}}-56^{\mathrm{v}}, 58^{\mathrm{r}-\mathrm{v}}, 62^{\mathrm{r}}-65^{\mathrm{r}}$ und 66 $-75^{\mathrm{r}}$; Teil 2, 9 $9^{\mathrm{v}}-10^{\mathrm{v}}$ und $11^{\mathrm{v}}-12^{\mathrm{r}}$; Teil 3, xviii ${ }^{\mathrm{v}}-\mathrm{xxii}^{\mathrm{r}}$, xxvi ${ }^{\mathrm{r}}-$

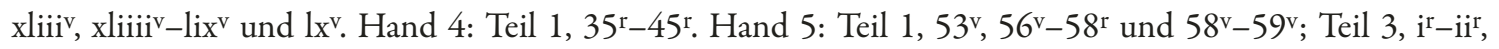

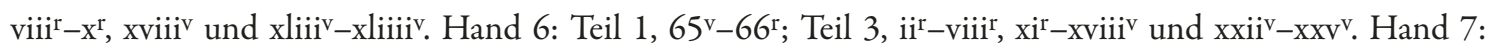
Teil 2, $1^{\mathrm{r}}, 6^{\mathrm{r}-\mathrm{v}}, 7^{\mathrm{v}}-9^{\mathrm{r}}, 11^{\mathrm{r}}$ und $12^{\mathrm{r}-\mathrm{v}}$; Teil 3, lxire ${ }^{\mathrm{r}-\mathrm{v}}$. Hand 8: Teil 2, 17r $-53^{\mathrm{v}}$. Hand 9: Teil 3, lix ${ }^{\mathrm{v}}-1 \mathrm{x}^{\mathrm{r}}$ und $1 \mathrm{x}^{\mathrm{v}}-1 \mathrm{xi}^{\mathrm{r}}$. Siehe zu den Schreibern unten (Herkunft). Kadellenartig verzierte Initialen. Marginalien, in Teil 1 wohl von Hand 3, in Teil 3 von Hand 7.

Korrekturen und Nachträge: Korrekturen von der Hand der Schreiber, z. B. Teil 1, 4v $, 13^{\mathrm{r}}, 29^{\mathrm{r}}, 40^{\mathrm{v}}$ und 57v; Teil 2, 2v $8^{\mathrm{r}}$ und 18 ${ }^{\mathrm{r}}$; Teil 3, $\mathrm{i}^{\mathrm{v}}$ und $\mathrm{xxxv}^{\mathrm{r}}$. Nachträge von der Hand des Johannes Friderich von Münnerstadt z. B. Teil 1, 4v (gleiche Korrektur auch in StiAB 01.01.718, iv ${ }^{\mathrm{v}}$ ) und vielleicht Teil 2, 26 ${ }^{\mathrm{r}}$; seine Subscriptiones in Teil 1,75 ${ }^{\mathrm{r}}$ und Teil 3, $\mathrm{x}^{\mathrm{r}}$; in Teil 1, 53 ${ }^{\mathrm{r}}$ jedoch von der Hand des Schreibers 2. Teil 1, 37v und Teil 3, lxiiii ${ }^{\mathrm{v}}$ Subscriptiones von Johannes Salzmann. Vereinzelt Inhaltsangaben diagonal in der oberen oder unteren Ecke, vgl. auch StiAB 01.01.718: Teil 1, 11 ${ }^{\mathrm{v}}$ Libellus articulatus actoris (oben), 41 ${ }^{\mathrm{r}}$ Articuli partis ree (unten), 60v Littera testimonialis pro parte reorum producta (obern) und Littera testimonialis reorum (unten); Teil 2, $1^{\mathrm{v}}$ Dicta testium pro parte actoris (oben), 17v Deposiciones testium pro parte Beronensium reorum productorum (unten) und 41 $1^{\mathrm{v}}$ Item deposiciones testium pro parte dominorum reorum (unten).

Einband: Ohne Einband, Fadenheftung am Kopf und am Schwanz, meist mit rotem Zwirn, auf zwei je einmal (vertikal) gefaltete Pergamentstreifen; darunter Reste möglicherweise eines Papierumschlags. Die Lagen sind unten gegen den Bund hin einmal durchstochen, im Gegensatz zu StiAB 01.01.718 finden sich jedoch keine Schnüre. Bl. i von Teil 1 und Bl. A von Teil 3 auf der Rectoseite verschmutzt und nachgedunkelt. Teil 3 zudem separat auf zwei Pergamentstreifen geheftet. Ein Teil der Lagen an den Heftstellen im Falz mit schmalen Pergamentstreifen verstärkt, vor allem in Teil 3. Auf $1^{\mathrm{r}}$ in violetter Tinte: $N^{o} I I$ (vgl. StiAB 01.01.718).

Herkunft: Die Akten des Prozesses um den Zehnten in Kleinwangen zwischen dem Stift Beromünster und der Johanniterkommende Hohenrain bilden eine Einheit mit dem Band StiAB 01.01.718, es handelt sich um Kopien der Basler Behörde (Dekanat) zuhanden der siegreichen Partei, dem Michaelsstift. Hand 1 gehört vielleicht Heinricus Ruwe (Subscriptio in Teil 1, 6r und StiAB 01.01.718, Teil 1, vv). Johannes Friderich von Münnerstadt, Notarius et Scriba huius cause (vgl. Teil 1, 24r ), gehört wohl die Hand 7, vgl. StiAB 01.01.718, zu ihm Peter-Johannes Schuler, Notare Südwestdeutschlands, Stuttgart 1987, Nr. 364. Hand 3 gehört wohl Johannes Salzmann (Schuler, Nr. 1117), Hand 5 dem Johannes Ytelclaus von Münnerstadt (SchUler, Nr. 619), vgl. StiAB 01.01.718, wo sich (bis auf Hand 6) die gleichen Hände in folgender Entsprechung finden: $1=1,2=7,3=3,4=6,5=9,7=2,8=4$ und 9=8. Zu Friderich und Salzmann siehe auch Rudolf WACKERNAGEL, Geschichte der Stadt Basel, Bd. 2.2, Basel 1916, S. 542 und Schuler, Registerband, S. 252 (Stammtafel 14).

Besitzer: -

Literatur: Riedweg, Beromünster, S. VII, 283f.; Melchior Estermann, Geschichte der alten Pfarrei Hochdorf des Johanniter-Ordenshauses Honrein wie der Tochterpfarreien: Honrein, Wangen, Ballwil und 
Rein und der Filialkapellen innerhalb der alten Pfarreigrenzen und Geschichtliche Mittheilungen über die alten bürgerl. Verhältnisse, Luzern 1891, S. 172-180; BüCHLER, Beromünster, S. XV (Erwähnung), S. 388 (Anm. 15 zu Joh. Teller).

Teil 1:

$1^{\mathrm{r}}-75^{\mathrm{r}}$ Acta cause inter domum S. Johannis in Hohenrein et capitulum S. Michaelis Beronensis de decimis ecclesiae in Wangen. 26. 1. 1459 - 16. 2. 1463. In nomine domini amen. Nos Laurentius Kron in decretis licenciatus, curie episcopalis officialis iudex in hac parte a venerabili et circumspecto viro domino Iohanne Wernhero de Flachslanden decano ecclesie Basiliensis et iudice ac conservator[e] iurium et privilegiorum venerabilium et religiosorum in Christo dominorum prioris generalis ac conmendatoris preceptorum fratrumque et domorum ordinis sancti Iohannis Iherusolomitani ... notum facimus ... $2^{\mathrm{r}}$ Tenores vero litterarum apostolicarum necnon subdelegatorum de quibus supra fit mencio sequuntur et sunt tales: Martinus episcopus servus servorum dei ... $6^{\mathrm{r}}$ Et ego Heinricus Ruwe clericus Maguntinensis dyocesis publicus apostolica et imperiali auctoritatibus notarius ... presens interfui etc. Ideo presens publicum documentum manu mea propria scriptum et subscriptum confeci et publicavi in fidem et testimonium omnium et singulorum premissorum. Mutatur annus ... Anno domini millesimo quadringentesimo 6v sexagesimo ... die vero Mercurii vicesima septima mensis Augusti ... Citatis coram nobis ... Querelis suis coram nobis super congrua porcione sibi domino conmendatori in Hohenrein pro inofficiatura ecclesie in Wangen et de fructibus eiusdem ecclesie ... $7^{\mathrm{r}}$ Comparuerunt coram nobis Laurencio Kron officiali et iudice subledegato antedicto dictis die hore et loco et in iudicio periti et providi viri magister Iohannes Mittelhusen in decretis licenciatus et procurator assertus antedictorum dominorum prepositi et cappituli ecclesie Beronensis citatorum ex una, et Wilhelmus Spüll procurator ut dixit religiosi fratris Iohannis Hort conmendatoris dicte domus in Hohenrein et pro eodem ex alia partibus ... - ... ad premissa vocatis pariter et rogatis. Johannes Friderich de Munderstat notarius cause hic subscripsit.

$75^{\mathrm{v}}-76^{\mathrm{v}}$ leer.

Teil 2:

$1^{\mathrm{r}}-53^{\mathrm{v}}$ Depositiones testium. Dicta et attestaciones testium in causa coram nobis Caspare de Reno custode et thesaurario ecclesie Basiliensis et iudice per venerabilem dominum Iohannem Wernherum de Flachslanden decanum ... Deposicio primi testis: Iohannes Holtzach de villa Wangen ... Sechs Zeugenaussagen zugunsten der Kläger (Hohenrein). 13 $3^{\mathrm{r}}-16^{\mathrm{v}}$ leer. $17^{\mathrm{r}}$ Venerabili et circumspecto viro domino Caspari zem Rin custodi ecclesie Basiliensis iudici ... 18v Deposicio primi testis: Hensslinus Hug de villa Hochdorff ... 23 ${ }^{v}$ Deposicio tercii testis: Dominus Iohannes Teller plebanus in Hochdorff ... vgl. BüCHLER, Beromünster, S. 388. Acht Zeugenaussagen zugunsten der Angeklagten (Beromünster). 40v leer. $41^{\mathrm{r}}$ Sequntur dicta et attestaciones testium in causa coram nobis, Caspare de Reno custode ecclesie Basiliensis a venerabili et circumspecto viro domino Iohanne Wernheri de Flachslanden decano supradicte ecclesie Bailiensis iudice ... 41 ${ }^{v}$ Deposicio primi testis: Rudinus Fugli de superiori Ebersoll ... - ... Et fuit testibus iniunctum ut fuit moris atque stili. Vier weitere Zeugenaussagen zugunsten der Angeklagten.

Teil 3:

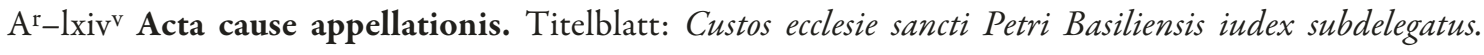
Daneben: Secunde instancie. Darunter: Registrum in causa appellacionis inter honorabilem et religiosum in Christo fratrem Iohannem Hort conmendatorem domus sancti Iohannis in Hohenrein appellantem ex una et 
venerabiles et honorabiles viros dominos prepositum et capitulum ecclesie Beronensis appellatos (ergänzt: de et super congrua porcione etc.) ex alia partibus in secunda instancia habitum et factum. Johannes Friderich notarius. Darunter: Registrum dominorum Beronensium appellatorum. Durchgestrichen: Ich clag dz ich nymand sag. Zuletzt: xv mensis Februarii lxiii appellatum. $A^{\mathrm{v}}$ leer. $\mathrm{x}^{\mathrm{r}}$ Akten, 23. 5. - 17. 7. 1463. In nomine domini amen. Anno a nativitate domini millesimo quadringentesimo sexagesimotercio ... $\mathrm{ii}^{\mathrm{r}}$ Iohannes Wernherus de Flachsslanden decanus ecclesie Basiliensis ... - ... Iohannes Friderich de Münderstat notarius he subscripsi. $\mathrm{x}^{\mathrm{v}}$ leer. $\mathrm{xi}^{\mathrm{r}}$ Akten, 27. oder 28. 9. 1463 - 12. 7. 1465. In nomine domini Amen. Nos Iohannes Grütsch in decretis licenciatus, custos ecclesie sancti Petri Basiliensis iudex ... - ... 1xiiiv Tenor itaque sentencie diffinitive unde supra fit mencio sequitur, et est talis: Christi nomine invocato ... In causa que coram eo ... lxiiiir tunc in prima vertebatur et nunc coram nobis, in secunda vertitur instanciis, bene fuisse et esse pronunciatum sentenciatum et diffinitum, ipsiusque domini custodis, sententenciam diffinitivam per nos confirmandam fore, et confirmamus, atque ab eadem pro parte dicti domini Iohannis Hort conmendatoris fuisse et esse, male, et inique provocatum et appellatum ... Nomine Iohannis Friderich notarii Iohannes Saltzman notarius he subscripsi.

\section{StiAB 01.01.736 FEUDENBUCH}

Pergament und Papier, 51 Blätter, 37,5-38 ×25-26,5 cm

Beromünster (?), um 1346/47; 1511-1563.

Lagen, Foliierung: Lagen: $\mathrm{I}^{\mathrm{II}}+\mathrm{V}^{20}+\mathrm{VI}^{44}+\mathrm{V}^{64}+(\mathrm{V}+\mathrm{II})^{92}+\mathrm{II}^{100}$, das erste Blatt der ersten Lage als Spiegelblatt in den Deckel geklebt; S. 83-90 zwei vor dem letzten Blatt der Lage eingebundene Doppelblätter kleineren Formats $(34 \times 24,5)$, S. 93/94 lose. Lagenzählung am Schluss der Lagen: [ii] ${ }^{u s}$ (S. 44) und iiius (S. 64), Zählung der Doppelblätter auf den Versoseiten in der ersten Lagenhälfte, sichtbar S. 8 und 10: $d$ und $e$, S. 32: $f$, S. 46, 48 und 52: $a, b$ und d. S. 93-100 Papier, Wasserzeichen: Bär, ähnlich Piccard, Wasserzeichenkartei Nr. 84896 (1524) oder Tschudin Nr. 368 (1522). Alte Foliierung: 1 (S. 1) - 14 (27), fehlerhaft ergänzt im 17. Jh.: 1 (S. I), 14 (S. 27) - 17 (S. 33). 17 (S. 35) - 38 (S. 77). 39 (S. 81) - 43 (S. 89). Neuere Paginierung, wohl anlässlich der Publikation im QW (siehe Literatur), ergänzt: [I-II]. 1-64. [65-100].

\section{Einrichtung und Ausstattung:}

Teil 1 (S. 1-64, um 1346/47 angelegt): Tintenliniierung, dreispaltig, Schriftraum 25-26,5 × 20 (mittlere Spalte 7,5, links und rechts 5-5,5), in der Mitte 24, seitlich 48 Zeilen; Einstichlöcher für die Liniierung am inneren und äusseren Rand. Textualis von einer Hand. Rubriziert, rote Paragraphenzeichen; in der mittleren Spalte rote Überschriften (Vorgaben teilweise im Bund sichtbar) und zweizeilige rote Initialen.

Teil 2 (S. I-II, 65-100, 1511 angelegt): Begrenzung des Schriftraums mit Tinte, ab S. 78 in Rot, oben und unten sowie mit vertikalen Doppellinien eine Mittelspalte, vorgezeichneter Schriftraum 26 × 8,5-9,5 (S. 8390 wieder in Schwarz: 23,5-25 × 8-11,5), Zeilenzahl und -länge sehr uneinheitlich. S. I-II und 65-72 Bastarda mit Schleifen von der Hand des Notars Andreas Erni; anschliessend mehrere frühneuzeitliche kursive Hände. S. 73 und 76 Überschriften in vergrösserter Auszeichnungsschrift.

Korrekturen und Nachträge: S. 61-63 am unteren Rand radiert, S. 69-75 weitgehend Palimpsest. S. I-II Nachtrag zu Teil 1, siehe Inhalt. Späteste Daten in Teil 1: 1720 (S. 15), 1713 (S. 45); in Teil 2: 1567 (S. 67), 1563 (S. 74). S. 44 Feudum A nachgetragen, vor 1379 (dem Todesjahr Heinrichs II. von Sursee). Hervorzu- 
heben: S. 7, Mittelspalte, von der Hand des A. Erni (?), darunter Notiz über eine Handänderung von 1560; S. 19 von der Hand des Stiftsnotars Johann Hitzmann, um 1570, vgl. EgLoff, Urbar, S. 371 (et passim) und 373 (Abb.) bzw. Herr in Münster, S. 294 (Abb.) und 295; weitere umfangreichere Nachträge dieser Art S. 20, 22, 28f., S. 33, 41f., 60 und 63. S. 91 Nachtrag, 17. Jh.: Reverendissimus Ordo et Series Canonicorum Beronae Anno M. D CXVIIII, Presbyteri: Simon Haas Senior ... S. 70 Titel nachgetragen, 17./ 18. Jh. Parochiae Lütishovenses. Lebensdaten einiger Chorherren am Rand ergänzt, 19./20. Jh.

Einband: Mit rot eingefärbtem Leder bezogene Holzdeckel, Kanten abgeschrägt, 16. Jh.; am Rücken Spuren einer Reparatur. Streicheisenlinien, Roll- und Einzelstempel, darunter EBDB s016794, s016795, s016798, s016799 (w002462: ar Monogamm), zudem Schriftband Paulus (ähnlich EBDB s016630), Adler in Rhombus, Lilie, z. T. kaum erkennbar. Ehemals zwei nach vorn greifende Langriemenschliessen, die untere samt der Riemenbefestigung abgerissen, die obere fast lose, mit Lederflicken verstärkt, Messingstifte eines verlorenen Beschlags; im Vorderdeckel zwei Eisenstifte. Spiegelblätter Pergament, darunter sichtbar fünf über den Rücken gezogene Pergamentstreifen, lat. Fragmente in kleiner gotischer Minuskel wohl des 14. Jhs. Auf dem Vorderdeckel ein Papierschild: Feudenbuch / de c. 1325. / gedruckt Geschichtsfreund 34, 311 ff., nach 1879, sowie Besitzeinträge und Korrektur der Datierung: 1350, 20. Jh. Auf dem Rücken Signaturschild: 736, 20. Jh.

Herkunft: Das sog. Feudenbuch, ein Pfrundlehenurbar (Einkünfte der sieben Chorherren Priester und der sieben Chorherren Diakonen), entstanden gewiss in Beromünster; zur Datierung von Teil 1 siehe QW II, 1, S. 240. Teil 2 wohl 1511 angelegt von Notar Andreas Erni und wahrscheinlich bald darauf gebunden; letzter Eintrag von seiner Hand 1514.

Besitzer: Auf dem Titelschild, im vorderen Spiegel, S. I sowie S. 23, 31, 45, 65 und 91 runder Stempel: Stiftsarchiv Beromünster, 20. Jh.

Literatur: Estermann, Stiftsschule, S. 19 und 85; Melchior Estermann, Das Feudenbuch der Stift Beromünster, in: Der Geschichtsfreund 34 (1879), S. 311-368, mit Nachtrag S. 396-400; LiebenaU, Urkundenbuch, Bd. 1, S. 24 (K); Konrad Lü TOLF, Stiftsgeschichte von Beromünster, in: Zeitschrift für schweizerische Geschichte 2 (1922), S. 468f.; Konrad LÜ TOLF, Filiationen und Inkorporationen am Stifte Beromünster, in: Zeitschrift für schweizerische Kirchengeschichte 19 (1925), S. 42f., 45, 49; QW II, 1, S. 239f.; BRUCKNER, Scriptoria 9, S. 19 sowie Taf. 36; Büchler, Beromünster, S. XV, 17, 139 und 266; Egloff, Urbar, S. 371,373 (Abb.), 374, 376, 378, 380-382, 387-389, 389 (Anm. 1), 390 (Anm. 29), 394 (Anm. 99); Egloff, Herr in Münster, S. 296-299, 294 (Abb. 12); Hugener, Buchführung, S. 71 (Anm. 270), 149 (mit Anm. 573 und 161 (mit Anm. 617).

Im vorderen Spiegel Nachträge:

Titel, möglicherweise von der Hand des Nachtrags von 1643 (s. unten): Descriptio Beneficiorum Praebendalium Canonicorum. Feuden Buch und Quotidian.

Inhaltsverzeichnis, möglicherweise von der Hand des Andreas Erni, die Seitenverweise 17. Jh. (Hand von 1643?): A: primum, fol. $i^{\circ}$ et 21. B: Quintum, 1. B. ... Daneben, 15. Jh.: Item diss sind die gütter In dem twing ze Witwil da vogt stür abgat gan Rotenburg. Item Hechtes güt oder Schüpes git je viii denarii ...

S. I-II Pfrundlehenurbar. Nachtrag zu Teil 1 von der Hand des Andreas Erni. Primum foedum: A. Renovatum anno domini $M^{\circ} \operatorname{ccccc}^{0} x^{\circ}$. Hec sunt decime possessiones et redditus pertinentes foedo prebendali, quod eo tunc temporis possidebat videlicet: Primo decima in Guntzwil. Item in Mentzikon una bub a de qua dantur iiiior porci bubales vi pulli autumpnales et iiiior carnispriviales, et lxxx ova in festo pasche ... Am Rand zuoberst, von gleicher 
Hand (Andreas Erni): Dominus Nicolaus de Winckel, vgl. BüCHLER, Beromünster, S. 403. Wohl von seiner Hand weiter: Dat modo dominus custos an der allmend de horreo suo. Dazu eine Aktualisierung von 1643, sowie von der gleichen Hand zuletzt: Vide eadem etiam fol. 21.6 (S. 44). Vgl. Estermann, Feudenbuch, S. 316, mit einem Teil der Nachträge von S. 44 sowie dem Nachtrag von 1643; QW II, 1, S. 256 (mit einem Teil der Nachträge von S. 44). S. II Quintum foedum: B. Anno cccccxi ${ }^{\circ}$. Hec sunt possessiones et redditus pertinentes foedo prebendali quod modo possidet videlicet ... Am Rand zuoberst (Andreas Erni): Dominus Petrus de Hertenstein, vgl. BüCHLER, S. 315f., dann weitere Ergänzungen, zuletzt durchgehend aktualisiert von der Hand von 1643. Vgl. Estermann, Feudenbuch, S. 316-318.

Teil 1:

S. 1-64 Pfrundlehenurbar. Sextum foedum: C. (von der Hand des A. Erni). > Hec sunt possessiones et decime pertinentes ad feoda prebendalia ecclesie Beronensis<. Omnes decime que proveniunt de bonis officiatorum ecclesie Beronensis, videlicet pincerne, coci, preconis, pistorum, sacristarum, cedunt feodo ... - ... Summa iugerum xxxvii. Linke Spalte (Inhaber der Lehen): Ad feodum prebendale, quod nunc possidet dominus custos. Nachträge verschiedener Hände: Nunc habet Johannes de Empcz. Dann: Nunc Wernherus de Schenken. Dann: Nunc Mathias Kupfernagel. Dann: Nunc Petrus Kündigpossidet. Dann: Kiel (gestrichen: Hertenstein), vgl. BüCHLER, S. 289, 367, 329, 327, 322. Rechte Spalte (Bebauer der Güter): Nunc decanus Fridolinus Witz adoptavit 1562. Dann: Renuardus Goldlin 1593. Dann: Nunc Gualterus Pfiffer secretarius adoptavit, anno 1649. Mittelspalte: Item decime provenientes de duabus scoposis, pertinentibus prepositure ecclesie Beronensis. Rechte Spalte: Quas colit Heinricus Ammans, vgl. Büchler, S. 318. Nunc Waltherus de Witwil. Dann: Nunc Heini Scherer ... Estermann, Feudenbuch, S. 316-344 (die Einträge der beiden seitlichen Spalten in den Text integriert, nur die älteren Nachträge ediert, z. T. ohne Abgrenzung zum Text der Mittelspalte; S. 343 ein längerer Nachtrag von S. 63, zudem S. 343f. auch Nachträge Ernis, die in der Hs. teilweise kaum mehr lesbar sind); QW II, 1, S. 240-263 (mit nur einem kleinen Teil der ältesten Nachträge, bis gegen 1450).

Teil 2:

S. 65-72 Urbar. Wangen. Item decima maior in Wangen ex observato iure inolitaque constuetudine locatur ... Links: Nota wie der gross Zenden umb ein summ gütts gelichen wirt ... Rechts: Undergang des Zenden vor der Burg ze Wolbusen ... S. 70 Item ecclesia in Wangen: de qua domini de capitulo annuatim dant plebano ... S. 71 Nota: als dann Ein herr probst und gemein Capitel der Stiffe ze Münster: den Caplanen daselbst jarlich uff Martini, sechs und zwentzig guldin an müntz von den fünff kilchen satzen: Nammlich Wangen ... - ... mit minem eygnen nammen unnd zu nammen underschriben: Andreas Erny Beronensis notaris scripsit. Darunter: Anno domini millesimo quingentesimo vicesimo primo venerabiles domini prepositus et capitulum Beronensis libere donaverunt in maius domini cultus augmentum ... Notum sit universis, quod circa annum domini M D XXX venerabilis dominus magister Erhardus Battmann ...

S. 73-91 Urbar. 1542-1563. Cottidianae presenciae census. Jacob Berttschiger gitt jerlich x gulden muntz uff Conversionis Pauli, vallt der erst zinss 1556 ... S. 76 der eigentliche Anfang: Cotidiane presentiae dominorum canonicorum annui census. Item die Statt Sempach soll järlich vier gullden, Nativitatis domini, Innhalts dess hoptbriefs ... - ... Welti Schallher sol ierlich uff Georii v gl. an muntz vallt der erst zinss Im 54, anschliessend Verweis auf die Fortsetzung S. 73-75. 
S. 92-93 Urbar. Nachträge. Hic sequuntur annue obvenciones et census ... Ad ordinationem Domini Erhardi Battman Anni 40 ... Item anno domini 1541 hand min herren Propst und Capitel ... Item 1551 hand mine gnedigen herren von capitel ... Am unteren Rand der Seite: Item 1561 hand mine g. h. vom capitel ... fortgesetzt am unteren Rand von S. 93: Unnd so der trager lept, zu ussgang der zechen Iaren sollent sy nüt In rhat zu geben schuldig sin. So es aber...

S. 93-97 Series canonicorum. Series Canonicorum, Anno supra Millesimo quingentesimo vicesimoquarto. Iohannes Pfiffer ... Anno 1534: Ioan Meyer ...

S. 94-95 leer.

S. 96-97 Urbar. 1546/47. Item min herren hand Hanns Loo lost seligen kind hundert guldin umm den geburlichen Ierlichen zinss gelichen Ist Peter hunenberg Burg vallt der zins uff ... fünf weitere Einträge, davon zwei gestrichen.

S. 98-100 leer. 
Anhang 


\section{Register der Verfasser, Namen, Orte und Sachen}

Acta concilii Pisani C 67, 201 ${ }^{\mathrm{r}}$

Acta decani Basiliensis StiAB 01.01.718 und 719

Ad habendum salutiferae confessionis ordinem C 8, 136r

Adalgerus episcopus (?), Admonitio ad Nonsuindam reclusam (Exzerpt) C 8, 185

Aegidius Romanus

- Sermones de sanctissima eucharistia C 63, 109ra

- Theoremata de corpore Christi, Exzerpt C 57, 133 ${ }^{\text {rb }}$

Albert von Münnerstadt OT (S) C 14, Teil 3

Albertus de Diessen C 51, $152^{\mathrm{r}}$

Albertus de Ferrariis, De horis canonicis C 57, 161 rb

Alexius Placentinus siehe Alexius de Seregno

Alexius de Seregno, Sermones C 52, 20v, $58^{v}$

Amalricus Augerius, Actus Romanorum pontificum C 54, $11^{\mathrm{r}}$

Andreae, Johannes siehe Johannes Andreae

Andreas de Escobar siehe Escobar, Andreas de

Anniversar siehe Jahrzeitbuch

Antiphonar (Einbandfragment, 12. Jh.) C 43

Antonius Caxal siehe Caxal, Antonius

Arbor consanguinitatis C 57, 138

Arrigoni, Jacobus siehe Jacobus Laudensis

Auctoritates C 8, 166 r

Augustinus, Aurelius

- Enchiridion C 57, $2^{\text {ra }}$

- Sermo de paenitentibus C 57, $79^{\mathrm{rb}}$

Ps.-Augustinus

- De cognitione verae vitae siehe Honorius Augustodunensis

- De continentia siehe Caesarius Arelatensis

- De ecclesiasticis dogmatibus siehe Gennadius

- De fide ad Petrum siehe Fulgentius Ruspensis

- De fuga mulierum siehe Caesarius Arelatensis

- De vera et falsa poenitentia C $57,76^{\mathrm{rb}}, 80^{\mathrm{rb}}$

- Dialogus quaestionum C 57, $88^{\mathrm{rb}}$

- Sermo de contemptu mundi C 57, $50^{\text {ra }}$

Augustinus Dati, Elegantiolae C 61, 284 ${ }^{\mathrm{r}}$

Ave Maria (deutsch) StiAB 01.01.617,34r

Balardi, Jacobus siehe Jacobus Laudensis

Bartholomaeus Pisanus, Summa de casibus conscientiae (Exzerpt) C $10,100^{v}$
Barzizius, Gasparinus, Epistulae (GW 3676) C 44, $138^{\mathrm{v}}$

Ps.-Beda, De quindecim signis C 8, $192^{\mathrm{r}}$

Bertholdus Ratisbonensis, Sermones C 53, $112^{\mathrm{ra}}, 121^{\mathrm{ra}}, 123^{\mathrm{rb}}$, $124^{\mathrm{va}}, 128^{\mathrm{va}}, 130^{\mathrm{rb}}, 137^{\mathrm{rb}}, 150^{\mathrm{ra}}, 159^{\mathrm{ra}}$

Biblia sacra

- AT III Rg 1 (Einbandfragment, 14. Jh.) C 46

- NT Evangelia C 64, $1^{\text {r }}$

- NT Epistolae Pauli apostoli A 66 fol., 13 (Rm - Hbr); C 46, $198^{\mathrm{r}}$ (I Th - Hbr)

Ps.-Boethius, De disciplina scholarium C 44, $112^{\mathrm{r}}$

Bonaventura (siehe auch Henricus de Turego)

- Breviloquium, Exzerpt C 57, 128vb, 129 $9^{\mathrm{ra}}$

- Legenda minor S. Francisci (Einbandfragment, 14. Jh.) C 42

- Tractatus de praeparatione ad missam C 14, 142v

Brevier (Einbandfragmente) C 57 (14. Jh.), C 42 (14./15. Jh.)

Buchschmuck

- Federzeichnungen C 49, 81 vb (TO-Karte); C 62, 36 $6^{\mathrm{ra}}$; C 65, $133^{\mathrm{ra}}$

- Initialen

Deckfarbeninitialen C 64, 38r , 74r $, 121^{\mathrm{r}}, 122^{\mathrm{v}}, 215^{\mathrm{r}}$; II C 1

Figureninitialen (ornamental gespalten) II C 1

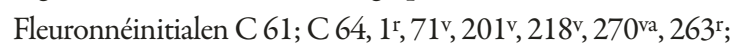

II C 1, 8r, 19r, 66rv, 69v $90^{\mathrm{v}}$, 94r ; StiAB 01.01.599

historisierte Initiale C 45, $1^{\mathrm{r}}$

ornamental gespaltene Initialen II C 1

Spaltleisteninitialen (Rankeninitialen) II C $3,2^{\mathrm{r}}, 36^{\mathrm{v}}, 37^{\mathrm{r}}, 52^{\mathrm{v}}$, $56^{\mathrm{r}}$

Buggi, Hans StiAB 01.01.714, 2v-7v, 10 $13^{\mathrm{r}}, 137^{\mathrm{v}}$

Buseck, Heinrich von C 44

Buseck, Johannes von C 44

Buseck, Konrad von C 44

Buseck, Ottilie von siehe Lütishofen, Ottilie von

Caesarius Arelatensis

- Ammonitio ut iugalis castitas conservetur et concubinae non habeantur C $57,75^{\mathrm{rb}}$

- De indigna familiaritate extranearum mulierum et de martyrio C $57,74^{\mathrm{va}}$

- Sermo C 54, 147 v

Caxal, Antonius, Sermo C 52, $84^{\mathrm{v}}$

Census siehe Urbar 
Christus resurrexit (Christ ist erstanden) StiAB 01.01.616, 46r StiAB 01.01.617, 33 v

Cicero, M. Tullius Epistulae ad familiares C 61, 300 r

Compendium rhetoricum (Ars epistolandi et praedicandi) C 44, 57v

Compendium rhetoricum (Partes dictaminis) C 44, $2^{\mathrm{r}}$

Concilium Lateranense IV, Constitutio 21 C 51, 142 ${ }^{\mathrm{r}}$

Confessio debet esse praevisa C 8, $114^{\mathrm{v}}$

Conradus Menger siehe Menger, Konrad

Conradus de Saxonia

- Sermo C 53, $159^{\mathrm{vb}}$

- Speculum Mariae C 65, $322^{\text {ra }}$

Costa Ben-Lucae siehe Johannes Hispalensis

Credo siehe Symbolum

Ps.-Cyprian, De duodecim abusivis saeculi (Capitula) C 8, $193^{\vee}$

Dati, Leonardo, Sermo C 52,75

Datierung der Handschriften

- Datierte Handschriften

1323 StiAB 01.01.599, Teil 1

1324 StiAB 01.01.599, Teil 2

1345 StiAB 01.01.600, Teil 1

1346/47 StiAB 01.01.600, Teil 2

$1388-1389$ C 53

1402 C 54

1408 C 51, Teil 2

1430 A 66 fol., Teil 5

1432 C 63

1438 C 44, Teil 4

1449 C 50

1451 C 40; C 64

1451-1452 C 41, Teil 2

1452-1456 C 44, Teil 1

$1455-1469$ C 46

1460 C 51, Teil 3

1461 C 9, 93 $-94^{\mathrm{v}}$ (Nachtrag)

1464 C 45

1468 C 57

1469 A 66 fol., Teil 6; C 57, $1^{\text {ra }}-24^{\text {ra }}$

1470 C 10, Teil 2

1471 C 10 (Nachtrag)

$1474-1475$ C 42

1474-1476 C 5 fol.

1479-1520 StiAB 01.01.714

1504 StiAB 01.01.635

1534-1537 StiAB 01.01.602
- Zeiträume

11. Jh., 1. Viertel II C 3

13. Jh. II C 2

um 1346/47 StiAB 01.01.709

14. Jh., 1. Hälfte II C 1, StiAB 01.01.634a

14. Jh., 2. Hälfte C 8

um 1370 C 14, Teil 3

14. Jh., Ende C 51, Teil 1; C 67

15. Jh., 1. Viertel C 9, Teil 4; C 14, Teil 2

15. Jh., 1. Drittel C 12

15. Jh., 1. Hälfte C 9, Teil 2; C 11; C 13

15. Jh., 2. Viertel C 9, Teil 5; C 14, Teil 1

15. Jh., mittleres Drittel C 9, Teil 3; C 49; C 55

um 1436/37 StiAB 01.01.736, Teil 1

15. Jh., Mitte C 9, Teil 1; C 41, Teil 1; C 52; C 69

15. Jh., 3. Viertel C 10, Teil 1; C 61; C 62; StiAB 01.01.718 und 719

15. Jh., 2. Hälfte C 43, II C 1 (107va $\left.-114^{\mathrm{vb}}\right)$, StiAB 01.01 .715

um 1453 C 44, Teil 2

um 1460 C 65

nicht nach 1472 C 44, Teil 3

15. Jh., letztes Viertel StiAB 01.01.616

um 1479-1492 StiAB 01.01.615

15. Jh., Ende StiAB 01.01.663

15. Jh., Ende / 16. Jh., Anfang StiAB 01.01.463

16. Jh., Anfang StiAB 01.01.603

16. Jh., 1. Viertel StiAB 01.01.617

um 1511-1563 StiAB 01.01.736, Teil 2

De dispositione ad celebrandum missam C $10,52^{\mathrm{v}}$

De expeditione infirmorum C 10, $101^{\mathrm{v}}$

De quinque floribus mundi contemnendis C $46,246^{\mathrm{r}}$

Decimae siehe Zehnten

Dialogus de septem sacramentis C 10, 60 ${ }^{\mathrm{r}}$

Dietrich von Münster siehe Theodoricus de Monasterio

Ps.-Dionysius Areopagita, De divinis nominibus C 46, 269 r

Discipulus siehe Herolt, Johannes

Dörflinger, Johannes (S) C 5 fol.; II C 1, A r, $107^{\mathrm{va}}-114^{\mathrm{vb}}$; II C 3, $1^{\mathrm{r}}$; StiAB 01.01.615; StiAB 01.01.616

Drucke, beigebundene

- Albertus Trottus, De horis cononicis A 66 fol., Teil 2

- Barzizius, Gasparinus, Epistulae C 44, Teil 3

- Henricus de Langenstein, Expisitio super orationem dominicam C 65, Teil 3

- Jacques Legrand, Sophilogium C 65, Teil 4

- Johannes Nider, Manuale confessorum C 65, Teil 1 
- Johannes Nider, Tractatus de morali lepra C 65, Teil 2

- Petrus Aureoli, Compendium sensus litteralis totius Sacrae Scripturae A 66 fol., Teil 3

- Pius II papa, De duobus amantibus, De remedio amoris C 65, Teil 5

- Ps.-Seneca, De quattuor virtutibus, De remediis fortuitorum A 66 fol., Teil 1

- Walahfridus Strabo, Scriptum compendiosum Psalterii intentionem declarans et exponens A 66 fol., Teil 4

Eadmer Cantuariensis, De beatitudine coelestis patriae

(Einbandfragment, 13./14. Jh.) C 52

Ebinger, Thomas (S) C 44, Teil 4

Eggli, Johannes (S) C 8, 141 ${ }^{\text {v }-149}$; C 53

Einbände, bemerkenswerte

- Elfenbeintafeln II C 2, II C 3

- Goldschmiedearbeit mit Emaille und Edelsteinen II C 1

- Kettenband (Catenatus) C 14

- Koperteinband aus Fell StiAB 01.01.634a

- Werkstätten:

Alberthus C 62, C 51

ar Monogramm StiAB 01.01.736

«Meister mit dem Eichelstempel» C 10

«Meister mit den Muschelstempeln» C 43, C 65

«Meister mit den Quadratblütenstempeln» C 40, C 41, C 64

Reussenhock C 61

Uoldaricus A 66 fol., C 42, C 46, C 52

Vierblatt-Blüthe V C 40

Englischer Gruss siehe Ave Maria

Epistolae Pauli apostoli siehe Biblia sacra

Epistolar II C 3

Erni, Andreas (S) StiAB 01.01.615, S. 70 (Nachtrag); StiAB 01.01.616, 45v (Nachtrag); StiAB 01.01.617 (?); StiAB 01.01.635; StiAB 01.01.663, 89v (Nachtrag); StiAB 01.01.714, 26v, 27v; StiAB 01.01.715, 7v-8r $10^{\mathrm{r}}, 11^{\mathrm{v}}$, $19^{\mathrm{r}}-23^{\mathrm{v}}, 25^{\mathrm{r}-\mathrm{v}}, 29^{\mathrm{v}}-56^{\mathrm{r}}, 59^{\mathrm{r}}-81^{\mathrm{r}}, 83^{\mathrm{r}}-85^{\mathrm{r}}, 88^{\mathrm{r}}-89^{\mathrm{r}}, 104^{\mathrm{v}}$,

$121^{\mathrm{r}-\mathrm{v}}, 125^{\mathrm{r}-\mathrm{v}}, 127^{\mathrm{r}}, 190^{\mathrm{r}}-191^{\mathrm{r}}, 198^{\mathrm{v}}-201^{\mathrm{v}}, 216^{\mathrm{r}}-219^{\mathrm{v}}$,

$223^{\mathrm{v}}-225^{\mathrm{r}}$; StiAB 01.01.736, Teil 2

Ernis Buch StiAB 01.01.635

Escobar, Andreas de, Lumen confessorum C 46, $251^{\mathrm{r}}$

Evangeliar C 64, $1^{\mathrm{r}}$

Evangelistar II C 1

Expositio hymnorum 'Conditor alme siderum' et 'Veni redemptor omnium' C 46, $258^{\text {ra }}$

Expositio Symboli Apostolorum C 51, $132^{\mathrm{va}}$
Expositio Symboli Athanasii C 51, $128^{\mathrm{v}}$

Expositio Symboli Nicaeni C 51, 135 ra

Feudenbuch (Pfrundlehenurbar) StiAB 01.01.736

Flachslanden, Johann Werner von, Chorherr von Beromünster und Basler Domdekan StiAB 01.01.718 und 719

Fragment (Einbandfragmente) siehe Anniversar; Antiphonar; Biblia sacra; Bonaventura, Legenda minor S. Francisci; Brevier; Eadmer Cantuariensis, De beatitudine coelestis patriae; Isaak ben Salomon Israeli; Jacobus de Thiacuria; Johannes de Garlandia; Ps.-Johannes Vitalis de Furno; Liber pontificalis; Liturgica; Missale; Notation, Neumen; Officium S. Francisci; Petrus Hispanus, Summulae logicales; Petrus Lombardus, Sententiae; Scholastica; Sermones; Thomas Cisterciensis, Commentaria in Cantica canticorum; Urkunde Franciscus Galvanus, Collationes super Lucam C 14, $153^{\mathrm{r}}$

Friderich von Münnerstadt, Johannes, Notar (S) StiAB 01.01.718 und 719

Fulgentius Ruspensis, De fide ad Petrum C 57, $51^{\text {va }}$

Galfredus Babio, Sermo C 53, $81^{\text {ra }}$

Galterius Map siehe Map, Walter

Gartner, Heinrich (S) StiAB 01.01.714

Gennadius, De ecclesiasticis dogmatibus C 57, $85^{\text {ra }}$

Gerardus du Puy, Sermo C 52, $111^{\text {r }}$

Gerardus Monachus, Defensorium iuris C 57, $148^{\text {va }}$

Gerlach, Dekan von St. Peter in Mainz (Einbandfragment, 1392) C 67

Gerson, Jean

- Kommentar zum Liber Floretus C 45, $1^{\mathrm{r}}$

- Opus tripartitum C 14, $118^{\text {r }}$

- Sermones C 52, 11v, $86^{\mathrm{v}}$

Glaubensbekenntnis siehe Symbolum

Glossarium hymnorum C 9, $61^{\text {r }}$

Goeckelmann, Henricus siehe Henricus de Turego

Göldin, Christoph Zacharias (S) StiAB 01.01.615 (Nachträge), StiAB 01.01.616 (Nachträge)

Göldlin von Tiefenau, Joachim (P) C 55

Göldlin von Tiefenau, Renward (P) C 55

Goltz, Heinricus (S) C 51, Teil 1, $142^{\mathrm{r}}-151^{\mathrm{r}}$

Gregorius I papa, Dialogi C 10, 108

Grünli, Růdolfus (S) C 57, $63^{\text {ra }}$

Guillelmus de Malliaco, Sermo C 53, 98va; C 8, $51^{v}$

Guillelmus Parisiensis siehe Dialogus de septem sacramentis Gundeldingen, Johannes von C 44 
Hagenbach, Nicolaus de (Einbandfragment, 1394) C 67

Hägglingen (Jahrzeitbuch) StiAB 01.01.617

Hallwil, Johann Rudolf von StiAB 01.01.714, $2^{\mathrm{r}}, 22^{\mathrm{r}}, 24^{\mathrm{v}}-25^{\mathrm{r}}$ und $33^{\mathrm{r}-\mathrm{v}}$

Handschriften, zitierte

- Basel, Universitätsbibliothek, A VI 4 C 51

- Basel, Universitätsbibliothek A X 59 C 14

- Basel, Universitätsbibliothek, A X 131 C 46

- Basel, Universitätsbibliothek, A XI 74 C 46

- Basel, Universitätsbibliothek F II 10 C 14

- Basel, Universitätsbibliothek, F IV 12 C 54

- Basel, Universitätsbibliothek, F V 5 C 42

- Bordeaux, Bibliothèque municipale, $247 \mathrm{C} 8$

- Freiburg im Breisgau, Universitätsbibliothek, Hs. 89 C 61

- Freiburg im Üechtland, Kantons- und Universitätsbibliothek, Ms. L 16 C 51

- Karlsruhe, Badische Landesbibliothek, Aug. pap. 145 C 40

- Mailand, Biblioteca Ambrosiana, E 17 Sup., 145 r $-155^{\mathrm{r}}$ C 10

- München, Bayerische Staatsbibliothek, Clm 4546 C 43

- München, Bayerische Staatsbibliothek, Clm 13698 C 9

- Neudorf, Pfarrarchiv, Jahrzeitbuch StiAB 01.01.615

- Olomouc, Vědecká knihovna, M II 138 C 46

- Paris, Bibliothèque nationale de France, lat. 5146 C 54

- St. Gallen, Stiftsbibliothek, Cod. Sang. 581 C 12

- Vatikan, Biblioteca Apostolica Vaticana, Pal. lat. 1589 C 44

Henmannus Murer (S) C 50

Henricus Bohicus, Distinctiones super primo libro decretalium C 67, $1^{\text {ra }}$

Henricus de Frimaria, Tractatus de decem praeceptis C 53, $15^{\text {ra }}$

Henricus de Langenstein

- De discretione spirituum C 14, 99v

- Expositio super orationem dominicam (GW 12242) C 65, $121^{\mathrm{r}}$

Henricus de Odendorp, Lectura capituli "Omnis utriusque sexus" de poenitentia C $51,142^{\mathrm{r}}$

Henricus de Turego, Abbreviatio Bonaventurae C 69, 17 rb

Henricus Goeckelmann siehe Henricus de Turego

Hermannus de Schildis, Introductorium iuris (Modus legendi) C 53, $1^{\text {ra }}$

Herolt, Johannes

- De eruditione Christifidelium C 13, $1^{\mathrm{r}}$

- Sermones dominicales, Pars aestivalis C 50, $1^{\text {ra }}$

Hertenstein, Hans von StiAB 01.01.714, 49 $9^{\mathrm{r}}-51^{\mathrm{r}}$

Hertenstein, Leodegar (P) C 14

Hilflin, Jacobus (P, S) C 10 (Teil 1)

Historia naturalis $\mathrm{C} 14,1^{\mathrm{r}}$
Hitzkirch (Provenienz I) C 14, Teil 3

Hitzmann, Johannes StiAB 01.01.603 (Nachtrag); StiAB 01.01.715, $92^{\mathrm{v}}-94^{\mathrm{r}}, 157^{\mathrm{v}}-158^{\mathrm{v}}, 160^{\mathrm{r}}, 165^{\mathrm{v}}-166^{\mathrm{v}}, 167^{\mathrm{v}}-170^{\mathrm{r}}, 172^{\mathrm{v}}-173^{\mathrm{v}}$, $182^{\mathrm{v}}, 202^{\mathrm{r}}, 222^{\mathrm{v}}, 227^{\mathrm{v}}, 233^{\mathrm{v}}-234^{\mathrm{r}}$

Hohenrain (Johanniterkommende), Prozess gegen StiAB 01.01.718 und 719

Holtnicker, Konrad siehe Conradus de Saxonia

Honorius Augustodunensis

- De cognitione verae vitae C 57, 63 ${ }^{\text {ra }}$

- Expositio in Cantica canticorum C 46, $1^{\mathrm{ra}}$; C 62, $1^{\mathrm{ra}}$

- Hexaemeron (Exzerpt) C 53, $181^{\text {va }}$

- Sermo C 8, 158v; C 53, 77rb

Hort, Johannes, Komtur der Johanniterkommende Hohenrain StiAB 01.01.718 und 719

Hugo Argentinensis, Compendium theologicae veritatis C 8, $141^{\mathrm{v}}$ (Exzerpt); C 53, 90 rb (Exzerpt); C 63, $3^{\text {ra }}$

Hugo de S. Caro, Sermo C 53 135 rb

Hymnen siehe Expositio hymnorum; Glossarium hymnorum

Ikonographie

- Anbetung der Könige C 45, $1^{\mathrm{r}}$

- Kanonbild C 5 fol.

- Maria (?) und Engel C 45, 2v

- Moses empfängt die Gesetzestafeln C 62, 36 $6^{\text {ra }}$

- Peter und Paul II C 2, Einband (Elfenbeinplatte)

Interpretationes nominum, quae in evangeliis reperiuntur C $43,293^{\text {rb }}$ Iordanus de Quedlinburgo, Sermones C 42, 257 ra

Isaak ben Salomon Israeli, Liber de urinis (Einbandfragment, 13./14. Jh.) C 41

Isidorus Hispalensis

- De natura rerum C 49, $13^{\text {ra }}$

- Etymologiarum libri XX C 49, $1^{\text {ra }}$

Italclaus siehe Ytelclaus

Jacobus de Cessolis, Liber de ludo scaccorum (Auszug) C 14, 262

Jacobus de Gruytrode (?), Lavacrum conscientiae C 10, $1^{\text {r }}$

Jacobus de Paradiso

- De apparitionibus animarum separatarum, C 46, $295^{\mathrm{ra}}$

- De potestate daemonum C 57, $98^{\mathrm{ra}}$

- Devota passionis Christi meditatio C 42, $302^{\text {ra }}$

- Passio domini secundum quatuor evangelistas C 42, 265 $5^{\text {ra }}$

- Sermo de defunctis C 42, $178^{\text {ra }}$

- Sermo de paenitentia C 42, $153^{\mathrm{va}}$

- Sermo de solutionibus debitorum C 42, $171^{\text {va }}$

- Sermones C 42, $1^{\text {ra }}$ und $184^{\mathrm{vb}}$ 
Jacobus de Thiacuria C 63, Einbandfragment

Jacobus de Voragine

- Legenda aurea (mit Provincia-Anhang) C 12, $2^{\mathrm{r}}$

- Sermones de tempore et de sanctis C 46,37ra

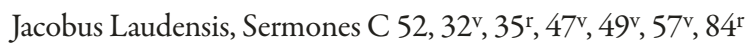

Jacobus Väsen siehe Väsen, Jakob

Jahrzeitbuch StiAB 01.01.599, $2^{\mathrm{r}}$ (Teil 1); StiAB 01.01.600, S. 9

(Teil 1); StiAB 01.01.602, 2 ${ }^{\mathrm{r}}$; StiAB 01.01.603, $1^{\mathrm{r}}$;

StiAB 01.01.615, S. 3; StiAB 01.01.616, 1' ; StiAB 01.01.617,

$2^{\mathrm{r}}$; StiAB 01.01.663, $1^{\mathrm{r}}$

- Einbandfragment, 14. Jh. C 14

Jean Gerson siehe Gerson, Jean

Johannes Andreae, Lectura super arboribus consanguinitatis et affinitatis C 57, 136 ra

Johannes Calceatoris de Lentzburg (S) C 40, Teil 2; C 41, Teil 1

Johannes de Deo, Liber poenitentiarius C 57, $117^{\mathrm{ra}}$

Johannes de Fonte, Conclusiones super quattuor libros Sententiarum C 57, 25ra

Johannes de Forda, Sermo C 53, $143^{\text {vb }}$

Johannes de Friburgo, Tractatus de instructionibus confessorum (Exzerpte) C 8, 124v, 137

Johannes de Garlandia, Synonyma (Einbandfragment, 14. Jh.) C 61

Johannes de Rocha, Sermones C 52, 25v, $128^{\mathrm{r}}$

Johannes de Sacrobosco, Tractatus de sphaera C 40, 199r

Johannes de Serravalle, Sermo C 52, 61 ${ }^{\mathrm{r}}$

Johannes de Werdena, Dormi secure C 11, 169r

Johannes Dörflinger siehe Dörflinger, Johannes

Johannes Gerson siehe Gerson, Jean

Johannes Hispalensis

- Ps.-Aristoteles, Libellus de regimine sanitatis C 57, $188^{\text {ra }}$

- Costa Ben-Lucae, De differentia animae et spiritus C 57, $189^{\text {rb }}$

Johannes Huguenetti, Sermo C 52, 29r

Johannes Mauburnus siehe Mauburnus, Johannes

Johannes Nider

- Manuale confessorum (GW M26875) C 65, $1^{\mathrm{r}}$

- Praeceptorium divinae legis C 62, 36ra

- Tractatus de morali lepra (GW M26867) C 65, 53 ${ }^{\mathrm{r}}$

Johannes Remishůb de Veltkirch siehe Remishůb, Johannes

Ps.-Johannes Vitalis a Furno, Commentarius in Librum de sex principiis (Einbandfragment, 14. Jh.) C 61

Johannes Zachariae, Sermones C 52, 52v, 67v

Kammeramtsurbar StiAB 01.01.600, S. 329 (Teil 2);

StiAB 01.01.663 (Anniversar)
Kelleramtsurbar StiAB 01.01.599, 70 7 ra $-79^{\text {va }}$ (Teil 2); StiAB 01.01.709, S. 1

Kilianus Lupi, Quaestiones super Aristotelis De caelo et mundo C $40,133^{r}$

Knab von Zwiefalten, Erhard, Aggregatorium rhetoricum (Buch 1 und 2) C 44, $8^{\mathrm{r}}$ und $64^{\mathrm{r}}$

Kopialbuch StiAB 01.01.463, StiAB 01.01.634a, StiAB 01.01.635

Kron, Laurentius, Offizial der Basler Kurie StiAB 01.01.718 und 719

Lactantius, Divinae institutiones (I,1-22) C 46, 316

Landgerichtsordnung StiAB 01.01.463 192 ${ }^{\mathrm{r}}$

Laurus Quirinus, Epistula de urbis Constantinopolis iactura et capitivitate ad Nicolaum V papam C 46, 170 ra

Lavacrum conscientiae siehe Jacobus de Gruytrode

Lectura capituli 'Omnis utriusque sexus' de poenitentia C 51, $142^{\text {r }}$

Legrand, Jacques, Sophilogium (GW M17639) C 65, 131 ra

Leonardus Statius siehe Dati, Leonardo

Liber anniversariorum siehe Jahrzeitbuch

Liber crinitus StiAB 01.01.634a

Liber Floretus $C$ 45, $1^{\text {r }}$

Liber ordinis rerum $C 9,1^{\mathrm{r}}$

Liber pontificalis (Einbandfragment, 14./15. Jh.) C 42

Liturgica (Einbandfragmente, 14./15. Jh.) C 54

Lucas de Bitonto, Sermo C 8, 159r

Luder, Petrus

- Modus epistolandi et orandi C 61,290r

- Rhetorica C 61, 294v

Lütishofen, Burkard von (P) C 64

Lütishofen, Friedrich von

(P) C 40, C 41, C 43, C 44, C 51, C 61, C 62, C 63, C 64, C 65

(S) C 40, C 43 (160vb-169vb), C 44 (Teile 1 und 2), C 61 (Glossen) Lütishofen, Konrad von C 44

Lütishofen, Ludwig von (P) C 44, Teil 4; C 50 (?)

Lütishofen, Ottilie von C 41, C 44

Luternau, Andreas von StiAB 01.01.714, 2 $2^{\mathrm{r}}, 18^{\mathrm{r}}-30^{\mathrm{r}}$ und $134^{\mathrm{r}}$

Luzerner Stadtrecht siehe Stadtrecht, Luzern

Map, Walter, Dissuasio Valerii C 57, 201 va

Mardach, Eberhard (?), Speculum de arte moriendi C 46, $338^{\text {ra }}$

Marquard von Lindau, De poenis inferni C 46, 304 $4^{\mathrm{va}}$

Marsilius de Inghen, Quaestiones super libris de generatione et corruptione Aristotelis C 41, $2^{\mathrm{r}}$

Matthaeus de Cracovia, Dialogus rationis et conscientiae A 66 fol., Teil 5, $1^{\text {ra }}$ 
Matthaeus von Königsaal, Sermo C 52, $71^{\mathrm{r}}$

Mauburnus, Johannes, Sermo C 52, $16^{\mathrm{v}}$

Mauritius de Praga, Sermones C 52, 94v, 98v, 101v, $104^{\mathrm{r}}$

Menger, Konrad (S) C 40, Teil 1; C 41, Teil 2

Meyger, Bernard StiAB 01.01.714, 137v

Meyger, Peter StiAB 01.01.714, 1v, $8^{\mathrm{r}}, 133^{\mathrm{v}}-134^{\mathrm{r}}$ und $135^{\mathrm{r}}$

Miracula C 8, 170 $\mathrm{r}, 191^{\mathrm{v}}$

Missale C 5 fol., C 55

- Einbandfragment C 10 (13./14. Jh.), StiAB 01.01 .635 (14. Jh.)

Moralia dogmata philosophorum C 51, $140^{\mathrm{r}}$

Münnerstadt von siehe Albert v. M.; Friderich v. M.; Ytelclaus v. M. Müntzinger, Johannes C 51, 128v, 132 va $135^{\text {ra }}$

Murer, Henmann siehe Henmannus Murer

Nicolaus IV. papa, Bulla «Supra montem» C 8, $149^{v}$

Nicolaus de Dinkelspuhel

- Casus missae C 64, 270va

- Sermones C 42, $241^{\text {ra }}$

Nicolaus Magni de Iawor, Sermo super quattuor passionibus DNI Christi C 10, $228^{\mathrm{r}}$

Nider, Johannes siehe Johannes Nider

Notation

- Hufnagelnotation StiAB 01.01.615, S. 57-66

- Neumen II C 1 ( $\left.8^{\mathrm{r}-\mathrm{v}}, 66^{\mathrm{v}}-67^{\mathrm{v}}, 94^{\mathrm{r}}-95^{\mathrm{r}}\right)$; II C 2, StiAB 01.01.634a (37rb-38va)

- Quadratnotation II C 2, 32v, 33 ${ }^{\mathrm{r}}$

- Einbandfragmente C 10 (13./14. Jh.), C 42 (12. Jh.), C 43 (12. Jh.), C 51, C 62, StiAB 01.01 .603 (13. Jh.)

Octo species turpitudinis C 9, 93

Officium Francisci (Einbandfragment, 14. Jh.) C 42

Osterlied StiAB 01.01.616, 46

Oswald OFM (P) C 12

Paternoster (deutsch) StiAB 01.01.617, 34 ${ }^{\mathrm{r}}$

Paulus apostolus siehe Biblia sacra

Peregrinus de Oppeln

- Sermo de assumptione BMV C 14, 264v

- Sermo de nativitate BMV C 53, $73^{\text {ra }}$

Petrus de S. Benedicto, Sermo C 53, $132^{\text {rb }}$

Petrus Hispanus, Summulae logicales (Einbandfragment, 13. Jh.) C 41

Petrus Lombardus, Sententiae (Einbandfragmente, 15. Jh.) C 10

Petrus de Pulka, Sermo C 52, 116r
Pfirter, Oswald (Einbandfragment, 1392) C 67

Pfrundlehenurbar StiAB 01.01.736, S. 1

Philippus Victoris (P) C 14

Physiologus (Exzerpte) C 8, 192v, $193^{\mathrm{v}}$

Pius II papa

- De curialium miseriis C $46,172^{\text {ra }}$

- De duobus amantibus (GW M33482) C 65, 299 ra

- Epistula de legatione Bohemica ad cardinalem Johannem C 46, $186^{\mathrm{ra}}$

- Oratio 'Constantinopolitana clades' C 46, $166^{\text {ra }}$

- De remedio amoris (GW M33482) C 65, 317vb

Propstei-Rotbuch StiAB 01.01.463

Provenienz I (Schriftheimat)

- Aargau (?) C 42

- Basel StiAB 01.01.718 und 719

- Beromünster (?) C 5 fol., C 52, II C 1 (107 $\left.7^{\mathrm{va}}-114^{\mathrm{vb}}\right)$, StiAB 01.01.463, StiAB 01.01.599, StiAB 01.01.600, StiAB 01.01.602, StiAB 01.01.603, StiAB 01.01.615, StiAB 01.01.616, StiAB 01.01.617, StiAB 01.01.634a, StiAB 01.01.635, StiAB 01.01.663, StiAB 01.01.709, StiAB 01.01.714, StiAB 01.01.715; StiAB 01.01.736

- Birndorf(?) C 54

- Buochs C 53

- Heidelberg (?) C 40

- Hitzkirch (?) C 14, Teil 3

- Reichenau (?) II C 3

- Schwarzenbach (?) C 5 fol., StiAB 01.01.615

Provenienz II (Besitzer) siehe Göldlin von Tiefenau, Joachim; Göldlin von Tiefenau, Renward; Hertenstein, Leodegar; Hilflin, Jacobus; Lütishofen, Friedrich von; Lütishofen, Ludwig von; Philippus Victoris; Selden, Werner von; Väsen, Jakob; Zeller, Ludwig

Psalterium glossatum, C 51, $1^{\text {r }}$

Quaestiones super Aristotelis libros de anima C 41, 114

Ratsamhausen (Ratzenhusen), Heinrich von (Einbandfragment) C 67

Reber von Laufenburg, Hermann (S) C 45

Rechnungsbuch StiAB 01.01.714

Reliquienverzeichnis II C 1, 107va; StiAB 01.01.615, S. 95

Remishůb, Johannes (S) C 61 (?), C 64

Rezept C 49, vorderer Spiegel

Rotbuch StiAB 01.01.463

Rotes Jahrzeitbuch StiAB 01.01.599 
Růdolfus Grünli siehe Grünli, Růdolfus

Ruwe, Heinrich, Notar (S) StiAB 01.01.718 und 719

Rvačka, Mauritius siehe Mauritius de Praga

Salzmann, Johannes, Notar (S) StiAB 01.01.718 und 719

Schaler, Werner (Einbandfragment, 1392) C 67

Schatt, Abraham (S) StiAB 01.01.715, 1 $1^{\mathrm{r}}-2^{\mathrm{r}}, 56^{\mathrm{r}}, 89^{\mathrm{v}}-90^{\mathrm{v}}, 105^{\mathrm{r}-\mathrm{v}}$, $112^{\mathrm{v}}-113^{\mathrm{r}}, 121^{\mathrm{v}}, 123^{\mathrm{v}}-124^{\mathrm{v}}, 126^{\mathrm{r}}-138^{\mathrm{r}}, 139^{\mathrm{r}}-143^{\mathrm{v}}$, $146^{\mathrm{r}}-148^{\mathrm{r}}, 165^{\mathrm{v}}-165^{\text {[bis] }} \mathrm{v}, 194^{\mathrm{r}}-195^{\mathrm{r}}, 219^{\mathrm{v}}-222^{\mathrm{r}}, 233^{\mathrm{r}}$

Schenkungsvermerk C 13 fol, $272^{\mathrm{vb}}$

Schinbein, Leodegar (S) StiAB 01.01.715, 92r $138^{\mathrm{v}}, 144^{\mathrm{r}}-145^{\mathrm{v}}$, $148^{\mathrm{v}}-151^{\mathrm{r}}, 153^{\mathrm{r}}-155^{\mathrm{v}}, 171^{\mathrm{r}}-172^{\mathrm{r}}, 202^{\mathrm{r}}$

Schoch, Konrad siehe Menger, Konrad

Scholastica (Einbandfragmente) C 11 (14. Jh.), C 54 (13./14. Jh.), C 57 (14.Jh.)

Schongau (Jahrzeitbuch) StiAB 01.01.616

Schreiber siehe Dörflinger, Johannes; Ebinger, Thomas; Eggli, Johannes; Erni, Andreas; Friderich von Münnerstadt, Johannes; Gartner, Heinrich; Goltz, Heinrich; Grünli, Rudolf; Hilflin, Jakob; Hitzmann, Johannes; Lütishofen, Friedrich von; Menger, Konrad; Albert von Münnerstadt; Murer, Henmann; Reber von Laufenburg, Hermann; Remishůb, Johannes von; Ruwe, Heinrich; Salzmann, Johannes; Schatt, Abraham; Schinbein, Leodegar; Schumacher, Johannes; Väsen, Jakob; Wachter, Ulrich; Ytelclaus von Münnerstadt, Johannes; Zeller, Ludwig Schreibervermerke C 5 fol., $131^{\mathrm{rb}}$ und 232 $2^{\mathrm{ra}}$ C $9,94^{\mathrm{v}}$; C 10, $52^{\mathrm{v}}$, $57^{\mathrm{r}}, 100^{\mathrm{r}}$ und 220v $; \mathrm{C} 14,261^{\mathrm{vb}} ; \mathrm{C} 40,211^{\mathrm{r}} ; \mathrm{C} 41,184^{\mathrm{r}}$ und

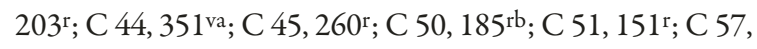
$48^{\mathrm{vb}}, 74^{\mathrm{rb}}, 116^{\mathrm{vb}}$ und $201^{\mathrm{rb}} ; \mathrm{C} 64,265^{\mathrm{r}}$

Schumacher (Calceatoris), Johannes siehe Johannes Calceatoris de Lentzburg

Schwarzbuch StiAB 01.01.715

Schwarzenbach (Jahrzeitbuch) StiAB 01.01.615

Selden, Werner von, gen. Oeristein (P) C 69

Sermones C 8, 50 r $51^{\mathrm{v}}, 53^{\mathrm{r}}, 107^{\mathrm{r}}, 154^{\mathrm{r}}, 158^{\mathrm{r}}, 158^{\mathrm{v}}, 159^{\mathrm{r}}, 159^{\mathrm{v}}, 161^{\mathrm{r}}$, $161^{\mathrm{v}}, 179^{\mathrm{v}}, 180^{\mathrm{r}}, 181^{\mathrm{v}} ;$ C 9, 100 $\mathrm{r}, 115^{\mathrm{ra}}$; C 42, 193 $3^{\mathrm{ra}}$

(Pfingsten), 229ra (Kirchweih), 234vb (Neujahr), 308 rb

(Pfingsten); C 46, 37 ra (Pfingsten - Dominicus); C 52, $1^{\mathrm{r}}$

- Einbandfragmente 15. Jh. C 57

Sermones de sanctissima eucharistia siehe Aegidius Romanus

Speculum clericorum, C 51, $152^{\mathrm{r}}$

Speculum peccatoris $\mathrm{C} 10,48^{\mathrm{r}}$

Stadtrecht, Luzern StiAB 01.01.463, 144 ${ }^{\mathrm{r}}$

Stephanus de Palecz, Sermo C 52, 130v
Summa poenitentiae Fratrum Praedicatorum C 8, $117 \mathrm{v}$

Symbolum C 8, 182v

Symbolum (deutsch) StiAB 01.01.617,34r

Symbolum Apostolorum C 51, $132^{\text {va }}$

Symbolum Athanasii glossatum cum expositione C 51, 128v

Symbolum Nicaenum C 51, $135^{\text {ra }}$

Terentius Afer, P. C 61, $1^{\text {r }}$

Theobaldus de Saxonia, Sermo C 52, 89v

Theodoricus de Monasterio, Sermo C 52, 63v $107^{\mathrm{v}}, 124^{\mathrm{v}}$

Thomas Cisterciensis, Commentaria in Cantica canticorum (Einbandfragment, 13./14. Jh.) C 52

Thomas Palmeranus, Manipulus florum (Acceptio personarum Conversatio) C 46, $281^{\text {ra }}$

Tractatulus de quinque floribus mundi contemnendis C 46, $246^{\mathrm{r}}$

Tractatus de adventu spirituali C 11, 133

Tropar II C 2, 60

Turibius episcopus Tudensis (Administrator der Diözese Tui) (Einbandfragment, 1392) C 67

Udalricus de Campo Liliorum, Concordantiae caritatis C 9, 192 ${ }^{\mathrm{r}}$

Ůlricus Wachter de Louffenberg (S) C 54

Urbar StiAB 01.01.599, Teil 2 (51 $\left.1^{\text {ra }}, 62^{\text {ra }}, 68^{\text {va }}, 69^{\text {ra }}, 70^{\text {ra }}, 81^{\text {ra }}\right)$; StiAB 01.01.600, Teil 2 (S. 209, 329); Urbar StiAB 01.01.603, 99r, 183' ; StiAB 01.01.736

Urkunden C 5 fol., 78 ${ }^{\mathrm{ra}}-82^{\mathrm{vb}}$; StiAB 01.01.615, S. 94-98; StiAB 01.01.616, 45 ${ }^{\mathrm{r}-\mathrm{v}}$ (Nachträge); StiAB 01.01.634a (Kopialbuch); StiAB 01.01.635 (Kopialbuch); StiAB 01.01.715 (Kopialbuch)

- Einbandfragmente

$1392 \mathrm{C} 67$

$1394 \mathrm{C} 67$

13./14. Jh. C 10

14. Jh. C 61, C 49

1435 C 63

14./15. Jh. C 57

um 1410 (?) C 64

Väsen, Jakob (S?, P) C 42

Vaterunser siehe Paternoster

Vergilius Maro, P., Eclogae C 61, $261^{\mathrm{r}}$

Vergilius Maro, P., Georgica C 61, $204^{\mathrm{r}}$

Versus alleluiatici II C 2, 31v, $53^{\mathrm{v}}$

Visio Pauli C 8, 183 ${ }^{\mathrm{r}}$

Vocabularium C 44, 198 ra 
Wachter, Ulrich siehe Ůlricus Wachter de Louffenberg Walter Map siehe Map, Walter

Weisses Jahrzeitbuch StiAB 01.01.600

Winterhalter, Heinrich StiAB 01.01.714, 33 $3^{\mathrm{r}}-35^{\mathrm{r}}$

Wolf, Kilian, siehe Kilianus Lupi

Ytelclaus von Münnerstadt, Johannes, Notar (S) StiAB 01.01.718 und 719
Zachariae, Johannes siehe Johannes Zachariae

Zacharias Chrysopolitanus, In unum ex quattuor C 43, 20 ra; C 52, $145^{\mathrm{ra}}$

Zehnten StiAB 01.01.599, 79vb (Teil 2)

Zeller von Brugg, Ludwig

(P) A 66 fol., C 9, C 10, C 11, C 12, C 13, C 45, C 57, C 69

(S) C $9\left(93^{\mathrm{r}}-94^{\mathrm{v}}\right)$, C 10 (Teil 2), C 57 


\section{Register der Initien}

Initien, die nicht im Katalogtext, sondern nur im Registerteil erscheinen, sind mit Stern gekennzeichnet.

* Abeuntes Pharisaei ... (Mt 22,15). Istud evangelium scribitur Matthaei $22^{\circ}$ capitulo, et legitur postquam Ihesus dixisset et proposuisset multas parabolas Iudeis ... Istud est evangelium in sensu suo: Abeuntes pharisaei etc. In isto evangelio $4^{\text {or }}$ sunt consideranda, duo ex parte phariseaorum et duo ex parte Christi C $11,124^{\mathrm{v}}$

* Abiit Ihesus trans mare ... (Io 6,1). Istud primum verbum, quod evangelium dicit: abiit Ihesus, hoc sic debet sonare et clamare in corde et spiritibus uniuscuiusque fidelis hominis C $53,50^{\mathrm{vb}}$

Abraham: Pater videns populum vel multitudinem, vel pater multarum (subaudis: gentium). Aminadab C 43, 293 ${ }^{\text {rb }}$

* Ad commendationem status virginalis notandum est, quod virginitas commendatur deo dilectissima, angelo similissima, homini utilissima C 53, 164rb

Ad eum veniemus ... (Io 14,23). His verbis consolatur dominus discipulos suos recessurus promittens se spiritualiter venturum C 53,71vb Ad habendum salutiferae confessionis ordinem C 8, 136

* Aemulor enim vos ... (2 Cor 11,2). Glossa: Aemulor vos, id est diligo vos; dei aemulatione, id est ad honorem dei, non meum C 53, $130^{\text {rb }}$ Alius frater impugnabatur a spiritu fornicationis C $8,187 \mathrm{v}$

* Amantissimus dei ... (Dt 33,12). Sancti de tribus in praesenti maxime solent dubitare: primo de statu in corpore C 53, $148^{\mathrm{vb}}$ Ambrosius autem in praefatione de hoc martyre sic ait C 12, 209v

* Amen, amen dico vobis (Io 10,1). Istud evangelium scribitur Iohannis $\mathrm{X}^{\mathrm{o}}$, et legitur ibidem quod postquam Ihesus curavit illum caecum ... Istud est evangelium in sensu suo: In isto evangelio tria ponuntur. Primum est quod dominus comparat se pastori C 11,76

* Amen, amen dico vobis ... (Io 16,23). Istud evangelium scribitur Iohannis 16, et legitur in eodem capitulo, quod dominus dixit ad discipulos suos: Modicum et iam non videbitis me ... Istud est evangelium in sensu suo etc.: Petite et accipietis. Est igitur notandum quod $4^{\text {or }}$ sunt nobis neccessaria si volumus a deo exaudiri C $11,68^{\mathrm{r}}$

* Amen, amen dico vobis ... (Mt 5,20). Istud evangelium scribitur Matthaei vo , et legitur postquam Ihesus dixit discipulis suis: Vos estis lux mundi ... Istud est evangelium in sensu suo: Vade prius reconciliari fratri tuo etc. Est igitur notandum quod quilibet christianus habet tres fratres C $11,90^{\mathrm{r}}$

Amen dico vobis ... (Mt 11,11). Laudari potest aliquando homo a seipso aliquando ab homine C 46, 85 ra

* Angelus domini apparuit ... (Mt 2,13). In his est notandum, quomodo dominus noster Ihesus Christus ex nimia pietate sua praecipit sacerdotibus $C 53,83^{\text {ra }}$

Anna concepit filium ... (I Sm 1,20). Carissimi, licet hoc verbum de matre Samuelis prophetae sit dictum, tamen convenienter possunt dici de sancta Anna, matre matris Christi C 9, 106

Anna tribus nupta tres sunt enixae Marias C 8, $193^{\mathrm{v}}$

Antequam lectura commenti tam sublimis tamque profundae indaginis ingredi praesumam, si lectura dici mereatur, tria seriatim habeo praeponere C $45,1^{\mathrm{r}}$

Apparuerunt illis dispertitae linguae ... (Act 2,3). Circa istas linguas in quibus apparuit spiritus sanctus tria videnda sunt: Primo quare in linguis apparuit C 46, $50^{\text {ra }}$

* Apparuit enim gratia dei ... (Tit 2,11). Originaliter Ad Titum ii ${ }^{\circ}$, et legitur in currentis sollemnitatis primo missali officio. Cum haec apparitio facta sit propter nos, causas eius perscrutemur C $52,142^{\mathrm{v}}$

* Apparuit gratia dei ... (Tit 2,11). Apparuit gratia salvatoris nostri etc. In quo apparuit? In hoc, quod filium suum nobis hodie dedit C 9 , $125^{\mathrm{ra}}$

* Apparuit gratia dei ... (Tit 2,11). Nota quod duplex est gratia dei, scilicet gratia gratis data, ut pulchritudo et fortitudo corporis et dulcedo vocis et huiusmodi C 9, $133^{\text {va }}$

* Apud provinciam Raetiam in civitate Augusta habitavit Afra cum matre sua nomine Hilaria C 12, 186v

* Ascendens Ihesus in naviculam ... (Mt 9,1). In evangelio isto tria nobis consideranda sunt: Primo, quod dominus per naviculam in civitatem suam transivit C $53,68^{\mathrm{rb}}$ 
* Ascendens Ihesus in naviculam ... (Mt 9,1). Istud evangelium scribitur Matthaei viiio, quia legitur in eodem capitulo postquam Ihesus curaverat socrum Simonis ... Istud est evangelium in sensu suo: Et ideo notandum est quod per mare intelligitur praesens mundum propter $4^{\text {or }}$ causas $\mathrm{C} 11,26^{\mathrm{r}}$

* Ascendens Ihesus in naviculam ... (Mt 9,1). Istud evangelium scribitur Matthaei 9º, et legitur postquam venit in terram Genezareth accurrerunt ei duo homines habentes daemonia ... Istud est evangelium in sensu suo: Ascendens Ihesus etc. In isto evangelio tria ponuntur, primo de navicula quam Ihesus intravit $\mathrm{C} 11,117^{\mathrm{r}}$

* Ascendente Ihesu in naviculam ... (Mt 8,23). In verbis istis notare possumus, quid mare, quid navicula, quid motus aquae C 53, $47^{\mathrm{ra}}$

* Assumpsit Ihesus xii discipulos suos ... (Lc 18,31). Istud evangelium scribitur Lucae xviii ${ }^{\circ}$, capitulo, quia in eodem capitulo legitur quod ille princeps Iudaeorum interrogabat Ihesum ... Istud est evangelium in sensu suo etc.: In isto evangelio tria tanguntur, primum est quod Christus praedixit suam passionem C $11,36^{\mathrm{r}}$

* Assumpsit Ihesus Petrum ... (Mt 17,1). Id est: qualis erat per naturam, talem se ostendit hic. Historia scholastica de transfiguratione domini C 9, $173^{\text {rb }}$

* Attendite a falsis prophetis ... (Mt 7,15). Hodie, dilectissimi, docet nos dominus noster Ihesus Christus in hodierno Evangelio ut nos caveamus a quibusdam hominibus $\mathrm{C} 53,62^{\text {ra }}$

* Attendite a falsis prohetis ... (Mt 7,15). Istud evangelium scribitur Matthaei vii ${ }^{\circ}$, et legitur quod quando dominus ad discipulos suos dixit: Omnia quaecumque vultis ut faciant vobis ... Istud est evangelium in sensu suo etc.: Attendite a falsis etc. Est igitur notandum quod tres sunt false prophetae a quibus quilibet christianus debet se cavere $\mathrm{C} 11,94^{\mathrm{r}}$

Augens fidem christianam Augustinus sane sanam dat doctrinam et prophanam damnat idolatriam C 5 fol., $177 \mathrm{rb}$

Augustinus: Sicut sine pane est mensa vilis, quia sicut panis est melior omnibus escis C 8, 166 ${ }^{\mathrm{r}}$

Avarus homo similis est inferno C 8, 192v

* Ave gratia plena ... (Lc 1,28). In verbis istis commendatur beata virgo Maria ut purissima propter omnis mali absentiam ibi Ave C 53, 157vb Ave gratia plena ... (Lc 1,28). In verbis propositis annuntiat caelestis nuntius plenitudinem gratiae virgini Mariae C 53, 156 va

Aves secundum Isidorum dictae sunt eo quod vias certas non habent C $14,1^{\mathrm{r}}$

Beatam me dicent ... (Lc 1,48). Merito omnes generationes fidelium gloriosam virginem beatam dicere et altis laudibus extollere propter triplex bonum C 53, $72^{\text {ra }}$

* Beati mortui ... (Apc 14,13). Nota, quod quattuor sunt genera hominum in mundo morientium: Alii moriuntur in domino C 53, 143 Beati mundo corde (Mt 5,8). Hoc est autem mundum cor, quod simplex ... C 52, $137^{\mathrm{r}}$

* Beati oculi qui vident ... (Lc 10,23). Istud evangelium scribitur Lucae $\mathrm{x}^{\mathrm{o}}$, et legitur quod dominus noster postquam misit lxxii discipulos binos et binos ... Istud est evangelium in sensu suo: Diliges dominum deum tuum. Est igitur notandum quod aliquis diligit alium propter $4^{\text {or }} \mathrm{C} 11,104^{\mathrm{r}}$

* Beati oculi qui vident ... (Lc 10,23). Notandum est ergo, quid viderint: ipsi namque viderunt magna et inaudita C 53, 65 ra

Beati qui persecutionem patiuntur ... (Mt 5,10). Originaliter Matthaei v ${ }^{\text {to }}$, et recitantur usualiter in instantis celeberrimae sollemnitatis evangelio. Tristitia vestra vertetur in gaudium ... (Io 16,20). His verbis secundum communes doctores invitantur ad perseverantiam C 52, $133^{\mathrm{r}}$

* Beatus homo qui invenit sapientiam ... (Prv 3,13). Multum laudantur, qui sciunt cavere ab astutiis diaboli C 53, $121^{\text {ra }}$

* Beatus Pantaleon fuit senatoris filius, qui misit eum Euphosino peritissimo medico nutriendum C 12, 184v

Bene omnia fecit ... (Mc 7,37). Matthaei vito et in evangelio currentis dominicae verba haec habentur. Salutiferum dirae pressurae victorem C 52, $89^{\mathrm{v}}$

* Benedic, domine, domum istam etc. Hodie, fratres carissimi, cum hymnis et canticis agimus anniversarium dedicationis huius ecclesiae C $53,75^{\mathrm{rb}}$

* Benedicat nos deus ... (Ps 66,8). Carissimi, in istis octo diebus celebravimus sollemnitatem sancti spiritus C 53, 58 ra

Benedicat nos deus ... (Ps 66,8). Sicut dicit Hieronymus ad Heliodorum: Grandis materiae ingenia non sufferunt et ideo in ipso conatu ultra vires ausa succumbunt $C 46,57^{\mathrm{ra}}$ 
Benedictus qui venit ... (Mt 21,9). Verba proposita dicta sunt de adventu Christi in carnem. In adventu autem suo in carnem attulit nobis Christus $\mathrm{x}$ benedictiones $\mathrm{C} 9,115^{\mathrm{ra}}$

* Bernardus: Computatio dilata multa oblivisci facit. Sic ille obliviscitur, qui differt confiteri C 53, $168^{\mathrm{rb}}$

Bonum certamen certavi ... (II Tim 4,7). Ut aliqua pugna sit strenua debet ibi esse causa, constantia, sapientia et victoria, respicit triumphum C 46, $109^{\text {ra }}$

* Caecus sedebat secus ... (Lc 18,35). Iste caecus petivit a domino, ut reciperet visum C 9, $153^{\text {va }}$

Cantemus de sancta Fide cum sonora cordis fide fideles magnalia C 55, $9^{\text {ra }}$

* Christus assistens pontifex ... (Hbr 9,11). Dicere propono, quomodo Christus sit pontifex animarum nostrarum C 9, 183 va

Circa initium libri de spiritu et anima sumitur haec propositio: Oportet nos speculari in rebus C 57, 192 va

Circa primum librum de caelo et mundo. Post librum Physicorum, in quo determinatum est de principiis et passionibus rerum naturalium in communi, sequitur in ordine librorum naturalium secundus, scilicet praesens liber De caelo et mundo, in quo determinatur in speciali de rebus naturalibus $\mathrm{C} 40,133^{\mathrm{r}}$

Confessio debet esse praevisa C $8,114^{\mathrm{v}}$

Confitebor ... (Mt 11,25). Beatus Matthaeus, qui hoc scribit evangelium, non dicit ad quid pertineat haec responsio. Lucas autem narrat C $53,47 \mathrm{v}$

* Confiteor tibi, domine ... (Mt 11,25). Quae sunt illa secreta consilia patris? Haec sunt inspirationes divinae C 53, 47va

* Convertimini ad me ... (Ioel 2,12). Dicit dominus peccatoribus: Convertimini ad me. Unde igitur? De peccatis, de mundo, de diabolo C $9,161^{\mathrm{rb}}$

Cor mundum crea ... (Ps. 50,12). In verbis propositis duo notantur, quae exiguntur principaliter in dei servitio. Primum est interioris hominis munditia ... C 53, $106^{\mathrm{ra}}$

Cottidie duplicem praebenda dat haec tibi panem StiAB 01.01.634a, 37 rb

* Cum appropinquaret dominus Hierosolymam ... (Lc 19,41). Et dixit: O Hierosolyma, quia si cognovisses supponit et tu scilicet cladem tibi futuram sicut ego C $53,63^{\text {va }}$

* Cum appropinquaret Ihesus Hierosolymam (Lc 19,41). Istud evangelium scribitur Lucae xix, et legitur quoniam dominus ivit ad Hierosolymam ... Istud est evangelium in sensu suo etc.: Vidit Ihesus civitatem. In isto evangelio notatur quod laetitia huius mundi statim vertitur C $11,97 \mathrm{v}$

* Cum appropinquasset Ihesus Hierosolymam ... (Mt 21,1) Istud evangelium scribitur Matthaei xxi ${ }^{\circ}$, legitur enim praecedenti capitulo, quod Ihesus assumpsit xxii discipulos suos secreto et ait illis: Ecce ascendimus Hierosolymam ... Istud est evangelium in sensu suo: In isto evangelio $4^{\text {or }}$ ponuntur in quibus dominus hodierna die fuit honorificatus $C 11,49^{\mathrm{r}}$

* Cum appropinquasset Ihesus ... (Mt 21,1). In hoc evangelio quinque occurrunt consideranda. Primum est asinus, secundum Christus C 9, $187^{\mathrm{vb}}$

Cum audieritis proelia et opiniones bellorum ... (Mt 24,6 resp. Mc 13,7). Quia magnum periculum quando rex sive miles nescit quae imminent C 46, $78^{\mathrm{rb}}$

Cum audisset Iohannes in vinculis ... (Mt 11,2). Istud evangelium scribitur Matthaei xi, quia legitur in praecedenti capitulo quod Ihesus dixit ad discipulos suos: Ecce ego mitto vos ... Istud est evangelium in sensu suo: Hodie enim et isto tempore peragitur festum de adventu domini C $11,2^{v}$

* Cum audisset Iohannes in vinculis ... (Io 11,2). Quod beatus Iohannes de carcere ad dominum misit duos nuntios, per hoc instruimur et admonemur C $53,44^{\mathrm{vb}}$

* Cum autem descendisset Ihesus ... (Mt 8,1). In verbis istis tria nobis consideranda sunt, quae ecclesiae sanctae ad doctrinam sunt scripta C 53, 46 va

* Cum complerentur dies Penthecostes ... (Act 2,1). Hodie in toto orbe terrarum cum hymnis et canticis colitur sanctissimus adventus spiritus sancti C 53, $57^{\mathrm{ra}}$

* Cum descendisset Ihesus de monte ... (Mt 8,1). Istud evangelium scribitur Matthaei xviiio (sic), quia legitur in eodem capitulo, quod Ihesus fuit in monte Tabor et docuit ibi discipulos suos ... Istud est evangelium in sensu suo: In isto evangelio iiiior considerantur, 
primo descensio de monte C $11,23^{\mathrm{v}}$

* Cum dilexisset suos ... (Io 13,1). Numquam aliquis alium tantum dilexit, sicut Christus nos. Quod apparet in tribus, ut de aliis taceam C 53, 99vb

* Cum dilexisset suos ... (Io 13,1) Tria magna signa dilectionis ostendit nobis dominus. Primum est, quod pro nobis factus est homo C 9 , $189^{\mathrm{va}}$

* Cum ergo sero esset die illa ... (Io 20,19). Istud evangelium scribitur Iohannis xxº , et legitur in eodem capitulo, quod postquam Maria Magdalena quaesivisset corpus domini in monumento ... Istud est evangelium in sensu suo: Infer digitum tuum huc etc. Dominus fecit Thomae sicut facit magister puerorum in scholis C $11,59^{\mathrm{v}}$

* Cum esset sero ... (Io 20,19). Beati qui non viderunt et crediderunt. Istud verbum est consolatorium C 53, $53^{\text {va }}$

* Cum factus esset Ihesus ... (Lc 2,42). In verbis istis tria notanda sunt, quae beatus evangelista hodie de Ihesu filio dei dicit C 53, 45vb Cum igitur de plurimis virtutibus te desiderem admonere, imprimis cupio, ut virtutem caritatis ante omnia studeas habere $\mathrm{C} 8,185^{\mathrm{r}}$

* Cum intraret Ihesus in domum ... (Lc 14,1). In verbis istis notandum est quod propter tria intravit in domum istius principis C 53, 67rb

* Cum intraret Ihesus in domum cuiusdam principis ... (Lc 14,1). Istud evangelium scribitur Lucae 14, et legitur postquam Ihesus dixisset haec verba ... Istud est evangelium in sensu suo: Et ecce homo hydropicus erat ante illum etc. Est igitur notandum quod per istum hydropicum intelligitur avarus C $11,113^{\mathrm{r}}$

* Cum intraret Ihesus in quoddam castellum ... (Lc 17,12). Castellum, in quod Ihesus intravit, praesentem mundum designat C 53, 65

* Cum natus esset Ihesus... (Mt 2,1). Cum creator omnium creaturarum formam servi pro servis suis acciperet C 53, 81 ra

* Cum sancta legio Thebaeorum ab episcopo Hierosolymitano nomine Zabdo fidem Christianam suscepisset C 12, 194

* Cum turba multa esset cum Ihesu (Mc 8,1). Istud evangelium scribitur Marci viiio, et legitur, quod postquam Ihesus curaverat illum mutum qui fuit ductus ad eum quando fuit apud mare Galileae ... Dicit enim Chrysostomus quod sit credendum quod homines qui secuti fuerunt dominum quod sine cibo venerunt ad eum in solitudine $\mathrm{C} 11,92^{\mathrm{r}}$

* Cum turbae irruerent in Ihesum ... (Lc 5,1). Istud evangelium scribitur Lucae vo, et legitur postquam Ihesus curaverat Simonem ... Istud est evangelium in sensu suo etc.: Cum turba etc. Est notandum quod $4^{\text {or }}$ tanguntur in isto evangelio, primo quod libenter debemus audire verbum dei C $11,88^{\mathrm{r}}$

* Cum turbae irruerunt ... (Lc 5,1). Per turbam istam intelliguntur homines, qui in iuventute sua, quando deo debebant servire, diabolo adhaeserunt C 53, 60vb

* Cum venerit filius hominis ... (Mt 25,31). Hic agitur de die extremi iudicii C 9, $121^{\text {ra }}$

* Cum venerit paracletus ... (Io 15,26). In verbis istis notare debemus, quod dominus noster spiritum sanctum propter tria in mundum misit C 53, 56 ra

* Cum venerit paracletus ... (Io 15,26). Istud evangelium scribitur Iohannis $\mathrm{xv}^{\mathrm{o}}$, quia postquam Ihesus exiens de mundo et ad caelos ascendens apostolos relinquit ... Istud est evangelium in sensu suo: Est igitur notandum quod in evangelio isto for $^{\text {tanguntur. Primo }}$ ostendit quod spiritus sanctus non solum a filio deberet venire nec a patre solum C $11,70^{\mathrm{r}}$

* Cum videritis abominationem ... (Mt 24,15). Istud evangelium scribitur Matthaei $24^{\circ}$ capitulo, et legitur, quia dominus exivit quodam die de templo et venerunt discipuli eius et dixerunt de aedificatione templi ... Istud est evangelium in sensu suo etc.: Videbunt filium hominis etc. Unde Isidorus in libro de summo bono: In iudicio reprobi humanitate $[\mathrm{m}]$ in qua iudicaturus esse videbunt eum ut doleant, divinitatem eius non videbunt ne gaudeant C 11, 128v

Daniel propheta vidit exire de mari $4^{\text {or }}$ bestias feroces C $8,161^{\mathrm{v}}$

De tribus salvandorum, quae significari possunt per tres propagines, ad nostram aedificationem dicendum esse propono C 53, $141^{\mathrm{rb}}$

* De tribus signis altae remunerationis secundum aliquam coniecturam tria dicam, quae significari possunt per solem, lunam et stellas, quas vidit Ioseph C 53, $141^{\mathrm{vb}}$

* Debemus inimicos nostros diligere propter ista: Primo ut Christum imitemur tamquam filii suum patrem C 53, $165^{\text {vb }}$

* Deus in adiutorium meum intende ... (Ps 69,2). Sicut vulgariter dicitur: Ille est bene adiutus, quem deus voluerit adiuvare C 53, $98^{\mathrm{va}}$

* Dicite filiae Sion ... (Mt 21,5). Verba ista possunt exponi de adventu domini ad cor hominis C 9, 122 vb

Dico autem vobis amicis meis ... (Lc 12,4). Secundum autem Augustinum duo amores et duo timores sunt causa omnis boni et omnis 
mali C 46, 97 va

Dirupisti domine vincula mea ... (Ps 115,17). Sancta mater ecclesia repraesentat hodie quadruplex beneficium sive opus quod ad honorem beati Petri deus fecisse videtur C 46, 139 rb

Discipulus unius eremite impugnabatur a spiritu fornicationis C $8,187^{\mathrm{r}}$

Dixit Simoni Petro ... (Io 21,15). In ceteros sanctos beatus Petrus quattuor magnas praerogativas habuisse videtur C 46, 101 ${ }^{\mathrm{vb}}$

* Dominus ad iudicium veniet ... (Is 3,14). Ad istud iudicium sicut ad aliud requiruntur septem, scilicet iudex, locus, tempus C 9, $118^{\mathrm{va}}$

* Dominus fundavit Sion ... (Is 14,32). Sion interpretatur speculum et signat hominem spiritualem, qui cottidie debet sagaciter speculari ad ea, quae sibi erunt salutifera C 53, $93^{\text {ra }}$

* Domus mea domus orationis vocabitur (Mt 21,13), in ea omnis qui petit accipit ... (Mt 7,8). Verba ista sunt scripta in Matthaeo. In quibus duo notare possumus, scilicet loci sanctitatem et dei largitatem C 53, 74 $\mathrm{rb}$

* Ductus est Ihesus in desertum ... (Mt 4,1). De tribus temptavit eum: primo de gula di[cens] si filius dei es, dic ut lapides isti panes fiant C 53, 49rb

* Ductus est Ihesus in desertum (Mt 4,1). Istud evangelium scribitur Matthaei, quia Ihesus statim post baptismum ductus est in desertum ... Illud est evangelium in sensu suo: Nota quod in isto evangelio $4^{\text {or }}$ tanguntur, primo quare temptare voluit a diabolo C $11,38^{\mathrm{r}}$

* Dum iret Ihesus in Hierosolymam (Lc 17,11). Istud evangelium scribitur Lucae xvii, et legitur, quod postquam Ihesus proposuisset discipulis suis diversas parabolas ... Istud est evangelium in sensu suo: In isto evangelio tria ponuntur. Primum est infirmitas istorum leprosorum C 11, 106

Duo fratres monachi abierunt in civitatem C $8,188^{\mathrm{r}}$

* Duo homines ascendebant in templum ... (Lc 18,10). Istud evangelium scribitur Lucae xviii ${ }^{\circ}$, et legitur, quod postquam dominus dixisset ad Pharisaeos unam parabolam de oratione ... Istud est evangelium in sensu suo: Duo homines etc. In isto evangelio duo ponuntur scilicet de Pharisaeo et publicano, quare pro informationem cuiuslibet peccatorem C $11,100^{\mathrm{r}}$

* Duo homines ascenderunt ... (Lc 18,10). In hac similitudine, quam audistis, ostendit nobis dominus quadruplicem doctrinam C 53 , $64^{\mathrm{ra}}$

Duodecim sunt abusiva huius saeculi C $8,193^{v}$

* [Ecce ascendimus Hierosolymam] ... (Lc 18,31). Ecce id est multotiens ascendimus Hierosolymam etc., sed ecce modo ascendimus ut consumentur omnia quae scripta sunt, id est quae prophetae praedixerunt de me, quia tradetur etc. Dominus sciens mortem suam instare C 53, $48^{\mathrm{vb}}$

* Ecce, ego mitto ... (Mt 23,34). Ad litteram dominus ad Iudaeos in Ierusalem misit nuntios suos, scilicet prophetas et apostolos C 9 , $126^{\mathrm{vb}}$

* Ecce motus magnus ... (Mt 8,24). Mare mundum significat propter suam amaritudinem, mundus enim est amarus C 9, 144

* Ecce nunc dies salutis ... (2 Cor 6,2). Verba sunt beati apostoli Pauli in epistola praesentis dominicae originaliter scripta $2^{\circ}$ ad Corinthos capitulo vit ${ }^{\text {to }}$. Carissimi, quia iuxta sacri canonis veritatem omnia suis debent convenire temporibus C 52, $140^{\mathrm{v}}$

Ecce quam bonum ... (Ps 132,1). Isti sancti martyres Iohannes et Paulus non tamen fuerunt fratres carne C 46, $95^{\mathrm{va}}$

Ecce rex tuus ... (Mt 21,5). Haec verba licet ad litteram dicta sunt de adventu Christi in carnem, tamen pro spirituali intellectu accipi possunt de adventu spirituali in devotam animam sive mentem ipsam C $11,133^{\mathrm{r}}$

Ecce rex tuus ... (Mt 21,5). In verbis istis innuit nobis evangelium tria: $1^{\mathrm{m}}$ est advenientis dignitas C 8, $50^{\mathrm{r}}$

* $\quad$ Ego et pater tuus ... (Lc 2,48). Istud evangelium scribitur Lucae $2^{\circ}$ capitulo, et dicit sic: Cum puer Ihesus esset annorum xii ... Istud est evangelium in sensu suo ... Notandum est quod in querendo deum iiii ${ }^{\text {or }}$ requiruntur C $11,18^{\mathrm{r}}$

* Ego sum pastor bonus ... (Io 10,11). In hoc quod dominus noster Ihesus Christus, qui est dominus et rex regum, assimilat se pastori et hoc duplici de causa C 53, 54ra

* Ego sum pastor bonus (Io 10,14). Istud evangelium scribitur Iohannis $\mathrm{x}^{\mathrm{o}}$, et legitur in eodem capitulo quod dominus noster Ihesus

Christus salvator noster dixit ad Pharisaeos ... Istud est evangelium in sensu suo etc.: Nota $4^{\text {or }}$ in pastore bono C $11,61^{\mathrm{v}}$

* Ego vos elegi ... (Io 15,19). Universitatis auctor deus omnia condidit, ut sibi servirent C 53, $112^{\text {ra }}$

* Ego vox clamantis in deserto ... (Lc 3,4). Per intellectum istius evangelii est notandum quod Herodes rex ... Istud est evangelium in 
sensu suo: Est igitur notandum quod triplex est via quam quilibet peccator debet ambulare C 11, $7^{\mathrm{r}}$

* Egredietur virga ... (Is 11,1). Consuetudo fuit antiquitus, quod reges et principes suum natalem celebrabant C 53, 73 ${ }^{\text {ra }}$

* Egredietur virga ... (Is 11,1). Originaliter leguntur Isaiae $\mathrm{xi}^{\mathrm{o}}$, et putavi ea exordialia pro praesentis proclamatorii sermonis exordiali titulo C 52, $142^{\mathrm{r}}$

* Egressus Ihesus secessit ... (Mt 15,21). Istud evangelium scribitur Matthaei xvo , quia legitur in eodem capitulo, quod postquam Ihesus fuit Genezareth et sanavit ibi multos infirmos ... Istud est evangelium in sensu suo: In isto evangelio tanguntur tria, primum est quare ista mulier invocavit dei misericordiam C $11,40^{\mathrm{v}}$

Elevata est magnificentia tua ... (Ps 8,2). Carissimi, pro introductione huius thematis dicit philosophus $4^{\circ}$ Physicorum: Quanto unaquaeque res est melius et perfectius, tanto sibi debetur locus altior $C 9,100^{\mathrm{r}}$

* Erant appropinquantes ad Hierosolymam ... (Lc 15,1). In his verbis attendere debemus, cum omnes simus peccatores C 53, 59vb

* Erant appropinquantes publicani ... (Lc 15,1). Istud evangelium scribitur Lucae $\mathrm{xv}^{\mathrm{O}}$, et legitur postquam Ihesus dixit ad Iudaeos illud evangelium ... Istud est evangelium in sensu suo: Gaudium est dei super uno peccatore etc. Est igitur notandum de conversione peccatorum gaudet deus, gaudet ecclesia C $11,85^{\mathrm{v}}$

* Erant Joseph et Maria mirantes ... (Lc 2,33). Et legitur in eodem capitulo quod Maria post purificationem secundum legem Mosi obtulit puerum suum in templo ... Istud est evangelium in sensu suo: In isto evangelio Simeon in sua prophetia qua prophetaverat de Christo domino primo domini panem et hoc per gladium, $2^{\circ}$ panis amaritudinem id est transibit animam tuam C $11,13^{\mathrm{v}}$

Erat autem alter episcopus laborans in oratione et ieiunio C $8,191^{\mathrm{v}}$

* Erat Ihesus eiciens daemonium ... (Lc 11,14). In hoc, quod evangelium ostendit, quod operatus est dominus miraculum in eiectione daemonis C 53, $50^{\text {va }}$

* Erat Ihesus eiciens daemonium ... (Lc 11,14). Istud evangelium scribitur Lucae xi ${ }^{\circ}$, legitur enim in eodem capitulo quod postquam dixisset ad discipulos: Quis vestrum habet amicum ... Istud est evangelium in sensu suo: In isto evangelio tria tanguntur istius infirmi C $11,42^{\mathrm{v}}$

Erat Petrus dormiens ... (Act 12,6). Quamvis ad litteram verum fuerit quod Petrus ab Herode devinculatus fuit et miraculose ab ipsis vinculis liberatus $C 46,140^{\text {ra }}$

* Erat proximum pascha ... (Io 6,4) Hac nocte lectum est, quod deus percussit Aegyptum x plagis maximis C 9, 181 $1^{\text {ra }}$

Erat quidam frater habitans in eremo et multum in opere domini laborabat C 8, 187v

* Erat quidam regulus (Io 4,46). Istud evangelium scribitur Iohannis, et legitur, quia salvator noster in tertiodecimo anno suo quadam die venit in Galilaeam ... Istud est evangelium in sensu suo: Erat quidam regulus etc. In isto evangelio tria ponuntur, primo ponitur hic istius reguli magna crudelitas $\mathrm{C} 11,120^{\mathrm{r}}$

* Erat quidam regulus ... (Io 4,46). Per regulum istum intelligitur quilibet fidelis homo, qui ita devote et intente deum deprecatur pro salute animae suae C $53,69^{\mathrm{rb}}$

Erit enim magnus ... (Lc 1,15). Angelus Gabriel qui nativitatem praecursoris venit nuntiare, primo Zachariam trepidantem confortavit C $46,82^{\mathrm{va}}$

* Erit enim magnus coram domino (Lc 1,15). Gabriel angelus praedicens de Iohanne, quod multi in nativitate eius gaudebuntur, causam subiunxit C 53, 159 vb

Erit magnus coram domino ... (Lc 1,15). Volens angelus magnitudinem et dignitatem Iohannis ostendere multipliciter hoc facit C 46, $87^{\mathrm{rb}}$

* Erunt signa in sole ... (Lc 21,25). Beatus evangelista Matthaeus in evangelio hodierno ostendit nobis quomodo dominus noster Ihesus Christus quadam die respondit discipulis suis C $53,44^{\mathrm{va}}$

Erunt signa in sole ... (Lc 21,25). Istud evangelium scribitur Lucae $2^{\circ}$, legitur in eodem capitulo, quod dominus postquam vidit quid partarent divites et seniores populi vidit ibi unam viduam ... Istud est evangelium in sensu suo: Nota quod Isidorus dicit quod in quolibet iudicio requiruntur $4^{\text {or }}$ persone $\mathrm{C} 11,1^{\mathrm{r}}$

Es ist ein kein dorff so klein, es werd alle Jar einest kilwi. Ita nulla reperitur villa, quin in anno ad minus semel fit dedicatio C $42,234^{\mathrm{ra}}$ Est puer unus hic ... (Io 6,9). In verbis istis notare debemus quid puer, quid quinque panes significent, et quid duo pisces $\mathrm{C} 53,71^{\mathrm{ra}}$

* Est una quaestio de accedentibus ad corpus Christi, utrum in habentibus libertatem accedendi sit melius saepe accedere vel raro C 53 , 
$170^{\mathrm{rb}}$

* Estote fortes in bello ... Verba ista recommendative ponit mater ecclesia pro evangelica antiphona et sparsim colliguntur ex scriptura authentica, decrevique ipsa in caput dicendorum statuenda. His verbis nos hortatur mater nostra, sancta ecclesia C 52, 11 ${ }^{\mathrm{r}}$

* Estote misericordes ... (Lc 6,36). Carissimi, dominus Christus, qui non vult mortem peccatoris, sed ut magis convertatur et vivat C 53, 60rb

* Estote misericordes (Lc 6,36). Istud evangelium scribitur Lucae vi ${ }^{\circ}$, et legitur, quod postquam Christus dixisset discipulis suis: Diligite inimicos vestros ... Istud est evangelium in sensu suo: Estote misericordes etc. Est igitur notandum quod homo debet esse $4^{\text {or }}$ modis misericors C $11,81^{\mathrm{r}}$

* Et cum ieiunasset Ihesus ... (Mt 4,2). Ieiunium aliquibus est fructuosum et aliquibus infructuosum C 9, 167va

Evangelizo vobis ... (Lc 2,10). Originaliter Lucae ii ${ }^{\circ}$, et recitantur hodie in evangelico officio. Verbis istis indicitur christifidelibus ipsius adventum C 52, $139 \mathrm{v}$

* Exaltavit illum ... (Sir 15,4). Et merito, quia habuit tria optima in mundo. Habet enim mundus tria optima C 53, 143 va

* Exiens Ihesus de finibus Tyri ... (Mc 7,31). In verbis istis, quae audistis, tria notanda sunt, quae ipse deus unicuique fideli homini ad doctrinam dedit C 53, 64va

* Exiens Ihesus de finibus Tyri ... (Mc 7,31). Istud evangelium scribitur Marci viio, et legitur, quod postquam Ihesus venisset in terram Tyri ... Istud est evangelium in sensu suo: Adducunt ei surdum etc. Per istum surdum et mutum peccator intelligtur C 11, 102

Exiit qui seminat ... (Mt 13,3 / Lc 8,5). In istis etenim verbis innuitur varia dispositio agri, circa quod sciendum est, quod quattuor sunt genera hominum, qui continue currunt ad praedicationem C 42, 256 ra

* Exiit qui seminat ... (Lc 8,5). Istud evangelium scribitur Lucae viii ${ }^{\circ}$, quia legitur in eodem capitulo quod postquam Ihesus exierat de domo Simonis... Istud est evangelium in sensu suo: In isto evangelio tria notantur, primo quis sit seminator C $11,33^{\mathrm{v}}$

* Exiit qui seminat ... (Lc 8,5 / Mt 13,3). Per hominem istum tres seminatores significati sunt, qui tam in hieme quam in aestate exeunt seminare C $53,48^{\mathrm{rb}}$

* Facite vobis amicos ... (Lc 16,9). Originaliter Lucae $\mathrm{xvi}^{\circ}$, et recitantur in currentis dominicae evangelio decrevique ipsa in caput dicendorum congruenter statuenda. His verbis admonemur ad pietatem $\mathrm{C} 52,5^{\mathrm{v}}$

Factum est autem ut morietur mendicus ... (Lc 16,22). Sanctus Franciscus mendicus fuit, quia omnia quae habuit propter Christum reliquit C 53, $145^{\mathrm{rb}}$

Fiet unum ovile ... (Io 10,16). Iohannis xviiio et in evangelio instantis dominicae. Ingeniti potentia, patris sapientia et procedentis ab utroque infinita gratia C $52,80^{\mathrm{r}}$

* Filius hominis venturus est ... (Mt 16,27). Tam in caelo quam in inferno diversimode dominus remunerat C 53, 135 rb

* Forma dilectionis nobis describitur Matthaei 22, Lucae 10: Diliges dominum deum tuum ex toto corde (Mt 22,37 / Lc 10,27).

Diligendus est ergo deus integraliter C $53,164^{\mathrm{vb}}$

Frequenter, fratres carissimi, ac manifeste de dei dignatione praeceptum nobis est C 8,154

Fuit quidam Abraham eremita et reclusus, serviens in orationibus et ieiuniis domino C 8, $190^{\mathrm{r}}$

Fuit quidam senator Antigonus nomine, iustus ac timens deum C 8, 188

* Futurum est enim, ut Herodes ... (Mt 2,13). Herodes diabolum significat C 9, 130 rb

* Futurum est enim, ut Herodes ... (Mt 2,13). Herodes, qui interpretatur versipellis, signat diabolum C 53, $151^{\text {va }}$

* Gaudeamus omnes in domino etc. Sancti, qui per inspirationem sancti spiritus hodiernum officium ordinaverunt, nolebant quod aliquis hodie tristaretur C 53, 84 $4^{\mathrm{rb}}$

Gloria et honore etc. (Ps 8,6). Verba proposita sunt verba psalmistae, et possumus ea dicere domino de martyre, cuius festum celebramus C $53,123^{\mathrm{rb}}$

* Gustate et videte ... (Ps 33,9). Originaliter psalmo $\mathrm{xxx}^{\mathrm{o}}$, transsumptive congruunt sollemnitati hodiernae. His verbis ad cenam domini magnam multis praeparatam invitamur C $52,3^{\mathrm{r}}$

* Hadrianus imperator et vi reges, qui venerant ei in auxilium, decem milia martyrum x Kalendas Iulii quia nolebant idolis sacrificare 
extinxit C 12, $176^{\mathrm{v}}$

* Haec dies quam fecit dominus ... (Ps 117,24). Et hac iocundissima festivitate ecclesiastica providentia persaepe repetenda C 52, 141 ${ }^{v}$

* Haec est dies ... (Ps 117,24). Fratres carissimi, modo peregimus cum devotione dies tristitiae C 53, $52^{\mathrm{va}}$

Haec est dies ... (Ps 117,24). In ista proposita materia hodie spiritus sanctus per os David ostendit laudem et gloriam virginis Mariae C $53,81^{\mathrm{vb}}$

* Haec est dies boni nuntii (4 Rg 7,9). Originaliter leguntur verba ista iiii ${ }^{\text {ti }}$ Regum viimo, et competunt currentis fesitivitatis annuntiationis intitulatae officiali obiecto. Haec dies, inquam, in kalendario nuntii sibi obtinet titulum C 52, $143^{\mathrm{r}}$

* Hesterna die Christus natus est in terris, ut hodie Stephanus nasceretur in caelis C 53, $79^{\text {rb }}$

Hi sunt ergo dies quibus hunc panem dare debes StiAB 01.01.634a, $35^{\mathrm{rb}}$

* Hic est, de quo scriptum est ... (Mt 11,10). Nota: Quidam vadunt per viam huius mundi quasi angeli C 53, 159ra

* Hic est, qui baptizat ... (Io 1,33). Hodie Christus baptizatus est in aqua, scilicet in Iordane C 9, 139ra

Hoc facite in meam commemorationem (Lc 22,19). Originaliter leguntur verba ista Lucae $22^{\circ}$, et in currenti octava persaepe et sedulo recitantur. Verbis istis exhortatur nos dominus ad crebram sui memoriam habendam C 52, $143^{\mathrm{v}}$

Hodie Christus natus est nobis, gaudeamus igitur non carnaliter, sed spiritualiter C 53, $78^{\mathrm{va}}$

* Homo quidam erat dives ... (Lc 16,1). Allegorice per divitem istum intelligitur dominus noster Ihesus Christus, in cuius potestate omnes divitiae subsistunt C 53,62 $\mathrm{vb}$

* Homo quidam erat dives (Lc 16,1). Istud evangelium scribitur Lucae xvi ${ }^{\circ}$, et legitur quod postquam salvator dixisset illam parabolam quod homo habuit duos filios ... Istud est evangelium in sensu suo: Dixit vilicus ... Istum vilicum ponet deus omnibus hominibus in exemplum C 11,95v

* Homo quidam erat dives ... (Lc 16,19). Vita et poena divitis et gloria ac patientia pauperis Lazari notantur in hoc evangelio C $53,58 \mathrm{vb}$

* Homo quidam fecit cenam magnam ... (Lc 14,16). Et legitur, quod postquam dominus dixisset ad Pharisaeos: Cum facis prandium ... Istud est evangelium in sensu suo et non idiget expositionem quia satis planum est: Homo quidam fecit cenam magnam etc. Iste homo est deus C $11,83^{\text {r }}$

* Homo quidam fecit cenam magnam ... (Lc 14,16). Secundum allegoriam homo iste est pius et misericors dominus C 53, $59^{\mathrm{rb}}$

Hunc librum Pauli doctoris denique summi Scripturis totum simul auro eboreque paratum Marchio Ůdalricus tibi, Christe, sanxit in usum, Qui post hanc vitam mereatur habere quietem II C 1 , A ; II C $3,1^{\text {r }}$

Hymnum cantate nobis ... (Ps 136,3). Quid hoc sit et quare hoc fiat, debetis scire C 8, $181^{\mathrm{v}}$

Iam non estis hospites ... (Eph 2,19). Apostolus de sanctis viris duo negat, scilicet quod non sunt hospites id est peregrini et advenae C 46, 69va

Ibat Ihesus in civitatem Naim ... (Lc 7,11). Per Naim intelligitur mundus, in quem intravit, quando de Maria natus fuit C 53, 66 vb

* Ibat Ihesus in civitatem que vocatur Naim (Lc 7,11). Istud evangelium scribitur Lucae vii ${ }^{\text {, }}$, et legitur postquam Ihesus intrasset civitatem Capharnaum ... Istud est evangelium in sensu suo: Ecce defunctus ille efferebatur etc. Est igitur notandum, quod per istum defunctum peccator intelligitur C $11,111^{\mathrm{r}}$

Ihesu bone rex cunctorum, dulcis pater orphanorum, tibi laus et gloria C 55, $203^{\mathrm{r}}$

* Ihesus proficiebat sapientia ... (Lc 2,52). Multi proficiunt in duobus primis in religione, pauci autem in tertio C 53, 137 rb In diebus illis erat vir in Israel nomine Ioachim ex tribu Iuda, et hic erat pastor ovium suarum C 53, 85 vb

* In illo tempore ingressus ... (Lc 19,1). Quotienscumque, fratres, dedicationis ecclesiae sollemnia colimus C 53, 76 vb

* Ingressa est regina Saba ... (3 Rg 10,2). Legitur originaliter in Regum $x^{0}$, et conveniunt huius sanctae dei genetricis recolendissimae celebritatis materiali obiecto C $52,142^{\mathrm{r}}$

* Ingressa regina Saba ... (3 Rg 10,2). Regina Saba mystice intellegitur sancta Katharina, quae naturaliter est regina C 53, $74^{\mathrm{ra}}$ Ingressus Ihesus perambulabat ... (Lc 19,1). Proverbium est commune quisquis amat suum et rem invitus perdet C $42,229^{\mathrm{ra}}$ Ingressus Ihesus ... (Lc 19,1). Zachaeus interpretatur iustus, sed quia iste iustus non erat, ideo dominum videre non poterat, et hoc propter tria C $53,74^{\mathrm{vb}}$

* Inter natos mulierum non surrexit maior Iohanne baptista, qui viam domino praeparavit C 53, 83 $3^{\text {vb }}$ 
* Inventa una pretiosa margarita ... (Mt 13,46). Nihil deus creavit pretiosius virtute C 53, $153^{\text {va }}$

Ioseph qui cognominatus est Barnabas ... (Act 4,36). Describit sanctus Lucas conversionem beati Barnabae apostoli C 46, 66rb Ipsa conteret caput ... (Gn 3,15). Deus dedit homini potestatem contra diabolum ut scilicet caput eius conterat et dedit potestatem diabolo contra hominem C 46, $117^{\mathrm{vb}}$

* Iste pauper clamavit ... (Ps 33,7). Verbum illud scriptum est in psalmo et intelligi potest de quolibet viro perfecto C 53, 144 Ita nulla reperitur villa, quin in anno ad minus semel fit dedicatio C $42,234^{\mathrm{ra}}$

Iterum beato abbati Moysi quodam tempore imposuit daemon duram impugnationem fornicationis $\mathrm{C} 8,187 \mathrm{v}$

* Iudas fuit dux eorum, qui comprehenderunt Ihesum C 53, $103^{\text {va }}$

* Iudith ingressa est ... (Idt 9,1). In his notantur 6 cuilibet homini fideli necessaria: primum confessio C 53, 97vb Iustorum autem animae ... (Sap 3,1). Magna consolatio sanctis viris quando habent securitatem de perseverantia gratiae C 46, 75vb Iustus cor suum dabit ... (Sir 39,6). Inter alia quae describit sapiens facere dicitur etiam iustus C 53, $128^{\text {va }}$

Laetatus sum in his ... (Ps 121,1) Hodiernum officium plenum est gaudio, sicut patet in introitu missae C 9, 180 ra

Lapidaverunt Stephanum ... (Act 7,58). Aliud thema: Nolite arbitrari ... (Mt 10,34). Proeliatur dominus contra peccatores, ut convertantur, mittens bellatores suos, id est praedicatores C 53, $119^{\mathrm{va}}$

* Lapidavit eum omnis populus ... (3 Rg 12,18). Originaliter $3^{\text {ii }}$ Regum xii ${ }^{\circ}$, et sententialiter excerpuntur ex hodierno epistolari officio. Quamquam autem verba haec litteraliter regi Roboam C 52, 140

Legitur de quodam sancto episcopo, qui stabat solito more iuxta altare ad celebrandum divinum officium C 8, 191 ${ }^{\mathrm{v}}$

* Leva in circuitu oculos tuos ... (Is 60,4). Alloquitur propheta caelestem Ierusalem praedicando ei multitudinem gentium advenire C 53 , $153^{\text {ra }}$

* Loquente Ihesu ad turbas ... (Mt 9,18). Istud evangelium scribitur Matthaei 9º, et legitur, quia dominus noster quando comederat cum publicano qui fecerat ei convivium ... Istud est evangelium in sensu suo: Filia mea modo defuncta est etc. Est igitur notandum quod filia significat quemlibet peccatorem C $11,126^{\mathrm{v}}$

Lux venit in mundum ... (Io 3,19). Quia adventu sancti spiritus mundus dicitur creatus et renovatus quantum ad mentes hominum C $42,310^{\text {ra }}$

Magister scimus quod verax es ... (Mt 22,16). In hoc verbo, quod dixit dominus: Reddite quae sunt Caesaris Caesari ... docet et praecipit nobis, ut reddamus unicuique quod suum est C 53, 70 rb

* Mane nobiscum domine ... (Lc 24,29). Istud evangelium scribitur Lucae 24, legitur in eodem capitulo: Postquam surrexit de sepulchro venerunt tres Mariae visitare sepulchrum ... Istud est evangelium in sensu suo: Est igitur notandum quod tria sunt quae cogunt dominum ad manendum C $11,53^{\mathrm{v}}$

* Manifestavit se iterum Ihesus ... (Io 21,1). Istud evangelium scribitur Iohannis 21, quia legitur in precedenti capitulo, quod cum Ihesus apparuisset discipulis suis simul exeuntibus ... Istud est evangelium in sensu suo etc.: Erant simul Simon Petrus, etc. Nota quod $4^{\text {or }}$ modis similes sunt homines quibus aliquando apparet $\mathrm{C} 11,57 \mathrm{v}$

Maria Magdalena etc. (Mt 28,1 / Mc 16,1). Isti dies qui modo transacti fuerunt, pleni sunt dolore C 8, $158^{\mathrm{r}}$

* Maria Magdalena et Maria Jacobi (Mc 16,1). Istud evangelium scribitur Marci 16, legitur enim cum Christus fuit mortuus et positus in sepulchrum venerunt tres Mariae ... Istud est evangelium in sensu suo: Primo est dicendum de istis mulieribus quare ipse prae ceteris venerunt ad monumentum $C 11,51^{\mathrm{r}}$

Maria optimam partem elegit (Lc 10,42). In his verbis altissime commendatur beata virgo, quod patet dupliciter C 53, 162 $2^{\text {ra }}$

* Maria optimam partem ... (Lc 10,42). Verba ista originaliter scripta sunt Lucae $\mathrm{x}^{\mathrm{mo}}$, recitative autem in huius nobis recolendissimae festivitatis evangelico officio. Quid colimus ignorare non debemus C 52, $7 \mathrm{r}$

* Misereor super turbam ... (Mt 15,32). Per turbam istam, super quam dominus misertus est, triplex turba designatur C 53, 61vb

* Miserere mei domine ... (Mt 15,22). Per mulierem istam, de qua audistis, intelligendum quilibet peccator C 53, 49va Miserunt Barnabam ... (Act 11,22). Ex his verbis ostenditur quod ipse fuit dilectus in sermone, strenuus in opere C 46, 67 rb

* Miserunt Iudaei ab Hierosolymis ... (Io 1, 19). Parate viam domino ... (Is 40,3). Quia ipse ad corda et animas vestras secundum magnam 
misericordiam suam de excelso solio suo descendere vult C $53,45^{\mathrm{rb}}$

Misit servum suum ... (Lc 14,17). Ista fuit magna ambasciata quam per servum suum beatum Dominicum pater familias fecit C 46 , $154^{\mathrm{ra}}$

Misit servum suum ... (Lc 14,17). Quantum deus desiderat salutem homini patet ex multitudine missorum, nam post misit prophetas C $46,152^{\mathrm{vb}}$

* Modicum et iam non videbitis me ... (Io 16,16). Istud evangelium scribitur Iohannis xvi ${ }^{\circ}$, quia salvator noster ante passionem suam praedixit discipulis suis quod vellet retardere ab eis et quod deberent contristari de eius absentia ... Istud est evangelium in sensu suo: Est igitur notandum quod Christus videbitur $4^{\text {or }}$ modis C $11,64^{\mathrm{r}}$

* Modicum et non videbitis me ... (Io 16,16). Haec verba praeposita dixit dominus discipulis suis in cena sedens C 53, 54 va

Mulier, magna est ... (Mt 15,28). Hodie de fide sanctae ecclesiae loqui proponimus ... C 9, 177vb

Mulierem fortem ... (Prv 31,10). Responderi potest, quod Quintianus scilicet beatam Agatham C 53, 154va

Multae filiae congregaverunt divitias ... (Prv 31,29). Animae fidelium quae sunt filiae dei multas spirituales divitias congregant C 46, $131^{\mathrm{ra}}$

Multae tribulationes iustorum ... (Ps ). Ecclesia dei a principio passa est tribulationes a Iudaeis, demum a paganis, postmodum a haereticis $\mathrm{C} 46,93^{\mathrm{vb}}$

* Multi veniunt ab oriente ... (Mt 8,11). Iocundum est hoc verbum, licet enim plures damnentur quam salventur C 9, $142^{\mathrm{vb}}$

* Nativitas tua, dei genetrix virgo, gaudium annuntiavit etc. Nativitas sanctae Mariae virginis triplex gaudium hodie humano generi attulit C $53,85^{\text {ra }}$

* Nemo potest duobus dominis servire (Mt 6,24). Istud evangelium scribitur Matthaei vio, et legitur, quod postquam dominus dixisset ad discipulos suos: Cum ieiunatis ... Istud est evangelium in sensu suo: Nemo enim potest duobus dominis servire. Est igitur notandum quod $4^{\text {or }}$ causae sunt quare homo non potest deo et Mammonae servire C $11,108^{\mathrm{v}}$

* Nemo potest duobus dominis servire (Mt 6,24), scilicet mente discordantibus, ut scilicet sunt diabolus et deus ... nam quod deus praecipit, diabolus dissuadet C 53, 66 ra

* Nemo potest venire ad me ... (Io 6,44). Et legitur in eodem capitulo, quod Ihesus dixit ad Iudaeos: Ego sum panis vitae ... Istud est evangelium in sensu suo: Nemo venit ad me nisi pater etc. Nota quod deus trahit hominem diversis modis, trahit enim hominem de peccato ad contritionem $\mathrm{C} 11,79^{\mathrm{r}}$

Nescit homo utrum amore ... (Ecl 9,1). Quia omnia in futurum reservantur incerta C 53, 140 rb

* Nescitis quod hi, qui in stadio currunt ... (1 Cor 9,24). Nota: Bravium significat regnum caelorum, quod est praemium omnium Christianorum C 9, $149^{\text {va }}$

* Nisi abundaverit iustitia vestra ... (Mt 5,20). In evangelio hodierno loquitur nobiscum dominus sicut loquebatur cum discipulis suis C $53,61^{\mathrm{rb}}$

* Nisi granum frumenti ... (Io 12,24). Iohannis xii ${ }^{\circ}$ et in hodierno evangelio leguntur in sollemnitate beati Laurentii, qui fuit granum frumenti rubicundus desiderio passionis C $52,142^{\mathrm{r}}$

Nisi manducaveritis carnem ... (Io 6,54). Nota proprietates hostiae, in quibus collige indigne et digne communicantes C 63, 142 ${ }^{\mathrm{rb}}$

* Noe vir iustus ... (Gn 6,9). Nota quod virtuosus homo in hac vita meretur tria magna bona et vitiosus econverso tria magna mala C 9 , $151^{\mathrm{vb}}$

* Nota quod ad hoc, quod homo mundetur a suis peccatis et in gratia et virtutibus proficiat et vivat, tria requiruntur C 53, 167 ra

* Nota quod ad hoc, quod oratio sit exaudibilis et deo placens ac grata, ista requiruntur C 53, 172 ${ }^{\text {rb }}$

Nota quod propter hoc non tollitur alicui clerico potestas cantandi, si videt aliquem interfici C 8, $108^{\mathrm{v}}$

* Nota quod quattuor modis solent homines peccare in divitiis temporalibus: Primo male acquirendo C 53, 166rb

* Nota quod sunt aliqui, qui confitendo peccata sua non sufficienter discutiunt nec distinguunt C 53,168 rb

Notandum ibi, attendens lector, modo sic triplex est recommendatio seu laus: quae est necessaria, quaedam utilis et quaedam levis seu voluntaria C 57,140 vb

* Nuptiae factae sunt ... (Io 2,1). Dic historiam evangelii, si placet. Iohannis ii. De nuptiis carnalibus nota quattuor bona C 9, 139va 
* Nuptiae factae sunt ... (Io 2,1). Evangelium istud pertinet ad coniugatos et virgines continentiam sectantes C 53, 46 ${ }^{\mathrm{rb}}$

* Nuptiae facte sunt ... (Io 2,1). Istud evangelium scribitur Iohannis $2^{\circ}$, quia legitur in precedenti capitulo, quod Johannes Baptista vidit Ihesum venientem ad se ... Istud est evangelium in sensu suo: In isto evangelio $4^{\text {or }}$ considerantur quae multum commendant illum miraculum ibi factum C $11,21^{\mathrm{r}}$

O altitudo divitiarum ... (Rm 11,33). Festum trinitatis olim ab ecclesia non fiebat, sed quia ipsam trinitatem multae haereses suscensebant, Carolus christianissimus imperator rogavit Albinum vel Alchimum magistrum suum ut historiam de trinitate componeret C $46,54^{\mathrm{rb}}$

O vos omnes, qui transitis ... (Lam 1,12). Carissimi, sicut scitis quod mos praedicantium est in principio ad beatam virginem recurrere C 9, $109^{\mathrm{r}}$

Obsecro vos in caritate sitis radicati (Ephes 3,17). Ex epistola istius dominicae praesens suscipitur exhortatio, quam Paulus apostolus in Romanae urbis taeterrimo scripsit et ad partes Assyriorum Ephesiis C 52, $91^{\vee}$

Occidit autem Iacobum ... (Act 12,2). Non solum beatus Iacobus multis privilegiis fuit dotatus in vita, sed etiam in morte C 46, 135

* Octo sunt, quae compellunt hominem ad conversionem: Primum est mortis incertitudo C 53, 174 $4^{\mathrm{vb}}$

Octo sunt turpitudines, quas coniugales inter se exercere solent $\mathrm{C} 9,93^{\mathrm{r}}$

* Omnes filii dei estis ... (Gal 3,7). Haec epistola legitur hodie secundum quosdam, in qua testatur de filio dei C 53, $152^{\text {va }}$

Omnibus haec panis ad festa datur cameralis StiAB 01.01.599, 53 rb; StiAB 01.01.600, S. 313; StiAB 01.01.634a, $35^{\text {ra }}$

* Oportet semper orare ... (Lc 18,1). Inter alia bona opera praecipue nos docet orationi dare operam, et hoc pluribus de causis ... C 53 , $106^{\mathrm{vb}}$

Opus fac evangelistae ... (II Tim 4,5). Evangelista idem est quod bonus nuntiator, sed non sufficit quod sit bonus nuntiator nisi sit etiam bonus operator ... Possumus etiam dicere quod in verbis praemissis ostenditur quam laudabiliter beatus Dominicus se habuit C 46, $155^{\mathrm{rb}}$

* Oswaldum puerum longo de sanguine regum Christus adoptavit C $12,185^{\mathrm{v}}$

* Othmarus in provincia Alemanniae natus atque nutritus est C 12, 199r

Paraclitus autem spiritus sanctus ... (Io 14,26). Secundum sententiam Aristotelis, primum quod cadit sub nostro appetitu est esse C 42, 308 rb Paravi lucernam ... (Ps 131,17). Verba haec sunt patris de filio volens eum mittere in hunc mundum C 46, 89va

* Parvulus natus est ... (Is 9,6). Cum sanctus Isaias multum prophetasset de adventu Christi et de eius incarnatione vidit turba communem totius mundi [salutem] eo quod homo a captivitate diaboli non potest liberari nisi per incarnationem filii dei C 11, 9 r

* Parvulus natus est ... (Is 9,6). Quare parvulus sit natus et filius datus sex causas assignare possumus C 53, 147 rb

Pater non dominus, quia amari appetit, non timeri C $57,186^{\mathrm{ra}}$

Pater noster caelestis misericors ... (Lc 6,36). Nam deus facit 7 magna ad conversionem peccatorum, et ista 7 signata sunt per 7 nuntios, quos misit rex Assuerus pro Vasti C 53, $101^{\mathrm{rb}}$

* Pater noster qui es in celis (Mt 6,9). Unusquisque homo quando clamat ad deum in caelis, filius dei debet esse et talem se praeparare C $53,171^{\mathrm{vb}}$

Patientes estote ... (Iac 5,8). Carissimi, tempus quod hodie incipit omni sanctitate plenum est C 53, 44 ra

* Pharisaei audientes ... (Mt 22,34). Istud evangelium scribitur Matthaei 22º et legitur ibidem, quod Sadducaei accesserunt ad Ihesum ... Istud est evangelium in sensu suo: Est igitur notandum quod propter $4^{\text {or }}$ causas debemus diligere dominum C 11, 115

* Poenitentiam agite ... (Mt 4,17). Ad veram poenitentiam quattuor sunt necessaria. Primum est vera contritio C 9, $163^{\text {ra }}$

Post consummati sunt dies octo ... (Lc 2,21). Hic notantur duo, scilicet domini circumcisio et nominis eius impositio sive declaratio C 9, $132^{\text {ra }}$

* Post haec abiit Ihesus trans mare ... (Io 6,1). Istud evangelium scribitur Iohannis vio, quia in praecedenti capitulo, quod Ihesus curavit illum infirmum iuxta piscinam probaticam ... Istud est evangelium in sensu suo: Nota quod haec dominica vocatur de panibus eo quod Christus quinque milia hominum de quinque panibus satiavit $\mathrm{C} 11,45^{\mathrm{r}}$

* Post triduum invenerunt ... (Lc 2,46). Pastores et magi, id est Iudaei et pagani quaesierunt puerum Ihesum et invenerunt eum in 
praesepio C 9, $137 \mathrm{vb}$

* Postquam consummati sunt ... (Lc 2,21). Hodiernum evangelium brevissimum est, sed optimam doctrinam dat C 53, 80 rb

Postquam consummati sunt ... (Lc 2,21). In his verbis duo tanguntur, que hodie sollemnizat sancta mater ecclesia. Primum est circumcisio infantis, secundum impositio nominis C $42,234^{\mathrm{vb}}$

* Postquam consummati sunt ... (Lc 2,21). Istud evangelium quod hodie legitur pro praesenti festivitate ... Licet istud evangelium breve sit tamen multa in eo continentur, et notantur duo in isto evangelio de circumcisione domini C $11,11^{\mathrm{v}}$

* Postquam impleti sunt dies purgationis ... (Lc 2,22). In his verbis beata virgo docet nos duo, primum in sensu litterali, secundum in spirituali C $53,154^{\mathrm{ra}}$

Potestas deus est ... (Ps 61,12). In divinis inveniuntur essentiae unitas in tribus personis ut nihilominus sint quaedam appropriata ipsis personis C $46,63^{\mathrm{rb}}$

* Praeparare in occursum ... (Amos 4,12). Originaliter Amos iiiio, et recitantur sententialiter in nocturnalis officii responsorio primo. A fine secundum rationem mediorum sumitur C 52, $137 \mathrm{r}$

Praerogativas plurimas habet missa: Primo quia celebratur a ieiunis, $2^{\circ}$ quia tantum in ecclesia C $53,90^{\mathrm{rb}}$

* Pretiosa in conspectu domini ... (Ps 115,15). Praeter alia multa tria dicuntur in scriptura esse pretiosa, videlicet mors sanctorum, anima hominis et gloria beatorum C $53,115^{\mathrm{rb}}$

Pretiosa in conspectu domini ... (Ps 115,15). Sicut dicit beatus Augustinus: Non potest male mori qui bene vixerit C 46, 74 ${ }^{\text {ra }}$

Primo dierum omnium etc. Expositionem: Primo, supple 'die': An dem ersten tag C 9, 61 ${ }^{\text {r }}$

Primo fiat confessio de puerilibus, utpote de inoboedientia, de offensa parentum C 8, 136 ${ }^{\mathrm{r}}$

Primus: Ab ipsa maiestate divina negant tertiam personam C 57, 160 va

Principium nostrae salutis est timor domini C $8,187^{\mathrm{r}}$

* Pueri Hebraeorum ... (Io 12,13). Carissimi, sancta ecclesia duo agit officia. Et primum cum gaudio incipit et terminatur C 53, $51^{\mathrm{vb}}$

* Pueri Hebraeorum ... (Io 12,13). Hodie, carissimi, sancta ecclesia duo officia colit, quae inter se sunt valde dissimilia C 53, 52 $2^{\mathrm{rb}}$

Quae habitas in hortis ... (Ct 8,13). Anima dei potest facere prostibulum diaboli ex se per luxuriam, et sentinam coquinae per gulam C 53, 109vb

* Quaecumque scripta sunt ... (Rm 15,4). Originaliter Romanorum $x^{\text {to }}$ et in currentis dominicae epistulari exordio. Insinuant verba ista secundum beatum Augustinum Christi vitam nostrae morum vitae fore disciplinam C 52, $138^{\mathrm{r}}$

* Quaerite dominum ... (Is 55,6). Nota, quod in triplici loco potest inveniri dominus. Primus locus est praesepium C 53, $98^{\text {ra }}$

Quaeritur circa primum de anima, utrum de anima est scientia tamquam de subiecto proprio et adaequato scientiae libri de anima etc.

Pro illa quaestione est primo notandum, quod licet scientia multis modis capitur, hic tamen dicit capi communiter et aggregative

C $41114^{\mathrm{r}}$

Quaeritur circa primum Physicorum, utrum naturalis philosophia est omnium rerum mundi considerativa. Pro illa quaestione est primo dicendum, quod philosophia sic potest describi: Est divinarum humanarumque cognitio C $40,1^{\mathrm{r}}$

Quasi stella matutina ... (Sir 50,6). Caelum spirituale sunt viri iusti et fideles in quibus deus inhabitat per gratiam et quiescit C 46, $146 \mathrm{vb}$

* Qui audit dicat veni ... (Apc 22,17). Praecipit nobis sacra scriptura ut, quae de deo et vita aeterna intelligamus, nobis intimemus C 53, $77 \mathrm{rb}$

Qui autem intrat per ostium ... (Io 10,2). Haec verba dixit Christus ad Iudaeos occasione caeci illuminati C 42, 195 ra

* Qui autem intrat per ostium ... (Io 10,2). Post generalem declarationem videnda sunt aliqua in speciali de quolibet pastore praedicto C $42,201^{\text {va }}$

* Qui autem intrat per ostium ... (Io 10,2). Quartus pastor est fortitudo. Ubi sciendum, quod non omnis fortitudo est donum spiritus sancti C $42,211^{\text {va }}$

* Qui autem intrat per ostium ... (Io 10,2). $2^{\text {us }}$ pastor est pietatis donum. Ubi notandum, quod quaedam est pietas naturalis $\mathrm{C} 42,205^{\mathrm{ra}}$

* Qui autem per ostium intrat ... (Io 10,2). Ad bonum pastorem pertinet, ut gregem bene pascat, custodiat, a bestiis defendat C 42, 199rb

* Qui etiam proprio filio suo ... (Rm 8,32). Ut de donis singularibus taceam, tria dona dat deus unicuique homini C 53, $114^{\mathrm{ra}}$

* Qui intrat per ostium ... (Io 10,2). $3^{\text {tius }}$ pastor, qui intrat in ovile ovium per Christum, et quem oves audiunt etc. est donum scientiae 
C $42,208^{\mathrm{vb}}$

Qui non accipit crucem suam ... (Mt 10,38). Vult igitur Christus, ut sequamur eum et crucem tollamus C 53, 124va

Qui non est mecum ... (Lc 11,23). Nota igitur, quod sicut tunc multi sequebantur dominum et curabantur ab eo ut hodiernus daemoniacus, ita et nunc multi secuntur eum C 9, 179vb

Qui non intrat per ostium ... (Io 10,1). Quintus pastor est consilium. Ubi sciendum, quod consilium quandoque causatur pro inquisitione $\mathrm{C} 42,217^{\mathrm{va}}$

* Qui post me venit ... (Io 1,15). Evangelium sic incipit, quia Iudaei miserunt nuntios ad Iohannem de Ierusalem scilicet sacerdotes et levitas ut interrogarent eum ... Istud est evangelium in sensu suo, in quo Iohannes duo tangit scilicet divinitatem et humanitatem C $11,5^{\mathrm{v}}$

Quia circa infirmos maius est periculum, ideo cum ipsis consultius procedendum C 10, $101^{\mathrm{v}}$

Quia vero sacrificium corporis et sanguinis Christi, domini nostri Ihesu Christi, quod in missa conficitur et sumitur C 10, 52v

Quindecim signa invenit sanctus Hieronymus in annalibus libris Hebraeorum C 8, 192r

* Quinque ex illis erant fatuae ... (Mt 25,2). Communiter dicitur, quod non possunt omnes esse sapientes C 53, 132 rb

* Quis ex vobis arguet me ... (Io 8,46). In his verbis tria notanda sunt et cuilibet homini scienda C 53, $51^{\text {rb }}$

* Quis ex vobis arguet me ... (Io 8,46). Istud evangelium scribitur Iohannis viiio, quia in eodem capitulo legitur, quod ipsi Iudaei dixerunt quod pater eorum Abraham esset ... Istud est evangelium in sensu suo: In isto evangelium $4^{\text {or }}$ tanguntur, primo quod Christus fuit innocenter passus et sine omni culpa C 11, 47 r

* Quod vobis dico, omnibus dico ... (Mc 13,37). Quidam libri falsi dicunt: quod unico dico, sed verus textus habet: quod vobis dico. Apostolus enim dixit esse vigilandum C 53, 126 va

* Quoniam acceptus eras deo ... ( Tb 12,13). Cum omnes tribulari oporteat secundum illud Iob: Homo natus ad laborem, ideo in tribulatione nolite multum contristari C $53,95^{\mathrm{va}}$

Quoniam carissime in via huius fugientis vitae simus, dies nostri sicut umbrae praetereunt $\mathrm{C} 10,48^{\mathrm{r}}$

Quoniam me saepius rogasti, Petre, postquam sacerdotii sacrum ordinem suscepisti C 10, 60

* Reddet deus mercedem laborum sanctorum (Sap 10,17). Vel aliud thema, si placet: Labores manuum tuarum etc. (Ps. 127,2). Deus ordinavit, ut hoc modo laboremus, quia quando primus homo fuit conditus C $53,102^{\text {ra }}$

* Reddet unicuique ... (Mt 16,27). Dominus ordinem nec sexum nec aetatem respicit, sed unicuique secundum opera sua tribuit $\mathrm{C} 53$, $94^{\mathrm{vb}}$

Reddite omnibus debita ... (Rm 13,7). Beatus Paulus vas electionis certissimus de sua fide et doctrina, quam non ab homine nec per hominem se accepisse testatur, sed per revelationem Ihesu Christi $C$ 42, $171^{\text {va }}$

Renovamini spiritu ... (Eph 4,23). Nota quod vi species renovationis in creaturis inveniuntur, quae ostendunt homini diversos modos suae renovationis $\mathrm{C} 8,107^{\mathrm{r}}$

Reverendissimi in Christo patres celeberrimique domini mei metuendi sacrosanctae Romanae ecclesiae cardinales benemeriti ... Nam teste philosopho Ethicorum primo sermones sunt exquirendi C 52, 38

Reverendissimi patres et domini, excedit multumque supereminet humanam eloquii facultatem praefati signi magnitudo C 52, $16 \mathrm{v}$

* Sanctus Goarus de Aquitania in territorium Treverini venit locumque elegit C 12, 180v

Sanctus sanctus sanctus ... (Is 6,3). In hoc cantico angelico seraphin primo glorificant beatam trinitatem et unitatem cum dicunt: Sanctus sanctus sanctus dominus deus C 46, $59^{\text {ra }}$

Sanctus Wilhelmus beatae virginis assignatus capellanus hanc sequentem scribit pro infirmorum excitanda devotione C $57,185^{\text {va }}$

Scitis quia post biduum pascha fiet ... (Mt 26). Ubi nota, quod passio domini nostri Ihesu Christi scribitur a Matthaeo capitulo octavo C $10,229^{r}$

* Scribe: Beati qui ad cenam... (Apc 19,9). Originaliter Apocalypsis xliio, et congruunt tam dedicationis quam dominicae currentis sollemni officio. His verbis insinuatur, quod familiaris proles sponsae ecclesiae Christo nuptae dedicatione heredetaria sit aeterna beatitudine $\mathrm{C} 52,4^{\mathrm{r}}$ 
Segregate mihi Barnabam ... (Act 13,2). Duo necessaria sunt praelato et praedicatori, scilicet sana doctrina et bona vita C 46, 68 ra

* Sequere me ... (Io 21,19f.). Dic legendam Johannis, si vis. Sequere me dixit Ihesus Petro tunc, sed hodie dicit cuilibet peccatori C 9 , $128^{\mathrm{va}}$

Sequitur de speciebus confessionis, que multae sunt: Prima est confessio se excusantium C 8, $122^{\mathrm{r}}$

* Si linguis hominum ... (1 Cor 13,1). Et si habuero prophetiam futurorum, quam etiam mali habuerunt ut Balaam, Saul et Caiphas C 9, $152^{\text {va }}$

* Si quid petieritis patrem ... (Io 16,23). Omnipotens deus, qui omni tempore in ecclesia bono opere laudatur et culpa exasperatur C 53 , $55^{\mathrm{va}}$

Si quis diligit me ... (Io 14,23). Ante adventum filii dei eramus omnes servi diaboli a divina salvatione exclusi C 46, $51^{\mathrm{vb}}$

* Si quis diligit me ... (Io 14,23). Istud evangelium scribitur Iohannis xiiii ${ }^{\circ}$, quia legitur ibidem quod imminentem domini passionem, cum dominus discipulis corpus suum dedisset ... Istud est evangelium in sensu suo: Paracletus autem spiritus sanctus. Hodie peragitur festum quo spiritus sanctus apostolis Christi datus fuit $\mathrm{C} 11,72^{\mathrm{r}}$

* Si vis esse perfectus, debes habere cognitionem dei veram, et hanc amor consequitur C 53, $173^{\text {rb }}$

Sic deus dilexit mundum ... (Io 3,16). Hoc evangelium ideo legitur in festo penthecostes, quia filius datus est nobis in mundum per spiritus sancti donum C $42,193^{\text {ra }}$

* Sic deus dilexit mundum ... (Io 3,16). In his verbis notatur triplex dilectio, quam deus instituit et ordinavit C 53, 57va

* Sic enim deus dilexit mundum ... (Io 3,16). Istud evangelium scribitur Iohannis $3^{\circ}$, legitur enim in eodem capitulo quod Nicodemus princeps Iudaeorum venit nocte ad Ihesum ... Istud est evangelium in sensu suo etc.: Sic deus dilexit mundum etc. Nota quod deus pater ostendit nobis $4^{\text {or }}$ signa intimae dilectionis C $11,74^{\mathrm{r}}$

Sicut dicit philosophus secundo Ethicorum: Malum non vitatur nisi praecognitum. Quia autem vitia sunt mala, ideo vitari non possunt nisi cognoscantur C 57, 174 $4^{\text {ra }}$

Signa servos dei in frontibus eorum (Apc 7,3). Sunt enim 12 signa amoris Christi, quae quicumque habuerit, omnipotens fit cum omnipotente C $53,163^{\text {ra }}$

Signum magnum ...(Apc 12,1). Quamvis verba ista per excellentiam communiter applicentur ad beatam virginem C 11, 167v

* Simile est regnum caelorum ... (Mt 13,24). Istud evangelium scribitur Matthaei 13, legitur enim in eodem capitulo, quod postquam dominus fuit egressus de domo ... Istud est evangelium in sensu suo: Nota quod in isto evangelio iiiior tanguntur sicut doctores ponunt C $11,28^{\mathrm{v}}$

* Simile est regnum caelorum ... (Mt 18,23). Istud evangelium scribitur Matthaei, et legitur, quia quando Petrus interrogavit dominum dicens: Quotiens peccabit frater meus ... Istud est evangelium in sensu suo etc.: Simile est regnum caelorum. Per istum regem possumus intelligere deum C $11,122^{\mathrm{r}}$

* Simile est regnum caelorum homini regi ... (Mt 18,23). Rex iste, de quo iam audistis, dominum Ihesum designat. Huius servi et ancillae sunt omnes C 53, 69vb

* Simile est regnum caelorum homini regi (Mt 22,2). Istud evangelium scribitur Matthaei $22^{\circ}$, et legitur postquam dominus dixisset diversas parabolas ... Istud est evangelium in sensu suo: Simile est regnum caelorum etc. Est igitur notandum quod in isto evangelio $4^{\text {or }}$ ponuntur, primo quis sit iste rex C $11,118^{\mathrm{v}}$

* Simile est regnum caelorum homini regi ... (Mt 22,2). Per regem istum intelligitur deus pater, qui est rex regum et dominus dominantium C 53, 68vb

* Simile est regnum caelorum patri familias ... (Mt 20,1). In verbis istis tria monstrantur, quae quemlibet fidelem hominem multum consolari possunt C 53, $48^{\text {ra }}$

* Simile est regnum caelorum patri familias ... (Mt 20,1). Istud evangelium scribitur Matthaei, legitur enim in praecedenti capitulo, quod cum dominus dixisset quod dives difficile intrabit in regnum caelorum ... Istud evangelium plenum est in sensu suo: Et igitur est notandum quod in isto evangelio $4^{\text {or }}$ considerantur $\mathrm{C} 11,30^{\mathrm{v}}$

Simile factum est regnum caelorum homini qui seminavit ... (Mt 13,24). In hoc notantur quattuor, videlicet divinum beneficium, diaboli maleficium C 9, 147va

Sitio primo ad te, pater, ut respicias hodie C $9,191^{\mathrm{r}}$ 
Solvite et adducite mihi ... (Mt 21,2) Quis possit peccatorem absolvere? C 9, $189^{\mathrm{va}}$

Spiritus domini replevit ... (Sap 1,7). In huius recolendissimae festivitatis capituli officio et eiusdem introitu his verbis, quod filii lucis et non tenebrarum simus, pignus accepimus $\mathrm{C} 52,1^{\mathrm{r}}$

Spiritus meus qui est in te ... (Is 59,21). Verum fructuosum praedicatorem tria commendant, scilicet vita sancta, doctrina assidua, proles sapiens et iocunda C 46, $149^{\text {ra }}$

* Stabat iuxta crucem ... (Io 19,25). Beatissimus Iohannes evangelista, qui hodiernam passionem manu sua conscripsit, sex causas praeponit nobis de passione domini C 53, $91^{\mathrm{vb}}$

* Stella, quam viderant ... (Mt 2,9). Quidam fuit gentilis propheta Balaam, qui longe ante de stella ista prophetavit C $9,135^{\mathrm{ra}}$

* Stetit Ihesus in medio discipulorum suorum ... (Lc 24,36). Cum esset sero die illa ... Istud est evangelium in sensu suo: Stetit Ihesus in medio discipulorum suorum, dicit enim Aristoteles, quod omnis virtus consistit in medio C $11,55^{\mathrm{v}}$

Super salutem et omnem pulcritudinem dilexi sapientiam et cetera (Sap 7,10). Haec propositio scribitur in libro sapientiae C 53, $3^{\mathrm{ra}}$

* Surrexit dominus vere ... (Lc 24,34). In his verbis notatur domini pietas et discipulorum incredulitas C 53, 53 $3^{\mathrm{ra}}$

Surrexit dominus vere ... (Lc 24,34). In hoc verbo quod dominus dicit: O stulti C 8, 159v

Suscepimus deus misericordiam tuam ... (Ps 41,10). Leguntur originaliter psalmo xlviio , et transsumuntur ad currentis festivitatis introitum. His verbis profitetur ecclesia in communi se in suis filiis felici gaudio iusti Simeonis participari ... C 52, $140^{\mathrm{r}}$

Timete dominum ... (Ios 24,14). Fili, accede ad servitutem dei ... (Sir 2,1). Multa bona habebis, si timueris dominum ... (Tb 4,23). Timenti dominum bene erit (Sir 1,13) C 53, 142 rb

* Transeuntes autem primam ... (Act 12,10). Haec verba dicere potuit beatus Petrus cum hodie ereptus ab omni incommodo huius exilii ad caelestem patriam transivit C 53,161 $\mathrm{rb}$

Tu domine qui nosti corda ... (Act 1,24). In hoc verbo, quod in Actis primo scribitur, tria nobis insinuantur. Primum maiestatis invocatio C $53,155^{\mathrm{vb}}$

* Ubi est qui natus est rex Iudeorum ... (Mt 2,2). Et istud evangelium sic scribitur: Cum ergo esset natus Ihesus in Bethlehem in terra Iuda in diebus Herodis regis ... Istud evangelium ergo est, plurem non indiget expositionem. Isti tres reges multum commendantur in evangelio praesenti C $11,16^{\mathrm{r}}$

* Vade in pace (Lc 7,50). Per totum annum festa multorum sanctorum celebramus, sed hodie celebramus festum peccatorum C 53, 104 ${ }^{\mathrm{rb}}$

* Vado ad eum qui misit me (Io 16,5). Istud evangelium scribitur Iohannis xvi, Christus enim ante suam ascensionem praedixit discipulis suis quod vellet retardere ab eis ... Istud est evangelium in sensu suo: Istud evangelium duo dicit C 11, 66 ${ }^{\mathrm{r}}$

Vado ad eum qui misit me ... (Io 16,5). Quasi diceret: Ascensio mea ita manifesta erit, quod nulli licebit me interrogare quo vadis C 53 , $55^{\mathrm{ra}}$

Valde honorandus est beatus Iohannes, qui supra pectus domini in cena recubuit C 53, 79vb

* Veni sancte spiritus ... Carissimi, ista verba per totam istam septimanam ad laudem et ad gloriam sancti spiritus cantamus C 53, 56 va

* Veniet desideratus ... (Agg 2,8). In verbo isto notantur tria, videlicet adventus domini, desiderium ipsius et utilitas eius C $9,123^{\mathrm{vb}}$

* Veniet desideratus ... (Agg 2,8). Tria genera hominum desiderabant Christi adventum, scilicet reges, prophetae et iusti C $9,116^{\text {ra }}$ Veniet dominus et illuminabit ... (1 Cor 4,5). Ista verba possunt exponi de adventu domini in mundum C 8, $53^{\mathrm{r}}$

* Venit filius hominis ... (Lc 19,10). In his verbis duo nobis describit evangelium: scilicet Christi adventum et advenientis fructum C 53 , $146^{\mathrm{va}}$

Venit sponsus ... (Mt 25,10). Una ex his virginibus, quae paratae erant, fuit beatissima Margaretha C 53, $133^{\mathrm{va}}$

* Venite ad me omnes ... (Mt 11,28). Nota, quod onus malorum est grave, bonorum vero leve C 53, $155^{\mathrm{rb}}$

Venite ad me omnes ... (Mt 11,28). Vult enim dominus, ut ad eum veniamus, scilicet in illam caelestem Hierosolymam C 53, 117rb

* Verena de nobilibus parentibus genita in regione Thebaeorum commissa fuit beato C $12,190^{\mathrm{r}}$

* Victorinus et Severinus fratres fuerunt, qui post obitum parentum simul optime vixerunt C 12, 184 ${ }^{\mathrm{r}}$

Viderunt oculi mei ... (Lc 2,30) Et sunt verba sancti Simeonis adventum filii in carnem desiderantis totum genus humanum alloquens 


\section{C $9,104^{\mathrm{r}}$}

* Vidit Iacob in somnis ... (Gn 28,12). Legitur in Genesi, quod Isaac patriarcha habuit duos filios, scilicet Iacob et Esau C 53, $76^{\text {ra }}$ Vidit Ihesus duos fratres ... (Mt 4,21). Magna dignitas istorum apostolorum qui non per hominem, nec per angelum, sed per ipsum dominum Ihesum Christum sunt vocati C $46,134^{\mathrm{rb}}$

* Vigilate, quia nescitis ... (Mt 24,42 / 25,13). Tria sunt loca, ubi homines morantur: scilicet in caelo, in inferno atque in mundo C 53 , $96^{\mathrm{va}}$

Virgo Elisabeth monialis coaetanea Hildegardis in Binga C 8, $178^{\mathrm{v}}$

* Virtutes caelorum movebuntur (Lc 21,26). Glosa: Virtutes caelorum sunt angeli, qui dicuntur moveri in die iudicii C 9, 117 ra Vos amici mei estis ... (Io 15,14). Magna dignatio dei, quia cum essemus indigni vocari servi, suos nos vocat amicos C $46,72^{\text {ra }}$ Vos estis cives ... (Eph 2,19). Aliter vivunt cives daemonum, aliter cives sanctorum. Qualiter autem C 53, $111^{\mathrm{rb}}$ Vos estis genus electum ... (1 Pt 9). Et notandum est, quod glosa hic tangit iiiior: primo sacerdotis nobilitatem C 8, $161^{\mathrm{r}}$

* Vos estis templum dei ... (2 Cor 6,16). Hodie, fratres carissimi, ad sanctam dedicationem huius templi convenistis C 53, 76 va

* Vox in Rama audita ... (Mt 2,18). Duae sorores, ut scitis, scilicet Rachel et Lia duas vitas in religione signant: Lia bonam vitam exteriorem C 53, 150 ra

Wilhelmus sanctissimus postquam ad honorem Christi missus est a Carolo terras a paganis obsessas plurimas deo lucratus est C 12, $170^{\mathrm{r}}$ 


\section{Verzeichnis der Verse und Sprüche nach WALTHER}

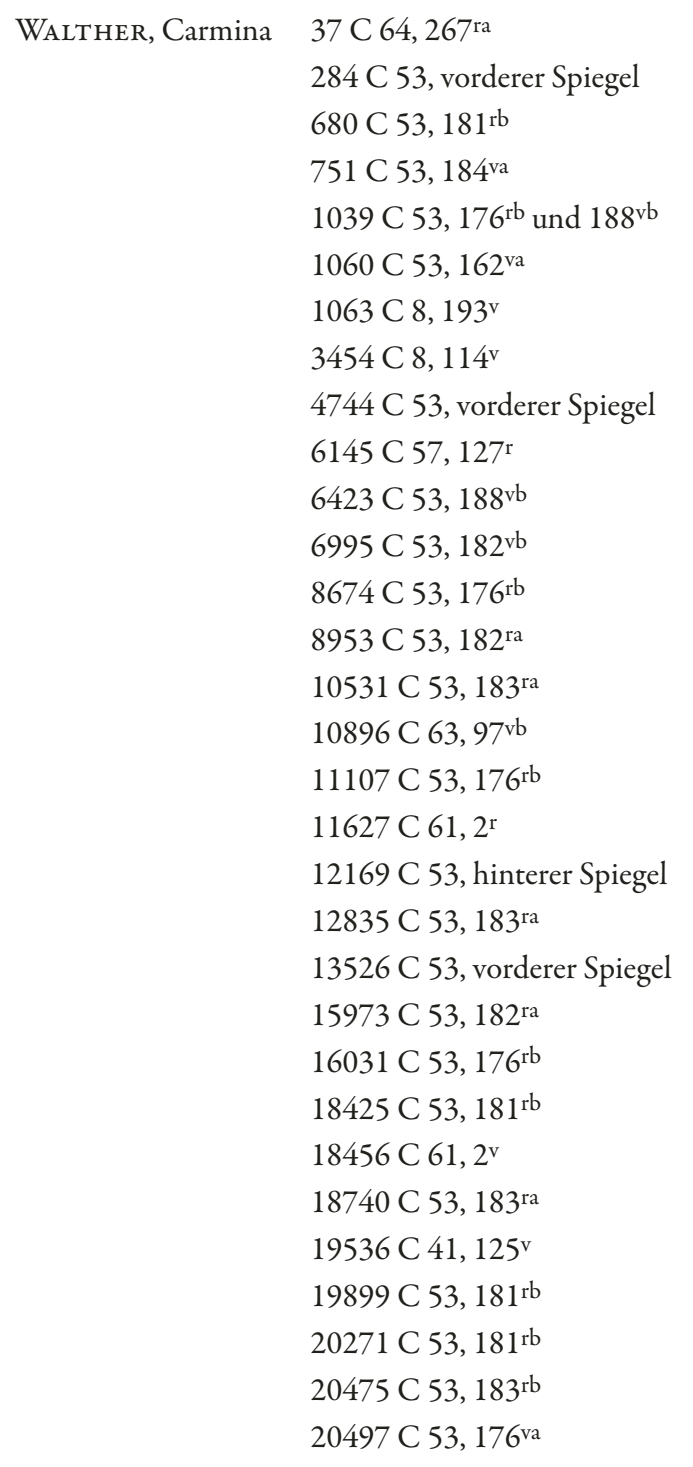

Walther, Proverbia 956 C 51, 140 r

$1172 \mathrm{C} 51,140^{\mathrm{vb}}$ $1330 \mathrm{C} 51,140^{\mathrm{vb}}$ 1408 a C 51, $141^{\text {ra }}$ $2129 \mathrm{C} 51,140^{\mathrm{vb}}$ $2750 \mathrm{C} 51,140 \mathrm{vb}$ 3432 C 51, $140^{\mathrm{va}}$ $3934 \mathrm{C} 51,140^{\mathrm{r}}$ $5162 \mathrm{C} 51,140^{\mathrm{r}}$ 6060a C 51, 140vb $6257 \mathrm{C} 51,140^{\mathrm{r}}$ $7836 \mathrm{~b} \mathrm{C} 51,140^{\mathrm{vb}}$ $7921 \mathrm{C} 51,140^{\mathrm{r}}$ $9923 \mathrm{C} \mathrm{51,140 \textrm {r }}$ $10178 \mathrm{C} 51,141^{\mathrm{rb}}$ 11095b C 51, $141^{\mathrm{ra}}$ 13337 C 51, $140^{\mathrm{r}}$ 14896 C $51,141^{\text {ra }}$ 15450 C 51, $141^{\mathrm{ra}}$ 15629 C 51, $140^{\mathrm{va}}$ 16672 C 51, 140 va $17498 \mathrm{C} 51,140^{\mathrm{vb}}$ 17515 C 51, $140^{\text {va }}$ 18359 C 51, $140^{\mathrm{r}}$ 19108 C 51, $141^{\text {ra }}$ $21677 \mathrm{~d} C 51,140^{\mathrm{vb}}$ 21754 C 51, $140^{v b}$ 21988 C 51, $140^{\text {va }}$ 24017 C 51, $140^{\text {va }}$ 24503 C 51,140 vb 24671a C 51, $140^{\mathrm{vb}}$ 24684 C $51,140^{r}$ 24802 C 51, $140^{\mathrm{r}}$ 24952 C $51,140^{\mathrm{r}}$ 25968 C $51,140^{\mathrm{r}}$ 27159 C $51,141^{\text {ra }}$ 27164 C 51, $140^{\text {va }}$ 30489 C 51, $141^{\mathrm{ra}}$ 





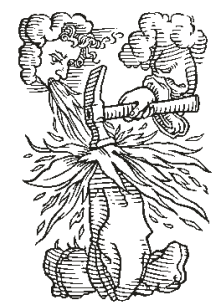

Das Signet des Schwabe Verlags ist die Druckermarke der 1488 in Basel gegründeten Offizin Petri, des Ursprungs des heutigen Verlagshauses. Das Signet verweist auf die Anfänge des Buchdrucks und stammt aus dem Umkreis von Hans Holbein. Es illustriert die Bibelstelle Jeremia 23,29:

«Ist mein Wort nicht wie Feuer, spricht der Herr, und wie ein

Hammer, der Felsen zerschmeisst?» 


\section{SCHWABE VERLAG}

www.schwabe.ch

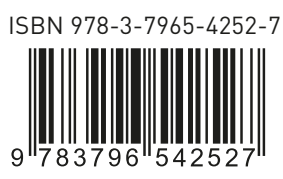

